FHWA/IN/JTRP-2008/12

Final Report

PERFORMANCE-BASED CONTRACTING FOR ROADWAY MAINTENANCE OPERATIONS IN INDIANA

Bob G. McCullouch

Kumares C. Sinha

Panagiotis Ch. Anastasopoulos

March 2009 


\section{TECHNICAL Summary}

INDOT Research

Technology Transfer and Project Implementation Information

TRB Subject Code: 33-1 Construction Control

March 2009

Publication No. FHWA/IN/JTRP-2008/12, SPR-3130

Final Report

\section{Performance-Based Contracting for Roadway Maintenance Operations in Indiana}

\section{Introduction}

Through Major Moves approximately 1,940 lane miles will be added. This equates to 58 new snow routes and additional maintenance needs. At current lane mile maintenance costs this will require an additional $\$ 8.5$ million annually. With falling gas tax revenue how will INDOT fund current and additional highway maintenance? This study investigated the use of Performance Based Contracting (PBC) as one option. Other options are:

1. Increase resources- equipment and personnel. This is politically unpopular and most likely not feasible due to economic factors.

2. Increase maintenance subcontracts including snow and ice removal activities.

3. Reduce the Level of Service across the network.

Items 1 and 2 require additional funding. Item 3 will lower the current level of maintenance, but allows for budget cuts. INDOT must determine what the controlling factors are before it can establish a maintenance plan to deal with current and future maintenance needs.

The project makes recommendations on PBC and produces a plan for INDOT to use if PBC is pursued. The plan describes the needs and process for creating and administering a PBC plan. PBC will cost INDOT more money than is currently being spent on maintenance. The extra money does bring some benefits to INDOT and these are described in the report.

The study also revealed that INDOT needs to define the condition of their current network through a Level of Service (LOS) program. This program can describe the visual impact on maintenance condition through budget changes. Also, a LOS program is needed to develop budget estimates for a PBC contract or the expanded subcontract option.

\section{Findings}

The following describes the study findings and recommendations.

- $\quad$ PBC will require INDOT to create an organization with staff, development time, resources, and training.

- $\quad$ Despite published reports, PBC will not save money. In most cases it costs more money.

- One important cost component when comparing $\mathrm{PBC}$ costs with in-house costs is overhead costs. Several agencies describe their procedure for calculating overhead costs.
- Indiana contractors are interested and capable of performing maintenance activities, even winter activities on a callout basis.

- Due to economic realities the PBC option has a lower ranking among the various maintenance options.

Maintenance Plan

- $\quad$ PBC is not recommended.

- $\quad$ Private contractors are a viable option.

- If snow and ice activities are the critical ones, develop subcontracts to utilize private contractors. INDOT should 
develop and test snow and ice subcontracts.

- Determine maintenance needs and develop a more comprehensive subcontract program. This is referred to as a "hybrid approach" where private local contractors are used to supplement agency forces and in some cases work together. Work with ICA (Indiana Contractors Association) to develop this program by growing the amount and number of available subcontractors.

- Identify and inventory activities and compare to availability of private sector entities throughout the state by Districts.

- $\quad$ Mowing

- $\quad$ Sign Maintenance Activities
- $\quad$ Road Maintenance Activities

- $\quad$ Bridge Maintenance Activities

- $\quad$ Road Painting Activities

- Risk is the biggest factor affecting contractor pricing. Minimize and share risk.

- INDOT needs to produce a LOS requirements description. This will establish a baseline and helps to establish budget numbers for higher or lower LOS. This will be necessary for building a request for additional maintenance funds from the legislature or thr impact of budget cuts on maintenance operations.

\section{Implementation}

Since PBC is not a viable financial option and requires significant upfront INDOT resources it is not recommended. However, the report does contain PBC implementation guidelines.
It is imperative that INDOT develop a maintenance plan. Options are described in the report. Equally important is that INDOT must have a LOS program with criteria defined and the complete network evaluated before it can move forward with a maintenance plan.

\section{Contacts}

For more information:

\section{Dr. Bob McCullouch}

Co-Principal Investigator

School of Civil Engineering

Purdue University

West Lafayette IN 47907

Phone: (765) 494-0643

E-mail: bgm@ecn.purdue.edu

\section{Indiana Department of Transportation}

Division of Research

1205 Montgomery Street

P.O. Box 2279

West Lafayette, IN 47906

Phone: (765) 463-1521

Fax: (765) 497-1665

\section{Purdue University}

Joint Transportation Research Program

School of Civil Engineering

West Lafayette, IN 47907-1284

Phone: (765) 494-9310

Fax: (765) 496-7996

E-mail: jtrp@ecn.purdue.edu

http://www.purdue.edu/jtrp 
Final Report

FHWA/IN/JTRP 2008-12

\title{
Performance-Based Contracting for Roadway Maintenance Operations in Indiana
}

\author{
by \\ Bob G. McCullouch \\ Kumares C. Sinha \\ Panagiotis Ch. Anastasopoulos \\ Joint Transportation Research Program \\ Project Number: C-36-73EE \\ File Number: 3-4-31 \\ SPR-3130
Prepared as Part of an Investigation Conducted by the
Joint Transportation Research Program
Purdue University
In cooperation with the
U.S. Department of Transportation \\ Federal Highway Administration
}

The contents of this report reflect the views of the authors who are responsible for the facts and accuracy of the data presented herein. The contents do not necessarily reflect the official views or policies of the Indiana Department of Transportation or the Federal Highway Administration at the time of publication. This report does not constitute a standard, specification, or regulation.

School of Civil Engineering

Purdue University

West Lafayette, Indiana 47907

March 2009 


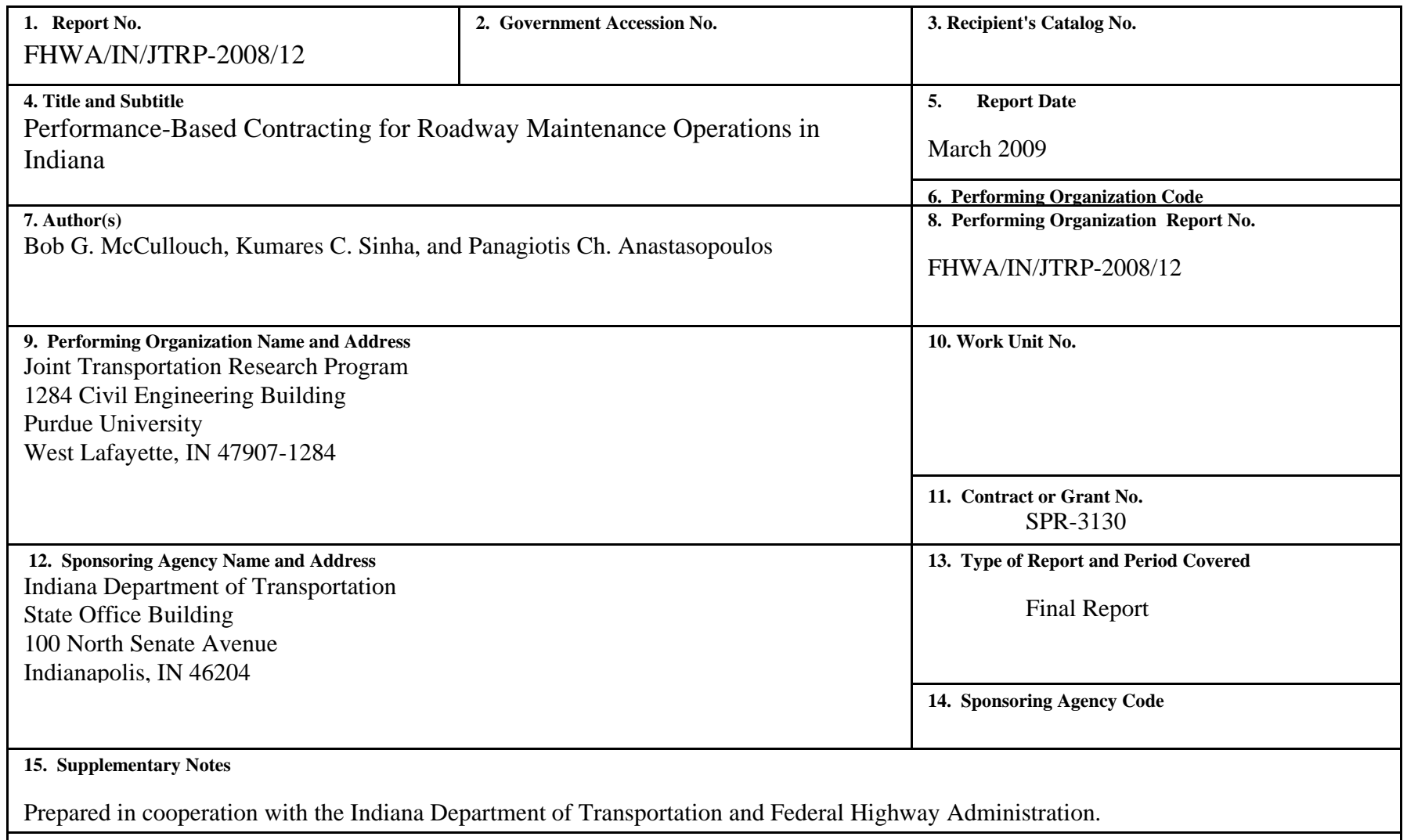

\title{
16. Abstract
}

INDOT initiated a study to investigate Performance Based Contracting of maintenance operations. One of the main impetus for the study is that INDOT started a ten year road building program called Major Moves that will add over a 1900 lane miles to the current network. With this addition and coupled with a trend of reduction in maintenance personnel, INDOT is planning how maintenance will be performed. One viable option is the use of performance based contracting (PBC). This study has evaluated many aspects of PBC and the current INDOT maintenance program. Study specifics included:

- Investigated foreign agencies PBC programs.

- Evaluated cost data

- Interviewed and analyzed three state agencies that use PBC, Virginia, Florida, and North Carolina. Other states studied included: South Carolina, Oklahoma, Massachusetts, and Texas.

- Evaluated contracting options and the Indiana contracting community.

- Investigated and defined the activities that are better performed In-House, and those that, potentially, could be privatized.

- Define the requirements for creating, contracting, monitoring, and managing a PBC system at INDOT.

- Develop an understanding and a plan for INDOT maintenance that includes the added capacity from Major Moves over the next 10 years.

- Analyze, define, and describe risk factors (e.g. contractor protection from $3^{\text {rd }}$ party lawsuits).

- Developed guidelines for INDOT that objectively states the facts learned from analyzing PBC.

- Describe maintenance options that could include PBC , expanding subcontracts, and INDOT Maintenance forces.

- Described how other state agencies calculate overhead costs and apply to maintenance costs.

- Description of Level of Service (LOS) programs developed and used by other state agencies.

PBC is being used extensively in some states while other states have tried and backed away for various reasons which are explained in the report. Due to higher costs experienced with PBC and the fact that long term contracts lock in prices leaving agencies with no flexibility to reduce during economic downturns; the report is not recommending PBC to INDOT. What is recommended is that INDOT should: establish a LOS program; develop and test snow and ice removal subcontracts; and further develop a hybrid maintenance program where private contracts are used to supplement INDOT maintenance force.

\section{Key Words}

maintenance, contracting, contracts, privatization, level of service

18. Distribution Statement

No restrictions. This document is available to the public through the National Technical Information Service, Springfield, VA 22161

\author{
19. Security Classif. (of this report) \\ Unclassified
}
20. Security Classif. (of this page)
Unclassified
21. No. of Pages
423

22. Price

Form DOT F 1700.7 (8-69) 
TABLE OF CONTENTS

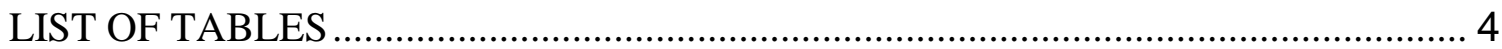

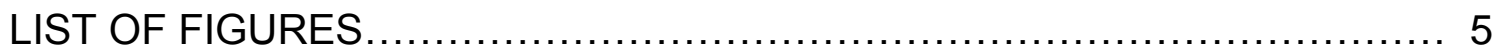

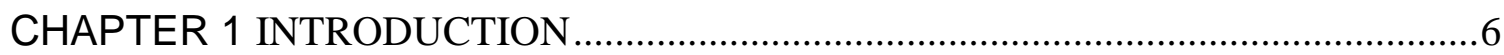

1.1. BACKGROUND AND PROBLEM STATEMENT............................................. 6

1.2. OBJECTIVES OF THE PRESENT STUDY ………...................................... 7

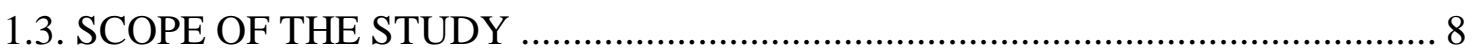

1.4. WORKPLAN: OVERVIEW OF THE STUDY APPROACH ……................... 9

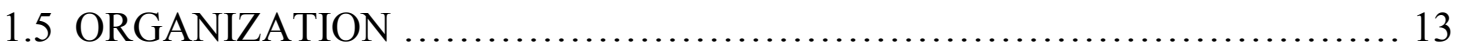

CHAPTER 2. LITERATURE REVIEW ...............................................................14

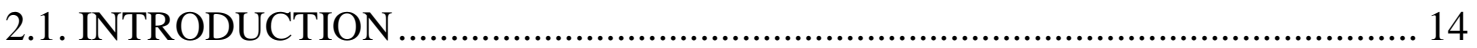

2.2. REASONS FOR OUTSOURCING ……….............................................. 14

2.3. DEFINITIONS AND ISSUES: TRADITIONAL CONTRACTING .................... 16

2.4. MOTIVATION FOR ALTERNATIVE CONTRACTING APPROACHES ........ 17

2.5. INNOVATIVE METHODS OF CONTRACTING ………................................ 19

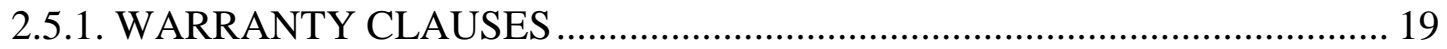

2.5.2. DESIGN-BUILD-OPERATE-MAINTAIN ................................................ 20

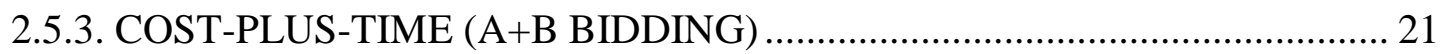

2.5.4. INCENTIVES/DISINCENTIVES ....................................................... 22

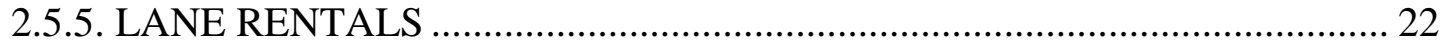

2.5.6. PERFORMANCE-BASED CONTRACTING (PBC) …………………….... 23

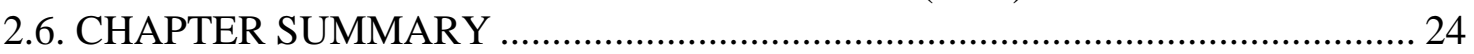

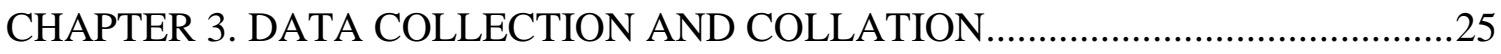

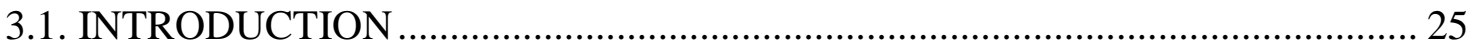

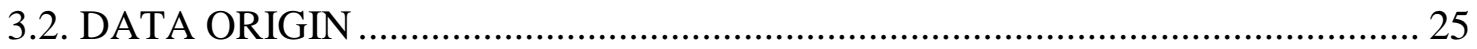

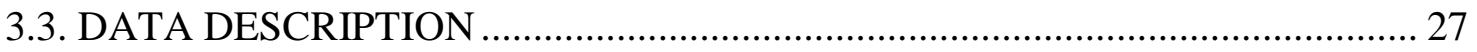

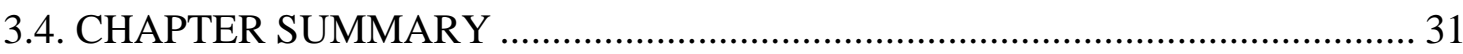

CHAPTER 4. PERFORMANCE-BASED CONTRACTING...........................................

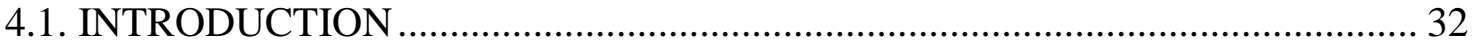

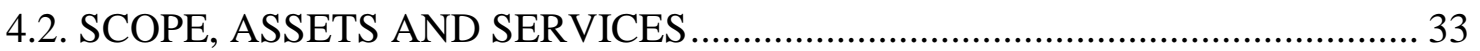

4.3. HISTORICAL BACKGROUND OF PBCS ……............................................ 34

4.4. REASONS FOR IMPLEMENTING PBCS FOR MAINTENANCE ACTIVITIES35

4.5. PERFORMANCE INDICATORS AND STANDARDS …………………......... 36

4.6. RISK ALLOCATION ……………........................................................ 39

4.7. PERFORMANCE MONITORING, ACCOUNTABILITY AND PAYMENT

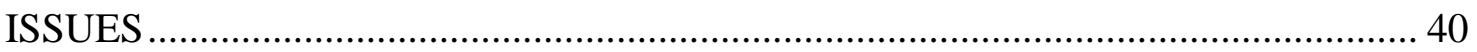

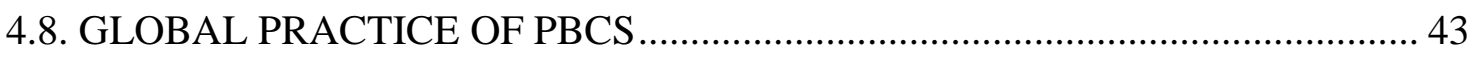

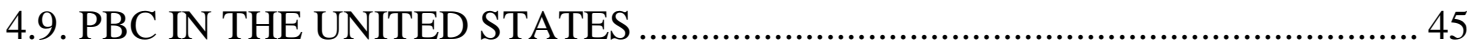

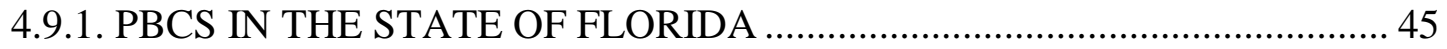

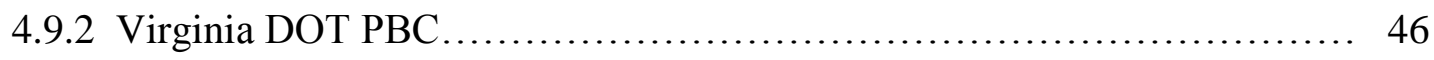

4.9.3 PBCS IN WASHINGTON D.C............................................................... 47

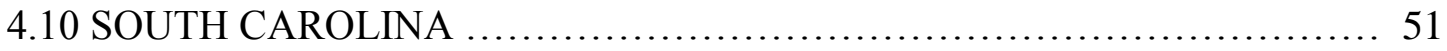




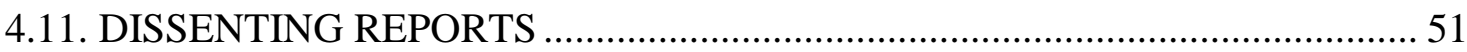

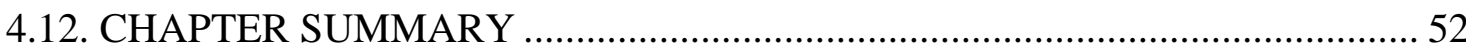
CHAPTER 5. ADVANTAGES AND LIMITATIONS OF CONTRACTING METHODS

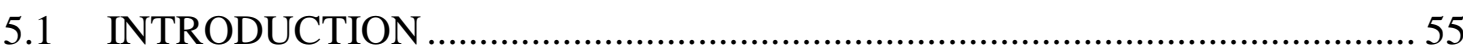

5.2 COMPARISON BETWEEN PBC AND TRADITIONAL CONTRACTING ... 56

5.3 COMPARISON BETWEEN PBC AND OTHER INNOVATIVE

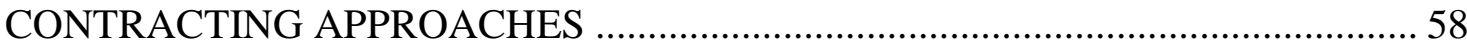

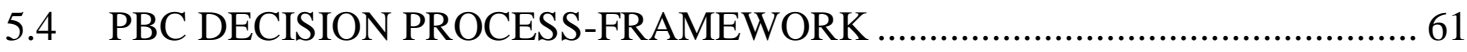

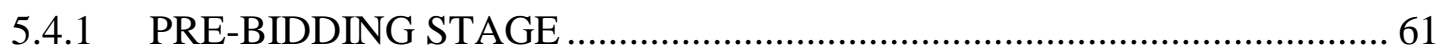

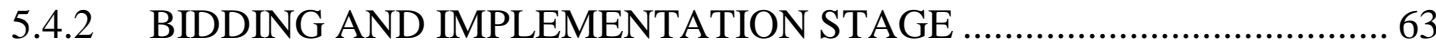

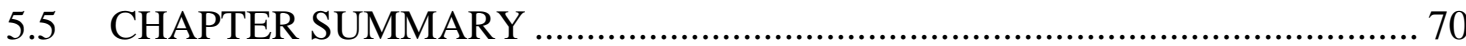

CHAPTER 6. CONTRACTING APPROACH SELECTION - STATE OF PRACTICE

6.1. INTRODUCTION

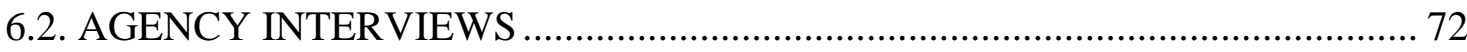

CHAPTER 7. AGENCY AND CONTRACTOR INTERVIEWS …………………........78

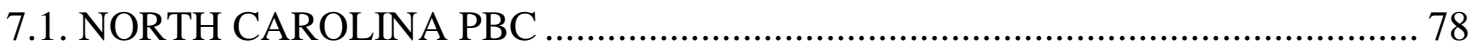

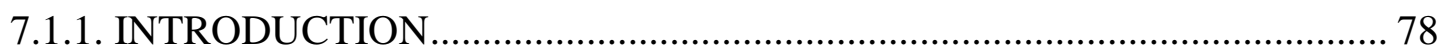

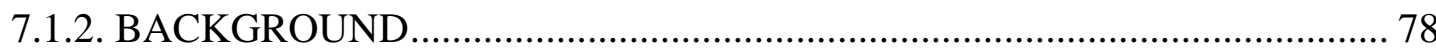

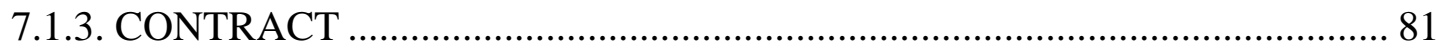

7.1.4. SNOW AND ICE REMOVAL ALTERNATE …………………………….... 85

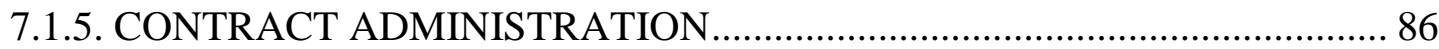

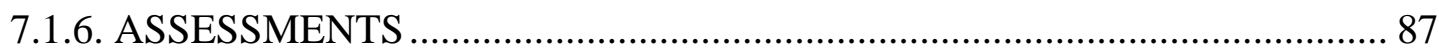

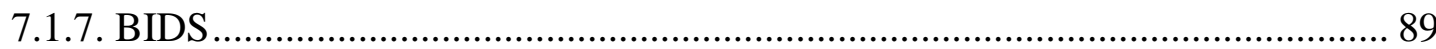

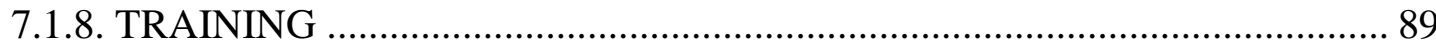

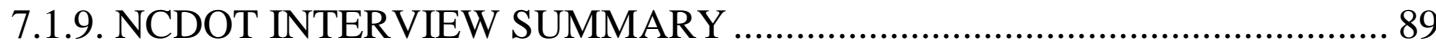

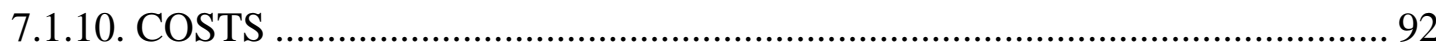

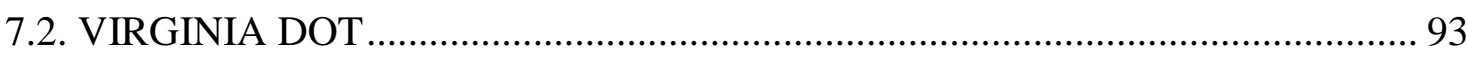

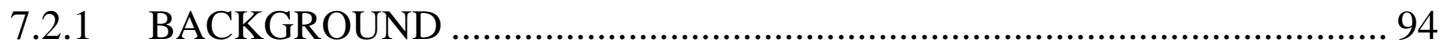

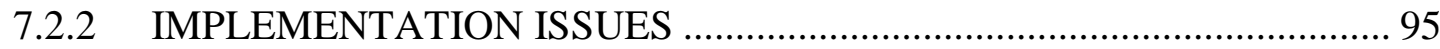

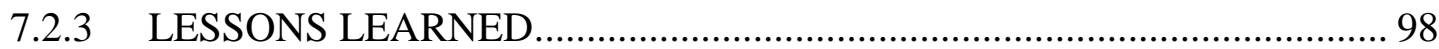

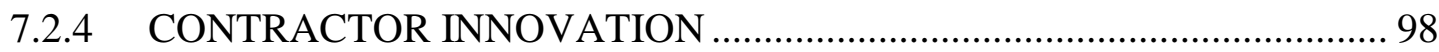

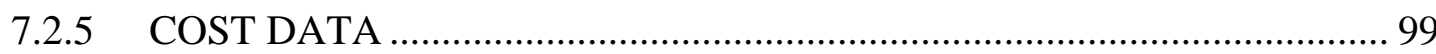

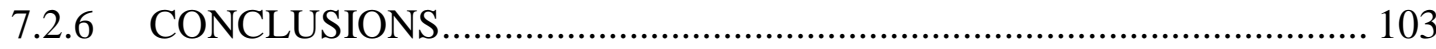

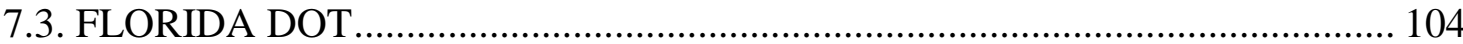

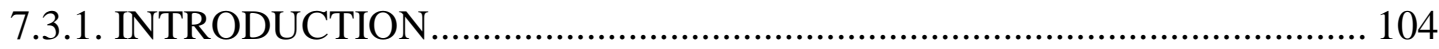

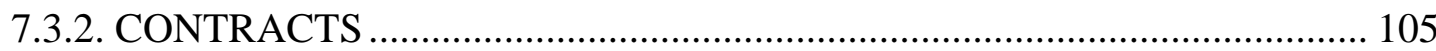

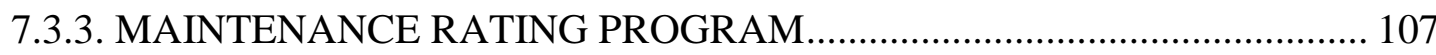

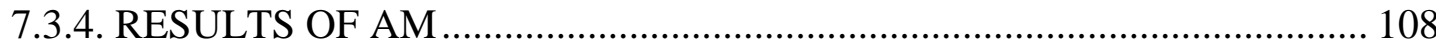

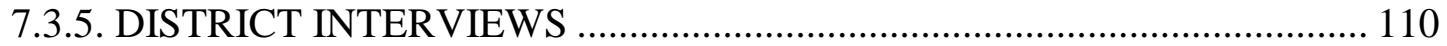

7.3.5.1 MIDWAY ................................................... 110

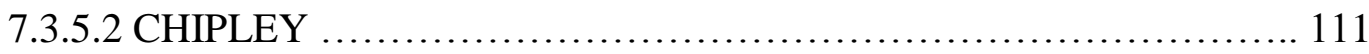

7.3.6. DISTRICT MAINTENANCE ENGINEERS INTERVIEW ........................ 113 


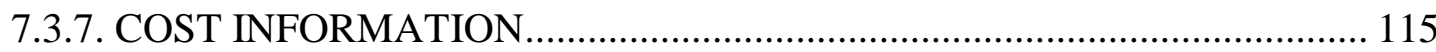

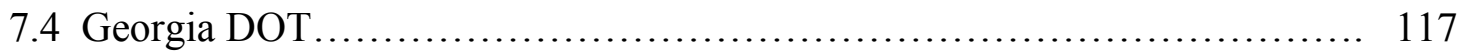

7.5. CONTRACTOR INTERVIEWS AND MEETINGS ………………………....... 118

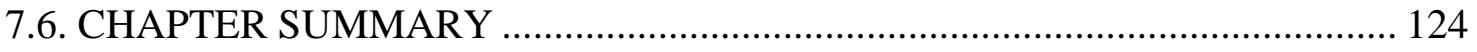

CHAPTER 8. CONCLUSIONS AND RECOMMENDATIONS .................................125

8.1. RESULTS OF THE INTERVIEWS AND MEETINGS................................... 125

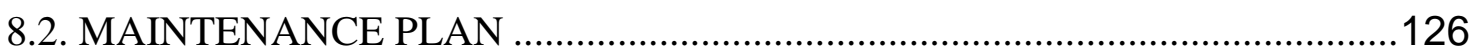

8.2.1 OPTION - INCREASE RESOURCES........................... 132

8.2.2 OPTION - INCREASE SUBCONTRACTS ........................ 132

8.2.3 OPTION - PBC PROGRAM ...................................... 133

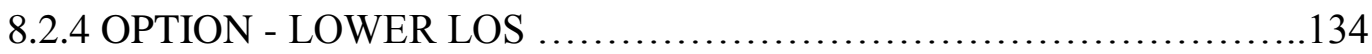

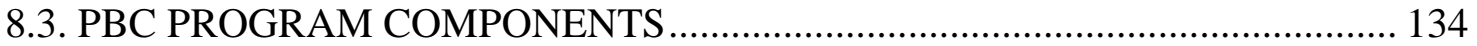

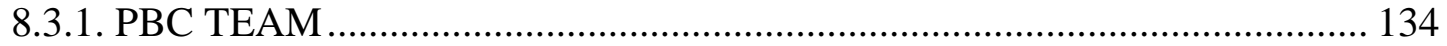

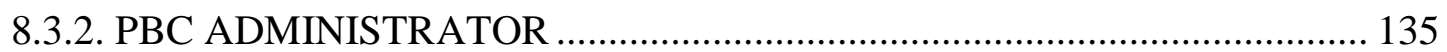

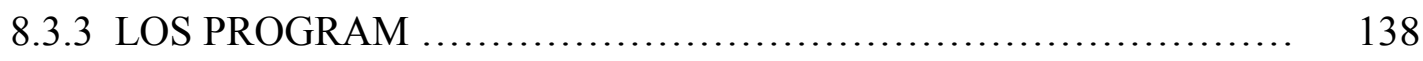

8.4. AGENCY AND CONTRACTOR COMPARISON ………............................. 142

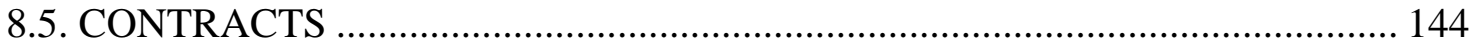

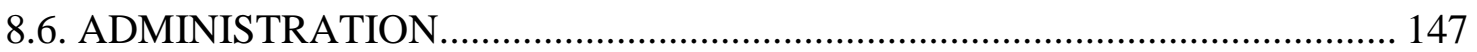

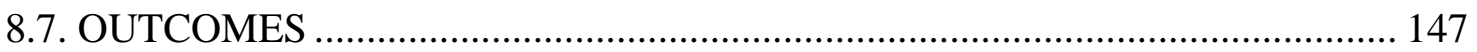

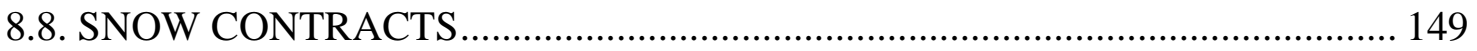

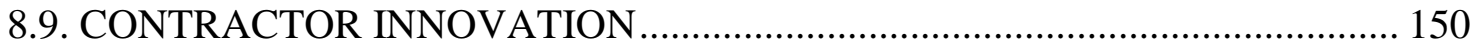

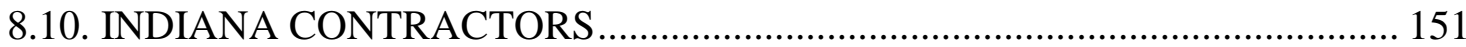

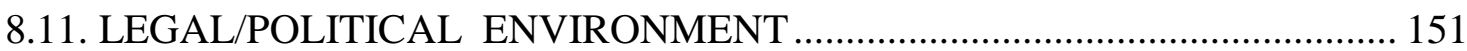

8.12 COST ANALYSIS ..................................................... 152

8.12.1 OVERHEAD COSTS ............................................ 153

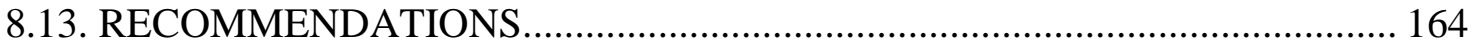

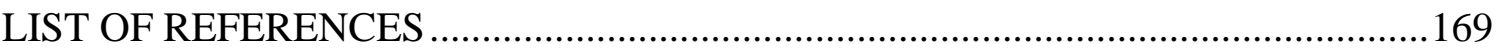

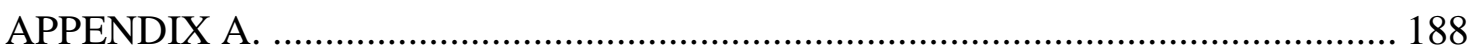

APPENDIX B NEW ZEALAND PERFORMANCE MEASURES............................ 189

APPENDIX C WASHINGTON DC PERFORMANCE MEASURES. ...................... 191

APPENDIX D TEXAS PERFORMANCE MEASURES........................................... 192

APPENDIX E VDOT PERFORMANCE MEASURES ............................ 194

APPENDIX F FDOT AM CONTRACT ........................................ 207

APPENDIX G TXDOT PBC CONTRACT .................................. 258

APPENDIX H NCDOT PBC CONTRACT .................................. 276

APPENDIX I VDOT TAMS CONTRACT

APPENDIX J NCDOT SNOW \& ICE REMOVAL CONTRACT

APPENDIX K FDOT MRP

APPENDIX L TXDOT OVERHEAD ACCOUNTS 


\section{LIST OF TABLES}

Table

Page

3.1 INTERNATIONAL CONTRACTS' DATA TYPES AND SOURCES..............29

$3.2 \quad$ U.S. CONTRACTS DATA TYPES AND SOURCES .....................................30

4.1 EXAMPLES OF PERFORMANCE STANDARDS APPLIED IN DIFFERENT

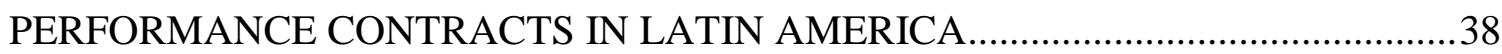

4.2 EXAMPLE OF PERFORMANCE STANDARDS APPLIED IN VIRGINIA PBC 39

4.3 PERFORMANCE CONTRACTS IN LATIN AMERICA 44

5.1 REPORTED COST SAVINGS OF DIFFERENT COUNTRIES UNDER PBC OVER CONVENTIONAL CONTRACTS 59

5.2 COST COMPARISON OF PBC, METHOD-BASED CONTRACTING AND FORCE ACCOUNT FOR 2007/2008 BY FDOT

5.3 PENALTIES FOR NON-COMPLIANCE WITH MANDATORY

REQUIREMENTS: CASE OF CREMA IN ARGENTINIA .....................................66

5.4 WEIGHT OF PRICE AND NON-PRICE CRITERIA IN THE PBC

PROCUREMENT PROCESS IN DIFFERENT COUNTRIES ..................................68

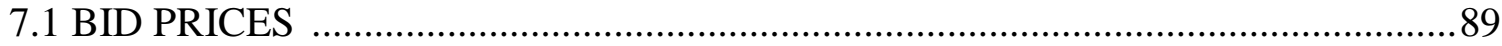

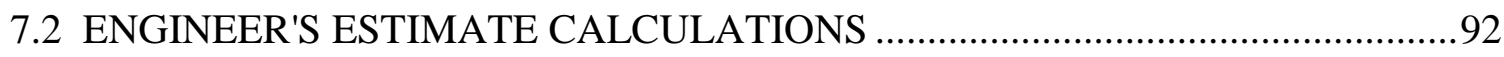

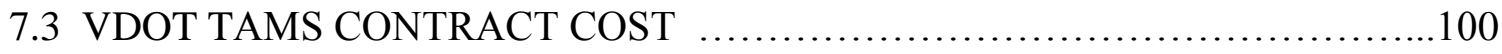

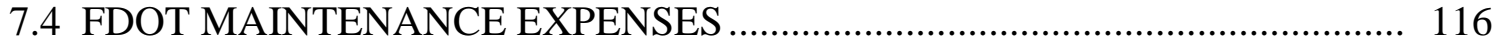

8.1 SNOW ROUTE ANALYSIS BY DISTRICTS ........................................... 127

8.2 POSSIBLE SNOW ROUTE REQUIREMENT BY YEAR .............................. 130

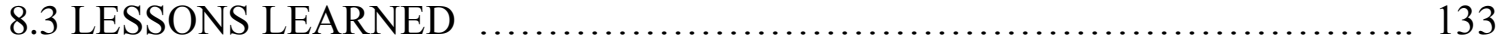

8.4 PBC ADMINISTRATOR - CONTRACT DEVELOPMENT PHASE DUTIES .135

8.5 PBC ADMINISTRATOR - ADMINISTRATION PHASE DUTIES ........... 137

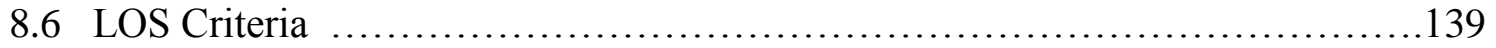

8.7 AGENCY AND CONTRACTOR COMPARISON ........................ 143

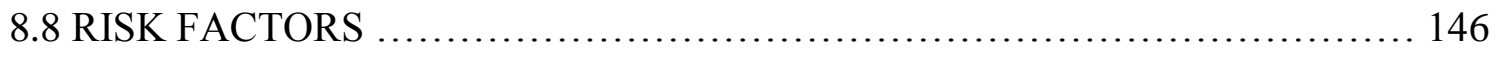

8.9 PBC PROGRAM RECOMMENDATIONS ............................ 166 


\section{LIST OF FIGURES}

Figure

Page

FIGURE 2.1 STUDY FRAMEWORK 12

FIGURE 4.1 PERFORMANCE-BASED CONTRACTS GLOBALLY [SOURCE: WORLD BANK, 2006] 44

FIGURE 4.2 PERFORMANCE-BASED CONTRACTS IN THE U.S. [U.S. MAP SOURCE: MAPS.COM] 46

FIGURE 4.3 MONTHLY EVALUATION RATING RESULTS (UNTIL JUNE 2004) PBC IN WASHINGTON D.C. [SOURCE: ROBINSON ET AL., 2005]

FIGURE 4.4 MONTHLY EVALUATION SCORES (UNTIL JUNE 2004) - PBC IN WASHINGTON D.C. [SOURCE: ROBINSON ET AL., 2005] ......................... 49

FIGURE 4.5 ANNUAL OBJECTIVE EVALUATION OF THE PBC IN WASHINGTON D.C.

[SOURCE: ROBINSON ET AL., 2005].... 50

FIGURE 4.6 COMPARISON OF MONTHLY AND ANNUAL SCORES OF THE PBC IN WASHINGTON D.C. [SOURCE: ROBINSON ET AL., 2005]....

FIGURE 5.1 PROCEDURE FRAMEWORK FOR PBC IMPLEMENTATION $(4+10$ STEPS TO PBC)

FIGURE 7.1 NCDOT PBC CONTRACT MAP

FIGURE 7.2 FDOT MAINTENANCE EXPENDITURE CURVES 116 Figure 7.3 FRAMEWORK FOR ROAD AGENCY AND CONTRACTOR INTERVIEWS AND MEETINGS 119

Figure 8.12.1. TXDOT Decision Tree. 


\section{CHAPTER 1 INTRODUCTION}

\subsection{Background and Problem Statement}

Performance-based contracting (PBC) emphasizes that all aspects of an acquisition be structured around the purpose of the work to be performed, as opposed to the manner in which the work is to be performed or broad, imprecise statements of work which preclude an objective assessment of contractor performance (OMB, 1998). It is designed to ensure that: (a) contractors or facility lessees are given freedom to determine how to meet the agency's performance objectives, (b) appropriate performance quality levels are achieved, and (c) payment is made only for services that meet these levels (Zietlow, 2005). Performance-based contracting for facility preservation has been widely practiced in Europe and Australia, but its inception in the United States is relatively recent. This study focuses on outsourcing maintenance of existing roadway sections.

The impetus for PBC for facility preservation and maintenance arises from a variety of factors that characterize the current roadway operating, financial and human resource environment. First is the issue of manpower. Since the 1980s, state highway agencies have implemented programs aiming at significantly reducing their personnel. As a result of such downsizing initiatives and the gradual aging of the baby boomer generation, the cumulative impact of these developments has been the depletion of the knowledge base and increasing scarcity of experienced personnel to provide close supervision and inspection of highways. Hence, it is becoming more and more appropriate to outsource the maintenance of roadway sections, allowing minimal supervision and inspection by the agency and maximum focus on the final product performance throughout the contract period. 
Another impetus is Statement 34 (GASB-34) of the government Accounting Standards Board (GASB) that emphasizes operational and financial accountability of state agencies for their infrastructure and encourages them to seek and implement the most cost-effective means of using tax-payer funds. It is envisaged that the adoption of innovative contracting practices to long-term maintenance facility outsourcing, will allow state roadway agencies render a better account of their stewardship of the public assets. Finally, recent research on innovative contracting methods for facility maintenance suggests that such practices can yield long-term benefits (Singh et al., 2004).

The results of the study attempt to compare the relative costs and benefits of traditional facility preservation practices (using traditional contracting and force account) vs. outsourced facility maintenance using $\mathrm{PBC}$ and other innovative contracting methods. The findings are expected to help improve the agency's public accountability as the costs and benefits of outsourced (or traditional) projects can be more clearly described to the public. A key aspect for the implementation of $\mathrm{PBC}$ is that the state agency and the contractor have conflicting economic interests. While the objective of the agency is to minimize the life cycle cost, the objective of the contractor is to maximize its own monetary profit. Obviously, a trade-off is required. The study provides insights for such trade-offs. Rules and guidelines are developed to help the agencies implement an optimal solution.

\subsection{Objectives of the Present Study}

The general objective of the study is to investigate the feasibility of innovative (performance-based) methods of contracting (including long-term outsourcing) for maintaining existing facilities. Guidelines that objectively state the facts learned from analyzing PBC are developed, and maintenance options that include PBC and road agencies' maintenance forces, are described. Specific objectives are to answer the following critical questions: 
- How to select facilities (pavement sections, bridges etc.) or project types (reconstruction, maintenance) for implementation of performance-based contracting.

- What are the items to consider in preparing performance-based maintenance contracts and agreements for various facilities and project types (size of project, choice of sections by road or by geographic area).

- Which activities are better performed in-house, and which, potentially, need to be privatized (in general, and under $\mathrm{PBC}$ in particular).

- How to identify monetary and non-monetary benefits and costs associated with performance-based contracts (how to measure cost).

- Comparison of traditional and performance-based contracts on the basis of their life-cycle costs and benefits.

- What are the requirements for creating, contracting, monitoring, and managing a PBC system at INDOT.

- How is risk (liability issues) defined and treated under performance-based contracting.

- How do you establish a Level of Service (LOS) program and its importance to INDOT's Operations.

- Recommendations to INDOT on the use of PBC.

\subsection{Scope of the Study}

The scope of the present study is carefully defined to address the problem statement in a comprehensive manner, while maintaining a realistic approach based on data availability. Various aspects of the study scope are described next.

\section{Coverage}

While INDOT does not have experience in performance-based contracting, the agency is familiar with privatizing some maintenance and/or rehabilitation activities 
(e.g., mowing, pavement resurfacing). In particular, warranty provision contracts involving hot-mix asphalt pavement, erosion control projects, and micro-surfacing have been used by INDOT (Singh, 2004). The present study focuses on maintenance activities. To comparatively assess in-house vs. outsourcing practices, and the contracting methods used under privatizing maintenance activities, contract information and characteristics of the same project under the in-house and the outsourcing modes were collected. The experience of other U.S. states and countries were also examined and documented in literature review and through interviews. Also included is a comprehensive analysis of PBC contracting and how it could impact INDOT if adopted.

\section{$\underline{\text { Work Description and Maintenance Status }}$}

As discussed earlier, although INDOT has no PBC experience, privatizing maintenance and rehabilitation activities is usual practice for the agency. In the past, INDOT has let out warranty contracts for pavement work mainly consisting of resurfacing, restoration, rehabilitation, and reconstruction work. Also, erosion control and mowing projects have been successfully outsourced. However, the vast majority of routine maintenance activities is performed in-house.

\subsection{Workplan: Overview of the Study Approach}

To answer the questions listed above, two tasks were implemented: a thorough literature review, and development of guidelines for performance-based contracting for facility maintenance. The three tasks are described below.

Task 1: Literature Review and Information Search. This task involved a detailed review of published research (publications and reports) on innovative performancebased contracting, particularly with respect to facilities outsourcing. This included documents on the best practices and lessons learned in PBC 
contracts and agreements, referring to various contracting methods for roadway preservation and maintenance. The limitations and benefits of these methods were comprehensively reviewed and discussed. Specifications that have been applied in traditional, innovative and performance-based contracts were reviewed. Finally, case studies of detailed analysis for past or ongoing PBC projects in the U.S. and worldwide are presented.

Task 2: Analysis and guidelines for performance-based contracting for facility maintenance. In this task, all facets of PBC contracting was analyzed and described. A similar analysis of Indiana conditions and INDOT operations was made. Consequently, the following were considered:

- Items for maintenance (main line pavement, paved and unpaved shoulders, traffic signs and signage, markings, row posts, fences, bridges, tunnels, culvert, ditches, gutters, drainage, delineators, emergency facilities, guardrail, illumination, landscape, litter removal, electrical and cable systems, mowing, rest areas, vegetation and tree control and removal).

- Contractual items : (a) contract delivery method (proposal or bid or negotiation) ; (b) bonding issues (bonding time period determination) ; (c) dealing mechanism for operation and maintenance of new construction and structural failures during the contracting period, (d) early termination of the contract (definition of reasons ; resources to recover financial losses ; contract renewal option) ; (e) payment terms, and (f) liability (INDOT's "umbrella" in third party liability).

- $\quad$ PBC advantages for INDOT (higher operational-maintenance-preservation level of service benefits ; cost savings ; alternative personnel usage opportunity cost - no layoffs ; overall higher network's level of service). 
An overview of the study approach used to address the problem statement is presented in Figure 1.1. First, the study objectives are established. Next, published literature on performance-based contracting and outsourcing are extensively reviewed, in order to document the current status of contracting methods in the roadway industry, to assess the position of INDOT's outsourcing program in relation to other states and countries, and to describe the U.S. and international experiences. 


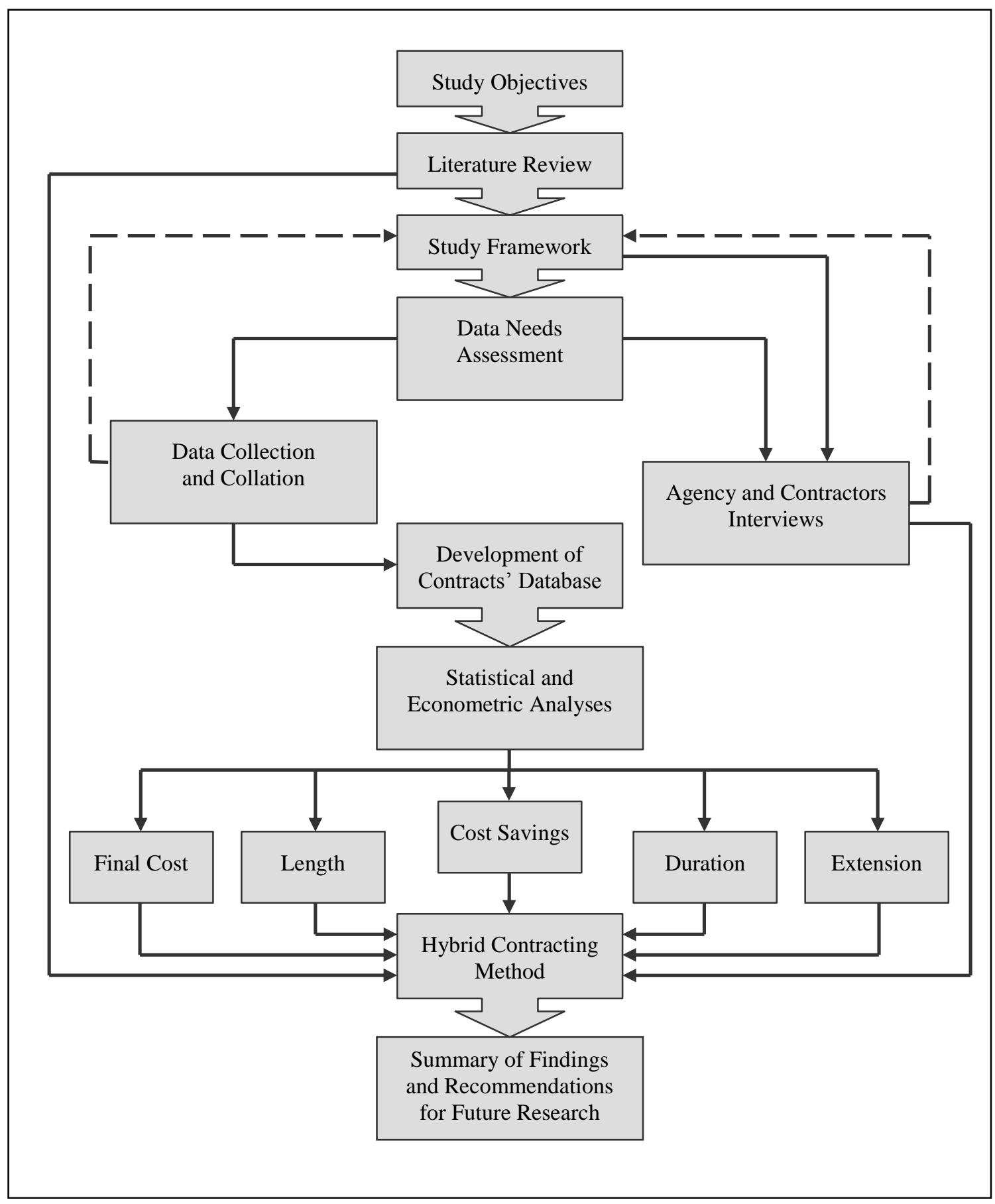

Figure 1.1 Study framework

A comprehensive and systematic study framework is also developed, and the data needs are carefully assessed to ideally fulfill the study objectives. Based on data availability, suitability, and the feedback from various resources, the study methodology 
was modified at various stages to address the research objectives in a generic manner. One of the main aspects of the study is the cost evaluation which therefore involved indepth analysis of the contracts' size, duration, extension, and length. Costs and characteristics of outsourcing and PBCs are therefore identified and quantified.

The analysis is also supplemented by interviews with several U.S. and international agencies' and contractors' officials, that were conducted to obtain information on the experiences, observations and evaluations on the effectiveness of performance-based contracts on maintenance projects. The final part of the study summarizes the findings, provides concluding remarks, and gives directions for implementing $\mathrm{PBC}$ at INDOT.

\subsection{Organization}

Chapter 1 of this study introduces the concepts and the state-of-practice of performance-based contracting in roadway maintenance and preservation, outlining the study's objectives and scope, and providing an overview of the study framework. Chapter 2 reviews the literature on outsourcing and contracting methods used when maintenance projects are privatized, investigates the emerging need for alternative contracting approaches, and discusses definition and issues concerning the traditional and innovative contracting methods. Chapter 3 describes the data collected for a statistical analysis. Chapter 4 describes historically and the current state of Performance Based Contracting. Chapter 5 focuses on performance-based contracting ; the PBCs' scope, assets, services, reasons for implementation, characteristics (performance standards, risk allocation, performance monitoring, accountability, payment issues, etc.), and U.S. and international implementation experiences are presented. In Chapter 6, the advantages and limitations of the presented contracting methods are illustrated, and PBCs are compared to the other methods. In Chapter 7 Agency and Contractor Interviews are described, and Chapter 8 deals contains Conclusions and Recommendations. 


\section{CHAPTER 2. LITERATURE REVIEW}

\subsection{Introduction}

The management of roadway maintenance has become increasingly complex over the years due to significant traffic growth and limited maintenance resources. In view of this, it is desired to implement innovative techniques that would result in efficient maintenance policies and potential cost savings. Consistent with this, government road agencies around the world are restructuring their traditional maintenance practices including privatization of the maintenance of entire sections of roadway/bridges.

Implementation of new contracting methods in roadway/bridge maintenance (and/or construction) should be preceded by a thorough review of available literature to assertain the feasibility of such methods. In the present study, an attempt has been made to document available information on innovative contracting methods in the United States and abroad. This chapter presents a comprehensive literature review that aims to develop a basic understanding of the concept and operation of innovative contracting methods.

\subsection{Reasons for Outsourcing}

A question that has been raised during the last few decades is "Why Outsource" road assets, activities, and/or services? It has been agreed that without tentative attention, roadway conditions will only continue to worsen. Government agencies are faced with uncertain fiscal results and public contestation; hence, governments need to start "doing more with less" (Zietlow, 2005). Outsourcing through public-private partnerships offers a solution to improve quality and save money. The goals that government agencies 
typically seek to achieve by outsourcing road segments are as follows (Segal et al., 2003):

(a) Reduce Costs: achieving cost savings is one of the most important reasons for outsourcing road and highway construction and maintenance operations. However, cost savings is not the only issue ; level of service, quality of the constructed, maintained and operated assets, and human resources are often disregarded. Hence, cost savings should not be considered as the only factor in determining whether to outsource or not.

(b) Increase Efficiency: literature has shown that a competitive system is more efficient and effective than traditional single-provider systems. In order to obtain the maximum possible value for money, some government agencies have outsourced their projects as part of efforts to improve overall system efficiency through competition and specialization. Outsourcing introduces competition, resulting in improvement of the government agencies' services. Since government services are threatened by a probable privatization, they need to become more efficient and finally provide better services to compete with the private sector.

(c) Improve Quality: in order to be more competitive, private agencies need to produce high quality work and ensure high performance. Besides, one of the most important factors for the awarding of contracts is past performance; hence, delivering low quality service could reduce the likelihood that a private agency is awarded future contracts.

(d) Motivate Innovation: outsourcing through public-private partnerships can produce innovative solutions. Since the overall goal to private agencies is profit, they try to achieve it by applying new methods in all levels ; this way, they become both more competitive and capable of producing higher quality services.

(e) Access Expertise: competitive private agencies typically have worked on various projects. As such, their experience is very significant; government 
agencies that employ such expertise can thus gain access to new and/or specialized expertise that is not available in-house.

(f)

Precipitate Project Delivery: government agencies do not have the required work force to maintain the existing infrastructure ; on the other hand, the private sector is flexible on shifting human resources in order to meet time constraints. There are exceptions to this because in responding to severe weather events, hurricanes or winter storms, DOTs are much better prepared and experienced than private contractors.

(g) Increase Flexibility: outsourcing to increase flexibility is related to meeting peak demand. Agencies can use contractors when needed, an option that is not feasible in the case of the agency employees.

\subsection{Definitions and Issues: Traditional Contracting}

The traditional approach to contracting for roadway construction projects has been design-bid-build using the lowest bid criterion, in which design is carried out independently of the construction process. After the owner/agency approves the design, the project proceeds to the construction phase. Under this approach, construction projects are awarded to the qualified bidder with the lowest total price, pay items are established on a unit-price basis, specifications are strictly focused on materials and method, and the role of the owner/agent is to inspect the construction and to preserve the facility after it has been constructed.

According to the evaluation report of the Utah I-15 National Test Bed (UDOT, 2001), government agencies have relied on competitive bidding to award roadway construction contracts. This process involves using detailed plans from the design phase, providing specifications and estimates for the work involved, soliciting of bids through public advertisement, and awarding the contract to the lowest responsible responsive bidder. 
Carpenter et al. (2003) underlines that "the basic intent of this approach is to minimize risk to the contractor by defining all requirements of the project and eliminating most unknown conditions". Any errors and omissions in the plans or unforeseen work is the responsibility of the agency. Quality is sought through prescriptive plans and specifications coupled with construction oversight and inspection by the public agency. Competitive bidding among contractors can help to control cost. The traditional lowest-and-responsive bidder system is used in most developed countries. Most contractors are comfortable with the procedure, understand its risks and rewards, and consider it fair.

Traditional contracts for roadway maintenance operations are similar to roadway construction contracts ; they are unit- or work-order oriented. Contracting agencies are paid for the amount of the work they do; not on the quality of the work that is provided. The activities that can be contracted include: maintenance, lane striping, litter removal, snowplowing, and pothole repair. A contract may include all maintenance activities on a set of roads. The amount of work can be increased or decreased by the contracting agency, and contracts are usually limited to one year with option of two more years' extension/prolongation.

In traditional contracts, there is little or no flexibility in determining work methods, as the contracting agency typically defines the work processes. In practice, the contractor follows the agency's procedures. Such method discourages innovation but reduces costs, gains access to workforce and staff, and achieves quality and efficiency improvements (Segal et al., 2003).

\subsection{Motivation for Alternative Contracting Approaches}

The need for alternative contracting methods to address some of the limitations of traditional contracting methods has been recognized as follows: 
(a) Reducing Time: a major factor for the use of innovative contracting methods is reducing the project duration (either if the scope is construction or maintenance). A challenge faced by government agencies is the growing roadway congestion that impedes on-time project completion. The time overruns typically experienced in low-bid contracting have to be reduced.

(b) Applying Improved Technology and Techniques (Carpenter et al., 2003): a departure from the traditional contracting approach is needed to take maximum advantage of advances in technology and techniques relating to construction materials, equipment, and methods. These innovative techniques and materials improve quality and reduce the duration of the construction project, and normally result in lower life-cycle costs.

(c) Deploying Contractor Innovation (Carpenter et al., 2003): the experiences and innovations by the construction industry can be implemented (for construction or maintenance operations) under innovative approaches. Innovative contracting methods provide incentives to the contractor to accept more risks and responsibility for providing higher product and service quality at lowest cost and within a shorter period of time. These new methods and specifications are expected to reduce the public impact of roadway construction and maintenance operations by accelerating the project, improving the quality and generally reducing costs.

(d) Reducing Impacts on the Public (Carpenter et al., 2003): roadway construction and maintenance projects have great impact on the public. Innovative contracting methods can reduce the time related to construction and maintenance operations ; this means shorter times driving through and around work zones and improving safety and productivity. In addition, the use of technologies, materials, and techniques that reduce noise and other environmental and socio-cultural impacts (water and wetlands pollution, air quality, social and cultural degradation, etc.) invariably reduce the public impacts of roadway construction and maintenance. Innovative contracting 
mechanisms offer the opportunity to reduce the negative impacts often associated with construction and maintenance.

\subsection{Innovative Methods of Contracting}

Starting in the mid-1980s, several initiatives were undertaken that led to significant changes in roadway contracting. National roadway agencies began to allow national, regional and local roadway departments to try innovative contracting approaches on federally funded projects. Several efforts were initiated to identify and promote the use of innovative contracting (Hancher, 1999). In subsequent subsections of this section, different innovative contracting methods used by government agencies for roadway construction, maintenance and operation contracts, are presented ${ }^{1}$.

\subsubsection{Warranty Clauses}

Warranty clauses provide an assurance to the owner that the product/service will serve its useful life without failure and if it does not, the contractor will repair or replace the product. Performance bonds are currently used in almost all government-funded projects to guarantee satisfactory materials and workmanship of the contractor during the project and up to one year (for traditional contracts) and several years (for warranty contracts) after project completion and acceptance. The premise is that warranties motivate the contractor to do a higher quality job than the one that would be done without such assurance of quality by making the contractor responsible for maintenance costs (Singh, 2004).

Two types of warranties are currently used in roadway construction and maintenance operations: (i) materials and workmanship warranties, and (ii) performance warranties. These warranty types differ by the degree to which the contractor is liable for

\footnotetext{
${ }^{1}$ These contracting methods are not mutually exclusive and can be combined in a single project. Although most of the innovative contracting methods are performance-associated, the terminology found in literature distinguishes the Performance-Based Contracts from the rest of the contracting approaches.
} 
product/service failure. In a materials-and-workmanship warranty, the contractor is responsible only for defects that result from poor materials and workmanship. On the other hand, a contractor undertakes greater responsibility for the product/service in a performance warranty and is responsible for the product/service meeting certain agreed upon performance thresholds. In either case, contractor liability should be properly balanced with the contractor's control of the design, construction and long-term maintenance of the pavement structure throughout the warranty period.

\subsubsection{Design-Build-Operate-Maintain}

Projects using a design-build approach are designed and constructed by a single company or a partnership of companies. Several varieties of design-build have evolved including design-build-maintain, design-build-operate-maintain (D-B-O-M or DBOM), and design-build-operate-maintain-warrant. Each version of design-build provides the government or owner with one source of responsibility for the project. Design-build can be specified in many different ways based on the magnitude of the project (Carpenter et al., 2003). The Innovative Contracting Best Practices Guide ${ }^{2}$ provides the following framework for implementing design-build:

(a) Low-End Design-Build Projects: these are pavement overlay or basic reconstruction projects that have little or no room for innovative design but have tight time constraints. Using design-build allows for the project to be completed faster. These projects are usually emergency projects for which most of the right-of-way, utility, and environmental issues have already been settled, allowing for the design-builder to step in and complete the project. In these reconstruction projects the project life usually is the main driver for implementing the design-build concept, therefore there is generally a maintenance or warranty provision based on certain carefully-worded performance specifications.

\footnotetext{
${ }^{2}$ Utah Technology Transfer Center, Best Practice Guide for Innovative Contracting Procedures.
} 
(b) Mid-Level Design-Build Projects: these refer to projects that use the designbuild concept to bring in new technology to implement the project faster than if the owner had to outsource the design. Unlike the low-end design build projects, these projects can benefit from innovations in design. These projects are usually related to bridge reconstruction or Information Technology Systems, with a high incentive for innovation in the design as well as the construction phases.

(c) Mega Design-Build Projects: those projects use the design-build concept because the traditional design-bid-build process would not allow for funding mechanisms or current infrastructure needs to accomplish the project. In the past, conducting mega-projects required decomposing the project into smaller projects because the funding and resources would not allow for all procedures to be carried out at once. Using the design-build innovative contracting technique allows for the owner to fund the project through the design-builder, and to use the resources of the design-builder to supplement some of its staff to be available for other projects. These projects tend to be time-dependent and very complex in design.

\subsubsection{Cost-Plus-Time (A+B Bidding)}

Cost-Plus-Time, also known as $\mathrm{A}+\mathrm{B}$ bidding or multi-parameter bidding, is a contracting method that not only considers the initial construction/maintenance/ rehabilitation cost in the bidding process, but also takes into account the time needed to complete the project. In order to estimate the cost of time, a road-user cost (in \$/day) is determined and multiplied by the required number of days for completion. The contract is then awarded based on the combined cost of time and construction material and services. Safety, quality, social impacts, and other factors (impacts of: air quality, noise, ecology, water, etc.) can be incorporated into the cost-plus-time contracts to form multiparameter contracts (Carpenter et al., 2003; Herbsman and Glagola, 1998). 


\subsubsection{Incentives/Disincentives}

Incentives/Disincentives (I/D) are commonly (but not exclusively) used in combination with A+B bidding (Carpenter et al., 2003). An Incentive/Disincentive provision is typically used to encourage the contractor to finish the project earlier than the contract bid time. Incentives/Disincentives are set using road-user cost values to calculate the cost of time for the $\mathrm{A}+\mathrm{B}$ bid. As an example, consider a project with $\mathrm{I} / \mathrm{D}$ provisions and a road-user cost of $\$ 10,000$ per day. If the contractor bids 50 days to complete a project and actually finishes 10 days early, the contractor would receive an incentive of $\$ 100,000$ or 10 days multiplied by the road-user cost of $\$ 10,000$. On the other hand, if the contractor finished 10 days late, the contractor would have to pay to the government agency $\$ 100,000$. $A+B$ bidding is not equally effective for all types of projects. $\mathrm{A}+\mathrm{B}+\mathrm{I} / \mathrm{D}$ is typically used for reconstruction, rehabilitation, and remediation projects in urban settings where the public impact is high.

\subsubsection{Lane Rentals}

Lane rental is a contracting provision used to accelerate the completion of a roadway construction or preservation project by assessing the contractor a fee for occupying lanes or shoulders during the work. Charges could be on hourly or daily basis and may vary with the time of day, amount of traffic, and other factors of user costs (Herbsman and Glagola, 1998). A road-user cost is calculated in order to determine the charge for lane closures. Although there is no standard calculation method for the roaduser cost, it is intended to take into account the public impact of lane closures. Cost of delay for the traveling public forms the basis for the road-user cost. A study of lane rentals in the United States and the United Kingdom defined three types of lane rentals currently being used (Herbsman and Glagola, 1998):

(a) The first and most common lane rental method used in the United States is the Lane-by-Lane rental. In this method, the contractor is charged for each time lanes are closed based on a predetermined fee in the bidding package. 
(b) The second method is Continuous Site Rental and is based on a lane rental fee for each day lanes are occupied.

(c) The third method is the Bonus/Rental Charge method. Like A+B bidding, it awards the contract based on a combined cost of work items cost and cost of time. In Bonus/Rental Charge method, the cost of time is based on the duration of lane closures and lane rental fees.

\subsubsection{Performance-Based Contracting (PBC)}

The traditional way of contracting out road construction and maintenance is based on the amount of work being measured and paid for on agreed rates for different work items. By contrast, Performance-based road construction and maintenance contracts define the minimum physical conditions of road, bridge, and traffic assets that have to be met by the contractor.

Payments are based on how well the contractor manages to comply with the performance standards defined in the contract, and not on the amount of work and services executed. PBC defines a final product/service and it is up to the contractor to achieve this target. Hence, work selection, design, construction and delivery are all the contractor's responsibility. Thus, the choice and application of technology and the adoption of innovative materials, processes and management are all left to the contractor. This means a higher risk to the PBC contractor compared to the traditional contract or, yet opens up opportunities to increase profit margins, especially where improved efficiencies and effectiveness of design, process, technology or management are able to reduce the cost of achieving the specified performance standards (Zietlow, 2005).

Most state agencies are handcuffed in that contracts are awarded only by low cost. When it comes to getting the best maintenance services this is not the best approach. Some agencies are using the best value and best and final offer approach which requires legislative approval. Best value offer process is when shortlisted contractors make a technical presentation and then submit a bid. The bid is evaluated by giving weights to 
the technical and cost components. For example technical may have $70 \%$ and cost $30 \%$ weights, so low cost may not be the best bid. Once a bid is submitted, then the details of the bid can be discussed. Discussion includes contract language, how interpreted, how that influenced their bid. Award can be made if the bid is within $10 \%$ of the engineer's estimate.

The best and final offer process occurs after the bids are opened. If the bids come back higher than the engineer's estimate, an agency can choose to do best and final offer. All the bidding contactors are interviewed and asked about risks, why the bid was high. They are given the option of changing or modifying their proposal and offered another opportunity to second bid based on those modifications. If the modified bid is within $10 \%$ of the estimate, award can be made. North Carolina uses this approach. More information on their contract and other details of their program is found in Chapter 7.

\subsection{Chapter Summary}

In spite of the abundance of opportunities offered by progress in technology, traditional design-bid-build contracting remains the approach commonly used by most government road agencies. However, there is a tremendous amount of effort focusing on the development and application of new contracting methods, aiming at reducing the service time and focusing on the reduction of time overruns, reducing cost, applying improved technology and techniques relating to construction materials, equipment, and methods, deploying contractor innovation to accelerate the project and improve the quality, and reducing public impacts. These innovative contracts have found their way into construction contracts but not maintenance with the exception of best value. 


\section{CHAPTER 3. DATA COLLECTION AND COLLATION}

\subsection{Introduction}

Existing literature addresses most of the performance-based contracting issues, including $\mathrm{PBC}$ characteristics (performance standards, liability issues, performance monitoring, operational functions, etc.), and quantitative (reported costs) and qualitative (road assets condition improvement, road users' satisfaction, etc.) comparisons of inhouse and innovative contracting practices. To better discuss the findings of the literature review, meaningfully justify some of the reported trends, and to address the main objectives and scope of this study, a thorough effort was made to acquire data that would provide answers and also to pose key questions on performance-based contracting. This chapter describes the data items and sources that were collected, documented, and critically reviewed.

\subsection{Data Origin}

For the present study, 1996 to 2007 contract data from the U.S. and abroad were used. Originally, there were $449^{3}$ contracts considered in the analyses (17 projects with Incentives/Disincentives clauses (I/D), 114 Warranty projects, 111 performance-based

\footnotetext{
${ }^{3}$ Analytically, 3 contracts originated from Argentina, 9 from Australia, 2 from Brazil, 1 from Burkina Faso, 1 from Cambodia, 6 from Canada, 1 from Cape Verde, 2 from Chad, 2 from Colombia, 1 from Democratic Republic of Congo, 3 from Denmark, 1 from Egypt, 1 from Estonia, 3 from Finland, 2 from Guatemala, 2 from Honduras, 1 from India, 1 from Lithuania, 1 from Madagascar, 2 from Nepal, 3 from New Zealand, 2 from Nicaragua, 2 from Paraguay, 3 from Peru, 3 from Philippines, 3 from Serbia and Montenegro, 2 from South Africa, 1 from Sweden, 2 from Tanzania, 1 from Thailand, 3 from the U.K., 2 from Uruguay, 374 from the U.S., 1 from Yemen and 2 from Zambia. It should also be noted that all the contracts that originated outside the U.S. were PBCs, whereas the ones that originated from the U.S., were I/D (14 contracts), Warranty clauses (114 contracts), Performance-Based Contracts (36 contracts), Traditional contracts (181 contracts), DBOM (6 contracts), Lane Rentals (6 contracts), and Cost-Plus-Time (A+B Bidding) projects (17 contracts).
} 
contracts, 181 Traditional contracts, 17 Cost-Plus-Time projects (A+B), 6 Design-BuildOperate-Maintain projects (DBOM), and 6 Lane Rentals), originating from Africa (13 contracts), Asia (5 contracts), Europe (15 contracts), Latin America (20 contracts), North America (380 contracts), and Pacific (15 contracts). Out of the 268 U.S. contracts, 7 were from Texas (all PBCs), 203 from Virginia (7 I/D, 96 Warranties, 14 PBC, 85 Traditional, and 1 Cost-Plus-time), 57 from Indiana (5 Warranties and 52 Traditional contracts), and 1 (PBC) from Alaska.

The data were collected and collated from the Word Bank Resource Guide Performance-based Contracting for Preservation and Improvement of Road Assets (http://www.worldbank.org/transport/roads/resource-guide/Country-Matix.htm), the Government of British Columbia - Ministry of Transportation - Highway Maintenance Contracts (http://www.th.gov.bc.ca/BCHighways/contracts/maintenance), the Republic of Serbia - Road Directorate (http://www.worldbank.org/transport/roads/resource-guide/ Docs-latest edition/bidding docs/serbia), the United Republic of Tanzania - Ministry of Works - Tanzania National Roads Agency (http://www.worldbank.org/ transport/roads/resource-guide/Docs-latest edition/bidding docs/tanzania), U.S. DOT FHWA (http://www.tfhrc.gov/focus/jan05/01.htm), G. Zietlow's PBC for Road Management and Maintenance website (http://www.zietlow.com), and from other resources (Zietlow, 2005 ; Zietlow, 2004 ; Stankevich et al., 2005 ; Pakkala, 2002 ; Pakkala, 2005 ; PIARC-Canada, 2004 ; Williams, 2005 ; Porter 2002 ; Segal et al., 2003 ; OPPAGA, 1999 and 2003 ; Zietsman, 2005 ; VMS, 2001 ; JLARC, 2001 ; Lande, 2005 ; FHWA, 2002 and 2004 ; Michael Baker Jr. Inc., 1999 ; Robinson and Raynault, 2005 ; Robinson et al., 2005). Also, data were collected from the departments of transportation of the following states: Indiana, Minnesota, Florida, Virginia, Texas, and Alaska. 


\subsection{Data Description}

The data consist of the following variables:

(a) Specific origin of the contracts:

(i) Continent/Region (Africa, Asia, Europe, Latin America, Middle East, North America, Pacific)

(ii) Country (Argentina, Australia, Brazil, Burkina Faso, Cambodia, Canada, Cape Verde, Chad, Colombia, Congo, Denmark, Egypt, Estonia, Guatemala, Honduras, India, Lithuania, Madagascar, Nepal, New Zealand, Paraguay, Peru, Philippines, Serbia, South Africa, Sweden, Tanzania, Thailand, UK, Uruguay, USA, Yemen, Zambia)

(iii) State or province (Alberta, British Columbia, Florida, Minnesota, New South Wales, Ontario, Portsmouth, Queensland, Tasmania, Texas, Victoria, Virginia, Washington D.C., Western Australia, Indiana, Alaska).

(b) Type of contract (contracting method):

(i) Cost-Plus-Time (A+B Bidding)

(ii) Design-Build-Operate-Maintain (DBOM)

(iii) Incentives/Desincentives (I/D)

(iv) Lane Rentals

(v) Warranties

(vi) Performance-based contracts (PBC)

(vii) Traditional contracting.

(c) Contract characteristics:

(i) Duration of the contract (converted and measured in years)

(ii) Extension (prolongation) of the contract's duration (measured in years)

(iii) Length of the outsourced road segments incorporated in the contract (converted and measured in lane-miles)

(iv) Specific location of the road segments that are incorporated in the contract (Interstate Highways, or Local Roads)

(v) Number of activities included in the contract. 
(d) Specific road assets/activities incorporated in the contract:

(i) Bridge-tunnel repair/maintenance/management

(ii) Crack sealing or pothole repair

(iii) Culvert/ditches/gutters/drainage repair/maintenance/replacement

(iv) Emergency facilities maintenance/response

(v) Guardrail repair/maintenance

(vi) Illumination repair/maintenance

(vii) Landscape repair/maintenance

(viii) Litter removal

(ix) Electrical/cable system repair/maintenance

(x) Mowing

(xi) Pavement repair/maintenance/treatment

(xii) Rest areas

(xiii) Shoulder repair/maintenance

(xiv) Traffic signs and signals

(xv) Vegetation/tree control/maintenance/removal

(xvi) All services ${ }^{4}$.

(e) Contracts' cost characteristics:

(i) Final cost of the contract (final cost of the outsourced contract)

(ii) In-house cost of the contract (final cost of the same outsourced contract's characteristics (number and specific activities, length, duration, etc. $)^{5}$, when performed in-house with the government agency's resources

(iii) Engineer's estimate of the contracted out projects

(iv) Cost savings

(v) Number of bids for the outsourced contract

\footnotetext{
4 In many cases (e.g., some European countries and Argentina) all road assets and activities are incorporated in the contract (usually in PBCs). Instead of outsourcing road assets and activities, road sections are contracted out, where all the activities are subject to maintenance.

${ }^{5}$ To account for some contract characteristics that may have been slightly different, the cost values were converted to USD/lane-mile/year (where the duration and extension/prolongation were aggregated in the year variable), and then extrapolated to form the final amounts.
} 
(vi) Highest bid for the outsourced contract

(vii) Difference between the awarded and highest bids.

The data needs identified and collected from the aforementioned sources are summarized in Tables 3.1 (international contracts) and 3.2 (U.S. contracts).

Table 3.1 International contracts' data types and sources

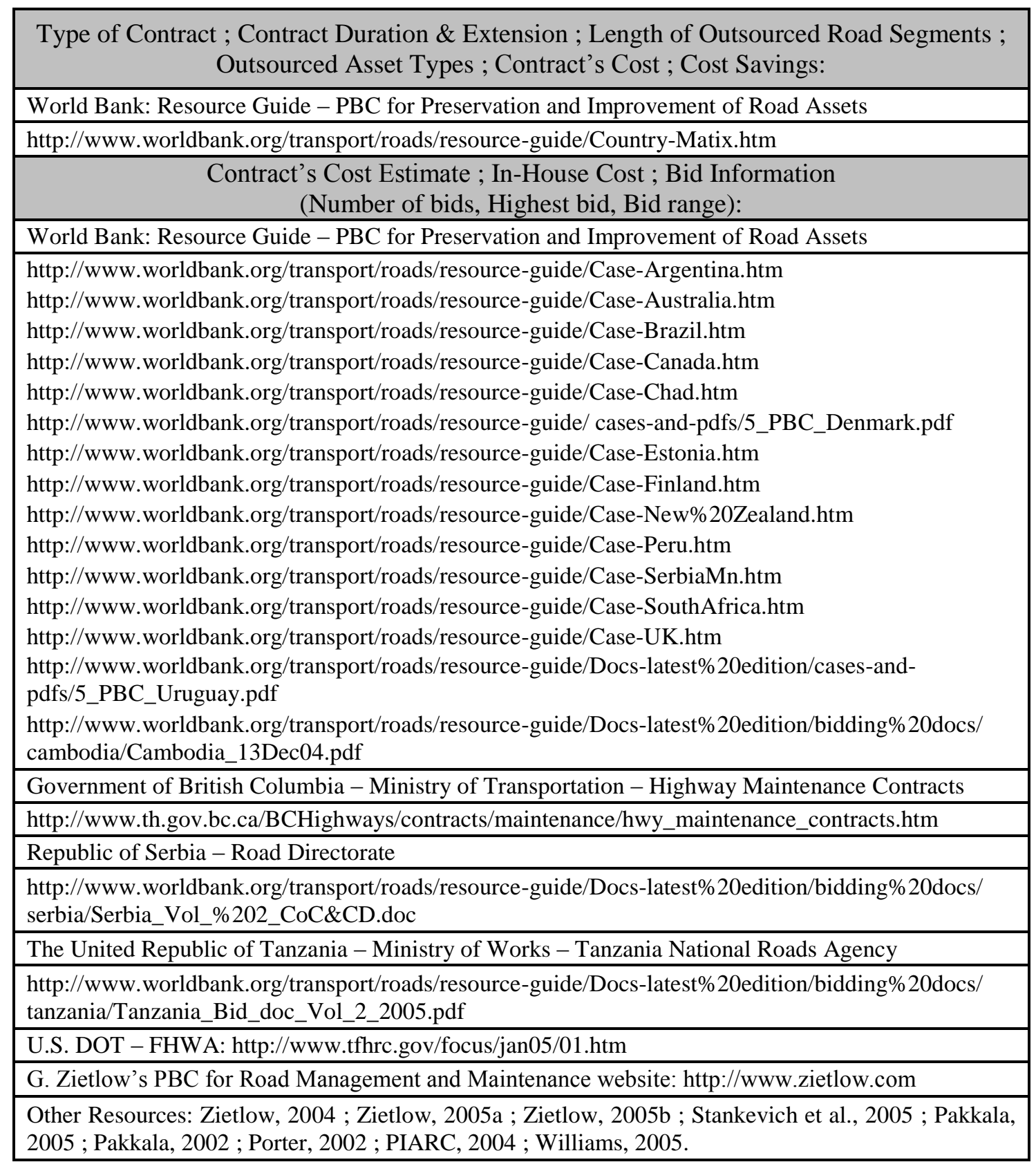


Table 3.2 U.S. contracts' data types and sources

\begin{tabular}{|c|}
\hline $\begin{array}{l}\text { FLORIDA } \\
\end{array}$ \\
\hline $\begin{array}{l}\text { Type of Contract ; Contract Duration \& Extension ; Length of Outsourced Road Segments ; } \\
\text { Outsourced Asset Types ; Contract's Cost ; Cost Savings: }\end{array}$ \\
\hline World Bank: http://www.worldbank.org/transport/roads/resource-guide/Case-USA.htm\#florida \\
\hline Contract's Cost Estimate ; In-House Cost ; Bid Information: \\
\hline $\begin{array}{l}\text { Florida DOT - Asset Management: http://www.dot.state.fl.us/statemaintenanceoffice/asset.htm } \\
\text { G. Zietlow's PBC for Road Management and Maintenance website: http://www.zietlow.com } \\
\text { Other Resources: OPPAGA, 1999; OPPAGA, } 2003 \text {; Segal et al., 2003. }\end{array}$ \\
\hline MINNESOTA \\
\hline All information acquired from: \\
\hline Innovative Contracting in Minnesota 2000 to 2005 - Minnesota DOT: www.dot.state.mn.us \\
\hline TEXAS \\
\hline All information acquired from: \\
\hline $\begin{array}{l}\text { Texas DOT: http://www.dot.state.tx.us/insdtdot/orgchart/cmd/cserve/results/awardedl.htm } \\
\text { Tammy Booker Sims, P. E. }\end{array}$ \\
\hline $\begin{array}{l}\text { Type of Contract ; Contract Duration \& Extension ; Length of Outsourced Road Segments ; } \\
\text { Outsourced Asset Types ; Contract's Cost ; Cost Savings: }\end{array}$ \\
\hline $\begin{array}{l}\text { World Bank: http://www.worldbank.org/transport/roads/resource-guide/Case-USA.htm\#texas } \\
\text { Zietsman, 2005. }\end{array}$ \\
\hline VIRGINIA \\
\hline All information acquired from: \\
\hline Virginia DOT: http://syip.virginiadot.org/LineItems.asp?syp_scenario_id=83\&tab=fund\& \\
\hline $\begin{array}{l}\text { Type of Contract ; Contract Duration \& Extension ; Length of Outsourced Road Segments ; } \\
\text { Outsourced Asset Types ; Contract's Cost ; Cost Savings: }\end{array}$ \\
\hline World Bank: http://www.worldbank.org/transport/roads/resource-guide/Case-USA.htm\#virginia \\
\hline Contract's Cost Estimate ; In-House Cost ; Bid Information: \\
\hline Segal et al., 2003 ; VMS Inc., 2001 ; JLARC, 2001 ; Lande, 2005. \\
\hline WASHINGTON D.C. \\
\hline $\begin{array}{l}\text { Type of Contract ; Contract Duration \& Extension ; Length of Outsourced Road Segments ; } \\
\text { Outsourced Asset Types ; Contract's Cost ; Cost Savings: }\end{array}$ \\
\hline World Bank: http://www.worldbank.org/transport/roads/resource-guide/Case-USA.htm\#dc \\
\hline Contract's Cost Estimate ; In-House Cost ; Bid Information: \\
\hline Segal et al., 2003; FHWA, 2002, 2004 ; M. Baker Jr. Inc., 1999 ; Robinson et al., 2004, 2005. \\
\hline ALASKA \\
\hline INDIANA \\
\hline \\
\hline
\end{tabular}


All monetary amounts were initially in USD, and were converted and expressed in year 2006 USD prices (1987 base), using the Price Trends for Federal-Aid Highway Construction (FHWA, 2007 ; Sinha and Labi, 2007):

$$
C^{*}=C_{r e f} \times \frac{I^{*}}{I_{r e f}},
$$

where, $C^{*}$ is the monetary cost in any year, $C_{r e f}$ the monetary cost in a reference year, $I^{*}$ the price index for the year of the $C^{*}$, and $I_{r e f}$ the price index for the reference year.

\subsection{Chapter Summary}

The data required for this study were identified and collected from various sources. A large part of the data was collected from the World Bank's database, and from the website databases of the U.S. Department of Transportation and National road agencies. Data types include the specific origin of the contracts (continent, country, state), general contract characteristics (duration, prolongation, length, number of activities), specific activities incorporated in the contracts, and cost (final cost, in-house cost, cost savings) and bidding (number of bids, highest bid, bid range) information.

A problem encountered was the unavailability of in-house cost data for all the contracts (in many cases, the engineer's estimate, was available instead). Hence, the total number of contracts for analysis was inevitably reduced. Due to this fact the statistical analysis results were excluded from this report however they are available in a Purdue University School of Civil Enginneering thesis, "Performance-Based Contracting for Roadway Maintenance Operations in Indiana”, by Panagiotis Anastasopolus. 


\section{Chapter 4. PERFORMANCE-BASED CONTRACTING}

\subsection{Introduction}

Performance-Based Contracting (PBC), in recent years, has been utilized all around the world for government projects such as new construction and routine maintenance. PBCs differ significantly from method-based contracts that have been traditionally used to build or maintain roads. PBC is a type of contract in which payments for the construction and maintenance of road assets are explicitly linked to the success of the contractor in complying with clearly-defined threshold performance criteria.

In traditional method-based contracts, the government agency, acting as the client, typically specifies techniques, technologies, materials and quantities of materials to be used, together with the time period during which work should be executed. The payment to the contractor is based on the amount of conducted work, i.e., the inputs (e.g., cubic meters of asphalt concrete, hours worked, etc.) (Stankevich et al., 2005). In PBC, the client does not specify any method or material requirements. Instead, the client sets specific performance standards, required to be met by the contractor when delivering maintenance services.

According to the World Bank Procurement Guidelines (2004), performancebased procurement, also termed output-based procurement, refers to competitive procurement processes resulting in a contractual relationship (where payments are made for measured outputs) instead of the traditional approach (where the measurement and payment reflects the quantity of input). For example, the contractor is not paid for the number of potholes patched, but for the work-output: no pothole remaining open (or $100 \%$ patched). Failure to comply with the performance indicators or to promptly rectify revealed deficiencies adversely affects the contractor's payment through a series of clearly defined penalties. In case of compliance, the payment is regularly made, usually in equal monthly installments, to the contractor. 
PBC within the road sector can be either "pure" or "hybrid" (Stankevich et al., 2005). The latter, combines features of both method- and performance-based contracting. Some services are paid on a unit rate basis while others are linked to meeting the performance standards.

\section{2 $\underline{\text { Scope, Assets and Services }}$}

A PBC for roadway maintenance operations may either cover only a specific type of assets (e.g., only bridges) or all types (Appendix A presents a sample list of assets) within a road corridor ${ }^{6}$. The level of complexity of a PBC can range from "simple" to "comprehensive" depending on the number of asset types and range of service types included in the contract (Stankevich et al., 2005). A "simple" PBC covers a single service (e.g., only mowing) and could be awarded for relatively short periods (a few months). A "comprehensive" $\mathrm{PBC}$, on the other hand, typically covers all road assets within the right-of-way and comprises the full range of services needed to manage and maintain the contracted road corridor. Such services include routine maintenance, periodic maintenance and traffic accident assistance, etc. As periodic maintenance activities (e.g. resurfacing, re-graveling, etc.) involve repetition within periods of reconstruction, the contract tenure typically ranges from 3-10 years but could be extended to 30 years. In a "comprehensive" $\mathrm{PBC}$, most of the work activities are often outsourced by the main contractor to subcontractors.

Rehabilitation is not a compulsory component of a "comprehensive" PBC. Some road agencies include rehabilitation as part of the PBC; others choose to handle rehabilitation using traditional method-based approaches.

\footnotetext{
${ }^{6}$ In highway construction, a PBC may cover either all asset types or one or more therefore.
} 


\subsection{Historical Background of PBCs}

The first road maintenance PBC was piloted in British Columbia, Canada, in 1988 (Zietlow, 2005). Later, PBCs were introduced and adopted in two other Canadian provinces: Alberto and Ontario. In 1995, Australia launched its first PBC which involved maintenance of urban roads in Sydney. Since then, New South Wales, Tasmania, and Southern and Western Australia have started using performance-based ${ }^{7}$ and "hybrid" approaches (Zietlow, 2005). In 1998 a PBC was introduced in New Zealand to maintain $405 \mathrm{~km}$ (250 miles approximately) of national roads (Zietlow, 2005). At present, 15\% of New Zealand's national network is covered under this type of contract.

In the U.S.A. ${ }^{8}$, PBCs were first introduced in the state of Virginia in 1996. Since then, four other states (Alaska, Florida, Oklahoma, Texas, North Carolina) and Washington, D.C., have started applying PBC approaches to maintain highways, bridges, tunnels, rest areas, and urban streets (FHWA 2005).

In the developing world, South (Latin) America was the first to develop and adopt its own performance-based contracting model. In 1995, Argentina introduced performance-based contracts ${ }^{9}$, which at present cover $44 \%$ of its national network (Liautaud, 2004). In the mid-nineties, Uruguay utilized PBCs first on a small portion of its national network and then on the main urban roads of Montevideo (Zietlow, 2005). Shortly thereafter, other Latin American countries, such as Brazil, Chile, Colombia, Ecuador, Guatemala, Mexico and Peru, also started adopting performance-based approaches in their contracts (Stankevich et al., 2005).

\footnotetext{
${ }^{7}$ PBCs are referred to as "Performance-Specified Maintenance contracts" (PSMC) in Australia and New Zealand.

${ }^{8}$ PBCs are also referred to as "Asset Management Contracts" in the USA.

9 PBCs in Argentina are called "CREMA" (Contrato de Recuperation y MAntenimiento which means Contract for Maintenance).
} 
Gradually, this trend has spread to other developed and developing countries in Europe, Africa and Asia, e.g., $\mathrm{UK}^{10}$, Sweden, Finland ${ }^{11}$, Netherlands, Norway, France, Estonia (63\% of national roads), Serbia and Montenegro (8\% of national roads), South Africa (100\% of national roads), Zambia, Chad (17\% of all season roads), the Philippines (231 km or 140 miles of national roads), etc. (Stankevich et al., 2005).

At present, preparations for launching PBC programs are underway in Albania, Cape Verde, Chad, Madagascar, Tanzania, Burkina Faso, India, China, Lebanon, Nigeria, Pakistan, Paraguay, Poland, Romania, Democratic Republic of Congo, Egypt, Cambodia, Thailand, Indonesia, Kenya, Vietnam and Yemen. Some of these countries use "pure" performance-based contracts while others (e.g., Finland, South Africa, Serbia and Montenegro) use "hybrid" contracts (Stankevich et al., 2005).

\subsection{Reasons for Implementing PBCs for Maintenance Activities}

The main reasons for contracting-out road maintenance implementing performance contracts include:

(a) Attempt to reduce maintenance costs through the application of more effective and efficient technologies and work procedures.

(b) Provision of transparency for road users, road administrations and contractors with regard to the road conditions.

(c) Improvement of control and enforcement of quality standards.

(d) Improvement of overall road condition.

Cost reductions have been reported in PBC contracts in Australia, the United States (reported but could not verify) and New Zealand. In Latin America, no cost reductions have been reported so far, because no cost-comparison studies have yet been

\footnotetext{
${ }^{10}$ PBCs are referred to as "Managing Agent Contracts" (MAC) in the UK.

${ }^{11}$ In Finland, they refer to maintenance PBCs as "Area Maintenance Contracts".
} 
undertaken. However, road conditions have notably improved on roads that are being maintained under this contracting scheme (Zietlow, 2005).

\subsection{Performance Indicators and Standards}

Performance-based contracts have emerged as a state-of-the-art contracting tool to give government agencies better control over contractors and greater assurance of accountability. A key starting point for making the partnership performance-based, is to maximize the potential and capacity for improved performance while managing the risks of performance shortfalls. The best way to accomplish this is through performance standards.

Through performance indicators and standards ${ }^{12}$, performance contracts depict the desired result expected by the contractor ; the manner in which the work is to be performed, however, is the contractor's choice. Contractors are given as much freedom as possible in finding ways to best meet the government's performance objectives. Performance objectives give contractors the incentive (by the use of either bonus or penalty) to increase productivity, cut costs and raise service quality or referred to as level of service (LOS) (Segal et al., 2003). They also shift much of the risk to the contractor who is rewarded for compliance to performance specifications but penalized for poor performance or exceeding costs.

It is a rather challenging task, however, to define the appropriate performance standards. The objective is to satisfy a set of goals such as:

(i) to minimize the total system cost, including the long-term cost of preserving road, bridge and traffic assets and the cost to the road user, and

(ii) to enhance the comfort and safety of road users.

\footnotetext{
${ }^{12}$ For a list of performance standards in several USA states and countries, see Appendices B-E.
} 
To avoid ambiguity, performance indicators and standards have to be clearly defined and objectively measurable. Typical performance standards are (Zietlow, 2005):

(a) The International Roughness Index (IRI), a measure of the roughness of the road surface, which affects vehicle operating cost.

(b) An index representing the presence, extent, and/or severity of potholes, cracks, and rutting which affects safety and pavement performance.

(c) An index of friction between tires and the pavement surface for safety reasons.

(d) Extent of siltation or other obstruction of the drainage system to avoid destruction of the road structure.

(e) Retro-reflectivity of road signs and markings for safety purposes.

In the performance contracts in Latin America, all performance standards have to be met $100 \%$. However, in Australia, New Zealand, and the USA, performance targets of PBCs can be less than $100 \%$ (see Tables 5.1 and 5.2). For each performance standard, there is a response time and often a penalty defined for non-compliance. For example, in the CREMA contracts in Argentina, for each pothole more than $2 \mathrm{~cm}$ deep, a penalty of 100 USD is applied for each day the pothole remains unsealed. 
Table 4.1 Examples of performance standards applied in different performance contracts in Latin America [Source: Zietlow, 2005]

\begin{tabular}{|c|c|c|}
\hline Asset Class & Component & Performance Standard \\
\hline Pavement & $\begin{array}{l}\text { Potholes } \\
\text { Roughness (asphalt) } \\
\text { Roughness (bituminous) } \\
\text { treatment) } \\
\text { Rutting } \\
\text { Cracks }\end{array}$ & $\begin{array}{l}\text { No potholes } \\
\text { IRI }<2.0 \text { (Argentina), IRI }<2.8 \text { (Uruguay) } \\
\text { IRI }<2.9 \text { (Argentina), IRI }<3.4 \text { (Uruguay) } \\
<12 \mathrm{~mm} \text { (Argentina), }<10 \mathrm{~mm} \text { (Uruguay, Chile) } \\
\text { Sealed }\end{array}$ \\
\hline $\begin{array}{l}\text { Gravel } \\
\text { surfaces }\end{array}$ & $\begin{array}{l}\text { Potholes } \\
\text { Roughness } \\
\text { Thickness of gravel layer }\end{array}$ & $\begin{array}{l}\text { No potholes } \\
\text { IRI }<6 \text { (Uruguay), IRI }<11 \text { (Chile) } \\
10 \mathrm{~cm} \text { (Chile, Uruguay) }\end{array}$ \\
\hline Shoulders & $\begin{array}{l}\text { Potholes } \\
\text { Cracks } \\
\text { Joints with pavement }\end{array}$ & $\begin{array}{l}\text { No potholes } \\
\text { Sealed } \\
\text { Vertical alignment }<1 \mathrm{~cm} \text { (Chile, Uruguay), sealed } \\
\text { (Peru) }\end{array}$ \\
\hline $\begin{array}{l}\text { Drainage } \\
\text { system }\end{array}$ & $\begin{array}{l}\text { Obstructions } \\
\text { Structures }\end{array}$ & $\begin{array}{l}\text { No obstructions. Should allow for free flow of water } \\
\text { (Chile, Uruguay) } \\
\text { Without damages and deformations (Chile, Peru) }\end{array}$ \\
\hline $\begin{array}{l}\text { Road signs } \\
\text { and } \\
\text { markings }\end{array}$ & $\begin{array}{l}\text { Road signs } \\
\text { Road markings } \\
\text { Reflectivity of road markings }\end{array}$ & $\begin{array}{l}\text { Complete and clean (Argentina, Chile, Peru) } \\
\text { Complete and visible (Argentina, Chile, Peru) } \\
160 \mathrm{mcd} / \mathrm{lx} / \mathrm{sqm} \text {. (Argentina) } \\
70 \mathrm{mcd} / \mathrm{lx} / \mathrm{sqm} \text {. (Uruguay) }\end{array}$ \\
\hline Right of way & $\begin{array}{l}\text { Vegetation } \\
\text { Foreign elements }\end{array}$ & $\begin{array}{l}<15 \mathrm{~cm} \text { height (Argentina, Uruguay) } \\
\text { No foreign elements allowed }\end{array}$ \\
\hline
\end{tabular}

In addition to performance standards that define asset conditions, there are other standards such as those that cover emergency response times and reporting procedures. Performance standards and response times vary widely from one contract to another. Each country seems to follow a slightly different path due to a variety of factors. One thing is clear: performance standards are still evolving and continue to be a subject of further analysis and debate. 
Table 4.2 Example of performance standards applied in the Virginia PBC [Source: Zietlow, 2005]

\begin{tabular}{|c|c|c|c|}
\hline Asset & Outcome & $\begin{array}{c}\text { Performance } \\
\text { Target } \\
\text { in \% of Asset }\end{array}$ & Performance Standards \\
\hline $\begin{array}{l}\text { Cross Pipes } \\
<36 \mathrm{ft} \mathrm{sq)}\end{array}$ & $\begin{array}{l}\text { Structurally } \\
\text { sound } \\
\text { Open drains } \\
\text { Joints intact } \\
\text { Adequate } \\
\text { capacity } \\
\text { No erosion }\end{array}$ & 95 & $\begin{array}{l}<10 \% \text { deteriorated barrel } \\
>90 \% \text { diameter open } \\
\text { Joints intact } \\
\text { End protection intact } \\
\text { No dip in road over pipe indicating } \\
\text { structural problems }\end{array}$ \\
\hline Paved Ditches & $\begin{array}{l}\text { Aligned } \\
\text { Structurally } \\
\text { sound } \\
\text { Clean }\end{array}$ & 95 & $\begin{array}{l}<1 \text { inch settlement } \\
<25 \% \text { spalled } \\
\text { no obstruction to flow of water }\end{array}$ \\
\hline $\begin{array}{l}\text { Sidewalks } \\
\text { and Ramps }\end{array}$ & $\begin{array}{l}\text { Smooth } \\
\text { Safe } \\
\text { Sound }\end{array}$ & 90 & $\begin{array}{l}\text { No settlement }>1 / 2 \text { inch } \\
\text { No unsealed cracks }>1 / 4 \text { inch } \\
<25 \% \text { spalled }\end{array}$ \\
\hline
\end{tabular}

\subsection{Risk Allocation}

In certain cases, a major obstacle in contractual partnerships is the allocation of risks. Government agencies and their private partners must review the risks and goals of the project, and determine the level of responsibility that the partners will incur over the contract life. Evaluating risks allows for the construction of a reasonable and prudent risk guarantee structure (Segal et al., 2003).

The government agencies need to consider risks of performance failure. Reasonable bonds or other sureties can assure that contractors are capable of performing the service. If the contractor fails to perform, the government receives the bond to cover any damages and costs associated with replacement service provision (Segal et al., 2003). However, government agencies should also be cautious that financial guarantees are set only as high as necessary ${ }^{13}$.

\footnotetext{
${ }^{13}$ If set too high, they may prevent some small but competent firms from participating and reduce the amount of competition, or result in driving up the user costs bid by all participants.
} 
It is important to strike the proper risk balance between the private operator and public entity. According to Segal et al. (2003), determining specific goals to be accomplished under privatization agreements will help determine which responsibilities should remain under the province of the local entity (e.g., environmental permitting, right of way) and which risks can be better managed by the contract operator (e.g., completion date, cost, performance quality).

The risk allocation for unpredictable costs in PBC implementations varies from country to country. Following, are some representative cases (Segal et al., 2003):

(a) In Virginia, USA, the contractor assumes the risk for unpredictable costs, including inflation, escalating material prices, accidents, etc.

(b) In Argentina PBCs allow for reimbursement of cost overruns in certain circumstances, such as those beyond the control of the contractor (earthquakes, hurricanes and pavement material shortages). The government uses the contractor's schedule of input prices submitted in the bid as a baseline for overruns estimates. The risk of excessive cost overruns is contained by a $25 \%$ cushion on these prices.

(c) In British Columbia, Canada, and Estonia performance-based contracts include an annual price adjustment process that takes into consideration changes in prices indices for labor and fuel.

\section{7 $\underline{\text { Performance Monitoring, Accountability and Payment Issues }}$}

Performance monitoring is important to the success of PBCs. The better-defined the performance standard, the easier is the contract monitoring. Performance standards should be written at the same time that the monitoring plan is developed, so as to ensure that no discrepancy exists between the two. Appropriate control procedures, as well as penalties for non-compliance, need to be well defined in the contract documents. Procedures defined in various contracts, as well as experiences, vary. 
In the case of PBC in Argentina, inspectors inspect the road and make random checks to verify compliance at least twice per month. Over time, inspectors become more experienced and familiar with trouble spots along the roads. Experience underlines the importance of having a well-documented inventory of the road as well as daily records of activities undertaken by the contractor (Zietlow, 2005). This helps to understand the specific behavior of the roads and contributes to better preventive maintenance. In Argentina, a key role is given to the active participation and control of the road user. Each toll station keeps a journal of complaints and suggestions and users are encouraged to report incidents. This mechanism has helped to improve road conditions and has revealed an increasing satisfaction of the road users with the new scheme. With regard to the CREMA contracts, performance monitoring and payment procedures are similar to the ones in Chile, discussed below.

In Chile, there are four kinds of inspections:

(i) Monthly inspections cover $10 \%$ of the roads under contract. Selection of stretches of $1 \mathrm{~km}$ each is based on a well defined random sample in the contract ;

(ii) Weekly inspections cover $5 \%$ of randomly selected roads ;

(iii) Non-programmed inspections to respond to complaints by road users ; and

(iv) Follow-up inspections to verify that appropriate action has been undertaken by the contractor to rectify any non-compliance.

Payments to the contractor are based on the results of the monthly inspections. A percentage of compliance is calculated on the basis of a formula that uses the results of each individual performance standard as input data (Zietlow, 2005). Full payment will only be made on $100 \%$ compliance. During the first two years of the contract, compliance has been around $95 \%$. Penalties are applied if the contractor does not rectify established deficiencies within a certain time limit. 
In order that the contractor manages the contract properly and the road administration monitors effectively, it is vital that the contractor has a proper management and quality control system in place (Zietlow, 2005). In this respect, the Argentinean, Chilean and Uruguayan PBCs are especially specific. Part of the obligations of the contractor is to keep records of all inspections, quality control procedures and works undertaken. This is especially important to monitor and to make necessary adjustments to the pilot projects as well as to gain experiences for further contracts.

In Australia, New Zealand, and the United States, the management and quality control systems used by the contractors in PBCs are even more sophisticated compared with those in Latin America. The maintenance management systems that are being used in the contracts in Virginia and recently in Texas, cover:

(a) Asset inventory and condition assessment (updated annually)

(b) Pavement management program

(c) Bridge management program

(d) Snow and ice control operations plan

(e) Safety management and traffic control plan

(f) Emergency response plan

(g) Hazardous materials communications plan

(h) Customer response and public information plan

(i) Implementation plan

(j) Annual work plan updated every 3 months

(k) Extensive reporting procedures

The monitoring of contractor performance is done on a monthly, bimonthly, or annual basis. 


\subsection{Global Practice of PBCs}

Zietlow (2005) has indicated that the PBC implementation approaches vary from country to country. The experience of the government agencies with outsourcing and the contractors' competence played a major role. Guatemala and Honduras started with 1-2 year PBCs for routine maintenance only. Interestingly, in those countries, all road maintenance was previously executed in-house. Brazil, Chile, and Uruguay have started with pilot contracts with a road network of approximately 300 kilometers (190 miles approximately) each. They both concentrated on roads with asphalt concrete and bituminous-treated surfaces (Zietlow, 2005). In some cases, gravel roads were included. Typical contract duration was between 3 to 5 years.

In Brazil, with exception of one contract in the State of Santa Catarina (which had to be terminated prematurely due to a shortage of funds), all contracts have been successful. Uruguay went already beyond the pilot stage and currently maintains over $50 \%$ of its network using PBCs. Chile, which has two PBCs, plans to extend the number of such contracts in the near future. Table 4.3 illustrates an overview of performance contracts in Latin America. The performance contracts in Australia and New Zealand, have reported substantial cost savings compared to the traditional form of contracting-out road maintenance. The PBC in Sydney had over 10\% cost savings, in the first PBC in New Zealand $15 \%$ and the second $20 \%$ lower compared to traditional contracting approaches and not in-house costs. These cost savings have been achieved mainly through better resource allocation, the introduction of new technologies and work procedures, and the training of subcontractors. At the same time, contractors maintain road, bridge, and traffic assets to a higher standard than under previous contracting approaches. Since these performance contracts are still in a pilot stage and road administrations as well as contractors have to gain experiences with this new kind of contract, it can be expected that costs will drop even further (Zietlow, 2005). Figure 4.1 presents graphically the application of performance-based contracts around the world. 
Table 4.3 Performance contracts in Latin America [Source: Zietlow, 2005]

\begin{tabular}{|l|c|c|c|c|c|c|c|}
\cline { 2 - 8 } \multicolumn{1}{c|}{} & $\begin{array}{c}\text { No of } \\
\text { Contracts }\end{array}$ & $\begin{array}{c}\mathbf{k m} \\
\text { (total) }\end{array}$ & $\begin{array}{c}\text { miles } \\
\text { (total) }\end{array}$ & $\begin{array}{c}\text { Miles } \\
\text { (average) }\end{array}$ & $\begin{array}{c}\text { Contract } \\
\text { Period years }\end{array}$ & $\begin{array}{c}\text { Type of } \\
\text { Maintenance }\end{array}$ & $\begin{array}{c}\text { Annual Cost } \\
\text { in US\$ per km }\end{array}$ \\
\hline Argentina 1 (c) & 59 & 11295 & 7059 & 119 & 5 & I-r & $11000(\mathrm{a})$ \\
\hline Argentina 2 (c) & 11 & 3623 & 2264 & 206 & 4 & $\mathrm{r}$ & $2100(\mathrm{~b})$ \\
\hline Brazil 1 (c) & 7 & 2000 & 1250 & 179 & 5 & $\mathrm{I}-\mathrm{r}$ & $7000(\mathrm{a})$ \\
\hline Brazil 2 (c) & 1 & 193 & 121 & 121 & 3 & $\mathrm{I}-\mathrm{r}$ & 1600 \\
\hline Chile (c) & 2 & 747 & 467 & 234 & 5 & $\mathrm{I}-\mathrm{r}$ & 3200 \\
\hline Colombia (m) & 280 & 11487 & 7179 & 26 & 1 & $\mathrm{r}$ & 1500 \\
\hline Colombia (mU) & 5 & 308 & 193 & 39 & $1 *$ & $\mathrm{r}$ & $1050(\mathrm{~b})$ \\
\hline Guatemala (m) & 130 & 4200 & 2625 & 20 & $1 *$ & $\mathrm{r}(\mathrm{d})$ & $1700(\mathrm{~d})$ \\
\hline Honduras (m) & 36 & 1670 & 1044 & 29 & 1 & $\mathrm{r}$ & $1200(\mathrm{~d})$ \\
\hline Nicaragua (m) & 27 & 1250 & 781 & 29 & 1 & $\mathrm{r}$ & $1000(\mathrm{~d})$ \\
\hline Uruguay (c) & 7 & 1486 & 929 & 155 & $4-5$ & $\mathrm{r}-\mathrm{p}$ & 7000 \\
\hline Uruguay (m) & 10 & 1823 & 1139 & 114 & $2 *$ & $\mathrm{r}$ & 3800 \\
\hline Uruguay (s) & 2 & 733 & 458 & 229 & $2 *-4$ & $\mathrm{r}$ & -- \\
\hline Uruguay (U) & 1 & 143 & 89 & 89 & $3 *$ & $\mathrm{r}-\mathrm{p}$ & $2 / \mathrm{m} 2$ \\
\hline Total & 579 & 40988 & 25618 & $\begin{array}{c}\text { (c): } 127 \\
(\mathrm{~m}): 26\end{array}$ & & & \\
\hline
\end{tabular}

I: initial rehabilitation; r: routine maintenance; p: periodic maintenance

(c): traditional contractors; (m):small-scale enterprises; in Colombia (mU) and in Guatemala with the participation of women; (U): urban roads; *: renewable for a further term; (a): includes initial rehabilitation cost

(b): small-scale enterprise, the Municipality of Popayán is providing materials and tools.

(d): covers only the drainage system and right of way

Note: Brazil has let performance-based contracts on more than $25000 \mathrm{~km}$ during the year 2002

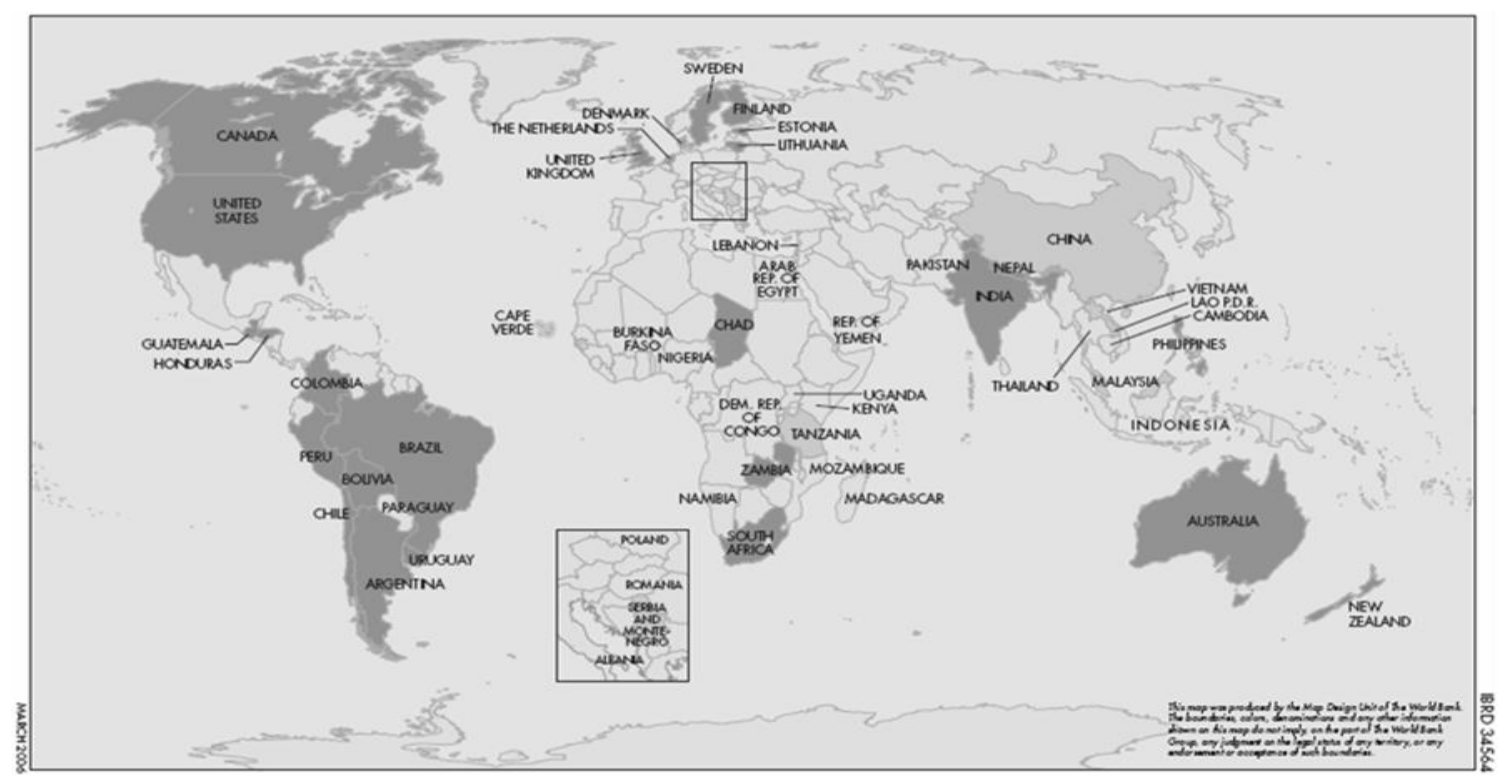

Note: the dark areas are countries that have already successfully implemented PBCs.

Figure 4.1 Performance-based contracts globally [Source: World Bank, 2006] 


\section{9 $\mathrm{PBC}$ in the United States}

During the last ten years, some State Departments of Transportation have let PBC for several road segments and activities. Following are reviewed the cases of Florida, Virginia, and Washington DC (District of Columbia). Figure 4.2 illustrates graphically the PBC implementation across the U.S.

\subsubsection{PBCs in the State of Florida}

In the last few years, the Florida Department of Transportation (FDOT) has let several contracts for some of Florida's busiest roads and highways, including the majority of I-75 and rest areas covering a large portion of the state. Infrastructure Corporation of America (ICA) was the first PBC company in Florida to offer an innovative alternate program to perform routine maintenance of management services related to roadway, bridge and toll facilities (Segal et al., 2003). 


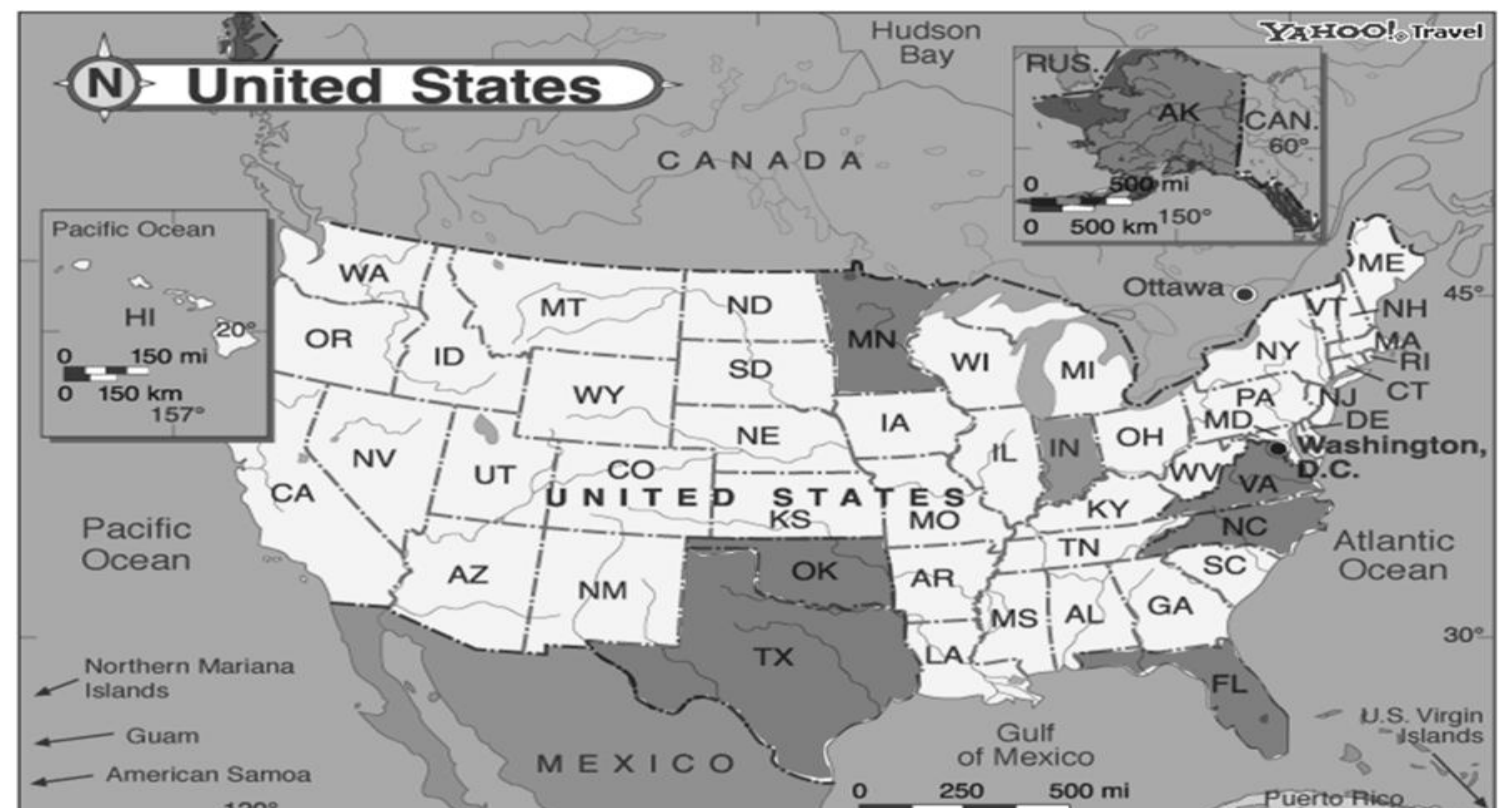

Figure 4.2 Performance-based contracts in the U.S. [U.S. Map Source: maps.com]

ICA currently performs PBC services and complete maintenance on 253 centerline miles of Interstate 75 in Florida. The PBC has duration of seven years, and costs $\$ 77.5$ million (Segal et al., 2003). Specifically, ICA’s winning bid was $12.2 \%$ below the Florida DOT's funding estimates in year one, ranging up to $22.2 \%$ below the estimate in year seven. At the same time, quality has not been sacrificed at the expense of cost savings. The last level of service rating conducted on the asset yielded a composite score of 90. This surpasses the required score of 80 set forth in the contract documents. The FDOT has experimented with several types of contracts that vary in length, magnitude, and quality.

\subsubsection{Virginia DOT Performance Based Contracting}

In 1995, the Virginia legislature passed the Public and Private Transportation Act (PPTA) mandating that the state DOT evaluate alternate proposals to maintain and 
reconstruct roads. The PPTA goals were to improve efficiency and to save valuable tax dollars. Proposals are compared with the Virginia Department of Transportation (VDOT) traditional methods. After an evaluation committee approves a proposal, the two parties negotiate price, work scope, and timelines (Segal et al., 2003). In 1996, VMS Inc, a highway construction and maintenance firm based in Virginia, was awarded a PBC VDOT maintenance contract. The initial contract was for $51 / 2$ years with a value of \$131.6 million covering 251 miles of interstate (Segal et al., 2003). VMS maintains state highways in urban Richmond, and in the southwest part of the state.

The contractor (VMS Inc.) is responsible for determining how it will maintain the road (e.g., what type of materials, techniques, and procedures). The contract requires VMS to maintain all fencing and guardrails, and to mow, snowplow, repair potholes and cracks, roadways and bridges as needed, and attend to vegetation, drainage, lighting, and striping concerns along the 251 miles of highway to standards established by the VDOT and VMS during contract negotiations (Segal et al., 2003). The VDOT team of engineers and consultants set standards that are fixed for the life of the contract. VDOT uses the same engineers and consultants to monitor the performance of VMS. An annual audit is conducted and a report card is issued describing VMS's progress toward the contract goals. In 2000, Virginia Tech conducted an independent assessment for the VDOT. It found cost savings between $\$ 16$ million and \$23 million over the five-year period (Cline, 2002). The savings were generated from lower input costs for materials, labor, and capital equipment. Recently, the VDOT approved a 5-year contract extension/prolongation of the VMS contract, reflecting the agency's satisfaction with the product (Segal et al., 2003).

\subsubsection{PBCs in Washington D.C.}

In 1998, The District of Columbia Department of Public Works and the Federal Highway Administration (FHWA) sought to establish a PBC for a specific portion of the National Highway System (NHS) within the District. The contract covers 344 lane-miles, 
2,950 catch basins, seven miles of drainage ditches, 450,000 feet of curb and gutter, 109 bridge structures, 4 major tunnels, and traffic and weather control (Sorenson, 1999).

The contract was awarded in 2000 to VMS Inc., which is responsible for maintenance of 75 miles of major streets and highways in the District. The DC project engineer monitors the contract using public surveys and monthly field inspections. Ratings (see Figures 4.3 - 4.7) of good, fair, and poor are given in relation to performance criteria, including cracking, skidding, and public satisfaction (Segal et al., 2003). Payment includes incentives for performance and depends on compliance with the performance measures. The five-year $\$ 69$ million contract was awarded on a best-value selection. The project is the largest transportation investment in DDOT's history and is also the first time that the FHWA has joined with a DOT on a program to preserve transportation assets. Since the contract was let, the District has seen major improvements in the quality of its roads. In the first year, performance was in the low 80 s (out of 100), up from the high 20s the roads scored before outsourcing (FHWA, 2003). This improvement is in part attributable to the specialization through subcontracting to smaller companies or companies that VMS Inc. creates for an area of maintenance.

According to Segal et al. (2003) VMS Inc., through the PBC implementation, has contributed towards the areas' economic development: new jobs, community service participation, and subcontracting. The DC government team is specifically satisfied with the progress on tunnels, which were dilapidated prior to the contract, snow removal, and emergency responses. Overall, DDOT, FHWA, DC public, and VMS Inc. are satisfied with the project in that the assets are generally in better condition (see Figures $4.3-4.7$ ) than they were before the PBC implementation (Segal et al., 2003). 


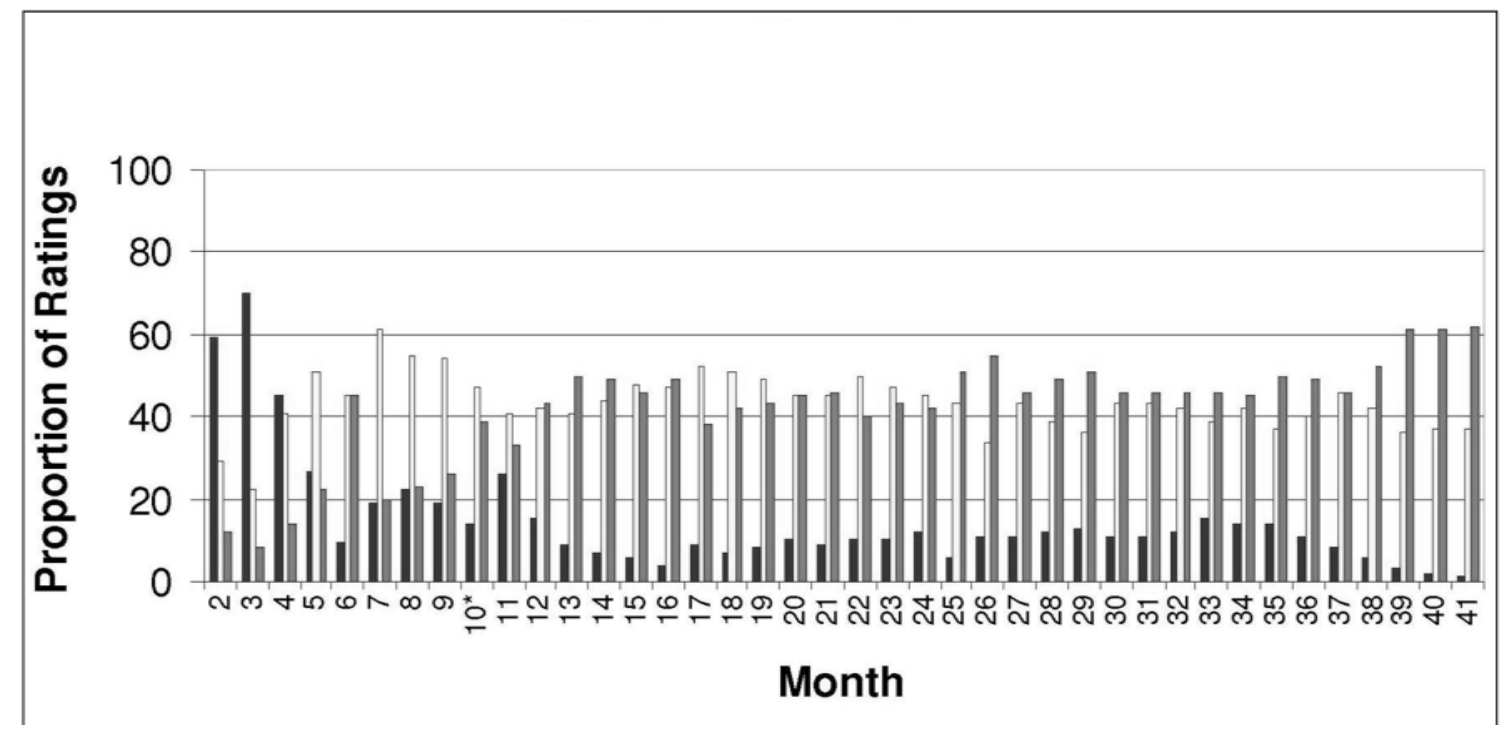

Figure 4.3 Monthly evaluation rating results (until June 2004) - PBC in Washington D.C. [Source: Robinson et al., 2005]

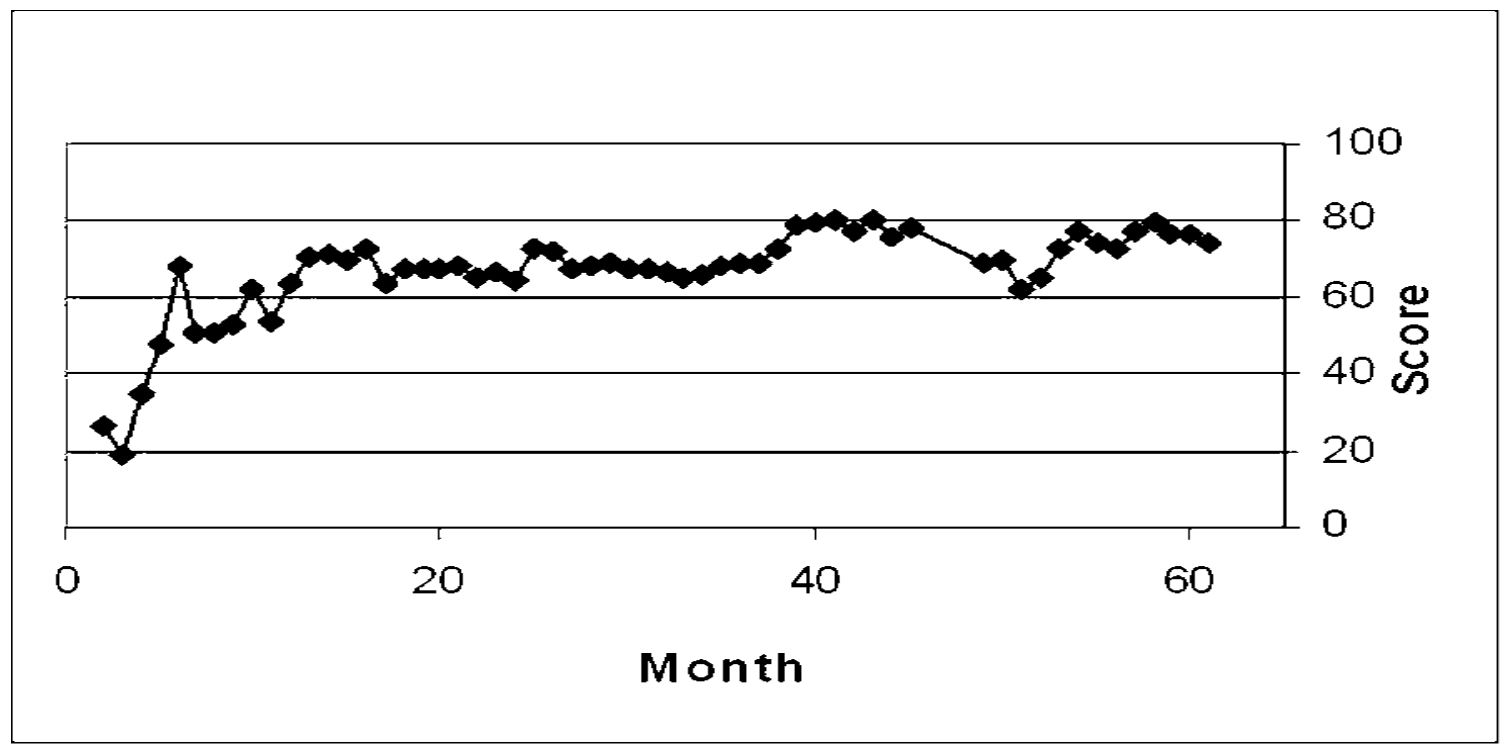

Figure 4.4 Monthly evaluation scores (until June 2004) - PBC in Washington D.C. [Source: Robinson et al., 2005]

Figure 4.4 shows the performance data improved initially and has leveled off. 


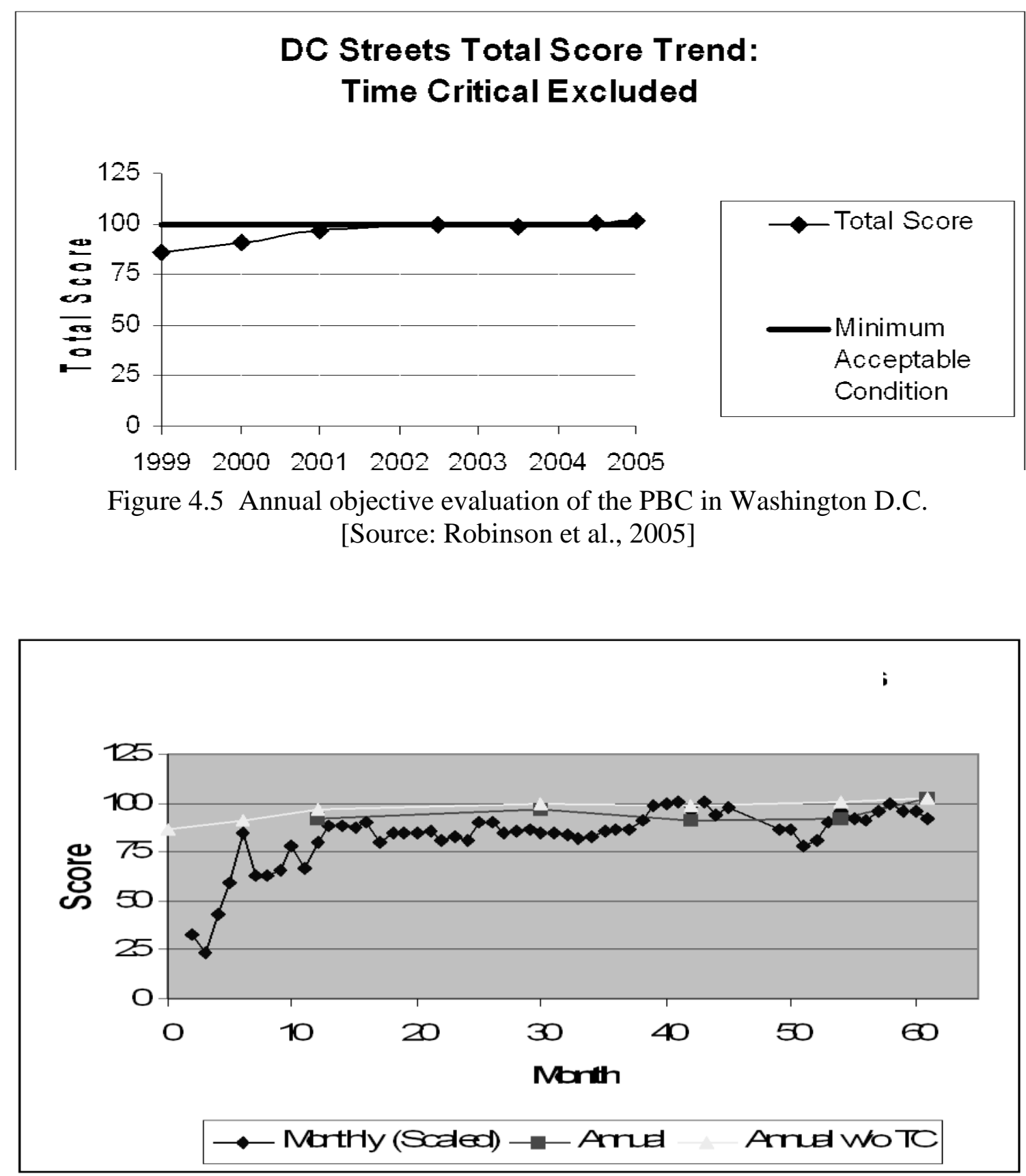

Figure 4.6 Comparison of monthly and annual scores of the PBC in Washington D.C. [Source: Robinson et al., 2005] 
Figure 4.6 shows the assesment scores by month, annual, and annual assessments without time critical activities included. This figure is similar to Figure 4.4 .

\section{$\underline{4.10 \text { South Carolina }}$}

South Carolina has investigated the use of PBC contracts. Two independent studies were performed (Dlesk and Bell, 2006) and (Berkland and Bell, 2007). The first study(2006) examined the relative merits of outsourcing highway maintenance activities as opposed to performing with in-house forces. Study findings indicate there are several factors that influence the decision on outsourcing, and that costs differences are negligible with most activities. The second study(2007) presented an analysis of PBC experienced by other state agencies. Also, workshops presented these findings and feedback indicated a lack of support for this approach. SCDOT has not tried PBC maintenace contracts.

\section{$\underline{4.11 \text { Dissenting Reports }}$}

Washington DOT investigated and produced a report on PBC in maintenance operations. Nicole Ribreau (Ribreau, 2005) of Washington DOT wrote an evaluation of PBC and has been called a critical assessment of the program. Her report states there are reocurring themes found in five states (Massachussetts, Virginia, Oklahoma, Texas, Florida) that have used PBC. These themes are " cost overruns instead of cost savings verified by audits, administration difficulties, contractor failures, public outcry, political loss of interest or support, and drops in LOS. "Summaries for these five states found in the report are the following :

- Massachussetts - In the early 90's a maintenace outsourcing project was performed in Essex county. It experienced several problems and an audit report 
issued in 1995 stated the state lost over \$1 million with the contract. Another indicator was that the state did not expand the Essex County project to other areas in the state.

- Virginia - An analysis of one contract was described with the main emphasis on reported cost savings. Reported cost savings were contradicted. A more detailed and current analysis of Virginia's program is found in Chapter 7.

- Oklahoma - In September 2001 ODOT started two five year PBC contracts in the Tulsa and Oklahoma City areas. Performance problems developed early and in March 2002 a snowstorm revealed serious performance issues with the contractor. In May 2002 both contracts were cancelled by the state legislature.

- Texas - Two contracts that expired in 2004 were described. Both experienced problems with winter storms and pavement maintenance. For the activity areas of pavement, traffic operations, and roadside maintenance, ratings dropped around 25 points over a 4 year period.

- Florida - Several audit reports of FDOT's Asset Management program described some of the issues associated with this approach. A more detailed analysis of this program is found in Chapter 7.

A followup report (Stowe, Nixon, others, 2006) was produced to update the information reported by Ribreau and to refute some of the claims. In this study the authors revisited some of the agencies cited by Ribreau and described some conflicting views. They did not completely refute or contradict Ribreau's claims and to some degree complimented her report. A phone call to Washington DOT revealed that the State of Washington Attorney General's Office reviewed, accepted, and supports the Ribreau report. Washington DOT is not pusuing the use of PBC.

\subsection{Chapter Summary}

This chapter presents the specific characteristics of performance-based contracting. The assets, activities and services that may be included in a PBC are first 
discussed: a PBC may either cover only a specific type of asset, activity and/or service, or incorporate all road assets, activities and/or services within a road section. Hence, a PBC may range from very simple (indicating a low level of complexity) to comprehensive (large number of assets and range of services). The historical background of PBC is then analyzed. The first PBC was launched in Canada in 1988. The first PBC in the United States was introduced in the State of Virginia in 1996. Since then, many other states have implemented PBC. PBCs were also implemented in the mid-90s in Latin America, with Argentina being the first. Gradually, several countries in Europe, Africa and Asia started using PBCs in their roadway construction and maintenance activities. The key reasons for implementing PBC are discussed. Reducing maintenance costs, providing transparency for road users, increasing the quality of the assets, and improving overall the road conditions are some of the reasons.

A major characteristic of PBC is the performance standards. Based on such predetermined standards, the road agency will monitor the contractor's performance and proceed to payments only when the standards are met. Also, for each performance standard there is a response time and often a penalty defined for non-compliance. The performance standards and the extent of compliance vary within countries. Another major issue in PBCs is the allocation of risks. The level of responsibility between the road agency and the contractors should be determined. Evaluating risks allows for the construction of a reasonable and prudent risk guarantee structure that enables smooth cooperation for both parties. The risk is managed differently throughout the nations, even among contracts in the same country. The proper risk balance between the road agency and the contractor should be cautiously assigned.

Another important characteristic of $\mathrm{PBC}$ is performance monitoring; this influences the success of PBCs. The better-determined the performance standards, the easier is the contract monitoring. The time that monitoring takes place varies (most agencies prefer monthly inspections at randomly selected locations). Several case studies 
of PBC implementations in the United States and globally are discussed. These suggest considerable cost savings and quality improvements of the outsourced assets. 


\section{CHAPTER 5 ADVANTAGES AND LIMITATIONS OF CONTRACTING METHODS}

\subsection{Introduction}

In this chapter, the advantages and limitations of traditional and innovative (warranty clauses, design-build-operate-maintain, cost-plus-time, lane rentals, and PBC) contracting methods are analyzed. Performance-based contracting is then compared to traditional contracting methods, and to the rest of the innovative contracting methods. The advantages and disadvantages are based on the literature and thorough examination of specific case studies in the United States and abroad. The PBC comparison with the traditional and innovative contracting methods, focuses both on qualitative and quantitative criteria. On the basis of the advantages and limitations, and the PBC comparisons with other contracting methods, a decision-making process for PBC adoption is deployed. Issues that need to be speculated in the pre-bidding and bidding process are discussed, followed by an empirical procedure framework.

Although design-bid-build and unit or work-order oriented methods been the primary contracting methods for the highway industry for quite some time,some limitations (Hancher, 1999) of the traditional methods have been identified ${ }^{14}$ :

(a) The system is slow and does not favor a life-cycle cost approach to projects

(b) The associated risks in terms of quality and maintenance are not the responsibility of the contractor, since the specifications are usually prescriptive and under the control of the public agency

\footnotetext{
${ }^{14}$ Those limitations seem to contradict the reasons for outsourcing mentioned before ; however, they are referred to the traditional methods of contracting and not to all contracting methods (including Performance-Based Contracting and other innovative contracting methods).
} 
(c) Innovation is often not encouraged ; prescriptive specifications and low-bid pricing result in no reward for the design and construction innovations

(d) There is little, if any, opportunity for contractor input into design, construction, maintenance and operation methods, and quality is often an issue of dispute

(e) The traditional system requires that the highway department have a large staff to conduct all of its necessary functions of highway design, construction, maintenance and operation.

\subsection{Comparison between PBC and Traditional Contracting}

The idea that risks should be encountered by the party that can manage them best is acknowledged in the literature (Stankevich et al., 2005 ; Queiroz, 2000 ; Amos, 2004). What significantly differentiates a PBC is that the contractor is assigned a number of the responsibilities and risks that used to be encountered by the government agency under traditional method-based contracts. On the one hand, the contractor is not limited by the government agency in making his decisions regarding "what to do", "when to do it" and "how to do it". The contractor is free to innovate with techniques and technologies to reduce costs, as long as the level of service specified in the bidding documents is achieved. On the other hand, the contractor has the entire risk in case of management and innovation failure - the contractor's errors in (Stankevich et al., 2005):

(i) Predicting deterioration of contracted assets

(ii) Determining appropriate design, specifications and materials

(iii) Planning needed maintenance interventions

(iv) Estimating quantities.

The selection process in PBC may be based on "the best value", which may not be necessarily "the lowest bid". Since more risks and management responsibilities are 
carried by the contractor, the government agency wants to ensure management capacity with the potential contractor, clear understanding of the new approach, new responsibilities and ability to handle the associated risks. The selection process involves choosing a contractor who has the capability to assess the condition of the assets, determine the timing of interventions, select materials, work methods and a suitable work plan, and arrange the monitoring of his own services. Hence, the "best value" approach tries to ensure a high quality product at a low overall cost.

In PBCs, payment is made on a fixed-price lump-sum basis normally through uniform installments, if the contractor continues to meet the performance targets. The contractor is not paid for physical works completed, but for the final delivered results (or levels of service).

The duration of PBCs is typically longer than that of traditional contracts as the contractor carries greater risk and responsibility and is obliged to undertake certain maintenance interventions that occur every few years (Stankevich et al., 2005).

Use of PBC requires the existence of a mature and well-developed contracting industry with capability to undertake long-term management of contracted assets, assume additional risks, and establish necessary programming and quality assurance mechanisms. This is often achieved through formal collaboration between construction management firms and traditional contractors (Zietsman, 2005).

A strong "partnering" philosophy is needed for a successful PBC. This is particularly critical in the initial stages when the PBC is being introduced, since neither the government agency nor the contractor has experience in this approach, and performance standards and monitoring procedures are still evolving (Stankevich et al., 2005). Good communication is essential among the government agencies, the contractors and the supervisor/engineer, to facilitate the discussion and prompt resolution of issues and concerns, so as to minimize the risk of future disputes and claims. 


\subsection{Comparison between PBC and other Innovative Contracting}

\section{Approaches}

Road agencies that have adopted a performance-based contracting approach have achieved (Stankevich et al., 2005):

(a) Cost savings from $10 \%$ up to $40 \%$. For example, the USA Virginia Department of Transportation pays USD 22,400 per mile per year under PBC, while traditional maintenance costs USD 29,500 per mile per year (FHWA, 2005). In New Zealand, there has been a $30 \%$ decrease in professional costs and $17 \%$ decrease in physical works with traffic growth by 53\% (FHWA, 2005). Further examples are given in Table 5.1. In addition, recent evaluations made by Liautaud (2004) indicate that the savings in costs accrued from the CREMA in Argentina are in order of $12-18 \%$ compared to the conventional method-based contracts. Cost comparisons are not readily available for other developing countries that have adopted a PBC approach.

(b) Expenditure certainty. As the contractor is paid a fixed price, based on a regular schedule the road agency enjoys full control of expenditures without unexpected variation orders.

(c) Reduction of the in-house workforce. For example, in Estonia, where $63 \%$ of the national network is under PBC, the workforce of the national and subnational road agencies has declined, specifically from 2,046 (administration staff - 561, workers -1,485) in 1999 to 692 employees (administration staff 343, workers - 349) in 2003 (ENRA, 2004). 
Table 5.1 Reported cost savings of different countries under PBC over conventional contracts [Source: Pakkala, 2005]

\begin{tabular}{|l|l|}
\hline \multicolumn{1}{|c|}{ Country } & \multicolumn{1}{c|}{ Cost savings (in \%) } \\
\hline Norway & About 20-40\% \\
\hline Sweden & About 30\% \\
\hline Finland & About 30-35\%; about 50\% less cost/km \\
\hline Holland & About 30-40\% \\
\hline Estonia & $20-40 \%$ \\
\hline England & $10 \%$ minimum \\
\hline Australia & $10-40 \%$ \\
\hline New Zealand & About $20-30 \%$ \\
\hline USA & $10-15 \%$ \\
\hline Ontario, Canada & About $10 \%$ \\
\hline Alberta, Canada & About $20 \%$ \\
\hline British Columbia, Canada & Some, but might be in the order of $10 \%$ \\
\hline
\end{tabular}

(d) Improved conditions of contracted road assets and reduction of roads in poor condition. Many road agencies have acknowledged that on completion of a $\mathrm{PBC}$, road assets are generally returned either in an improved condition or in a condition similar to when the PBC was awarded, but definitely not in a worse condition. The Texas Department of Transportation has reported that after the first year of the PBC implementations, road facilities condition had improved (it was rated at an average of 91\%, an 18-point increase over their pre-contract condition) (FHWA, 2005). Argentina has reduced the share of roads in poor condition from 25 percent to less than 5 percent by the end of 1999 due to the PBC approach (Liautaud, 2004).

(e) Greater road user satisfaction. Road users appear to become more satisfied with the services delivered and the condition of the roads maintained under PBCs. Although, no quantified results of improved road user satisfaction (reflecting PBC implementation) have been reported to date, some agencies have noticed a decline in the number of complaints from road users. For example, in Chad the road users were more satisfied for the road conditions after the PBC implementation (they appreciated that the road was always in good condition). Especially important was that they could use the PBC- 
maintained roads when it rained (which was impossible before) (Zietlow, 2005).

Multi-year financing of a maintenance program. For example, "by making the long-term payment obligations legally binding on the government, the CREMA contracts in Argentina have deterred the Treasury from failing to provide funding for road maintenance" (Liautaud, 2004).

Table 5.2 Cost Comparison of PBC, method-based contracting and force account for 2007/2008 by Florida Department of Transportation [Source: Holmes, 2005]

\begin{tabular}{|l|c|c|c|}
\cline { 2 - 4 } \multicolumn{1}{c|}{} & PBC & $\begin{array}{c}\text { Method-based } \\
\text { contract }\end{array}$ & In-House \\
\hline Annual Maintenance Cost & $\$ 121 \mathrm{~m}$ & $\$ 139 \mathrm{~m}$ & $\$ 148 \mathrm{~m}$ \\
\hline Percentage Cost Savings & $13 \%$ & $6 \%$ & 0 \\
\hline Number of contracts & 28 & 993 & 0 \\
\hline Number of invoices to process annually & 336 & 11,916 & 0 \\
\hline $\begin{array}{l}\text { Contract advertisements and letting or } \\
\text { renewals annually }\end{array}$ & 4 & 962 & 0 \\
\hline In-House maintenance staffing & 38 & 124 & 3,049 \\
\hline In-House non-maintenance staffing & 2 & 30 & 123 \\
\hline Performance or task oriented & Performance & Task & $\begin{array}{c}\text { Performance } \\
/ \text { Task }\end{array}$ \\
\hline
\end{tabular}

Increased application of PBC approaches to other roads in a network is often a good indicator of its success. The department of transportation in Washington D.C. recognizes $\mathrm{PBC}$ as an effective way to keep assets at or above their current condition. It has therefore decided to apply this approach for management and maintenance of tunnels, street lighting, and other streets in Washington, D.C. Peru has expanded its program of $\mathrm{PBC}$ of micro-enterprises from the rural to the national network. Argentina is currently conducting preparations to expand PBCs from the national roads to provincial roads. The Florida department of transportation plans to increase PBCs from the current 19 to 28 by 2008 (see Table 5.2). 


\subsection{PBC Decision Process-Framework}

Historically, the move towards performance-based maintenance contracts has originated from one of several sources (Stankevich et al., 2005): (i) higher levels of government, (ii) external financing agencies, or (iii) the private sector. Following, it will be analyzed the type of decision-making process needed to move towards a PBC approach.

\subsubsection{Pre-Bidding Stage}

At the pre-bidding stage the following need to be considered by INDOT:

(a) Reasons to consider a PBC approach. The government agencies need to clearly understand their main objectives in adopting a PBC approach. These may be one or more of the following:

(i) Need to cut costs

(ii) Implement higher level government directive

(iii) Manage the road network with fewer staff

(iv) Receive long-term funding for the maintenance program either from the government treasury or external financial sources that support a PBC approach

(v) Improve customer satisfaction and LOS

(vi) In response to the private sector's offer to deliver more cost effective maintenance services.

Depending on its main objective, the agency should determine the appropriate PBC format, i.e., extent (number of miles, km, or lane-miles, lane-km) and tenure of the contract, types of services and range of assets to be outsourced.

(b) Existing legislation. The selected PBC format needs to comply with the country's legal and regulatory framework. Some aspects of the contract format may be dictated by the prevailing environment. In this case, the agency may need to promote necessary changes to achieve the desirable 
format. For example, if the legislation permits a maximum two-year contract, the agency may start with a two-year contract. However, once the appropriate changes permitting longer-term contracts are approved in the legislation, the agency can move to longer-term contracts.

(c) Capacity (skills, expertise) and changing the role of the government agency. First, the government agency must be ready to switch from the role of a "micromanager" to that of a strategic manager, regulator and auditor. Secondly, the agency has to acquire new skills and expertise to be effective in this new role. Some countries may decide to seek technical assistance from countries more experienced in the PBC approach, to build up their agency capacity. Others may find it more cost-effective to engage consultants for assisting with this role, provided the domestic consulting industry possesses appropriate skills. Finally, the agency needs to identify what procedures need modification to match the selected PBC format. For example, the provision of required annual funding for multi-year contracts should be incorporated in the agency's budget process to ensure stable funding for PBCs.

(d) Capacity and unionization of the contracting industry. The government agency needs to match the complexity of the PBC to the capacity of the contracting industry available in the country (Stankevich et al., 2005). Where the industry is less developed, it would make sense to start with shorter-term, simple PBCs, e.g., contracts for routine maintenance or street lighting only. In addition, the unionization level of the contracting industry needs to be taken into account. The prospective PBC format should not be perceived by the industry as depriving most contractors of business opportunities, while placing a privileged few in a dominant position. Therefore, it is essential that the contracting industry be engaged at an early stage in the process of moving towards PBCs and appropriately consulted to adjust the format to suit local circumstances. 


\subsubsection{Bidding and Implementation Stage}

At the bidding and implementation stage, the following issues need to be considered:

(a) Inventory of potentially contracted assets and determination of their condition. Prior to developing an "Invitation for Bids", the agency should arrange the inventory and collection of data. There is a need to:

(i) Accurately determine the conditions of the road assets to be contracted out

(ii) Define performance indicators in the contract

(iii) Undertake preliminary cost estimates

(iv) Specify a monitoring process.

(b) Performance standards. Performance standards should be established for each asset to be contracted out. The selection and definition of standards should be based on:

(i) Road user needs

(ii) The expectation of the client to have assets back on contract completion at the same level as they were contracted out or better

(iii) Affordability or the level of funding available.

The agency should avoid setting performance standards too high, since ambitious goals might significantly affect the bid price. The definitions of performance standards should be simple, clear and easy to understand, and achievable by the contractor.

(c) Methodology to measure performance standards. The agency needs to determine the methodology (i.e., methods and tools) which will be applied to measure performance standards for each contracted service. It should be simple and inexpensive. The methodology should be clearly and accurately described in the contract to prevent any misunderstanding from the contractor's side and avoid potential disputes. The contractor's performance is usually evaluated at three levels (Stankevich et al., 2005): management, long-term, and operational. Management performance standards drive the 
planning, management and implementation aspects of the contract. They usually incorporate plans for quality, traffic, health, safety, and reporting requirements. Long-term performance standards relate to the overall condition of the pavement, roughness, skid resistance, texture, rutting, surface life, structural conditions, etc. These "drive" the contractors' maintenance interventions. Operational performance standards apply to daily serviceability of the road network being maintained and include conditions of the pavements and road furniture.

(d) Payment conditions. The payment conditions should be linked to the performance standards described in the contract. The contractor is paid a fixed price lump sum price in case of compliance with these standards. Periodically, penalties for non-compliance should be set for each indicator and deducted from scheduled payments to the contractor (see Table 5.3). Building in a reward mechanism in the contract is recommended to reward the contractor if retaining or exceeding the desired level of service for a sustained period is managed. Such a mechanism provides an incentive to the contractor to innovate and deliver high standards.

(e) Contract conditions. As a PBC involves a significant shift in risk and management responsibilities to the contractor, the conditions of contract should clearly define the new roles of the client and contractor. They should clearly identify all potential risks and allocate these to the party that can manage them best. This applies, for example, to risks in predicting the growth in traffic and equivalent standard axles loads, and risks for unpredictable costs under circumstances that are beyond the contractor's control (Stankevich et al., 2005).

(f) Preliminary cost estimates. The agency should prepare preliminary estimates for services to be contracted out under a PBC. The objective is to obtain a benchmark price for the contract against the bids with which it will be compared later. 
(g) Bid evaluation and selection. Several criteria have been used for selection of contractors under PBC, based on:

(i) Price only or price and non-price criteria

(ii) Pre-qualification of bidders or post-qualification

(iii) Joint evaluation of technical and cost proposals or short listing of bidders based on the evaluation results of technical proposals prior to the evaluation of cost proposals.

If both price and technical criteria are taken into account, then the agency should determine:

(i) Technical criteria to be applied

(ii) Weight of technical criteria vs. price

(iii) Whether the winner will be selected based on the "lowest bid", highest score for the technical proposal, or highest overall score for the both cost and technical proposals. 
Table 5.3 Penalties for non-compliance with mandatory requirements: Case of CREMA in Argentina, 2004-2005 [Source: Stankevich et al., 2005]

\begin{tabular}{|c|c|c|c|}
\hline Section & Parameter & Performance Requirements & US\$ equivalent \\
\hline \multirow[t]{7}{*}{$\begin{array}{l}\text { Subject to } \\
\text { rehabilitation }\end{array}$} & Pavement Roughness & $\begin{array}{l}\text { IRI } \max .=3(\mathrm{AC}) \text { IRI } \max .=3.5 \\
\text { (S.T./RC) }\end{array}$ & 250/week/km \\
\hline & Pavement Rut Depth & $1 \mathrm{~cm} \max$. & 500/week/km \\
\hline & Pavement Edge Break & $0 \mathrm{~cm}$ & 500/week/sector \\
\hline & Pothole $>2.5 \mathrm{~cm}$ & $100 \%$ patched & 500/day/pothole \\
\hline & Cracking & $\begin{array}{l}100 \% \text { sealed, and }<15 \% \text { type } 2 \text { or } \\
4\end{array}$ & 250/week/km \\
\hline & $\begin{array}{l}\text { Concrete pavement joint } \\
\text { cracks }\end{array}$ & $100 \%$ sealed & 250/week/km \\
\hline & Ravelling & $0 \%$, and $<2 \%$ if surface treatment & 250/week/km \\
\hline \multirow{13}{*}{$\begin{array}{l}\text { Subject to } \\
\text { Routine } \\
\text { Maintenance } \\
\end{array}$} & Edge Break & $3 \mathrm{~cm} \max$ & $500 /$ week/sector \\
\hline & Cracking & $100 \%$ sealed up to type 4 & 250/week/km \\
\hline & Pothole & $100 \%$ patched & 500/day/pothole \\
\hline & Ravelling & $100 \%$ patched & 250/week/km \\
\hline & Paved Shoulders & $\begin{array}{l}\text { Pothole/raveling }=0 \text { Edge break }=0 \\
\text { Rutting }<12 \mathrm{~mm} \text { Cracks sealed up } \\
\text { to type } 4\end{array}$ & $500 /$ week/km \\
\hline & Unpaved Shoulders & $\begin{array}{l}\text { No erosion, no rut, good } \\
\text { transversal slope; } \\
\text { edge break }<2 \mathrm{~cm} \text {; width }>=3 \mathrm{~m} \text {. }\end{array}$ & 500/week/km \\
\hline & Bush Clearing & Bush height $<15 \mathrm{~cm}$ over $15 \mathrm{~m}$ & 50/ha/week \\
\hline & $\begin{array}{l}\text { Culvert/drains/bridge } \\
\text { cleaning }\end{array}$ & Clean/Unobstructed & 250/day/km \\
\hline & $\begin{array}{l}\text { Cleaning of Right-of- } \\
\text { Way }\end{array}$ & No debris; maintain green areas & $250 /$ day $/ \mathrm{km}$ \\
\hline & Vertical Signs & $\begin{array}{l}\text { Well maintained and visible day } \\
\text { and night }\end{array}$ & 50/day/sign \\
\hline & Lighting & Well maintained & 50/day/light \\
\hline & Horizontal Marking & $\begin{array}{l}\text { Well maintained and visible day } \\
\text { and night }\end{array}$ & 100/day/line/km \\
\hline & Guardrails & In good condition & 500/week/location \\
\hline \multicolumn{4}{|c|}{$\begin{array}{l}\text { Notes: } 1 \text {. Penalty application are waived during initial } 3 \text { months of contract, generally; } 2 \text {. Roughness on sections subject to routine } \\
\text { maintenance is measured for indicative purposes only; } 3.10 \% \text { of the contracted network has to be inspected every month, by } \\
\text { individual segments of } 2 \mathrm{~km} \text {; } 4 \text {. Reduction of original thickness of wearing course not allowed; } 5 \text {. Milling of rut allowed only if } \\
\text { material milled is replaced; } 6 \text {. Surface treatment over Asphalt concrete not allowed; } 7 \text {. When crack type }>4 \text {, sealing may be } \\
\text { replaced by other treatment (ex: slurry seal, micro-asphalt); } 8 \text {. One month routine maintenance }=\text { USD } 200 / \text { month } * 200 \mathrm{~km}=\mathrm{USD} \\
40,000 / \text { month, on average per network; } 9 \text {. Ex: } 1 \text { pothole remaining open every } 10 \mathrm{~km} \text { during one week }=500 * 7 \text { days } * 200 / 10 \mathrm{~km}= \\
\text { USD } 70,000 \text { penalty; } 10.4 \text { horizontal marking lines missing over } 10 \mathrm{~km} \text { during } 1 \text { week }=4 * 100 * 7 * 10=\text { USD } 28,000 \text { penalty; } 11 \text {. } \\
\text { More than half of the above penalty parameters related to road safety concerns (risk of accidents) }\end{array}$} \\
\hline
\end{tabular}

Non-price criteria that have been used in PBC procurement include management team, relevant management and technical experience, past performance, methodology suggested and technical skills available. Some 
examples of such criteria are provided in Table 5.4. Due to the allocation of management responsibilities and risks to the contractor by a $\mathrm{PBC}$, some agencies opt for a "best value" approach in selecting a "winner", arguing that the "lowest bid" approach does not ensure relevant experience and appropriate understanding of the PBC approach. However, these concerns can be addressed through appropriate pre- or post-qualification. Pre-qualification of bidders, based on clearly defined technical, financial, past experience, and other relevant criteria, is usually the preferred approach. The use of a consortium of contractors and consultants is encouraged because of the total asset management concept inherent in such contracts. The World Bank guidelines (World Bank, 2004) recommend that contracts should be awarded to the bidder who meets the appropriate standards of capability and resources and whose bid has been determined: (i) to be substantially responsive to the bidding documents, and (ii) to offer the lowest evaluated cost.

(h) Performance and payment security. Legislation in some countries may require performance security based on the contract value. In case of multi-year PBCs, this requirement may become a significant issue, since it could tie up a contractors' security capacity and restrict the number of potential bidders on other contracts. To overcome this problem, some countries started with shorter-term PBCs, whereas in others, authorities require either a two-year bond $^{15}$ renewable annually (e.g., in Texas) or one-year value bond (e.g., in Washington, D.C.). Alternatively, contracts may provide for a percentage of each periodic payment to be held as retention money until final acceptance of the services (World Bank, 2004).

(i) Quality assurance program. Monitoring and evaluation of the contractor's performance should be arranged to ensure the contractor's compliance with the performance specifications. The government agency should determine the manner and frequency of monitoring inspections, the composition of the joint inspection panel, the party responsible for arranging regular inspections, the

\footnotetext{
${ }^{15}$ In the USA, bonds are a common form of security.
} 
procedures of scheduling and arranging inspections, the rules of selecting road segments to be tested, etc. (Zietlow, 2005). Typically, the inspection panel may consist of the representatives of each concerned party: agency, contractor and supervisor. As performance standards presented in the PBC generally reflect road user needs, road users could also participate in performance monitoring to voice their concerns about the quality of service delivered.

Table 5.4 Weight of price and non-price criteria in the PBC procurement process in different countries [Source: Pakkala, 2002]

\begin{tabular}{|l|l|}
\hline \multicolumn{1}{|c|}{ Country } & \multicolumn{1}{c|}{ Weight of Selection Criteria } \\
\hline Australia, Sydney, and Tasmania & $50 \%$ - price, $50 \%$ - others (varies with territory) \\
\hline Alberta, Canada & $78 \%$ - price, $22 \%$ - others \\
\hline British Columbia, Canada & $40 \%$ - price, $60 \%$ - others \\
\hline Ontario, Canada & $90 \%$ - price, $10 \%$ - others \\
\hline U.K. & $30-40 \%$ - price, $60-70 \%$ - others \\
\hline Finland & $75 \%$ - price, $25 \%$ - others \\
\hline New Zealand & $50 \%$ - price, $50 \%$ - technical criteria \\
\hline Sweden & $90 \%$ - price, $10 \%$ - others \\
\hline U.S.A. & $50 \%$ - price, $50 \%$ - others and negotiated \\
\hline
\end{tabular}

(j) Partnering. A partnering agreement should be concluded between the agency, contractor and supervisor, as many PBC-related issues need attention from each party to ensure delivery of the desired level of service (Stankevich et al., 2005). This type of contract is not about "execution of the client's instructions", but about satisfying road user needs, which requires commitment from all the parties involved. The partnering process allows the parties to establish more effective working relationships and better understand the associated risks. In some countries, the partnership agreement is signed by management, contractors and supervising agencies. 
Figure 5.1 suggests a general framework for the performance-based contracting approach implementation procedure.

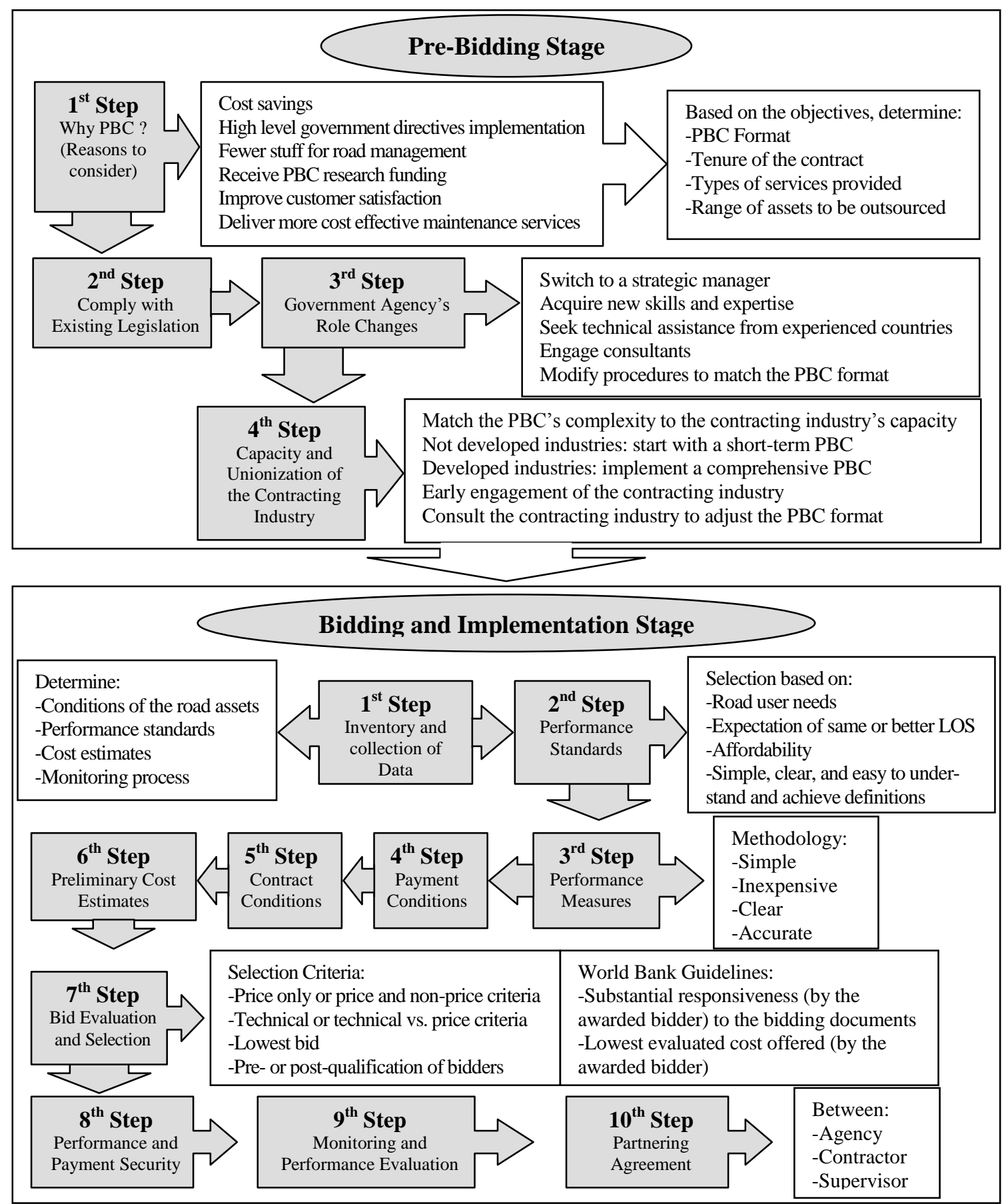

Figure 5.1 Procedure framework for PBC implementation (4+10 Steps to PBC) 


\subsection{Chapter Summary}

The type of decision-making process needed to move towards a performancebased contracting approach is analyzed in this chapter. In the pre-bidding stage the following need to be considered: (i) reasons to consider a PBC approach, (ii) existing legislation, (iii) skills, expertise and role of the government agency, and (iv) capacity of the contracting industry. In the bidding and implementation stage, reasonable assumptions are required for the: (a) inventory of potentially contracted assets and determination of their condition, (b) performance standards and a methodology to measure them, (c) payment and contract conditions, (d) preliminary cost estimates, (e) bid evaluation and selection criteria, (f) performance and payment security, (g) quality assurance, and (h) partnering agreement. Using all these components, a procedure framework for PBC implementation can be developed. 


\section{CHAPTER 6 CONTRACTING APPROACH SELECTION - STATE OF PRACTICE}

\subsection{Introduction}

To combine the theoretical and empirical findings and to support the results illustrated in the previous chapters, it appeared to be essential to solicit the perspectives of road agencies and contractors. In the case of Indiana, the PBC program is at an initial (investigation) stage, and as such it is important to identify the areas that may require modifications before implementation.

Several officials at transportation agencies in the U.S. and abroad as well as at major contractor organizations (located in Indiana) were asked to discuss, suggest, and comment on their PBC experience (if any) and their point of view and intentions. The purpose of the interviews and discussion panels was to gather information and to gain insight into the current status of PBC in roadway maintenance operations in the U.S. and other countries, and also identify and mitigate any identified obstacles.

The interview questionnaire and meeting agendas were designed to address various aspects of $\mathrm{PBC}$ and to directly "involve" the respondents with the $\mathrm{PBC}$ program. The perceptions of the officials provided better understanding of performance-based contracting practice in the U.S. and worldwide, accurately highlighted the benefits, limitations, and potential obstacles associated with the use of PBC, and indicated several issues and concerns which need to be addressed for successful implementation of performance-based contracts in Indiana in the future.

Some of the issues addressed in the interviews and meetings included cost savings under $\mathrm{PBC}$, location of the $\mathrm{PBC}$ (interstates, local roads, maintained assets 
located near contractor's facilities), number of activities and specific activities included in a contract, INDOT's potential on personnel reduction, liability issues, contractor bonding capacity, risk allocation, PBC size (duration, length of the outsourced road segments, etc.), road users satisfaction from PBC implementation (in terms of level of service, road safety, etc.), PBC selection criteria, PBC performance standards and measures etc.

\subsection{Agency Interviews}

For the interviews and meetings, a large (more than fifteen) number of officials from INDOT, Virginia DOT and North Carolina DOT were involved, one official from the FHWA, one from the City of Indianapolis, one from Germany and one from Finland $^{16}$. Five group meetings were held, two e-interviews ${ }^{17}$, and one phone-interview.

One of the agency officials (INDOT) requested the study to investigate other related aspects related to $\mathrm{PBC}$ : initially, the $\mathrm{PBC}$ project focused on maintenance activities only, hence examining the use of contractors not only to maintain, but also to preserve road segments in a particular area near their facilities for a specified period of time, was suggested. A new perspective introduced, was that these new types of contracts should be limited to state and secondary roads, whereas interstates should not be incorporated in the PBC. Also, the specific activities that should be incorporated in a performance-based contract, was one of the initial questions raised by the respondents. In the same perspective, it was suggested that the contractor should focus only on road activities within the right-of-way.

Another issue pointed out was the need to have a "satisfied" contractor, in order to obtain benefits for INDOT. It was suggested that contractors should be interviewed to collect their perspective on issues related to PBC. It was also commented that the project

\footnotetext{
${ }^{16}$ PBCs have been widely used in these countries and their expertise opinions were of great importance in this study.

${ }^{17}$ Specific questions and answers were addressed to and received by the interviewees via e-mail.
} 
should be viewed not only from the maintenance approach but also from a life-cycle perspective. Interestingly ${ }^{18}$, INDOT's officials excluded the option of reducing the agency's working force (under a PBC implementation) in any way; hence, the project benefits should not be affiliated to that perspective (i.e., personnel reduction). INDOT's activities that are currently outsourced were identified as: mowing and guardrail maintenance. Also, snow-removal (and related) activities were suggested for outsourcing.

Moreover, examining which is more beneficial to INDOT, was suggested: to perform maintenance activities with in-house resources, or to outsource them to a contractor. In that context, the activities included in the PBC should be identified. As indicated, a good idea would be a PBC application in one minor highway, and two secondary roads, where the level of service and the safety level would increase, and the cost could decrease without reducing the agency's workforce.

It was also stated that a short-term PBC should be initially implemented in Indiana to minimize the risk, since such a contract would also maximize the $\mathrm{PBC}$ benefits for inexperienced users (agencies and contractors). To additionally investigate the PBC implementation from the road users' perspective was suggested: since road users are directly interested in most of the maintenance assets and activities such as roadway safety, pollution (environmental and noise) and aesthetics, their perspectives should be taken into account. The best bid selection was suggested to be based on best value criteria (currently prohibited in Indiana), since the selection criteria play a crucial role in the contract implementation and success. In that perspective, the need of the agency cordially collaborating with the contractor to achieve a "win-win" situation was stressed; such a "partnership" would indeed produce adequate benefits for both parties.

\footnotetext{
${ }^{18}$ In most of the international (non U.S.) PBCs, cost savings were achieved partially due to personnel reduction.
} 
The "quality" of the reported cost savings in the case studies found in literature was intensively discussed. It was implied that accounting "maneuvers" can lead to "fabricated" information. Thus, the need of further investigation of the cost information might be a future issue ${ }^{19}$. Besides the cost issues, it was suggested that the provided level of service and the impact to the community (due to the PBC implementation) should also be considered and further discussed. Although INDOT already measures the provided level of service, a major issue is how customer satisfaction is assured and whether the government agency (or the contractor if stated as such in the contract) has the ability and/or capacity to provide customer service under PBC. Selecting the PBC characteristics (type of the outsourced assets/activities, duration and extension of the contract, length and type -interstates or local roads- of the outsourced roadway segments, etc.) was agreed that depends on several criteria (performance measures): cost savings, level of service, safety, public/political acceptability.

Based on their rich PBC-related expertise and experience in the German and Finish Road Administrations, the government road agency officials suggested that normally road conditions improve when using PBC. When asked about the liability issue, the European officials mentioned that it was an important issue only in the U.S. They stressed that such liabilities did not present a major threat to the contractor; otherwise prices would increase. But since this is a legal issue, consulting with a lawyer was basically suggested. It was also suggested that in the long run it would be better to outsource all maintenance activities. However, this requires that Contractors as well as road administrations are well qualified for the new task. In that perspective, it was underlined that such a practice would need time. It was also discussed that the qualifications of most of the contractors that have not previously worked under PBCs, is not sufficient for a performance-based partnership. Both parties (the contractors and the road administrations) will have to get familiar with the new system and feel comfortable before moving towars a holistic PBC approach.

\footnotetext{
${ }^{19}$ The cost savings reliability issue was extensively investigated, and is analytically addressed in Chapter 7 of the present study.
} 
The Washington D.C. example was also illustrated, where the road agency was very skeptical at the beginning and was monitoring the work of the contractor (VMS Inc.) almost every day until it realized that VMS Inc. was successfully performing the assigned tasks. Referring to a possible hybrid approach, where road activities and/or assets which can be efficiently performed by the government agency are kept in-house and the rest are outsourced, it was mentioned that such approach could increase competition. However, this way both sides could learn from the experience in a controlled manner. Also, if both the contractors' qualifications and the competition are strong, a longer term contract should be preferred (e.g. 20-yearsPBC); otherwise, a 5 year PBC with the possibility of an extension/prolongation of another 5 years (as the first contract in Virginia) was proposed. It was also noted that with hybrid contracts, the contract period could be longer but the incentive for introducing innovative methods might be reduced. Therefore, in the case of Indiana, a less "offensive" strategy could be followed and only a few activities could be outsourced under short period PBCs, following Virginia's example.

Other key issues addressed in the meetings and interviews are as follows:

- Allow extra time for new startup, particularly with a new contractor.

- Within the DOT, organization and communication changes are expected to occur (the maintenance group organization structure is expected to change).

- Information for DOT employees on the impact of going to a PBC program (how it will impact their job, activities and work program, and what new opportunities will occur) is crucial.

- $\mathrm{PBC}$ was welcomed in the areas where a shortage of resources existed; other areas where it "cut" jobs it was not welcomed.

- A PBC contract is suggested to have the ability to write work orders to the contractor when additional help is needed by the DOT. 
- Over time, DOT employees develop "ownership" over the system they maintain. Under PBC, this "ownership" feeling may be lost. This could be recovered to a degree by giving the contractor an allowance for pavement and bridge repair.

- When developing the contract, it is crucial to try to maintain the same level of service that currently exists.

- PBC monitors/inspectors do not direct the contractor. They are responsible for contractor accountability and performance monitoring.

- Performance-based contracts contain timeliness criteria with associated penalties.

- Virginia DOT savings have occurred in benefits, retirements, health care costs, and disability claims. Virginia DOT is moving towards a program where they sub out various maintenance activities, so the "middle man" is removed thereby saving money.

- Snow and Ice is the biggest risk and therefore the biggest expense on PBC. If the DOT would limit snow and ice removal to a specific number of events this would lower this cost significantly. Hence, in "snow belt" states it is economically better to remove snow and ice from these contracts.

- Assessment and monitoring training should be done by VDOT before the annual assessment occurs. For the baseline assessment it is recommended to "GPS" every item. The baseline is used to establish contract requirements.

- In Virginia DOT, liability is capped at $20 \%$ of the annual contract. Contractor has liability insurance to protect from lawsuits. A 5-year history on accident occureneces is investigated.

- Performance-based contracts may take about 6-9 months to develop.

- Monitors should be on call 24 hours and work an average of 50-60 hours a week (they are paid overtime; however, the PBC administrator is not paid overtime).

- Weekly work plans and accomplishment reports from the contractor are suggested.

- When a contractor is penalized for performance, the penalty can be recovered by satisfying the criteria. 
- Liquidated damages are suggested to be passed onto subcontractors with some exceptions for small contractors.

- The "middle man" should be eliminated, a contract management program should be developed, and employees should be trained to act as contract managers.

- Asset performance criteria need to be described in plain language and eliminate all ambiguity.

- A good approach would be to have a balance between state and private companies. (DOT needs to maintain a minimum level of capabilities and resources to handle a certain level of work, and the contractors can be utilizied supplementary; use annual subcontracts on a unit price basis).

- A good Public Relations (PR) program (following North Carolina DOT example) with maintenance employees to alleviate misunderstandings and fears would be of great benefit.

Finally, to better comprehend the PBCs' operation, management, benefits and limitations, lessons learned should be collected for possible answers for PBC related issues. For that purpose, government agencies and contractors involved in PBC should be contacted to learn from their experiences. 


\section{CHAPTER 7. AGENCY AND CONTRACTOR INTERVIEWS}

Chapter 4 summarized published information on various PBC programs. One important part of the project was to visit some of these agencies, collect information, and report findings. This section describes the findings from visiting three agencies, North Carolina, Virginia, and Florida.

\subsection{North Carolina PBC}

\subsubsection{Introduction}

In November of 2007 a meeting was held with several North Carolina DOT (NCDOT) officials for the purpose of understanding their PBC program. The interviewees were from the project, divison, and central office locations. The following describes their program.

\subsubsection{Background}

In the 2005 North Carolina general assembly, the following clause was attached to the DOT funding bill, "The DOT may implement up to 2 performance based contracts for routine maintenance operations, exclusive of resurfacing. Selection of firms will be based on best value process. Prior to any advertisement for the proposed project, the DOT shall report on the contract selection for criteria to be used. Shortly after the bill 
was passed, NCDOT started deliberations on how to respond to the key word in the legislation "may," it's not a mandate.

NCDOT decided to be proactive and use it on one contract with the scope similar to the TAMS contracts in Virginia. NCDOT approached from a perspective to see how it comes out from a cost and operational standpoint, before further legislation may mandate it. The legislation was prompted by PBC firms who hired lobbyists. Currently there is only one contract underway. However, other possible contracts being considered are:

- movable span bridges that would be an ideal performance/maintenance type contract form because it's such a specialty item and requires almost $100 \%$ attention to specialties that can be subcontracted out.

- rest areas.

- roadway lighting.

NCDOT wants to evaluate the first contract before deciding on a second contract. Based on the results from the first contract, NCDOT may move ahead with another PBC contract or end the program and report the results back to the legislature.

The initial contract started on July 1, 2007 and consisted of a 131 road mile contract on rural and urban interstate sections in the Charlotte area. The below map shows the location of the contract with the contract sections denoted in red. 


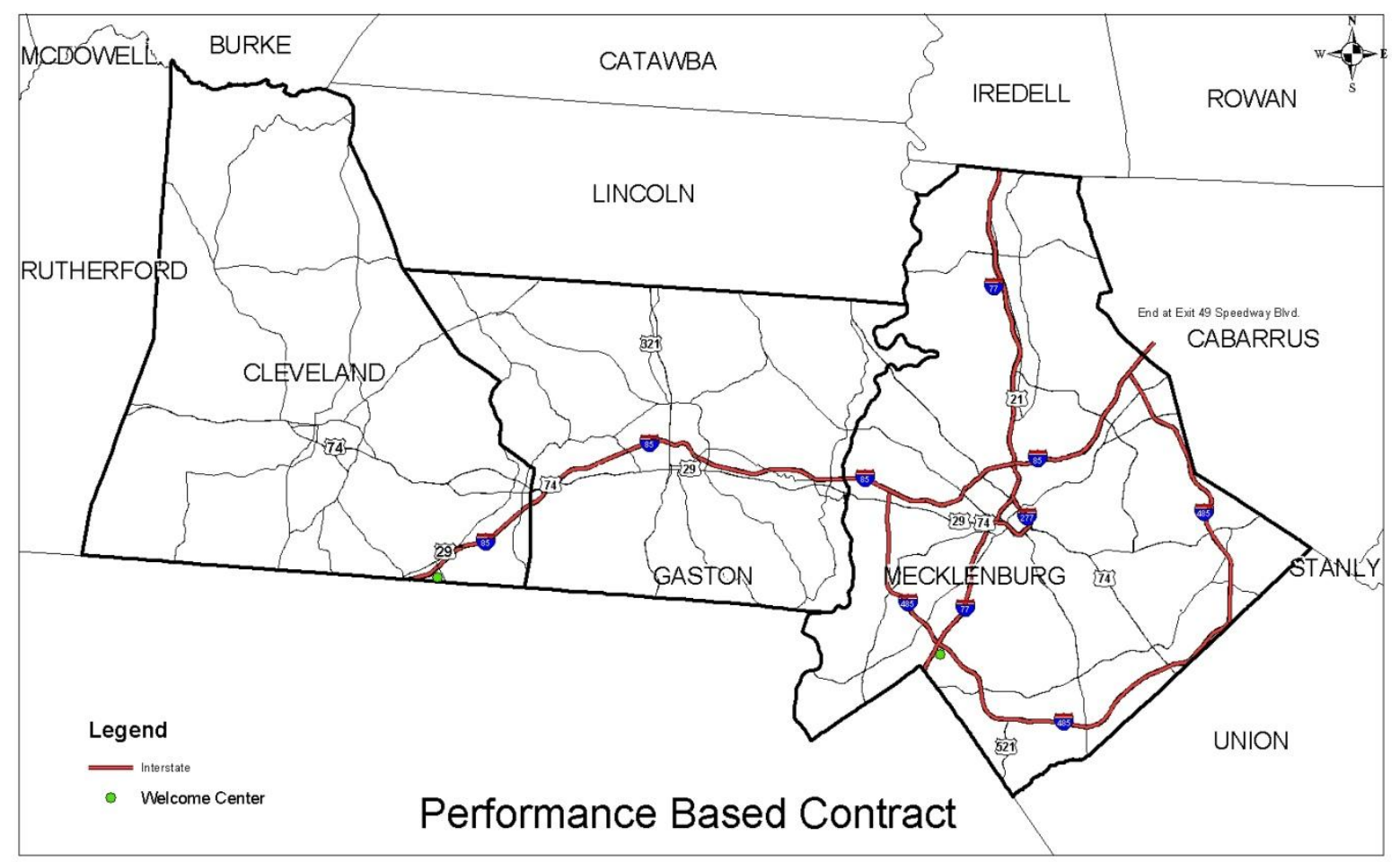

Figure 7.1 NCDOT PBC Contract Map

NCDOT has the second largest road network in the country, second to Texas. NCDOT maintains county roads, state roads, and interstates, with the only ones not maintained are municipal roads inside a city, the total is about 79,000 road miles that are maintained by NCDOT. NCDOT has approximately 7000 employees.

NCDOT maintenance operations are decentralized, while the design/planning/environmental units are all centralized. Divisions (Districts) can generate maintenance contracts up to a limit of $\$ 1.2$ million per contract. Anything above that amount has to go through the central office. There are different Level of Service (LOS) requirements for each tiered system level that is comprised of state, regional, and sub-regional road networks. This is a new classification system for NCDOT. State consists of interstate, US, and some NC routes; Regional consists of the rest of the NC routes and some secondary; Sub-regional are the secondary roads. 
The maintenance budget is derived by an allocation formula based on population, road condition, and road miles. A better formula is one based on vehicle miles traveled because it's a dynamic formula and as other areas of the state grow, the formula adjusts accordingly so it's a dynamic allocation of funds. The general maintenance budget for NCDOT is in the $\$ 300$ million range, $49^{\text {th }}$ among DOTs in $\$$ spent per lane mile. NCDOT is changing their approach to funding allocations based on the tiered level system. NCDOT is making a conscious effort to bring the statewide system up to a higher LOS compared to regional and sub regional tiers.

\subsubsection{Contract}

This section contains various issues that NCDOT went through to develop their intial PBC contract. State Road Maintenance was charged with developing the contract, a copy is in Appendix H. NCDOT spent 3-6 months collecting data from other states on their contracts and evaluating their performance criteria. For the next six months up to ten different individuals were involved in developing the contract. NCDOT Road Maintenance had 2-3 staff dedicate approximately $90 \%$ of their time during this phase, contracts had two people involved and two Divisions had individuals involved in developing the contract. During this time there were numerous iterations of the contract. After developing this initial contract, NCDOT recommends agencies allow 18 months for contract development. After establishing LOS requirements it was determined that NCDOT needed to upgrade portions of the roadway to prepare it for contract. This cost more than $\$ 200,000$ to improve segments before the contract was bid.

One important activity during this phase is to receive input from the contracting community through question/answer sessions. These sessions allow contractors to provide input and help to identify contractor risk issues. Another recommendation is to involve the future project manager in contract development. Interstate Maintenance Funds, these are federal funds, can be used in these contracts. 
The initial contract contains 131 centerline miles or approximately 700 lane miles. Other state agencies that have used PBC say that somewhere around 120-140 centerline miles is optimal for a PBC contract. Anything smaller you don't get the return on your investment, and anything larger becomes unmanageable.

Another reason for selecting the interstate system in the Charlotte area is that NCDOT has not added any state forces in this area while capacity has been added. The outer loop around Charlotte when fully completed will be 68 road miles or about 300350 lane miles. Also, capacity was added by widening I-85and I-77 where it goes into Gaston and Cleveland counties without additional state forces to maintain. So instead of NCDOT hiring to maintain the added capacity, a PBC is being used.

The contract is for five years with an option for another five year period, for a total of ten years. Within this time period, the loop around Charlotte will be completed so there is a provision in the contract that says as these sections come online the contractor is responsible to take over maintenance.

NCDOT was already performing individual subcontracts, for example, mowing, guardrail repair, concrete barrier repair on the interstate in the Charlotte area. This contract replaces these individual contracts.

NCDOT is responsible for evaluating structural condition and health and recommending rehab methods. On this contract the contractor is simply responsible for maintenance. However, the contractor must comply with the standard specs for materials and methods used in maintenance. NCDOT views the contractor as an extension of their services.

When the RFP went out seven to eight companies indicated interest. These companies were asked to submit a technical proposal. The proposals were reviewed and 
scored. The selection process is a combination of bid and technical proposal score. If the contractor scores a 100 on the technical score then the bid price is reduced by $20 \%$ for award purposes. If a contractor makes an 80 on the technical score then their bid price is not reduced. Technical scores between 100 to 80 , the bid price is adjusted accordingly, $20 \%$ to $0 \%$. This reduction is for bidding purposes and award only, the selected contractor is reimbursed by their actual bid amount.

The contractor award process is a two step process called best value and best and final offer. The best value offer process is when shortlisted contractors make a technical presentation and then submit a bid. Once a bid is submitted, then the details of the bid can be discussed. Discussion includes contract language, how interpreted, and how that influenced their bid. Award can be made if the bid price is within $10 \%$ of the engineer's estimate.

The best and final offer process occurs after the bids are opened. If the bids come back higher than the engineer's estimate, NCDOT can choose to do best and final offer. This involves all the bidding contactors who are interviewed and asked about risks, in an effort to learn why the bid was high. The bidders are given the option of changing or modifying their proposal and offered an opportunity to submit a second bid based on those modifications. If the modified bid is within $10 \%$ of the estimate, award can be made.

NCDOT recommends that the engineer's estimate not be revealed. For this contract, the original bids were higher than the $10 \%$ level so NCDOT asked for a rebid and two of the bidders best and final offer was 9.8 and $9.9 \%$ higher than the engineers estimate, therefore the contract was awarded. Because the engineer's estimate had been released, the contractors knew the ceiling and bid accordingly.

NCDOT recommended during contract development to look at ways to reduce contractor risks, because this can save money. Some examples are to reduce bond from 
24 to 6 months and allow a $2^{\text {nd }}$ assessment of roadside elements if contractor disagrees with the assessment results. Higher risks for the contractor mean higher costs. NCDOT went with a 6 month bond or approximately \$2.5 million. NCDOT viewed this as the amount of money needed by NCDOT to ramp up and take over the contract in the case of contractor default. While establishing bonding requirements, one issue to include is how do you penalize the contractor in the last six months of the contract for poor performance? NCDOT covered this in the performance and payment bond and with a monthly retainage.

The contract requires the contractor to perform a minimum of $15 \%$ of the total contract with own forces, while in realty the contractor is performing about $20 \%$ of the contract. Most of the subcontracts are with local contractors.

Contract duration is five years and it was an arbitrary decision. There are three options at the end of the contract:

1. Renew with the current contractor- based on assessment scores and timeliness.

2. Rebid the next period.

3. Dissolve the contract and let state forces assume maintenance.

Contractor out of pocket expense for unrecoverable property damage is $20 \%$ of the annual contract cost. Any costs above that amount are paid by NCDOT. Also, the contractor assumes third party risk with no limits on claims. NCDOT has protection in this area with a $\$ 1$ million limit on third party lawsuits. This is one additional cost in PBC contracts because the contractors include insurance to cover these expenses and the premiums are included in the contract.

NCDOT modified their existing performance standards after evaluating standards from VDOT and TXDOT. Performance measures need to be tested and validated before developing a contract. Two important issues that are difficult to test are timeliness and 
liquidated damages clauses. Care should be taken to properly establish these because of price implications. When deriving performance standards care must be taken so that the criteria are not higher than normal practice, or the PBC section will have a noticeable different look and quality than the adjacent sections. INDOT needs to establish performance criteria to get a handle on cost and LOS relationships.

There are minority participation requirements, MBE $(5 \%)$ and WBE $(3 \%)$ in the contract. The contractor DBI, was the apparent low bidder but was not awarded the contract because it did not meet the minority requirements. ICA was awarded the contract because it satisfied these minority goals.

Another contract issue is emergency response requirements. These were excluded due to low a occurrence frequency of about 12 times a year. NCDOT decided they would perform this internally and it would lower the risks to the contractor and therefore lower costs.

Any PBC contract will contain a list of exclusions. One recommended way to develop this list is to evaluate cost and risk factors. For this contract it was decided to exclude side lighting. The local Division said this would be a large capital cost for the contractor and it would be more economical to keep it in-house.

\subsubsection{Snow and Ice Removal Alternate}

During risk assessment, snow removal was determined to be a big risk for NCDOT. Due to its very high variability it was decided to make it an alternate bid. For this activity NCDOT's minimum level of service is one lane open at all times. The following describes the two tpes of snow and ice removal contracts that NCDOT uses.

1. A contractor provides a truck equipped with spreader and plow and is reimbursed on an hourly basis. The contractor is responsible for outfitting the truck and is 
not reimbursed for the outfitting costs. NCDOT furnishes material to the contractor, whether solids or liquids.

2. A contractor bids on outfitting the truck and NCDOT sets the hourly rate(was $\$ 75 / \mathrm{hr}$. a couple years ago). This is a five year contract so the contractor is reimbursed $20 \%$ of the equipment outfitting cost annually for 5 years. NCDOT furnishes the material.

Brine has been contracted out in the past. One example was a sod farmer used his tanker trucks outfitted with a spray bar. He was paid for making the brine ( $\$ .05$ a gallon) and an hourly rate for applying the brine. A copy of the NCDOT snow and ice subcontract is found in Appendix $\mathbf{J}$.

\subsubsection{Contract Administration}

NCDOT has three employees assigned to this contract, a project manager and two inspectors. The inspectors are equipped with tablets, cameras, wireless cards, and GPS to record daily inspections and report deficiencies. NCDOT is spending approximately \$150k annually to cover these costs and this does not include the semi-annual assessments which are costing approximately $\$ 500,000$ annually.

Weekly and monthly planning meetings are required with the contractor. The contractor submits a weekly plan on Wednesday and Thursday is the weekly meeting.

The inspectors have tablet software that can generate a report about an issue and send out appropriate emails. The software has been very beneficial for daily contract administration and is also used by the assesment teams.

The contractor is planning a lot of night work. This will require NCDOT to provide nighttime coverage by their inspectors. The contractor is required to coordinate work with the Traffic Information System, for activity information to be displayed on 
variable message boards. Inspectors can work both day and night and they get comp time asa compensation.

During the first month of the contract two liquidated damages occurred due to improper lane closures. Another problem to date has been communication problems between the contractor and subcontractors. The contractor has included liquidated damages in their contracts with their subs. So a subcontractor may be responsible for any liquidated damages they may have caused.

ICA does not have an inspector overseeing their subcontractors. NCDOT recommends this should be a requirement in a $\mathrm{PBC}$ contract. The current contractor typically has 3-4 crews working full time.

Contractor payment is not based on activities but compliance with the performance measures of the contract which is the basis of reimbursement on PBC contracts.

\subsubsection{Assessments}

There are two types of assessments. One is called the baseline, is used to determine the initial condition of the roadway system and is performed before the contract is finalized. The baseline assesment is used to develop the engineer's estimate. For each contract item, for example a clogged drop inlet, a cost estimate was developed. An initial GPS inventory of the contract features was also performed. It is recommended the project manager be involved in the baseline assessment. This assesment required approximately 6 months to develop. Initial assessment of roadway condition is very important. Another purpose of the baseline, it establishes a LOS definition for the facility components. These are used to establish contract requirements for LOS attainment goals. For example, NCDOT had items where they ramped up LOS levels. Some items started at 80 , then to 85 , and then 90 over a specified period of time. A 
contractor needs time to get some items up to the prescribed LOS and by providing a reasonable time period costs can be moderated.

The second assessment type is the semi-annual assessment of the contractor's performance. The assessment is done by teams of NCDOT personnel. If failed items are discovered during the assessment, the contractor is penalized for the next 6 months. The sample contract in Appendix H contains an example on how contractor payment is calculated. It is costing NCDOT approximately $\$ 500,000$ annually to perform these assessments.

Assessments are done from the shoulders for safety reasons. The inspected sections are 0.2 miles in length and include both sides of the Interstate. The inspected sections are made up of linear sections and point items. Linear sections include items like litter, shoulders, pavement, etc. Point items are a particular item, for example signs. There are approximately 300 random segments evaluated during an assessment which provides a $95 \%$ confidence level. Assessments are performed by $9-2$ person teams. Assessment teams consist of construction and maintenance personnel with some specialty personnel needed for items like vegetation and bridges. Grades are assigned to each element, and the contract in Appendix H provides examples of this. Assessments take approximately $6-8$ weeks to perform. The first assessment done on the contract was a trial assessment and the results did not affect the contractor's payment. . Assessments can be done at any time during the 6 month time period and NCDOT recommends that the assessment time be unknown to the contractor. Assessments teams are equipped with tablets to record the inspection.

Does a contractor have recourse if there is a disagreement over the assessment outcome? NCDOT may use independent third party assessment like a university, VDOT uses Virginia Tech. In comparison, FDOT allows contractor self- assessment. 


\subsubsection{Bids}

A technical review committee of seven members reviewed the bidder's qualifications (technical proposal) and their prices. The contract is for $\$ 5.6$ million annually or approximately $\$ 468 \mathrm{~K}$ a month. Table 7.1 is the bid prices for this contract.

Table 7.1 - Bid Prices

\begin{tabular}{|c|c|c|c|c|}
\hline & 60 Months & Unit Bid & $\%$ of Estimate & Cost Per Ln-Mi/Year \\
\hline Balfour & $\$ 36,870,000$ & $\$ 614,500$ & $30.44 \%$ & $\$ 9,594$ \\
\hline DBI & $\$ 28,182,660$ & $\$ 469,711$ & $9.99 \%$ & $\$ 7,333$ \\
\hline ICA & $\$ 28,080,000$ & $\$ 468,000$ & $9.66 \%$ & $\$ 7,307$ \\
\hline
\end{tabular}

\subsubsection{Training}

The two inspectors assigned to the contract were sent to VDOT for a week and trained with their inspectors. Assessor crews are trained through the Maintenance Condition Assessment program which is a 2 day training course developed and presented by NCDOT.

\subsubsection{NCDOT Interview Summary}

Based on various personal and group interviews and followup calls and questions the below are some conclusions formed from the interviews.

- Initially the contractor had difficulty finding subs. Approximately $80 \%$ of the contract is subbed out. 
- Performance has been less than desirable and the contractor has been docked payment after some assessments.

- Litter pickup has been good.

One possible outcome of the PBC program is to use the results to justify soliciting the legislature for more funds. If the legislature likes the results then they would be approached for additional funding. This approach is unlikely now with the economic climate.

NCDOT views PBC as another tool to use for maintaining their system. This gives them additional flexibility or another option for augmenting their forces. They realize that certain system features can be maintained more economically by private firms, like moveable bridge spans.

This PBC contract will put additional pressure on the Division to maintain adjacent sections to the same LOS since the LOS requirements differ. The traveling public will not understand or care about contracts or the way maintenance is performed, they just see the results. So the PBC contract with higher LOS requirements will probably appear different from adjacent sections. This has been a source of contention since the adjacent sections LOS is at a lower level

\section{Advantages and Disadvantages of PBC:}

- Manpower savings and lower administration costs.

- NCDOT can perform maintenance more economically by managing various subcontracts but this would require more people to manage the contracts.

Increasing DOT forces is not politically expedient but economically it may be the best option. There are efficiencies with using subcontracts to perform maintenance work on demand. A good approach is to have a balance between state and private companies. 
A DOT needs to maintain a minimum level of capabilities and resources to handle a certain level of work. Contractors can be used to supplement.

The PBC contractor is renting space that includes an office, garage, and materials storage space. Also, NCDOT has made available to the contractor space at three of their facilities to accommodate their operations.

This contract requires both Division 12 and 10, which is where the contract is located, to reallocate local maintenance resources to the interstate system. The return is an expected higher level of service. The legislature gave the local divisions no additional money for this contract. Therefore, the chief engineer through the general maintenance budget is transferring from the overall maintenance budget one million dollars annually to supplement this contract.

There were three change orders in the first 4 months of the contract. The first change order was needed because the award date changed. NCDOT needed the change to give the contractor the ability to mobilize. The second one was an issue with the signs. The contractor discovered that for new signs, they would have a hard time getting them for the cost that NCDOT paid. The change order states that NCDOT will pay for every white on green sign. The third change order stipulated how the signs would be provided.

NCDOT did a good PR program with maintenance employees to alleviate misunderstandings and fears. NCDOT lost two employees to the contractor.

NCDOT recommends setting up an office to handle maintenance subcontracts with some of the same conditions contained in the PBC. This would require an office in each INDOT District. It would save money by eliminating the contractor overhead and profit. The office would consist of contract managers and inspectors. This option would 
give INDOT the flexibility to add private contractors to supplement their forces while maintaining control over Snow and Ice removal operations.

\subsubsection{Costs}

The winning contractor bid amount was approximately $\$ 7200 /$ lane mile. NCDOT was spending approximately $\$ 3800 /$ lane mile but at a lower LOS. The engineer's estimate was $\$ 6946 /$ lane mile. The engineer's estimate evaluated each maintenance element and the additional cost for a higher LOS. For example, adding another mowing cycle or litter pickup, raised the LOS. Below shows some sample calculations that NCDOT used to determine the Engineer's estimate.

Table 7.2 Engineer's estimate calculations

\begin{tabular}{|l|r|r|l|}
\hline & Cost & & \\
\hline & (per lane-mile/year) & & \\
\hline NCDOT Cost & $\$ 4,330$ & & $\begin{array}{l}\text { Higher LOS so the lane mile } \\
\text { costs increased from } \$ 3800 .\end{array}$ \\
\hline (Exclusive of snow and ice removal) & & & \\
\hline Litter (24 cycles per year) & $\$ 1,000$ & $33.09 \%$ & $\begin{array}{l}\text { Total percent increase } \\
\text { to achieve LOS }\end{array}$ \\
\hline & & $\begin{array}{l}(\$ 1,000+\$ 533=\$ 1,533) / \\
\$ 4,330\end{array}$ \\
\hline Additional cost to achieve LOS (10\%) & $\$ 433$ & & \\
\hline & $\$ 433$ & & \\
\hline Additional cost for risk (10\%) & $\$ 6,196$ & & \\
\hline Subtotal & $\$ 620$ & & \\
\hline Profit (10\%) & $\$ 62$ & & \\
\hline Bonding cost (1\%) & $\$ 6,878$ & & \\
\hline Total & & & \\
\hline & & & \\
\hline Total Number of Lane Miles & $\$ 5,286,299$ & & \\
\hline & & & \\
\hline Annual Amount (No Mobilization) & & & \\
\hline
\end{tabular}




\begin{tabular}{|l|r|l|l|}
\hline Mobilization per Month & $\$ 4,405$ & & \\
\hline (5\% of Annual Amount ) & & & \\
\hline Annual Amount & $\$ 5,339,162$ & & \\
\hline & & & \\
\hline Lane Mile Cost & $\$ 6,946$ & & \\
\hline & & & \\
\hline Monthly Amount & $\$ 444,930$ & & \\
\hline & & & \\
\hline Total Amount (60 months) & $\$ 26,695,810$ & & \\
\hline & & & \\
\hline
\end{tabular}

Looking at the cost figures provided, NCDOT is spending over $\$ 850,000$ annually for contractor risk, profit, and bonding. The lane mile cost went from $\$ 4330$ to over $\$ 7300$, but this included an increase in LOS. With increased LOS the annual lane mile cost is $\$ 6196$. So the estimated cost difference is $(7300-6196=\$ 1104)$ making the annual cost difference, $\$ 1104 \times 768.63=\$ 847,872$.

The writers acknowledge that it is difficult to perform cost comparisons when LOS is not equal between before and after PBC. A baseline LOS inventory is necessary for calculating cost differences. INDOT does not have this baseline and if PBC is implemented it would be impossible to do cost comparisons. Table 7.2 calculations are only possible since NCDOT had a baseline inventory.

Since no NCDOT facilities closed or employees eliminated with this contract, the overhead cost did not change. Therefore this one possible benefit from a PBC was not experienced.

\subsection{Virginia DOT}

The information reported in this section was collected from a series of interviews with VDOT officials. The information is presented in a interview summary or minutes style. 
Those interviewed included district and central office maintenance personnel and a contractor.

\subsubsection{Background}

Maintenance PBC started in Virginia in 1997 on the interstate system. The first contracts were called PPTA - Public/Private Transportation Act. The contracts were for 5 years and all the assets, fence to fence, were the responsibility of the contractor. This included pavement and bridge condition. On some of the contracts this resulted in the contractor taking a band-aid approach resulting in performing a lot of patches and slurry seal instead of replacement or rehab. This resulted in revising the PBC approach to just include maintenance from fence line to fence line and this type of contract was named Turnkey Asset Maintenance Services (TAMS). VDOT is responsible for road and bridge condition in TAMS. By July 2009 all interstate maintenance will be performed on a TAMS contract. A typical TAMS contract size is $70-150$ road miles.

VDOT's annual maintenance budget is approximately $\$ 1.3$ billion and this is for approximately 58,000 miles of roadway including approximately 1,100 miles of interstate. VDOT has $9800+$ positions with $5700+$ assigned to "Maintenance and Operations." This includes Central Office Maintenance positions, Traffic Engineering positions, Operations positions, Field Management positions and Field Maintenance positions.

Since the program started, VDOT has had no layoffs but there has been a reduction of approximately 2000 employees through attrition. For example, at one maintenance shop the number of employees went from 125 to 85 . Also the amount of equipment has shrunk but no specific numbers have been provided and some facilities have closed resulting in contractors leaseing some of these facilities and storage. 


\subsubsection{Implementation Issues}

Allow extra time for a new startup, particularly with a new contractor. Within the DOT, organization and communication changes will occur. The maintenance group organization structure will change. Inform DOT employees on the impact of going to a PBC program; how it will impact their job, activities, and work program; and what new opportunities will occur.

PBC was welcomed in the areas where a shortage of resources existed. Other areas where it cut jobs it was not welcomed by VDOT employees.

Snow and ice removal activities determined the level of resources needed in most agencies that perform these services. VDOT has learned that contractors respond differently in snow and ice events primarily by the level of effort and approach taken.

One contractural component that a PBC contract should have is the ability to generate work orders to the contractor when additional help is needed by the DOT. This primarily occurs with a severe weather event.

Over time, DOT employees develop"ownership" over the system they maintain. This "ownership" feeling was lost with the TAMS contracts. This could be recovered to a degree by giving the contractor an allowance for pavement and bridge repair. When developing the contract try to maintain the same level of service that currently exists.

A VDOT's engineer's estimate is based on historical expenditures and includes consideration for overhead. A copy of such an estimate was not provided.

TAMS monitors/inspectors do not direct the contractor. They are only responsible for contractor accountability and performance monitoring. 
VDOT has not saved money with TAMS contracts. Savings have occurred in the areas of benefits, retirements, health care costs, and disability claim but overall costs have increased. VDOT is moving towards a program where they increase subbing out various maintenance activities.

A big item in TAMS contracts is snow and ice removal since the extreme case must be covered by the contractor. One advantage realized is with the contractor covering snow and ice removal, VDOT is able to dedicate more resources to the primary and secondary roads in winter weather events. This is one of the more costly items in a TAMS contract because of the uncertainty and associated risk. Experience has shown that contractors do well on an average storm but not on large storms. A big reason is that a DOT can bring in resources from other areas of the state while a contractor is limited to their own resources. On one snow and ice subcontract twenty percent is done by in-house crews performing spot treatments and incident management. The other $80 \%$ is done by two contractors; one is a WBE general contractor and the other is an equipment dealer that uses 12 trucks from their clients. A private contractor (ICA) does a 50 year analysis on snow and ice weather events with their price based on these averages. If the DOT would limit snow and ice removal to a specific number of events this would lower this cost significantly. One VDOT District Maintenance engineer said that on one contract, approximately half the cost is snow and ice removal. In Snow Belt states it is economically advantageous to remove snow and ice from these contracts due to the way contractors price this activity.

Assessment training for monitors is done by VDOT before the annual assessment occurs. The assessment program is administered through Virginia Tech (VT) who in turn works with two consulting firms. VT is responsible for the baseline and annual assessments. Performance standards should be the same for the baseline and the contractor assesments. For the baseline assessment it is recommended to GPS every item. The baseline is used to establish contract requirements and a cost estimate. A 
Web based program is used to monitor and report on TAMS contracts. Monitors are on call 24 hours and work an average of 50-60 hours a week. Monitors are paid overtime. The TAMS administrator is not paid overtime.

VDOT awards contracts using a two step process. 1. Contractors submit a technical proposal which is evaluated and scored. Those that make an acceptable score their bid is opened. 2. Low bid of those that passed the technical proposal is awarded the contract. VDOT prefers the best value approach that NCDOT utilizes. The best value approach is described in the NCDOT section and requires legislative approval since award is not totally based on low price.

Some miscellaneous generalities about TAMS contracts are:

- Liability is capped at $20 \%$ of the annual contract. Contractor has liability insurance to protect from lawsuits.

- VDOT requires weekly work plans and accomplishment reports from the contractor.

- When a contractor is penalized for performance they can recover the penalty by satisfying the criteria.

- On one contract, ICA has the $80 / 20$ rule; $80 \%$ is subbed and $20 \%$ performed by contractor personnel. Another contract is 60/40. So it varies with the contract and its location.

- TAMS contracts limit third party lawsuits to $80 \%$ of the annual contract cost. ICA looks at a 5 year history on these accident occurrences and that is what they use in a bid. 
- ICA passes liquidated damages onto subcontractors with some exceptions for small contractors.

- Personnel costs are lower for the contractor. For example, VDOT has a $75 \%$ overhead rate on their employees while ICA has a $35 \%$ rate and with hourly labor rates close to the same ICA has lower labor costs in most cases.

\subsubsection{Lessons Learned}

- VDOT should eliminate the middle man and develop a contract management program and train employees to act as contract managers.

- Asset performance criteria need to be described in plain language and eliminate all ambiguity. Involve the appropriate employees in the complete PBC process.

- Adequately train monitors.

\subsubsection{Contractor Innovation}

VDOT thinks that the TAMS contracts encourages and creates innovation from the contractor. Several examples are described in this section.

In the past 10 years, VMS (a PBC contractor) performed different types of pavement treatments that typically have not been done on the interstate, this included slurry seal, crack sealing, and other preventative maintenance. The contractor has used creative methods when it comes to incident management, and incident response, and these have been well received by the state police.

Another example is contractors have more flexibility in negotiating contracts. Twelve years ago, in a very rural southwest area of Virginia, VDOT put out a contract 
for interstate mowing. Prices came back very high because there were no mowing companies in the area. The contractor, VMS, came in and grew the market for VDOT. They went out and solicited people to start a mowing business and helped them get loans. Because of this VDOT can now advertise and there are contractors available at a reasonable cost.

\subsubsection{Cost Data}

From a press release dated February 20, 2007 the following information was reported. Four contracts were awarded for a total of $\$ 157.3$ million covering 562 miles of interstate. The contracts are for five years and include:

- Roadway maintenance (litter pickup, pothole repair);

- Drainage system maintenance;

- Mowing;

- Guardrail and sign repair;

- Snow removal; and

- Incident response.

Specific contract information:

1. $\$ 43$ million to maintain 149 miles in the Bristol area which is rural. Annual cost per mile $=\$ 43$ million $/ 49(5$ years $)=\$ 57,718$. Assuming 4 lanes per mile then the lane mile cost $=\$ 57,718 / 4=\$ 14,429$.

2. $\$ 28.6$ million contract for 105 miles in the Salem area. Annual cost per mile $=$ $\$ 28.6$ million $/ 105(5)=\$ 54,476$.

3. \$55 million to maintain 170 miles north and south of Richmond. Annual cost per mile $=\$ 55$ million $/ 170(5)=\$ 64,705$

4. $\$ 30.7$ million to maintain 138 miles. Annual cost per mile $=\$ 30.7$ million/ $138(5)=\$ 44,492$.

VDOT did provide project cost data and their corresponding activities. This information is shown in the below table and the contract items described in the following text. 
Table 7.3 VDOT TAMS Contract cost

\begin{tabular}{|c|c|c|c|c|}
\hline NAME & LOCATION & $\begin{array}{c}\text { COST/contract } \\
\text { duration }\end{array}$ & $\begin{array}{l}\text { LANE MILES } \\
\text { (Approximate) }\end{array}$ & $\begin{array}{c}\text { Annual } \\
\text { Cost/lane } \\
\text { mile(\$) }\end{array}$ \\
\hline $\begin{array}{l}\text { Hampton } \\
\text { Roads }\end{array}$ & Urban & $\begin{array}{c}\$ 32,214,570.00 \\
5 \text { year }\end{array}$ & 436.88 & 14,747 \\
\hline $\begin{array}{c}\text { Staunton } \\
\text { North }\end{array}$ & Rural & $\begin{array}{c}\$ 20,493,885.00 \\
5 \text { year }\end{array}$ & 402.00 & 10,196 \\
\hline $\begin{array}{c}\text { Staunton } \\
\text { South }\end{array}$ & Rural & $\begin{array}{c}\$ 27,000,000.00 \\
5 \text { year }\end{array}$ & 482.00 & 11,203 \\
\hline Salem & Rural \& Urban & $\begin{array}{c}\$ 28,560,000.00 \\
5 \text { year }\end{array}$ & 420.20 & 13,594 \\
\hline Bristol & Rural & $\begin{array}{c}\$ 42,952,440.00 \\
5 \text { year }\end{array}$ & 597.48 & 14,378 \\
\hline $\begin{array}{l}\text { Richmond } \\
\text { North }\end{array}$ & Urban & $\begin{array}{c}\$ 54,995,040.00 \\
5 \text { year }\end{array}$ & 682.80 & 16,108 \\
\hline $\begin{array}{l}\text { Richmond } \\
\text { South }\end{array}$ & Rural & $\begin{array}{c}\$ 30,675,040.00 \\
5 \text { year }\end{array}$ & 553.40 & 11,086 \\
\hline I-64 West & Rural & $\begin{array}{c}\$ 10,800,000.00 \\
3 \text { year }\end{array}$ & 349.40 & 10,303 \\
\hline I-64 East & Rural \& Urban & $\begin{array}{c}\$ 14,590,000.00 \\
3 \text { year }\end{array}$ & 268.24 & 18,131 \\
\hline
\end{tabular}

\section{TAMS ROUTINE MAINTENANCE ACTIVITIES}

_Environmental Work

_ Engineering Duties

_ Asphalt Pothole Repair (Manual) 
_ Asphalt Pothole Repair (Mechanical)

_ Base Repair

_ Pressure Grouting

_ Concrete Pavement Joint Repair

_ Concrete Slope Pavement Joint Repair

_ Concrete Pavement Surface Pothole Repair

_ Repairing Non-Paved Shoulders, Front

Slopes and Roadside Ditches (Manual)

_ Seeding, Fertilizing and Mulching

_ Reworking Non-Paved Shoulders, Front

Slopes and Roadside Ditches (Mechanical)

_ Miscellaneous Slope and Ditch Repair

_ Clean Drainage Structures

_ Repair Storm Drains, Side Drains, Cross

Drains

_ Concrete Repair

_ Concrete Sidewalk Repair

_ Unpaved Ditches - Clean and Reshape

_ Paved Ditches - Clean and Repair

_ Large Machine Mowing

_ Slope mowing

_ Intermediate Machine Mowing

_ Small Machine Mowing

_ Weed Control (Manual)

_ Wildflowers

_ Fertilizing

_ Tree Trimming and Removal

_ Landscape Area Maintenance

_ Chemical Weed and Grass Control

_ Chemical Weed and Grass Control 
Selective Weeding

_ Storm Water Management

_ Delineators

_ Signs (Ground Signs 30 square Feet or

Less)

_ Signs (Ground Signs Over 30 Square Feet and all Overlane Signs)

_ Sign Cleaning

_ Guardrail Repair

_ Fence Repair

_ Attenuator Repair

_ Raised Pavement Marker Replacement

_ Graffiti Removal

_ Roadside Litter Removal

_ Road Sweeping (Manual)

_ Road Sweeping (Mechanical)

_ Edging and Sweeping

_ Highway Lighting Maintenance

_ Overhead Sign Structure Maintenance

_ Supervision, Inspection and/or Engineering

of Roadway Maintenance

_ Contract Maintenance Supervision,

Engineering and Inspection

_ Emergency Maintenance

_ Glare Foil

_ Maintenance Support Services

_ Barrier Wall

_ Bridge \& Culvert Maintenance

_ Rumble Strip Sealing

_ Winter Weather Events 
_ Incident Management

\subsubsection{Conclusions}

One VDOT District Maintenance Engineer's opinion was to outsource certain maintenance activities. He recommended VDOT retain snow removal, because it is the most risky piece of a PBC contract.

In snow and ice removal the TAMS contractor typically hire road contractors. One example of contractor snow and ice removal efforts on one contract VDOT used approximately 70 trucks for that geographic area, and a contractor used 45 . The contractor did not have enough resources available when a significant winter event occurred.

One outcome of $\mathrm{PBC}$ is to have the DOT be the contract manager. One of the dangers with this approach is the possible loss of efficiency and innovation that comes with PBC contracts. Putting contracts together can help maximize efficiency with the same number of employees. Another valuable component that should be in a PBC contract is the ability to develop change orders with the contractor. This provides the mechanism for a quick response to unexpected needs.

Best value is preferred over low bid and contract renewal langusge should be included. Recently, VDOT asked for bids for a five year contract extension. On the renewal bid another contractor was low bid by approximately $\$ 1$ million over the current contractor. With no other provisions for continuation award VDOT had to award to low bidder even though it was going to be more costly for VDOT to administer and "break in" a new contractor. There should be contract provisions that allow for extension in lieu of rebidding if the agency is satisfied with contractor performance. 


\subsection{Florida DOT}

\subsubsection{Introduction}

At FDOT, Performance Based Contracting (PBC) for Maintenance is defined as a contract that describes precise end-result performance expectations with clearly defined performance measures to be met by the contractor. PBC is referred to as Asset Maintenance (AM). FDOT has learned that AM functions best in long term contracts with lengths ranging from 5 to 10 years. AM contracts are dynamic, meaning that current specs and procedures apply to the contract.

In 2000, Governor Bush gave all government agencies a directive to reduce the workforce by $25 \%$. The AM program was started in July 2000 and developed through a task team representing Districts and Central Office. Within the first five years of AM implementation, maintenance forces were reduced $25 \%$ through attrition. The first AM contract covered the I-75 corridor, and went through 4 districts, it was an unsolicited proposal.

FDOT uses four types of AM contracts:

1. Road Corridor centered around a core roadway.

2. Facility contracts including rest areas, weigh stations, and welcome centers.

3. Geographic contracts with multiple transportation facility types consisting of interstates, U.S. routes, and state routes.

4. Fixed and movable bridge contracts.

Two state statutes 287 and 337, helped to establish AM by allowing for the privatization of maintenance services and approving the Best Value approach for awarding contracts. At FDOT the Best Value approach award is based on approximately $70 \%$ the technical proposal, and 30\% the cost proposal. The Technical 
Evaluation Committee (TEC) is done at the Districts and grades the technical proposal part. The TEC has representation from the central office.

What has been the overall impact of AM on Maintenance operations? In 1994 FDOT performed $60 \%$ of maintenance with in-house forces and contracted out $40 \%$. In 2008, 20\% of maintenance work was performed in-house, $40 \%$ through AM contracts, and $40 \%$ with traditional subcontracts. So since the inception of AM, the percentage of traditional contracts has stayed the same while in-house has gone from $60 \%$ to $20 \%$ and AM from $0 \%$ to $40 \%$. There are currently 28 AM contracts in Florida for a total annual cost of $\$ 102$ million.

\subsubsection{Contracts}

Contract formation was developed by a task team consisting of representatives from each District. This was called the Asset Maintenance Liaison Committee and it included representatives from industry. Central Office developed the scope and boiler plate language, which took about a year. It took a team of 8 from the district and one from the central office to put together the first contract. One exception is the Escambia contract in District 3 has taken about 3 years to develop. The reasons for this extended time are a Traffic Management Center (TMC), funding issues, five different alternative MRP scores to bid on and innovative ideas in the contract.

It took another year to develop the procedure, so it took FDOT a total of about two years to get the AM program started with the first contract. A monitoring plan was developed which is basically a QA/QC plan. The monitoring plan is called a grading plan, which has a numerical score, with a pass/fail score of 80 . One exception to this is for safety items, where the pass/fail score is 100 . If the grading plan score is less than 80 in two consecutive periods the contractor can be declared not responsive and not allowed to bid on any other AM contracts. 
FDOT has developed a web tool to help standardize the contract scope. With the tool it takes about 5 minutes to put together the scope on new contracts. Utilizing this tool and experience with AM, a new contract can be developed in about 6 months now. Developing a baseline assessment of the roadway condition takes a considerable amount of time so with most AM contracts a year is required to get everything developed. FDOT's Maintenance Rating Program (MRP) program provides the initial assessment rating and helps to develop the budget. The MRP develops a baseline condition survey and and is used to evaluate contractor performance.

Contract managers are used to supervise these contracts. Contractor liability is usually limited to $50 \%$ of the annual contract but some current contracts have no liability cap. "Reasonably obtainable" is in the contract for collecting liability claims. A contractor may take years to collect these damages. In most contracts, any single incident above a defined value, FDOT will be responsible for.

There is no formula or general rules that determine contract size. For FDOT it generally depends on what is within the geographic area. All road types are included in a contract: State, US, and Interstate routes.

Built into AM contracts is an inflation factor of $2.5 \%$ annually, this is applied to the renewal contracts. This provides for cost control in establishing future maintenance budgets. No other cost adjustments or price indexes are allowed. For example, in a seven year contract, costs are allowed to increase to $15 \%$ in the seventh year, an average of $2.5 \%$ annually. This will be the starting cost for the contract renewal. Contracts can be rebid at the end of contracts or awarded to the existing contractor, it is left up to the discretion of the Districts. 


\subsubsection{Maintenance Rating Program (MRP)}

This program was developed by FDOT in 1985 to provide a numerical grade on maintenance features. Appendix $\mathrm{K}$ is the complete document on the FDOT MRP. The procedures and guidelines describe an objective evaluation method. Each contract is evaluated three times annually using MRP. MRP inspections teams consist of maintenance personnel and consultants. MRP inspections are done by one team in each district, where a team is comprised of two individuals. The contractor can also inspect as well. Thirty samples are required per cost center, a cost center is roughly the size of a county. FDOT collects sufficient samples to obtain a 98\% statistical confidence level in the inspection results.

MRP teams are certified and QA/QC is performed on their inspections. FDOT runs the certification program. Annual training for the inspection teams lasts a week. Inspections are done from the shoulder and use paper based forms. The collected data is entered into a main frame computer program for processing and reporting.

MRP inspection by FDOT team is the one that is not contested. FDOT assesment team numbers can be adjusted by 2 points, for a margin of error. Inspections can be performed by the contractor and compared with FDOT's MRP team. No daily inspections are performed on the contracts. The general guidelines for MRP inspections are: three annual inspections are performed; inspection periods 1 and 2 if contractor doesn't meet minimum MRP scores, a retainage is assessed. After the third period if contractor passes, the retainage is returned. If the contractor fails the third one then the retained amount is deducted from their payment.

MRP inspection dates are known by the contractor, so some contractors have waited to perform certain activities before these inspections. It would be better not to 
advertize the dates of the inspections and performed them at any time within the 4 month time period.

Contractor responsiveness is not monitored but spot checks are done by FDOT. The public can report issues and the contractor has to respond in a timely manner as described in the contract. The public contacts FDOT and these issues are routed to the contractor.

\subsubsection{Results of AM}

The following are outcomes reported by FDOT.

- Some maintenance yards have closed and consolidated.

- A contractor has to immediately ramp up elements to minimum standards. FDOT does partner with the contractor that allows them some extra time to achieve these goals.

- Since AM started the budget has increased. But the increases have slowed.

- FDOT does not lose many employees to private contractors. Contractors have hired retired FDOT employees.

- Before AM, FDOT had individual maintenance contracts, each one inspected, so now in AM they can group 35 of these individual contracts into one and save on manpower by not having to inspect. Administration can be reduced which saves FDOT a considerable amount of time and money.

- FDOT develops an AM budget by using inventory budget items. Overhead costs are included in the budget costs. Overhead costs for facilities are not included in the budget estimate.

- AM contractors sub out most their work, approximately $75 \%$. Items typically contracted out include: tree trimming, stripping, rpms, mowing, sweeping and edging, and pipe cleaning.

- Penalties have not worked well with the contractor and should be reanalyzed. 
- Contractor innovation examples are: use of rubberized mulch at rest stops; on Hi mast lighting, the contractor installed a lightning arrestor system which has proven to save money over the duration of the contract. Giving the contractor a long duration contract provides the contractor an opportunity for innovation in order to save money over the contract time period.

- Security guard contracts were audited and found that FDOT was getting a better price through the contractor than with FDOT contracts.

- FDOT cannot prove that they are saving money with AM nor can they prove they are not saving money.

- FDOT LOS achievements depend on the contractor. Performance varies by the contractor.

- Morale has been affected. District personnel feel like AM has taken their jobs. Bumping and lay offs due to attrition, started in 1992. Some districts have embraced AM, some districts have not.

- Each road type has different criteria and weighting values. So the LOS is different, but the target value is 80 .

- All resurfacing is done by construction. Due to long term contracts the contractor will tend to perform repair work that is effective for the specific time period. Item replacements have to be in-kind or similar.

- One repeated issue is contractor performance at the end of the contract period.

- Train people on AM contracts. AM was forced on the department and this caused personnel problems. A uniform procedure on AM would be helpful.

- A sore point is minimum performance. For example there are 10 potholes, by contract the contractor only has to fix 8 of them. This is frustrating for FDOT since by contract FDOT cannot force them to fix the remaining pot holes.

- Better relationship with the contractor improves their performance. A partnering agreement is recommended on these contracts.

- Customer service is handled by the contractor. FDOT receives the complaints and passes them onto the contractor. FDOT has considered placing signs that 
informs the public on who to call, e.g. contractor. The contractor has two days to respond satisfactorily to FDOT District Interviews

\subsubsection{District Interviews}

Two Chipley District locations were visited, one at Midway, a subdistrict office, and the other at the Chipley District office. At each location various FDOT and contractor personnel were interviewed. Chipley is a panhandle District.

\subsubsection{Midway}

Interviewed Greg Outz(11 years with FDOT) and Mike Horton(14 years) both are FDOT employees assigned to the VMS(contractor) contract. This is a 5 county contract for complete maintenance. The road classes are rural arterial, rural limited access, and urban arterial. Most classes are two lane roads with some interstate, I -10. The contract started in June 2001 and was renewed in July 2008. The first contract was $\$ 33$ million for 7 years.

As a result of this contract several observations were expressed by the interviewees. Both felt this type of contract allows a contractor to utilize construction contracts to upgrade road segments. A contractor will look at the 5 year work program and try to use it to their advantage. Both said the overall maintenance condition has slipped in the contract. One example of this is in mowing, by stretching cycle times the contractor will try to eliminate one mowing cycle. Contractor performance can be characterized by doing just enough to get by. Typically scores are just above the minimum. If the first two inspections have low scores they will dedicate more resources during the final period to pass the deficient items and recover retainage. So generally a contractor will respond when they have to or when payment is threatened. 
No FDOT facilities have been affected with this contract. Some facilities have been closed and consolidated but this would have happened regardless of the AM contract. The impact on FDOT equipment allocation has been neglible.

The contractor has multiple facilities scattered around the area with no facility leased fron FDOT. A contractor can function out of a smaller facility since they subcontract out most of the work. Typically a contractor does not stockpile many materials therefore each facility is only about an acre in size.

Maintenance of Traffic is done by the contractor and they must inform FDOT if a lane closure will be performed. The safety record of the contractor has been good.

Emergency response contracts are handled separately and not included in the AM contracts. An AM contractor does get involved in maintenance activities resulting from hurricanes, floods, and fires. Hurricane Dennis washed out parts of 98 around Pensacola and the AM contractor could not handle the repair of the damaged sections so FDOT took over.

\subsubsection{Chipley District}

The following are comments recorded and summarized from an interview with the District maintenance engineer, a consultant, and a AM contractor..

Each district handles AM differently. Some districts say that AM does not work while Chipley believes in AM. Chipley believes that AM success depends on the contractor.

Currently there are three AM contracts in the Chipley District, two road and one facility. The facility contract covers rest areas. Typical rest area contracts are for 10 years while the other AM contracts are 7 year contracts. Rest areas AM contracts are 
inspected daily. The public can submit comment cards at the rest areas and these are collected and used in the AM contractor evaluation. Rest area maintenance requires a lot of man-hours. Several rest areas along I-10 in the Chipley District were visited and they looked great.

Asset Mangement has allowed Chipley to reduce staff, budget, and the number of vehicles. As Chipley has reduced personnel through attrition, the money savings have been directed to AM contracts. The AM budget has increased annually by approximately $\$ 1$ million.

FDOT morale - initially was poor when AM started, but has improved. The majority of FDOT maintenance employees believe that in-house can do it better.

Some units have consolidated with others while eight maintenance facilities have closed. These facilities are turned over to an internal state trust board where some facilities are leased and some are turned over to cities and counties.

Contractor innovation is somewhat limited due to satisfying requirements in the specifications and standards. There is not much leeway for innovation within the specs.

Chipley believes that it is cost effective to use AM contract over internally managing all the subcontracts. Approximately 80-90\% of the AM contracts are subbed out to local companies. The number of bidders on these contracts has increased from 3 up to 5, with most of the bidders national PBC companies.

The five county AM contract has roads that are more rural than urban. In most contracts the contractor has exceeded expectations. One AM contract has been troublesome and the most likely cause was the contractor underbid. Overall, AM has worked well in the Chipley District. 


\subsubsection{District Maintenance Engineers Interview}

A videoconference was held with all eight districts, below are the questions posed and their responses.

1. District 1, Contract (This District had a contractor default on a I-95 contract) default, what caused it and what was the outcome?

The contractor under estimated the cost and was not performing well. It was a mutual agreement to end the contract. FDOT revised the scope and rebid it. It gave the district a chance to refine the contract and give the contractor an opportunity to get out.

2. What impact has AM had on your operations?

District 1 - Freed up their crews to focus on the arterials. AM contracts are on limited access roads. Also incident management took a lot of time and AM contracts have helped to mitigate this time requirement.

District 2 - Costs have gone up. No reduction in oversight requirements.

District 5 - I-75 contract. They had the opportunity to find the right places for AM. This freedom is very important in developing contracts. The District has 4 different AM contracts. One is the I-75 contract. This particular corridor was taking a lot of time for routine maintenance. Another one is in a rural area, an hour away from the closest maintenance facility and they developed a contract with a local government to maintain that network. They also have a moveable bridges AM contract. The District has other PBC contracts for aesthetics combined into one contract; items include mowing, litter, tree trimming, edging, etc. By combining items there were able to save about $30 \%$ over performing individual contracts. They are using a PBC contract on highway lighting.

District 6 - This District has three AM contracts. The I-95 contract has been a nightmare due to the contractor's poor LOS and lack of responsiveness. The contractor has appealed every MRP score. This contract has created some real negative publicity in the district. The other two contracts have gone better because the contractors have performed better. 
District 7 - If an agency is looking for AM to do away with oversight it will not happen. Monitoring AM contracts takes a lot of time and effort.

District 8 - The turnpike has over 200 miles of AM contracts and all contracts have been favorable.

3. What are the advantages and disadvantages of AM?

District 1 - Advantages- Effort is reduced to oversee maintenance operations. The success or failure depends on the contractor. Coming up with an accurate estimate is a challenge because FDOT charges their work by counties.

District 2 - Advantage - fixed costs, you know what it will cost you over the contract period. Disadvantage - oversight effort required with a bad contractor.

District 4 - It is cheaper to do it in-house. Over a 7 year period the costs are more in-line in with FDOT in years 6 and 7. Years 1 and 2 costs are higher. Permitting should not be included in AM contracts. Also, add more penalty clauses to the contracts will help with contractor performance.

District 5 - Advantages - fixed cost you know what it will be for the next 7 years. Not having to oversee numerous contracts saves time and effort. Incident response is a huge advantage on corridors that have a high incident rate. Getting the right FDOT people involved is also very important.

District 6 - There are not a lot of advantages with AM. A bad contractor is hard to get rid of. Costs can be lower with in-house crews. When they dissolved the I-75 contract FDOT did the work and the costs were about half of what they were paying the contractor who had underbid.

District 7 - Fixed costs are an advantage. In general, costs are higher and the oversight takes more time than originally thought it would take. In years 5 and 6 the contractor tends to slack off. 
District 8 - Success or failure is heavily dependent on the contractor.

4. What changes would you make to the existing AM program in future contracts?

District 2 - Look at different performance criteria other than MRP criteria.

District 4 - Develop handback requirements with some retainage requirement in the last year of the contract. This could be used to insure performance in the last year. Need additional performance criteria for evaluation.

District 5 - Look at District in-house work load to establish PBC requirements.

District 6 - Re-evaluate contractor selection process.

District 7 - Establish handback requirements when a contract is taken back and turned over to another contractor. Add other performance requirements.

District 8 - Performance measures should be improved.

\subsubsection{Cost Information}

The below cost data was provided by FDOT. It shows maintenenace expenditures by categories starting in years $98-99$. The costs are graphically plotted to better illustrate trends. Between 2000 and 2007, the maintenance budget has gone from $\$ 371.7$ million to $\$ 479.2$ million this is an increase of $\$ 107.5$ million. This is a percentage increase of $107.5 / 371.7=29 \%$ increase or an annual increase of $4.14 \%$. During this period the consumer price index (CPI) increased an average of $2.8 \%$. For the previous seven year time period (1993 - 2000), the budget grew from $\$ 303.1$ million to $\$ 371.7$ million, an increase of $\$ 68.6$ million. The percentage increase was $68.6 / 303.1=23 \%$ increase or an annual increase of $3.28 \%$. During this time period the CPI increased an average of $2.45 \%$. So with AM the maintenance budget has increased at a higher rate even considering CPI values. 
Table 7.4 FDOT Maintenance expenditures

\begin{tabular}{|r|r|r|r|r|r|r|r|r|r|}
\hline $\begin{array}{l}\text { Program } \\
\text { Areas }\end{array}$ & $\mathbf{9 8 - 9 9}$ & $\mathbf{9 9 - 0 0}$ & Start AMC & $\mathbf{0 1 - 0 2}$ & $\mathbf{0 2 - 0 3}$ & $\mathbf{0 3 - 0 4}$ & $\mathbf{0 4 - 0 5}$ & $\mathbf{0 5 - 0 6}$ & $\mathbf{0 6 - 0 7}$ \\
\hline $\begin{array}{r}\text { IN- } \\
\text { House }\end{array}$ & 163.6 & 169.3 & 172.7 & 156.4 & 158.5 & 145.5 & 151.3 & 161.1 & 144.0 \\
\hline $\begin{array}{r}\text { M\&O } \\
\text { Contracts }\end{array}$ & 157.5 & 171.9 & 181.0 & 219.5 & 242.2 & 254.6 & 266.2 & 279.6 & 317.1 \\
\hline Consult. & 17.3 & 16.7 & 18.1 & 17.0 & 17.4 & 16.3 & 18.1 & 15.5 & 18.0 \\
\hline $\begin{array}{r}\text { Maint. } \\
\text { Budget }\end{array}$ & 338.4 & 357.9 & 371.7 & 393.0 & 418.1 & 416.5 & 435.6 & 456.2 & 479.2 \\
\hline $\begin{array}{r}\text { CPI + } \\
\text { 2\% RCI }\end{array}$ & 336.4 & 354.7 & 372.0 & 385.4 & 402.1 & 421.1 & 444.1 & 467.6 & 490.5 \\
\hline $\begin{array}{r}5 \% \\
\text { Increase }\end{array}$ & 337.3 & 354.1 & 371.8 & 390.4 & 409.9 & 430.4 & 452.0 & 474.6 & 498.3 \\
\hline $\begin{array}{r}\text { Schedule } \\
\text { B Charts }\end{array}$ & 343 & 348 & 374 & 388 & 420 & 405 & 427 & 443 & 464 \\
\hline CPI & 166.60 & 172.20 & 177.10 & 179.88 & 183.96 & 188.90 & 195.30 & 201.60 & 207.34 \\
\hline
\end{tabular}

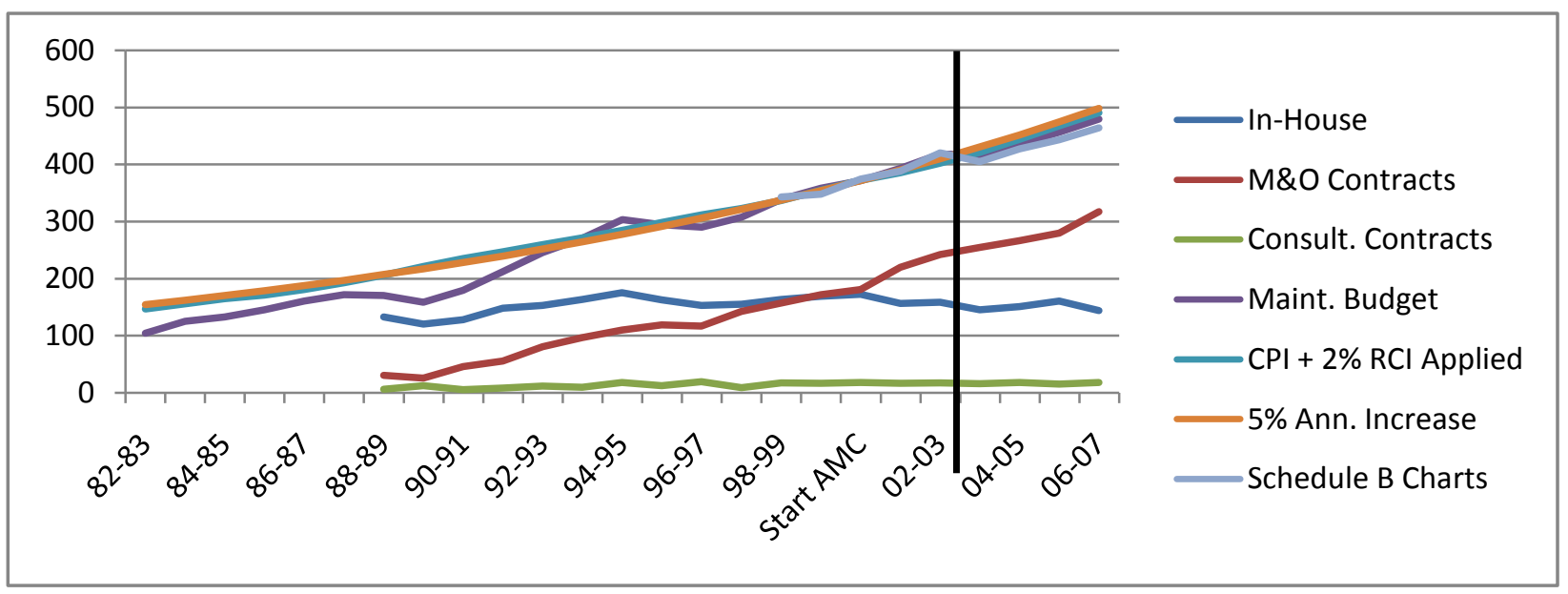

Figure 7.2 FDOT Maintenance Expenditure Curves 
- Starting in 98-99 in-house costs have decreased by approximately $\$ 20$ million while contract maintenance costs have increased by more than $\$ 159$ million. The overall maintenance budget has increased by $\$ 140.9$ million. So FDOT is performing more maintenance through AM.

A geographic contract in the Chipley District was completed in July 2008. It was a seven year contract for $\$ 33$ million that consisted of 925 lane miles. The average cost per lane per year is

$$
\frac{\$ 33,000,000}{(7 * 925)}=\$ 5096
$$

Snow and ice removal is not required in this contract.

\subsection{Georgia DOT}

Georgia DOT (GADOT) scheduled a PBC contract on a 126 mile segment of interstate in the Atlanta area in 2008. But due to various reasons the contract has been delayed. GADOT performed an initial baseline assessment which took one month time to perform. The PBC contract was based on current LOS criteria.

GADOT was spending $\$ 32,000$ per mile on this segment of interstate. The engineer's estimate for PBC was \$48,500 per mile, a 50\% increase. The contract will be assessed every 6 months. Project staff to be assigned is a project manager and three inspectors. The bond is for the full five year contract and there is a liability limit of $\$ 200 \mathrm{~K}$ on accidents. 


\subsection{Contractor Interviews and Meetings}

Four major Indiana contractor agencies were asked to discuss, suggest, and comment on their PBC's experiences (if any) and/or their point of view and intentions (relative to $\mathrm{PBC}$ ).

Figure 7.2 describes the topics discussed during the meetings and interviews. Contractor officials were asked to comment and make suggestions on the following issues: payment terms (e.g., USD per lane-mile per month), their 24/7 call out availability, contract characteristics (activities included in the contract, contract type, number and specific activities included in the contract (in the case of Indiana, significant interest was expressed on snow removal activities), contract duration, prolongation, and length of the outsourced road sections, performance monitoring and its relation with the payment periods, etc.), liability issues related to third party lawsuits and indemnification, the criteria used by INDOT when selecting the best bid, and cost escalations originating from materials and resources.

These interviews and meetings aimed at developing some general guidelines on designing a contracting approach that would be beneficial for both parties (the road agency and the contractor). This way, a strong partnership can be formed where the level of service is financially efficient and satisfactory to both parties. 


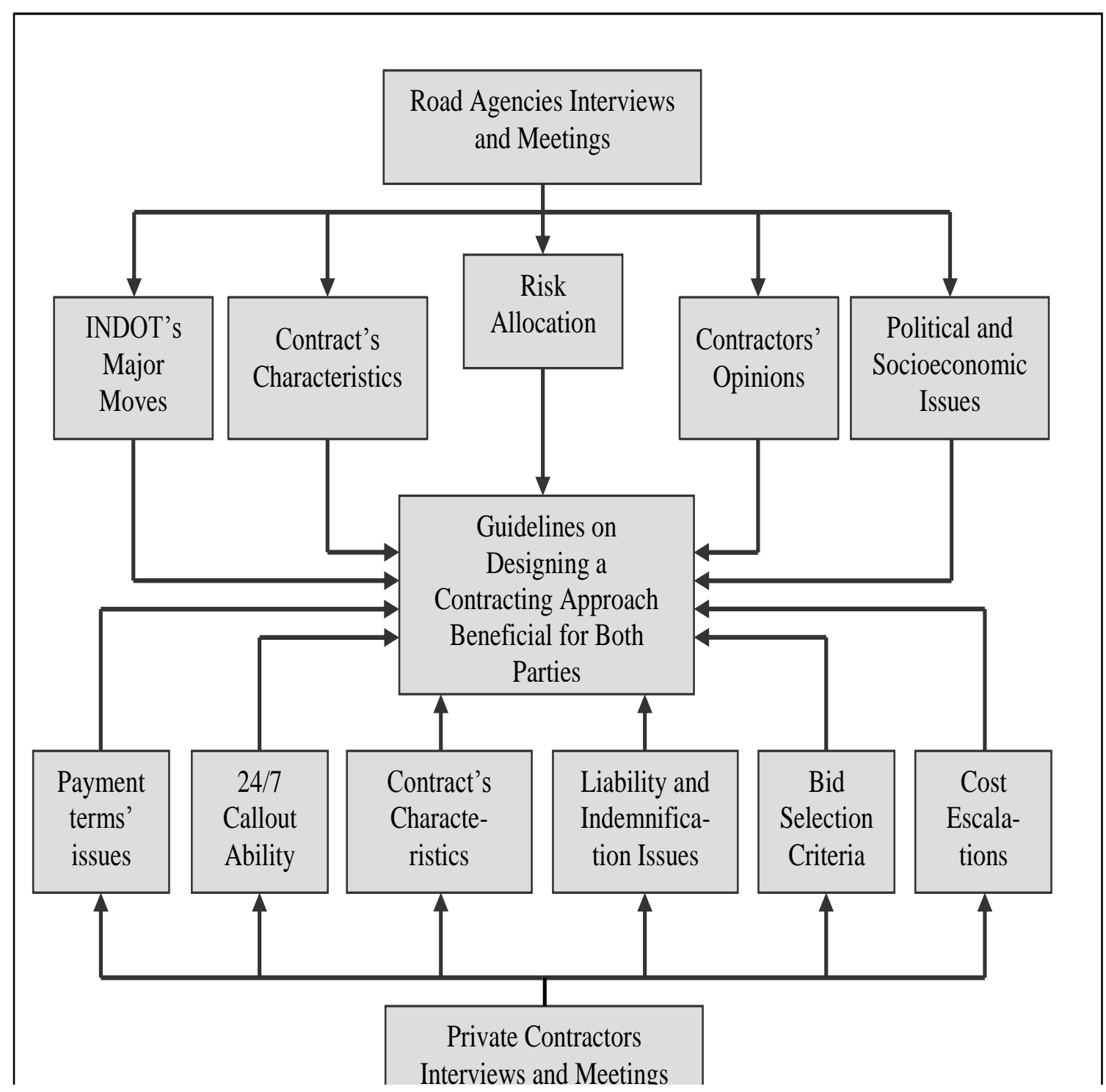

Figure 7.3 Framework for road agency and contractor interviews and meetings

The contractor interviews included four officials from E+B Paving, two officials from Milestone, one from Brooks Construction, and one from Rieth-Riley. There were two phone-interviews and one face-to-face meeting held to collect the contractors' points of view. The criteria used by road agencies in selecting the best bid for a PBC was a first major concern, followed by the contractor's responsibility in case of accidents, the 
estimation of the actual and reported cost savings, and the cost determination from the contractor's/agency's perspective. In the question of whether the contractors are willing and can manage the snow removal activity if outsourced under PBC, the contractors agreed that INDOT had been successfully performing this activity for many years, making it less desirable for the contractors.

It was also stressed that since INDOT has been performing snow removal, the contractors did not have the necessary equipment for such a task. At this point there was a disagreement of whether the contractors would be interested in undertaking this activity: half of them believed that there was no interest for snow removal activities, whereas the other half suggested that although snow removal was a low motivator for the contractors, they could manage if needed. As far as leasing or even buying the related equipment from INDOT is concerned, it was agreed that if snow removal was the contractors' responsibility, they would be able to handle it. In other words, leasing or buying snow removal equipment from INDOT would be an option worth considering. The case of Oklahoma was also discussed, where snow removal was included in the PBC, but after a severe blizzard and contractor's failure to respond, Oklahoma DOT decided to cancel the PBC program.

As far as the 24/7 callout contractor's responsibility under PBC is concerned, it was mentioned that, although cleaning the accident scenes in a timely fashion is very difficult to manage, it can still be managed. Another question raised was whether the outsourced road segments under PBC would better be located near the contractor's facilities. The contractors unanimously stated that it depended on the activities included in the contract, but also indicated that such an option would be beneficial to them.

The case of the City of Indianapolis was also discussed, where many maintenance activities (e.g. pothole repair, stripes maintenance, solid waste, resurfacing, etc.) were outsourced in the early 1990s, by redesigning and realigning their processes. The activities/assets that were contracted out resulted from a thorough investigation: the 
activities where Indianapolis was not good at maintaining were contracted out. Cost tools were developed and used to convert the costs to activity level, overhead cost, and labor level, and based on this segmentation, specific activities were decided to be outsourced. The City of Indianapolis also submitted bids, winning almost $80 \%$ of all contracts.

Also, the need to clarify the cost issues (cost saving origins, estimations, and segmentation) was stressed. To monitor the outsourced activities/assets, independent inspectors are needed. It was suggested that experience and common sense be used for cost segmentation. In the case of the City of Indianapolis, however, instead of outsourcing road segments, specific activities were contracted out (although such an option was first discussed). Another example from the case of the City of Indianapolis was traffic signals and signs maintenance, where the contractors chose not to submit a bid, since the government agency was much more competitive. As far as the contract duration is concerned, it was usually one-year contracts with just a few exceptions (e.g., solid waste projects were $3+2$ years $^{20}$ ).

The liability issue was also a big concern, and especially the protection from third party lawsuits and indemnification that have to be provided to the contractor. Again, taking the City of Indianapolis as an example, it was suggested that each party's (contractor and agency) responsibility should be clearly identified in the contract. Even if the contractor is responsible, the road users will still blame the road agency. The contractors agreed that as soon as they take full responsibility of a road asset/activity, the agency should not be "bothered". The need to have a successful partnership (between the agency and the contractors) was stressed. Also, it was suggested that there should be risk sharing as part of this partnering, and that accurate and clearly defined performance measures and detailed lists of specific items (including acts of nature, e.g., tornados) that are included in the contract should be prepared and incorporated in the contract agreement.

\footnotetext{
${ }^{20}$ Three years duration, plus two years renewal (extension/prolongation) option.
} 
Some of the contractors suggested that they would prefer an activity-based approach, where specific activities would be contracted out. On the other hand, other contractors disagreed, stating that they would prefer the performance-based approach. The issue of pavement maintenance and how the pavement's infrastructure is worsened by only maintaining it (without resurfacing) was also addressed. The monitoring process was also discussed. It was the contractors' belief that monitoring on a monthly basis (as suggested by the literature) would be beneficial neither to the contractor nor to the agency. A yearly-basis monitoring was favored by the contractors.

A combination of (re)construction and maintenance activities included in the contract was suggested by the contractors, as this way there is no need to worry what work has already been performed by different contractors. Also, there was a stated optimism that after the first PBC implementation in Indiana all issues will be clarified and the next PBCs will conclude in more beneficial results to all parties involved.

Another issue addressed was whether the government funding would address long-term contracts (i.e., 10 or 20 years PBCs). It was generally commented that it is difficult to predict or make assumptions. On the question of whether the contractors would have the ability to deal with INDOT's major moves (INDOT's added capacity), the contractors responded positively, but stressed that that political changes could affect INDOT's major moves ; hence, there would be uncertainty and it would be difficult to make predictions. In the question of whether the contractors would bid in the case that the funding for the major moves would be 1.4 billion USD (as planned), the contractors replied positively.

As far as payment terms were concerned, the contractors agreed that this would not a problem, and a USD/lane-mile/month would be suitable. However, the payment should not be based on the contractor's activity, but on meeting the performance standards. The contractors also discussed that they had the resources (equipment and manpower) for most of the maintenance activities, with some exceptions (e.g., striping 
and herbicides) where special equipment would be required. Such activities would be sub-contracted out and they would be more cost effective if a larger area was available then just one single location. Furthermore, the case wheret maintenance includes reconstruction (e.g., adding new drives or turn lanes) was discussed. In that perspective, execution and reimbursement options need to be determined: the contractors agreed that escalation clauses would need to be included in the contract to address such cases.

The contractors also agreed on the agency's belief that the PBC program (if implemented) would better to start with short-term pilot contracts (no greater than 2 years in duration) and use such practices to modify and improve the concept. Then the contract-period could be increased. The area to include (or the number of lane-miles) in the contract and the contractor's bonding capacity were some of the critical issues discussed.

Finally, the need to thoroughly examine all problems and issues related to PBCs, prior to their implementation was stressed. Especially, since legislations and budgets are different for each country and state, all aspects concerning PBC implementation should be carefully considered. In all cases, obviously because all contractors are familiar with INDOT maintenance activities, it was agreed that adapting in new contracting methods would not be problematic. 


\subsection{Chapter Summary}

Interviews and meetings were designed and planned to solicit opinions of government agencies and contractors. However, there is evident skepticism on all aspects that will determine the success of a new contracting method such as PBC.

Some of the issues addressed were: how many activities should be incorporated in a PBC, which specific activities should be included in a PBC, should snow removal be an activity, what happens to INDOT's equipment, how many miles (or lane-miles) should be covered in a PBC, what duration should a PBC have, should an extension be included, how are liability issues managed under PBC, what about the risk transferred to the contractor, how often should road facilities be monitored, what specific performance standards should be used, in what payment terms, etc. In all cases, the respondents from the agencies and contractors were optimistic that performance-based contracting will eventually produce the benefits that are described in literature and its implementation will be successful. However, the need to thoroughly investigate all issues and aspects related to the $\mathrm{PBCs}$ ' implementation, before applying them, was identified. 


\section{CHAPTER 8. CONCLUSIONS AND RECOMMENDATIONS}

At the current time, there is considerable global experience with the practice of performance-based contracts. This experience is accompanied by contestation on the true outcomes produced by PBCs, with regard to qualitative (offered level of service) and quantitative (cost savings) results. Collected cost data indicates that PBC is not effective in saving Agency money as reported in previous reports. Overall trends, advantages, and disadvantages are reported herein.

While U.S. agencies and other foreign road administrations are increasingly implementing performance-based contracting, a number of challenges are also being identified. First, agencies tend to be concerned that they may lose valuable in-house expertise due to the reduction of their involvement in roadway maintenance, as a result of outsourcing. Another issue is the level of service required for the outsourced facilities (and/or activities) that are included in the performance-based contract. There is also concern regarding the risk allocation from the road agency to the contractor, and the ways the latter can manage it. Finally, there is a need to evaluate whether and under what conditions PBCs will lead to overall assets' improvement, and if they are cost-effective in the long-term.

\subsection{Results of the Interviews and Meetings}

To bridge the gap between theory and, the point of view of road agencies and contractors was investigated. Officials from several U.S. state DOTs, international road agencies and several major contractors were contacted to discuss, suggest, and comment 
on their experiences regarding outsourcing of roadway maintenance operations, including PBC.

Major conclusions from these discussions are summarized: (i) do not incorporate snow removal activities in PBC, (ii) initially, launch a 2-year PBC where few activities are incorporated in minor highways or secondary roads, (iii) experienced agencies and contractors may move towards a long-term (20 years) comprehensive PBC, (iv) "best value" should be the selection bid criterion, (v) the performance measures for specifying the PBC's characteristics are the cost savings, level of service, and public/political acceptability, (vi) cost savings can only be realized from well qualified contractors, strong competition and long-term contracts, (vii) the liability issue is an important concern in the U.S.A., (viii) hybrid contracts are the "right" approach to increase competition (and for the agency to feel more comfortable), the hybrid approach utilizes agency forces as the foundation for maintenance services and the use of contractors to supplement, (ix) "24/7" callout is manageable by the contractors (however, cleaning crash scenes in a timely fashion is difficult), (x) outsourcing roadway assets located near the contractor's facilities would be beneficial for both parties, (xi) performance monitoring should be performed at a frequency and level to adequately determine contractor performance, (xii) requirements should be developed to assure contractor meets requirements throughout the life of the contract, (xiii) and clearly identify the contractor and agency responsibility in the contract, and develop a risk management sharing system.

\subsection{Maintenance Plan}

To determine the impact Major Moves will have on INDOT's maintenance operations an internal study at INDOT produced the following information.

In order to determine the impact, the study looked at the number of lane miles Major Moves will add to the INDOT system the following lane miles. There will be a 
total of approximately 1,940.68 lane miles added to the system including I-69. The following charts show the number of lane miles and anticipated additional snow routes by INDOT district and sub-district. .

Table 8.1 Snow Route Analysis By Districts

\begin{tabular}{|l|r|c|}
\hline \multicolumn{3}{|c|}{ Crawfordsville by Sub-district (610) } \\
\hline Sub-district & Lane miles & \# Routes \\
\hline Frankfort & 191.3 & 6 \\
\hline $\begin{array}{l}\text { Terre } \\
\text { Haute }\end{array}$ & 28.76 & 1 \\
\hline Cloverdale & 15.16 & 0 \\
\hline TOTAL & 235.22 & 7 \\
\hline
\end{tabular}

Ft. Wayne by Sub-districts (620)

\begin{tabular}{|l|r|c|}
\hline Sub-district & Lane miles & \# Routes \\
\hline Ft. Wayne & 84.92 & 2 \\
\hline Elkhart & 39.26 & 2 \\
\hline Angola & 10.6 & 0 \\
\hline TOTAL & 134.78 & 4 \\
\hline
\end{tabular}

\begin{tabular}{|l|r|c|}
\hline \multicolumn{3}{|c|}{ Greenfield by Sub-districts (630) } \\
\hline & & \\
Sub-district & Lane miles & \# Routes \\
\hline Indianapolis & 130.52 & 4 \\
\hline Tipton & 182.59 & 5 \\
\hline Centerville & 17.27 & 0 \\
\hline
\end{tabular}




\begin{tabular}{|l|r|c|} 
Greenfield & 40.65 & 1 \\
\hline Albany & 30.85 & 2 \\
\hline TOTAL & 401.88 & 12 \\
\hline
\end{tabular}

\begin{tabular}{|l|r|c|}
\hline \multicolumn{2}{|c|}{ LaPorte by Sub-districts (640) } \\
\hline & & \\
Sub-district & Lane miles & \# Routes \\
\hline Rensselaer & 6.72 & 0 \\
\hline LaPorte & 14.58 & 1 \\
\hline Plymouth & 128.9 & 4 \\
\hline Gary & 16.45 & 0 \\
\hline TOTAL & 166.65 & 5 \\
\hline
\end{tabular}

\begin{tabular}{|l|r|c|}
\hline \multicolumn{3}{|l|}{ Seymour by Sub-districts (650) } \\
\hline Sub-district & Lane miles & \# Routes \\
\hline Falls City & 17.47 & 0 \\
\hline Columbus & 59.75 & 2 \\
\hline Bloomington & 21.16 & 1 \\
\hline Madison & 20.60 & 0 \\
\hline \multirow{3}{|c|}{118.98} & 3 \\
TOTAL & \\
\hline
\end{tabular}

\begin{tabular}{|l|r|c|}
\hline \multicolumn{3}{|l|}{ Vincennes by Sub-districts (660) } \\
\hline $\begin{array}{l}\text { Sub- } \\
\text { district }\end{array}$ & Lane miles & \# Routes \\
\hline Tell City & 88.62 & 3 \\
\hline Evansville & 49.95 & 2 \\
\hline
\end{tabular}




\begin{tabular}{|l|r|r|} 
Paoli & 144.60 & 4 \\
\hline TOTAL & 283.17 & 9 \\
\hline
\end{tabular}

\begin{tabular}{|l|c|c|}
\hline & Lane Miles & \# Routes \\
\hline Total & $1,340.68$ & 40 \\
I-69 & 600 & 18 \\
Grand & & \\
Total & 1940.38 & 58 \\
\hline
\end{tabular}

The average miles comprising one (1) snow route for a Class 1 road is 30 lane miles and for a Class 2 road is between 40 and 45 lane miles. Since the majority of the roads created by Major Moves will most likely be Class 1, 32.5 lane miles is used to calculate the additional snow routes. To be counted as a new snow route for a subdistrict, the length has to be greater than 20 lane miles.

Based on the above figures INDOT will require 58 additional snow plow routes to meet the new demand created through Major Moves. Additional factors to take into consideration are:

1. If Major Moves generates complex interchanges like those currently being built (example being the interchange at I 74/I 465), each of these interchanges will generate an additional snow route due to the 'deadhead' time, the length of ramps, and the complexity of plowing fly over ramps.

2. Due to funding concerns for personnel and equipment, only a few new routes were requested and approved during the past 15 to 20 years. Therefore, it is anticipated that current routes are not sufficient.

3. The above calculation does not consider the access roads that may be required for the I 69 extension to Evansville.

Table 8.2 shows the expected times when new snow routes will be required by year. 
Table 8.2 Possible Snow Route

Requirement By Year

\begin{tabular}{|c|c|c|c|c|c|c|c|c|c|c|c|c|c|}
\hline & 610 & & 620 & & 630 & & 640 & & 650 & & 660 & & $\begin{array}{l}\text { Rout } \\
\text { es } \\
\text { Per } \\
\text { Year }\end{array}$ \\
\hline 2006 & 8.92 & & 3.80 & & 16.86 & & 7.86 & & 1.70 & & 14.52 & & \\
\hline 2007 & 0 & & 9.34 & & 6.84 & 1 & 15.53 & & 5.17 & & 0 & & 1 \\
\hline 2008 & 27.32 & 1 & 25.86 & 1 & 27.52 & 1 & 0 & & 4.46 & & 18.78 & 1 & 4 \\
\hline 2009 & 15.00 & & 20.28 & 1 & 3.43 & & 19.44 & 1 & $\begin{array}{r}20.1 \\
0\end{array}$ & & 24.76 & 1 & 3 \\
\hline 2010 & 0 & & 8.00 & & 33.97 & 1 & 25.90 & 1 & $\begin{array}{r}22.8 \\
0\end{array}$ & 1 & 28.75 & 1 & 4 \\
\hline 2011 & $\begin{array}{r}137.0 \\
4\end{array}$ & 4 & 26.18 & 1 & 29.92 & 1 & 36.20 & 1 & 15.8 & 1 & 17.40 & 1 & 9 \\
\hline 2012 & 20.12 & 1 & 0 & & 69.41 & 2 & 9.72 & & 0 & & 11.16 & & 3 \\
\hline 2013 & 0 & & 5.60 & & 66.84 & 2 & 0 & & 0 & & 8.00 & & 2 \\
\hline 2014 & 26.82 & 1 & 21.90 & 1 & 61.94 & 2 & 0 & & $\begin{array}{r}29.4 \\
1\end{array}$ & 1 & $\begin{array}{r}159.8 \\
0\end{array}$ & 5 & 10 \\
\hline 2015 & 0 & & 13.82 & & 85.15 & 2 & 52.00 & 2 & $\begin{array}{r}19.5 \\
2\end{array}$ & & 0 & & 4 \\
\hline Miles & 235.2 & & 134.7 & & 401.8 & & 166.6 & & 118 & & 283.1 & & \\
\hline
\end{tabular}




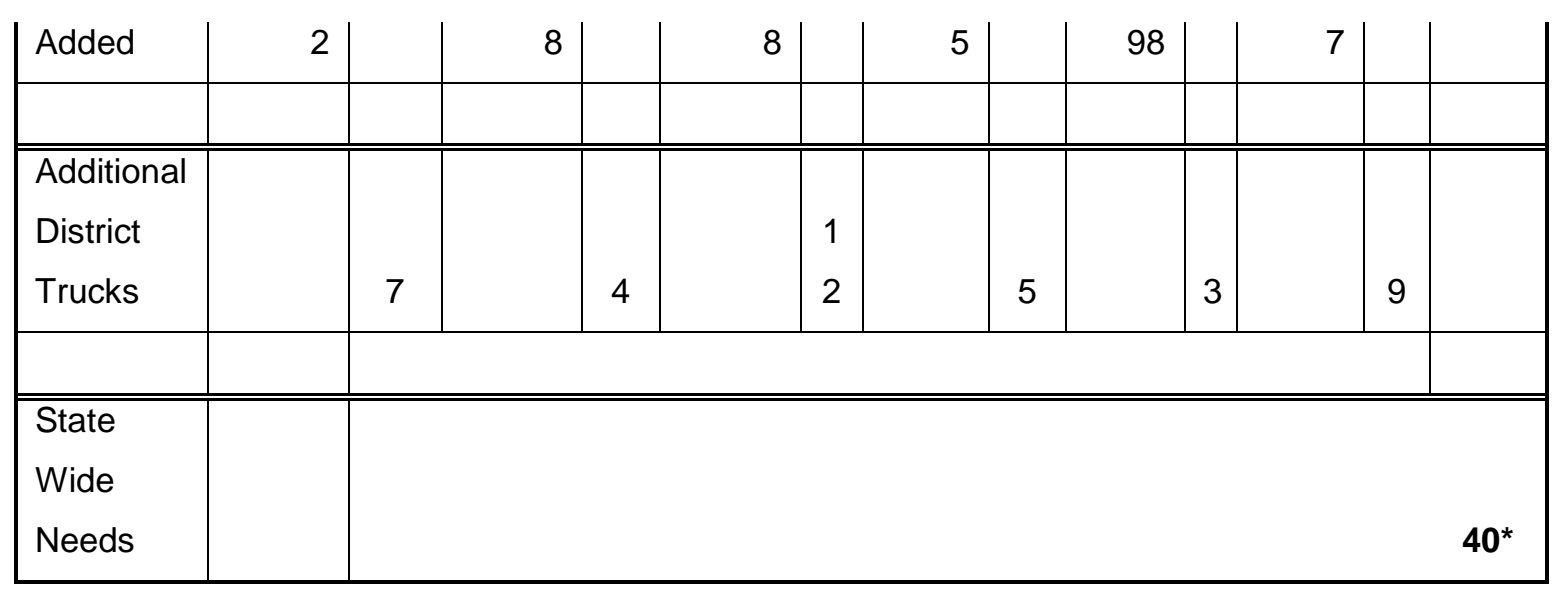

- Does not include I-69 routes.

The additional snow routes will create challenges for INDOT. More trucks and drivers will be needed or some of the routes will have to be covered by private contractors. One option for INDOT is to investigate the use of snow plow routing software to analyze the impact of the additional lane miles. In most Districts the routes will need to be reanalyzed. Approximately eight years ago INDOT utilized a JTRP software package called CASPER to analyze snow routes. It was tried in two districts and eliminated approximately $10 \%$ of the snow routes in these Districts.

As shown in the above tables, the amount of lane miles INDOT must maintain will increase significantly in the next several years. However, due to falling tax revenue, INDOT's maintenance budget is being cut. INDOT has the following possible options to deal with this challenge:

1. Increase resources - equipment and personnel. This is highly unlikely.

2. Increase maintenance subcontracts including snow and ice removal activities.

3. Implement a PBC program that includes winter operations.

4. Reduce the Level of Service across the network.

Items 1, 2, and 3 require additional funding. Item 4 approach lowers the quality of the end product, but saves money. However, this may generate complaints from Indiana 
drivers and tax payers and negatively affect INDOT's public perception. INDOT needs to select an option and develop plans for it now. The following lays out information for evaluating and selecting these options.

\subsubsection{Option - Increase Resources}

Major Moves projects will add approximately 1940 lane miles to the current network. Other capacity will be added through the normal work program. These additional requirements if maintained with state forces will require additional equipment, material, and people. INDOT analysis described in the previous section says that 40 new trucks will be needed to man the additional snow routes. From average lane mile cost data the additional annual maintenance expenditure is $\$ 8,497,200$. From a political perspective this is the least preferred option because it grows government, however from a cost perspective it may be the best. A cost analysis of PBC contracts is covered later in the report

\subsubsection{Option - Increase sub-contracts}

INDOT currently has a well-developed maintenance sub-contract program. Activities such as mowing, guard rail repair, cable-barrier repair, and other activities are done through subcontracts. With this experience and capability INDOT can easily expand this option and would require the following:

- More contract managers will have to be developed..

- Inspection criteria may need to be refined or developed for new activities.

- An evaluation of the subcontracting industry by state region. This evaluation involves looking at activities and the availability of qualified and adequate number of subcontractorss for competition reasons. This evaluation will take time and should be performed by each District. 
- $\quad$ Develop a training program for contract managers and inspectors to insure a uniform and well structured program.

\subsubsection{Option- PBC Program}

Section 8.3 describes what is required for a PBC program and how to establish one. PBC will allow INDOT to shrink its workforce and equipment needs. PBC will utilize private contractor resources to supplement public resources, a form of "redistribution" of resources. Other facets such as innovation are advantageous and documented in the report. Plusses and minuses of this option have been well documented by other studies and summarized herein in other report sections. Lessons learned from evaluating the PBC approach is summarized in Table 8.3.

Table 8.3 - Lessons Learned

\begin{tabular}{|l|}
\hline Most PBC programs are initiated for political reasons and not business reasons. \\
\hline PBC contracts are generally not cost effective for geographic contracts. \\
\hline PBC contracts that are facility specific (e.g. rest areas, bridge maintenance) have proven \\
\hline PBC contracts create an environment for innovative solutions. \\
\hline PBC contracts have not handeled snow and ice events well. Costs are for extreme \\
weather events over a long time period for risk reasons. Most contractors are not \\
equipped for extreme events while Agencies can pull resources from less affected areas. \\
\hline PBC requires an agency to create a new organization, develop LOS criteria, perform \\
baseline assessments, develop an assesment program, and produce a training program. \\
\hline Indiana contracting community is interested in performing maintenance activities. \\
\hline Snow and Ice subcontracts are a viable option for INDOT. \\
\hline
\end{tabular}




\subsubsection{Option - Lower LOS}

This is certainly not a desireable option but one that currently exists. The Operations budget is being cut and this will be reflected in lower LOS for most activities including snow and ice removal activities. How much lower LOS is not known at this time. Certainly the robbing "Peter to pay Paul" principle will occur with this approach. For example, salt costs have increased significantly since the 2007-2008 winter. And next year's costs could double over this year. So will INDOT order less salt and run the risk of running out? To cover this increase, other activities LOS will have to be cut. Since INDOT does not have a defined field LOS program it is not possible to determine the ramifications from LOS reductions.

\subsection{PBC Program Components}

This section describes the requirements for establishing a PBC program at INDOT. A PBC program consists of an organization and two major components, developing contracts and and contract administration. This section describes this organization and what should occur in the different phases of the program.

\subsubsection{PBC Team}

A PBC program requires a new organization within an agency. This organization will be responsible for staffing, developing contracts, overseeing the contracts, performing assessments, and determining contractor conformance and compliance to contract requirements. This organization must be put into place before contract development and selection occurs. What does this organization look like? 
Initially a PBC program will run from the central office even though an agency maybe decentralized like INDOT. An individual in Operations support will be in charge of developing the program. Initially this individual will spend a majority of their time in developing a contract. After that phase less of their time will be required to administer the contract.

For explanation purposes this individual will be called the PBC Administrator. To describe this individual and the PBC organization, the below tables contains a job description and time requirement estimates for each program phase.

\subsubsection{PBC Administrator}

Table 8.4 PBC Administrator - Contract Development Phase Duties

\begin{tabular}{|c|l|c|}
\hline \multicolumn{2}{|c|}{ PBC Administrator } \\
\hline Phase & \multicolumn{1}{|c|}{ Activities } & $\begin{array}{c}\text { Estimated Time } \\
\text { requirements }\end{array}$ \\
\hline Contract Development & $\begin{array}{l}\text { 1. Project selection. } \\
\text { Determine project location, } \\
\text { project length, and activities } \\
\text { to include. }\end{array}$ & One month \\
\cline { 2 - 3 } & $\begin{array}{l}\text { 2. Baseline assessment. } \\
\text { This requires a team of } \\
\text { approximately 2-3 to } \\
\text { perform a field inventory of } \\
\text { asset condition. }\end{array}$ & Two months \\
& $\begin{array}{l}\text { 3. Engineers estimate. } \\
\text { This is created from the } \\
\text { baseline assessment. Also, } \\
\text { LOS criteria will establish } \\
\text { engineer's estimate. } \\
\text { Engineers estimate is } \\
\text { adjusted by LOS } \\
\text { requirements. }\end{array}$ \\
\hline
\end{tabular}




\begin{tabular}{|c|c|c|}
\hline \multirow[t]{5}{*}{ Contract Development } & $\begin{array}{l}\text { 4. Develop and test } \\
\text { performance } \\
\text { standards. } \\
\text { Do standards exist? Other } \\
\text { state standards should be } \\
\text { consulted for comparison or } \\
\text { for developing particular } \\
\text { standards. The same team } \\
\text { that performed the baseline } \\
\text { assessment will be involved } \\
\text { in this activity. }\end{array}$ & 6 months \\
\hline & $\begin{array}{l}\text { 5. Legislative action. } \\
\text { Develop bill for legislative } \\
\text { approval for best value and } \\
\text { best and final offer bids. } \\
\text { This is the preferred } \\
\text { contract form. }\end{array}$ & 12 months \\
\hline & $\begin{array}{l}\quad \text { 6. Develop contract } \\
\text { language. } \\
\text { This requires putting } \\
\text { together a team comprised } \\
\text { of legal, contracts, contract } \\
\text { field manager, Indiana } \\
\text { constructors association, } \\
\text { others. Use other agency } \\
\text { contracts as a guide. See } \\
\text { below for contract specifics. }\end{array}$ & 12 months \\
\hline & $\begin{array}{l}\text { 7. Develop assessment } \\
\text { program } \\
\text { Issues to be decided are: } \\
\text { who will perform the } \\
\text { assessments, how many } \\
\text { teams needed, rating system } \\
\text { used. }\end{array}$ & 2 months \\
\hline & $\begin{array}{l}\text { 8. Training program } \\
\text { Training programs need to be } \\
\text { developed for assessment } \\
\text { teams and contract inspectors. }\end{array}$ & 2 months \\
\hline
\end{tabular}


Contract development activities can be performed in parallel. This phase will take approximately 18 months to develop the initial contract. This phase may involve up to ten employees. This will require a full time administrator.

The Administration phase is the execution of the contract and Table 8.5 describes the administrator duties.

Table 8.5 PBC Administrator - Administration Phase Duties

\begin{tabular}{|l|l|l|}
\hline Administration & $\begin{array}{l}\text { Develop field team and } \\
\text { guidelines for inspecting } \\
\text { and documenting. }\end{array}$ & One month \\
& $\begin{array}{l}\text { Establish a partnering } \\
\text { arrangement with the } \\
\text { contractor. }\end{array}$ & \\
\cline { 2 - 3 } & $\begin{array}{l}\text { Perform assessments and } \\
\text { determine contract pay } \\
\text { amounts. }\end{array}$ & At specified intervals. \\
\hline & $\begin{array}{l}\text { Administer annual training } \\
\text { for assessment teams. }\end{array}$ & One month \\
\hline
\end{tabular}

This phase will not require a full time administrator. That individual will be available for other maintenance duties. This phase does require a fulltime contract administration team, consisting of a supervisor and inspectors. NCDOT had three full time employees in their contract, FDOT uses two employees per contract, and VDOT has three employees involved in each TAMS contract.

The supervisor and inspectors will be responsible for the daily administration of a PBC contract. The full time administrator is not involved in the daily contact activities but takes on an overseer role. 


\subsubsection{Level of Service (LOS) Program}

An important aspect of a PBC program is establishing appropriate LOS criteria. This criteria is needed for establishing contract LOS requirements, developing a cost estimate, and for performing assessment evaluations of the contractor performance. As stated previously this criteria must be clearly understood by the agency, the assessment team, and the contractor. The individual items must be described in language that leaves little room for misinterpretation and dispute.

In 2003, the JTRP study "Maintenance Quality Assurance Program” was completed and report issued. The project developed a Maintenance QA program for INDOT. One of the key components is a field inspection program that has performance criteria for maintenance activities. This criteria was developed from criteria developed by other state agencies, specifically Florida, Maryland, Colorado, and Utah.

FDOT started their MRP program in 1985 and is the most mature one in the United States. Their surveys and level of service scores were initially used as a baseline of condition assessment and in the following years used to evaluate improvements. The MRP program has resulted in raising the value and quality of their system facilities and also helped to establish uniformity across the state. Other outcomes are an improved balance of work among the maintenance activities and lower unit and total costs. Some of the particulars are there are five categories evaluated; pavement, roadside, traffic services, drainage, and vegetation/aesthetics. Each of these categories is comprised of multiple items and each item has criteria that define a maintenance condition to meet. Their sample segment length is 0.1 mile. Their program has been very successful and was used as a guide to develop the criteria for INDOT.

A LOS rating system consists of establishing a set of condition standards, assign weight values, and developing the process to collect, analyze, and report LOS data. The below LOS rating criteria was developed and can be used as a starting document for an 
INDOT PBC program. There are five categories: Pavement(flexible and rigid), Shoulders, Roadside, Drainage, and Traffic Control. Each category consists of items that have been assigned a weight based on importance. These weight values can be removed in a PBC LOS program.

Table 8.6 LOS Criteria

\begin{tabular}{|c|c|c|c|}
\hline & & & VAL \\
\hline Categories & Criteria & Weight & $\mathbf{U E}$ \\
\hline $\begin{array}{c}\text { Flexible } \\
\text { Pavement }\end{array}$ & & & \\
\hline Smoothness & Minimum as established by IRI. & 1 & 25 \\
\hline Rutting & Not to exceed $1 / 2$ inch in depth & 2 & 13 \\
\hline Depressions/Bu & & & \\
\hline mps & $\begin{array}{l}\text { Not to exceed } 1 / 2 \text { inch for } 8-10 \mathrm{ft} \text {. length. } \\
\text { No defects greater than } 1 \text { sq.ft in area and } 1.5\end{array}$ & 3 & 13 \\
\hline Potholes & inches deep. & 4 & 13 \\
\hline Shoving/Rutting & Shoving area not to exceed 25 sq. $\mathrm{ft}$. & 5 & 13 \\
\hline Cracking & $75 \%$ of roadway is free of unsealed cracks. & 6 & 13 \\
\hline Raveling(includi & & & \\
\hline ng edge) & $90 \%$ of roadway free of raveling. & 7 & 10 \\
\hline Rigid Pavement & & & 100 \\
\hline Smoothness & Minimum as established by IRI. & 1 & 25 \\
\hline Joints & $\begin{array}{l}75 \% \text { of transverse and longitudinal joint material } \\
\text { appears to keep water out. }\end{array}$ & 2 & 15 \\
\hline
\end{tabular}




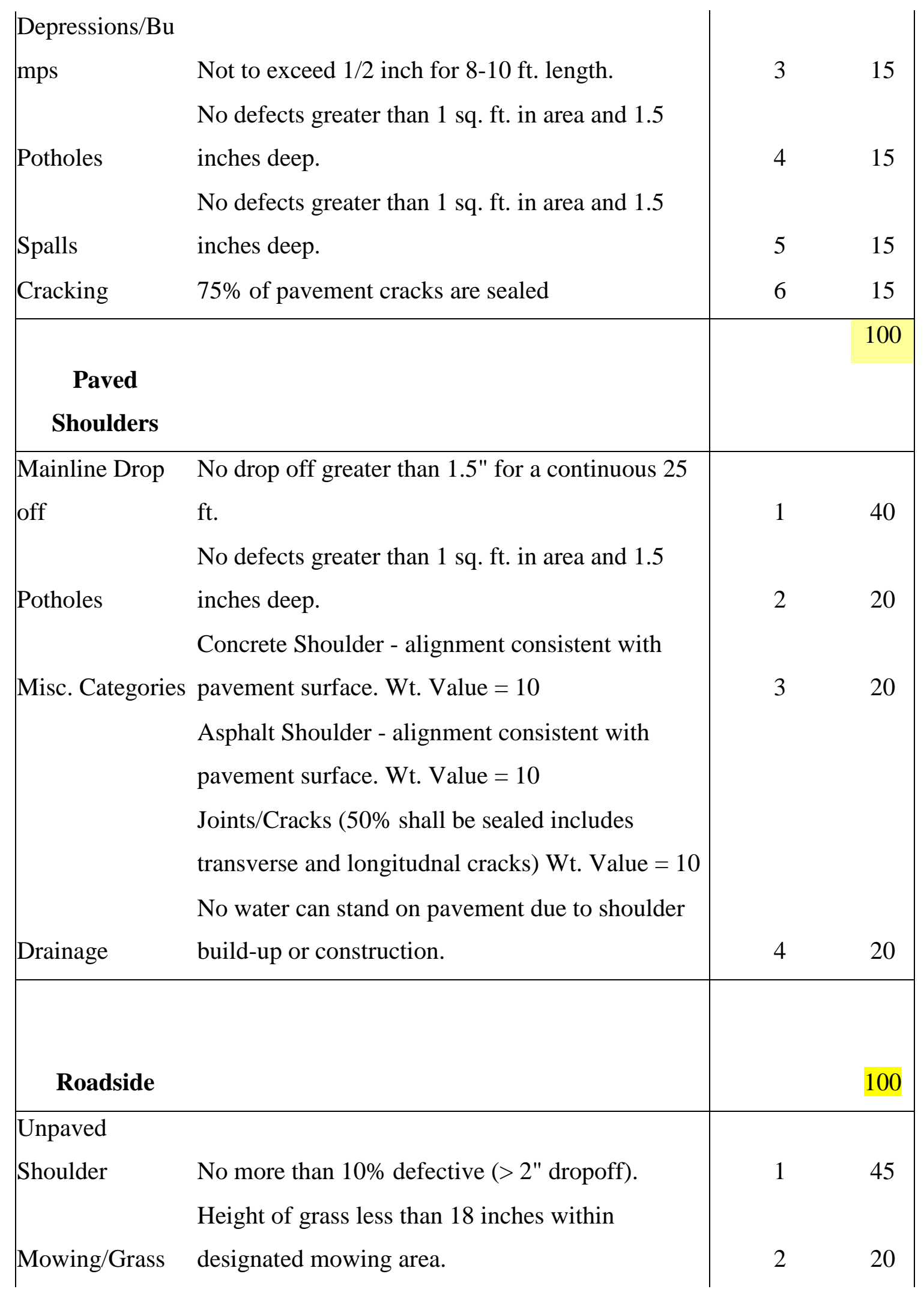




\begin{tabular}{|ll|cc|} 
& No more than 20 pieces of litter 1 sq. ft or larger & & \\
Litter/Debris & for 2 lane, 40 for 4 lane. & 3 & 5 \\
Fence & No more than 5\% shall be damaged or missing. & 5 & 5 \\
Tree/Brush & No obstructed signs. No trees or limbs over & 4 & 5 \\
Control & roadway lower than 16 ft. & & \\
Noxious Weed & Evidence of control by mowing or herbicide \\
Control & application. & & 20 \\
\hline
\end{tabular}

\section{Drainage}

\begin{tabular}{|c|c|c|c|}
\hline Ditches & $\begin{array}{l}\text { Ditch lines are clean and there is no evidence of } \\
\text { standing water. }\end{array}$ & 1 & 35 \\
\hline Culverts/Pipes & $75 \%$ of a structure shall be open. & 2 & 30 \\
\hline Catch & & & \\
\hline Basins/Drop & & & \\
\hline Inlets & $50 \%$ of capacity is available & 4 & 10 \\
\hline Curb/Gutter & $\begin{array}{l}90 \% \text { of curb and gutter areas are free of structural } \\
\text { distress }\end{array}$ & 5 & 10 \\
\hline Subsurface & $90 \%$ of outlets are open and suitability marked. & & \\
\hline (Underdrains) & Rodent screens are in place. & 3 & 15 \\
\hline \multicolumn{2}{|l|}{ Traffic Control } & & 100 \\
\hline Striping & $\begin{array}{l}\text { Verified by Operations Support Reflectometer } \\
\text { testing } \\
\text { All signs are functioning are intended. ( Shall not }\end{array}$ & & \\
\hline Signs & lean more than $1 "$ per foot of post) & 1 & 25 \\
\hline Delineators & No more than $10 \%$ are defective & & 5 \\
\hline Attenuators & $\begin{array}{l}\text { Good alignment and functions as intended and no } \\
\text { attenuators shall be defective. }\end{array}$ & 2 & 20 \\
\hline Guardrail & No more than $5 \%$ shall be defective. & 3 & 20 \\
\hline
\end{tabular}




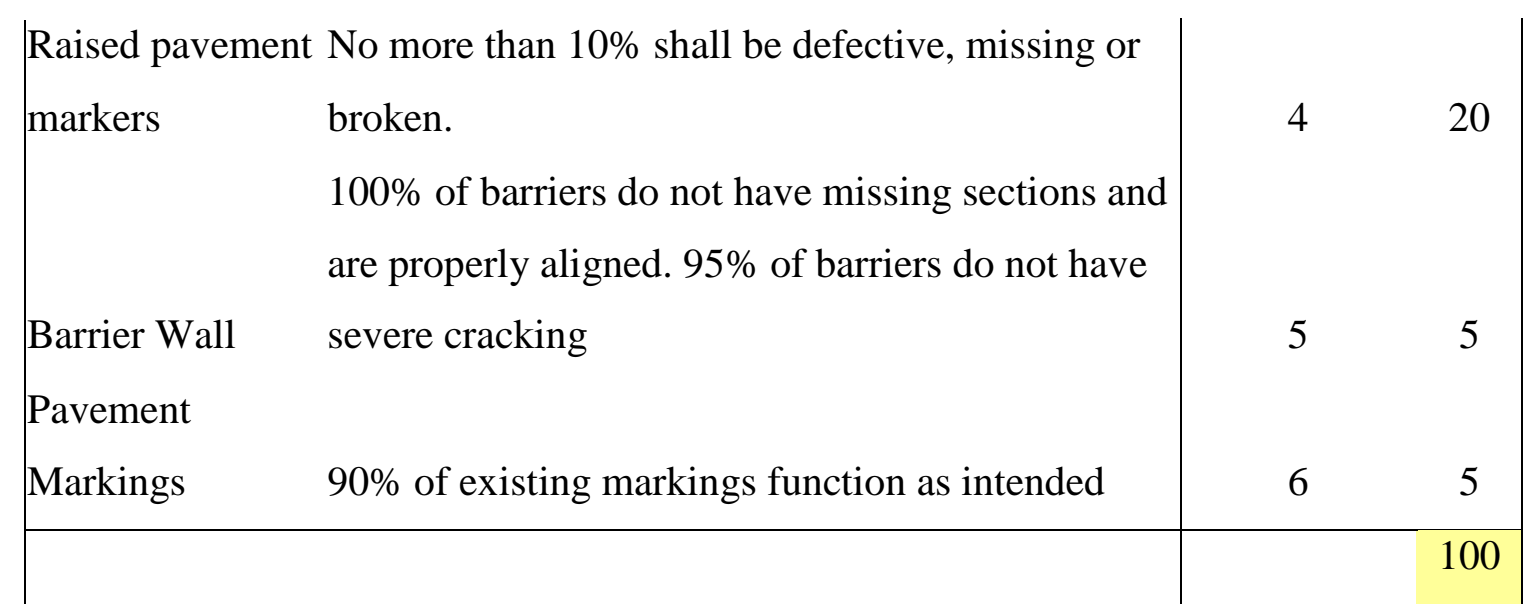

One of the big tasks in collecting LOS information is the manual recording and processing of data. NCDOT uses tablets to collect LOS data and a software program to calculate the ratings for each category.

Appendices B,C,D,E are performance measures used by New Zealand, Washington DC, Texas, and Virginia respectively. Also, Appendices G,H,and I are PBC contracts used by Texas, North Carolina, and Virginia respectively and each contract contains the binding performance measures. Finally Appendix J, is the FDOT Maintenance Rating Program. INDOT should reference these Appendix resources and the JTRP Project "Maintenance Quality Assurance Program" to develop their LOS criteria and program.

\subsection{Agency and Contractor Comparison}

One aspect of PBC analysis is to compare agency and contractor. Table 8.5 is a comparison of various factors. This comparison helps to identify the various strengths and weaknesses of a PBC program as well as requirements. 
Table 8.7 Agency and contractor comparison

\begin{tabular}{|c|c|c|}
\hline Factors & INDOT & Contractor \\
\hline Cost & $\begin{array}{l}\text { Lane mile costs are lower } \\
\text { with DOT forces. }\end{array}$ & $\begin{array}{l}\text { Liability and insurance } \\
\text { costs are added expenses. }\end{array}$ \\
\hline Cost Control & & $\begin{array}{l}\text { Long term contracts with } \\
\text { fixed costs over a multi- } \\
\text { year period control costs } \\
\text { and helps with budgets. }\end{array}$ \\
\hline Innovation & & $\begin{array}{l}\text { More innovation due to less } \\
\text { restrictions on private } \\
\text { companies. More } \\
\text { motivation to reduce costs } \\
\text { through innovation. }\end{array}$ \\
\hline Experience & $\begin{array}{l}\text { Higher levels. More local } \\
\text { knowledge. }\end{array}$ & $\begin{array}{l}\text { National firms will bid and } \\
\text { sub out up to } 90 \% \text { of work. } \\
\text { Experience level based on } \\
\text { subcontractors. }\end{array}$ \\
\hline Manpower needs & $\begin{array}{l}\text { Fixed. Reduced through } \\
\text { attrition. }\end{array}$ & $\begin{array}{l}\text { Flexibility in responding to } \\
\text { manpower needs. }\end{array}$ \\
\hline Equipment Resources & Fixed & $\begin{array}{l}\text { Construction equipment. } \\
\text { Respond better to changing } \\
\text { needs. }\end{array}$ \\
\hline Snow and Ice Removal & $\begin{array}{l}\text { Experience and resources. } \\
\text { Able to shift resources in } \\
\text { emergency situations. }\end{array}$ & $\begin{array}{l}\text { Higher costs due to } \\
\text { planning for worst case } \\
\text { scenario. Extreme event } \\
\text { experience and resources } \\
\text { are questionable. }\end{array}$ \\
\hline Administration & $\begin{array}{l}\text { Less administration } \\
\text { required for PBC contracts. }\end{array}$ & \\
\hline PBC Contract Development & $\begin{array}{l}\text { Requires up to } 18 \text { months } \\
\text { involving 5-10 INDOT } \\
\text { employees. }\end{array}$ & \\
\hline Best Value vs. Low bid & $\begin{array}{l}\text { Best value preferred but } \\
\text { requires legislation. }\end{array}$ & \\
\hline $\begin{array}{l}\text { Baseline Assessment } \\
\text { Program }\end{array}$ & $\begin{array}{l}\text { Standards and baseline } \\
\text { inspection program has to } \\
\text { be developed. }\end{array}$ & \\
\hline
\end{tabular}




\begin{tabular}{|l|l|l|}
\hline Inspection Program & $\begin{array}{l}\text { Requires inspection } \\
\text { program development, } \\
\text { administration and training. }\end{array}$ & $\begin{array}{l}\text { Typically lease space. } \\
\text { Typically do not own or } \\
\text { lease a DOT facility. }\end{array}$ \\
\hline Facilities & Fixed. & Less competition over time. \\
\hline Long -term impact & $\begin{array}{l}\text { Loss of experience and } \\
\text { facilities. }\end{array}$ & \\
\hline
\end{tabular}

A PBC program is comprised of many different activities and participants; these fall into two main phases: Contracts and Administration.

\subsection{Contracts}

Developing an initial PBC contract takes a considerable amount of time and effort. Contract development may take up to 18 months to develop an initial contract involving up to 10 individuals. Items to consider for inclusion in the contract are the following.

- Work items. May include from ROW to ROW or variations. Be specific and descriptive.

- Performance standards. Try to eliminate any gray and make the requirements specific ( black and white). There should be very little room for interpretation.

- Selection criteria. Best Value - Combination of cost and technical qualifications, $70 \%$ technical proposal and 30\% cost proposal or some variation. Best and Final Offer used if bids exceed engineer's estimate. Do not release engineer's estimate. INDOT will need legislative action to allow for Best Value. Currently INDOT can only accept low bid contracts.

- Bond requirements. Bonds should be viewed as costs for the DOT to take over the contract if the contractor defaults. Instead of requiring a bond for the total contract (total duration), only a portion of the contract (1 year or 6 months).

- Liability limitations. Usually limited to a percentage of annual contract cost. One example is contractor out of pocket expense for unrecoverable property 
damage is $20 \%$ of the annual contract cost. Expenses over that will be picked up by the agency. Shared liability helps to keep costs down.

- Contractor assumes third party risk with no limits on claims. For example, a $\$ 1$ million limit on third party lawsuits. Contractors have insurance to cover these expenses and the premiums are included in the contract.

- Response times, performance requirements, and penalty clauses must be clearly defined to minimize misunderstandings.

- Change Order provisions help give the contract flexibility when conditions change.

- Make it a living contract so that current specifications and standards apply.

- Define how assessments will be done, frequency, who will perform, etc. Also, payment penalties for lack of performance and retainages should be clearly explained. Contested assessments and allowable recourses should have a provision.

Risk analysis should be performed when developing a PBC contract. An important aspect of this analysis is risk sharing allocation. A proper balance between agency and contractor is the right approach because it affects the contract cost and performance expectations. A risk analysis looks at both agency and contractor responsibilities and tries to minimize exposure by looking at strengths and weaknesses of each.

A contractor tries to minimize risk. As perceived risk increases this is reflected in increasing contractor cost. For those risks that are unpreventable by the contractor, insurance is sought to cover these. So it is mutually beneficial to evaluate risk and include the results of this analysis in the contract. Table 8.6 lists some typical risk factors that need to be considered while developing the contract. 


\section{Table 8.8 Risk Factors}

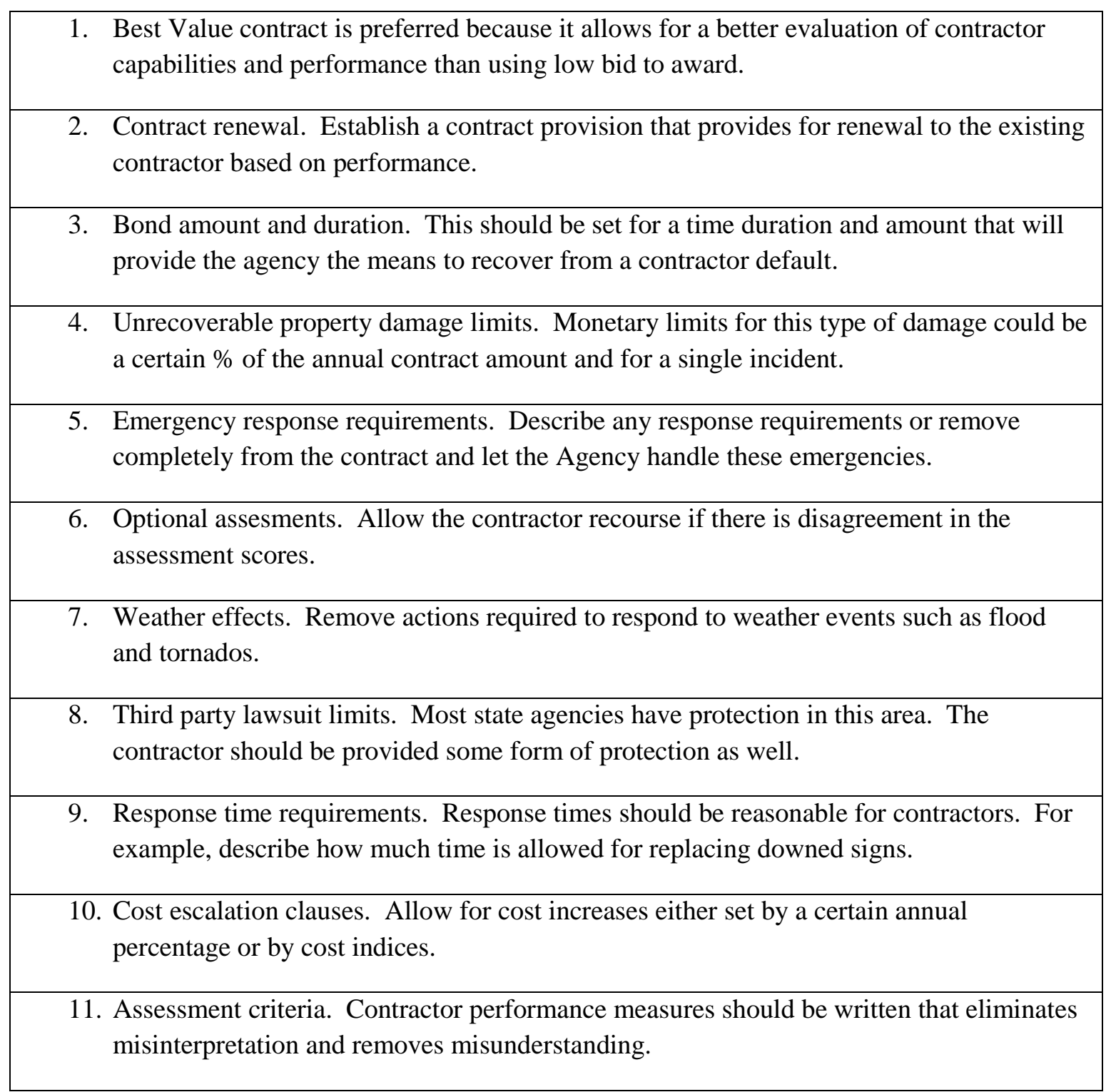

Sample contracts from Florida, Texas, North Carolina, and Virginia are in the Appendices F - I. 


\subsection{Administration}

The contract administration phase are the activities performed during the execution of the project. This mainly consists of daily supervision requirements and the assessment program.

- For a typical size project, approximately 130 road miles, usually three individuals are needed including the field manager, costing approximately $\$ 150,000$ annually. A field office or one close to the contract is a preferred.

- Partnering should be a part of any PBC contract.

- The assessment program is very important. Administrating will take time and resources. Objectivity, speed, accuracy, and safety are key ingredients. NCDOT is spending approximately $\$ 250,000$ annually to assess one contract. .

- Annual training is important for assessors, inspectors and contract administrators. Training should happen before the contract starts and annually throughout the life of the contract.

\section{7 $\underline{\text { Outcomes }}$}

This section describes some outcomes experienced by agencies that have implemented PBC.

The Virginia DOT (VDOT) program started in 1997 mandated by the state legislature. Its goal is to use PBC on all interstates by 2009. To date no layoffs have occurred but reduction of approximately 2000 employees through attrition. Currently there are approximately 5700 employees in Maintenance. The overall impact on maintenance facilities and equipment has not been reported.

The FDOT program started in 2000 and as a result maintenance forces have reduced $25 \%$ through attrition. In 1994, FDOT performed $60 \%$ of maintenance work and contracted out $40 \%$. In 2008, $20 \%$ of maintenance performed in-house, $40 \%$ through 
AM, and $40 \%$ with traditional contracts. Some maintenance yards have closed and consolidated. FDOT has lost capabilities due to lack of experience.

Some Canadian Provinces have privatized all maintenance, so they have reached a point of no return. In other words the agency has all maintenance performed by private contractors. The number of bidders has diminished over the years.

Typically, PBC contractors sub out most of their work, 75-80\%. Subcontractors are usually local contractors. Since snow and ice is an important activity for INDOT very few private contractors in Indiana have the equipment or experience for this activity.

Contractor performance at end of contract period has been a problem due to lack of penalty. If assessment times are known then contractor performance will fluctuate. Minimum performance is a sore point. For example if LOS is 80 , then filling 8 of 10 potholes meets the standard. PBC contracts seem to be successful when the contractor is diligent in meeting the requirements and the contracts are structured that mandate their performance.

North Carolina completed the first year(July 2008) of their initial PBC contract. The contractor is not satisfying performance requirements, so the monthly pay of $\$ 482,976$ is being reduced $\$ 90,000$ until the next assessment, which is done every 6 months.

Contracts have worked well in high incident areas.

Contracts have not worked well in emergency conditions wrought by weather events.

One agency is spending less on rest stops and security through PBC. 
PBC is driven by performance standards which tend to focus contractors on appearance and short term "repair and patch activities." This can have a negative effect on longterm asset condition.

Possible sources of savings

- Less management overhead due to consolidating subcontracts into one and less inspection required.

- In some cases contractor can lower labor costs through improved productivity and lower labor rates.

- More efficient use of equipment.

- Quicker implementation of newer technologies and equipment.

- Innovation is a possible outcome and often that creates savings.

One of the advantages touted with PBC is that costs are set and multiyear budgets can be established. On the otherhand agencies have lost flexibility and the ability to reduce maintenance costs currently needed or required in an economic recession. PBC contracts usually do not have the option of reducing contract amounts. This cost lock-in is currently creating problems for agencies that are extensively using PBC contracts.

\subsection{Snow Contracts}

Approximately 44\% of INDOT's maintenance budget is spent on snow and ice removal on the interstates. As previously stated additional resources will be needed for this activity. One option is to use subcontracts. Virginia includes snow and ice removal in their PBC contracts. North Carolina has developed subcontracts. Both these approaches are described.

VDOT says that snow and ice removal is the largest cost item since contractor plans on a 50 year extreme case occurring during the contract life. In one TAMS contract approximately $50 \%$ of the contract cost was for snow and ice removal. Also, it has been 
witnessed in Virginia and Oklahoma that contractors do well on average storms and not on larger winter events.

NCDOT uses two types of subcontracts.

- Contractor provides truck equipped with spreader and plow. NCDOT provides material. Contractor is reimbursed on hourly basis.

- Contractor bids on outfitting truck and NCDOT sets the hourly rate. A 5 year contract is established, so the contractor is reimbursed $20 \%$ annually for the equipment. Brine distribution is included in the contract.

Call out requirements are included in both contracts.

The option of INDOT receiving more equipment and personnel in maintenance operations is unlikely. INDOT will need to develop a subcontracting program for snow and ice removal. This program should be tested over a couple winter seasons before implementation. The program should evaluate how private companies can best supplement INDOT efforts under what weather conditions and on what road type. Appendix $\mathbf{J}$ is the NCDOT Snow and Ice removal contract.

\subsection{Contractor Innovation}

PBC contracts provide an environment that fosters contractor innovation. Contractors have the latitude to meet the performance standards and the time(multi-year contracts) to be innovative. A long term contract allows for spending upfront money that pays off over the contract life through innovation. Some cited examples are:

- Different types of pavement treatments.

- Incident management.

- Contractors have more flexibility in negotiating subcontracts and developing subs over the contract period. 


\subsection{Indiana Contractors}

One reason for utilizing contractors particularly for winter operations is they have equipment and personnel available during this time of the year. This is their slow season and these resources are usually idle. So why not utilize these resources for snow and ice removal.

Multiple meetings were held with Indiana contractors in which PBC contracts were explained and discussed. Out of these discussions came the following:

- Liability issues are a big concern. Protection from third party lawsuits and indemnification is desired by the contractor.

- Most contractors have the resources to do all maintenance activities with a few exceptions. Those exception activities they can respond through subcontracts.

- Recommend starting the program with a short term contract(2 years) to evaluate approach.

- Escalation clauses desired for materials and fuel.

\subsection{Legal/Political Environment}

Legal issues and risk have a significant impact on the PBC approach. Most states have indemnification protection from law suits. This protection usually limits damages to a certain amount. Contractors do not have this protection so this risk is covered through insurance and these premiums are in their costs. Contractors generally view these risks very conservatively by planning and charging for the worst case scenario. 
These hidden costs significantly influence PBC costs. The current legal environment or atmosphere in this country increases these risks.

Currently Indiana's political environment is swinging away from privatization. Audits and studies are revealing that some privatization programs are costing taxpayers more money than if the services were performed by a state agency. These findings can make it politically very difficult to get legislative approval for these contracts.

\subsection{2 $\quad \underline{\text { Cost Analysis }}$}

A good cost analysis requires all comparison factors to be equal or close to each other. This is very difficult when comparing PBC contracts with in-house costs. Factors such as varying LOS, activities included and excluded, the way agencies record and track costs, overhead costs, influence the cost comparisons,

Looking at bottom line numbers doesn't favor PBC. Looking back at reported cost data, the data indicate the following.

\section{Agency in-house Unit Costs}

INDOT - \$4380\%/lane mile on Interstates(includes snow and ice control) INDOT - $\$ 2350^{*} /$ lane mile on Interstates (excludes snow and ice control) NCDOT - \$3800/lane mile on Interstates(includes snow and ice control) *developed from internal cost data

\section{PBC Contract Costs}

FDOT - \$5000/lane mile(excludes snow and ice control)

NCDOT - \$7200/lane mile(excludes snow and ice control)

VDOT - \$10,000 - \$18,000/lane mile(includes snow and ice control)

These comparisons can be disputed as not being on equal basis, which is probably true. But you cannot ignore the magnitude of difference from double to four 
times greater for PBC contracts. With this much difference, it appears that transportation agencies are not saving money by using PBC contracts.

The above costs are lane mile costs because this basis of comparison is easily understood. However, one uncertainity is overhead costs because each agency calculates and assigns overhead differently, see the next section. Also, another source of savings attributed to $\mathrm{PBC}$ is reduction in force and savings from closing maintenance facilities and reducing equipment. For example, VDOT states they have reduced the payroll by 2000 employees and closed a number of facilities as a result of PBC. But actual cost numbers are difficult to calculate and even though requested, unobtainable to date.

\subsubsection{Overhead Costs}

When a cost comparison is made between different contracting options and between agencies, one question arises and that is the comparison on an equal basis? One cost area that creates this uncertainity is in the area of overhead costs. To help INDOT understand how to calculate overhead costs and assign to maintenance activities, this question was posed to other Transportation agencies and the following responses were received.

\section{$\underline{\text { British Columbia }}$}

The Ministry of Transportation and Infrastructure for the Province of British Columbia contracts all of it's maintenance activities to the private sector. The Ministry currently uses a Quality Audit model for contractor oversight.

Given this delivery model the agency does not specifically track agency costs and distribute them against maintenance activities as these two activities are funded through different accounts within the provincial budget. 
A method of calculating the total $\mathrm{OH}$ burden for MoTI would be to consider those employees who figure prominently in the administration of the maintenance contracts and to apportion a percentage of their time (say 40\%) to maintenance oversight. This could also be done for associated costs such as IT, vehicles etc.

It would include internal staff such as Road \& Bridge Area Managers, District Operations Managers, District Managers of Transportation and Operations Technicians, multiplied by their time percentage and payroll burden for an estimated total of \$ XXX involved in highway maintenance oversight for the province for the year (similarly for the other associated costs).

If this were to be done it should be kept simple and straightforward as the true effort (and associated costs) will always be in flux depending on vacancies, length of time to fill positions, maintenance issues that evolve over time etc. It is likely that the variance over time across the organization would be low in any event.

For additional information contact Reg Fredrickson at REG.FREDRICKSON@GOV.BC.CA.

$\underline{\text { Florida }}$

In order to calculate overhead costs for in-house maintenance, FDOT has distinguished maintenance projects in their work program as either product related or inhouse related. These "direct cost groups" accumulate costs directly charged to maintenance projects and are used in determining the indirect cost rate to apply. The Department has also identified the maintenance cost centers that do not charge to direct projects and have placed them in their own maintenance indirect cost pool. This pool accounts for all overhead maintenance charges not associated to a particular project.

This information is input into a cost allocation model, which distributes the overhead to the applicable cost groups based upon direct maintenance charges. The 
direct charges will either be contained in the two cost groups above or in another cost group where those cost centers have charged directly to a maintenance phase. Some other cost groups that charge to maintenance phases include, but are not limited to, Preliminary Engineering, Construction Engineering Inspection, Construction, and Traffic Operations.

In order to calculate the in-house maintenance rate, FDOT takes the amount of overhead allocated to the in-house maintenance cost group and divides it by the direct expenditure amount within that same cost group.

Please note that calculations are usually based upon averaging historical indirect charges to determine the amount of overhead to allocate and historical direct charges to know what to expect for current year maintenance direct costs.

For additional information contact Michael Sprayberry at MIKE.SPRAYBERRY@DOT.STATE.FL.US.

$\underline{\text { Idaho }}$

The Idaho Transportation Department's Indirect Cost Allocation Plan (ICAP) is based on Federal OMB Circular A-87. Their ICAP is audited and approved by the FHWA Idaho Division Office on an annual basis. The ICAP rate is applied to the maintenance activities.

OMB Circular A-87 describes the types of overhead costs allowable on Federal contracts or grants. The cost categories are primarily office expenses.

For additional information contact Ned Parrish at NED.PARRISH@ITD.IDAHO.GOV. 


\section{Missouri}

Missouri Department of Transportation (MoDOT) charges the following direct costs based on actual hours (direct labor) charged to a maintenance job using job costing within the financial system:

- related insurance, deferred comp, and employer's social security/Medicare matches

- $\quad$ salary additive, based on the actual direct payroll wages for fringe benefits not directly charged. These include: post-employment health benefits, worker's compensation, unemployment compensation, and paid leave

Additionally, MoDOT charges the following to maintenance jobs using job costing within the financial system:

- Equipment usage based on established equipment rental rates. Rental rates are established based on actual costs for equipment operation, including depreciation and actual usage from prior fiscal year based on type of equipment.

MoDOT does not charge a general administrative overhead rate to maintenance jobs

For additional information contact Bill Stone at William.Stone@ modot.mo.gov

\section{Montana}

Montana Transportation Department (MDT) follows the guidance in OMB Circular A-87 in calculating our indirect cost rate (IDC) rate. MDT calculates one department-wide rate for all of their programs (including Maintenance). 
The indirect pool includes "central" department indirect costs as well program related indirect costs (i.e. Maintenance Division, Construction, Aeronautics, etc.) Their "central" indirect costs include the salary \& operational costs that benefit the department as a whole, such as our accounting, budgeting, payroll, purchasing, legal, Director's Office, etc. The program indirect costs are those costs that benefit the program as a whole but cannot be specifically assigned to a particular project.

MDT base cost is direct costs. Those costs that are specifically identifiable to a project or direct function of the department.

In addition, MDT builds in a Carry Forward amount as per OMB A-87. MDT's rate is based on data that is 2 years old, so there is a need to determine what the true costs are versus what is built into the rate. For example, in FY09 MDT is building FY10's rate, using FY08 data. Since FY08 is the last fiscal year that was closed, that is the data you have to work with. So in FY11, MDT will compare what actually happened in FY10 to the FY08 data and this difference will be built into FY12's rate. The difference is called Carry Forward. This calculation tells MDT whether Under collected or Over collected occurred due to the timing of the data. An Under recovery is added to the next years rate, while an Over recovery is subtracted from the rate. This reconciles the rate to Actuals as per the federal guidance.

The IDC rate is calculated as follows:

IDC Rate $=($ Indirect Costs $+/-$ Carry Forward $) /$ Direct Costs

For additional information contact Brenda Bokovoy at BBOKOVOY@MT.GOV.

\section{$\underline{\text { South Dakota }}$}

In their financial tables, maintenance activities are charged to a road segment, interstate, priority, nonpriority, or maintenance overhead. They correlate highway segments to type (interstate, priority, or nonpriority). The overhead is allocated to the 
highway type based on labor hours directly charged to that highway type, in that fiscal period. For example: if 5 hours is charged to manage maintenance staff and 15 hours is charged snow removal, 10 hours is charged to maintain delineators, but 0 hours were charged to mowing, The allocation would be the cost of 3 hours of maintenance management staff would go to the highway types charged to snow removal, 2 hours to maintain delineators, and 0 to mowing.

South Dakota allocates overhead costs down to the unit. Any charges to overhead, such as accounts payable, are allocated based on labor charges to highway type.

The overhead that benefits the department, such as accounting, legal, department secretary, etc., is allocated in the same way but to projects (construction, research, planning, etc.) as well as road types. Facility costs are allocated as a cost of an employee or position. Each facility is identified as housing certain employees and their positions are allocated costs on a FTE basis. (1 share for permanent employees and 0.5 share for seasonal.)

For additional information contact Johna Leidholt at JOHNA.LEIDHOLT@STATE.SD.US.

$\underline{\text { Texas }}$

TXDOT has developed some procedures for assigning overhead costs. One is an expenditure tree shown below. 


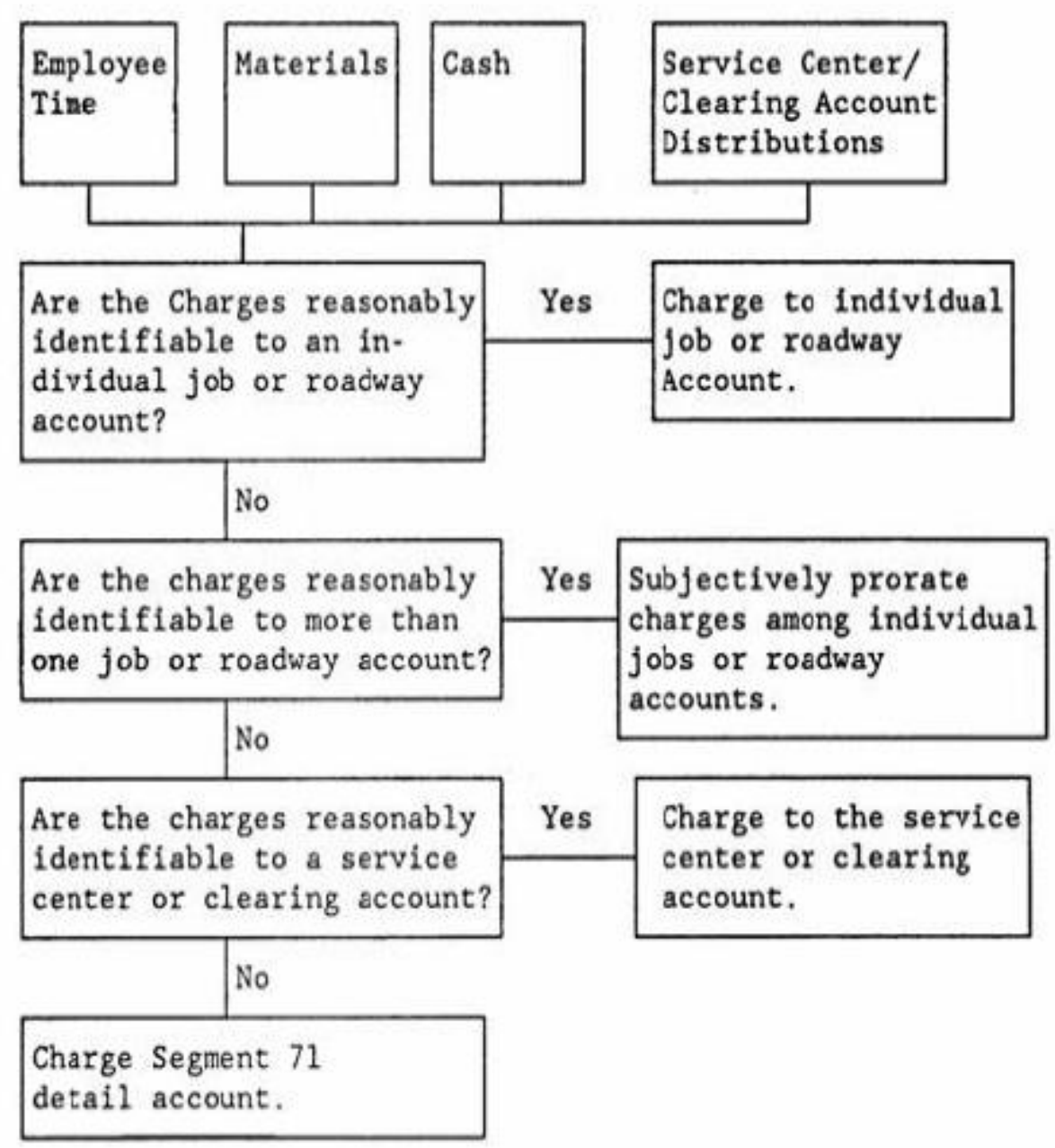

Figure 8.12.1 - TXDOT Decision Tree

The expenditure decision tree is what TXDOT employees use to decide how to record an expense. The preferred choice is to charge an expense to the project or roadway and activity which benefitted from the expense. If a specific project or roadway cannot be identified, then the second choice would be to prorate the expense to several projects or roadways. If no specific projects or roadway benefitted from an expense then it should be determined if the expense was related to a service center/clearing account. Appendix K contains a code chart 80 that summarizes the types of service center/clearing accounts and the methods by which the charges to those accounts are distributed back to projects and roadways. The last choice for recording an expense is to the segment 71 
functional accounts, which are general and administrative accounts (i.e. accounting, purchasing, auditing, administration, etc.). The charges to the general and administrative accounts go into the DOT's indirect cost plan and get allocated back to projects and roadways.

All employees complete a time sheet and labor costs including labor additives are distributed to the projects and roadways to which they charge their time. When equipment is used, an equipment utilization report is completed and the cost of owning(depreciation), operating (gas and oil) and maintaining the equipment are charged to roadway maintenance activities or projects based on the useage(miles driven or hours used) times their rental rates. The accounting system automatically adjusts these distributions each month so that the charges accumulated in the equipment clearing accounts are neither over or under distributed.

Items from stock are issued (expensed) to roadway maintenance activities and other projects based on the quantity issued times the weighted average cost of the stock item.

For more information contact Brandye Payne at BPAYNE1@DOT.STATE.TX.US.

\section{$\underline{\text { Vermont }}$}

Vermont does not charge overhead costs to maintenance activities. They do charge employee fringe benefits including paid time off.

\section{$\underline{\text { Virginia }}$}

Overhead cost is comprised of two categories: variable and fixed.

Variable overhead costs are those indirect costs that vary with output or an activity. They include material handling, delivery, and testing costs; drafting and 
engineering labor (if any) associated with the activity; labor fringe benefits, social security taxes and compensation insurance; foremanship associated with the activity; indirect shop labor (e.g., preparation of gauges, instruments, special tools, or equipment maintenance); power (such as fuel and electricity) associated with the activity; travel costs to and from the work site; departmental supplies associated with the activity; any training costs of a special or non-routine nature associated with the activity; and set up and tear down time for the preparation or modification of equipment.

Fixed overhead costs are those costs that are unavoidable regardless of the action chosen, i.e., whether a contract is let or not. For example, if a firm prepays six months of insurance premium of which no portion is refundable or prorated, then insurance costs are fixed. Those terms usually termed as fixed cost or fixed overhead are the following: general administration, general insurance, building repairs and maintenance, and payroll, accounting and associated labor.

For additional information contact Robert Kardian at BOB.KARDIAN@VDOT.VIRGINIA.GOV.

\section{Washington}

Since Washington DOT does very little maintenenace contracting work, they have not established an overhead calculation methodology for their maintenance activities.

\section{$\underline{\text { West Virginia }}$}

The only agency overhead costs that are distributed to routine maintenance operations are those associated with payroll costs. The WVDOH uses a payroll additive rate as the means of allocating costs associated with employee benefits and employment 
taxes to all direct labor charges. The components that make up the additive rate consist of the following:

- Employer Social Security

- Worker's Compensation

- State Retirement

- State Insurance (PEIA)

- Department of Personnel Fees

- Employment Security

- $\quad$ Leave Time

- Increment (Longevity Pay)

The payroll additive rate is calculated each year (usually in February or March and is effective for one year, starting with the next fiscal year.

Payroll additive rates are calculated using actual and projected figures obtained from current operations. The information obtained from the Payroll Section of Finance Division and Human Resources Division is entered into an Excel spreadsheet that is formulated to calculate the additive rate. This spreadsheet contains 7 pages of attachments for the calculation of the rate and the supporting schedules for all these figures. Known increases/decreases in figures are utilized instead of current figures if the increase/decrease can be reasonably estimated.

For additional information contact Donald L. Williams at DONALD.L.WILLIAMS@WV.GOV.

Wyoming

The Wyoming Department of Transportation allocates some overhead costs 
to maintenance operations in several different ways. There are two big overhead costs that are distributed to maintenance costs.

Fleet repair overhead is allocated through the hourly equipment rates. The fleet overhead includes, but is not limited to, facility costs, direct administrative support, the cost of computer networks \& the cost of any tools purchased by WYDOT to do this work.

Direct maintenance overhead items, such as facility costs, direct administrative support \& others, are accumulated in what is called Maintenance Overhead. Currently this cost is not allocated across the various maintenance activities.

The hard part of this equation is the more indirect overhead, such as the financial programs, human resources, purchasing, materials lab, employee safety and other areas of the department that provide both frequent and infrequent support to the maintenance operations. WYDOT has had discussions in the past about this, but currently they aren't allocating those costs across the maintenance activities.

For additional information contact Ken Shultz at KEN.SHULTZ@DOT.STATE.WY.US.

\section{Current NCHRP Study on Maintenance Costs}

Cambridge Systematics is performing a NCHRP study 14-18 "Determining Highway Maintenance Costs," that will provide some information on overhead costs. One part of the study is investigating how agencies tally the "full costs" of maintenance 
with the goal of recommending and demonstrating a procedure that other DOTs can use to estimate these costs, including overhead. The expected completion date is 7/20/2010.

For additional information contact James Maconochie at JMACONOCHIE@CAMSYS.COM.

\section{$\underline{\text { Overhead summary }}$}

From the agency responses, some agencies have developed procedures for assigning overhead costs to maintenance activities while others have not. Those agencies that do assign overhead use various approaches. It does not appear that a standard procedure has been developed and used by agencies. The current NCHRP study PI states that TXDOT has developed the most complete methodology for calculating and assigning overhead costs to maintenance activities. What does come out of the agency survey is that it takes a team consisting of various agency groups(finance, accounting, software controls, operations, etc.) to develop and utilize a procedure.

INDOT can use this information to develop their own procedure for assigning overhead costs to maintenance activities.

\subsection{Recommendations}

- $\quad$ PBC will require development time, new organization, capabilities, resources, and training.

- During economic downturns where state agency budgets are reduced, PBC contracts "lock-in" costs and are very difficult to reduce. This lack of flexibility will put additional pressures on maintenance. 
- Based on lane mile costs it appears that PBC will not save money in most cases. There are some cases where money has been saved through PBC contracts, for example rest areas, movable bridges, and security contracts.

- Indiana contractors are interested and capable of performing maintenance activities.

- Current conditions, declining income and growing network, INDOT needs a plan.

- With 1940 additional lane miles @ \$4380/lane mile (Interstate lane mile costs)= $\$ 8,497,200$ annual increase in operations budget will be needed.

- Due to economic realities the PBC option has a lower ranking.

Maintenance Plan

There are several discoveries from this project. One is INDOT needs to develop a Maintenance plan. Some of the particulars for the plan are:

- $\quad \mathrm{PBC}$ is not recommended.

- Private contractors are a viable option.

- Since snow and ice activities are the critical ones, develop subcontracts to utilize private contractors.

- Determine maintenance needs and develop a more comprehensive subcontract program. This referred to as a "hybrid approach" where private local contractors are used to supplement agency forces and in some cases work together. Work with ICA (Indiana Construction Association) to develop this program by growing the amount and number of available subcontractors.

- Identify and inventory activities and compare to availability of private sector entities through out the state

- $\quad$ Mowing

- $\quad$ Sign Maintenance Activities

- Road Maintenance Activities

- Bridge Maintenance Activities

- Road Painting Activities 
- INDOT needs to produce a LOS requirements description. This helps to establish a baseline and establish budget numbers for higher or lower LOS. This will be necessary for building a request for additional maintenance funds from the legislature or for describing the results from reduced funding. This is a critical need for Operations.

\section{$\underline{\text { PBC Program Recommendations }}$}

If INDOT decides to pursue PBC for maintenance operations, this study makes recommendations on the best way to implement and what to look out for. This is summarized in the below Table 8.7.

\section{Table 8.9 PBC Program Recommendations}

1. Central Office PBS Administrator work with Indiana Construction Association (ICA) to market the concept and develop contractor interest. Survey contractors and develop a list of capabilities that contractors possess for maintenance activities. Analyze what areas of the state would be conducive for implementing PBC contracts which is dependent on contractor resources and availability. Develop state legislation to get Best and Final Offer contract type approved. This will take lobbying effort and time..

2. After determining the best fit District, select District PBC manager. C.O. PBC administrator and District Manager select road network to develop contract. Optimum PBC contract length is between 120-140 road miles.

3. Develop budget for PBC contract and determine where the funds will come from. PBC contracts can cost up to 5 times as much as in-house costs. Besides contract cost the budget needs to include administration costs, which could be in the range $\$ 150,000$ annually, the assessment cost (NCDOT is spending $\$ 250,000$ per assessment), and training costs. 
4. PBC team. The PBC administrator and manager needs to assemble a team( could involve up to 10 senior individuals) to develop the following, which will probably take up to 18 months:

- Develop LOS criteria. Test and evaluate criteria before using.

- Perform baseline assessment

- Determine scope of work

- Develop engineer's estimate

- Develop contract requirements and bidding documents

- Develop assessment program. Determine frequency, assessors, inspection tools, and software requirements. Specify confidence level (e.g. 95\%) as this will determine the number of inspection segments.

- Develop contract administration guidelines and job descriptions. Select contract manager and assign to the contract development team.

- Develop training program for contract administrator and inspectors, and the assessment program.

- Develop PR approach targeting current INDOT employees. Internal morale could suffer so measures should be taken to address this issue.

5. Contract requirements.

- Look at other agency PBC contracts, which are in the Appendices.

- Describe the contractor selection procedure.

- Most PBC contracts duration is between 3-7 years.

- Describe performance criteria.

- Decide on anti-icing and de-icing activities.

- Determine limits on subcontracts(\% level, say 70-80\%) and inspection requirements of contractor.

- Establish payment penalty requirements. Requirements are needed for the last evaluation period to insure contractor performance.

- Rehabiltation items should not be included in PBC contracts.

- Determine minority participation requirements.

- Make the contract dynamic in that current current specs and procedures apply.

- Adequately define responsiveness requirements.

- Include the ability to write work orders to the contractor to assist the agency when additional help is needed.

- Develop report requirements.

- The level of effort at this stage is very important. Since this is a new contract type be careful about requirements and risk allocation. Partnering should be included in the contract. 
6. Contract Administration

- Develop inspection procedures

- Implement a partnering arrangement with the contractor

- Establish a meeting pattern with the contractor.

- Comply with reporting requirements.

- Monitor incident response and emergency repairs.

- Evaluate and approve traffic control plans. 


\section{LIST OF REFERENCES}

Aldrich, J. H., Nelson, F. D. (1984) "Linear probability, logit, and probit models". Sage University Press, Beverly Hills.

Amemiya, T. (1973) "Regression-analysis when dependent variable is truncated normal”. Econometrica 41(6), 997-1016.

Amemiya, T., (1985) Advanced Econometrics. Harvard University Press.

Amos, P., (2004) "Public and Private Sector Rules in the Supply of Transport Infrastructure and Services", Operational Guidance for the World Bank Staff, Transport Paper - 1, Washington DC: The World Bank.

Anastasopoulos, P. Ch., Bhargava, A., Bordat, C., Labi, S. Mannering, F. L. (2007a) "Frequency of change orders in highway construction contracts: An assessment of alternate count-data modeling methods". Working Paper.

Anastasopoulos, P. Ch., Tarko, A. P., Mannering, F. L. (2007b) "Tobit analysis of vehicle accident rates on interstate highways". Forthcoming in Accident Analysis and Prevention.

Armstrong M., (1996) "Management Processes and Functions". London CIPD ISBN 085292-438-0

Armstrong, S., J., (1982). "The Value of Formal Planning for Strategic Decisions". Strategic Management Journal 3: 197-211. 
Armstrong. M., (2006) “A Handbook of Human Resource Management Practice (10th edition)”. Kogan Page, London ISBN 0-7494-4631-5.

Berkland, Troy and Bell, Lansford, "Performance Based Contracting and Improving the Current Contracting Process," Summary Report - FHWA-SC-07-06, November 2007, Clemson University.

British Columbia Ministry of Transportation, BC MOT (2004) "Best Management Practices for Highway Maintenance Activities." Victoria, British Columbia. http://www.th.gov.bc.ca/publications/eng_publications/environment/MoT_Hwy_Maint_ BMP.pdf (Accessed Nov. 2006)

Bloxam, M., (2003) "Evaluation Using The Quality Price Risk Trade Off (QPRTO)." Paper for the Bay Roads Exposed Conference, Rotorua, April 27 to 29, 2003. Bloxam Burnett \& Olliver.

Bordat, C., Labi, S., McCullouch, B., and Sinha, K. (2004) “An Analysis of Cost Overruns and Time Delays of INDOT Projects". Technical Report prepared for: INDOT-FHWA-JTRP.

Brodie, C. 2003. "Seal Extension Design Review." Paper for the Bay Roads Exposed Conference, Rotorua, April 27 to 29, 2003. http://www.wbopdc.govt.nz/NR/rdonlyres/ 4ACEF038-1BE6-4073-AAB5-5413B70A9B11/0/ColinBrodie.pdf (Accessed Nov. 2006)

Brown, M. "The Works Infrastructure Perspective." Paper for the Bay Roads Exposed Conference, Rotorua, April 27 to 29, 2003. New Zealand Works Infrastructure. http://www.wbopdc.govt.nz/NR/rdonlyres/1E514C08-C817-4DD6-BA57-8C7DD2B8F8 37/0/MurrayBrown.pdf (Accessed Nov. 2006) 
Butt, A., A., Shahin, M., Y., Feighan, K., J, and Carpenter, S., H., (1987) "Pavement Performance Prediction Model using the Markov Process." Transportation Research Record 1123, 12-19.

Carpenter, B., Fekpe, E., Gopalakrishna, D., (2003) "Performance-Based Contracting for the Highway Construction Industry", Washington DC: Koch Industries Inc., Final Report.

Carson, J., and Mannering, F. (2001) "The Effect of Ice Warning Signs on Accident Frequencies and Severities.” Accident Analysis and Prevention, Vol. 33, No. 1, 99-109.

Chin, H., C., and Quddus, M., A. (2003) "Modeling Count Data with Excess Zeroes." Sociological Methods \& Research, Vol. 32, No. 1, 90-116.

Cody, R., P., Smith, J., K., (2006) "Applied Statistics and the SAS Programming Language". Fifth Edition. Pearson Prentice Hall.

Dlesk, Ryan and Bell, Lansford, "Outsourcing Versus in-house Highway Maintenance: Cost Comparison and Decision Factors, “ SCDOT Research Project 653, Department of Civil Engineering, Clemson University, April 2006.

Douglas-Crane, M., (1999) "Commercialisation of Road Management in VicRoads." Presentation for the World Bank. December 1999. http://worldbank.org/transport/ rdmgmnt/mdc_1.pdf (Accessed Oct. 2006)

Engelke, T., (2003) “An international Perspective - Long-term Performance-based Road Maintenance Contracts in Western Australia." Paper for the Bay Roads Exposed Conference, Rotorua, April 27 to 29, 2003. http://www.wbopdc.govt.nz/NR/rdonlyres/ F3490F6E-DF36-470E-9CB1-9417A1CFEF66/0/TomEngelke.pdf (Accessed Nov. 2006) 
Ernzen, J., Feeny, T., (2002) “Contractor Led Quality Control and Quality Assurance Plus Design-Build: Who is Watching the Quality?", TRB Conference Paper.

Estonian National Road Administration, ENRA (2004) “Annual Report 2003”, Tallinn, Finland.

Federal Highway Administration, FHWA (2002) "Pavement Preservation Compendium: "DC Streets” is a Capital Success." http://www.fhwa.dot.gov/pavement/preservation/ ppc0306.cfm (Accessed Feb. 2007)

Federal Highway Administration, FHWA (2003) "DC Streets' is a Capital Success", Focus. http://www.fhwa.dot.gov/pavement/preservation/ ppc0306.cfm (Accessed Sept. 2006)

Federal Highway Administration, FHWA (2004) "DC Streets: Innovation Yields Results." Focus.

Federal Highway Administration, FHWA (2005) "Highway Maintenance Contracting 2004. World State of Practices", Report of the National Highway Maintenance Contract Seminar, Orlando, Florida, USA.

Federal Highway Administration, FHWA (2006) "Scanning Tour Brings Back New Approaches to Construction Management" (FHWA-HRT-05-023). http://www.tfhrc.gov/ focus/jan05/ 01.htm (Accessed Feb. 2007).

Federal Highway Administration, FHWA (2007) "Price Trends for Federal-Aid Highway Construction". http://www.fhwa.dot.gov/programadmin/pt2006q4.cfm (Accessed Apr. 2007). 
Federal Highway Administration, FHWA (2007) "Price Trends for Federal-Aid Highway Construction". http://www.fhwa.dot.gov/programadmin/pt2006q4.cfm (Accessed Apr. 2007).

Florida Department of Transportation (2007) Asset Management web site: http://www.dot.state.fl.us/statemaintenanceoffice/asset.htm (Accessed June 2007)

Florida Department of Transportation (2000) “Highway Construction and Engineering and Transportation System Maintenance Programs". Office of Program Policy Analysis and Government Accountability, Report 99-29.

Frost, M., and Lithgow, C., (1996) "Improving Quality and Cutting Costs through Performance Contracts. Australian Experience." Paper for the World Bank Road Management Training Seminar. http://www.zietlow.com/docs/frost.htm (Accessed Dec. 2006)

Gharaibeh, N., G., and Darter, M., I., (2003) "Probabilistic Analysis of Highway Pavement Life for Illinois". Transportation Research Record 1823, 111-120.

Gharaibeh, N., LaTorre, F., Darter, M., and Lippert, D., (1997) "Use of Pavement Management System Data For Pavement Engineering Applications." Transportation Research Record 1592, 35-45.

Gilbertson, T., (2003) "The Hybrid Performance Based Management Strategy." Opus International Consultants Ltd. REAAA/ARRB International Conference. Cairns, Queensland, Australia. http://www.opus.co.nz/detail_pages/papers/gilbertson_2.pdf (Accessed Aug. 2007) 
Gkritza, K., Labi, S., (2006) "Likelihood of Occurrence, Magnitude and Rate of Cost Discrepancies in Highway Contracts." Presented at the 85th Transportation Research Board Annual Meeting, 22-26 January 2006, Washington D.C.

Gkritza, K., Mannering, F. L., (2007) "Mixed logit analysis of safety-belt use in singleand multi-occupant vehicles". Forthcoming in Accident Analysis and Prevention.

Gourieroux, C., Monfort, A., Trogon, A., (1984) "Pseudo maximum likelihood methods: theory." Econometrica 52, 681-700.

Government of British Columbia. (2006) Ministry of Transportation. Highway Maintenance Contracts. http://www.th.gov.bc.ca/BCHighways/contracts/maintenance/ (Accessed Dec. 2006).

Greene, W., (2007). Limdep Version 9.0. Econometric Software, Inc., Plainview, NY. USA.

Greene, W. H., (2000) Econometric analysis. Prentice-Hall, Englewood Cliffs, N.J.

Gullberg, Jan (1997). "Mathematics: from the birth of numbers". W. W. Norton \& Co.

Hancher, D., E., (1999) “Contracting Methods for Highway Construction”, Transportation Research Board, Washington DC, USA.

Hardy, P., (2001) “Austroads Review of Performance Contracts: The Potential Benefits of Performance Contracts." Opus International Consultants Ltd. http://www.opus.co.nz/ detail_pages/papers/austroadsreview.pdf (Accessed Nov. 2007)

Hartwig, T., Mumssen, Y. and Schliessler, A., (2005) "Output-based Aid in Chad: Using Performance-based Contracts to Improve Roads." Global Partnership on Output-based Aid. Note No 06. Washington, D.C.: World Bank. 
Hayes, B., (2003) "The Integration of Transit and WBOPDC Requirements into a Single Performance-based Contract." Paper for the Bay Roads Exposed Conference, Rotorua, April 27 to 29. Bloxam Burnett \& Olliver. (Accessed Nov. 2006)

Heckman, J., Singer, B., (1984) "A method for minimizing the impact of distributional assumptions in econometric models for duration data." Econometrica 52, 271-320.

Herbsman, Z., J., Glagola, C.R., (1998) "Lane Rental: Innovative Way to Reduce Road Construction Time", ASCE Journal of Construction and Engineering Managements, Vol. 124(5), 411-417.

Hill, T. \& R. Westbrook (1997). “SWOT Analysis: It's Time for a Product Recall”. Long Range Planning 30 (1), 46-52.

Holmes, S., (2005) “Florida Asset Management." Presentation at the TRB Workshop on "Performance-based Contracting". April 27, Washington, D.C.: Office of Maintenance, Florida Department of Transportation.

Hunter, E. and Kyle, R., (2004) "A Review of Achievable Efficiencies and Associated Issues Under Output and Performance-based Contracts.” Opus International Consultants Ltd. http://www.opus.co.nz/detail_pages/papers/achievableff.pdf (Accessed May 2007)

Institut des Sciences et des Techniques de l'Equipement et de l'Environnement pour le Développement, ISTED, (2002) "Contracting Road Maintenance: Example of the Province of Alberta in Canada", No 26, October 2002. http://www.isted.com/ periodiques/lettre/lettre_pdf/lettra26.pdf (Accessed Sept. 2006) 
Jackson, N., C., Deighton, R., and Huft, D., L., (1996) "Development of Pavement Performance Curves for Individual Distress Indexes in South Dakota Based on Expert Opinion.” Transportation Research Record 1524, 130-136.

Joint Legislative Audit and Review Commission of the Virginia General Assembly, JLARC. (2001) “Review of VDOT's Administration of the Interstate Asset Management Contract." Virginia.

Kockelman, K., (2006) "Safety Impacts and Other Implications of Raised Speed Limits on High-Speed Roads." Technical Report prepared for: National Cooperative Highway Research Program - Transportation Research Board of the National Academies.

Labi, S., and Sinha, K., C., (2003) "Life-Cycle Evaluation of Highway Pavement Preventive Maintenance." 82nd Annual Transportation Research Board Meeting. 21 p.

Lande, K., (2005) "Privatized Highway Asset Management: Performance-based Management and Maintenance of Roads: Virginia Case Study." Presentation for the World Bank Transport Forum. USA.

Lee, J., Mannering, F., (2002) "Impact of roadside features on the frequency and severity of run-off-roadway accidents: An empirical analysis." Accident Analysis and Prevention, Vol. 34, No. 2, 149-161.

Liautaud, G., (2004) "Maintaining Roads: Experience with Output-based Contracts in Argentina", Washington DC: World Bank, USA.

Loveless, R. "Measures for Carriageway Lighting." Paper for the Bay Roads Exposed Conference, Rotorua, April 27 to 29, 2003. Odyssey Energy Ltd. 
http://www.wbopdc.govt.nz/NR/rdonlyres/ 0A767198-02A1-4ECA-8CEE6C9C79C1163 2/0/RogerLoveless.pdf (Accessed Nov. 2006)

Lund, E.A., (1996) "Privatization of Road and Bridge Maintenance in British Columbia. Transfer of Public Employees to the Private Sector, British Columbia Experience." Paper presented for the World Bank Road Management Training Seminar, December 18, 1996. Washington, D.C.: World Bank. http://siteresources.worldbank.org/INTROADSHI GHWAYS/Resources/338993-1122496826968/cn_ntk5a.pdf (Accessed Oct. 2006)

Maddala, G. S. (1983) "Limited-dependent and qualitative variables in econometrics". Cambridge University Press. New York, USA.

Magee, L. J. (1990) "R2 Measures based on W and LR joint significance test statistics". The American Statistician 44, 250-253.

McCullouch, Bob G. (2003) "Maintenance Quality Assurance Program," Joint Transportation Program, Purdue University.

McDonald, J. F., Moffitt, R. A., (1980) “The uses of Tobit analysis". The Review of Economics and Statistics 62(2), 318-321.

McLawhorn, Nina - Research Administrator, Wisconsin Department of Transportation, “Contract Maintenance - A synthesis report," Septem ber 26, 2002.

Meister, M. and Koorey, G. "Corridor Safety Performance Measures." Paper for the Bay Roads Exposed Conference, Rotorua, April 27 to 29, 2003. Opus International Consultants, Ltd., and Opus Central Labs. http://www.wbopdc.govt.nz/NR/rdonlyres/ 7286D592-7B59-4278-8EAF-B65E252B45CE/0/GlenKoorey.pdf (Accessed Nov. 2006) 
Menon, A. et al. (1999) “Antecedents and Consequences of Marketing Strategy Making”. Journal of Marketing 63, 18-40.

Michael Baker Jr., Inc. (1999) “Asset Preservation Plan for the District of Columbia National Highway System." Prepared for the Federal Highway Administration U.S. Department of Transportation and District of Columbia Department of Public Works. Washington, D.C.

Milton, J. C., Shankar, V. N., Mannering, F. L., (2007) "Highway accident severities and the mixed logit model: An exploratory empirical analysis". Forthcoming in Accident Analysis and Prevention.

Moore A., (2006) "Private Transportation and Competition." Testimony to U.S. House Subcommittee on Energy Policy, Natural Resources and Regulatory Affairs Committee on Government Reform. May 18 2006. http://www.reason.org/commentaries/moore_ 20040518.shtml (Accessed Aug. 2007)

National Cooperative Highway Research Program (NCHRP), (2001) “Guidelines for Warranty, Multi-Parameter, and Best Value Contracting." Report 451, Washington, DC.

National Cooperative Highway Research Program, (2003) "State DOT Outsourcing and Private-Sector Utilization." Synthesis 313, Tom Warne and Associates, LLC, Washington, DC.

Newhouse, J., (2004) "2003/2004 Maintenance Contracts. Request for Proposals." Presentation. British Columbia Ministry of Transportation. http://www.th.gov.bc.ca/ BCHighways/contracts/maintenance/Nov_15_Meeting_Full_Presentation.pdf (Accessed Dec. 2006) 
Nolan, A., (2002) “The determinants of urban households' transport decision: A microeconomic study using Irish data". Presentation to the VIIth Spring Meeting of Young Economists, Paris.

Office of Program Policy Analysis and Government Accountability, OPPAGA (1999) “PB2Performance Report”. Report No. 98-59, Florida.

Office of Program Policy Analysis and Government Accountability, OPPAGA (2003) "Progress Report". Report No. 03-30, Florida.

Ohio Department of Transportation, (2001) "Six-State Survey of Construction Administration Practices and Procedures." Final Report.

OMB (1998) "A Guide to Best Practices for Performance-Based Service Contracting”, Final Edition, Office of Federal Procurement Policy (OFPP), Office of Management and Budget (OMB), Executive Office of the President, Washington, D.C.

Organisation for Economic Co-operation and Development, OECD (2005) "Performance-based Standards for the Road Sector." Transport Research Centre. http://www.cemt.org/pub/pubresearch.htm (Accessed July 2007)

Ozbek, M. E. (2004) "Development of Performance Warranties for Performance Based Road Maintenance Contracts.” Thesis for a Master Degree. Blacksburg, Virginia. April 23.

Pakkala, P., (2002) "Innovative Project Delivery Methods for Infrastructure. International Perspective". Finnish Road Enterprise. Helsinki, Finland. 
Pakkala, P., (2005) "Performance-based Contracts - International Experiences". Finnish Road Administration. Presentation at the TRB Workshop on "Performance-based Contracting”. April 27, 2005, Washington, D.C. USA.

Parkman, C., Hallett, J., Henning, T., and Tapper, M., (2003) "Pavement Deterioration in Long-term Performance-based Contracts: How Far Does It Mitigate the Risk For Client and Contractor?" Transit New Zealand. ARRB Conference, June 2003. Cairns, Australia.

Pavement Management Services. (2004) "Getting Ready for the First Renewal of the Sydney PSMC.” Road Runner. Issue 4. http://www.pavement.com.au/downloads/ road runner_04.pdf (Accessed Dec. 2006)

PIARC, The World Road Association - Canada (2004) "Maintenance Delivery in Ontario". Prepared for PIARC, Kananaskis.

PIARC, The World Road Association (1999) "The Quality of Road Service, Evaluation, Perception and Response Behavior of Road Users." Pages 72 to 78, 108 to 118. http://rru. worldbank.org/Documents/Toolkits/ Highways/pdf/96.pdf (Accessed Dec. 2006)

Porter, T. (2002) "International Trends in Procurement Models for Highway Maintenance”. Opus International Consultants, Ltd. http://www.opus.co.nz (Accessed Sept. 2006).

Prozzi, J., A., and Madanat, S., M., (2000) "Using Duration Models to Analyze Experimental Pavement Failure Data”. Transportation Research Record 1699, 87-94.

Qi, Y., Smith, B. L. and Guo, J., (2007) "Freeway accident likelihood prediction using a Panel data analysis approach." Journal of Transportation Engineering (ASCE) 133, 149156. 
Queiroz, C. (2000) "Contractual Procedures to Involve the Private Sector in Road Maintenance and Rehabilitation”. 24th International Baltic Road Conference, Riga, Latvia.

Queiroz, C., (2005) "Options for Implementing Performance-based Contracts." Presentation for the World Bank Transport Forum 2005. Washington, D.C.: World Bank. http://www.worldbank.org/transport/learning/presentations/Roads\%20Tuesday/Qu eiroz_Performance-Based\%20Contracts.ppt (Accessed Mar. 2007)

Republic of Serbia (2006) Road Directorate. http://www.worldbank.org/transport/roads/ resource-guide/Docs-latest\%20edition/bidding\%20docs/serbia/Serbia_Vol_\%202_CoC\& CD.doc (accessed Oct. 2006).

Ribreau, Nicole, (2005) "Synopsis of WSDOT's Review of Highway Maintenance "Outsourcing" Experience", Transportation Research Board Committee A3C01, Washington DC.

Robinson, M., (2005) "Lessons Learned in Performance-based Maintenance Contracting." Presentation for AASHTO Maintenance Subcommittee. SAIC. McLean, VA, USA.

Robinson, M. and Raynault, E., (2005) "Performance-based Contracting in Road Management: Experiences and Lessons Learned in the DC Streets Project.” Presentation for the World Bank. SAIC. McLean, VA, USA.

Robinson, M. et al., (2005) "The DC Streets Performance-based Asset Preservation Experiment - Current Quantitative Results and Suggestions for Future Contracts.” 
Presentation for Transportation Research Board's 2006 Annual Meeting. Washington, D.C.

Roncek, D. W., (1992) “Learning more from Tobit coefficients: Extending a comparative analysis of political protest”. American Sociological Review 57(4), 503-507.

Schnedler, W., (2005) "Likelihood estimation for censored random vectors." Econometric Reviews 24(2), 195-217.

Segal, G.F., Moore, A. T., McCarthy, S., (2003) "Contracting for Road and Highway Maintenance.” Los Angeles: Reason Public Policy Institute.

Segal, G. F. and Montague, E. (2004). Competitive Contracting for Highway Maintenance: Lessons Learned from National Experience. Washington Policy Center Publication, January 2004.

http://www.wips.org/Transportation/PBMontagueSegalReasonHighwayMaintena nce.htm

Seidenstat, P., (1999) "Contracting Out Government Services." Westport, Conn.: Praeger.

Shankar, V., Milton, J. and Mannering, F., (1997) "Modeling Accident Frequencies as Zero-Altered Probability Processes: An Empirical Inquiry." Accident Analysis and Prevention, Vol. 29, 829-837.

Singh, P., (2004) "An Evaluation of Cost-effectiveness of Highway Pavement Warranties in Indiana". Thesis for a Masters Degree, Purdue University. West Lafayette, Indiana. 
Singh, P., Oh, J., E., Labi, S., and Sinha, K., C., (2007) "Cost-Effectiveness Evaluation of Warranty Pavement Projects.” Journal of Construction Engineering and Management. 133 (3), 217-224.

Sinha, K., C., Labi, S., (2007) “Transportation Decision-Making: Principles of Project Evaluation and Programming", John Wiley \& Sons Inc.

Smith, K., L., Smith, K., D., Evans, L., D., Hoerner, T., E., Darter, M., I., Woodstrom, J., H., (1997) "Final Report: Smoothness Specifications for Pavements." NCHRP Web Document 1. Publisher: National Cooperative Highway Research Program, 576 p.

Stankevich, N., Qureshi, N. and Queiroz, C., (2005) "Contrats basés sur les résultats pour la préservation et l'amélioration des actifs routiers". Transport Note TN-27. Washington, D.C.: The World Bank. USA.

Stowe, Robert, Nixon, Wilfrid, Kirkland, Ken, Asset Insight Technologies, "Highway Maintenance Outsourcing," June 2006, Washington State Department of Transportation..

Talley, W., K., (1995) "Safety investments and operating conditions: Determinants of accident passenger-vessel damage cost.” Southern Economic Journal 61, 819-829.

The World Bank Group Website (2006) http://www.worldbank.org (accessed Feb. 2007).

Tobin, J., (1958) "Estimation of relationships for limited dependent variables". Econometrica 26, 24-36.

Train, K., (2003) "Discrete choice methods with simulation." Cambridge University Press. Cambridge, UK. 
Transport Research Board, TRB (2003) “Outsourcing of State DOT Capital Program Delivery Functions." Transport Research Board. Vienna, Virginia, November 2003. http://trb.org/publications/nchrp/nchrp_w59.pdf (Accessed Apr. 2007)

Utah Department of Transportation, (2001) "I-15 Corridor Reconstruction Project Design-Build Evaluation", Annual Report, June 2001.

United Republic of Tanzania. Ministry of Works (2006) Tanzania National Roads Agency http://www.worldbank.org/transport/roads/resource-guide/ (accessed Feb. 2007).

Veall, M. R., Zimmermann, K. F., (1996) "Pseudo-R2 for some common limited dependent variable models". Journal of Economic Surveys 10(3), 241-259.

Virginia Department of Transportation (1995) "Public-Private Transportation Act of 1995." http://www.virginiadot.org/business/ppta-default.asp (Accessed Aug. 2006)

VMS, Inc. (2001) "Best Practices of Outsourcing Winter Maintenance Services." Richmond. Virginia.

Vuong, Q., (1989) "Likelihood ratio tests for model selection and non-nested hypotheses.” Econometrica, Vol. 57, 307-334.

Wang, Y., Mahboub, K. C., and Hancher, D., E., (2005) "Survival Analysis of Fatigue Cracking for Flexible Pavements Based on Long-Term Pavement Performance Data." Journal of Transportation Engineering 131 (8), 608-616.

Warne, Thomas R., NCHRP Synthesis 313 - State DOT Outsourcing and Private-Sector Utilization, 2003, Federal Highway Administration, Transportation Research Board. 
Washington, S. P., Karlaftis, M. G., Mannering, F. L., (2003) "Statistical and Econometric methods for transportation data analysis". Chapman \& Hall/CRC.

Williams, G., (2005) "Assessment of PMMR Implementation Potential in Africa." Presentation for the World Bank Transport Forum 2005. BCEOM. Washington, D.C.: World Bank. USA.

Wisconsin Department of Transportation, (1998) "Asphaltic Pavement Warranties." Three-Year Progress Report.

Word Bank Resource Guide (2006) Performance-based Contracting for Preservation and Improvement of Road Assets. http://www.worldbank.org/transport/roads/resource-guide (Accessed Mar. 2007).

World Bank (2004) "Procurement under IBRD Loans and IDA Credits: Guidelines." Washington, D.C.: World Bank. http://siteresources.worldbank.org/INTPROCUREMEN T/Resources/Procurement-May-2004.pdf (Accessed Aug. 2006)

World Bank (2005) "Procurement of Works and Services under Output- and Performance-based Road Contracts: Sample Bidding Document." September 2005. Washington, D.C.: World Bank. http://web.worldbank.org/WBSITE/EXTERNAL/ PROJECTS/PROCUREMENT/0,,contentMDK:20646773 menuPK:84284 pagePK:842 69 piPK:60001558 theSitePK:84266,00.html (Accessed Jan. 2007)

World Bank (2005) "Project Appraisal Document on a Proposed Loan in the Amount of USD 150 million to the Argentine Republic for a Provincial Road Infrastructure Project" Washington, D.C. May 12, 2005. 
World Bank (2005) "Structuring Output-based Aid Approaches in World Bank Group Operations. Guidance Note for Staff.” Washington, D.C. http://www.gpoba.org/ documents/OBAGuidanceNoteFinalNov162005.pdf (Accessed Feb. 2007)

Yang, J., (2007) "Estimation of Pavement Lifespan Using Stochastic Duration Models." 86th Annual Transportation Research Board Meeting. 12 p.

Yu, J., (2005) "Pavement Service Life Estimation and Condition Prediction." Ph.D. Dissertation: University of Toledo. 100 p.

Zietlow, G., (2004) “Implementing Performance-based Road Management and Maintenance Contracts in Developing Countries - An Instrument of German Technical Cooperation." November 2004. Eschborn, Germany.

Zietlow, G., (2005) "Cutting Costs and Improving Quality through Performance-Based Road Management and Maintenance Contracts - The Latin American and OECD Experiences." Birmingham, April 24-29. University of Birmingham (UK). Senior Road Executives Programme, Restructuring Road Management.

Zietlow, G., (2005) “Using Micro-Enterprises to Create Local Contracting Capacity The Latin American Experience." Birmingham, April 24-29. University of Birmingham (UK), Senior Road Executives Programme, Restructuring Road Management.

Zietlow, G., (2007) PBC for Road Management and Maintenance. http://www.zietlow.com (Accessed Apr. 2007).

Zietsman, J., (2005) "Performance Measures for Performance Based Maintenance Contracts", Texas Transportation Institute, USA. 
APPENDICES 


\section{Appendix A.}

Example of assets/activities for construction, maintenance and/or operation

Lighting;

Pavement surface;

Fencing;

Shoulders;

Guardrails;

Slopes;

Barriers;

Potholes;

Attenuators;

Open drainage system (paved and unpaved

ditches and swales);

Street trees, shrubs and other plantings;

Vegetation and aesthetics;

Catch basins;

Pavement markings;

Oil/grit separators on bridges.
Drains;

Pavement striping;

Inlets;

Raised pavement striping;

Curbs;

Highway and sign lights;

Gutters;

Tunnels;

Sidewalks;

Bridges;

Roadsides;

Rest areas,

Medians;

Over-height detectors;

Signs and traffic signals; 


\section{Appendix B.}

Performance Measures in New Zealand [Source: Transit New Zealand, 1999]

\begin{tabular}{|c|c|c|c|c|c|c|c|}
\hline \multirow[b]{2}{*}{ Feature } & \multirow{2}{*}{$\begin{array}{l}\text { Desire } \\
\text { Outcome }\end{array}$} & \multirow[b]{2}{*}{ Category } & \multicolumn{3}{|l|}{ Base Tender } & \multirow{2}{*}{$\begin{array}{l}\text { Response } \\
\text { time to } \\
\text { correct } \\
\text { deficiency }\end{array}$} & \multirow{2}{*}{$\begin{array}{l}\text { Recommend } \\
\text { ed } \\
\text { Boundary } \\
\text { Criteria for } \\
\text { Alternative } \\
\text { Offer }\end{array}$} \\
\hline & & & $\begin{array}{l}\text { Base } \\
\text { Condition } \\
\text { Standard }\end{array}$ & $\begin{array}{l}\text { Handback } \\
\text { Compliance }\end{array}$ & $\begin{array}{l}\text { Compliance } \\
\text { During PSMC } \\
\text { Period }\end{array}$ & & \\
\hline & & & & & & & \\
\hline \multirow[t]{2}{*}{ Bleeding } & $\begin{array}{ll}\text { Binder no } \\
\text { picked up on } \\
\text { any time }\end{array}$ & All Roads & No free binder & $\begin{array}{l}100 \% \text { at base } \\
\text { condition }\end{array}$ & $\begin{array}{l}\text { All bleeding } \\
\text { surfaces treated }\end{array}$ & 2 hours & $\begin{array}{l}\text { No free } \\
\text { binder which } \\
\text { results in } \\
\text { user } \\
\text { complaints }\end{array}$ \\
\hline & $\begin{array}{l}\text { No surprise for } \\
\text { drivers. Safe }\end{array}$ & & $\begin{array}{l}\text { All required } \\
\text { temporary } \\
\text { warning signs } \\
\text { erected before } \\
\text { grit spread }\end{array}$ & $\begin{array}{l}100 \% \text { at base } \\
\text { condition }\end{array}$ & $\begin{array}{l}\text { All temporary } \\
\text { warning signs } \\
\text { required by the } \\
\text { Manual of } \\
\text { Traffic Signs } \\
\text { and Markings } \\
\text { erected and } \\
\text { maintained } \\
\text { when grit } \\
\text { spread }\end{array}$ & At all times & $\begin{array}{l}\text { Base } \\
\text { condition }\end{array}$ \\
\hline Snow & $\begin{array}{l}\text { No surprise for } \\
\text { drivers. Safe }\end{array}$ & All Roads & $\begin{array}{l}\text { Road closure } \\
\text { signs erected if } \\
\text { road } \\
\text { impassable. } \\
\text { Emergency } \\
\text { notification } \\
\text { procedures and } \\
\text { contingency } \\
\text { plan enacted }\end{array}$ & $\begin{array}{l}100 \% \text { at base } \\
\text { condition }\end{array}$ & $\begin{array}{l}100 \% \text { at base } \\
\text { condition }\end{array}$ & 1 hour & $\begin{array}{l}\text { Base } \\
\text { condition }\end{array}$ \\
\hline Ice & $\begin{array}{l}\text { No surprise for } \\
\text { drivers. Safe }\end{array}$ & All Roads & $\begin{array}{l}\text { All necessary } \\
\text { permanent } \\
\text { warning signs } \\
\text { in place during } \\
\text { periods when } \\
\text { ice may be } \\
\text { present }\end{array}$ & $\begin{array}{l}100 \% \text { at base } \\
\text { condition }\end{array}$ & $\begin{array}{l}\text { All permanent } \\
\text { warning signs } \\
\text { required by the } \\
\text { Manual of } \\
\text { Traffic Signs } \\
\text { and Markings } \\
\text { erected at } \\
\text { places where } \\
\text { icing ing } \\
\text { frequently a } \\
\text { problem }\end{array}$ & $\begin{array}{l}\text { At all times } \\
\text { in winter } \\
\text { months }\end{array}$ & $\begin{array}{l}\text { Base } \\
\text { condition }\end{array}$ \\
\hline $\begin{array}{l}\text { Road Closures } \\
\text { for Emergency } \\
\text { Events }\end{array}$ & $\begin{array}{l}\text { Motorist } \\
\text { advised of road } \\
\text { closure }\end{array}$ & All Roads & $\begin{array}{l}\text { Appropriate } \\
\text { temporary road } \\
\text { closure signs \& } \\
\text { barriers erected } \\
\text { at the point of } \\
\text { closure }\end{array}$ & $\begin{array}{l}100 \% \text { at base } \\
\text { condition }\end{array}$ & $\begin{array}{l}\text { All closures } \\
\text { sign posted } \\
\text { correctly } \\
\text { within response } \\
\text { times }\end{array}$ & $\begin{array}{l}2 \text { hours } \\
6.00 \mathrm{am} \text { to } \\
6.00 \mathrm{pm} \\
4 \quad \text { hours } \\
6.00 \mathrm{pm} \text { to } \\
6.00 \mathrm{am}\end{array}$ & $\begin{array}{l}\text { Base } \\
\text { condition }\end{array}$ \\
\hline \multicolumn{8}{|c|}{ ASSET GROUP: SEALED CARRIAGEWAY (including sealed shoulders) } \\
\hline \multirow[t]{2}{*}{$\begin{array}{l}\text { Skid } \\
\text { Resistance }\end{array}$} & $\begin{array}{l}\text { Adequate Skid } \\
\text { Resistance } \\
\text { Safety }\end{array}$ & $\begin{array}{l}\text { All Roads, Site } \\
\text { Cat.1 } \\
\text { Intervention } \\
\text { Level } 0.45 \\
\text { SFC }\end{array}$ & $\begin{array}{l}\text { No Cat } 1 \text { sites } \\
\text { with } 100 \% \\
\text { SFC }<0.50\end{array}$ & $\begin{array}{l}100 \% \text { at base } \\
\text { condition }\end{array}$ & $\begin{array}{l}100 \% \text { at base } \\
\text { condition }\end{array}$ & 2 years & $\begin{array}{l}\text { Response } \\
\text { time } \\
\text { extended } \\
1 \text { month to } 3 \\
\text { month } \\
3 \text { months to } \\
6 \text { months } \\
1 \text { year to } 2 \\
\text { years } \\
2 \text { years to } 3 \\
\text { years }\end{array}$ \\
\hline & & & No Cat 1 sites & $100 \%$ at base & $100 \%$ at base & 1 year & \\
\hline
\end{tabular}




\begin{tabular}{|c|c|c|c|c|c|c|c|}
\hline & & & $\begin{array}{l}\text { with average } \\
\mathrm{SFC}<0.45\end{array}$ & condition & condition & & \\
\hline \multirow[t]{2}{*}{ Potholes } & $\begin{array}{l}\text { Safety, } \\
\text { Smoothness, } \\
\text { Comfort }\end{array}$ & $\begin{array}{l}\text { North Network } \\
\& \quad \text { associated } \\
\text { urban }\end{array}$ & No Potholes & $\begin{array}{l}100 \% \text { at base } \\
\text { condition }\end{array}$ & $\begin{array}{l}<10 \text { potholes } \\
\text { with a diameter } \\
>100 \mathrm{~mm} \text { on } \\
\text { any continues } 5 \\
\mathrm{~km} \text { of lane } \\
\text { length }\end{array}$ & 4 days & $\begin{array}{l}\text { Up to } 40 \\
\text { potholes in } \\
\text { any } 5 \mathrm{~km} \text { of } \\
\text { lane length } \\
\text { with no } \\
\text { pothole } \\
>200 \mathrm{~mm} \\
\text { diameter } \\
\text { and/or } \\
\text { response } \\
\text { time up to } 1 \\
\text { week }\end{array}$ \\
\hline & & $\begin{array}{ll}\text { South } & \& \\
\text { East/West } & \\
\text { Networks } & \& \\
\text { associated } & \\
\text { urban } & \end{array}$ & No Potholes & $\begin{array}{l}100 \% \text { at base } \\
\text { condition }\end{array}$ & $\begin{array}{l}<15 \text { potholes } \\
\text { with a diameter } \\
>100 \mathrm{~mm} \text { on } \\
\text { any continuous } \\
5 \mathrm{~km} \text { of lane } \\
\text { length }\end{array}$ & 8 days & $\begin{array}{l}\text { Up to } 60 \\
\text { potholes in } \\
\text { any } 5 \mathrm{~km} \text { of } \\
\text { lane length } \\
\text { with no } \\
\text { potholes } \\
>200 \mathrm{~mm} \\
\text { diameter } \\
\text { and/or } \\
\text { response } \\
\text { time up to } 3 \\
\text { weeks } \\
\end{array}$ \\
\hline Rutting & $\begin{array}{l}\text { Safety, } \\
\text { Smoothness, } \\
\text { Comfort }\end{array}$ & All Roads & $\begin{array}{l}\text { No ruts greater } \\
\text { than } 30 \text { mm } \\
\text { deep which } \\
\text { concentrate } \\
\text { runoff to a } \\
\text { depth which } \\
\text { induces } \\
\text { aquaplaning or } \\
\text { create safety } \\
\text { problems }\end{array}$ & $\begin{array}{l}100 \% \text { at base } \\
\text { condition }\end{array}$ & $\begin{array}{l}\text { Not more than } \\
5 \mathrm{~m} \text { in any } \\
100 \mathrm{~m} \text { length of } \\
\text { wheel track in } \\
\text { any lane with } \\
\text { rutting } \\
\text { exceeding } \\
30 \mathrm{~mm} \text { depth }\end{array}$ & 12 months & $\begin{array}{l}\text { Base } \\
\text { condition }\end{array}$ \\
\hline \multicolumn{8}{|c|}{ ASSET GROUP: DRAINAGE } \\
\hline $\begin{array}{l}\text { Culverts } \\
(<3-4 \quad \text { sqm } \\
\text { waterway area })\end{array}$ & Functional & All Roads & $\begin{array}{l}\text { All culverts > } \\
90 \% \text { functional }\end{array}$ & $\begin{array}{l}100 \% \text { at base } \\
\text { condition }\end{array}$ & $\begin{array}{l}\text { All culverts } \\
\text { with al least } \\
80 \% \text { waterway } \\
\text { area clear } \\
\text { September to } \\
\text { April inclusive }\end{array}$ & 2 months & $\begin{array}{l}\text { Each culvert } \\
>\quad 80 \% \\
\text { functional at } \\
\text { all times }\end{array}$ \\
\hline $\begin{array}{l}\text { Side Drains } \\
\text { and Surface } \\
\text { Water } \\
\text { Channel }\end{array}$ & Functional & All Roads & $\begin{array}{l}\text { All side drains } \\
\text { and surface } \\
\text { water channels } \\
\text { with > }>00 \% \\
\text { design } \\
\text { waterway } \\
\text { capacity } \\
\text { available }\end{array}$ & $\begin{array}{l}100 \% \text { at base } \\
\text { condition }\end{array}$ & $\begin{array}{l}\text { All side drains } \\
\text { and surface } \\
\text { water channels } \\
\text { with at least } \\
80 \% \text { waterway } \\
\text { area clear Sep } \\
\text { to April incl, }\end{array}$ & 2 months & $\begin{array}{l}\text { All side } \\
\text { drains and } \\
\text { surface water } \\
\text { channels } \\
\text { with al least } \\
80 \% \text { of the } \\
\text { waterway } \\
\text { area clear at } \\
\text { all times }\end{array}$ \\
\hline $\begin{array}{l}\text { Sumps, } \\
\text { Manholes, } \\
\text { Droppers, } \\
\text { Catchpits } \\
\end{array}$ & Functional & All Roads & $\begin{array}{l}\text { All assets } \\
>75 \% \\
\text { functional }\end{array}$ & $\begin{array}{l}100 \% \text { at base } \\
\text { condition }\end{array}$ & $\begin{array}{l}\text { All assets } \\
>75 \% \\
\text { functional Sep- } \\
\text { Apr }\end{array}$ & 3 months & $\begin{array}{l}\text { Base } \\
\text { condition }\end{array}$ \\
\hline $\begin{array}{l}\text { Other } \\
\text { Drainage } \\
\text { Control } \\
\text { Structures }\end{array}$ & Functional & All Roads & $\begin{array}{l}\text { All other } \\
\text { drainage } \\
\text { structures are } \\
\text { functioning } \\
\text { satisfactory } \\
\end{array}$ & $\begin{array}{l}100 \% \text { at base } \\
\text { condition }\end{array}$ & $\begin{array}{l}\text { All drainage } \\
\text { control and } \\
\text { other structures } \\
\text { functional at all } \\
\text { times }\end{array}$ & 2 months & $\begin{array}{l}\text { Base } \\
\text { condition }\end{array}$ \\
\hline $\begin{array}{l}\text { Preventive } \\
\text { maintenance }\end{array}$ & $\begin{array}{l}\text { Effects } \\
\text { erosion } \\
\text { mitigated }\end{array}$ & All Roads & $\begin{array}{l}\text { No identified } \\
\text { potential } \\
\text { erosion sites } \\
\text { without } \\
\text { preventive } \\
\text { treatment or in } \\
\text { place }\end{array}$ & $\begin{array}{l}100 \% \text { at base } \\
\text { condition }\end{array}$ & $\begin{array}{lr}\text { All potential } \\
\text { erosion } & \text { and } \\
\text { scour } & \text { site } \\
\text { identified } & \end{array}$ & N/A & $\begin{array}{l}\text { Base } \\
\text { condition }\end{array}$ \\
\hline
\end{tabular}




\section{Appendix C.}

\section{Example Performance Measures and their Associated Levels of Service in Washington}

D.C. [Source: Robinson et al., 2006]

\begin{tabular}{|c|c|c|c|c|c|c|c|c|}
\hline $\begin{array}{c}\text { Maintenance } \\
\text { Category }\end{array}$ & $\begin{array}{c}\text { Maintenance } \\
\text { Element }\end{array}$ & $\begin{array}{l}\text { Performance } \\
\text { Measure }\end{array}$ & $\underset{\#}{\operatorname{LOS}}$ & Excellent 5 & Good 4 & Fair 3 & Poor 2 & Very Poor 1 \\
\hline \multirow[t]{7}{*}{$\begin{array}{l}\text { Pavement } \\
\text { Structure }\end{array}$} & \multirow[t]{7}{*}{$\begin{array}{l}\text { Pavement } \\
\text { Surface }\end{array}$} & $\begin{array}{l}\text { IRI - Roads } \\
\text { reconstructed } \\
\text { in } \\
\text { the past } 5 \text { years }\end{array}$ & 1 & IRI $<110$ & $110 \leq \mathrm{IRI}<181$ & $181 \leq \mathrm{IRI}<250$ & $250 \leq \mathrm{IRI}<320$ & $I R I \geq 320$ \\
\hline & & \multirow[t]{2}{*}{$\begin{array}{l}\text { IRI - Roads } \\
\text { not } \\
\text { reconstructed } \\
\text { in } \\
\text { the past } 5 \text { years }\end{array}$} & 2 & $\begin{array}{l}\% \text { of } \\
\text { pavement } \\
\text { with } \\
\text { IRI }<181 \\
\text { increased } \\
\text { by } \\
10 \% \text { or } \\
\text { more }\end{array}$ & $\begin{array}{l}\% \text { of pavement } \\
\text { with IRI }<181 \\
\text { remained the } \\
\text { same or } \\
\text { increased up to } \\
10 \%\end{array}$ & $\begin{array}{l}\% \text { of } \\
\text { pavement } \\
\text { with IRI < } \\
181 \\
\text { decreased up } \\
\text { to } \\
10 \%\end{array}$ & $\begin{array}{l}\% \text { of pavement } \\
\text { with IRI }<181 \\
\text { decreased from } \\
10 \text { to } 20 \%\end{array}$ & $\begin{array}{l}\% \text { of } \\
\text { pavement } \\
\text { with IRI } \\
<181 \\
\text { decreased } \\
\text { more } \\
\text { than } 20 \%\end{array}$ \\
\hline & & & 3 & $\begin{array}{l}\% \text { of } \\
\text { pavement } \\
\text { with } \\
\text { IRI } \geq 250 \\
\text { decreased } \\
\text { by } 10 \% \text { or } \\
\text { more }\end{array}$ & $\begin{array}{l}\% \text { of pavement } \\
\text { with IRI } \geq 250 \\
\text { remained the } \\
\text { same or } \\
\text { decreased up } \\
\text { to } 10 \%\end{array}$ & $\begin{array}{l}\% \text { of } \\
\text { pavement } \\
\text { with } I R I \geq 250 \\
\text { increased up } \\
\text { to } 10 \%\end{array}$ & $\begin{array}{l}\% \text { of pavement } \\
\text { with IRI } \geq 250 \\
\text { increased from } \\
10 \text { to } 20 \%\end{array}$ & $\begin{array}{l}\% \text { of } \\
\text { pavement } \\
\text { with } \\
\text { IRI } \geq 250 \\
\text { increased } \\
\text { more than } \\
20 \%\end{array}$ \\
\hline & & $\begin{array}{l}\text { PCI - Roads } \\
\text { reconstructed } \\
\text { in } \\
\text { the past } 5 \text { years }\end{array}$ & 4 & PCI $>90$ & $90 \geq \mathrm{PCI}>80$ & $80 \geq \mathrm{PCI}>60$ & $60 \geq \mathrm{PCI}>50$ & $\mathrm{PCI} \leq 50$ \\
\hline & & \multirow[t]{2}{*}{$\begin{array}{l}\text { PCI - Roads } \\
\text { not } \\
\text { Reconstructed } \\
\text { in } \\
\text { the past } 5 \text { years }\end{array}$} & 5 & $\begin{array}{l}\% \text { of } \\
\text { pavement } \\
\text { with } \\
\text { PCI>80 } \\
\text { increased } \\
\text { by } \\
10 \% \text { or } \\
\text { more }\end{array}$ & $\begin{array}{l}\% \text { of pavement } \\
\text { with } \mathrm{PCI}>80 \\
\text { remained the } \\
\text { same or } \\
\text { increased up to } \\
10 \%\end{array}$ & $\begin{array}{l}\% \text { of } \\
\text { pavement } \\
\text { with } \text { PCI }>80 \\
\text { decreased up } \\
\text { to } \\
10 \%\end{array}$ & $\begin{array}{l}\% \text { of pavement } \\
\text { with } \mathrm{PCI}>80 \\
\text { decreased from } \\
10 \text { to } 20 \%\end{array}$ & $\begin{array}{l}\% \text { of } \\
\text { pavement } \\
\text { with } \text { PCI }>80 \\
\text { decreased } \\
\text { more } \\
\text { than } 20 \%\end{array}$ \\
\hline & & & 6 & $\begin{array}{l}\% \text { of } \\
\text { pavement } \\
\text { with } \\
\text { PCI } \leq 60 \\
\text { decreased } \\
\text { by } 10 \% \text { or } \\
\text { more }\end{array}$ & $\begin{array}{l}\% \text { of pavement } \\
\text { with } \mathrm{PCI} \leq 60 \\
\text { remained the } \\
\text { same or } \\
\text { decreased up } \\
\text { to } 10 \%\end{array}$ & $\begin{array}{l}\% \text { of } \\
\text { pavement } \\
\text { with } \mathrm{PCI} \leq 60 \\
\text { increased up } \\
\text { to } 10 \%\end{array}$ & $\begin{array}{l}\% \text { of pavement } \\
\text { with } \mathrm{PCI} \leq 60 \\
\text { increased from } \\
10 \text { to } 20 \%\end{array}$ & $\begin{array}{l}\% \text { of } \\
\text { pavement } \\
\text { with } \mathrm{PCI} \leq 60 \\
\text { increased } \\
\text { more than } \\
20 \%\end{array}$ \\
\hline & & $\begin{array}{l}\text { Friction } \\
\text { Number }\end{array}$ & 7 & $\begin{array}{l}\text { Skid } \\
\text { Number > } \\
45\end{array}$ & $\begin{array}{l}45 \geq \text { Skid } \\
\text { Number }>40\end{array}$ & $\begin{array}{l}40 \geq \text { Skid } \\
\text { Number }>35\end{array}$ & $\begin{array}{l}35 \geq \text { Skid } \\
\text { Number }>30\end{array}$ & $\begin{array}{l}\text { Skid } \\
\text { Number } \leq \\
30\end{array}$ \\
\hline
\end{tabular}




\section{Appendix D.}

\section{Performance Measures and Ratings used in Texas PBC implementations}

\section{[Source: Texas DOT, 2004]}

\begin{tabular}{|c|c|c|c|c|c|}
\hline Component & Excellent & Good & Fair & Poor & Failed \\
\hline $\begin{array}{l}\text { Traffic } \\
\text { Operations }\end{array}$ & 5 & $\mathbf{4}$ & $\mathbf{3}$ & 2 & 2010 \\
\hline $\begin{array}{l}\text { Large Signs } \\
\text { (Installed } \\
\text { on I or H } \\
\text { beams or } \\
\text { sign bridge) }\end{array}$ & $\begin{array}{l}\text { Signs like new, } \\
\text { with all } \\
\text { background, } \\
\text { lettering, borders } \\
\text { and shields clean } \\
\text { and reflective. } \\
\text { No damage. }\end{array}$ & $\begin{array}{l}\text { Signs generally good; } \\
\text { background, lettering, } \\
\text { borders and shields may } \\
\text { be slightly faded. May } \\
\text { have very minor } \\
\text { damage. }\end{array}$ & $\begin{array}{l}\text { Signs borderline } \\
\text { acceptable; } \\
\text { background, } \\
\text { lettering, borders and } \\
\text { shields may be } \\
\text { slightly faded or } \\
\text { mildewed. May have } \\
\text { some damage. } \\
\end{array}$ & $\begin{array}{l}\text { Signs unacceptable with dirt } \\
\text { or mildew. May be faded or } \\
\text { have substantial damage. } \\
\text { May have one or two high or } \\
\text { low bases. }\end{array}$ & $\begin{array}{l}\text { Signs totally } \\
\text { unacceptable with } \\
\text { severe dirt, mildew or } \\
\text { fading. May be } \\
\text { damaged or totally } \\
\text { knocked down. Several } \\
\text { bases are high or low. }\end{array}$ \\
\hline $\begin{array}{l}\text { Small Signs } \\
\text { (Chevron } \\
\text { are signs) }\end{array}$ & $\begin{array}{l}\text { Signs like new, } \\
\text { on standard } \\
\text { posts, no repairs } \\
\text { needed. All } \\
\text { straight }\end{array}$ & $\begin{array}{l}\text { All on standard } \\
\text { supports. Very minor } \\
\text { repairs needed. All } \\
\text { required signs are in } \\
\text { place. No high or low } \\
\text { bases. Most are straight }\end{array}$ & $\begin{array}{l}\text { All on standard } \\
\text { supports, }<50 \% \\
\text { leaning or with dirty, } \\
\text { damaged or bad sign } \\
\text { faces. No high or low } \\
\text { bases. }\end{array}$ & $\begin{array}{l}\text { All on standard supports, } \\
\text { most leaning or dirty, } \\
\text { damaged or bad sign faces. } \\
\text { One non-regulatory maybe } \\
\text { missing. } \\
\text { Some may have high or low } \\
\text { bases. }\end{array}$ & $\begin{array}{l}\text { Signs not on standard } \\
\text { supports or any } \\
\text { regulatory sign missing } \\
\text { or more than one other } \\
\text { sign missing. MOST } \\
\text { ALL are leaning and } \\
\text { bad or damaged sign } \\
\text { faces. }\end{array}$ \\
\hline Attenuator & $\begin{array}{l}\text { New or like new } \\
\text { to current } \\
\text { standards with } \\
\text { no damage. }\end{array}$ & $\begin{array}{l}\text { Attenuator not damaged; } \\
\text { may not be latest } \\
\text { standard. }\end{array}$ & $\begin{array}{l}\text { Attenuator functional } \\
\text { but with very minor } \\
\text { damage. May need } \\
\text { painting. }\end{array}$ & $\begin{array}{l}\text { Attenuator with moderate } \\
\text { damage but will still function } \\
\text { as designed. }\end{array}$ & $\begin{array}{l}\text { Attenuator that will not } \\
\text { function as designed }\end{array}$ \\
\hline $\begin{array}{l}\text { Delineators } \\
\text { (OM3 or } \\
\text { delineators) }\end{array}$ & $\begin{array}{l}\text { Delineators, new } \\
\text { or like new, } \\
\text { straight, installed } \\
\text { in accordance } \\
\text { with standards. } \\
\text { No repairs } \\
\text { needed. }\end{array}$ & $\begin{array}{l}\text { Delineators posts }<50 \% \\
\text { slightly leaning or with } \\
\text { some damaged and non } \\
\text { reflective delineators }\end{array}$ & $\begin{array}{l}\text { Delineators <50\% } \\
\text { slightly leaning and } \\
<50 \% \text { delineators } \\
\text { damaged or non } \\
\text { reflective, or most } \\
\text { post slightly leaning, } \\
\text { or most delineators } \\
\text { non reflective. }\end{array}$ & $\begin{array}{l}\text { Most post slightly leaning and } \\
\text { delineators non reflective or } \\
\text { one or two post bent, broken, } \\
\text { down or missing. }\end{array}$ & $\begin{array}{l}\text { Several bent, broken } \\
\text { damaged or missing. } \\
\text { Not installed in } \\
\text { accordance with } \\
\text { standards }\end{array}$ \\
\hline $\begin{array}{l}\text { Guardrail } \\
\text { ( Rate as } \\
\text { needed) }\end{array}$ & $\begin{array}{l}\text { Guardrail like } \\
\text { new, } \\
\text { appropriately } \\
\text { placed, installed } \\
\text { to the latest } \\
\text { standards. }\end{array}$ & $\begin{array}{l}\text { Guardrail all functional. } \\
\text { May have one minor } \\
\text { dent or may not be the } \\
\text { latest standard. }\end{array}$ & $\begin{array}{l}\text { Guardrail all } \\
\text { functional with } \\
\text { several minor dents } \\
\text { or out of alignment. }\end{array}$ & $\begin{array}{l}\text { Guardrail has been hit and is } \\
\text { not functional. Guardrail has } \\
\text { standup ends instead of turn } \\
\text { down or turn down instead of } \\
\text { GET. Guardrail is low. }\end{array}$ & $\begin{array}{l}\text { Guardrail has major } \\
\text { damage and should be } \\
\text { repaired as soon as } \\
\text { possible. Guardrail is } \\
\text { required and not } \\
\text { installed at bridge ends }\end{array}$ \\
\hline Roadside & 5 & 4 & 3 & 2 & 1 \\
\hline $\begin{array}{l}\text { Litter (Do } \\
\text { not rate in } \\
\text { C/G } \\
\text { section) }\end{array}$ & $\begin{array}{l}\text { ROW clean with } \\
\text { no or very minor } \\
\text { litter. Litter not } \\
\text { visible at posted } \\
\text { speed limit. }\end{array}$ & $\begin{array}{l}\text { ROW generally clean } \\
\text { with only a few pieces } \\
\text { of litter or debris visible } \\
\text { at posted speeds. }\end{array}$ & $\begin{array}{l}\text { ROW acceptable } \\
\text { with one or two } \\
\text { objectionable spots } \\
\text { of litter or debris. } \\
\text { Several single pieces } \\
\text { of litter, or debris. } \\
\end{array}$ & $\begin{array}{l}\text { ROW unacceptable, with } \\
\text { much litter or debris. }\end{array}$ & $\begin{array}{l}\text { ROW totally } \\
\text { unacceptable with large } \\
\text { quantities of litter or } \\
\text { debris. }\end{array}$ \\
\hline $\begin{array}{l}\text { Drainage } \\
\text { (Do not rate } \\
\text { in } \mathrm{C} / \mathrm{G} \\
\text { section) }\end{array}$ & $\begin{array}{l}\text { Ditches and } \\
\text { channels like } \\
\text { originally } \\
\text { constructed, } \\
\text { clear of silt or } \\
\text { erosion. } \\
\text { Vegetation as } \\
\text { appropriates in } \\
\text { ditches. No high } \\
\text { shoulders }\end{array}$ & $\begin{array}{l}\text { Ditches and channels } \\
\text { like originally } \\
\text { constructed may have } \\
\text { minor silt or erosion. } \\
\text { Vegetation as } \\
\text { appropriates in ditches. } \\
\text { Minor spots of high } \\
\text { shoulders }\end{array}$ & $\begin{array}{l}\text { Ditches and channels } \\
\text { like originally } \\
\text { constructed, may } \\
\text { have some silt or } \\
\text { erosion (pipes } 50 \% \\
\text { full). Vegetation as } \\
\text { appropriates in } \\
\text { ditches. Several areas } \\
\text { of high shoulders }\end{array}$ & $\begin{array}{l}\text { Substantial erosion or } \\
\text { siltation in ditches or } \\
\text { channels. Does not function } \\
\text { as designed. Potential exists } \\
\text { for additional erosion. High } \\
\text { shoulders may trap water on } \\
\text { pavement. Washouts around } \\
\text { culverts, bridges and etc. }\end{array}$ & $\begin{array}{l}\text { Extreme erosion or } \\
\text { siltation in ditches or } \\
\text { channels. Does not } \\
\text { function as designed. } \\
\text { Potential exists for } \\
\text { additional erosion. } \\
\text { Erosion has created a } \\
\text { safety hazard. High } \\
\text { shoulders may trap } \\
\text { water in travel lanes. }\end{array}$ \\
\hline \multicolumn{6}{|l|}{$\begin{array}{l}\text { Embank- } \\
\text { ment }\end{array}$} \\
\hline $\begin{array}{l}\text { Public } \\
\text { Rating }\end{array}$ & $\begin{array}{l}\text { All required } \\
\text { signs straight } \\
\text { and clean, no } \\
\text { litter, vegetation } \\
\text { of uniform } \\
\text { height, }\end{array}$ & $\begin{array}{l}\text { Few signs may be } \\
\text { leaning slightly, minor } \\
\text { litter, vegetation of } \\
\text { uniform height }\end{array}$ & $\begin{array}{l}\text { Non required signs } \\
\text { missing, minor litter, } \\
\text { vegetation borderline } \\
\text { with small amount of } \\
\text { noxious weeds. }\end{array}$ & $\begin{array}{l}\text { Missing required signs, lot of } \\
\text { litter, vegetation needs } \\
\text { mowing and/or herbicide } \\
\text { work. }\end{array}$ & $\begin{array}{l}\text { Signing faded and } \\
\text { leaning, or missing } \\
\text { regulatory signs, } \\
\text { unacceptable amount of } \\
\text { litter on shoulders and } \\
\text { roadside, vegetation } \\
\text { totally unacceptable. }\end{array}$ \\
\hline
\end{tabular}




\begin{tabular}{|c|c|c|c|c|c|}
\hline $\begin{array}{l}\text { Vegetation } \\
\text { Manage- } \\
\text { ment }\end{array}$ & 5 & 4 & 3 & 2 & 1 \\
\hline $\begin{array}{l}\text { Mowing* } \\
\text { *excluding } \\
\text { designated } \\
\text { non-mow } \\
\text { areas. }\end{array}$ & $\begin{array}{l}\text { Vegetation } \\
\text { maintained } \\
\text { within the height } \\
\text { range specified } \\
\text { in contract. No } \\
\text { evidence of } \\
\text { roostertails or } \\
\text { swirled stubble, } \\
\text { or decaying } \\
\text { weed stubble } \\
\text { present. }\end{array}$ & $\begin{array}{l}\text { Vegetation maintained } \\
\text { within the height range } \\
\text { specified in contract. No } \\
\text { visible evidence of } \\
\text { roostertails or swirled } \\
\text { stubble. }\end{array}$ & $\begin{array}{l}\text { Vegetation } \\
\text { maintained within the } \\
\text { height range } \\
\text { specified in contract. } \\
\text { Visible evidence of } \\
\text { roostertails, swirled } \\
\text { stubble. }\end{array}$ & $\begin{array}{l}\text { Less than } 40 \% \text { of vegetation } \\
\text { taller than maximum } \\
\text { allowable height in contract, } \\
\text { or vegetation has been } \\
\text { mowed shorter than minimum } \\
\text { allowable height in specified } \\
\text { in contract. }\end{array}$ & $\begin{array}{l}40 \% \text { or more vegetation } \\
\text { taller than maximum } \\
\text { allowable height by } \\
\text { contract. }\end{array}$ \\
\hline $\begin{array}{l}\text { Vegetation } \\
\text { Control }\end{array}$ & $\begin{array}{l}\text { No more than } 5 \\
\text { areas per lane } \\
\text { mile actively } \\
\text { growing } \\
\text { vegetation. }\end{array}$ & $\begin{array}{l}\text { Between } 6 \text { and } 15 \text { areas } \\
\text { per lane mile with } \\
\text { actively growing weeds. } \\
\text { No obstruction of } \\
\text { guardrail or sight } \\
\text { distance from roadway. }\end{array}$ & $\begin{array}{l}\text { More than } 20 \text { areas } \\
\text { per lane mile with } \\
\text { actively growing } \\
\text { weeds. No } \\
\text { obstruction of } \\
\text { guardrail or sight } \\
\text { distance from } \\
\text { roadway. }\end{array}$ & $\begin{array}{l}\text { Unacceptable with large } \\
\text { amounts of actively } \\
\text { vegetation growing in } \\
\text { intermitted stands. } \\
\text { Obstruction of guardrail or } \\
\text { sight distance from roadway. }\end{array}$ & $\begin{array}{l}\text { Totally unacceptable } \\
\text { with large amounts of } \\
\text { actively growing } \\
\text { vegetation in solid } \\
\text { stands. Obstruction of } \\
\text { guardrail or sight } \\
\text { distance from roadway. }\end{array}$ \\
\hline $\begin{array}{l}\text { Noxious } \\
\text { Weed } \\
\text { Control }\end{array}$ & $\begin{array}{l}\text { No more than } 5 \\
\text { areas per lane } \\
\text { mile with } \\
\text { actively growing } \\
\text { weeds. No } \\
\text { obstruction of } \\
\text { fixtures or sight } \\
\text { distance from } \\
\text { roadway. }\end{array}$ & $\begin{array}{l}\text { Between } 6 \text { and } 15 \text { areas } \\
\text { per lane mile with } \\
\text { actively growing weeds. } \\
\text { No obstruction of } \\
\text { fixtures or sight distance } \\
\text { from roadway. }\end{array}$ & $\begin{array}{l}\text { More than } 20 \text { areas } \\
\text { per lane mile with } \\
\text { actively growing } \\
\text { weeds. No } \\
\text { obstruction of } \\
\text { fixtures or sight } \\
\text { distance from } \\
\text { roadway. }\end{array}$ & $\begin{array}{l}\text { Unacceptable with large } \\
\text { amounts of weeds growing in } \\
\text { intermitted stands. } \\
\text { Obstruction of fixtures or } \\
\text { sight distance from roadway. }\end{array}$ & $\begin{array}{l}\text { Totally unacceptable } \\
\text { with large amounts of } \\
\text { weeds growing in solid } \\
\text { stands. Obstruction of } \\
\text { fixtures or sight distance } \\
\text { from roadway, complete } \\
\text { vegetation kill around } \\
\text { fixtures, or herbicide } \\
\text { damage to desirable } \\
\text { vegetation. }\end{array}$ \\
\hline $\begin{array}{l}\text { Brush } \\
\text { Control* } \\
\text { *within } 30 \\
\text { foot clear } \\
\text { zone. }\end{array}$ & $\begin{array}{l}1 \text { to } 5 \text { areas per } \\
\text { lane mile of } \\
\text { actively growing } \\
\text { brush. }\end{array}$ & $\begin{array}{l}\text { Between } 6 \text { to } 10 \text { areas } \\
\text { per lane mile of actively } \\
\text { growing brush. }\end{array}$ & $\begin{array}{l}\text { More than } 10 \text { areas } \\
\text { per lane mile of } \\
\text { actively growing } \\
\text { brush. No obstruction } \\
\text { of fixtures or sight } \\
\text { distance from } \\
\text { roadway. }\end{array}$ & $\begin{array}{l}\text { Unacceptable with large } \\
\text { amounts of brush growing in } \\
\text { intermitted stands. } \\
\text { Obstruction of fixtures or } \\
\text { sight distance from roadway. }\end{array}$ & $\begin{array}{l}\text { Totally unacceptable } \\
\text { with actively growing } \\
\text { brush growing in solid } \\
\text { stands obstructing signs, } \\
\text { fixtures, or sight } \\
\text { distance. }\end{array}$ \\
\hline
\end{tabular}

The following items are excluded from the PBC in Texas:

(a) Roadside Assistance

(b) Intelligent Transportation System devices (such as cameras, permanent changeable message signs, Automatic Vehicle Identification readers/antennae, etc.)

(c) Executing Agreements, such as utility permits, driveway permits, Multiple Use Agreements, construction and maintenance agreements, and other similar type agreements

(d) Logo signing and Graffiti Removal

(e) Rest and Picnic Areas

(g) Pavement Markings and Raised Pavement Markers

(i) Drainage

(j) Highway Sweeping, Traffic signals and Channels 


\section{Appendix E}

VDOT Performance Standards

VDOT Performance Criteria

\begin{tabular}{|c|c|c|c|c|}
\hline ASSET & OUTCOME & $\begin{array}{c}\text { TARGET } \\
(\%)\end{array}$ & TOLERANCE \& CRITERIA & UOM \\
\hline \multicolumn{5}{|c|}{ ROADSIDE ASSET GROUP } \\
\hline Vegetation & $\begin{array}{c}\text { Healthy } \\
\text { Growing } \\
\text { Neat appearance } \\
\text { Acceptable } \\
\text { coverage } \\
\text { Proper sight } \\
\text { distance }\end{array}$ & 90 & $\begin{array}{l}\text { - }<10 \% \text { of mowable area to exceed } 12^{\prime \prime} \text { in height (unless } \\
\text { otherwise noted) } \\
\text { - All sight distances are clear } \\
\text { - Neat / trimmed around guardrail, headwalls, paved ditches, } \\
\text { signs and other fixed objects } \\
\text { - }<10 \% \text { bare ground per } 10^{\text {th }} \text { mile section } \\
\text { - No cut less than } 4 \text { " in height } \\
\text { - No invasive species in mowable areas ( Canadian Thistle, } \\
\text { - Litter pickup shall occur in advance of each mowing cycle } \\
\text { - Prevent the growth of unwanted weeds, grass, brush and trees } \\
\text { Timeliness Requirement: } \\
\text { - Vegetation affecting sight distance presenting a safety hazard } \\
\text { shall be removed within } 24 \text { hours of notification or discovery. }\end{array}$ & Acre \\
\hline Brush \& Trees & $\begin{array}{l}\text { No hazardous trees } \\
\text { Unobstructed sight } \\
\text { distance } \\
\text { Vertical clearance } \\
\text { Structure } \\
\text { inspection \& } \\
\text { repairs } \\
\text { unobstructed }\end{array}$ & 90 & $\begin{array}{l}\text { - No trees or brush affecting sight distance } \\
\text { - Vertical clearance of } 20^{\prime} \text { over roadway (includes shoulders) } \\
\text { - No leaning or dead trees that present a hazard } \\
\text { - No brush or trees that affect the inspection or repair of bridges } \\
\text { - or other structures } \\
\text { - No brush or trees that affect utility company reading or } \\
\text { inspection } \\
\text { Timeliness Requirement: } \\
\text { - Trees/brush affecting sight distance to regulatory signs and/or } \\
\text { creating safety hazard shall be removed within } 48 \text { hours of } \\
\text { notification }\end{array}$ & Acre \\
\hline Debris \& Road kill & $\begin{array}{l}\text { Roadway free of } \\
\text { debris \& road kill } \\
\text { No dump sites }\end{array}$ & 100 & $\begin{array}{l}\text { - No dump sites on right-of-way } \\
\text { - Debris and Road kill promptly removed from the right-of-way }\end{array}$ & Each \\
\hline
\end{tabular}




\begin{tabular}{|c|c|c|c|c|}
\hline ASSET & OUTCOME & $\begin{array}{c}\text { TARGET } \\
(\%)\end{array}$ & TOLERANCE \& CRITERIA & UOM \\
\hline & & & $\begin{array}{l}\text { and properly disposed } \\
\text { Owner of household pets to be notified if identification is } \\
\text { available } \\
\text { Timeliness Requirement: } \\
\text { - Contractor shall respond immediately upon notification or } \\
\text { discovery, } 30 \text { minute response time during normal work hours } \\
\text { and } 60 \text { minute response time outside normal work hours }\end{array}$ & \\
\hline Litter & $\begin{array}{c}\text { Right-of-way neat } \\
\& \text { attractive }\end{array}$ & 90 & $\begin{array}{l}\text { - }<20 \text { items per } 10^{\text {th }} \text { mile section } \\
\text { Timeliness Requirement: } \\
\text { - Contractor shall to respond locations of excessive litter } \\
\text { immediately upon notification or discovery within } 24 \text { hours. }\end{array}$ & Acre \\
\hline $\begin{array}{l}\text { Landscaping, Wildflowers } \\
\text { Beds, Bulb Beds, } \\
\text { Ornamental Shrub Beds }\end{array}$ & $\begin{array}{c}\text { Neat } \\
\text { Attractive } \\
\text { Growing }\end{array}$ & 90 & $\begin{array}{l}\text { Bulb beds } \\
\text { - }<10 \% \text { of bed contains weeds } \\
\text { - Bed is mulched } \\
\text { - }<10 \% \text { of bed not growing } \\
\text { Ornamental / Shrub beds } \\
\text { - neat appearance and pruned } \\
\text { Wildflower beds } \\
\text { - }<10 \% \text { of bed contains weeds } \\
\text { - }<10 \% \text { of bed not growing }\end{array}$ & Acre \\
\hline Illegal signs/ structures & $\begin{array}{l}\text { Right-of-way free } \\
\text { of illegal signs or } \\
\text { structures }\end{array}$ & 100 & $\begin{array}{l}\text { - No illegal signs on the right-of-way } \\
\text { - No illegal structures on the right-of-way } \\
\text { Timeliness Requirement } \\
\text { - Contractor shall remove illegal signs/structures within } 72 \text { hours } \\
\text { of notification or discovery. }\end{array}$ & Each \\
\hline Concrete Barriers & $\begin{array}{c}\text { Safe } \\
\text { Structurally sound }\end{array}$ & 90 & $\begin{array}{l}\text { - Free of vegetation } \\
\text { - }<10 \% \text { joint material damaged or missing } \\
\text { Timeliness Requirement: } \\
\text { - Damaged or misaligned barriers due to accidents/ incidents } \\
\text { shall be mitigated immediately upon notification or discovery }\end{array}$ & Each \\
\hline
\end{tabular}




\begin{tabular}{|c|c|c|c|c|}
\hline ASSET & OUTCOME & $\begin{array}{c}\text { TARGET } \\
(\%)\end{array}$ & TOLERANCE \& CRITERIA & UOM \\
\hline & & & $\begin{array}{l}\text { or before accident scene is cleared } \\
\text { - Repairs to barriers shall be completed within } 10 \text { days of } \\
\text { notification or discovery }\end{array}$ & \\
\hline Sound Barriers & $\begin{array}{l}\text { Structurally sound } \\
\text { Functional }\end{array}$ & 90 & $\begin{array}{l}\text { - Free of damaging vegetation } \\
\text { Timeliness Requirement: } \\
\text { - Damaged or misaligned barriers due to accidents/ incidents } \\
\text { shall be mitigated immediately upon notification or discovery } \\
\text { or before accident scene is cleared. } \\
\text { - A plan for repairs to barriers shall be completed within } 10 \\
\text { days of notification or discovery }\end{array}$ & LFT \\
\hline Slopes & $\begin{array}{c}\text { Stable } \\
\text { No erosion }\end{array}$ & 90 & $\begin{array}{l}\text { - }<8 \text { " deep erosion } \\
\text { - No pattern of erosion that endangers the stability of the slope } \\
\text { - }<105 \text { feet greater than } 2 \text { "lower than paved shoulder within } .1 \\
\text { mile sample unit } \\
\text { - }<105 \text { feet greater than } 2 \text { " higher than paved shoulder within } .1 \\
\text { mile sample unit } \\
\text { Timeliness Requirement: } \\
\text { - Any safety hazard that results from a sink hole, slide, high slope } \\
\text { or low slope areas shall be mitigated immediately. } \\
\text { - Repairs to sink holes and slides shall be completed within in } 7 \\
\text { days of notification or Discovery. } \\
\text { - High and or low slope areas shall be repaired within } 30 \text { days. }\end{array}$ & LFT \\
\hline Fence & $\begin{array}{l}\text { Functional } \\
\text { Structurally sound }\end{array}$ & 90 & $\begin{array}{l}\text { - }<10 \% \text { fence in need of repair } \\
\text { - No damage that allows access } \\
\text { Timeliness Requirement: } \\
\text { - Any damaged or fallen fencing holding livestock must be } \\
\text { replaced/repaired with in } 24 \text { hours after notification or discovery. }\end{array}$ & LFT \\
\hline
\end{tabular}




\begin{tabular}{|c|c|c|c|c|}
\hline ASSET & OUTCOME & $\begin{array}{c}\text { TARGET } \\
(\%)\end{array}$ & TOLERANCE \& CRITERIA & UOM \\
\hline $\begin{array}{l}\text { Crossovers/Police Parking } \\
\text { Locations }\end{array}$ & $\begin{array}{c}\text { Safe } \\
\text { Functional }\end{array}$ & 95 & $\begin{array}{l}\text { - Properly signed if open } \\
\text { - Properly signed / blocked if restricted access } \\
\text { - Pree of potholes } \\
\text { - Properly maintained driving surface (as constructed) }\end{array}$ & Each \\
\hline Retaining Walls & $\begin{array}{l}\text { Structurally sound } \\
\text { Safe } \\
\text { Clean } \\
\text { Stable }\end{array}$ & 90 & $\begin{array}{l}\text { - Free of vegetation } \\
\text { - } \text { Weep holes open } \\
\text { - No damaged or missing parts } \\
\text { - Joint components free of rust joint material intact } \\
\end{array}$ & Each \\
\hline \multicolumn{5}{|c|}{ DRAINAGE ASSET GROUP } \\
\hline $\begin{array}{l}\text { Pipes \& Box Culverts ( } \leq \\
36 \text { sq. ft.) }\end{array}$ & $\begin{array}{l}\text { Structurally Sound } \\
\text { Open \& Drains } \\
\text { Joints intact } \\
\text { Functional } \\
\text { Free of damage }\end{array}$ & 90 & $\begin{array}{l}\text { - }<10 \% \text { diameter closed } \\
\text { - No separated joints } \\
\text { - }<1 \text { missing joint material } \\
\text { - End walls \& end section intact and free of damage (includes } \\
\text { load carrying grates) } \\
\text { Timeliness Requirement: } \\
\text { - Culverts or structures beyond } 50 \% \text { diameter closed shall be } \\
\text { cleaned and opened within } 30 \text { days } \\
\text { - Culverts/structures structurally near collapse as determined by } \\
\text { the VDOT Structure \& Bridge Engineer shall be mitigated } \\
\text { immediately }\end{array}$ & Each \\
\hline $\begin{array}{l}\text { Pipes \& Box Culverts (> } 36 \\
\text { sq. ft.) }\end{array}$ & $\begin{array}{l}\text { Structurally Sound } \\
\text { Open \& Drains } \\
\text { Joints intact } \\
\text { Functional } \\
\text { Free of damage }\end{array}$ & 90 & $\begin{array}{l}\text { - }<10 \% \text { diameter closed } \\
\text { - No missing joints material } \\
\text { - Free of damaging vegetation } \\
\text { - End walls \& end sections intact and free of damage (includes } \\
\text { load carrying grates) } \\
\text { Timeliness Requirement: } \\
\text { - Culverts or structures beyond } 50 \% \text { diameter closed shall be } \\
\quad \text { cleaned within } 30 \text { days }\end{array}$ & Each \\
\hline
\end{tabular}




\begin{tabular}{|c|c|c|c|c|}
\hline ASSET & OUTCOME & $\begin{array}{c}\text { TARGET } \\
(\%)\end{array}$ & TOLERANCE \& CRITERIA & UOM \\
\hline & & & $\begin{array}{l}\text { - Culverts/structures structurally near collapse as determined by } \\
\text { the VDOT Structure \& Bridge Engineer shall be mitigated } \\
\text { immediately }\end{array}$ & \\
\hline Ditches, Paved & $\begin{array}{l}\text { Structurally sound } \\
\text { Joints intact } \\
\text { Open \& Drains }\end{array}$ & 90 & $\begin{array}{l}\text { - } \quad<2 \text { inches settlement \& joints intact. } \\
\text { - No undermining or undercutting } \\
\text { - } \quad<25 \% \text { spalling of surface area } \\
\text { - No damaged or missing sections (includes energy dissipaters) } \\
\text { Timeliness Requirement: } \\
\text { - Open complete blockages and abate significant erosion } \\
\text { immediately upon discovery or notification } \\
\text { - Clean debris or remove vegetation impeding flow to clear flow } \\
\text { - Dines within } 90 \text { days from notification or discovery } \\
\text { notification or discovery unless flow is impaired refer to the } \\
\text { above for timeframes }\end{array}$ & LFT \\
\hline Ditches, Unpaved & $\begin{array}{l}\text { Open \& Drains } \\
\text { Minimal Erosion }\end{array}$ & 90 & $\begin{array}{l}\text { - No water ponding } \\
\text { - No erosion }>6 \text { " deep } \\
\text { Timeliness Requirement: } \\
\text { - Open complete blockages and abate significant eroision } \\
\text { immediately upon discovery or notification } \\
\text { - Clean debris or remove vegetation to clear flow lines within } 90 \\
\text { days from notification or discovery }\end{array}$ & LFT \\
\hline $\begin{array}{l}\text { Under drains \& Edge } \\
\text { drains }\end{array}$ & $\begin{array}{l}\text { Structurally Sound } \\
\text { Functional }\end{array}$ & 90 & $\begin{array}{l}\text { - }<10 \% \text { damage or deterioration to outlet pipe } \\
\text { - } \quad<10 \% \text { blockage of pipe or end protection } \\
\text { No damaged or missing end protection (includes rodent } \\
\text { screen) }\end{array}$ & Each \\
\hline Storm Drains \& Drop & Structurally sound & 90 & - No damage or missing parts ( includes steps, grate, cover \& & Each \\
\hline
\end{tabular}




\begin{tabular}{|c|c|c|c|c|}
\hline ASSET & OUTCOME & $\begin{array}{c}\text { TARGET } \\
(\%)\end{array}$ & TOLERANCE \& CRITERIA & UOM \\
\hline Inlets & Functional & & $\begin{array}{l}\text { throat) } \\
\text { - No obstructions ( }<10 \% \text { of opening) (includes top, throat \& } \\
\text { drop inlet) } \\
\text { Timeliness Requirement: } \\
\text { - Storm Drains and Drop Inlets beyond } 50 \% \text { closed shall be } \\
\text { cleaned within } 30 \text { days } \\
\text { - Safety issues shall be mitigated immediately }\end{array}$ & \\
\hline $\begin{array}{l}\text { Curb \& Gutter, Curbing } \\
\text { Raised, Concrete Median }\end{array}$ & $\begin{array}{c}\text { In line } \\
\text { Draining } \\
\text { Structurally sound }\end{array}$ & 90 & $\begin{array}{l}\text { - No obstruction which impedes the flow of water } \\
\text { - } \quad<25 \% \text { of surface area spalling } \\
\text { - No damaged or missing section } \\
\text { - Joints and joint material intact } \\
\end{array}$ & LFT \\
\hline $\begin{array}{l}\text { Storm water Management } \\
\text { Ponds }\end{array}$ & $\begin{array}{c}\text { Safe } \\
\text { Structurally sound } \\
\text { Functional }\end{array}$ & 90 & $\begin{array}{l}\text { - No damage to stem pipes, weirs, grates, drainage tubing or } \\
\text { debris racks } \\
\text { - Free of debris (stem pipes, weirs, grates, drainage tubing \& } \\
\text { debris racks) } \\
\text { - No vegetation that affects the function (mowed, sprayed) } \\
\text { - No fence missing or damaged (if present at start of contract) } \\
\text { Timeliness Requirement: } \\
\text { - Inspection once every six months and after every significant } \\
\text { storm event (documentation shall be maintained according to } \\
\text { applicable state regulations) } \\
\text { - All deficiencies reported or discovered shall be corrected } \\
\text { within } 45 \text { days. }\end{array}$ & Each \\
\hline \multicolumn{5}{|c|}{ TRAFFIC ASSET GROUP } \\
\hline Signs - Post Mounted & $\begin{array}{l}\text { Meets Reflectivity } \\
\text { Standards } \\
\text { Clean \& Clear } \\
\text { Free of Damage }\end{array}$ & 95 & $\begin{array}{l}\text { - Meets current reflectivity standards, as updated (replacements) } \\
\text { - Reflective at } 120^{\prime} \text { day or night } \\
\text { - Surface clean \& legible } \\
\text { - holes) } \\
\text { - No down or missing signs } \\
\end{array}$ & Each \\
\hline
\end{tabular}




\begin{tabular}{|c|c|c|c|c|}
\hline ASSET & OUTCOME & $\begin{array}{c}\text { TARGET } \\
(\%)\end{array}$ & TOLERANCE \& CRITERIA & UOM \\
\hline & & & $\begin{array}{l}\text { - Mile markers are at least } 60 \text { to achieve uniform appearance } \\
\text { Timeliness Requirement: } \\
\text { - Damaged Regulatory / Warning signs shall be mitigated } \\
\text { immediately upon notification or discovery } \\
\text { - Damaged Regulatory / Warning signs shall be repaired or } \\
\text { replaced within } 2 \text { days of notification or discovery. } \\
\text { - All other signs repaired or replaced within } 30 \text { days of } \\
\text { notification or discovery. }\end{array}$ & \\
\hline $\begin{array}{l}\text { Signs - Overhead and } \\
\text { Bridge Mounted }\end{array}$ & $\begin{array}{l}\text { Structurally Sound } \\
\text { Meets Reflectivity } \\
\text { standards } \\
\text { Free of Damage }\end{array}$ & 90 & $\begin{array}{l}\text { - Meets current reflectivity standards, as updated (replacements) } \\
\text { - Reflective at } 120^{\circ} \text { day or night } \\
\text { - Surface clean \& legible } \\
\text { - holes) } \\
\text { - No damage to surface of sign (scratches, dents, bullet } \\
\text { - Structure \& support areas kept free of dirt \& debris... (clean \& } \\
\text { - flush) } \\
\text { VDOT Structure Report shall be used for other maintenance } \\
\text { needs. } \\
\text { Timeliness Requirement: } \\
\text { - Damaged sign structures shall be mitigated immediately upon } \\
\text { notification or discovery } \\
\text { - Damaged sign structures shall be repaired within } 60 \text { days of } \\
\text { notification or discovery } \\
\text { - Damaged signs shall be repaired or replaced within } 60 \text { days }\end{array}$ & Each \\
\hline Pavement Markings & $\begin{array}{c}\text { Present } \\
\text { Reflective }\end{array}$ & 90 & $\begin{array}{l}\text { - }<10 \% \text { damaged or missing due to incidents, patching } \\
\text { operations, or snow removal operations } \\
\text { - }<10 \% \text { covered by debris } \\
\text { - All markings to be VDOT approved durable, high quality } \\
\text { materials }\end{array}$ & LFT \\
\hline $\begin{array}{l}\text { Pavement Markers (Raised } \\
\text { \& Recessed) }\end{array}$ & $\begin{array}{c}\text { Present } \\
\text { Reflective }\end{array}$ & 90 & $\begin{array}{l}\text { - } \quad<30 \% \text { missing or damaged within a tenth mile section } \\
\text { - Meets reflectivity standards } \\
\text { - Missing pavement marker lenses shall be repaired or replaced } \\
\text { Timeliness Requirement } \\
\text { - Pavement markers that present a hazard shall be removed }\end{array}$ & Each \\
\hline
\end{tabular}




\begin{tabular}{|c|c|c|c|c|}
\hline ASSET & OUTCOME & $\begin{array}{c}\text { TARGET } \\
(\%)\end{array}$ & TOLERANCE \& CRITERIA & UOM \\
\hline & & & immediately & \\
\hline Pavement Messages & $\begin{array}{c}\text { Present } \\
\text { Reflective }\end{array}$ & 90 & $\begin{array}{ll}\text { - } & <10 \% \text { damaged } \\
\text { - } & <10 \% \text { covered by debris } \\
\text { - } & \text { Meets reflectivity standards }\end{array}$ & Each \\
\hline Lighting - Roadway & $\begin{array}{c}\text { Operational } \\
\text { Structurally sound }\end{array}$ & 90 & $\begin{array}{l}\text { - Conventional Lighting (single bulb structure): Working at all } \\
\text { times } \\
\text { - High Mast Lighting: }>50 \% \text { of bulbs per structure working at } \\
\text { all times } \\
\text { - No damaged or missing parts } \\
\text { - VDOT Structure Report shall be used for other maintenance } \\
\text { needs } \\
\text { Timeliness Requirement: } \\
\text { - Damaged or non - functional lights/ structures shall be } \\
\text { repaired or replaced within } 7 \text { days of notification or discovery }\end{array}$ & Each \\
\hline Lighting - Sign & $\begin{array}{c}\text { Operational } \\
\text { Structurally sound }\end{array}$ & 90 & $\begin{array}{l}\text { - No damaged or missing parts } \\
\text { - nDOT Structure Report shall be used for other maintenance } \\
\text { - Properly Working at all times, with no more than } 30 \% \text { of } \\
\text { bulbs, per structure in non-functional condition } \\
\text { Timeliness Requirement: } \\
\text { - Non- functional lights shall be repaired or replaced within } 7 \\
\text { days of notification or discovery }\end{array}$ & Each \\
\hline Lighting - Under deck & $\begin{array}{l}\text { Operational } \\
\text { Safe }\end{array}$ & 90 & $\begin{array}{l}\text { - No damaged or missing parts } \\
\text { Properly working at all times, with no more than } 30 \% \text { of the } \\
\text { bulbs, per structure in non-functional condition. } \\
\text { Timeliness Requirement: } \\
\text { - Non- functional lights shall be repaired or replaced within } 7 \\
\text { days of notification or discovery }\end{array}$ & Each \\
\hline $\begin{array}{l}\text { Lights - Warning, Bridge } \\
\text { Mounted Navigation, anti- } \\
\text { collision }\end{array}$ & $\begin{array}{c}\text { Operational } \\
\text { Structurally sound }\end{array}$ & 100 & $\begin{array}{l}\text { - Functional at all times } \\
\text { Timeliness Requirement: } \\
\text { - Repair or replace within } 24 \text { hours of notification or discovery }\end{array}$ & Each \\
\hline
\end{tabular}




\begin{tabular}{|c|c|c|c|c|}
\hline ASSET & OUTCOME & $\begin{array}{c}\text { TARGET } \\
(\%)\end{array}$ & TOLERANCE \& CRITERIA & UOM \\
\hline Guardrail & $\begin{array}{l}\text { Functional } \\
\text { Undamaged }\end{array}$ & 100 & $\begin{array}{l}\text { - No damage or rust that affects the structural integrity, no } \\
\text { missing damaged post } \\
\text { - No loose or missing parts } \\
\text { - No cables loose or improperly secured } \\
\text { - Meets NCHRP } 350 \text { standards } \\
\text { Timeliness Requirement: } \\
\text { - Badly damaged guardrail shall be mitigated immediately upon } \\
\text { notification or discovery } \\
\text { - Badly damaged guardrail shall be repaired or replaced within } 3 \\
\text { days of notification or discovery. } \\
\text { - Damaged but functional guardrail shall be repaired or replaced } \\
\text { within } 7 \text { days of notification or discovery }\end{array}$ & LFT \\
\hline Impact Attenuators & $\begin{array}{l}\text { Functional } \\
\text { Undamaged }\end{array}$ & 100 & $\begin{array}{l}\text { - No damaged or missing parts } \\
\text { Timeliness Requirement: } \\
\text { - Damaged attenuators shall be mitigated immediately upon } \\
\text { notification or discovery or discovery. } \\
\text { - Damaged attenuators shall be repaired within } 7 \text { days and/ or } \\
\text { replaced within } 30 \text { days of notification or discovery or } \\
\text { discovery. }\end{array}$ & Each \\
\hline $\begin{array}{l}\text { Object Markers \& } \\
\text { Delineators }\end{array}$ & $\begin{array}{l}\text { Present } \\
\text { Reflective } \\
\text { Functional }\end{array}$ & 90 & $\begin{array}{l}\text { - }<10 \% \text { missing or damaged parts } \\
\text { - Post mounted delineator height } 4 \text { foot ( }+/-6 \text { inches to achieve } \\
\text { uniform appearance) mileage markers are at least } 60 \text { " to } \\
\text { achieve uniform appearance. } \\
\text { - Meets reflectivity standards }\end{array}$ & Each \\
\hline Glare Foils & $\begin{array}{l}\text { Present } \\
\text { Functional }\end{array}$ & 90 & $\begin{array}{l}\text { - }<10 \% \text { missing or damaged } \\
\text { - Properly mounted } \\
\text { - Uniform in appearance }\end{array}$ & Each \\
\hline \multicolumn{5}{|c|}{ ROADWAY \& SHOULDER ASSET GROUP } \\
\hline Asphalt Surface & $\begin{array}{c}\text { Safe } \\
\text { Durable }\end{array}$ & 95 & $\begin{array}{l}\text { - No potholes } \\
\text { - Patches }-<1 / 2 \text { " higher or lower than surrounding pavement }\end{array}$ & Sq. Ft \\
\hline
\end{tabular}




\begin{tabular}{|c|c|c|c|c|}
\hline ASSET & OUTCOME & $\begin{array}{c}\text { TARGET } \\
(\%)\end{array}$ & TOLERANCE \& CRITERIA & UOM \\
\hline & Smooth & & $\begin{array}{l}\text { - No pavement obstructions that present a safety hazard } \\
\text { Timeliness Requirement } \\
\text { - Temporary repairs to potholes } 6 \text { " } 6 \text { " } 61 \frac{1 / 2 \text { " deep or larger }}{\text { shall be repaired immediately upon notification or discovery. }} \\
\text { All others within } 2 \text { days of notification or discovery } \\
\text { - Permanent repairs to potholes/ pavement failures shall be } \\
\text { completed within } 30 \text { days of notification or discovery during } \\
\text { seasons when asphalt plants are operating or within } 30 \text { days of } \\
\text { asphalt plants opening for the season } \\
\text { - Pavement obstructions that present a safety hazard shall be } \\
\text { mitigated immediately }\end{array}$ & \\
\hline $\begin{array}{l}\text { Paved Shoulders and } \\
\text { Rumble Strips (Asphalt) }\end{array}$ & $\begin{array}{c}\text { Safe } \\
\text { Smooth } \\
\text { Functional }\end{array}$ & 90 & $\begin{array}{l}\text { - No potholes } \\
\text { - }<105 \text { linear feet edge drop off high or low }>11 \frac{112 "}{2} \text { linear feet separation }>1 / 2 \text { " wide } \\
\text { - No false ditch or build up on shoulder that causes water to } \\
\text { stand on shoulder or drain onto the travel lanes } \\
\text { - }<10 \% \text { of rumble strips needs to be sealed } \\
\text { Timeliness Requirement: } \\
\text { - Temporary repairs to potholes }>6 \text { " } \mathrm{X} 6 \text { " } \mathrm{X} 11 / 2 \text { "deep shall be } \\
\text { completed within } 2 \text { days of notification or discovery } \\
\text { - Permanent repairs to potholes shall be completed within } 30 \\
\text { days of notification or discovery during seasons when asphalt } \\
\text { plants are operating or within } 30 \text { days of asphalt plants } \\
\text { opening for the season. }\end{array}$ & Sq. Ft. \\
\hline Unpaved Shoulders & $\begin{array}{l}\text { Safe } \\
\text { Smooth }\end{array}$ & 90 & $\begin{array}{l}\text { - No potholes } \\
\text { - No false ditch or build up on shoulder that causes water to } \\
\text { stand on shoulder or drain onto the travel lanes } \\
\text { - No erosion }>2 \text { " deep } \\
\text { Timeliness Requirement: } \\
\text { - All potholes shall be repaired within } 7 \text { days of notification or } \\
\text { discovery } \\
\text { - Erosion }>2 \text { " deep shall be repaired within } 7 \text { days of }\end{array}$ & Sq. Ft \\
\hline
\end{tabular}




\begin{tabular}{|c|c|c|c|c|}
\hline ASSET & OUTCOME & $\begin{array}{c}\text { TARGET } \\
(\%)\end{array}$ & TOLERANCE \& CRITERIA & UOM \\
\hline & & & notification or discovery & \\
\hline Concrete Surface & $\begin{array}{c}\text { Safe } \\
\text { Durable } \\
\text { Smooth }\end{array}$ & 95 & $\begin{array}{l}\text { - No potholes } \\
\text { - }<10 \% \text { of surface area has cracks }>1 / 4 " \text { wide } \\
\text { - }<25 \% \text { surface area has spalling }>1 \text { " deep } \\
\text { - }<25 \% \text { of joint material missing No grass growing in joint. } \\
\text { - No pavement obstructions that present a safety hazard } \\
\text { Timeliness Requirement: } \\
\text { - Temporary repairs to potholes } 6 " \times 6 \text { " } \times 1 \text { 1/2" deep or larger } \\
\text { shall be repaired immediately upon notification. All others } \\
\text { within } 2 \text { days } \\
\text { - Permanent repairs to potholes/ pavement failures shall be } \\
\text { completed within } 30 \text { days of notification } \\
\text { - Pavement obstructions that present a safety hazard shall be } \\
\text { mitigated immediately. }\end{array}$ & $\begin{array}{l}\text { Sq. } \\
\text { Ft }\end{array}$ \\
\hline \multicolumn{5}{|c|}{ BRIDGE ASSET GROUP } \\
\hline Deck & $\begin{array}{c}\text { Safe } \\
\text { Structurally Sound } \\
\text { Free of Dirt/ } \\
\text { Debris }\end{array}$ & 90 & $\begin{array}{l}\text { - Perform all routine/ordinary maintenance including sweeping, } \\
\text { washing and cleaning. } \\
\text { - No potholes } \\
\text { - } \leq 10 \% \text { surface area spalling }>1 \text { " deep } \\
\text { - Temporary patches }-<1 / 2 \text { " higher or lower than surrounding } \\
\text { concrete deck surface } \\
\text { - Joints intact } \\
\text { - No damaged or missing bridge railings. Railings are intact } \\
\text { and connections are tight } \\
\text { - Drains/ scuppers open and functional } \\
\text { - The deck is free of foreign material (grass, stones, limbs, trash, } \\
\text { etc.) } \\
\text { - Joints are clean and joint material is present and functioning as } \\
\text { designed. } \\
\text { - Drainage system (drains, scuppers, trough, etc) is clean and } \\
\text { functioning as designed. } \\
\text { - VDOT Structure Report shall be reference for other routine } \\
\text { maintenance and minor repair needs }\end{array}$ & Sq. Ft \\
\hline
\end{tabular}




\begin{tabular}{|c|c|c|c|c|}
\hline ASSET & OUTCOME & $\begin{array}{c}\text { TARGET } \\
(\%)\end{array}$ & TOLERANCE \& CRITERIA & UOM \\
\hline & & & $\begin{array}{l}\text { Timeliness Requirement: } \\
\text { - Temporary repairs to potholes } 6 \text { " } \times 6 \text { " } \times 1 \text { 1/2" deep or larger } \\
\text { shall be repaired immediately upon notification or discovery. } \\
\text { All others within } 2 \text { days of notification or discovery } \\
\text { - Permanent repairs to potholes shall be completed within } 30 \\
\text { days of notification or discovery and flush with surrounding } \\
\text { surface } \\
\text { - Damaged/ missing bridge railing shall be mitigated } \\
\text { immediately upon notification or discovery } \\
\text { - Damaged/missing railing shall be repaired or replaced within } \\
30 \text { days }\end{array}$ & \\
\hline $\begin{array}{l}\text { Superstructure (Includes } \\
\text { Parapet Walls) }\end{array}$ & $\begin{array}{l}\text { Structurally Sound } \\
\text { Free of Debris }\end{array}$ & 90 & $\begin{array}{l}\text { - Perform all routine/ordinary maintenance including sweeping, } \\
\text { washing, clearing of all obstructions. } \\
\text { - No spalling }>1 \text { " deep } \\
\text { - Bearing assemblies clean and free of debris } \\
\text { - No damaged or missing parts } \\
\text { - Bridge components are free of damaging vegetation. } \\
\text { VDOT Structure Report shall be reference for other routine } \\
\text { maintenance and minor repair needs }\end{array}$ & Sq. Ft \\
\hline Substructure & $\begin{array}{l}\text { Structurally Sound } \\
\text { Free of debris }\end{array}$ & 90 & $\begin{array}{l}\text { - Seats clean and free of debris } \\
\text { - VDOT Structure Report shall be reference for other routine } \\
\text { maintenance and minor repair needs }\end{array}$ & Sq. Ft \\
\hline Slope Protection & $\begin{array}{l}\text { Structurally Sound } \\
\text { Minimal Erosion }\end{array}$ & 90 & $\begin{array}{l}\text { - No trend or pattern of erosion }>2 " \text { deep } \\
\text { - No settlement }>2 " \\
\text { - No damaging vegetation }\end{array}$ & Sq. Ft \\
\hline Weep Holes & Functional & 90 & - $\geq 90 \%$ of diameter open & Each \\
\hline \multicolumn{5}{|c|}{ SERVICES GROUP } \\
\hline $\begin{array}{l}\text { Incident/Emergency } \\
\text { Response }\end{array}$ & $\begin{array}{l}\text { Timely } \\
\text { Efficient } \\
\text { Safe } \\
\text { Effective }\end{array}$ & 100 & $\begin{array}{l}\text { - The contractor shall provide equipment/personnel as } \\
\text { necessary to support EMS operations } 24 \text { hours, } 7 \text { days a week. } \\
\text { - The contractor after arriving on site shall take necessary action } \\
\text { using appropriate resources to handle any and all traffic } \\
\text { control needs to insure the safety of the incident scene and }\end{array}$ & Each \\
\hline
\end{tabular}




\begin{tabular}{|c|c|c|c|c|}
\hline ASSET & OUTCOME & $\begin{array}{c}\text { TARGET } \\
(\%)\end{array}$ & TOLERANCE \& CRITERIA & UOM \\
\hline & & & $\begin{array}{l}\text { traveling public } \\
\text { - The Contractor shall provide proper notification of all } \\
\text { incidents to the Smart Traffic Center } \\
\text { Timeliness Requirement: } \\
\text { - On site response during normal business hours within } 30 \\
\text { minutes of notification or discovery } \\
\text { - On site response after normal business hours, and on } \\
\text { weekends and holidays within } 60 \text { minutes of notification or } \\
\text { discovery } \\
\text { - Temporary lane closures if needed, shall installed immediately } \\
\text { - upon arrival on scene } \\
\text { Permanent lane closures if needed shall be installed within } 60 \\
\text { minutes of arrival on scene }\end{array}$ & \\
\hline Customer Response & $\begin{array}{c}\text { Timely } \\
\text { Efficient } \\
\text { Effective } \\
\text { Productive }\end{array}$ & 100 & $\begin{array}{l}\text { - All customer concerns/ requests shall be resolved to the } \\
\text { Department's satisfaction } \\
\text { Timeliness Requirement: } \\
\text { - Contact the customer within } 2 \text { days following the initial } \\
\text { customer inquiry } \\
\text { - Work resulting from request shall be scheduled within } 2 \text { days } \\
\text { of the initial customer contact } \\
\text { - Follow - up contact within } 3 \text { days of the completion of work }\end{array}$ & Each \\
\hline Snow \& Ice Control & $\begin{array}{c}\text { Safe } \\
\text { Effective } \\
\text { Efficient }\end{array}$ & 100 & $\begin{array}{l}\text { - During Snow/Ice Event, all travel lanes, turn lanes, } \\
\text { intersections and interchanges, and toll plazas shall be kept } \\
\text { free of snow and ice so that traffic can proceed in a safe and } \\
\text { orderly manner without service delay except in periods of } \\
\text { heavy falling or drifting snow and ice throughout the winter } \\
\text { weather event. } \\
\text { Timeliness Requirements } \\
\text { The Following Timeframes are for removal of Precipitation from non } \\
\text { Travel Surface Areas After the Cessation of the Weather Event: } \\
\text { (Included but not limited to Shoulders, Gore Areas, Crossovers) } \\
\text { - } 0 \text { "-4" accumulation (Including Ice and Freezing rain)-Within } 8 \\
\text { hours. }\end{array}$ & Each \\
\hline
\end{tabular}

\begin{tabular}{|c|c|c|c|c|}
\hline ASSET & OUTCOME & $\begin{array}{c}\text { TARGET } \\
(\%)\end{array}$ & TOLERANCE \& CRITERIA & UOM \\
\hline & & & $\begin{array}{l}\text { - }>12 "-18 \text { " accumulation- Within } 24 \text { hours } * * \\
\text { - }>18 \text { " accumulation- Within } 48 \text { hours ** } \\
* * \text { The contractor shall remove piles, mounds, windrows of snow and ice from all } \\
\text { toll plazas } 24 \text { hours after the winter event and after all other contract criteria has } \\
\text { been met }\end{array}$ & \\
\hline Roadway Sweeping & $\begin{array}{l}\text { Neat, Clean } \\
\text { appearance } \\
\text { Free of Debris }\end{array}$ & 90 & $\begin{array}{l}\text { - No debris (sand, gravel, dirt) at barrier walls, retaining walls, } \\
\text { sidewalks, or curb and gutter } \\
\text { - Contractor to provide schedule of planned sweeping } \\
\text { operations. }\end{array}$ & Each \\
\hline Graffiti Removal & None present & 90 & $\begin{array}{l}\text { Timeliness Requirements } \\
\text { - Graffiti to be removed within } 48 \text { hours from notification } \\
\text { or discovery. }\end{array}$ & Each \\
\hline
\end{tabular}


Appendix F

FDOT AM Contract 


\section{SCOPE OF SERVICES \\ HIGHWAY ASSET MAINTENANCE CONTRACT}

(REV. 10-13-2006)

\section{CONTRACT ADMINISTRATION}

\section{Contract Number: E3F65-RO}

Financial Project Number (s): 41583617201

\section{OBJECTIVE}

This performance-based contract requires the management and performance of the maintenance of all components of the transportation facility as identified herein. All maintenance activities the Department's Maintenance Division formerly performed within the limits of this contract are now to be performed by the Contractor, unless otherwise exempted in this contract. Rather than the Department directing specific work as in most traditional maintenance contracts, this performance-based contract requires the Contractor to continually produce a quality product. The Department will continually evaluate the Contractor's quality of work performed and if applicable rules and procedures were followed to achieve results. The Department is entrusting the Contractor to care for and maintain select segments of Florida's State Roads and fully expects the Contractor to take pride in performing a high level of maintenance. The continual quality of the maintenance of the roadways will be a direct reflection, under public scrutiny, of the quality and integrity of the Contractor. The roadways and facilities included in the scope of this contract are as follows:

\begin{tabular}{|c|c|c|c|c|c|c|c|c|}
\hline & MS & SR & SR & NAME & MILE & NAME & MILE & $\begin{array}{c}\text { MILEAGE } \\
\text { NET } \\
\text { ROADWAY } \\
\text { ID }\end{array}$ \\
ROUTE & NUMBER & NUMBER & & BEGIN & BEGIN & END & END & $\begin{array}{c}\text { CENTER } \\
\text { LINE } \\
\text { LOINT }\end{array}$ \\
\hline 48003000 & US 98 & SR 289 & & $\begin{array}{c}\text { SR 30 CENTER } \\
\text { LINE }\end{array}$ & 0 & $\begin{array}{l}\text { SR 290 } \\
\text { CENTER }\end{array}$ & 7.281 & 7.281 \\
\hline
\end{tabular}




\begin{tabular}{|c|c|c|c|c|c|c|c|c|}
\hline & & & & & & LINE & & \\
\hline 48004000 & & SR 727 & SR 295 & $\begin{array}{c}\text { SR } 292 \text { CENTER } \\
\text { LINE }\end{array}$ & 0 & SR 289 & 10.043 & 10.043 \\
\hline 48005000 & & SR 752 & & $\begin{array}{c}\text { FAIRFIELD DR/ } \\
\text { SR295 }\end{array}$ & 0 & $\begin{array}{l}\text { 9TH AVE. } \\
\text { S.R.289 }\end{array}$ & 1.185 & 1.185 \\
\hline 48006000 & & SR 196 & & S TARRAGONA ST & 0 & $\begin{array}{l}\text { EAST } \\
\text { CHASE } \\
\text { STREET }\end{array}$ & 1.02 & 1.02 \\
\hline 48008000 & & SR 750 & & S.R.289/N 9TH AVE & 0 & $\begin{array}{l}\mathrm{N} 12 \mathrm{TH} \\
\mathrm{AVE}\end{array}$ & 0.582 & 0.582 \\
\hline 48010000 & US 90 & SR 10 & & SECTION BEGINS & 0 & $\begin{array}{l}\text { S.ROSA } \\
\text { CO/L. E } \\
\text { END B }\end{array}$ & 16.171 & 16.171 \\
\hline 48012000 & & SR 296 & & $\begin{array}{c}\text { SR } 10 \text { A MOBILE } \\
\text { HWY. }\end{array}$ & 0 & SR $10 \mathrm{~A}$ & 9.66 & 9.66 \\
\hline 48013000 & & SR 742 & & 487310000 & 0 & SR $10 \mathrm{~A}$ & 6.346 & 6.346 \\
\hline 48013001 & & SR 742 & & $\begin{array}{c}\text { CENTER/L. SR95 } \\
\text { US } 29\end{array}$ & 19.439 & $\begin{array}{l}\text { CENTER/L. } \\
\text { C.R.95 A }\end{array}$ & 20 & 0.561 \\
\hline 48013002 & & SR 742 & & $\begin{array}{c}42^{\prime} \text { W OF } \\
\text { PLANTATION }\end{array}$ & 1.608 & $\begin{array}{l}\text { LANIER } \\
\text { DR. }\end{array}$ & 2.985 & 1.377 \\
\hline 48020000 & US 90 & SR 10A & & BEGIN SECTION & 0 & $\begin{array}{l}\text { BULLNOSE } \\
@ \text { US90-A }\end{array}$ & 26.759 & 26.759 \\
\hline 48030000 & & SR 290 & & $\begin{array}{l}\text { OLD PALAFOX } \\
\text { RD/CR95A }\end{array}$ & 0 & $\begin{array}{l}\text { SR } 10 \mathrm{~A} / \mathrm{US} \\
90\end{array}$ & 5.48 & 5.48 \\
\hline 48040000 & US 29 & SR 95 & & $\begin{array}{c}\text { SR- } \\
\text { 10A/CERVANTES } \\
\text { ST. }\end{array}$ & 0 & $\begin{array}{l}\text { SR 97 } \\
\text { ATMORE } \\
\text { HWY }\end{array}$ & 23.561 & 23.561 \\
\hline 48050000 & & SR 292 & & $\begin{array}{c}\text { ALABAMA ST.LINE } \\
\text { SIGN }\end{array}$ & 0 & & 19.695 & 19.695 \\
\hline 48050000 & US 98 & SR 292 & & & 19.88 & SR 95 & 23.745 & 3.865 \\
\hline 48050001 & US 98 & SR 292 & & $\begin{array}{l}\text { AT BULLNOSE } \\
\text { GORE }\end{array}$ & 0 & $\begin{array}{l}\text { C/LINE } \\
\text { PACE } \\
\text { BLVD }\end{array}$ & 1.011 & 1.011 \\
\hline 48060000 & US 29 & SR 95 & & SR-97 & 0 & $\begin{array}{l}\text { ALABAMA } \\
\text { STATE } \\
\text { LINE }\end{array}$ & 20.075 & 20.075 \\
\hline 48070000 & & SR 291 & & $\begin{array}{c}\text { SR } 30 \text { (GREGORY } \\
\text { ST) }\end{array}$ & 0 & SR 10 & 8.75 & 8.75 \\
\hline 48070101 & & SR 291 & & 36TH AVE & 0 & $\begin{array}{l}\text { GREGORY } \\
\text { ST. }\end{array}$ & 2.47 & 2.47 \\
\hline 48080000 & US 98 & SR 295 & SR 30 & $\begin{array}{c}\text { BAYOU GRANDE } \\
\text { BR N.E. }\end{array}$ & 0 & $\begin{array}{l}\text { SR } 727 \text { \& } \\
\text { RUBY AVE. }\end{array}$ & 4.785 & 4.785 \\
\hline 48080060 & US 98 & SR 30 & & S.R.295 & 0 & $\begin{array}{l}\text { GREGORY } \\
\text { ST. }\end{array}$ & 4.463 & 4.463 \\
\hline 48080061 & & SR 294 & & $\begin{array}{l}\text { S.R.295 CENTER } \\
\text { LINE }\end{array}$ & 0 & $\begin{array}{l}\text { S.R.30 } \\
\text { NAVY } \\
\text { BLVD.C/L }\end{array}$ & 0.216 & 0.216 \\
\hline 48080062 & & SR 295 & & $\begin{array}{c}\text { SR } \\
\text { 295/WARRINGTON } \\
\text { RD }\end{array}$ & 0 & $\begin{array}{l}\text { SR 10A } \\
\text { MOBILE } \\
\text { HWY }\end{array}$ & 0.499 & 0.499 \\
\hline 48100000 & US 98 & SR 30 & & $\begin{array}{c}\text { E END OF BR } \\
480035\end{array}$ & 0 & $\begin{array}{l}\text { PALAFOX ST } \\
\text { CENTER/L }\end{array}$ & 4.529 & 4.529 \\
\hline 48100001 & US 98 & SR 30 & & N PALAFOX ST & 0 & $\begin{array}{l}\text { GREGORY } \\
\text { ST }\end{array}$ & 1.296 & 1.296 \\
\hline 48100001 & & & & & 1.319 & $\begin{array}{l}\text { END OF } \\
\text { PAVEMENT }\end{array}$ & 1.319 & 0 \\
\hline 48110000 & US 98 & SR 30 & SR 298 & $\begin{array}{l}\text { MIDDLE OF } \\
\text { BR.PED.BAY }\end{array}$ & 0.388 & SR 295 & 10.84 & 10.452 \\
\hline 48130000 & & SR 97 & & $\begin{array}{l}\text { CR 95A/OLD } \\
\text { PALAFOX }\end{array}$ & 0 & $\begin{array}{l}\text { ALABAMA } \\
\text { STATE/L } \\
\text { SIGN }\end{array}$ & 22.507 & 22.507 \\
\hline
\end{tabular}




\begin{tabular}{|c|c|c|c|c|c|c|c|}
\hline 48140000 & & SR 4 & SR 95 & 0 & $\begin{array}{l}\text { SANTA } \\
\text { ROSA CO } \\
\text { LINE }\end{array}$ & 1.846 & 1.846 \\
\hline 48140001 & & SR 4 & $\begin{array}{l}\text { OLD ALIGN } \\
48140000\end{array}$ & 0 & $\begin{array}{l}\text { E END ESC } \\
\text { RIV } \\
\text { BRIDGE }\end{array}$ & 1.44 & 1.44 \\
\hline 48190000 & & SR 297 & $\begin{array}{c}\text { CIL OF MEDIAN } \\
10-A\end{array}$ & 0 & $\begin{array}{l}\text { SR 10/ALT } \\
\text { US90 }\end{array}$ & 4.38 & 4.38 \\
\hline 48205000 & & SR 173 & & 0.721 & $\begin{array}{l}\text { PINE } \\
\text { FOREST } \\
\text { RD SR297 }\end{array}$ & 12.707 & 11.986 \\
\hline 48260000 & I 10 & SR 8 & $\begin{array}{l}\text { PERDIDO RIVER } \\
\text { W.END }\end{array}$ & 0 & $\begin{array}{l}\text { S.ROSA } \\
\text { CO/L } \\
\text { W.END BR }\end{array}$ & 16.549 & 16.549 \\
\hline 48270000 & I 110 & SR $8 A$ & SR 30 CHASE ST. & 0 & $\begin{array}{l}\text { N END OF } \\
\text { BRIDGE } \\
068\end{array}$ & 6.341 & 6.341 \\
\hline 48280000 & US 98 & SR 30 & $\begin{array}{c}\text { SR298(LILLIAN } \\
\text { HWY) }\end{array}$ & 0.232 & $\begin{array}{l}\text { SR 295- } \\
\text { NAVY } \\
\text { BLVD. }\end{array}$ & 6.067 & 5.835 \\
\hline
\end{tabular}

\section{Call Boxes}

The Contractor shall be responsible for Call Box Maintenance for the following counties: Escambia, Santa Rosa, Okaloosa, Walton, Holmes, Washington, Jackson, Gadsden and Leon.

\section{GENERAL REQUIREMENTS}

\section{Current Standards and Subsequent Updates}

Perform all work to current Department Standards and Specifications throughout the contract duration, as may be updated throughout the life of the contract. Manage and perform the maintenance of all assets within the project limits as identified in this scope, perform work that is consistent with the Department's maintenance practices, and produce end results in accordance with Contract Documents in effect at the time of the performance of any work. Contract Documents include Florida Statutes, Florida Administrative Code, Design Standards, Maintenance Activity Standards, Rules, Procedures, Handbooks, Guides, Manuals, and applicable Department Specifications. Obtain the latest Department Specifications, including the Standard Specifications for Road and Bridge Construction, Workbook of Implemented Modifications to the 
Standard Specifications, and Mandatory Revisions to the Workbook, from the State Specifications Office Website on the Internet (HTTP://WWW.DOT.STATE.FL.US/SPECIFICATIONSOFFICE/). Obtain the latest Standard Maintenance Special Provisions from the Maintenance Office Website on the Internet (HTTP:/WWW.DOT.STATE.FL.US/STATEMAINTENANCEOFFICE/SMSP.HTM).

\section{Contract Length}

Contract duration is 5 years with a renewal option for one or more additional terms. The combined length of all renewal terms is not to exceed the length of the original term of the contract. If the Department elects to renew, the renewal period lump sum amount shall be calculated as follows:

$$
\begin{aligned}
& a=\text { Original Total Lump Sum Contract Amount } \\
& b=\text { Number of Years of Renewal Term } \\
& c=\text { Number of Years of Original Contract Term }
\end{aligned}
$$

Inflation factor $=0.0215$ (represents $2.15 \%$ per year- determined by Districts) Inflation $=a^{*} b *$ Inflation factor Renewal Period Total Lump Sum Amount $=(a * b / c)+$ Inflation

The Renewal Period Total Lump Sum Amount will be calculated in this manner at each contract renewal.

\section{Invoicing and Compensation}

This is a lump sum contract. Invoice the Department monthly according to the monthly amounts shown in payout schedule. Breakdown the monthly invoice by maintenance 
area for all work units completed for each Maintenance Management System (MMS) activity number.

\section{Organizational Structure}

Upon contract execution, provide a detailed organizational structure. Clearly define the responsibilities of each position identified in the organization structure. Provide qualifications of all personnel. Throughout the contract duration, submit all changes to organizational structure or position responsibility to the Department.

Decisions regularly require engineering judgment that may affect public health and safety. These decisions require the services of a Professional Engineer registered in the State of Florida. Identify at least one (1) individual licensed as a Professional Engineer in the State of Florida to perform these services. Identify a person in responsible charge of the contract who has the ability to instill public confidence and can responsibly act as a representative of the State of Florida Department of Transportation.

\section{Performance Expectations and Evaluation}

This contract is a performance-based contract. Maintain the road system uniformly and consistently throughout the contract period by meeting the performance specifications/measures established in this scope. The Department will evaluate Contractor performance in two ways: 1) by comparing actual work performance to the performance criteria established within this scope, and 2) by semiannually grading the Contractor according to the Asset Maintenance Contracts Procedure. Unsatisfactory performance of work or failure to perform in accordance with the Contractor's technical proposal or other contract documents will affect the Contractor's semiannual grade and may further result in contract default.

\section{Partnering}


For this Contract, a non-bid pay item has been established for Partnering in the amount of $\$ 3,000$. The objective of partnering is to establish a partnership charter and action plan between the Contractor, the Department and other parties associated with this Contract.

\section{Contractor Responsibilities}

Review and confirm for validity the data contained on the project $\mathrm{CD}$, which is provided by the Department in conjunction with the Request for Proposal (RFP). Use the supplied project $\mathrm{CD}$ to assist in developing a complete understanding of all quantities and workloads pertaining to this scope of work.

Continually monitor all Department policies, procedures, specifications, and other Contract Documents for changes and updates. Be prepared to comply with any revisions.

Manage the maintenance of all assets identified in this scope. Tasks include work needs assessment; resource management; work activity planning and execution; and quality control performance to ensure work complies with contractual requirements. Develop an annual work plan to ensure the desired maintenance is performed.

Perform Routine and Periodic maintenance activities at a frequency that ensures uniform and consistent compliance with the Maintenance Rating Program (MRP) criteria, the required maintenance rating level, and any other established requirements of the Department. Research maintenance activity numbers, activity descriptions, and units of measure in the Department's Maintenance Cost Handbook.

Take proper health and safety measures to ensure safety for the traveling public, Department employees, Contractor employees, and Subcontractor employees.

Manage and coordinate existing Department contracts within the limits of this contract until expiration of the Department contracts (Attachment II). Existing Department contracts will continue until money exhaustion or time expiration on the contract, whichever comes first. Document any instances of poor performance by the existing 
Department Contractor. If the Department prematurely terminates any existing contract, the Department will compensate the Asset Maintenance Contractor, in accordance with Asset Maintenance Contracts Procedure, for assuming the unanticipated workload remaining on the terminated contract.

Comply with current lane closure restrictions, requirements, and individual lane closure analysis results. In some locations this may require nighttime work. Lane closure restrictions are subject to change due to updated traffic counts or various other events. Work with Department staff to coordinate lane closures during special events.

Develop and implement a Customer Service Resolution Plan. Maintain a customer service log detailing complaints and requests and the resolution of the items contained in the log. Include Customer name and contact information in the log.

Before performing any non-standard repairs or implementing any innovative ideas, submit the non-standard repair or innovative idea to the Department for approval.

Purchase (via monthly invoice deduction) all needed sign panels from the State Sign Shop in Lake City using the statewide process for requesting and receiving finished sign panels; or, as an alternative, obtain sign panels from a source of the Contractor's choosing. Before installation, ensure sign panels meet minimum design requirements. Maintain a record of all Department provided sign panels.

Monitor and report to the Department all DBE utilization properly detailed as required in Specifications.

Participate in the Adopt-A-Highway program as required by Chapter 403.4131 (3), Florida Statutes.

Consider participation in the Department's Youth Work Experience Program, as provided by Chapter 334.351, Florida Statutes.

Provide any lists, summaries, logs, reports, or other documents to the Department for review as requested. 
Pay all fines, fees, and penalties levied to the Department by any Governmental Agency resulting from negligent maintenance.

Pay all tolls required for usage of roads and bridges.

\section{Department Responsibilities}

The Department will provide all potential Contractors (bidders) with a project CD containing a variety of data and information about the roadways within the limits of this contract. Although the information on the $\mathrm{CD}$ is not complete, it will be useful in determining the extent of expected maintenance activities. The Department will place the following items on the project $\mathrm{CD}$ :

(a) Historical Contract Reports

(b) Historical MRP Reports

(c) Summary Spreadsheet for MRP Workloads

(d) RCI Converted Inventory

(e) General Bridge Information

(f) In-House-Crew Unit Cost Reports

Upon request, the Department will provide finished sign panels to the Contractor for sign maintenance and repair on the State Highway System within the project limits. The Department will verify that the Contractor has made a deduction from the Contractor's monthly invoice for the cost of each sign panel obtained from the Lake City Sign Shop.

Annually, the Department will provide additional compensation to the Contractor via Supplemental Agreement or Unilateral Payment if the Contractor experiences a combined substantial economic impact during the previous year due to compliance with any of the following four (4) possible occurrences.

(a) A change to Statewide maintenance programs or practices

(b) A change to any of the policies, procedures, standards, manuals, handbooks, guides, specs, or any other State, Local, or Federal documents used to monitor the performance of this contract.

(c) Increased maintenance due to the construction of roadways, structures, and facilities that were not included in the Department's Work Program at the time of the Contractor's proposal due date. Increased maintenance due to the transfer of ownership 
to the Department of non-state roadways, structures, and facilities within the contract limits.

A substantial economic impact is defined as documented financial burden on the Contractor exceeding five percent (5\%) of the annual contract amount. If additional compensation is warranted, the Department will compensate only for the value of economic impact beyond the five percent (5\%) threshold. The five percent $(5 \%)$ is not cumulative year to year; it is reset each anniversary of contract start date.

Similarly, the Department will reduce payment to the Contractor if the Contractor experiences a combined substantial economic savings during the previous year due to occurrence of any of the following four (4) possibilities:

(a) A change to Statewide maintenance programs or practices

(b) A change to any of the policies, procedures, standards, manuals, handbooks, guides, specs, or any other State, Local, or Federal documents used to monitor the performance of this contract.

(c) Reduced maintenance due to the elimination or planned destruction of roadways, structures, and facilities.

(d) Reduced maintenance due to the transfer of ownership of Departmentowned roadways, structures, and facilities to other non-Department entities.

A substantial economic savings is defined as a cost savings exceeding five percent (5\%) of the annual contract amount. If cost savings are identified, payment to the Contractor will be reduced only for savings greater than the five percent $(5 \%)$ threshold. The five percent $(5 \%)$ is not cumulative year to year; it is reset each anniversary of contract start date.

\section{EMERGENCY MANAGEMENT}

\section{General}

The Department categorizes Emergency Management into two classifications: "Governor Declared Emergencies" and "Other Emergencies". For Governor Declared Emergencies, perform pre-event preparation and provide initial response post-event to protect the traveling public from grievous hazards created by the event. For Other Emergencies, perform all aspects of responding 
to the incident/event, including pre-event preparation, post-event initial response, and post-event cleanup and repair. For both classifications of Emergency Management, perform the following six (6) activities before every foreseeable Emergency Management incident/event:

(a) Contact vendors and subcontractors to verify quantity, availability, and priority of appropriate equipment and personnel (e.g. MOT devices, variable message boards, chainsaws, sand spreaders, etc.). Develop a complete up-todate list of equipment resources and staging locations and of all stockpiled materials and their locations.

(b) In case of possible area evacuations, prepare for implementation of contraflow, including the pre-staging of necessary contraflow resources.

(c) If directed by the Department implements contraflow and remove contraflow devices when complete.

a. Secure and lockdown bascule structures covered under this contract.

(d) In preparation for high winds, rains, and other impending elements, secure all existing worksites associated with this contract.

(e) Lower all high mast lights within the projected path of a hurricane where wind speeds are projected to be category two or higher at location of high mast lights, or as otherwise directed by the Department. Lower lights to within ten (10) feet of the ground. If the lowered position of lights places them at risk of adjacent tree damage, place lights as low as possible while avoiding tree damage risk. Do not lower high mast lights on routes that are expected to be used for contraflow.

If high mast lighting has been lowered, repaired, or raised due to preparation/reaction to storm events, submit a separate informational invoice detailing the cost of such lowering, repairing, and raising of the high mast lights. Show the high mast lighting costs by maintenance area, by Financial Project Number, and by activity (lower, repair, raise). Retain all documentation required for the Department to apply for Federal Reimbursement for this activity.

For any contraflow activities performed to preparation/reaction to storm events, submit a separate informational invoice detailing the cost of such contraflow activities. Show the contraflow costs by maintenance area, by Financial Project Number, and by activity (lower, repair, raise). Retain all documentation required for the Department to apply for Federal Reimbursement for contraflow activities. 
For any activities associated with securing bascule bridges in preparation/reaction to storm events, submit a separate informational invoice detailing the cost of such activities. Show the costs to secure bascule bridges by maintenance area, by Financial Project Number, and by activity (lower, repair, raise). Retain all documentation required for the Department to apply for Federal Reimbursement for these activities.

Unless otherwise noted in this contract, the Department will not provide additional compensation to the Contractor through this contract for any Emergency Management activities, including the six activities described above.

For all Emergency Management activities, the Department reserves the right to take control of the incident and/or perform recovery work with its own or other contracted forces when the Department determines it is in the Department's best interest to do so.

\section{Emergency Management Plan}

Know the applicable District Comprehensive Emergency Management Plan as well as the FHWA and FEMA guidelines for federal reimbursement. Ensure compliance with all State and Federal Emergency Management Requirements. Administer all response and recovery efforts in accordance with these documents. Develop an Emergency Management Plan that sufficiently replicates the intent of the District's Comprehensive Emergency Management Plan and incorporate this plan with the Technical Proposal. Include details in the Emergency Management Plan including, but not limited to:

- $\quad$ procedures for incident/event management

- $\quad$ agency \& public notifications

- $\quad$ assurance of motorist safety

- $\quad$ handling of hazardous waste

- $\quad$ coordination with Law Enforcement and other appropriate agencies

- $\quad$ traffic control

- $\quad$ coordination with the Department and other agencies to establish or implement pre-established detour routes

- $\quad$ maintenance of detour routes 
- $\quad$ making emergency repairs

- debris removal

- evacuation/contraflow response

- $\quad$ submission of incident/event reports

- $\quad$ plan for compliance with the Open Roads Policy

- detailed organizational structure with the functions, qualifications, experience level, and contact information of staff assigned to respond to incidents/events

Comply with all Department plans and with all Local, State, and Federal laws and regulations concerning evacuation routes and the handling and disposal of hazardous waste. Update the Emergency Management Plan in April of each year by engaging in an iterative process of discussion between the Department and the Contractor whereby lessons learned from past experience can be implemented for future use. Prior to the occurrence of any incidents/events, ensure an approved Emergency Management Plan is in effect and be prepared to act upon that plan.

\section{Specific Contractor Responsibilities for Governor Declared Emergencies}

Governor Declared Emergencies are incidents/events that prompt the Governor of Florida to declare a State of Emergency in response to the incident/event. Governor Declared Emergencies will most commonly be major hurricanes and other natural disasters, but can include smaller natural disasters/events/storms (Acts of God), marine collisions with bridges and/or bridge fender systems, and incidents/events resulting from human interactions.

If directed by the Department in writing, perform the following three (3) Pre-Event activities and separately track and invoice the Department for associated costs. The Department will compensate the Contractor for their direct costs of performing these three (3) Pre-Event activities as described in the Department's written directions to the Contractor:

(a) Supplement Road Ranger Service Patrols and provide fuel assistance to stranded motorists.

(b) Provide additional security at Rest Areas and Welcome Center 
facilities.

(c) Provide additional portable rest room facilities at Rest Areas, Weigh Stations, Welcome Centers, and other locations as directed by the Department. (Perform the following five (5) Post-Event activities. The Department will not provide additional compensation to the Contractor for the performance of these six (6) Post-Event activities:

(a) Search all roadways covered by this contract for grievous hazards (roadway washouts/cave-ins, downed electrical lines, non-traversable bridges, etc.). This may include clearing some debris from the roadway in order to access these hazardous areas. Minimal clearing required to access hazardous areas will not be considered first-push roadway clearing.

(b) Immediately respond to perform traffic control, set up safety devices, and layout established or improvised detour routes in order to protect the traveling public from grievous hazards created by the incident/event. When detour routes are required due to an incident/event occurring on a roadway covered by this contract, manage and maintain the entire detour route within the State of Florida, even if the route extends onto roadways not covered by this contract (state or non-state). For portions of a detour route extending outside Florida, coordinate detour setup and maintenance with the appropriate State.

(c) Notify the Department's designated contact person immediately upon occurrence of all major incidents/events and immediately upon road closure for all roadway closures exceeding one (1) hour. Notify the Department again upon roadway reopening.

(d) Inspect, perform any minor repairs, and raise all high mast lighting back to their original position as directed by the Department. "Minor repairs" is defined as repairs not eligible for Federal reimbursement.

(e) Assist the Department in performing damage assessment reviews.

Do not perform first-push activities, debris removal, cleanup, or federally reimbursable repair work necessitated by a Governor Declared Emergency incident/event.

\section{Specific Contractor Responsibilities for Other Emergencies}

Other Emergencies are incidents/events that do not prompt the Governor of Florida to declare a State of Emergency in response to the incident/event. Other Emergencies will most commonly be traffic crashes, guardrail hits, severe potholes, debris within travel lanes, attenuator hits, roadway shoulder wash-outs, roadway cave-ins, and downed light poles but can include natural 
disasters/events/storms (Acts of God), marine collisions with bridges and/or bridge fender systems, and incidents/events resulting from human interactions.

Respond and deploy resources according to the goals established in the Open Roads Policy. Arrive on-site, prepared to take necessary action with necessary manpower and emergency response equipment. Working hours referenced under the Department responsibilities in the Open Roads Policy are defined as Monday through Friday 7:00 am to 5:30 pm. Be available to relieve Law Enforcement personnel of traffic control functions within fifteen (15) minutes of arriving onsite.

Manage all aspects of traffic control related to an incident/event, including coordination with Governmental agencies when incidents/events spill over onto roadways not covered by this contract. When detour routes are required due to an incident/event occurring on a roadway covered by this contract, manage and maintain the entire detour route, even if the route extends onto roadways not covered by this contract (state or non-state). Notify the Department's designated contact person immediately upon occurrence of all major incidents/events and immediately upon road closure for all roadway closures exceeding one (1) hour. Notify the Department again upon roadway reopening.

When an incident/event causes damage to any Department facilities, the Department authorizes the Contractor to pursue claims against any responsible party for reimbursement of expenses incurred as per Department procedure. The sequence of reimbursement for damages shall be as follows:

(a) Pursue claims against the individual or entity responsible for causing damages, or their insurers.

(b) If Department insurance coverage is available, request reimbursement through the District Property Insurance Coordinator. The Department has insurance coverage on some facilities such as Rest Areas, Weigh Stations and bridges. To the extent of coverage availability, the Department may transfer the qualifying reimbursement amounts to the Contractor to offset the Contractor's actual costs to restore the system.

(c) Use Contractor insurance coverage The Contractor's responsibility to make damage repairs at its own expense, in each twelve (12)-month period beginning with the date of the original contract, shall be limited to $\$ 750,000$ per year, non-accumulative. Such $\$ 750,000$ per year 
cap shall be in addition to any amounts reasonably obtainable under items (a), (b) and (c) above, and any damage repairs caused by the Contractor's negligence. The annual contract amount as used above means each twelve (12)-month period beginning with the date of the original contract and each annual anniversary date thereafter

For repairing damage resulting from an act that is officially declared by the State of Florida as an "act of terrorism", the Department will compensate the Contractor/who ever the Department determines will provide the best interest to the Department with via Supplemental Agreement or Unilateral Payment for "act of terrorism" damage repair costs.

\section{CONTRACT DOCUMENTS}

The following list of procedures, manuals, guides, and handbooks is provided for the Contractor's convenience only and is not all inclusive. Obtain the complete, up-to-date list of Contract Documents incorporated as a part of this contract from the Maintenance Office Website on the Internet (HTTP://WWW.DOT.STATE.FL.US/STATEMAINTENANCEOFFICE/AMCONTRACTDOCUMENTS.HTM).

- Topic Number 850-065-002 Maintenance Rating Program

- Topic Number 850-000-015 Roadway and Roadside Maintenance

- Topic Number 850-000-005 Maintenance Responsibilities on Construction Projects

- Topic Number 850-055-025 Single and Multi-Post Sign Inspection

- Topic Number 850-055-003 Reporting Attenuator Inventory and Inspection

- Topic Number 850-050-004 Highway Safety Memorial Markers

- Topic Number 850-005-001 Reporting Incidents and Management of Damage Repair

- Topic Number 850-010-030 Bridge and Other Structures Inspection and Reporting Procedures Manual

- Topic Number 850-010-035 Bridge Load Rating, Permitting and Posting

- Topic Number 850-010-031 Bridge Operations and Maintenance Manual 
- Topic Number 850-010-011 Bridge Underwater Operations Manual

- Topic Number 850-055-035 Motorist Aid System Testing and Routine Maintenance

- Topic Number 850-050-003 Guardrail Inspection and Maintenance

- Topic Number 850-000-001 Transportation Data Collection, Storage and Reporting

- Topic Number 225-085-001 General Liability Claims

- Topic Number 625-010-021 Median Opening and Access Management Decision Process

- Topic Number 375-020-002 Contract Maintenance Inspection and Reporting

- Topic Number 375-000-005 Asset Maintenance Contracts

- Topic Number 650-030-001 Wildflower Program

- Topic Number 750-000-001 Roadway Characteristics Inventory Traffic Engineering and Operations Data

- Topic Number 500-000-104 Emergency Management Program

- Maintenance Rating Program Handbook

- Guide to Turf Management

- Guide to Roadside Mowing

- Chemical Weed and Grass Control

- Guide to Asphalt Pavement Repair

- Florida Highway Landscape Guide

- Utility Accommodations Manual

- Bridge Loading Rating, Permitting, \& Posting Manual

- Bridge Underwater Operations Manual

- Bridge Work Order Handbook

- Manual on Uniform Traffic Control Devices (MUTCD)

- Bridge and other Structures Inspection Reporting Procedures Manual

- Bridge Operations and Maintenance Manual

- Bridge Inventory Database User's Handbook

- Maintenance Cost Handbook

- Maintenance Roadway Characteristics Inventory Manual

- Plans Preparation Manual

- Florida Administrative Code Rule Chapter 14-48, Bridge Inspection Standards

- FHWA "Guidelines for the Installation, Inspection, Maintenance and Repair of Structural Supports for Highway Signs, Luminaries, and Traffic Signals"

ASSET MAINTENANCE PERFORMANCE MEASURES

MRP SCORES

MRP NOTES: The Department will hold the retainage withheld from MRP

Periods $1 \& 2$ until the Department calculates the Final Annual Rating. If the 


\begin{abstract}
Final Annual calculated deduction is less than the total accumulated retainage for the fiscal year, the balance of the retainage will be paid to the Contractor. If the Final Annual calculated deduction exceeds the total accumulated retainage for the fiscal year, the balance will be deducted from the Contractor's payment. All deductions withheld from the Contractor and all retainage refunds to the Contractor will occur through adjustments to the next appropriate monthly invoice amount.
\end{abstract}

\begin{tabular}{|c|c|}
\hline Deficiency Identification & Deduction/Retainage \\
\hline $\begin{array}{l}\text { a. Failure to meet overall } \\
\text { MRP score requirements } \\
\text { (Periods } 1 \& 2 \text { ) }\end{array}$ & $\begin{array}{l}\text { Retain one half percent }(.5 \%) \text { of one-third of the } \\
\text { annual contract amount for each MRP point below } \\
\text { procedural requirements for overall MRP score }\end{array}$ \\
\hline $\begin{array}{l}\text { b. Substandard MRP for } \\
\text { individual elements } \\
\text { (Periods } 1 \text { \& 2) }\end{array}$ & $\begin{array}{l}\text { Retain one quarter percent (.25\%) of one-third of the } \\
\text { annual contract amount for each MRP point below } \\
\text { procedural requirements for each element rating }\end{array}$ \\
\hline $\begin{array}{l}\text { c. Substandard MRP for } \\
\text { individual characteristics } \\
\text { (Periods } 1 \& 2 \text { ) }\end{array}$ & $\begin{array}{l}\text { Retain one eighth percent (.125\%) of one-third of the } \\
\text { annual contract amount for each MRP point below } \\
\text { procedural requirements for each characteristic } \\
\text { rating }\end{array}$ \\
\hline $\begin{array}{l}\text { d. Failure to meet overall } \\
\text { MRP score requirements } \\
\text { (Final Annual Rating) }\end{array}$ & $\begin{array}{l}\text { Deduct one half percent }(.5 \%) \text { of the annual contract } \\
\text { amount for each MRP point below procedural } \\
\text { requirements for overall MRP score }\end{array}$ \\
\hline $\begin{array}{l}\text { e. Substandard MRP for } \\
\text { individual elements } \\
\text { (Final Annual Rating) }\end{array}$ & $\begin{array}{l}\text { Deduct one quarter percent (.25\%) of the annual } \\
\text { contract amount for each MRP point below } \\
\text { procedural requirements for each element rating }\end{array}$ \\
\hline $\begin{array}{l}\text { f. Substandard MRP for } \\
\text { individual characteristics } \\
\text { (Final Annual Rating) }\end{array}$ & $\begin{array}{l}\text { Deduct one eighth percent (.125\%) of the annual } \\
\text { contract amount for each MRP point below } \\
\text { procedural requirements for each characteristic } \\
\text { rating }\end{array}$ \\
\hline PERFORMANCE CRITERIA NOTES: & IA NOTES: \\
\hline
\end{tabular}


"Time Allowed/Criteria" is PER APPLICABLE PROCEDURE. If the applicable procedure is non-specific for time allowed or criteria, then use the "Time Allowed/Criteria" given in the applicable chart.

2) For all times allowed in all charts found in this scope, the District Maintenance Engineer/Administrator may grant a time extension for unusual circumstances if the extension is requested during the original time period allowed.

3) All deductions withheld from the Contractor will occur through adjustments to the next monthly invoice amount.

\section{GUARDRAIL}

\begin{tabular}{|c|c|c|}
\hline $\begin{array}{l}\text { Deficiency } \\
\text { Identification }\end{array}$ & Time Allowed/Criteria & Deduction \\
\hline $\begin{array}{l}\text { a. Failure to perform } \\
\text { timely inspections }\end{array}$ & $\begin{array}{l}\text { Per Procedure 850-050- } \\
003\end{array}$ & $\begin{array}{l}500 \text { per day per } \\
\text { delinquent inspection }\end{array}$ \\
\hline $\begin{array}{l}\text { b. Failure to timely submit } \\
\text { Inspection } \\
\text { Sheets/Reports }\end{array}$ & $\begin{array}{l}\text { Due within } 15 \text { days after } \\
\text { completion of inspection }\end{array}$ & $\begin{array}{l}\$ 100 \text { per day per } \\
\text { delinquent report }\end{array}$ \\
\hline $\begin{array}{l}\text { c. Failure to make repairs } \\
\text { identified in Inspection } \\
\text { Reports }\end{array}$ & $\begin{array}{l}\text { Within } 30 \text { days of } \\
\text { identification }\end{array}$ & $\begin{array}{l}\$ 500 \text { per day per } \\
\text { guardrail }\end{array}$ \\
\hline $\begin{array}{l}\text { d. Failure to make } \\
\text { temporary safety repairs } \\
\text { resulting from incidents }\end{array}$ & $\begin{array}{l}\text { Must secure with proper } \\
\text { MOT before leaving the } \\
\text { site }\end{array}$ & $\begin{array}{l}\$ 1,000 \text { per day per } \\
\text { guardrail }\end{array}$ \\
\hline $\begin{array}{l}\text { e. Failure to make } \\
\text { permanent repairs } \\
\text { resulting from incidents }\end{array}$ & $\begin{array}{l}\text { Repair within } 10 \text { calendar } \\
\text { days of Incident }\end{array}$ & $\begin{array}{l}\$ 1,000 \text { per day per } \\
\text { guardrail }\end{array}$ \\
\hline \multicolumn{3}{|l|}{ ATTENUATORS } \\
\hline $\begin{array}{l}\text { Deficiency } \\
\text { Identification }\end{array}$ & Time Allowed/Criteria & Deduction \\
\hline $\begin{array}{l}\text { a. Failure to perform } \\
\text { timely inspections }\end{array}$ & $\begin{array}{l}\text { Per Procedure 850-055- } \\
003\end{array}$ & $\begin{array}{l}500 \text { per day per } \\
\text { delinquent inspection }\end{array}$ \\
\hline $\begin{array}{l}\text { b. Failure to timely submit } \\
\text { Inspection }\end{array}$ & $\begin{array}{l}\text { Per Procedure 850-055- } \\
003\end{array}$ & $\begin{array}{l}\$ 100 \text { per day per } \\
\text { delinquent report }\end{array}$ \\
\hline
\end{tabular}




\begin{tabular}{|l|l|l|}
\hline Sheets/Reports & & \\
\hline $\begin{array}{l}\text { c. Failure to make repairs } \\
\text { identified in Inspection } \\
\text { Reports }\end{array}$ & $\begin{array}{l}\text { Within 30 days of } \\
\text { identification }\end{array}$ & $\begin{array}{l}\$ 500 \text { per day per } \\
\text { attenuator }\end{array}$ \\
\hline $\begin{array}{l}\text { d. Failure to make } \\
\text { temporary safety repairs } \\
\text { resulting from incidents }\end{array}$ & $\begin{array}{l}\text { MoT before leaving the } \\
\text { site }\end{array}$ & $\begin{array}{l}\$ 1,000 \text { per day per } \\
\text { attenuator }\end{array}$ \\
\hline $\begin{array}{l}\text { e. Failure to make } \\
\text { permanent repairs } \\
\text { resulting from incidents }\end{array}$ & $\begin{array}{l}\text { Repair within 5 calendar } \\
\text { days of Incident }\end{array}$ & $\begin{array}{l}\$ 1,000 \text { per day per } \\
\text { attenuator }\end{array}$ \\
\hline $\begin{array}{l}\text { SIGNS } \\
\text { Deficiency } \\
\text { Identification }\end{array}$ & Time Allowed/Criteria & Deduction \\
\hline $\begin{array}{l}\text { a. Failure to perform } \\
\text { timely Inspections }\end{array}$ & $\begin{array}{l}\text { Per Procedure 850-055- } \\
025\end{array}$ & $\begin{array}{l}\$ 500 \text { per day per } \\
\text { delinquent inspection }\end{array}$ \\
\hline $\begin{array}{l}\text { b. Failure to timely submit } \\
\text { Inspection } \\
\text { Sheets/Reports }\end{array}$ & Due within 15 days after \\
completion of inspection & $\begin{array}{l}\$ 100 \text { per day per } \\
\text { delinquent report }\end{array}$ \\
\hline $\begin{array}{l}\text { c. Failure to make repairs } \\
\text { identified in Inspection } \\
\text { Reports }\end{array}$ & $\begin{array}{l}\text { Per Procedure 850-055- } \\
025\end{array}$ & $\begin{array}{l}\$ 500 \text { per day per sign } \\
\text { assembly }\end{array}$ \\
\hline $\begin{array}{l}\text { d. Failure to replace } \\
\text { missing signs and signs } \\
\text { downed by incidents }\end{array}$ & Per Procedure 850-055- & $\begin{array}{l}\text { Permanent regulatory } \\
\text { and warning signs } \$ 2,000 \\
\text { per day per sign } \\
\text { assembly. } \\
\text { Temporary signs } \$ 100 \\
\text { per day per sign } \\
\text { assembly. } \\
\text { Permanent signs } \$ 500\end{array}$ \\
\hline
\end{tabular}




\begin{tabular}{|c|c|c|}
\hline & & $\begin{array}{l}\text { per day per sign } \\
\text { assembly }\end{array}$ \\
\hline \multicolumn{3}{|l|}{ CALL BOXES } \\
\hline $\begin{array}{l}\text { Deficiency } \\
\text { Identification }\end{array}$ & Time Allowed/Criteria & Deduction \\
\hline $\begin{array}{l}\text { a. Failure to perform } \\
\text { timely inspections and } \\
\text { testing }\end{array}$ & $\begin{array}{l}\text { Per Procedure 850-055- } \\
035\end{array}$ & $\begin{array}{l}100 \text { per day per } \\
\text { delinquent inspection }\end{array}$ \\
\hline $\begin{array}{l}\text { b. Failure to timely repair } \\
\text { deficiencies identified by } \\
\text { inspection, testing, or } \\
\text { highway patrol }\end{array}$ & $\begin{array}{l}\text { Per Procedure 850-055- } \\
035\end{array}$ & $\$ 500$ per day per call box \\
\hline $\begin{array}{l}\text { c. Failure to replace non- } \\
\text { repairable call boxes } \\
\text { identified by inspection, } \\
\text { testing, or highway patrol }\end{array}$ & $\begin{array}{l}\text { Within } 3 \text { days of } \\
\text { identification }\end{array}$ & $\$ 500$ per day per call box \\
\hline $\begin{array}{l}\text { d. Failure to repair non- } \\
\text { critical deficiencies } \\
\text { identified by inspection, } \\
\text { testing, or highway patrol }\end{array}$ & $\begin{array}{l}\text { Per Procedure 850-055- } \\
035\end{array}$ & $\$ 100$ per day per call box \\
\hline $\begin{array}{l}\text { e. Failure to replace call } \\
\text { boxes damaged by } \\
\text { Incidents }\end{array}$ & $\begin{array}{l}\text { Per Procedure 850-055- } \\
035\end{array}$ & $\$ 500$ per day per call box \\
\hline \multicolumn{3}{|c|}{ CLEAR ZONE OBSTRUCTIONS } \\
\hline $\begin{array}{l}\text { Deficiency } \\
\text { Identification }\end{array}$ & Time Allowed/Criteria & Deduction \\
\hline $\begin{array}{l}\text { a. Failure to temporarily } \\
\text { secure reported or } \\
\text { discovered clear zone }\end{array}$ & $\begin{array}{l}\text { Must respond within } 1 \\
\text { hour \& secure with } \\
\text { proper MOT before }\end{array}$ & $\begin{array}{l}\text { Response }-\$ 100 \text { per } \\
\text { hour per location } \\
\text { Secure - } \$ 1,000 \text { per day }\end{array}$ \\
\hline
\end{tabular}




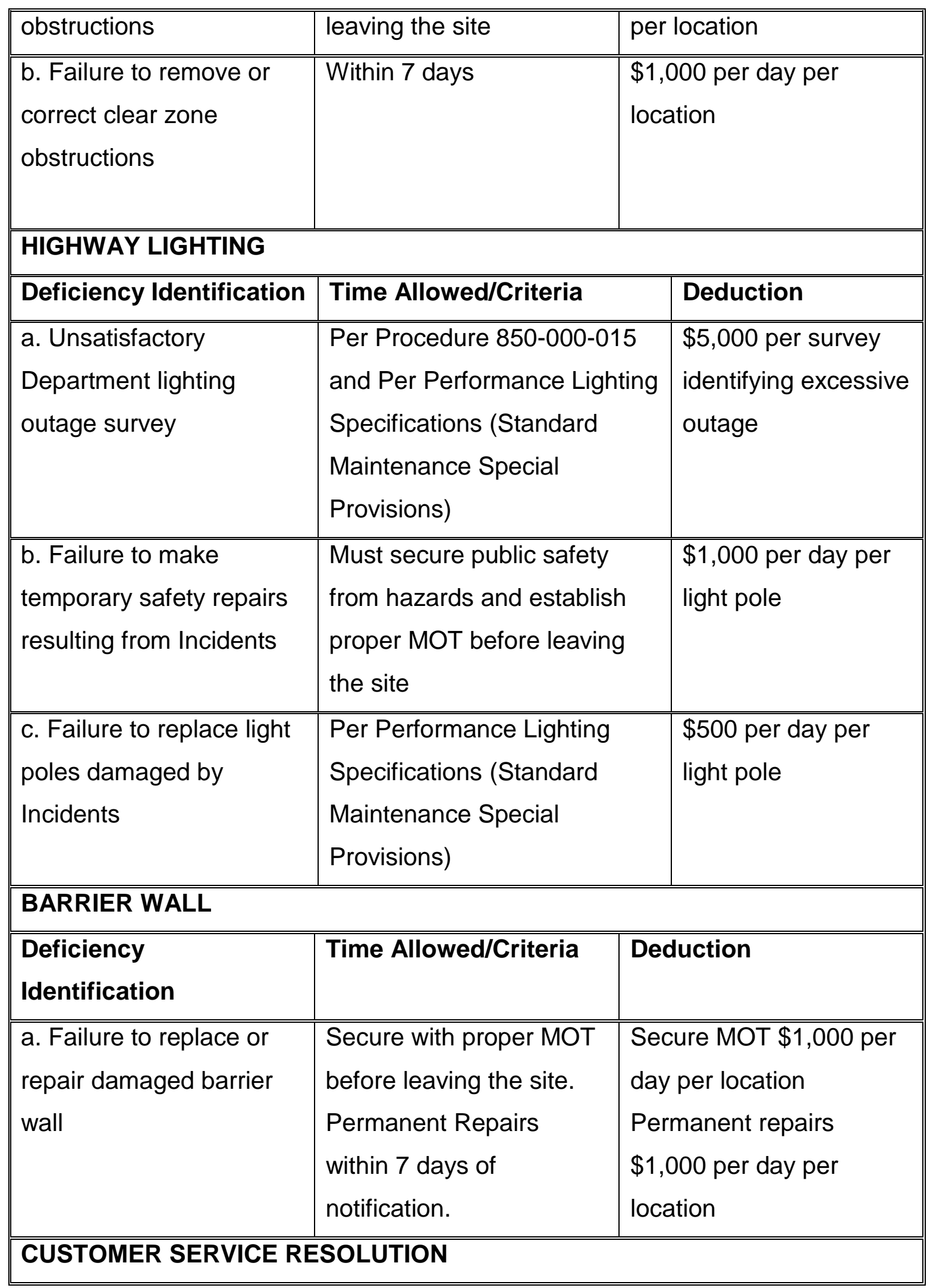




\begin{tabular}{|c|c|c|}
\hline Deficiency Identification & Time Allowed/Criteria & Deduction \\
\hline $\begin{array}{l}\text { a. Failure to contact } \\
\text { customer }\end{array}$ & $\begin{array}{l}\text { Contact customer } \\
\text { within } 24 \text { hours }\end{array}$ & $\begin{array}{l}\$ 500 \text { per day per } \\
\text { customer }\end{array}$ \\
\hline $\begin{array}{l}\text { b. Failure to resolve } \\
\text { customer service request to } \\
\text { the satisfaction of the } \\
\text { Department }\end{array}$ & $\begin{array}{l}\text { Resolve within } 2 \text { weeks } \\
\text { of customer contact }\end{array}$ & $\begin{array}{l}\$ 500 \text { per day per } \\
\text { customer request }\end{array}$ \\
\hline \multicolumn{3}{|l|}{ EMERGENCY RESPONSE } \\
\hline Deficiency Identification & Time Allowed/Criteria & Deduction \\
\hline $\begin{array}{l}\text { a. Failure to properly } \\
\text { respond to incidents/events } \\
\text { as required in Emergency } \\
\text { Management section of this } \\
\text { scope or according to the } \\
\text { goals established in the } \\
\text { Open Road Policy. }\end{array}$ & $\begin{array}{l}\text { Per Emergency } \\
\text { Management section } \\
\text { requirements } \\
\text { established in this } \\
\text { scope and in the Open } \\
\text { Road Policy. }\end{array}$ & $\begin{array}{l}\$ 1,000 \text { per hour, } \\
\text { prorated, per } \\
\text { incident/event }\end{array}$ \\
\hline \multicolumn{3}{|c|}{ EMERGENCY DEBRIS REMOVAL (INCLUDING DEAD ANIMALS) } \\
\hline Deficiency Identification & Time Allowed/Criteria & Deduction \\
\hline $\begin{array}{l}\text { a. Failure to promptly and } \\
\text { properly remove and } \\
\text { dispose of emergency } \\
\text { debris }\end{array}$ & $\begin{array}{l}\text { Per Emergency } \\
\text { Response for Debris } \\
\text { Removal Specifications } \\
\text { (SMSP) }\end{array}$ & $\$ 500$ per day per incident \\
\hline \multicolumn{3}{|l|}{ GRAFFITI } \\
\hline Deficiency Identification & Time Allowed/Criteria & Deduction \\
\hline $\begin{array}{l}\text { a. Failure to promptly } \\
\text { remove or cover graffiti }\end{array}$ & $\begin{array}{l}\text { Remove or cover graffiti } \\
\text { within } 36 \text { hours of } \\
\text { discovery }\end{array}$ & $\begin{array}{l}\$ 1,000 \text { per day per } \\
\text { roadway mile }\end{array}$ \\
\hline \multicolumn{3}{|c|}{ SUBMISSION OF DEPARTMENT REQUESTED DOCUMENTS } \\
\hline Deficiency Identification & Time Allowed/Crit & Deduction \\
\hline
\end{tabular}




\begin{tabular}{|l|l|l|}
\hline $\begin{array}{l}\text { a. Upon Department request, } \\
\text { failure to submit any documents } \\
\text { the Contractor is required to } \\
\text { maintain }\end{array}$ & $\begin{array}{l}\text { Submit document by the } \\
\text { end of the business day } \\
\text { following the day of the } \\
\text { Department's request }\end{array}$ & $\begin{array}{l}\text { \$100 prorated per } \\
\text { business day per } \\
\text { requested } \\
\text { document }\end{array}$ \\
\hline DEPARTMENT POLICIES AND PROCEDURES \\
\hline \hline Deficiency Identification & Deduction \\
\hline $\begin{array}{l}\text { a. Violation of any Department procedures, } \\
\text { policies, handbooks, or any other contract } \\
\text { document }\end{array}$ & $\begin{array}{l}\$ 500 \text { per occurrence of } \\
\text { violation }\end{array}$ \\
\hline \begin{tabular}{l} 
CONTRACTOR'S TECHNICAL PROPOSAL \\
\hline Deficiency Identification
\end{tabular} & $\begin{array}{l}\text { Deduction } \\
\text { violation } \\
\text { statements, guarantees, or other assurances } \\
\text { made within the Contractor's original Technical } \\
\text { Proposal }\end{array}$ \\
\hline
\end{tabular}

\section{MAINTENANCE RATING PROGRAM PERFORMED BY THE} DEPARTMENT

Achieve and maintain a Maintenance Rating Program (MRP) rating as required in Department procedures for all elements and characteristics. Use the criteria established in Department procedures to constantly evaluate the level of maintenance attained to ensure a uniform and consistent level of maintenance at all times.

The Department will perform a complete MRP rating three (3) times per year using the criteria outlined in the MRP Handbook. The Department will randomly generate locations to be rated each period. The Department will calculate the MRP scores for the Contractor. The Department may perform interim MRP ratings for specific characteristics as quality control checks of the Contractor and to ensure that the Contractor is consistently maintaining the state highway system. The Department will use the randomly generated points when performing interim MRP checks. The 
Department will consider these interim rating scores when the Department determines the Contractor's semiannual grades, as per Asset Maintenance Contracts Procedure. At least five (5) working days in advance of scheduled MRP evaluation, the Department will invite the Contractor to accompany the Department MRP team in their review. The Contractor may accompany the Department's MRP team with a maximum of two trained MRP team members. If the Contractor does not attend the MRP evaluation, they cannot contest the MRP scores. Upon encountering any disagreement associated with an MRP evaluation, attempt to resolve the dispute in the field with the Department MRP team. If no resolution can be reached in the field, both parties will document the dispute and elevate the issue to the Department's Contract Administrator. Failure to reach resolution of the dispute at this level will result in further escalation through the District Maintenance Administrator/Engineer and finally up to the Director of the Office of Maintenance whose decision is final. Beginning from the time the dispute is elevated to the Contract Administrator, the Department is allowed a total of ten (10) business days to resolve the dispute. If the ten (10) business day's elapse before the dispute is resolved or if the dispute is resolved in favor of the Contractor, the disputed MRP characteristic will be changed to reflect the Contractor's evaluation for the disputed MRP sample point. After all disputes are resolved, the Department will recalculate official MRP scores accordingly.

\section{PERMITS COORDINATION, PROCESSING, ADMINISTRATION, \&} INSPECTION

Perform all permitting activities within or associated with Department Right of Way. Meet all the requirements in Florida Administrative Code (F.A.C.), Rule.

Coordinate, process, administer, and inspect all permits on the roadways covered by this contract. Enter all permit related data into the Permits Information Tracking System. Collect all permit fees and turn them over to the Department's representative. The Department will retain all approvals and signatures as required by the F.A.C. Rule. Process all permits expeditiously as required by Florida Statutes and F.A.C. Rule. Process all permits to completion, which is either approval, denial or void. The scope of 
this contract does not include permitting of outdoor advertising billboards or permitting of overweight/overdimension vehicles.

In the Technical Proposal, include a Permit Processing Plan which details the permitting process, adherence to permitting requirements, and processes to ensure customer satisfaction.

\section{Permits Performance Criteria}

\begin{tabular}{|l|l|l|}
\hline PERMITS & \multicolumn{2}{|l|}{} \\
\hline Deficiency Identification & Time Allowed/Criteria & Deduction \\
\hline $\begin{array}{l}\text { a. Failure to timely } \\
\text { processed permits via } \\
\text { permits Information }\end{array}$ & Per Florida Statutes & $\$ 500$ per day per permit \\
and F.A.C. & \\
\hline $\begin{array}{l}\text { b. Failure to inspect } \\
\text { permitted activity as } \\
\text { required }\end{array}$ & $\begin{array}{l}\text { Per Florida Statutes, } \\
\text { p.A.C., procedures, }\end{array}$ & \\
\hline
\end{tabular}

ROADWAY CHARACTERISTICS INVENTORY (RCI)

Update the Maintenance Roadway Characteristics Inventory (RCI) when changes occur to any roadway characteristic within the project limits. Verify and update each RCI characteristic periodically as directed by the Maintenance Roadway Characteristics Inventory Manual. Maintain updated coding sheets in Contractor files.

\section{RCI Performance Criteria}

ROADWAY CHARACTERISTICS INVENTORY

\begin{tabular}{|l|l|l|}
\hline Deficiency Identification & Time Allowed/Criteria & Deduction \\
\hline a. Failure to timely and & Per RCl Manual & $\$ 100$ per day per \\
\hline
\end{tabular}




\begin{tabular}{|l|l|l|}
\hline accurately update $\mathrm{RCl}$ & $\begin{array}{l}\text { delinquent or incorrect } \mathrm{RCl} \\
\text { data entry }\end{array}$ \\
\hline
\end{tabular}

\section{REST AREAS, WELCOME CENTERS, and WAYSIDE PARKS (Not Included)}

The scope of this contract does not include the management, operation, or maintenance of Rest Areas, Welcome Centers, and Wayside Parks.

\section{REST AREA SECURITY (Not Included)}

The scope of this contract does not include providing any Security Guard Services at any Rest Area facilities.

\section{WELCOME CENTER SECURITY}

The scope of this contract does not include providing any Security Guard Services at any Welcome Center facilities.

\section{ROAD RANGER SERVICE PATROL}

The scope of this contract does not include providing Road Rangers Service Patrols.

\section{PAYMENT OF REST AREA UTILITY BILLS}

The scope of this contract does not include payment of utility bills (water, electric, sewer) associated with each Rest Area.

\section{PAYMENT OF WELCOME CENTER UTILITY BILLS}

The scope of this contract does not include payment of utility bills (water, electric, sewer) associated with each Welcome Center.

\section{WEIGH STATIONS}

The scope of this contract does not include Weigh Station maintenance.

\section{PAYMENT OF WEIGH STATION UTILITY BILLS}


The scope of this contract does not include payment of utility bills (water, electric, sewer) associated with each Weight Station.

\section{OVERLANE SIGN STRUCTURE MAINTENANCE}

Perform overlane sign structure maintenance, including collision damage repair.

\section{Overlane Sign Structure Performance Criteria}

\begin{tabular}{|l|l|l|}
\hline \multicolumn{2}{|l|}{ OVERLANE SIGN STRUCTURES } \\
\hline $\begin{array}{l}\text { Deficiency } \\
\text { Identification }\end{array}$ & Time Allowed/Criteria & Deduction \\
\hline $\begin{array}{l}\text { a. Failure to make repairs } \\
\text { identified in Inspection } \\
\text { Reports }\end{array}$ & $\begin{array}{l}\text { Within 30 days of } \\
\text { identification }\end{array}$ & $\begin{array}{l}\$ 1,000 \text { per day per } \\
\text { overlane sign structure }\end{array}$ \\
\hline $\begin{array}{l}\text { b. Failure to make } \\
\text { temporary safety repairs } \\
\text { resulting from incidents }\end{array}$ & $\begin{array}{l}\text { Must secure public safety } \\
\text { from hazards and } \\
\text { establish proper MOT } \\
\text { before leaving the site }\end{array}$ & $\begin{array}{l}\$ 1,000 \text { per day per } \\
\text { location }\end{array}$ \\
\hline $\begin{array}{l}\text { c. Failure to replace sign } \\
\text { structures damaged by } \\
\text { incidents }\end{array}$ & $\begin{array}{l}\text { Temporary signs installed } \\
\text { within 7 days } \\
\text { Permanent signs }\end{array}$ & $\begin{array}{l}\text { Temporary signs } \$ 500 \\
\text { per day per location } \\
\text { Permanent signs } \$ 500 \\
\text { installed within 180 days }\end{array}$ \\
\hline \hline
\end{tabular}

HIGH MAST LIGHT STRUCTURE INSPECTION AND MAINTENANCE Perform all high mast light structure maintenance, including collision damage repair.

High Mast Light Structure Maintenance Performance Criteria HIGH MAST LIGHT POLES

\begin{tabular}{|l|l|l|}
\hline $\begin{array}{l}\text { Deficiency } \\
\text { Identification }\end{array}$ & Time Allowed/Criteria & Deduction \\
\hline
\end{tabular}




\begin{tabular}{|l|l|l|}
\hline $\begin{array}{l}\text { a. Failure to make repairs } \\
\text { identified in Inspection } \\
\text { Reports. }\end{array}$ & $\begin{array}{l}\text { Within 30 days of } \\
\text { identification. }\end{array}$ & $\begin{array}{l}\$ 1,000 \text { per day per } \\
\text { overlane sign structure }\end{array}$ \\
\hline $\begin{array}{l}\text { b. Failure to make } \\
\text { temporary safety repairs } \\
\text { resulting from incidents. }\end{array}$ & $\begin{array}{l}\text { Must secure public safety } \\
\text { from hazards and } \\
\text { establish proper MOT } \\
\text { before leaving. }\end{array}$ & $\begin{array}{l}\$ 1,000 \text { per day per } \\
\text { location }\end{array}$ \\
\hline $\begin{array}{l}\text { c. Failure to replace sign } \\
\text { structures damaged by } \\
\text { incidents. }\end{array}$ & $\begin{array}{l}\text { Temporary signs installed } \\
\text { within } 7 \text { days. } \\
\text { Permanent signs } \\
\text { installed within } 180 \text { days. }\end{array}$ & $\begin{array}{l}\text { Temporary signs } \$ 500 \\
\text { per day per location. } \\
\text { Permanent signs } \$ 500\end{array}$ \\
\hline
\end{tabular}

\section{MOVABLE BRIDGE INSPECTION}

The scope of this contract does not include inspection of any movable bridges.

\section{NON-MOVABLE BRIDGE INSPECTION}

The scope of this contract does not include inspection of any non-movable bridges.

\section{MOVABLE \& NON-MOVABLE BRIDGE MAINTENANCE}

The scope of this contract does not include maintenance of any movable or non-movable bridges.

\section{NON-MOVABLE BRIDGE MAINTENANCE}

Bridge tasks are divided into appropriate maintenance activities as described in the Department's Maintenance Cost Handbook. Perform Routine/Preventive Bridge Maintenance and Minor Bridge Repair, including collision damage repair, defined as follows:

(a) Routine/Preventive Maintenance: The preservation and upkeep of a structure, including all its appurtenances, maintenance and servicing of mechanical, electrical and 
hydraulic systems, in its original condition (or as subsequently improved) insofar as practical. Preventive maintenance includes any activity intended to maintain an existing condition or to prevent deterioration. Examples include but are not limited to: cleaning, lubrication, spot painting, dirt and debris removal, and application of protective systems. Ideally, preventive maintenance is anticipated (i.e. planned) routine maintenance and does not require a Bridge Work Order to accomplish the work.

(b) Minor Repair: The restoration of a structure, including all its appurtenances, to its original condition (or as subsequently improved) insofar as practical. Minor repairs include any activity intended to correct the effects of minor material deterioration by restoring the damaged member. Minor repairs are generally defined as repairs to bridge elements that are structurally sound (i.e., no loss of strength), but may have minor section loss, cracking, spalling, or scour. Minor repairs are un-anticipated routine maintenance, usually identified by bridge inspectors and require a Work Order to schedule and accomplish the work. Examples include but are not limited to repair and/or replacement of an in-kind deck joint and localized material restoration of: deck expansion joints and joint systems, deck surfaces, sidewalks, drainage systems, bridge railing systems, superstructure members and bearing devices, substructure members, waterway channels, approach slabs, anchorages, all fender system components, mechanical, electrical or hydraulic systems, replacement of individual parts of the mechanical, electrical or hydraulic systems and structural crack injection and matrix loss restoration. Should a joint or joint system be partially or completely damaged, then the entire bridge width of the joint and affected nosing portion of joint system shall be replaced.

The scope of this contract does include performance of Periodic Bridge Maintenance and Major Repair defined as follows:

(a) Periodic Maintenance and Major Repair: The restoration of a structure, including all its appurtenances, to its original condition (or as subsequently improved) insofar as practical. Major repairs include any activity intended to correct deteriorated members. Conditions requiring major repairs 
include loss of section, deterioration, spalling, or scour that affect the strength of the member, replacement or upgrading of the mechanical, electrical or hydraulic systems. Engineering analysis is often performed to determine the extent of the lost strength. With prior approval of the District Feasible Action Review Committee, the District will enter into the work program all periodic and major repair work. At the Department's option, the contractor will perform the following Structure repairs. Excluding incident response and emergency repairs, the contractor will not be required to perform Periodic Maintenance and Repair in excess of $\$ 400,000.00$ without consideration by the Department for additional compensation. The Feasible Action Review Committee (FARC) will be responsible for the review and approval of the repair method, cost and time of each project assigned to the contractor. The Department will reserve the right to complete bridge repair work through its own Work Program or other means if necessary. The Contractor will not be entitled to the funds unless the work is performed on qualified projects as approved by the FARC. The funding for Periodic Maintenance and Repair is a limiting amount and will be invoiced under the corresponding financial project number. All prices will be in accordance with District Three contract prices.

Examples include but are not limited to localized or full material restoration of: deck expansion joints and joint systems, deck surfaces, sidewalks, drainage systems, bridge railing systems, superstructure members and bearing devices, substructure members, waterway channels, approach slabs, anchorages, all fender system components, concrete restoration requiring reinforcement splicing, structural crack injection and matrix loss restoration, and metal fabrication to restore the integrity of or to replace structural elements.

The scope of this contract does not include performance of Bridge Rehabilitation defined as follows:

(a) Rehabilitation: The improvement or betterment of a structure, including all its appurtenances, to a condition meeting or exceeding current design standards, insofar as practical. Examples of rehabilitation include: widening a bridge to meet lane/shoulder 
width requirements, replacement of substandard bridge rails, raising a bridge to meet clearance requirements, strengthening a bridge to increase load carrying capacity to accepted limits, and upgrading the operational equipment of a movable span.

The Department will periodically perform quality assurance reviews by inspecting bridge repairs and maintenance activities recently completed by the Contractor.

\section{Bridge Maintenance Performance Criteria}

\begin{tabular}{|c|c|c|}
\hline \multicolumn{3}{|l|}{ BRIDGE MAINTENANCE } \\
\hline $\begin{array}{l}\text { Deficiency } \\
\text { Identification }\end{array}$ & Time Allowed/Criteria & Deduction \\
\hline $\begin{array}{l}\text { a. Failure to timely make } \\
\text { repairs identified in } \\
\text { bridge work orders } \\
\text { (delinquent work orders) }\end{array}$ & $\begin{array}{l}\text { Per Procedure, Codes, } \\
\text { Manuals, etc. }\end{array}$ & $\begin{array}{l}\$ 1,000 \text { per day per } \\
\text { delinquent work order }\end{array}$ \\
\hline $\begin{array}{l}\text { b. Failure to make } \\
\text { temporary safety repairs } \\
\text { resulting from Incidents }\end{array}$ & $\begin{array}{l}\text { Must secure public safety } \\
\text { from hazards and } \\
\text { establish proper MOT } \\
\text { before leaving the site }\end{array}$ & $\begin{array}{l}\$ 1,000 \text { per day per } \\
\text { location }\end{array}$ \\
\hline $\begin{array}{l}\text { c. Failure to replace or } \\
\text { repair damaged bridge } \\
\text { railing }\end{array}$ & $\begin{array}{l}\text { Temporary repairs within } \\
24 \text { hrs of notification } \\
\text { Permanent repairs within } \\
7 \text { days of notification }\end{array}$ & $\begin{array}{l}\text { Temporary repairs } \$ 2000 \\
\text { per day per location } \\
\text { Permanent repairs } \$ 1000 \\
\text { per day per location }\end{array}$ \\
\hline \multicolumn{3}{|l|}{ NAVIGATION LIGHTING } \\
\hline $\begin{array}{l}\text { Deficiency } \\
\text { Identification }\end{array}$ & Time Allowed/Criteria & Deduction \\
\hline $\begin{array}{l}\text { a. Failure to temporarily } \\
\text { repair outage following } \\
\text { notification or discovery }\end{array}$ & $\begin{array}{l}\text { Per Performance Lighting } \\
\text { Specifications (Standard } \\
\text { Maintenance Special }\end{array}$ & $\begin{array}{l}\text { Per Performance Lighting } \\
\text { Specifications (SMSP) }\end{array}$ \\
\hline
\end{tabular}




\begin{tabular}{|c|c|c|}
\hline & Provisions) & \\
\hline $\begin{array}{l}\text { b. Failure to permanently } \\
\text { repair outage following } \\
\text { notification or discovery }\end{array}$ & $\begin{array}{l}\text { Per Performance Lighting } \\
\text { Specifications (Standard } \\
\text { Maintenance Special } \\
\text { Provisions) }\end{array}$ & $\begin{array}{l}\text { Per Performance Lighting } \\
\text { Specifications (SMSP) }\end{array}$ \\
\hline \multicolumn{3}{|l|}{ QUALITY CONTROL } \\
\hline $\begin{array}{l}\text { Deficiency } \\
\text { Identification }\end{array}$ & Time Allowed/Criteria & Deduction \\
\hline $\begin{array}{l}\text { a. Failure to properly } \\
\text { complete bridge repairs } \\
\text { as identified through } \\
\text { QAR }\end{array}$ & $\begin{array}{l}\text { Per Procedure, Codes, } \\
\text { Manuals, Design } \\
\text { Standards, etc. }\end{array}$ & $\begin{array}{l}\$ 500 \text { per day per location } \\
\text { until deficient repair is } \\
\text { corrected }\end{array}$ \\
\hline
\end{tabular}

MOVABLE BRIDGE TENDING \& PREVENTATIVE MAINTENANCE The scope of this contract does not include movable bridge tending duties or bridge tender preventative maintenance.

\section{PAYMENT OF MOVABLE BRIDGE UTILITY BILLS}

The scope of this contract does not include payment of utility bills (water, electric, sewer) associated with each movable bridge.

\section{TRAFFIC SIGNAL MAINTENANCE}

Maintain all flashing signs and traffic signals that are not covered by a maintenance agreement with a city or county. Perform maintenance according to applicable procedures, specifications, and other contract documents.

Traffic Signal Maintenance Performance Criteria TRAFFIC SIGNAL MAINTENANCE

\begin{tabular}{|l|l|l|}
\hline Deficiency Identification & Time Allowed/Criteria & Deduction \\
\hline \hline a. Failure to make & Must secure public safety & $\$ 1,000$ per day per \\
\hline
\end{tabular}




\begin{tabular}{|l|l|l|}
\hline $\begin{array}{l}\text { temporary safety repairs } \\
\text { resulting from Incidents }\end{array}$ & $\begin{array}{l}\text { from hazards and } \\
\text { establish proper MOT } \\
\text { before leaving the site }\end{array}$ & location \\
\hline $\begin{array}{l}\text { b. Failure to repair } \\
\text { damaged or } \\
\text { malfunctioning signal or } \\
\text { flashing sign }\end{array}$ & $\begin{array}{l}\text { Repairs made within } 48 \\
\text { hours of discovery }\end{array}$ & $\begin{array}{l}\$ 1,000 \text { per day per } \\
\text { location }\end{array}$ \\
\hline
\end{tabular}

\section{TRAFFIC OPERATIONS WORK ORDERS (}

The routine maintenance activities 520,521,532, 534, 537 shall be expanded to cover work orders issued from Traffic Operations studies The Contractor will be required to complete all work related to Florida Department of Transportation Traffic Services Requests within forty-five (45) days of receipt. These may include any system modifications, deletions, or additions related to but not limited to signing, pavement marking and safety related features including all labor and materials. This related work will not exceed $\$ 15,000.00$ cumulatively during any single contract year based upon the Department's unit prices. Costs must be based on established FDOT state contract prices.

Over-lane and cantilever structures and signs that are required by a Traffic Operations work order will be installed by others and the Asset Maintenance Contractor will be required to maintain the sign(s), structure and attachment(s) under the normal maintenance work effort once the installation is finished. Workloads are reflected in the "In House Crews Unit Cost Reports" on CD.

\section{Traffic Operations Work Orders Performance Criteria}

\section{TRAFFIC OPERATIONS WORK ORDERS}

\begin{tabular}{|l|l|l|}
\hline Deficiency Identification & Time Allowed/Criteria & Deduction \\
\hline a. Traffic Operations & Work must be completed & $1 \%$ of Work Order \\
Work Order not & within timeframe & amount per day late \\
\hline
\end{tabular}




\begin{tabular}{|l|l|l|}
\hline $\begin{array}{l}\text { completed within allowed } \\
\text { timeframe }\end{array}$ & established in Work Order. & \\
\hline b. Traffic Operations & Work must be completed & Re-perform the work \\
Work Order not & according to requirements & until correct plus any \\
completed correctly or & established in the Work & deductions due to \\
according to & Order, procedures, & exceeding allowed \\
requirements & specifications, and other & timeframe \\
& Contract Documents. & \\
\hline
\end{tabular}

\section{INTELLIGENT TRANSPORTATION SYSTEMS (ITS)}

The scope of this contract does not include any ITS components. 


\section{PAYMENT SCHEDULE}

The Contractor shall be paid monthly according to the schedule below. After the contract is awarded, the factors found in the Asset Maintenance RFP will be used to fill in actual monthly payment amounts into the Payment Schedule Chart below. For all contract years of the original contract term, the monthly dollar amount will be the total Contract amount multiplied by the monthly factor listed in the Asset Maintenance RFP divided by number of years of original contract term. For each renewal year, the monthly dollar amount will be the total Renewal amount multiplied by the monthly factor listed below divided by number of years of renewal term.

\begin{tabular}{|c|c|c|c|c|}
\hline Month & $\begin{array}{c}\text { Contract } \\
\text { Year 1 }\end{array}$ & $\begin{array}{c}\text { Contract } \\
\text { Years 2- } \\
4\end{array}$ & $\begin{array}{c}\text { Contract } \\
\text { Year 5 }\end{array}$ & $\begin{array}{c}\text { Each } \\
\text { Renewal } \\
\text { Year }\end{array}$ \\
\hline 1 & & & & \\
\hline 2 & & & & \\
\hline 3 & & & & \\
\hline 4 & & & & \\
\hline 5 & & & & \\
\hline 6 & & & & \\
\hline 7 & & & & \\
\hline 8 & & & & \\
\hline 9 & & & & \\
\hline 10 & & & & \\
\hline 11 & & & & \\
\hline
\end{tabular}




\begin{tabular}{|l|l|l|l|l|}
\hline 12 & & & & \\
\hline
\end{tabular}

Yearly

Amount

\section{OTHER CONTRACTUAL REQUIREMENTS}

1. The routine maintenance activities shall be modified as shown:

Activity 861 Bridge Electrical Maintenance shall be expanded to cover the following:

The wrong way detection system on the Pensacola Bay Bridge shall be maintained as designed. The maintenance of the complete system shall be reported under Activity 861 .

Activity 941 Supervision, Inspection and/or Engineering of Roadway Maintenance is expanded as follows:

The District's Community Awareness Plan shall be incorporated into all areas of maintenance activities. Notification of roadway closures/restrictions, due to 
routine maintenance operations, shall be forwarded to the District Public Information Office at a minimum of 48 hours.

2. The contractor will adhere to no daytime lane closures on Pensacola Bay Bridge, except for emergency situations.

PAYMENT OF ROADWAY ELECTRIC UTILITY BILLS

The Department will pay all highway lighting electric bills, including those for navigational lights on bridges. The contractor will be required to pay all other utility bills associated with this contract, including the utility bills associated with Kupfrain Park.

\section{Maintenance of Traffic Performance Criteria}

Maintenance of Traffic The contractor shall be responsible for all traffic control associated with but not limited to the following: structure inspection, survey crew activities, testing lab activities and highway patrol DUI check points. Contractor shall provide this service with a minimum of 72 hours notice. Contractor shall provide a trained individual certified in Maintenance of Traffic on-site to supervise these operations. There will be an anticipated thirty-five (35) callouts annually for Maintenance of Traffic for the duration of this project

\begin{tabular}{|l|c|c|}
\hline Deficiency Identification & Time Allowed/Criteria & Deduction \\
\hline $\begin{array}{l}\text { A. Failure to set up the } \\
\text { traffic control devices } \\
\text { by the begin schedule } \\
\text { time. }\end{array}$ & $\begin{array}{c}\text { Must have all traffic } \\
\text { control devices in } \\
\text { operation by the } \\
\text { scheduled time to } \\
\text { begin work. }\end{array}$ & $\begin{array}{l}\$ 100 \text { Per hour. } \\
\$ 5,000 \text { Per Site for } \\
\text { failure to appear. }\end{array}$ \\
\hline $\begin{array}{l}\text { B. Failure to provide a } \\
\text { Certified Maintenance } \\
\text { of Traffic Supervisor } \\
\text { on-site. }\end{array}$ & $\begin{array}{c}\text { Certified Maintenance of } \\
\text { Traffic Supervisor } \\
\text { must be in on-site. }\end{array}$ & \$500 Per Hour. \\
\hline
\end{tabular}

\section{PERMIT ADMINISTRATON REQUIREMENT BY CONTRACTOR}

All permits shall be date stamped on the day of receipt. All time requirements set forth in the specifications (Contract Documents) will be measured from the date of receipt. (90 day clock starts with receipt of complete package)

All 90-day requirements set forth in the Florida Statutes, Chapter 120, will not be exceeded. 
For all District Office reviews, time will be 14 calendar days.

Prior to the submission of any permit to the District or Field office for further processing, the contractor shall perform a review of the permit application to insure that the permit package meets all criteria established in the Department's publications applicable to permit processing (UAM, Standards specifications for Road and Bridge Construction, Design Standards, etc.).

The Contractor will monitor right-of-ways for appropriate use of permits.

The Contractor will comply with any interim rules in place at the time of contract execution and any future permanent rule changes in the application of the permitting process.

The following table will identify requirements for the Contractor to accomplish when dealing with various types of permits.

PERMIT RESPONSIBILITY DELINEATION SHEET

\begin{tabular}{|c|c|c|c|}
\hline $\begin{array}{l}\text { F.A.C. } \\
\text { RULE }\end{array}$ & PERMIT TYPE & $\begin{array}{l}\text { CONTRACTOR'S } \\
\text { RESPONSIBILITY }\end{array}$ & $\begin{array}{l}\text { D.O.T. } \\
\text { RESPONSIBILITY }\end{array}$ \\
\hline $14-20$ & $\begin{array}{c}\text { Bus Shelters } \\
\text { Part II General Use }\end{array}$ & $\begin{array}{l}\text { Recommend contact } \\
\text { to appropriate local } \\
\text { government Monitor } \\
\text { right-of-way for } \\
\text { violation of clear } \\
\text { zones and sight } \\
\text { distance criteria. }\end{array}$ & None \\
\hline $14-28$ & $\begin{array}{l}\text { Public Use of Rest } \\
\text { Areas, Wayside } \\
\text { Parks \& Solicitation } \\
\text { on State Facilities }\end{array}$ & $\begin{array}{l}\text { Approve } 850-040-71 \\
\text { in accordance with } \\
\text { rule. Refer applicant } \\
\text { to District Office for } \\
\text { approval of permit }\end{array}$ & $\begin{array}{l}\text { Approve } 850-040-70 \text { in } \\
\text { accordance with rule. }\end{array}$ \\
\hline
\end{tabular}




\begin{tabular}{|c|c|c|c|}
\hline $\begin{array}{l}\text { F.A.C. } \\
\text { RULE }\end{array}$ & PERMIT TYPE & $\begin{array}{l}\text { CONTRACTOR'S } \\
\text { RESPONSIBILITY }\end{array}$ & $\begin{array}{l}\text { D.O.T. } \\
\text { RESPONSIBILITY }\end{array}$ \\
\hline $14-40$ & $\begin{array}{l}\text { Highway } \\
\text { Beautification \& } \\
\text { Landscape } \\
\text { Management }\end{array}$ & $\begin{array}{l}\text { Refer to District } \\
\text { Maintenance Office. }\end{array}$ & $\begin{array}{l}\text { Review and approve by } \\
\text { District Office (District } \\
\text { Landscape Manager } \\
\text { review by rule) }\end{array}$ \\
\hline $14-43$ & $\begin{array}{l}\text { Regulation of } \\
\text { Encroachments Over } \\
\text { State Right-of-Ways }\end{array}$ & $\begin{array}{l}\text { Refer to District } \\
\text { Maintenance Office. }\end{array}$ & $\begin{array}{l}\text { Review for compliance \& } \\
\text { issue permit. }\end{array}$ \\
\hline U.A.M. & $\begin{array}{l}\text { Railroads/Utilities } \\
\text { Installation or } \\
\text { Adjustments }\end{array}$ & $\begin{array}{l}\text { (1) Refer permits } \\
\text { located within 5-year- } \\
\text { Work Program } \\
\text { project limits, to the } \\
\text { District Utilities } \\
\text { Office. } \\
\text { (2) Review permits } \\
\text { not in the } 5 \text {-Year - } \\
\text { Work Program for } \\
\text { compliance with } \\
\text { U.A.M. and obtain } \\
\text { approval signature } \\
\text { from Project } \\
\text { Manager. } \\
\text { (3) Forward } \\
\text { completed copy to } \\
\text { the District Public } \\
\text { Information Office. }\end{array}$ & $\begin{array}{l}\text { (1) Coordinates with } \\
\text { Work Program Projects. } \\
\text { (2) If necessary, } \\
\text { coordinate with FHWA. } \\
\text { Approve Permit }\end{array}$ \\
\hline
\end{tabular}




\begin{tabular}{|c|c|c|c|}
\hline $\begin{array}{l}\text { F.A.C. } \\
\text { RULE }\end{array}$ & PERMIT TYPE & $\begin{array}{l}\text { CONTRACTOR'S } \\
\text { RESPONSIBILITY }\end{array}$ & $\begin{array}{l}\text { D.O.T. } \\
\text { RESPONSIBILITY }\end{array}$ \\
\hline $14-63$ & House Moving & $\begin{array}{l}\text { Assume duties of } \\
\text { area Maintenance } \\
\text { Engineer or his } \\
\text { designee as outlined } \\
\text { in the rule. }\end{array}$ & $\begin{array}{l}\text { Reviews application \& } \\
\text { issues house moving } \\
\text { permit. }\end{array}$ \\
\hline $14-65$ & $\begin{array}{l}\text { Temporary Closing \& } \\
\text { Special Use of State } \\
\text { Roads }\end{array}$ & $\begin{array}{l}\text { Refer to District } \\
\text { Maintenance Office. }\end{array}$ & $\begin{array}{c}\text { Review for compliance } \\
\text { with rule and issue } \\
\text { permit. }\end{array}$ \\
\hline $14-86$ & $\begin{array}{l}\text { Drainage } \\
\text { Connections }\end{array}$ & $\begin{array}{l}\text { Receive permit and } \\
\text { send to District } \\
\text { Design Office. }\end{array}$ & $\begin{array}{c}\text { DOT Design approves } \\
\text { permit. }\end{array}$ \\
\hline $14-96$ & $\begin{array}{c}\text { State Highway } \\
\text { System Connection } \\
\text { Permits, } \\
\text { Administrative } \\
\text { Process }\end{array}$ & $\begin{array}{l}\text { (1) Accept permit } \\
\text { fee, issue } \\
\text { receipt, forward } \\
\text { fee to District } \\
\text { Office. Log into } \\
\text { PITS. } \\
\text { (2) Review for } \\
\text { completeness } \\
\text { per rule and } \\
\text { applicable } \\
\text { standards. } \\
\text { Send completed } \\
\text { application to } \\
\text { District Office. } \\
\text { (3) Receive and } \\
\text { process either } \\
\text { Letter of Intent } \\
\text { or } \\
\text { completeness } \\
\text { Review Form. } \\
\text { (4) Ensure } \\
\text { conditions on }\end{array}$ & $\begin{array}{c}\text { Review for conformance } \\
\text { to Rule } 14-97 \text { and other } \\
\text { Department } \\
\text { requirements. Issue } \\
\text { Notice of Intent or } \\
\text { Completeness Review } \\
\text { Form. }\end{array}$ \\
\hline
\end{tabular}




\begin{tabular}{|c|c|c|c|}
\hline $\begin{array}{l}\text { F.A.C. } \\
\text { RULE }\end{array}$ & PERMIT TYPE & $\begin{array}{l}\text { CONTRACTOR'S } \\
\text { RESPONSIBILITY }\end{array}$ & $\begin{array}{l}\text { D.O.T. } \\
\text { RESPONSIBILITY }\end{array}$ \\
\hline & & $\begin{array}{l}\text { Letter of } \\
\text { Intent, if any, } \\
\text { are met. Obtain } \\
\text { Project } \\
\text { Manager's } \\
\text { approval of } \\
\text { permit }\end{array}$ & \\
\hline $62-642$ & $\begin{array}{c}\text { Municipal Separate } \\
\text { Storm Sewer } \\
\text { Systems } \\
\text { (N.P.D.E.S) }\end{array}$ & $\begin{array}{l}\text { (1) Assume all } \\
\text { duties assigned } \\
\text { to the } \\
\text { Department of } \\
\text { Transportation } \\
\text { as outlined in } \\
\text { the existing } \\
\text { permit number } \\
\text { FLS000019. } \\
\text { (2) Complete } \\
\text { annual reporting } \\
\text { requirements } \\
\text { and submit for } \\
\text { Department } \\
\text { review and } \\
\text { approval }\end{array}$ & $\begin{array}{l}\text { Review for conformance } \\
\text { with permit requirements } \\
\text { and sign annual report. }\end{array}$ \\
\hline
\end{tabular}

Permits Performance Criteria, Page 17, Table is expanded by adding the following: 


\begin{tabular}{|l|l|l|}
\hline $\begin{array}{c}\text { Deficiency Identification } \\
\text { required inspection } \\
\text { and/or reporting } \\
\text { requirements or fails to } \\
\text { adhere to the NPDES } \\
\text { permit requirements. }\end{array}$ & $\begin{array}{c}\text { Time Allowed/Criteria } \\
\text { District's NPDES } \\
\text { Permit }\end{array}$ & $\begin{array}{c}\text { Deduction } \\
\text { violation }\end{array}$ \\
\hline $\begin{array}{l}\text { Failure to conduct review } \\
\text { of permit for } \\
\text { compliance with the } \\
\text { Department's } \\
\text { publications applicable } \\
\text { to permit processing }\end{array}$ & As established in this \\
amendment & $\$ 300$ per violation. \\
\hline
\end{tabular}

\section{MISCELLANEOUS MAINTENANCE}

All system modifications as previously handled by Florida Department of Transportation maintenance forces will be the responsibility of the Contractor including all system drainage modifications as required by the Project Manager from the recommendation of the District Drainage Engineer. These may include but not be limited to any system changes, additions or deletions in accordance with District directions. These shall include all labor and materials. These modifications will not exceed $\$ 10,000.00$ cumulatively during any single contract year. Cost shall be based on established FDOT District Three contract prices.

\begin{tabular}{|l|l|l|}
\hline \multicolumn{2}{|l|}{ MISCELLANEOUS MAINTEANCE } \\
\hline Deficiency Identification & Time Allowed/Criteria & Deduction \\
\hline $\begin{array}{l}\text { a. Miscellaneous } \\
\text { Maintenance Work Order } \\
\text { not completed within } \\
\text { allowed timeframe }\end{array}$ & $\begin{array}{l}\text { Work must be completed } \\
\text { within timeframe } \\
\text { established in Work Order. }\end{array}$ & $\begin{array}{l}1 \% \text { of Work Order } \\
\text { amount per day late }\end{array}$ \\
\hline $\begin{array}{l}\text { b. Miscellaneous } \\
\text { Maintenance Work Order }\end{array}$ & $\begin{array}{l}\text { Work must be completed } \\
\text { according to requirements }\end{array}$ & $\begin{array}{l}\text { Re-perform the work } \\
\text { until correct plus any }\end{array}$ \\
\hline
\end{tabular}




\begin{tabular}{|c|c|c|}
\hline $\begin{array}{l}\text { not completed correctly or } \\
\text { according to } \\
\text { requirements }\end{array}$ & $\begin{array}{l}\text { established in the Work } \\
\text { Order, procedures, } \\
\text { specifications, and other } \\
\text { Contract Documents. }\end{array}$ & $\begin{array}{l}\text { deductions due to } \\
\text { exceeding allowed } \\
\text { timeframe }\end{array}$ \\
\hline
\end{tabular}

\section{QUALITY MANAGEMENT}

Quality Assurance targets are used as a measure of a contractor's compliance with all contract requirements. The individual performance indicators listed in the contract may or may not be all inclusive as to the requirements listed in the regulating documents. It is the contractor's responsibility to familiarize themselves with all governing documents and to establish Quality Management practices that validate the contractor's compliance with all documents. The contractor's Quality Management Plan will be dynamic in nature in order to readily adapt to changes in Policy, Procedure, Rule, Statutes, or Operations Plans.

\begin{tabular}{|c|c||c||}
\hline QUALITY ASSURANCE & \multicolumn{2}{|c|}{} \\
\hline Deficiency Identification & Time Allowed/Criteria & $\begin{array}{c}\text { Deduction Per \% Point } \\
\text { Below Criteria }\end{array}$ \\
\hline Permits & $\begin{array}{c}90 \% \text { of Permits } \\
\text { administered } \\
\text { conforms to contract } \\
\text { requirements }\end{array}$ & $\$ 500$ \\
\hline Bridge Repairs & $\begin{array}{c}90 \% \text { of Repairs conforms } \\
\text { to contract } \\
\text { requirements. }\end{array}$ & $\$ 2000$ \\
\hline Highway Lighting & $\begin{array}{c}90 \% \text { of Highway Lighting } \\
\text { conforms to contract } \\
\text { requirements }\end{array}$ & $\$ 1000$ \\
\hline
\end{tabular}




\begin{tabular}{|c|c|c|}
\hline Emergency Response & $\begin{array}{l}\text { 95\% of Emergency } \\
\text { Responses conforms } \\
\text { to contract } \\
\text { requirements }\end{array}$ & $\$ 1000$ \\
\hline Barrier Wall & $\begin{array}{l}95 \% \text { of Barrier Wall } \\
\text { maintenance } \\
\text { conforms to contract } \\
\text { requirements }\end{array}$ & $\$ 1000$ \\
\hline Graffiti Removal & $\begin{array}{l}100 \% \text { of Graffiti conforms } \\
\text { to contract } \\
\text { requirements }\end{array}$ & $\$ 200$ \\
\hline $\begin{array}{c}\text { Traffic Operations Work } \\
\text { Orders }\end{array}$ & $\begin{array}{l}100 \% \text { of Traffic } \\
\text { Operations Work } \\
\text { Orders conforms to } \\
\text { contract } \\
\text { requirements }\end{array}$ & $\$ 200$ \\
\hline Maintenance of Traffic & $\begin{array}{l}100 \% \text { of Maintenance of } \\
\text { Traffic conforms to } \\
\text { contract } \\
\text { requirements }\end{array}$ & $\$ 200$ \\
\hline $\begin{array}{c}\text { Roadway Characteristic } \\
\text { Inventory }\end{array}$ & $\begin{array}{l}90 \% \text { of the activities of } \\
\text { the Roadway } \\
\text { Characteristic } \\
\text { Inventory process } \\
\text { conform to contract } \\
\text { requirements. }\end{array}$ & $\$ 500$ \\
\hline
\end{tabular}




\begin{tabular}{|c|c|c|}
\hline $\begin{array}{l}\text { Miscellaneous } \\
\text { Maintenance }\end{array}$ & $\begin{array}{l}100 \% \text { of Miscellaneous } \\
\text { Maintenance } \\
\text { conforms to contract } \\
\text { requirements. }\end{array}$ & $\$ 100$ \\
\hline Clear Zone Obstructions & $\begin{array}{l}100 \% \text { of Clear Zone } \\
\text { maintenance } \\
\text { conforms to contract } \\
\text { requirements. }\end{array}$ & $\$ 500$ \\
\hline Navigation Lights & $\begin{array}{l}100 \% \text { of Navigation Light } \\
\text { maintenance } \\
\text { conforms to contract } \\
\text { requirements. }\end{array}$ & $\$ 1000$ \\
\hline Adopt-A-Highway & $\begin{array}{l}100 \% \text { of Adopt-A- } \\
\text { Highway program } \\
\text { conforms to contract } \\
\text { requirements. }\end{array}$ & $\$ 100$ \\
\hline Motorist Aid Call Boxes & $\begin{array}{l}90 \% \text { of Motorist Aid Call } \\
\text { Box maintenance } \\
\text { conforms to contract } \\
\text { requirements. }\end{array}$ & $\$ 2000$ \\
\hline $\begin{array}{l}\text { Existing Contract } \\
\text { Administration }\end{array}$ & $\begin{array}{l}95 \% \text { of Existing } \\
\text { Contracts } \\
\text { administration } \\
\text { conforms to contract } \\
\text { requirements. }\end{array}$ & $\$ 200$ \\
\hline Customer Service & $\begin{array}{l}100 \% \text { of Customer } \\
\text { Service operations } \\
\text { conform to contract } \\
\text { requirements. }\end{array}$ & $\$ 200$ \\
\hline
\end{tabular}




\begin{tabular}{|c|c|c|}
\hline $\begin{array}{c}\text { Guard Rail (Non-MRP } \\
\text { requirements) }\end{array}$ & $\begin{array}{l}90 \% \text { of Guard Rail } \\
\text { maintenance } \\
\text { conforms to contract } \\
\text { requirements }\end{array}$ & $\$ 500$ \\
\hline $\begin{array}{c}\text { Attenuators (Non-MRP } \\
\text { requirements) }\end{array}$ & $\begin{array}{l}90 \% \text { of Attenuator } \\
\text { maintenance } \\
\text { conforms to contract } \\
\text { requirements }\end{array}$ & $\$ 500$ \\
\hline $\begin{array}{l}\text { Signs (Non-MRP } \\
\text { requirements) }\end{array}$ & $\begin{array}{l}90 \% \text { of Sign } \\
\text { maintenance } \\
\text { conforms to contract } \\
\text { requirements. }\end{array}$ & $\$ 500$ \\
\hline $\begin{array}{c}\text { Regulatory documents } \\
\text { (Policies, Procedures, } \\
\text { statues, rules manuals, } \\
\text { guidelines, etc) }\end{array}$ & $\begin{array}{l}100 \% \text { application and } \\
\text { conformance of } \\
\text { regulatory } \\
\text { documents }\end{array}$ & $\$ 100$ \\
\hline Traffic Signal Maintenance & $\begin{array}{l}95 \% \text { of Traffic Signal } \\
\text { Maintenance } \\
\text { conforms to contract } \\
\text { requirements. }\end{array}$ & $\$ 500$ \\
\hline $\begin{array}{c}\text { Disadvantaged Business } \\
\text { Enterprise }\end{array}$ & $\begin{array}{l}100 \% \text { of D.B.E. } \\
\text { utilization conforms } \\
\text { to contract } \\
\text { requirements. }\end{array}$ & $\$ 500$ \\
\hline $\begin{array}{c}\text { Maintenance Management } \\
\text { System Reporting }\end{array}$ & $\begin{array}{l}90 \% \text { of Maintenance } \\
\text { Management System } \\
\text { reporting conforms to } \\
\text { contract } \\
\text { requirements. }\end{array}$ & $\$ 100$ \\
\hline
\end{tabular}




\section{ATTACHMENT I}

\section{MAINTENANCE AREAS AND COUNTY NUMBERS}

\section{DISTRICT 1}

\begin{tabular}{|c|c|c|}
\hline MAINTENANCE UNIT & COST CENTER & COUNTY \& NUMBER \\
\hline Bartow & 190 & 16 - Polk \\
\hline Sebring & 191 & $\begin{array}{l}09-\text { Highlands } \\
91-\text { Okeechobee }\end{array}$ \\
\hline Fort Myers & 192 & $\begin{array}{l}01-\text { Charlotte } \\
12-\text { Lee }\end{array}$ \\
\hline Labelle & 193 & $\begin{array}{l}05-\text { Glades } \\
07-\text { Hendry }\end{array}$ \\
\hline Sarasota & 194 & $\begin{array}{l}13-\text { Manatee } \\
17-\text { Sarasota }\end{array}$ \\
\hline Arcadia & 195 & $\begin{array}{l}04-\text { Desoto } \\
06-\text { Hardee }\end{array}$ \\
\hline Naples & 197 & $03-$ Collier \\
\hline
\end{tabular}

\section{DISTRICT 2}

\begin{tabular}{|c|c|c|}
\hline MAINTENANCE UNIT & COST CENTER & COUNTY \& NUMBER \\
\hline Gainesville & 291 & $\begin{array}{l}26-\text { Alachua } \\
28-\text { Bradford }\end{array}$ \\
\hline Lake City & 292 & $\begin{array}{l}27 \text { - Baker } \\
29 \text { - Columbia } \\
32 \text { - Hamilton } \\
37 \text { - Suwannee } \\
39 \text { - Union }\end{array}$ \\
\hline Perry & 293 & $\begin{array}{l}33 \text { - Lafayette } \\
35 \text { - Madison } \\
38 \text { - Taylor }\end{array}$ \\
\hline Jacksonville & 294 & $\begin{array}{l}71 \text { - Clay } \\
72 \text { - Duval } \\
74-\text { Nassau }\end{array}$ \\
\hline Chiefland & 296 & $\begin{array}{l}30-\text { Dixie } \\
31-\text { Gilchrist } \\
34-\text { Levy }\end{array}$ \\
\hline St. Augustine & 297 & $\begin{array}{l}76-\text { Putnam } \\
78-\text { St. Johns }\end{array}$ \\
\hline
\end{tabular}

\section{DISTRICT 3}

\begin{tabular}{|c|c|c|}
\hline MAINTENANCE UNIT & COST CENTER & COUNTY \& NUMBER \\
\hline \multirow{2}{*}{ Defuniak Springs } & \multirow{2}{*}{390} & $\begin{array}{l}57-\text { Okaloosa } \\
60-\text { Walton }\end{array}$ \\
\hline \multirow{2}{*}{ Panama City } & \multirow{2}{*}{391} & $46-$ Bay \\
& & $47-$ Calhoun \\
& & $51-$ Gulf \\
\hline \multirow{2}{*}{ Midway } & \multirow{2}{*}{392} & $49-$ Franklin \\
& & $50-$ Gadsden \\
& & $54-$ Jefferson \\
& & $55-$ Leon \\
& & $56-$ Liberty \\
& & $59-$ Wakulla \\
\hline
\end{tabular}




\begin{tabular}{|l|l|l|}
\hline Marianna & 393 & $\begin{array}{l}52-\text { Holmes } \\
53-\text { Jackson } \\
61-\text { Washington }\end{array}$ \\
\hline Milton & & $58-$ Santa Rosa \\
\hline Pensacola & 394 & 48 - Escambia \\
\hline
\end{tabular}

\section{DISTRICT 4}

\begin{tabular}{|c|c|c|}
\hline MAINTENANCE UNIT & COST CENTER & COUNTY \& NUMBER \\
\hline Fort Pierce & 490 & $\begin{array}{l}88-\text { Indian River } \\
89-\text { Martin } \\
94-\text { St. Lucie }\end{array}$ \\
\hline Fort Lauderdale & & $86-$ Broward \\
\hline West Palm Beach & 491 & $93-$ Palm Beach \\
\hline
\end{tabular}

\section{DISTRICT 5}

\begin{tabular}{|c|c|c|}
\hline MAINTENANCE UNIT & COST CENTER & COUNTY \& NUMBER \\
\hline Cocoa & 590 & $\begin{array}{l}70-\text { Brevard } \\
75-\text { Orange } \\
79-\text { Volusia } \\
92-\text { Osceola }\end{array}$ \\
\hline Deland & 591 & $\begin{array}{l}11 \text { - Lake } \\
18 \text { - Sumter } \\
75 \text { - Orange } \\
77 \text { - Seminole }\end{array}$ \\
\hline Leesburg & 592 & $\begin{array}{l}11-\text { Lake } \\
18-\text { Sumter } \\
75 \text { - Orange } \\
77 \text { - Seminole }\end{array}$ \\
\hline Oviedo & 593 & $\begin{array}{l}75 \text { - Orange } \\
77 \text { - Seminole }\end{array}$ \\
\hline Orlando & 594 & $\begin{array}{l}75-\text { Orange } \\
92-\text { Osceola }\end{array}$ \\
\hline Ocala & 595 & $36-$ Marion \\
\hline
\end{tabular}

\section{DISTRICT 6}

\begin{tabular}{|c|c|c|}
\hline MAINTENANCE UNIT & COST CENTER & COUNTY \& NUMBER \\
\hline South Dade & 690 & 87 - Dade \\
\hline North Dade & 691 & 87 - Dade \\
\hline Marathon & 692 & $90-$ Monroe \\
\hline
\end{tabular}

\section{DISTRICT 7}

\begin{tabular}{|c|c|c|}
\hline MAINTENANCE UNIT & COST CENTER & COUNTY \& NUMBER \\
\hline Tampa & 796 & $10-$ Hillsborough \\
\hline \multirow{2}{*}{ Brooksville } & 798 & $08-$ Hernando \\
& & $14-$ Pasco \\
& 799 & $02-$ Citrus \\
\hline Pinellas & & 15 - Pinellas \\
\hline
\end{tabular}




\section{FLORIDA TURNPIKE}

\begin{tabular}{|c|l|l|}
\hline MAINTENANCE UNIT & COST CENTER & COUNTY \& NUMBER \\
\hline Turnpike Facilities & 852 & See Counties Listed Above \\
\hline Turnpike Roadway & 853 & See Counties Listed Above \\
\hline
\end{tabular}




\section{ATTACHMENT II}

\section{DEPARTMENT CONTRACTS THAT WILL CONTINUE INTO THE ASSET} MAINTENANCE CONTRACT

\begin{tabular}{|c|c|c|c|c|}
\hline $\begin{array}{r}\text { DISTRICT/ } \\
\text { AREA }\end{array}$ & $\begin{array}{c}\text { CONTRACT } \\
\text { NUMBER }\end{array}$ & DESCRIPTION & $\begin{array}{c}\text { CONTRACT } \\
\text { END } \\
\text { DATE }\end{array}$ & CONTRACTOR \\
\hline & & & & \\
\hline & & & & \\
\hline & & & & \\
\hline & & & & \\
\hline & & & & \\
\hline & & & & \\
\hline & & & & \\
\hline & & & & \\
\hline & & & & \\
\hline & & & & \\
\hline & & & & \\
\hline & & & & \\
\hline & & & & \\
\hline & & & & \\
\hline & & & & \\
\hline & & & & \\
\hline & & & & \\
\hline & & & & \\
\hline & & & & \\
\hline & & & & \\
\hline & & & & \\
\hline & & & & \\
\hline & & & & \\
\hline & & & & \\
\hline & & & & \\
\hline & & & & \\
\hline
\end{tabular}


Appendix G

TXDOT PBC Contract 


\section{SUMMARY OF: TEXAS DOT SPECIAL SPECIFICATIONS ON PERFORMANCE BASED ROADSIDE MAINTENANCE OF HIGHWAYS}

\section{Performance Standards}

Listed below are performance standards, which are utilized to schedule work on Highway segments on Texas State:

\section{(a) Routine Roadside Maintenance}

Litter and Debris Pickup

- The right of way shall be kept in a neat condition and free of litter and debris.

- Dead animals that can be handled by one person shall be removed immediately upon discovery. Large animals shall be immediately removed from the paved surfaces. Large animals shall be disposed of at an approved site within 24 hours of discovery and/or notification.

- Tires or tire tread shall be removed from paved surfaces daily upon discovery.

- All litter collected shall become the property of the Contractor and shall be disposed of at an approved solid waste site(s). Bagged litter shall be picked up and removed from the right-of way on the same day of collection.

- All vehicles used in transporting litter shall be equipped to prevent the accumulated litter from being strewn along the roadway.

- The Contractor shall immediately remove potentially dangerous debris.

- $\quad$ "Lost and Found" items are to be forwarded to the Engineer.

Embankments

- Care should be taken, when working on the right-of-way, to avoid damaging slopes and embankments.

- Repair erosion or damage by filling to bring the right of way back to the original lines and grades.

- Riprap (concrete slope protection) shall have all joints free from vegetation.

- Slope failures shall be repaired by a method approved by the Engineer. Slopes shall approximately conform to the original cross-section and shall be revegetated.

- Retaining walls shall be maintained vertical, with drain holes clear. Reinforced earth walls shall be monitored for movement or for loss of backfill and repaired as approved by the Engineer. 
- Adequate sodding, seeding, fertilizer, erosion control blankets, silt fences, rock berms, etc. shall be provided to allow repaired areas to revegetate.

\section{(b) Roadside Vegetative Maintenance}

Vegetation Management

- The height of grass and weeds shall be kept between 7 in. and 30 in. Mowing shall begin before vegetation reaches 30 in.

- Spot mowing at intersections, ramps or other areas shall be performed as needed to maintain visibility of appurtenances and sight distance or as directed by the Engineer.

- Grass shall not be allowed to encroach into or on paved shoulders, main lanes, sidewalks, islands, riprap, traffic barrier or curbs. Chemical edging will be required.

- Utilize only the herbicides listed in the Herbicide Operations Manual to develop a herbicide program to control noxious weeds and to eliminate grass in pavement or concrete. The Contractor will follow the Department's herbicide plan.

- A full width mowing cycle shall be completed after the first frost or as directed by the Engineer.

- Wildflowers shall be preserved utilizing the guidelines in the mowing specifications and vegetation management manuals.

- Herbicide application records and proof of purchases for all herbicides shall be submitted weekly to the Engineer. A complete set of records and proof of purchases shall be submitted annually from date of contract initiation.

Landscaped Areas

- All landscaped areas shall be maintained to their originally constructed condition. Landscaped areas will be as designated in the plans.

- Items include but are not limited to mowing, litter pickup, irrigation system maintenance and operation, plant maintenance, pruning, insect, disease and pest control, fertilization, mulching, bed maintenance, watering, etc.

- The height of grass and weeds shall be kept between 4 in. and 8 in. Mowing shall begin before vegetation reaches 8 in. The Contractor shall replace any damaged or dead vegetation in a timeframe approved by the Engineer. 
Tree and Brush Control

- Trees, brush and ornamentals on the right of way, except in established non-mow areas, shall be trimmed in accordance with Department standards to allow mowers access. Trees, brush and ornamentals shall be trimmed to insure they do not interfere with vehicles or sight distance, or inhibit the visibility of signs. Dead trees, brush, ornamentals and branches shall be removed within 2 months, unless considered to be a hazard. Potentially dangerous trees or limbs shall be removed as soon as possible.

- All undesirable trees and vegetation shall be removed as determined by the Engineer.

\section{(c) Traffic Operations}

Signs (includes overhead signs)

- Perform night sign inspections on six-month intervals and replace non-reflective signs within 30 days.

- Maintain all sign posts vertical with all break-away sign mounts clear of silt or other debris that could impede break-away features. Posts shall not be rusted.

- Replace damaged to vandalized signs unless otherwise approved by the Engineer.

- Longitudinal placement must be in accordance with SMD standard sheets.

- Lateral placement must be in accordance with Department's Sign Crew Field Book.

- Replace damaged warning and regulatory signs as soon as possible upon discovery, or as directed by the Engineer.

- Large signs knocked down shall be removed immediately beyond the limits of the clear zone or off the ROW, upon discovery, and shall be repaired or replaced within two months. Sign faces shall be properly washed prior to reinstallation.

- Open signs warning of ice on bridges in the fall and close in the spring on a schedule as directed by the Engineer.

- Install temporary ground-mounted signs immediately upon discovery for damaged exit signs.

\section{Highway Lighting}

- Perform monthly night inspection of luminaires and all deficiencies shall be repaired within 1 week after inspection. 
- $100 \%$ of access panels present and secured.

- Non-functional lights will be repaired within a week of discovery or notification.

- Luminaire poles knocked down shall be removed immediately upon discovery and/or notification, and shall be repaired or replaced within 3 weeks.

- Replace broken or damaged transformer bases within 3 weeks of discovery and/or notification.

Guardrail

- Damaged guardrail that will no longer function as designed shall be repaired or replaced within 1 week; remove debris and install warning signs immediately upon discovery.

- Damaged, but functional, guardrail shall be replaced or repaired within one month after discovery.

- If, in the opinion of the Engineer, they are required for access control, the Contractor shall install new post and cable fence.

- Repair or replace damaged post and cable fencing within 1 month of discovery.

\section{Cable Barrier}

- Repair or replace damaged cable barrier within 1 week of discovery.

\section{Bridge Railing}

- Repair or replace damaged bridge rail, approach guardrail, end treatments or attenuators within 1 week; install warning signs and temporary railing as appropriate immediately upon discovery or as approved by the Engineer

- All bridge rails shall be free of rust.

\section{Impact Attenuators.}

- Damaged impact attenuators that will no longer function as designed shall be repaired or replaced within 1 week. Remove debris and install warning signs immediately upon discovery of damage.

- Inspect every 6 month and clean or adjust as necessary to ensure proper operation. 
- Damaged, but functional, attenuators shall be replaced or repaired within one month.

Overhead Sign Structures.

- Remove overhead sign structures that present a safety hazard immediately upon discovery.

- Overhead sign structures that must be replaced will be done so by the Department.

Object Markers and Delineators.

- Repair or replace defective delineators. They will be considered defective if they are not reflective, are not vertical or are missing. Use like type of delineators when replacing unless approved by the Engineer.

\section{Contractor Performance - Non-performance Procedure}

(a) The Texas Department will notify the Contractor of a performance standard as shown above ("Performance Standards"), that has not been met. After notification, if the Performance Standard is not met in a time frame determined by the Engineer, the Contractor will be charged $\$ 5,000$ per day (including Saturdays, Sunday and holidays), per item of work, per standard until the standard is met. The costs associated with these measures will be deducted from any monies due the Contractor.

(b) In addition, the Department may take steps to have the work corrected. This may include the use of State Forces or Emergency Contracts. Once the Contractor is notified that the Department is taking corrective action, the Contractor shall refrain from performing work on the item in question unless approved by the Engineer. The costs associated with these measures will be deducted from any monies due the Contractor.

(c) Formal Condition Assessment: Also, in addition, the Department will perform random formal condition monthly. Each assessment will be performed on at least $10 \%$ of the length of all roadways including frontage roads and both main lanes. Sections to be inspected will be selected randomly in approximately one mile length segments. Table 1 shows the required minimum standards and the reduced compensation that will be made per month when the standards are not met. 
Table 1: Reduced Compensation

\begin{tabular}{|c|c|c|c|}
\hline \multirow[t]{4}{*}{$\frac{\text { Payment }}{\underline{\text { Reduction }}}$} & Items & Minimum Standard & $\begin{array}{l}\text { Reduced compensation per } \\
\text { month with performance } \\
\text { below minimum standards. * }\end{array}$ \\
\hline & "Element" & $70 \%$ & $\begin{array}{l}=\$ 2.00 \times \mathrm{P} \times \mathrm{LM} \\
\text { for each Element }\end{array}$ \\
\hline & "Component" & $80 \%$ & $\begin{array}{l}=\$ 5.00 \times \mathrm{P} \times \mathrm{LM} \\
\text { for each Component }\end{array}$ \\
\hline & "Overall" & $90 \%$ & $=\$ 10.00 \times \mathrm{P} \times \mathrm{LM}$ \\
\hline $\begin{array}{l}* \text { Definition } \\
\text { of Term }\end{array}$ & \multicolumn{3}{|c|}{$\begin{array}{l}\mathrm{P} \text { - the percentage below the minimum standard } \\
\text { LM -total lane miles in the total project } \\
\mathrm{X} \text { - multiplication sign } \\
\text { The elements, components and the overall items are listed on the inspection form } \\
\text { that follows. Descriptions of how these items are rated and examples calculations of } \\
\text { values area also shown. }\end{array}$} \\
\hline
\end{tabular}

Source: "Special Specifications on Performance Based Roadside Maintenance of Highways",

Texas Department of Transportation, 2004.

For any element, component, or the overall average shown in the plans that meets minimum standards in Table 1 the Contractor will be required to meet the standards in Table 1 from the start of the contract.

The Contractor will be given the time listed in Table 2 to bring the components up to standards in Table 1.

Table 2: Components 


\begin{tabular}{|l|l|}
\hline Components & $\begin{array}{l}\text { Time } \\
\text { Allotted at } \\
\text { the } \\
\text { beginning } \\
\text { of contract } \\
\text { to bring } \\
\text { TxMAP } \\
\text { scores up } \\
\text { to } \\
\text { minimum } \\
\end{array}$ \\
\cline { 2 - 2 } & standards \\
\hline Traffic & 4 \\
Operations & months \\
\hline Roadside & 3 \\
& months \\
\hline Vegetation & 3 \\
\hline Management & months \\
\hline
\end{tabular}

Source: "Special Specifications on Performance Based Roadside Maintenance of Highways", Texas Department of Transportation, 2004.

The Contractor will be given the time listed in Table 3 to bring the elements up to the standard in Table 1.

Table 3: Elements 


\begin{tabular}{|c|c|c|}
\hline Component & $\begin{array}{l}\text { Component } \\
\text { Element }\end{array}$ & $\begin{array}{l}\text { Time } \\
\text { Allotted } \\
\text { at the } \\
\text { beginning } \\
\text { of } \\
\text { contract } \\
\text { to bring } \\
\text { TxMAP } \\
\text { scores up } \\
\text { to } \\
\text { minimum } \\
\text { standards }\end{array}$ \\
\hline \multirow[t]{5}{*}{$\begin{array}{l}\text { Traffic } \\
\text { Operations }\end{array}$} & Signs - Large & 2 months \\
\hline & Signs - Small & 2 months \\
\hline & Attenuators & 1 month \\
\hline & Delineators & 2 months \\
\hline & Guard Rails & 1 month \\
\hline \multirow[t]{4}{*}{ Roadside } & Litter & 1 month \\
\hline & Sweeping & 1 month \\
\hline & Drainage & 6 months \\
\hline & Encroachments & 2 months \\
\hline \multirow[t]{4}{*}{$\begin{array}{l}\text { Vegetation } \\
\text { Management }\end{array}$} & Mowing & 1 month \\
\hline & $\begin{array}{l}\text { Vegetation } \\
\text { Control }\end{array}$ & 2 months \\
\hline & $\begin{array}{l}\text { Noxious Weed } \\
\text { Control }\end{array}$ & 2 months \\
\hline & Brush Control & 3 months \\
\hline
\end{tabular}

Source: "Special Specifications on Performance Based Roadside Maintenance of Highways",

Texas Department of Transportation, 2004. 
Listed below is the Formal Assessment inspection form, an example of the scoring sheet and the scoring criteria for each of the elements.

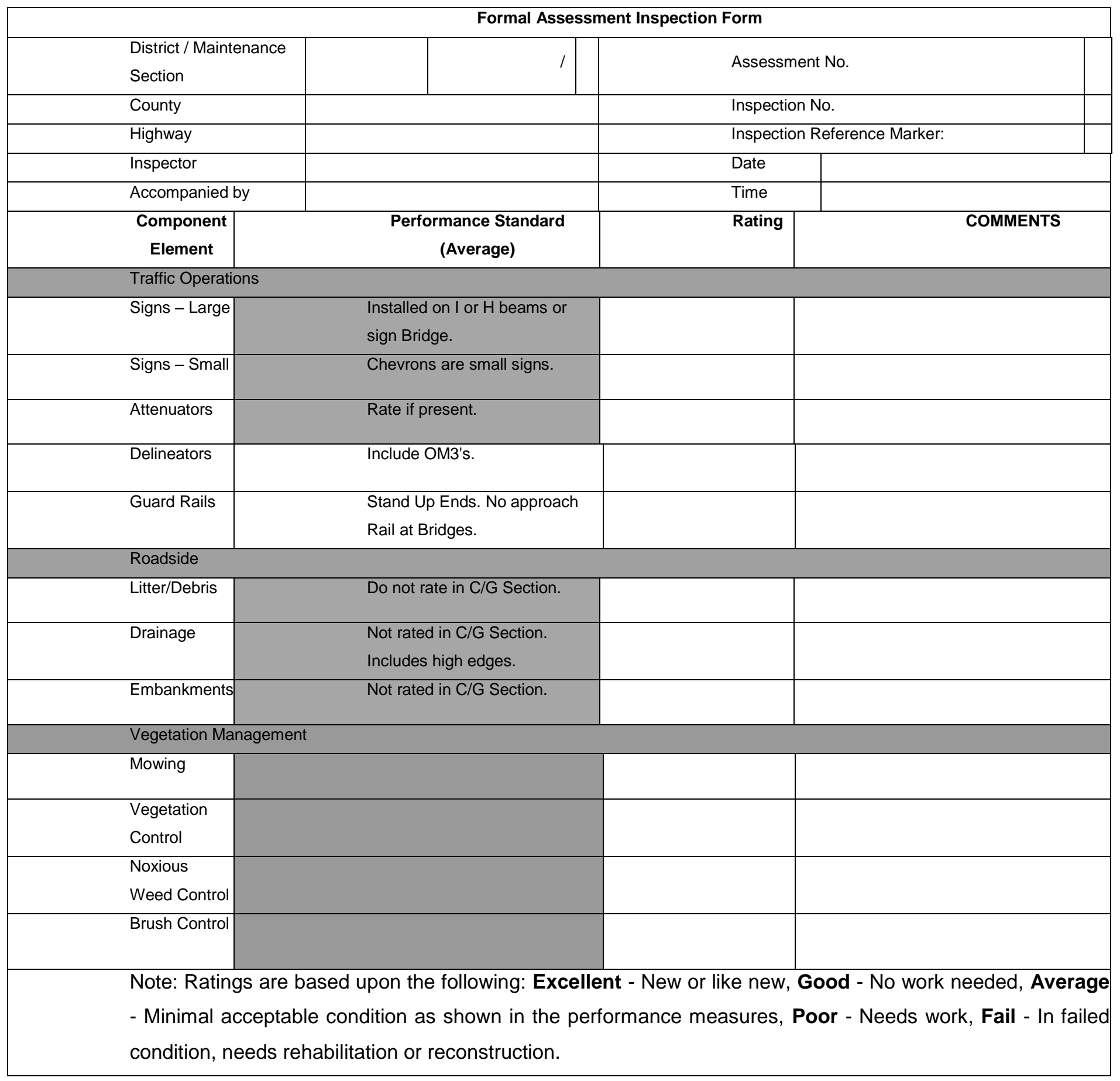




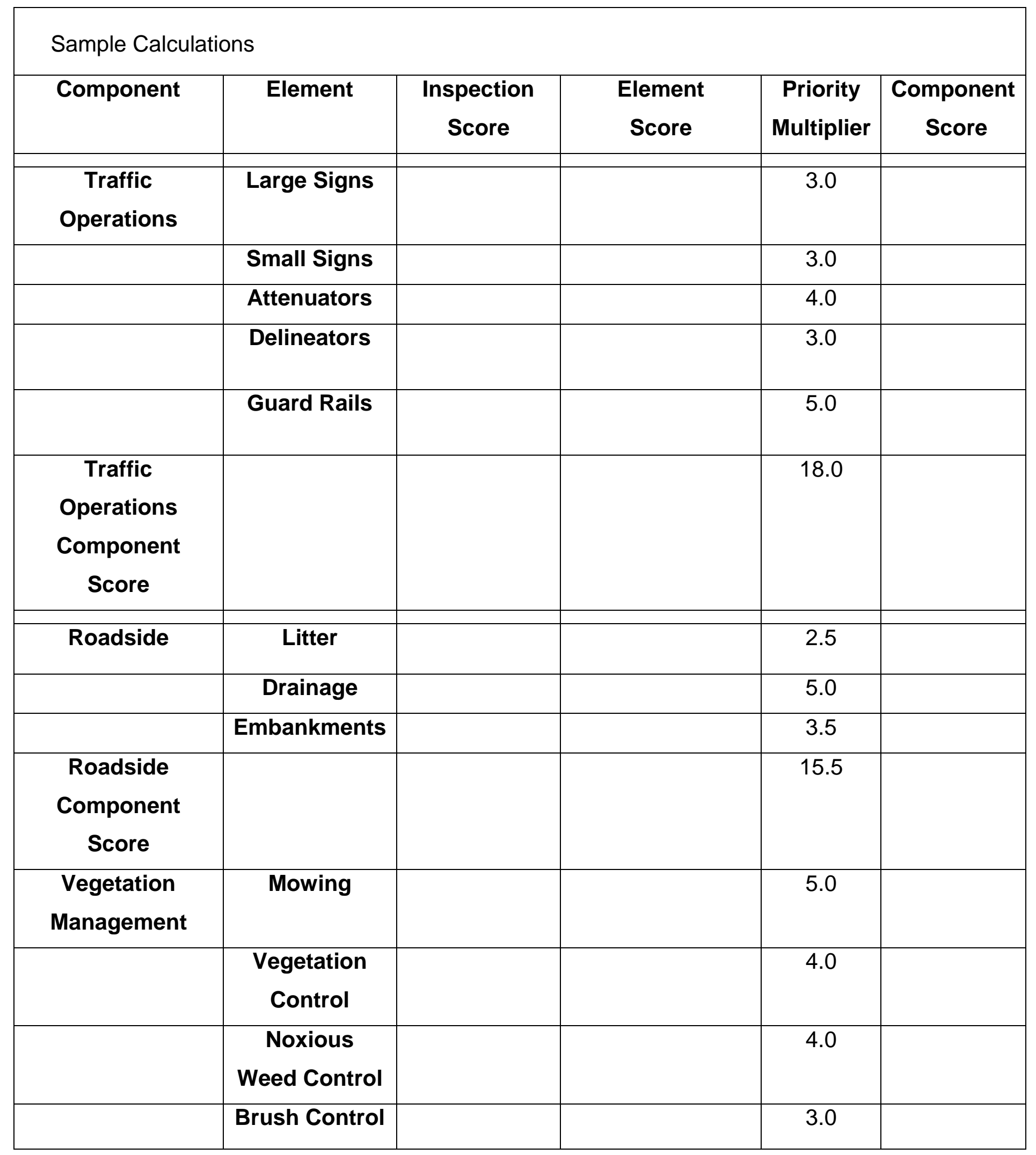




\begin{tabular}{|c|l|l|l|l|l|}
\hline & & & & \\
\hline $\begin{array}{c}\text { Vegetation } \\
\text { Score }\end{array}$ & & & & 16.0 & \\
\hline Overall Score & & & & & \\
\hline
\end{tabular}

Source: "Special Specifications on Performance Based Roadside Maintenance of Highways", Texas Department of Transportation, 2004.

* Multiplier for elements that are not present in the section of highway rated are not included in the sum. 
RATINGS ARE BASED UPON THE FOLLOWING

CONDITIONS:

\begin{tabular}{|c|c|c|c|c|c|}
\hline Component & Excellent & Good & Fair & Poor & Failed \\
\hline Traffic Operations & 5 & 4 & 3 & 2 & 1 \\
\hline $\begin{array}{l}\text { Large Signs } \\
\text { (Installed on I or H } \\
\text { beams or sign } \\
\text { bridge) }\end{array}$ & $\begin{array}{l}\text { Signs like new, } \\
\text { with all } \\
\text { background, } \\
\text { lettering, borders } \\
\text { and shields clean } \\
\text { and reflective. No } \\
\text { damage. }\end{array}$ & $\begin{array}{l}\text { Signs generally } \\
\text { good; background, } \\
\text { lettering, borders } \\
\text { and shields may } \\
\text { be slightly faded. } \\
\text { May have very } \\
\text { minor damage. }\end{array}$ & $\begin{array}{l}\text { Signs borderline } \\
\text { acceptable; } \\
\text { background, } \\
\text { lettering, borders } \\
\text { and shields may } \\
\text { be slightly faded } \\
\text { or mildewed. } \\
\text { May have some } \\
\text { damage. }\end{array}$ & $\begin{array}{l}\text { Signs } \\
\text { unacceptable } \\
\text { with dirt or } \\
\text { mildew. May be } \\
\text { faded or have } \\
\text { substantial } \\
\text { damage. May } \\
\text { have one or two } \\
\text { high or low } \\
\text { bases. }\end{array}$ & $\begin{array}{l}\text { Signs totally } \\
\text { unacceptable with } \\
\text { severe dirt, mildew } \\
\text { or fading. May be } \\
\text { damaged or totally } \\
\text { knocked down. } \\
\text { Several bases are } \\
\text { high or low. }\end{array}$ \\
\hline $\begin{array}{l}\text { Small Signs } \\
\text { (Chevron are } \\
\text { signs) }\end{array}$ & $\begin{array}{l}\text { Signs like new, } \\
\text { on standard } \\
\text { posts, no repairs } \\
\text { needed. All } \\
\text { straight }\end{array}$ & $\begin{array}{l}\text { All on standard } \\
\text { supports. Very } \\
\text { minor repairs } \\
\text { needed. All } \\
\text { required signs are } \\
\text { in place. No high } \\
\text { or low bases. } \\
\text { Most are straight }\end{array}$ & $\begin{array}{l}\text { All on standard } \\
\text { supports, }<50 \% \\
\text { leaning or with } \\
\text { dirty, damaged } \\
\text { or bad sign } \\
\text { faces. No high or } \\
\text { low bases. }\end{array}$ & $\begin{array}{l}\text { All on standard } \\
\text { supports, most } \\
\text { leaning or dirty, } \\
\text { damaged or bad } \\
\text { sign faces. One } \\
\text { non-regulatory } \\
\text { maybe missing. } \\
\text { Some may have } \\
\text { high or low } \\
\text { bases. }\end{array}$ & $\begin{array}{l}\text { Signs not on } \\
\text { standard supports } \\
\text { or any regulatory } \\
\text { sign missing or } \\
\text { more than one } \\
\text { other sign missing. } \\
\text { MOST ALL are } \\
\text { leaning and bad or } \\
\text { damaged sign } \\
\text { faces. }\end{array}$ \\
\hline Attenuator & $\begin{array}{l}\text { New or like new to } \\
\text { current standards } \\
\text { with no damage. }\end{array}$ & $\begin{array}{l}\text { Attenuator not } \\
\text { damaged; may not } \\
\text { be latest standard. }\end{array}$ & $\begin{array}{l}\text { Attenuator } \\
\text { functional but } \\
\text { with very minor } \\
\text { damage. May } \\
\text { need painting. }\end{array}$ & $\begin{array}{l}\text { Attenuator with } \\
\text { moderate } \\
\text { damage but will } \\
\text { still function as } \\
\text { designed. }\end{array}$ & $\begin{array}{l}\text { Attenuator that will } \\
\text { not function as } \\
\text { designed }\end{array}$ \\
\hline $\begin{array}{l}\text { Delineators } \\
\text { (OM3 or } \\
\text { delineators) }\end{array}$ & $\begin{array}{l}\text { Delineators, new } \\
\text { or like new, } \\
\text { straight, installed } \\
\text { in accordance }\end{array}$ & $\begin{array}{l}\text { Delineators posts } \\
<50 \% \text { slightly } \\
\text { leaning or with } \\
\text { some damaged }\end{array}$ & $\begin{array}{l}\text { Delineators }<50 \% \\
\text { slightly leaning } \\
\text { and }<50 \% \\
\text { delineators }\end{array}$ & $\begin{array}{l}\text { Most post slightly } \\
\text { leaning and } \\
\text { delineators non } \\
\text { reflective or one }\end{array}$ & $\begin{array}{l}\text { Several bent, } \\
\text { broken damaged } \\
\text { or missing. Not } \\
\text { installed in }\end{array}$ \\
\hline
\end{tabular}




\begin{tabular}{|l|l|l|l|l|l|}
\hline & $\begin{array}{l}\text { with standards. } \\
\text { No repairs } \\
\text { needed. }\end{array}$ & $\begin{array}{l}\text { and non reflective } \\
\text { delineators }\end{array}$ & $\begin{array}{l}\text { damaged or non } \\
\text { reflective, or most } \\
\text { post slightly } \\
\text { leaning, or most } \\
\text { delineators non } \\
\text { reflective. }\end{array}$ & $\begin{array}{l}\text { or two post bent, } \\
\text { broken, down or } \\
\text { missing. }\end{array}$ & $\begin{array}{l}\text { accordance with } \\
\text { standards }\end{array}$ \\
\hline $\begin{array}{l}\text { Guardrail } \\
\text { (Rate as needed) }\end{array}$ & $\begin{array}{l}\text { Guardrail like } \\
\text { new, appropriately } \\
\text { placed, installed } \\
\text { to the latest } \\
\text { standards. }\end{array}$ & $\begin{array}{l}\text { Guardrail all } \\
\text { functional. May } \\
\text { have one minor } \\
\text { dent or may not } \\
\text { be the latest } \\
\text { standard. }\end{array}$ & $\begin{array}{l}\text { Guardrail all } \\
\text { functional with } \\
\text { several minor } \\
\text { dents or out of } \\
\text { alignment. }\end{array}$ & $\begin{array}{l}\text { Guardrail has } \\
\text { been hit and is not } \\
\text { functional. } \\
\text { Guardrail has } \\
\text { standup ends } \\
\text { instead of turn } \\
\text { down or turn } \\
\text { down instead of } \\
\text { GET. Guardrail is }\end{array}$ & $\begin{array}{l}\text { Guardrail has } \\
\text { major damage } \\
\text { and should be } \\
\text { repaired as soon } \\
\text { as possible. } \\
\text { Guardrail is } \\
\text { required and not } \\
\text { installed at bridge } \\
\text { ends }\end{array}$ \\
& & & & \\
\hline
\end{tabular}




\begin{tabular}{|c|c|c|c|c|c|}
\hline & 5 & 4 & 3 & 2 & 1 \\
\hline $\begin{array}{l}\text { Litter } \\
\text { (Do not rate in } \\
\text { C/G section) }\end{array}$ & $\begin{array}{l}\text { ROW clean with no } \\
\text { or very minor litter. } \\
\text { Litter not visible at } \\
\text { posted speed limit. }\end{array}$ & $\begin{array}{l}\text { ROW generally } \\
\text { clean with only a } \\
\text { few pieces of litter } \\
\text { or debris visible at } \\
\text { posted speeds. }\end{array}$ & $\begin{array}{l}\text { ROW acceptable } \\
\text { with one or two } \\
\text { objectionable } \\
\text { spots of litter or } \\
\text { debris. Several } \\
\text { single pieces of } \\
\text { litter, or debris. }\end{array}$ & $\begin{array}{l}\text { ROW } \\
\text { unacceptable, } \\
\text { with much litter or } \\
\text { debris. }\end{array}$ & $\begin{array}{l}\text { ROW totally } \\
\text { unacceptable with } \\
\text { large quantities of } \\
\text { litter or debris. }\end{array}$ \\
\hline $\begin{array}{l}\text { Drainage } \\
\text { (Do not rate in } \\
\text { C/G section) }\end{array}$ & $\begin{array}{l}\text { Ditches and } \\
\text { channels like } \\
\text { originally } \\
\text { constructed, clear } \\
\text { of silt or erosion. } \\
\text { Vegetation as } \\
\text { appropriates in } \\
\text { ditches. No high } \\
\text { shoulders }\end{array}$ & $\begin{array}{l}\text { Ditches and } \\
\text { channels like } \\
\text { originally } \\
\text { constructed may } \\
\text { have minor silt or } \\
\text { erosion. } \\
\text { Vegetation as } \\
\text { appropriates in } \\
\text { ditches. Minor } \\
\text { spots of high } \\
\text { shoulders }\end{array}$ & $\begin{array}{l}\text { Ditches and } \\
\text { channels like } \\
\text { originally } \\
\text { constructed, may } \\
\text { have some silt or } \\
\text { erosion (pipes } \\
50 \% \text { full). } \\
\text { Vegetation as } \\
\text { appropriates in } \\
\text { ditches. Several } \\
\text { areas of high } \\
\text { shoulders }\end{array}$ & $\begin{array}{l}\text { Substantial } \\
\text { erosion or } \\
\text { siltation in ditches } \\
\text { or channels. } \\
\text { Does not function } \\
\text { as designed. } \\
\text { Potential exists } \\
\text { for additional } \\
\text { erosion. High } \\
\text { shoulders may } \\
\text { trap water on } \\
\text { pavement. } \\
\text { Washouts around } \\
\text { culverts, bridges } \\
\text { and etc. }\end{array}$ & $\begin{array}{l}\text { Extreme erosion or } \\
\text { siltation in ditches } \\
\text { or channels. Does } \\
\text { not function as } \\
\text { designed. } \\
\text { Potential exists for } \\
\text { additional erosion. } \\
\text { Erosion has } \\
\text { created a safety } \\
\text { hazard. High } \\
\text { shoulders may trap } \\
\text { water in travel } \\
\text { lanes. }\end{array}$ \\
\hline \multicolumn{6}{|l|}{ Embankment } \\
\hline Public Rating & All required signs & Few signs may & Non required & Missing required & Signing faded and \\
\hline
\end{tabular}




\begin{tabular}{|c|c|c|c|c|c|}
\hline & $\begin{array}{l}\text { straight and } \\
\text { clean, no litter, } \\
\text { vegetation of } \\
\text { uniform height, }\end{array}$ & $\begin{array}{l}\text { be leaning } \\
\text { slightly, minor } \\
\text { litter, vegetation } \\
\text { of uniform height }\end{array}$ & $\begin{array}{l}\text { signs missing, } \\
\text { minor litter, } \\
\text { vegetation } \\
\text { borderline with } \\
\text { small amount of } \\
\text { noxious weeds. }\end{array}$ & $\begin{array}{l}\text { signs, lot of litter, } \\
\text { vegetation needs } \\
\text { mowing and/or } \\
\text { herbicide work. }\end{array}$ & $\begin{array}{l}\text { leaning, or missing } \\
\text { regulatory signs, } \\
\text { unacceptable } \\
\text { amount of litter on } \\
\text { shoulders and } \\
\text { roadside, } \\
\text { vegetation totally } \\
\text { unacceptable. }\end{array}$ \\
\hline $\begin{array}{l}\text { Vegetation } \\
\text { Management }\end{array}$ & 5 & 4 & 3 & 2 & 1 \\
\hline $\begin{array}{l}\text { Mowing* } \\
\text { *excluding } \\
\text { designated non- } \\
\text { mow areas. }\end{array}$ & $\begin{array}{l}\text { Vegetation } \\
\text { maintained within } \\
\text { the height range } \\
\text { specified in } \\
\text { contract. No } \\
\text { evidence of } \\
\text { roostertails or } \\
\text { swirled stubble, } \\
\text { or decaying weed } \\
\text { stubble present. }\end{array}$ & $\begin{array}{l}\text { Vegetation } \\
\text { maintained within } \\
\text { the height range } \\
\text { specified in } \\
\text { contract. No } \\
\text { visible evidence } \\
\text { of roostertails or } \\
\text { swirled stubble. }\end{array}$ & $\begin{array}{l}\text { Vegetation } \\
\text { maintained within } \\
\text { the height range } \\
\text { specified in } \\
\text { contract. Visible } \\
\text { evidence of } \\
\text { roostertails, } \\
\text { swirled stubble. }\end{array}$ & $\begin{array}{l}\text { Less than } 40 \% \text { of } \\
\text { vegetation taller } \\
\text { than maximum } \\
\text { allowable height } \\
\text { in contract, or } \\
\text { vegetation has } \\
\text { been mowed } \\
\text { shorter than } \\
\text { minimum } \\
\text { allowable height } \\
\text { in specified in } \\
\text { contract. }\end{array}$ & $\begin{array}{l}40 \% \text { or more } \\
\text { vegetation taller } \\
\text { than maximum } \\
\text { allowable height by } \\
\text { contract. }\end{array}$ \\
\hline Vegetation Control & $\begin{array}{l}\text { No more than } 5 \\
\text { areas per lane } \\
\text { mile actively } \\
\text { growing } \\
\text { vegetation. }\end{array}$ & $\begin{array}{l}\text { Between } 6 \text { and } \\
15 \text { areas per lane } \\
\text { mile with actively } \\
\text { growing weeds. } \\
\text { No obstruction of } \\
\text { guardrail or sight } \\
\text { distance from } \\
\text { roadway. }\end{array}$ & $\begin{array}{l}\text { More than } 20 \\
\text { areas per lane } \\
\text { mile with actively } \\
\text { growing weeds. } \\
\text { No obstruction of } \\
\text { guardrail or sight } \\
\text { distance from } \\
\text { roadway. }\end{array}$ & $\begin{array}{l}\text { Unacceptable } \\
\text { with large } \\
\text { amounts of } \\
\text { actively } \\
\text { vegetation } \\
\text { growing in } \\
\text { intermitted } \\
\text { stands. } \\
\text { Obstruction of } \\
\text { guardrail or sight } \\
\text { distance from } \\
\text { roadway. }\end{array}$ & $\begin{array}{l}\text { Totally } \\
\text { unacceptable with } \\
\text { large amounts of } \\
\text { actively growing } \\
\text { vegetation in solid } \\
\text { stands. } \\
\text { Obstruction of } \\
\text { guardrail or sight } \\
\text { distance from } \\
\text { roadway. }\end{array}$ \\
\hline $\begin{array}{l}\text { Noxious } \\
\text { Weed Control }\end{array}$ & $\begin{array}{l}\text { No more than } 5 \\
\text { areas per lane }\end{array}$ & $\begin{array}{l}\text { Between } 6 \text { and } \\
15 \text { areas per lane }\end{array}$ & $\begin{array}{l}\text { More than } 20 \\
\text { areas per lane }\end{array}$ & $\begin{array}{l}\text { Unacceptable } \\
\text { with large }\end{array}$ & $\begin{array}{l}\text { Totally } \\
\text { unacceptable with }\end{array}$ \\
\hline
\end{tabular}




\begin{tabular}{|c|c|c|c|c|c|}
\hline & $\begin{array}{l}\text { mile with actively } \\
\text { growing weeds. } \\
\text { No obstruction of } \\
\text { fixtures or sight } \\
\text { distance from } \\
\text { roadway. }\end{array}$ & $\begin{array}{l}\text { mile with actively } \\
\text { growing weeds. } \\
\text { No obstruction of } \\
\text { fixtures or sight } \\
\text { distance from } \\
\text { roadway. }\end{array}$ & $\begin{array}{l}\text { mile with actively } \\
\text { growing weeds. } \\
\text { No obstruction of } \\
\text { fixtures or sight } \\
\text { distance from } \\
\text { roadway. }\end{array}$ & $\begin{array}{l}\text { amounts of } \\
\text { weeds growing in } \\
\text { intermitted } \\
\text { stands. } \\
\text { Obstruction of } \\
\text { fixtures or sight } \\
\text { distance from } \\
\text { roadway. }\end{array}$ & $\begin{array}{l}\text { large amounts of } \\
\text { weeds growing in } \\
\text { solid stands. } \\
\text { Obstruction of } \\
\text { fixtures or sight } \\
\text { distance from } \\
\text { roadway, complete } \\
\text { vegetation kill } \\
\text { around fixtures, or } \\
\text { herbicide damage } \\
\text { to desirable } \\
\text { vegetation. }\end{array}$ \\
\hline $\begin{array}{l}\text { Brush Control* } \\
\text { *within } 30 \text { foot } \\
\text { clear zone. }\end{array}$ & $\begin{array}{l}1 \text { to } 5 \text { areas per } \\
\text { lane mile of } \\
\text { actively growing } \\
\text { brush. }\end{array}$ & $\begin{array}{l}\text { Between } 6 \text { to } 10 \\
\text { areas per lane } \\
\text { mile of actively } \\
\text { growing brush. }\end{array}$ & $\begin{array}{l}\text { More than } 10 \\
\text { areas per lane } \\
\text { mile of actively } \\
\text { growing brush. } \\
\text { No obstruction of } \\
\text { fixtures or sight } \\
\text { distance from } \\
\text { roadway. }\end{array}$ & $\begin{array}{l}\text { Unacceptable } \\
\text { with large } \\
\text { amounts of brush } \\
\text { growing in } \\
\text { intermitted } \\
\text { stands. } \\
\text { Obstruction of } \\
\text { fixtures or sight } \\
\text { distance from } \\
\text { roadway. }\end{array}$ & $\begin{array}{l}\text { Totally } \\
\text { unacceptable with } \\
\text { actively growing } \\
\text { brush growing in } \\
\text { solid stands } \\
\text { obstructing signs, } \\
\text { fixtures, or sight } \\
\text { distance. }\end{array}$ \\
\hline
\end{tabular}

Source: "Special Specifications on Performance Based Roadside Maintenance of Highways",

Texas Department of Transportation, 2004.

\section{Items Excluded from the Contract}

The following items are excluded from the contract:

(a) Roadside Assistance

(b) Intelligent Transportation System devices (such as cameras, permanent changeable message signs, Automatic Vehicle Identification readers/antennae, etc.) 
(c) Executing Agreements, such as utility permits, driveway permits, Multiple Use Agreements, construction and maintenance agreements, and other similar type agreements

(d) Logo signing

(e) Rest Areas

(f) Picnic Areas

(g) Pavement Markings

(h) Raised Pavement Markers

(i) Drainage

(j) Highway Sweeping

(k) Graffiti Removal

(l) Traffic signals

(m) Channels 
Appendix $\mathrm{H}$

NCDOT PBC Contract

Sample 


\title{
FINAL RFP for BEST AND FINAL OFFER (BAFO)
}

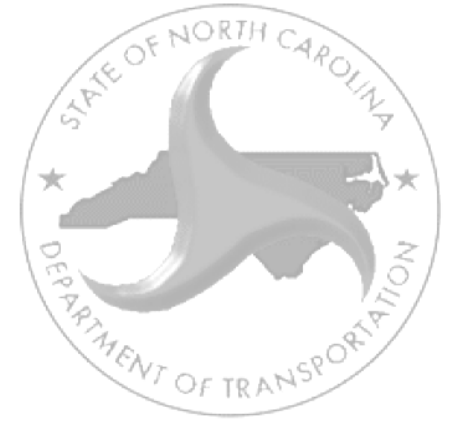

\author{
Interstate Maintenance \\ WBS Element 40682
}

January 10, 2007

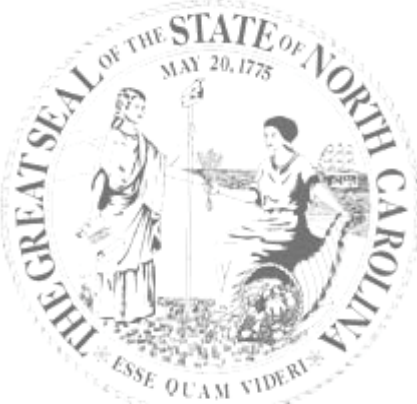

VOID FOR BIDDING

\section{DATE AND TIME OF PRICE PROPOSAL SUBMISSION: January 24, 2007 AT 4:00 PM \\ DATE AND TIME OF PRICE PROPOSAL OPENING: January 25, 2007 AT 10:00 AM}

WBS ELEMENT NO. 40682

COUNTIES: $\quad$ Mecklenburg, Gaston, Cabarrus, and Cleveland

ROUTE NO. I-77, I-85, I-485, \& I-277

MILES: $\quad 131$ Centerline miles

LOCATION: $\quad$ I-77, I-85, I-485 and I-277 in Mecklenburg, Gaston, Cabarrus, and Cleveland Counties

TYPE OF WORK: INTERSTATE MAINTENANCE AS SPECIFIED IN THE SCOPE OF WORK CONTAINED IN THE REQUEST FOR PROPOSAL

NOTICE:

ALL PROPOSERS SHALL COMPLY WITH ALL APPLICABLE LAWS REGULATING THE PRACTICE OF GENERAL CONTRACTING AS CONTAINED IN CHAPTER 87 OF THE GENERAL STATUTES OF NORTH CAROLINA WHICH REQUIRES THE PROPOSER TO BE LICENSED BY THE N.C. LICENSING BOARD FOR CONTRACTORS WHEN BIDDING ON ANY NON-FEDERAL AID PROJECT WHERE THE BID IS \$30,000 OR MORE, EXCEPT FOR CERTAIN SPECIALTY WORK AS DETERMINED BY THE LICENSING BOARD. PROPOSERS SHALL ALSO COMPLY WITH ALL OTHER APPLICABLE LAWS REGULATING THE PRACTICES OF ELECTRICAL, PLUMBING, HEATING AND AIR CONDITIONING AND REFRIGERATION CONTRACTING AS CONTAINED IN CHAPTER 87 OF THE GENERAL STATUTES OF NORTH CAROLINA. NOT WITHSTANDING THESE LIMITATIONS ON BIDDING, THE PROPOSER WHO IS AWARDED ANY PROJECT SHALL COMPLY WITH CHAPTER 87 OF THE GENERAL STATUTES OF NORTH CAROLINA FOR LICENSING REQUIREMENTS WITHIN 60 CALENDAR DAYS OF BID OPENING, REGARDLESS OF FUNDING SOURCES.

$$
5 \% \text { BID BOND OR BID DEPOSIT REQUIRED }
$$

This BAFO RFP contains Addendum \#1 and \#2. The highlighted changes in this RFP reflect only the changes made as a result of the Best and Final Offer process. 


\title{
PROPOSAL FORM FOR INTERSTATE MAINTENANCE, WBS ELEMENT 40682,
}

\author{
IN MECKLENBURG, GASTON, CABARRUS \\ AND CLEVELAND COUNTIES, NORTH CAROLINA \\ Date \\ , 2007 \\ DEPARTMENT OF TRANSPORTATION, \\ RALEIGH, NORTH CAROLINA
}

The Proposer herein acknowledges that it has carefully examined the location of the proposed work to be known as Interstate Maintenance, WBS Element Number 40682, has carefully examined the Final Request for Proposal (RFP) and all addendums thereto, specifications, special provisions, the form of contract, and the forms of contract payment bond and contract performance bonds, which are acknowledged to be part of the Contract; and thoroughly understands the stipulations, requirements and provisions. The undersigned Proposer agrees to be bound upon their execution of the Contract and including any subsequent award to them by the Board of Transportation in accordance with this Contract to provide the necessary contract payment bond and contract performance bond within fourteen calendar days after the written notice of award is received by them.

The undersigned Proposer further agrees to provide all necessary materials, machinery, implements, appliances, tools, labor, and other means of maintenance and construction, except as otherwise noted, to perform all the work and required labor to perform all the work for Interstate Maintenance, WBS Element Number 40682, in Mecklenburg, Gaston, Cabarrus and Cleveland Counties during the Contract period specified in the Final RFP and in accordance with the requirements of the Engineer, the Final RFP, the 2006 Standard Specifications for Roads and Structures, specifications prepared by the Department, the Technical Proposal prepared by the Proposer, at the lump sum price(s) bid by the Proposer in their Price Proposal.

The Proposer acknowledges that project documents furnished by the Department are provided solely to assist the Proposer. Unless otherwise noted herein, the Department does not warrant or guarantee the sufficiency or accuracy of any information furnished by the Department.

The Department does not warrant or guarantee the sufficiency or accuracy of any investigations made, nor the interpretations made or opinions of the Department as to the type of materials and conditions to be encountered at the project site. The Proposer is advised to make such independent investigations, as they deem necessary to satisfy their self as to conditions to be encountered on this project. The Proposer shall have no claim for additional compensation or for an extension of contract time for any reason resulting from the actual conditions encountered at the site differing from those indicated in any of the information or documents furnished by the Department except as may be allowed under the provisions of the Standard Specifications.

The Proposer shall be fully and totally responsible for the accuracy and completeness of all work performed under this contract, and shall indemnify and hold the Department harmless for any additional costs and all claims against the Department or the State which may arise due to errors or omissions of the Department in furnishing the preliminary project designs and information, and of the Proposer in performing the work. 
The published volume entitled North Carolina Department of Transportation, Raleigh, Standard Specifications for Roads and Structures, July 2006, as well as, all design manuals, policy and procedures manuals, and AASHTO publications and guidelines referenced in the Request For Proposal, with all amendments and supplements thereto, are by reference, incorporated and made part of this contract; except as herein modified, all the design, maintenance, repair and construction included in this contract is to be done in accordance with the documents noted above.

If the Proposal is accepted and the award is made, the Technical Proposal submitted by the Proposer is by reference, incorporated and made part of this contract. The contract is valid only when signed either by the Contract Officer or such other person as may be designated by the Secretary to sign for the Department of Transportation. The conditions and provisions herein cannot be changed except by written approval as allowed by the Request For Proposal.

Accompanying this Proposal shall be a bid bond secured by a corporate surety licensed to do business in North Carolina, or certified check payable to the order of the Department of Transportation, for five percent of the total Price Proposal for "Maintenance Services Excluding Snow and Ice Removal", which deposit is to be forfeited as liquidated damages in case this bid is accepted and the Proposer shall fail to provide the required payment and performance bonds with the Department of Transportation, under the condition of this proposal, within 14 calendar days after the written notice of award is received by them, as provided in the Standard Specifications; otherwise said deposit will be returned to the Proposer. 


\section{TABLE OF CONTENTS}

\section{COVER SHEET}

PROPOSAL SHEETS

PROJECT SPECIAL PROVISIONS (GREEN SHEETS) PAGE NO.

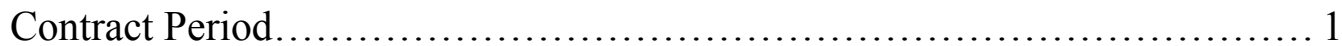

Compensation..................................................... 1

Alternative Bid Item for Snow and Ice Removal........................ 1

Basis for Contractor Selection........................................... 1

Annual Price Adjustments............................................. 2

Mobilization ............................................................. 2

Third Party Claims................................................... 2-3

Damage Reimbursement............................................. 3-4

Liquidated Damages.................................................. 4-6

Division One of 2006 Standard Specifications........................... 6

Contractor Prequalification...........................................6 6

Bid Bonds......................................................... 6

Contract Performance and Payment Bonds.............................. 7

Alterations to Contract................................................... 7

Coordination of Contract Documents................................ 7-8

Contractor's Responsibility For Work .................................. 8

Subletting of Contract............................................... 8

Maintenance of Traffic............................................ 8

Liability Insurance................................................. 8

Materials and Testing.............................................. 9

Joint Use Staging Areas.............................................. 9

Contractor's License Requirements.................................... 10

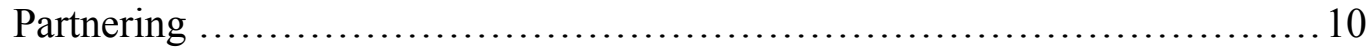

Availability of Funds-Termination of Contracts......................... 10-11

Execution of Signature Sheets and Debarment Certification.................... 11

Submission of Proposal............................................... 11-12

Minority and Women Business....................................... 12-20

Small Business Enterprises.......................................... 20

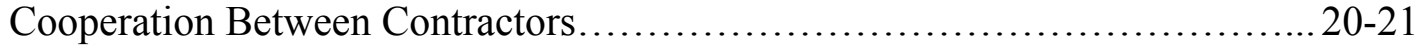

Bid Documentation................................................... 21-23

Twelve-Month Guarantee........................................... 23-24

Outsourcing Outside the USA...................................... 24

Books and Records..................................................... 24

Vegetation Management............................................... 24-25

NCDOT General Seed Specifications for Seed Quality...................... 25-28

Plant and Pest Quarantines........................................... 28-29

Minimum Wages....................................................29

Errata................................................................... 29-31 
CONTRACTOR PROPOSAL AND EVALUATION (GREEN SHEETS)

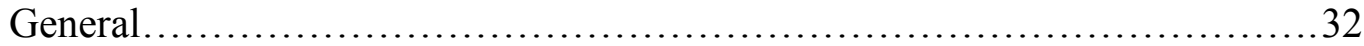

No Contact Clause.................................................... 32

Design References....................................................... 32

Design Submittals.................................................... 32-33

Ethics Policy ....................................................... 33

Approval of Personnel............................................... 33-34

Submittal of Technical and Price Proposals............................ 34

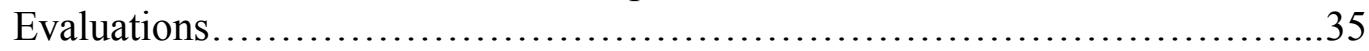

Technical Proposal Evaluation Criteria................................... 35-37

Selection Procedure.................................................... 37-39

Opening of Price Proposals............................................. 39

Best and Final Offer......................................................... 39-40

SCOPE OF WORK (GREEN SHEETS)

Overview............................................................. $41-42$

Exclusions.......................................................... 43

Definitions......................................................... 44-45

Work Plans and Reports............................................ $45-47$

Emergency Preparation Response........................................ 47

Incident Response................................................... 48

Emergency Maintenance Repairs..................................... 48

Permits............................................................ 48

Traffic Control........................................................ 48-50

Hazardous Waste Removal............................................ 50-51

Snow and Ice Control (Alternate Bid Item) .......................... 51-52

PERFORMANCE CRITERIA AND CONTRACT PAYMENT (GREEN SHEETS)

Performance Criteria................................................... 53

Evaluation Procedures.................................................. 53

Maintenance Condition Assessment (MCA) Rating..........................55

Phased Performance Targets.............................................. 54

Partial Payments Based on Perfromance.................................. 54-55

Timeliness Targets ................................................. 55

Performance Criteria and Target Tables ...................................56-67

Example of Partial Payment Calculation ............................... 68

\section{PROPOSAL FORM ITEM SHEET, ETC.}

$\begin{array}{ll}\text { Itemized Proposal Sheet } & \text { (WHITE SHEET) } \\ \text { Listing of MB and WB Subcontractors } & \text { (YELLOW SHEETS) } \\ \text { Signature Sheets } & \text { (YELLOW SHEETS) } \\ \text { Debarment Certification of Bidders } & \text { (YELLOW SHEETS) }\end{array}$




\section{*** PROJECT SPECIAL PROVISIONS ***}

\section{CONTRACT PERIOD}

The Date of Availability for this contract is May 1, 2007. The term of the contract shall be for five years with a completion date of April 30, 2012. At the option of the Department, this contract may be renewed for one additional period of five years. The Engineer will notify the Contractor in writing by July 1, 2011 if the contract will be renewed. The Contractor must notify the Engineer in writing by August 1, 2011 of acceptance or rejection of this offer. Failure of the Contractor to reply in writing will be received as a rejection of contract renewal.

\section{COMPENSATION}

The Contractor will be paid on a monthly lump sum basis in an amount equal to the unit price bid on the Itemized Proposal sheet and as adjusted in accordance with this RFP. In addition, a Mobilization line item is provided for the alternate bid item "Maintenance Services Including Snow and Ice Removal". All references made to measurement and payment in the 2006 Standard Specifications or applicable NCDOT special provisions do not apply.

\section{ALTERNATE BID ITEM FOR SNOW AND ICE REMOVAL}

The Contractor shall complete the Itemized Proposal sheet. The amount bid for "Maintenance Services Excluding Snow and Ice Removal" shall be for all services required for this contract, excluding snow and ice removal, and shall be for the entire contract period (60 months). The amount bid for "Maintenance Services Including Snow and Ice Removal" shall be for all services required for this contract, including those related to snow and ice removal, and shall be for the entire contract period (60 months).

The Department will notify the Contractor upon Notice of Award as to which alternate bid item is accepted by the Department.

After April $1^{\text {st }}, 2009$, the Department reserves the sole right to terminate the snow and ice removal portion of this contract for the remainder of the contract period. This termination may be for cause. This termination must be communicated in writing to the Contractor no later than June $15^{\text {th }}$ in order for the termination to be in effect before the following winter season. In the event that the Department exercises this termination right, the monthly payments to the Contractor will revert to the unit price bid for "Maintenance Services Excluding Snow and Ice Removal" and as adjusted in accordance with the Project Special Provision "Annual Price Adjustments" and "Performance Criteria and Contract Payment" section of this RFP.

\section{BASIS FOR CONTRACTOR SELECTION}

The Contractor will be selected based on both the Price Proposal and the quality of the Technical Proposal. For the purpose of Contractor selection, the Contractor's amount bid for "Maintenance Services Excluding Snow and Ice Removal" will be used in the calculation of the Adjusted Bid. Reference the "Evaluation Criteria" section found elsewhere in this RFP. 


\section{ANNUAL PRICE ADJUSTMENTS}

Assuming all performance and timeliness criteria are met, the first twelve months of the contract period will be paid at the unit price bid for "Maintenance Services Including Snow and Ice Removal" or "Maintenance Services Excluding Snow and Ice Removal" whichever alternate bid item is chosen by the Department.

Beginning with the May 2008 partial payment and with each May partial payment thereafter, monthly payments for the subsequent twelve-month period will be adjusted annually based on the unadjusted index (e.g. May $2006=232.8$ ) of the Services Category of Table 4 "Consumer Price Index for Urban Wage Earners and Clerical Worker (CPI-W)".

The monthly payments beginning in May 2008 will be the unit price bid increased or decreased by a percent equal to the percent change in the aforementioned CPI reported between January 2007 and January 2008, or five percent, whichever is less. The baseline payments for subsequent twelve-month periods will be the CPI-adjusted monthly payments from the previous twelvemonth period.

In the event that the contract is renewed in accordance with the Project Special Provision "Contract Period", monthly payments for the first twelve-month period of the second contract term will be adjusted from the payments for the last twelve-month period of the first contract period.

\section{MOBILIZATION}

Replace the entire Article 800-2 of the 2006 Standard Specifications with the following:

In the event the Department elects to pursue the alternate bid item, "Maintenance Services Including Snow and Ice Removal", the Contractor will be compensated for mobilization as submitted with their Price Proposal and subject to the following restrictions.

The lump sum bid for "Mobilization (Including Snow and Ice Removal)" shall not exceed five percent of the amount bid for "Maintenance Services Including Snow and Ice Removal".

Partial payments for Mobilization will be made beginning with the first partial pay estimate paid on the contract. Payment will be made at the rate of 50 percent of the lump sum amount bid for Mobilization. The remaining 50 percent will be paid with the second partial payment.

\section{THIRD PARTY CLAIMS}

The Contractor shall promptly notify the Department of damage caused by third parties to real or personal property within the project limits. When a third party causes damage to any of the Department's facilities, the Contractor shall make corrective measures to the facility at no additional cost to the Department, except as may be provided for under the Special Provision for Damage Reimbursement. The Department authorizes the Contractor to pursue claims against the responsible party for reimbursement of all Contractor expenses. The Contractor shall cooperate with Department in providing all necessary information to the Department with respect to the 
cost of such repair, regardless of whether any separate or additional compensation is owed to the Contractor in connection with undertaking any such repair.

\section{DAMAGE REIMBURSEMENT}

Advance preparation, response, inspection, repairs, and replacement required as a result of natural disaster, catastrophic or emergency response, or collision to bridges, retaining walls, noise walls, and overhead sign structures will be considered part of the contract responsibilities. The Contractor will not receive any additional compensation from the Department except (1) as otherwise outlined herein and (2) qualifying FHWA funds the Department receives as a result of the Contractor seeking qualifying FHWA reimbursement. The Department authorizes the Contractor to pursue claims of any emergency reimbursement in response to the disaster. It is the Contractor's responsibility to provide all information needed to pursue such claims in a timely manner.

The sequence of reimbursement for damages will be as follows:

1) Pursuit of claims against the individual or entity which caused damages, or their insurers

2) If eligible, compensation from FHWA for qualifying reimbursements. Reference the FHWA Emergency Relief Manual (http://www.fhwa.dot.gov/reports/erm/erm.pdf).

\section{3) Contractor insurance coverage}

The Contractor's responsibility to make damage repairs at its own expense, in each twelvemonth period beginning May $1^{\text {st }}$ of each year, shall be limited to $20 \%$ of the contract amount for that twelve-month period. This $20 \%$ cap will not include any amounts reasonably obtainable under items 1, 2 and 3 above, and any damage repairs caused by the Contractor's operations. In addition, administrative, indirect, and legal expenses borne by the Contractor in pursuit of damage reimbursement will not be considered eligible expenses against the $20 \%$ cap. Prior to making claim for reimbursement from the Department, the Contractor shall demonstrate due diligence in the pursuit of all damage reimbursement and supply documentation thereof to the Department. Delay in reimbursement from any third party will not constitute justification for reimbursement from the Department. If due diligence is adequately demonstrated and the $20 \%$ cap is exceeded within the twelve-month period beginning May $1^{\text {st }}$ of each year, the portion of work over the $20 \%$ cap will be considered Extra Work and reimbursed through supplemental agreement.

Failure to provide timely and detailed information for the pursuit of eligible compensation from the FHWA shall result in the Contractor bearing all cost for the damage repairs at its own expense and such costs will not apply toward the annual $20 \%$ Cap.

In the event the Department chooses to take responsibility for system restoration, the amount of reimbursements obtained in items 1 and 2 above will be retained by the Department. The Department may generally exercise this right under declared States of Emergency in which mobilization of state forces may be needed to supplement or replace Contractor forces. 
In the event of an act that is officially declared by the State of North Carolina or appropriate Federal Entity as an "act of terrorism", the Contractor will not be liable for damage beyond the extent of the amounts obtained in items 1 and 2 above.

For all FHWA qualifying reimbursements, it is the Contractor's responsibility to generate and keep the necessary documentation for the qualifying reimbursement. The Department will assist in this reimbursement process by processing and forwarding to the FHWA all necessary documentation paperwork as provided by the Contractor.

\section{LIQUIDATED DAMAGES}

Liquidated damages for timeliness requirements presented elsewhere in this RFP are calculated using the prescribed intermediate contract times. The Contractor is responsible for logging the time of the start of each intermediate contract time and the completion of the task subject to the intermediate contract time. This information shall be made accessible to the Engineer as part of each Monthly Report and on an interim basis as required by the Engineer to assess liquidated damages.

In the event a Department design is required for the repair or replacement of an item covered by an intermediate contract time, that intermediate contract time will be adjusted if there is a delay in providing the design. In addition, for the case of major structural items, the intermediate contract time will be adjusted if the Contractor demonstrates due diligence in the pursuit of materials that are not reasonably available within the applicable intermediate contract time.

*** Removed reference to Liquidated Damages for Customer Responses and Resolutions. ***

*** Removed reference to Liquidated Damages for Incident Response. ***

Liquidated damages for various intermediate contract times apply to snow and ice removal. Reference "Snow and Ice Removal (Alternate Bid Item)" found elsewhere in this RFP.

Liquidated damages for planned lane closures, shoulder closures, lane narrowing, and holiday and event time restrictions apply. Reference "Traffic Control" found elsewhere in this RFP.

\section{Pavement}

An intermediate contract time of 2 days from notification or discovery will apply to the temporary repair of all pavement failures. In the event that the Contractor fails to repair such failures within 2 days, liquidated damages in the amount of $\$ 500$ per day, or portion thereof, will be deducted from the monies due to the Contractor.

An intermediate contract time of 60 days from notification or discovery will apply to the permanent repair of all pavement failures. In the event that the Contractor fails to repair such failures within 60 days, liquidated damages in the amount of $\$ 500$ per day, or portion thereof, will be deducted from the monies due to the Contractor. 
For the purpose of this discussion, pavement failures are defined as either (1) paved shoulder failures greater than $1 \mathrm{ft}^{2} \times 1.5^{\prime \prime}$ depth; (2) asphalt pavement potholes greater than $1 \mathrm{ft}^{2} \times 1.5^{\prime \prime}$ depth; (3) CRC punchout failures; (4) concrete slabs broken into four or more piece; or (5) concrete slabs with movement.

\section{Guardrail, Guiderail, and Attenuators}

An intermediate contract time of 7 days from notification or discovery will apply to the repair of all damaged impact attenuators and all damaged, non-functional, guardrail, and guiderail. In the event that the Contractor fails to repair damaged impact attenuators and damaged non-functional guardrail or guiderail within 7 days, liquidated damages in the amount of $\$ 750$ per day, or portion thereof, will be deducted from the monies due to the Contractor.

An intermediate contract time of 30 days from notification or discovery will apply to the replacement of all damaged impact attenuators. In the event that the Contractor fails to replace damaged impact attenuators within 30 days, liquidated damages in the amount of $\$ 750$ per day, or portion thereof, will be deducted from the monies due to the Contractor.

An intermediate contract time of 30 days from notification or discovery will apply to all damaged but functional guardrail. In the event that the Contractor fails to repair or replace damaged but functional guardrail within 30 days, liquidated damages in the amount of $\$ 500$ per day, or portion thereof, will be deducted from the monies due to the Contractor.

\section{Signs}

The Contractor shall immediately respond to mitigate damaged signs and sign structures that pose imminent risk to the travelling public. An intermediate contract time of 2 hours from notification or discovery will apply to all badly damaged overhead signs and sign structures that pose imminent risk to the travelling public. In the event that the Contractor fails to mitigate these badly damaged overhead signs or sign structures within 2 hours, liquidated damages in the amount of $\$ 1,000$ per hour, or portion thereof, will be deducted from the monies due to the Contractor.

An intermediate contract time of 60 days from notification or discovery will apply to all damaged but functional overhead signs. In the event that the Contractor fails to repair damaged but functional overhead signs within 60 days, liquidated damages in the amount of $\$ 500$ per day, or portion thereof, will be deducted from the monies due to the Contractor.

An intermediate contract time of 8 hours from notification or discovery will apply to all nonfunctional Stop, Do Not Enter, Wrong Way, and Yield signs. In the event that the Contractor fails to repair or replace any of these non-functional regulatory signs within 8 hours, liquidated damages in the amount of $\$ 1,000$ per hour per sign, or portion thereof, will be deducted from the monies due to the Contractor.

An intermediate contract time of 5 days from notification or discovery will apply to all other damaged or missing signs, including sign posts. In the event that the Contractor fails to repair or replace any other badly damaged but functional sign within 5 days, liquidated damages in the 
amount of $\$ 200$ per day, or portion thereof, will be deducted from the monies due to the Contractor.

\section{Emergency Repairs}

An intermediate contract time of 2 hours from notification or discovery will apply to initiating corrective measures for emergency repairs. In the event that the Contractor fails to initiate corrective measures within 2 hours, liquidated damages in the amount of $\$ 5,000$ per hour per sign, or portion thereof, will be deducted from the monies due to the Contractor.

\section{DIVISION ONE OF 2006 STANDARD SPECIFICATIONS}

Division One of the 2006 Standard Specifications apply to this contract unless otherwise noted or modified in this RFP. Specifically, the following articles of Division One do not apply:

\begin{tabular}{|l|l|l|l|}
\hline Article 102-5 & Article 105-9 & Article 108-2 & Article 109-4 \\
\hline Article 102-14(A) & Article 105-17 & Article 108-8 & Article 109-5(A) $*$ \\
\hline Article 102-16(D) & Article 106-7 & Article 108-10(B)(1) & Article 109-6 * \\
\hline Article 103-4(B) & Article 107-10 & Article 109-1 & Article 109-7 \\
\hline Article 104-5 & Article 107-17 & Article 109-2 & Article 109-8 \\
\hline Article 105-3 & & & \\
\hline
\end{tabular}

* These articles do not apply except as they may apply to work that is deemed to be Extra Work in accordance with Article 104-7.

In addition, all articles or subarticles related to the electronic bids do not apply to this contract.

The terms "Bidder" and "Proposer", as used throughout this RFP and the 2006 Standard Specifications, are considered synonymous. The terms "Bid" and "Price Proposal" are also considered synonymous. The terms "lowest responsible bidder" and "lowest bidder" shall be considered synonymous with the phrase "Proposer with the lowest adjusted price". The term "construction" as used throughout Division One shall be construed to mean any maintenance, repair, or construction activity undertaken to fulfill the requirements of this RFP.

\section{CONTRACTOR PREQUALIFICATION}

The prequalification requirements of Article 102-2(A) of the 2006 Standard Specifications do not apply to the Prime Contractor. All subcontractors must be on the Department's Approved Subcontractors List.

\section{BID BONDS}

A bid bond or bid deposit is required in accordance with this RFP and Article 102-11 of the 2006 Standard Specifications. The bid bond or bid deposit shall be an amount equal to 5\% of the amount bid for "Maintenance Services Excluding Snow and Ice Removal". 


\section{CONTRACT PERFORMANCE AND PAYMENT BONDS}

Replace the entire Article 103-7 of the 2006 Standard Specifications with the following:

The successful bidder shall provide the Department with performance and payment bonds within 14 calendar days after the notice of award is received by the bidder. The bonds shall be in an amount equal to the initial unit price bid for "Maintenance Services Excluding Snow and Ice Removal" multiplied by six (6). In the event the Department exercises its option to include Snow and Ice Removal in the contract, the bond amount shall be equal to the initial unit price bid for "Maintenance Services Including Snow and Ice Removal" multiplied by six (6).

The initial term of these bonds shall be one year from the Date of Availability. These bonds shall be renewed annually.

On or before 45 days prior to the end of the first and all subsequent twelve-month periods of the contract, the Contractor shall provide renewed performance and payment bonds in the amount specified above. These bonds shall be effective until the end of the subsequent twelve-month period. Once the renewed performance and payment bonds are executed, the Surety will no longer be responsible for the previous year's bonds.

The corporate surety furnishing the bonds shall be authorized to do business in the State of North Carolina.

\section{ALTERATIONS TO CONTRACT}

The Engineer reserves the right to make, at any time during the contract period, such alterations in the contract requirements as may be found necessary or desirable. The provisions of Article 104-3 of the 2006 Standard Specifications shall apply to such an alteration of the contract.

\section{COORDINATION OF CONTRACT DOCUMENTS}

Replace the entire Article 105-4 of the 2006 Standard Specifications with the following:

This RFP, 2006 Standard Specifications, contractor-produced plans, and all supplementary documents are essential parts of the contract and a requirement occurring in one is as binding as though occurring in all. They are intended to be complementary and provide and describe the complete contract.

In case of discrepancy or conflict, the order in which they govern shall be as follows:
(A) Request for Proposals
(B) Technical Proposal from Contractor
(C) Accepted Plans and Details from Contractor
(D) Standard Drawings
(E) Standard Specifications 
Where dimensions on the plans are given or can be computed from other given dimensions they shall govern over scaled dimensions.

The Contractor shall not take advantage of any error or omission in any of the contract components. In the event the Contractor discovers an error or omission, the Contractor shall immediately notify the Engineer.

\section{CONTRACTOR'S RESPONSIBILITY FOR WORK}

Replace the entire $1^{\text {st }}$ paragraph of Article 107-18 with the following:

During the contract period, the Contractor shall have the charge and care thereof and shall take every precaution against injury or damage to any part thereof by the action of the elements, or from any other cause, whether arising from the execution or from the nonexecution of the work. The Contractor shall rebuild, repair, restore, and make good all injuries or damages to any portion of the work occasioned by any of the above causes during the contract period and shall bear the expense thereof, except as provided in other sections of the Specifications.

\section{SUBLETTING OF CONTRACT}

Replace the last sentence of the $1^{\text {st }}$ paragraph of Article 108-6 of the 2006 Standard Specifications with the following:

In case such consent is given, the Contractor will be permitted to sublet a portion thereof, but shall perform with its own organization, work amounting to not less than 15 percent of the total original contract amount, except:

Replace the second paragraph of Article 108-6, Page 1-74 of the 2006 Standard Specifications with the following:

In any event, the Contractor shall perform with its own organization work amounting to not less than $15 \%$ of the total amount bid.

\section{MAINTENANCE OF TRAFFIC}

Replace the entire $2^{\text {nd }}$ paragraph of Article 150-1 of the 2006 Standard Specifications with the following:

The Contractor shall be responsible for maintaining in a safe, passable, and convenient condition, such part or parts of existing roads as are being used by the Contractor to maintain traffic within the limits of the project for the entire contract period.

\section{LIABILITY INSURANCE}

The Contractor shall obtain from an insurance company, duly authorized to do business in North Carolina, Public Liability and Property Damage Insurance to protect the Contractor and subcontractors performing work covered under this contract from claims that may arise from 
operations under this contract. Insurance coverage shall be maintained during the life of this contract and shall extend to operations performed by the Contractor or subcontractors, and by anyone employed directly or indirectly by either of them.

Public Liability Insurance shall be in an amount not less than one million $(\$ 1,000,000)$ for injuries, including accidental death, to any one person, and subject to the same limit for each person, in an amount not less than one million dollars $(\$ 1,000,000.00)$ on account of one accident. Property Damage Insurance shall be in an amount not less than five hundred thousand dollars $(\$ 500,000.00)$.

The Contractor shall be also be responsible for obtaining additional insurance as may be required by railroad companies.

Proof of insurance shall be furnished with the Performance and Payment Bonds.

\section{MATERIALS AND TESTING}

The Engineer reserves the right to perform all sampling and testing in accordance with Section 106 of the 2006 Standard Specifications and the Department's "Materials and Test Manual." However the Engineer may reduce the frequency of sampling and testing where the Engineer deems it appropriate for the project under construction.

The Contractor shall furnish the applicable certifications and documentation for all materials as required by the 2006 Standard Specifications. Material which is not properly certified will not be accepted.

In the event the Engineer finds the materials or the finished product in which the materials are used for the work performed are not in reasonably close conformity to the contract requirements and have resulted in an inferior or unsatisfactory product, the work or materials shall be removed and replaced or otherwise corrected by the Contractor at no cost to the Department.

\section{JOINT USE STAGING AREAS}

The Department has the sites listed below available for joint staging use by Department and Contractor forces at no charge to the Contractor. The Contractor will be responsible for preparing/modifying the site's stormwater management plan, and, if necessary, NPDES permit application prior to use. In no case will the Contractor be allowed to store pesticides or herbicides at these sites. An agreement between the Department and the Contractor is necessary prior to the Contractor use of Department property. In addition, the Contractor will be required to restore or remediate that portion of the site used by Contractor prior to the end of the contract period.

- Southeast quadrant of I-485 and NC24/27 in Eastern Mecklenburg County (Approximately 3.8 acres)

- 12101 Mount Holly-Huntersville Road in North Mecklenburg County (Approximately 2 acres)

- Interchange of US74 and I-85 in Division 12 (Approximately 1 acre) 


\section{CONTRACTOR'S LICENSE REQUIREMENTS (7-1-95)}

If the Contractor does not hold the proper license to perform any plumbing, heating, air conditioning, or electrical work in this contract, the Contractor will be required to sublet such work to a contractor properly licensed in accordance with Article 2 of Chapter 87 of the General Statutes (licensing of heating, plumbing, and air conditioning contractors) and Article 4 of Chapter 87 of the General Statutes (licensing of electrical contractors).

\section{PARTNERING}

As a part of its quality management program, the Department intends to encourage the formation of a cohesive relationship with the Contractor and its principal subcontractors and suppliers. This relationship will be structured to draw on the strengths of each organization to identify and achieve reciprocal goals. The objectives are safe, effective, and efficient contract performance. This relationship will be bilateral in makeup and individual participation will be totally voluntary.

To implement this initiative prior to starting work in accordance with the requirements of Section 108 of the Standard Specifications, the Contractor's management personnel and the Division Engineers will initiate a partnering development seminar/team building workshop. Project personnel will determine attendees at the workshop, agenda of the workshop, duration, and location. Persons required to be in attendance will be key personnel from the Department, including the contract administrator and assessors, the Contractor's senior management personnel, the Contractor's on-site project manager, and key project supervisory personnel for both the Contractor and principal subcontractors and suppliers.

Follow-up workshops may be held periodically throughout the duration of the contract as agreed by the Contractor and the Department. The establishment of the partnering charter on a project will not change the legal relationship to the contract nor relieve either party from any of the terms of the contract.

\section{AVAILABILITY OF FUNDS - TERMINATION OF CONTRACTS}

In accordance with G.S. 143-28.1 (6), Subsection (5) of G.S. 143-28.1 is hereby incorporated verbatim in this contract. G.S. 143-28.1(5) is as follows:

“(5). Amounts Obligated - Payments subject to the Availability of Funds - Termination of Contracts. Highway maintenance and construction appropriations may be obligated in the amount of allotments made to the Department of Transportation by the Office of State Budget and Management for the estimated payments for maintenance and construction contract work to be performed in the appropriation fiscal year. The allotments shall be multi-year allotments and shall be based on estimated revenues and shall be subject to the maximum contract authority contained in subdivision (2) above. Payment for highway maintenance and construction work performed pursuant to contract in any fiscal year other than the current fiscal year will be subject to appropriations by the General Assembly. Highway maintenance and construction contracts shall contain a schedule of estimated completion progress and any acceleration of this progress 
shall be subject to the approval of the Department of Transportation provided funds are available. The State reserves the right to terminate or suspend any highway maintenance or construction contract and any highway maintenance or construction contract shall be so terminated or suspended if funds will not be available for payment of the work to be performed during that fiscal year pursuant to the contract. In the event of termination of any contract, the Contractor shall be given a written notice of termination at least 60 days before completion of schedule work for which funds are available. In the event of termination, the Contractor shall be paid for the work already performed in accordance with the contract specifications".

Payment will be made on any contract terminated pursuant to the special provision in accordance with Article 108-13, Item E, of the 2006 North Carolina Department of Transportation Standard Specifications for Roads and Structures.

The Department of Transportation's schedule of estimated completion progress for this project as required above is as follows:

$\begin{array}{cc}\text { Fiscal Year } & \underline{\text { Progress (Dollar Value) }} \\ 2007(5 / 01 / 07-6 / 30 / 07) & 5 \% \text { of Total Amount Bid } \\ 2008(7 / 01 / 07-6 / 30 / 08) & 20 \% \text { of Total Amount Bid } \\ 2009(7 / 01 / 08-6 / 30 / 09) & 20 \% \text { of Total Amount Bid } \\ 2010(7 / 01 / 09-6 / 30 / 10) & 20 \% \text { of Total Amount Bid } \\ 2011(7 / 01 / 10-6 / 30 / 11) & 20 \% \text { of Total Amount Bid } \\ 2012(7 / 01 / 11-4 / 30 / 12) & 15 \% \text { of Total Amount Bid }\end{array}$

\section{EXECUTION OF SIGNATURE SHEETS AND DEBARMENT CERTIFICATION (9-7-05)}

The Proposer's attention is directed to the various sheets contained herein which are to be signed by the Proposer. A list of these sheets is shown below. The signature sheets are located behind the item sheet(s) contained herein. The NCDOT bid bond form is available on-line at: http://ncdot.org/doh/forms/files/bidbond.pdf or by contacting the Records and Documents office at 919-250-4124.

1. Applicable Signature Sheets: 1, 2, 3, 4, 5, or 6 (Bid)

2. Bid Bond

The Proposer shall certify to the best of their knowledge all subcontractors, material suppliers and vendors utilized herein current status concerning suspension, debarment, voluntary exclusion, or determination of ineligibility by any federal agency, in accordance with the "Debarment Certification" located behind the signature sheets in the proposal forms. Execution of the bid signature sheets in conjunction with any applicable statements concerning exceptions, when such statements have been made on the "Debarment Certification", constitutes the Proposer's certification of "status" under penalty of perjury under the laws of the United States.

\section{SUBMISSION OF PROPOSAL}

The Proposer's attention is directed that each Proposer shall comply with the following requirements in order for their Proposal to be responsible and considered for award. 
1. The Proposer shall deliver the Proposal to the place indicated, and prior to the time indicated in the Request for Proposals.

2. The Proposal documents shall be signed by an authorized employee of the Proposer.

3. The Proposal shall be accompanied by Bid surety in the form of a Bid bond or Bid deposit.

4. The Proposer shall complete the form Listing of MB/WB Subcontractors contained elsewhere in this proposal in accordance with the Project Special Provision "Minority and Women Business."

5. The Proposal shall address all the requirements as specified in the Request For Proposal document.

In addition to the above requirements, failure to comply with any of the requirements of Articles 102-8, 102-9, 102-10 or 102-11 of the 2006 Standard Specifications may result in a Proposal being rejected.

\section{MINORITY AND WOMEN BUSINESS}

\section{Policy}

It is the policy of the North Carolina Department of Transportation that minority and women businesses shall have the maximum opportunity to participate in the performance of contracts financed by Non-Federal Funds.

The contractor is also encouraged to give every opportunity to allow MB/WB participation including Supplemental Agreements.

\section{Obligation}

The contractor and any subsequent Subcontractor shall ensure that minority and women businesses have the maximum opportunity to participate in the performance of the work included in this contract. The contractor and any subsequent Subcontractor shall take all necessary and reasonable steps to ensure that minority and women businesses have the maximum opportunity to compete for and perform a portion of the work included in this contract and shall not discriminate on the basis of race, color, national origin or sex. Failure on the part of the contractor to carry out the requirements set forth herein shall constitute a breach of contract and after proper notification, may result in award disqualification, termination of the contract, disqualification from bidding, or other appropriate remedy.

\section{Goals}

Pursuant to the requirements of North Carolina General Statute 136-28.4, the following goals for participation are established for this contract:

\section{Minority Business Enterprises Women Business Enterprises}

\section{$5 \%$ of the maintenance contract costs}

$3 \%$ of the maintenance contract costs

This goal is to be met through utilization of highway maintenance contractors. Utilization of $\mathrm{MB} / \mathrm{WB}$ firms performing design-related functions are not included in this goal. 
The contractor shall exercise all necessary and reasonable steps to ensure that Minority Businesses (MB) and Women Businesses (WB) participate in at least the percentage of the contract as set forth above as goals for this contract.

\section{Listing of MB and WB Subcontractors}

All bidders, at the time the bid proposal is submitted, must also submit a listing of MB and WB participation on the appropriate form (or facsimile thereof) contained elsewhere in this proposal in order for the bid to be considered responsible. Bidders must indicate the total dollar value of $\mathrm{MB}$ and $\mathrm{WB}$ participation of the contract. In the event the bidder has no $\mathrm{MB}$ and $\mathrm{WB}$ participation, the bidder is still required to indicate this on the forms by entering the word or number zero. Blank forms will not be deemed to represent zero participation. BIDS SUBMITTED WHICH DO NOT HAVE MB AND WB PARTICIPATION INDICATED ON THE APPROPRIATE FORM WILL NOT BE READ PUBLICLY DURING THE OPENING OF BIDS. These bids will not be considered for award by the Department and they will be returned to the bidder. Bidders have the option of submitting their MB and WB participation in an abbreviated format as required in Paragraph A below, or the bidders may submit their MB and WB participation in the additional detail required by Paragraph $\mathrm{B}$ below. In the event the bidder elects to submit MB and WB participation in accordance with Paragraph A and is determined to be the apparent lowest responsive bidder, that bidder must deliver to the Department no later than 12:00 noon of the sixth day following the opening of bids, a detailed MB and WB submittal as required by Paragraph B below.

Only those MB and WB firms with current certification by the Department will be considered acceptable for listing in the bidders submittal of MB and WB participation.

A. The contractor shall indicate on the form for listing of MB and WB Subcontractors the following required information:

(1) The names of MB and WB firms committed to participate in the contract;

(2) The Contract Item Numbers of work to be performed by each MB and WB firm; and

(3) The total dollar amount to be paid to each MB and WB based on agreed upon unit prices.

B. In lieu of submitting the information required by (A) above, the bidder may submit the detailed information required below along with the bid proposal form.

(1) The names of MB and WB firms committed to participate in the contract;

(2) The Contract Item Numbers and Contract Item Descriptions and agreed upon unit prices of work to be performed by each MB and WB firm; and

(3) The total dollar amount to be paid to each MB and WB based on agreed upon unit prices.

Failure to indicate the required information of either Part A or B on the specified form will cause the bid to be considered non-responsible and it may be rejected. 
The Department will not allow any substitutions, deletions, or other alterations to the listing of firms committed for MB and WB participation and/or the respective listed contract item numbers after opening of bids. The Department will not allow adjustments to total dollar amount of MB and/or WB participation after the opening of bids which would result in the MB and/or WB participation being less than the contract goal. The only exceptions to the requirements of this paragraph will be: (1) to allow for replacement of a MB or WB firm that had been decertified after opening of bids, and (2) to allow alteration of the listed contract item numbers subject to the Bidder submitting sufficient documentation to verify an obvious error in the initial submittal.

C. If the bid of the lowest responsible bidder exceeds $\$ 500,000$ and if the MB and/or WB participation submitted in response to Paragraph B exceeds the algebraic sum of the MB and WB goals by $\$ 1000$ or more, the excess will be placed on deposit by the Department for future use by the bidder. Separate accounts will be maintained for MB and WB participation and these may accumulate for a period not to exceed 24 months.

If the $\mathrm{MB}$ and $\mathrm{WB}$ participation submitted in response to Paragraph $\mathrm{A} / \mathrm{B}$ does not meet or exceed the MB and WB contract goals, the apparent lowest responsive bidder shall submit information to satisfy the North Carolina Department of Transportation that sufficient reasonable efforts have been made to meet the contract goals. One complete set and nine copies of this information must be received in the office of the State Contractual Services Engineer no later than 12:00 noon of the sixth day following opening of bids. Where the information submitted includes repetitious solicitation letters it will be acceptable to submit a sample representative letter along with a distribution list of the firms being solicited. Documentation of MB and WB quotations shall be a part of the good faith effort submittal as necessary to demonstrate compliance with the factors listed below which the Department considers in judging good faith efforts. This documentation may include written subcontractor quotations, telephone log notations of verbal quotations, or other types of quotation documentation.

Where the bidder fails to provide this information by the deadline, the Department may impose the following sanctions: (1) disqualify the contractor and any affiliated companies from further bidding for a period of time of no more than 90 days from the date of disqualification as established in notification by certified mail; and (2) disqualify the contractor and any affiliated companies for award of all contracts for which bids have been received and opened.

The Department will consider the following factors in judging whether or not the bidder has made adequate good faith effort:

(1) Whether the bidder attended any pre-bid meetings that were scheduled by the Department to inform MBs and WBs of subcontracting opportunities;

(2) Whether the bidder provided written notice to a reasonable number of specific MBs and WBs that their interest in the contract is being solicited and whether the firms solicited could have reasonably been expected to quote the work in the contract

(3) Whether the bidder followed up on initial solicitations of interests by contacting MBs and WBs to determine with certainty whether they were interested; 
(4) Whether the bidder selected portions of the work to be performed by MBs and WBs in order to increase the likelihood of meeting the contract goals;

(5) Whether the bidder provided interested MBs and WBs with adequate information about the plans, specifications and requirements of the contract;

(6) Whether the bidder negotiated in good faith with interested MBs and WBs not rejecting them as unqualified without sound reasons based on a thorough investigation of their capabilities;

(7) Whether quotations were received from interested MB and WB firms but rejected as unacceptable without sound reasons why the quotations were considered unacceptable;

(8) Whether the bidder made efforts to assist interested MBs and WBs in obtaining any required insurance or bonding that may be required by the bid proposal or by the bidder;

(9) Whether the bidder specifically negotiated with Subcontractors to assume part of the responsibility to meet the contract $\mathrm{MB}$ and $\mathrm{WB}$ goal when the work to be sublet includes potential for MB and WB participation.

Where the apparent lowest responsible bidder fails to submit sufficient participation by MB firms to meet the contract goal, as part of the good faith effort the Department will consider allowing the bidder to withdraw funds to meet the MB goal so long as there are adequate funds available from the bidders MB bank account.

Where the apparent lowest responsive bidder fails to submit sufficient participation by WB firms to meet the contract goal, as part of the good faith effort the Department will consider allowing the bidder to withdraw funds to meet the WB goal so long as there are adequate funds available from the bidders WB bank account.

Where the apparent lowest responsive bidder fails to submit sufficient participation by MB and WB firms to meet the contract goal and upon a determination by the Goal Compliance Committee based upon the information submitted that the apparent lowest responsible bidder failed to make sufficient reasonable efforts to meet the contract goal, the Department may reject the bid.

In the event that the Department does not award the contract to the apparent lowest responsible bidder, the Department reserves the right to award the contract to the next lowest responsible bidder that can satisfy the Department that the contract goal can be met or that adequate good faith efforts have been made to meet the goal.

\section{Directory of Certified Businesses}

A searchable list of Businesses which have been certified by the North Carolina Department of Transportation is available at the following website:

$$
\text { http://apps.dot.state.nc.us/Vendor/Directory/Cert.aspx }
$$


Only those MB firms with current certification may be used to meet the contract $\mathrm{MB}$ goal and only those WB firms with current certification may be used to meet the contract WB goal.

The listing of an individual firm certified by the Department shall not be construed as an endorsement of the firms capability to perform certain work.

\section{Replacement of MBs and WBs}

\section{(A) Performance Related}

If any MB or WB Subcontractor indicated on the form for listing of MB and WB Subcontractors, contained elsewhere in this proposal, does not perform satisfactorily to the extent indicated or anticipated, the contractor shall take all necessary, reasonable steps to replace the MB Subcontractor with another MB Subcontractor and/or the contractor shall take all necessary, reasonable steps to replace the WB Subcontractor with another WB Subcontractor.

Any substitution of MB or WB firms after award of the contract shall be approved by the Department. The Contractor shall submit any requests for substitutions through the Engineer and the request must provide a valid basis or reason for the proposed substitution.

To demonstrate necessary, reasonable efforts, the contractor shall document the steps taken to replace any MB or WB Subcontractor that is unable to perform successfully with another MB or WB Subcontractor. Such documentation shall include but not be limited to the following:

(1) Copies of written notification to $\mathrm{MBs} / \mathrm{WBs}$ that their interest is solicited in subcontracting the work defaulted by the previous MB or WB Subcontractor or in subcontracting other items of work in the contract.

(2) Efforts to negotiate with $\mathrm{MBs}$ and WBs for specific subbids including at a minimum:

(a) The names, addresses, and telephone numbers of MBs and WBs that were contacted;

(b) A description of the information provided to MBs and WBs regarding the plans and specifications for portions of the work to be performed; and

(c) A statement of why additional agreements with MBs and WBs were not reached.

(3) For each $\mathrm{MB}$ or $\mathrm{WB}$ contacted but rejected as unqualified, the reasons for the contractor's conclusion.

(4) Efforts made to assist the MBs and WBs contacted, if needed, in obtaining bonding or insurance required by the contractor.

Failure of the contractor to demonstrate reasonable efforts to replace a MB or WB firm that does not perform as intended or anticipated, shall be just cause to disqualify the Contractor from further bidding for a period of up to 6 months after notification by certified mail.

(B) Decertification

1. If the Department has approved a Request for Subcontract for a particular MB or WB Subcontractor and that MB or WB Subcontractor is subsequently decertified 
by the Department; then the Department will not require the Contractor to solicit replacement $\mathrm{MB}$ or WB participation equal to the remaining work to be performed by the decertified firm.

2. If a Contractor has listed a MB or WB firm in the low bid submittal and the MB or WB firm is decertified prior to the Department approving a Request for Subcontract for the named MB or WB firm, the Contractor may be required to make a good faith effort to:

(a) Replace the decertified firm with a certified firm, or

(b) To obtain replacement MB or WB participation in other areas of work.

\section{Definitions}

(A) For purposes of this provision, the following definition will apply:

Minority Business or MB means a small business concern, which is owned and controlled by one or more minorities. Except that such term shall not include any concern or group of concerns controlled by the same minority or minorities which has average annual gross receipts over the preceding 3 fiscal years in excess of $\$ 14,000,000$, as adjusted by the Department for inflation. For the purposes of this part, owned and controlled means a business:

(a) Which is at least 51 percent owned by one or more minorities or in the case of a publicly owned business, at least 51 percent of the stock of which is owned by one or more minorities; and

(b) Whose management and daily business operations are controlled by one or more such individuals.

(B) Minority is defined as a citizen or lawful permanent resident of the United States and who is:

(1) Black (a person having origins in any of the black racial groups of Africa);

(2) Hispanic (a person of Mexican, Puerto Rican, Cuban, Central or South American, or other Spanish culture or origin, regardless of race);

Asian American (a person having origins in any of the original peoples of the Far East, Southeast Asia, the Indian subcontinent, or the Pacific Islands);

American Indian

(C) Women Business or WB means a small business concern, which is owned and controlled by one or more women. Except that such term shall not include any concern or group of concerns controlled by the same woman or women which has average annual gross receipts over the preceding 3 fiscal years in excess of $\$ 14,000,000$, as adjusted by the Department for inflation. For the purposes of this part, owned and controlled means a business: 
Which is at least 51 percent owned by one or more women or in the case of any publicly owned business, at least 51 percent of the stock of which is owned by one or more women; and

Whose management and daily business operations are controlled by one or more of the women who own it.

\section{Counting MB/WB Participation Toward Meeting the MB/WB Goal}

(A) If a firm is determined to be an eligible MB or WB firm and certified by the Department, the total dollar value of the participation by the MB or WB will be counted toward the appropriate $\mathrm{MB}$ or $\mathrm{WB}$ goal. The total dollar value of participation by a certified $\mathrm{MB}$ or WB will be based upon unit prices agreed upon by the contractor and MB or WB Subcontractor.

(B) The contractor may count toward its MB or WB goal a portion of the total dollar value of participation with a joint venture, eligible under the standards of this provision, equal to the percentage of the ownership and controls of the MB or WB partner in the joint venture.

(C) (1) The contractor may count toward its MB or WB goal only expenditures to MBs or WBs that perform a commercially useful function in the work of a contract. A $\mathrm{MB}$ or WB is considered to perform a commercially useful function when it is responsible for execution of a distinct element of the work of a contract and carrying out its responsibilities by actually performing, managing, and supervising the work involved. To determine whether a MB or WB is performing a commercially useful function, the Department will evaluate the amount of work subcontracted, industry practices, and other relevant factors.

(2) Consistent with normal industry practices, a MB or WB may enter into subcontracts. If a $\mathrm{MB}$ or WB Contractor or Subcontractor subcontracts a significantly greater portion of the work of the contract than would be expected on the basis of normal industry practices, the MB or WB shall be presumed not to be performing a commercially useful function. The MB or WB may present evidence to rebut this presumption to the Department. The Department's decision on the rebuttal of this presumption shall be final.

(D) A Contractor may count toward its MB or WB goal 60 percent of its expenditures for materials and supplies required to complete the contract and obtained from $\mathrm{MB}$ or $\mathrm{WB}$ regular dealer and 100 percent of such expenditures to a MB or WB manufacturer.

(1) For purposes of this provision, a manufacturer is a firm that operates or maintains a factory or establishment that produces on the premises the materials or supplies obtained by the Contractor.

(2) For purposes of this provision, a regular dealer is a firm that owns, operates, or maintains a store, warehouse, or other establishment in which the materials or supplies required for the performance of the contract are bought, kept in stock, and regularly sold to the public in the usual course of business. To be a regular dealer, the firm must engage in, as its principal business and in its own name, the purchase and sale of the products in question. A regular dealer in such bulk items 
as steel, cement, gravel, stone, and petroleum products need not keep such products in stock, if it owns or operates distribution equipment. Brokers and packagers shall not be regarded as manufacturers or regular dealers within the meaning or this section.

(E) A contractor may count toward its $\mathrm{MB}$ or WB goal the following expenditures to $\mathrm{MB}$ or WB firms that are not manufacturers or regular dealers:

(1) The fees or commissions charged for providing a bona fide service, such as professional, technical, consultant or managerial services and assistance in the procurement of essential personnel, facilities, equipment, materials or supplies required for performance of the contract, provided that the fee or commission is determined by the Department to be reasonable and not excessive as compared with fees customarily allowed for similar services.

(2) The fees charged for delivery of materials and supplies required on a job site (but not the cost of the materials and supplies themselves) when the hauler, trucker, or delivery service is not also the manufacturer of or a regular dealer in the materials and supplies, provided that the fee is determined by the Department to be reasonable and not excessive as compared with fees customarily allowed for similar services.

(3) The fees or commissions charged for providing any bonds or insurance specifically required for the performance of the contract provided that the fee or commission is determined by the Department to be reasonable and not excessive as compared with fees customarily allowed for similar services.

\section{Reports}

Within 30 days after receipt of materials, supplies, or services from MBs or WBs, not otherwise documented by Request for Subcontracts (RS-1A/RS-1B), the Contractor shall furnish to the Engineer appropriate documentation (canceled checks, paid invoices, etc.) to verify expenditures with $\mathrm{MB}$ and $\mathrm{WB}$ concerns. The documentation should also indicate the percentage $(60 \%$ or $100 \%$ ) of expenditures claimed for MB or WB credit.

All requests for subcontracts involving MB or WB Subcontractors shall be accompanied by a certification executed by both the Contractor and the MB or WB Subcontractor attesting to the agreed upon unit prices and extensions for the affected contract items. This document shall be on the Departments Form RS-1-D, or in lieu of using the Department's Form, copies of the actual executed agreement between the Contractor and the MB or WB Subcontractor may be submitted. In any event, the Department reserves the right to require copies of actual subcontract agreements involving MB and WB Subcontractors.

The RS-1-D certification forms may be obtained from the Engineer. These certifications shall be considered a part of the project records, and consequently will be subject to any penalties under State Law associated with falsifications of records related to projects.

\section{Reporting Minority Business Enterprise or Women Business Enterprise Participation}

When payments are made to Minority Business Enterprise firms or Women Business Enterprise firms, including material suppliers, contractors at all levels (prime, subcontractor, or second tier 
subcontractor) shall provide the Engineer with an accounting of said payments. This accounting shall be furnished to the Engineer for any given month by the end of the following month. Failure to submit this information accordingly may result in (1) withholding of money due in the next partial pay estimate; or (2) removal of an approved contractor from the prequalified bidders list or the removal of other entities from the approved subcontractors list. The accounting shall list for each payment made to a MB/WB Enterprise firm the following:

- DOT Project Number

- Payee Contractor Name

- Receiving Contractor or Material Supplier

- MB/WB Certification Basis, e.g., Woman Owned, Native American, African American, etc.

- Amount of Payment

- Date of Payment

A responsible fiscal officer of the payee Contractor, subcontractor, or second tier subcontractor who can attest to the date and amounts of the payments shall certify that the accounting is correct. A copy of an acceptable report may be obtained from the Engineer.

\section{SMALL BUSINESS ENTERPRISES}

In addition to $\mathrm{MB}$ and $\mathrm{WB}$ utilization, the contractor is strongly encouraged to utilize Small Business Enterprises throughout this project. Any payments made to certified Small Businesses shall be reported as outlined in the Project Special Provision "Minority and Women Business."

A searchable list of Businesses which have been certified by the North Carolina Department of Transportation is available at the following website:

$$
\text { http://apps.dot.state.nc.us/Vendor/Directory/Cert.aspx }
$$

\section{COOPERATION BETWEEN CONTRACTORS}

The Contractor's attention is directed to Article 105-7 of the 2006 Standard Specifications. A contract for a truck bypass system at weigh stations may be in effect during the life of this contract. The maintenance of all equipment installed as a part of the truck bypass system contract is the responsibility of the other contractor, but may require coordination between contractors. For all other projects, the Contractor is responsible for monitoring NCDOT websites for current and upcoming projects that may exist within, above or below the interstates within the project boundaries.

The interstate rehabilitation projects, I-4720 and I-4721A\&B, are expected to be completed in 2007. In addition, an interstate rehabilitation project in both directions of I-85 extending from the Gaston/Mecklenburg County Line for approximately 0.65 miles to the beginning of the concrete pavement in Mecklenburg County is expected to be completed in 2007. These projects may reduce certain maintenance and repair expenditures required as part of this contract. In addition, the Department intends to replace all pavement markings along I-85 in Gaston and Cleveland Counties with thermoplastic pavement markings in the fall of 2006. The Department makes no guarantee that these projects will occur within the timeframes outlined above nor that these projects will reduce maintenance or repair expenditures incurred by this Contractor. 
The Contractor on this project shall cooperate with other Contractors working within or adjacent to the limits of this project to the extent that the work can be carried out to the best advantage of all concerned.

\section{BID DOCUMENTATION $\quad(5 / 6 / 04)$}

\section{General}

The successful Proposer (Contractor) shall submit the original, unaltered bid documentation or a certified copy of the original, unaltered bid documentation used to prepare the Price Proposal for this contract to the Department. Such documentation shall be placed in escrow with a banking institution or other bonded document storage facility selected by the Department and preserved by that institution or facility as specified in the following sections of this provision.

\section{Bid Documentation}

The term "bid documentation" as used in this provision means all written information, working papers, computer printouts, electronic media, charts, and all other data compilations which contain or reflect information, data, and calculations used by the Proposer in the preparation of their Price Proposal. The term "bid documentation" includes, but is not limited to, Contractor equipment rates, Contractor overhead rates, labor rates, efficiency or productivity factors, arithmetical calculations, and quotations from subcontractors and material suppliers to the extent that such rates and quotations were used by the Proposer in formulating and determining the Price Proposal. The term "bid documentation" also includes any manuals, which are standard to the industry used by the Proposer in determining the bid. Such manuals may be included in the bid documentation by reference. Such reference shall include the name and date of the publication and the publisher. The term does not include bid documents provided by the Department for use by the Proposer in bidding on this project.

\section{Submittal of Bid Documentation}

A representative of the Proposer shall deliver the original, unaltered bid documentation or a certified copy of the original, unaltered bid documentation to the Department, in a container suitable for sealing, within ten (10) days after the notice of award is received. Bid documentation will be considered a certified copy if the Proposer includes a letter to the Department from a chief officer of the company stating that the enclosed documentation is an EXACT copy of the original documentation. The letter must be signed by a chief officer of the company, have the person's name and title typed below the signature, and the signature MUST be notarized at the bottom of the letter. The Department will not execute the contract until the original, unaltered bid documentation or a certified copy of the original, unaltered bid documentation has been received by the Department. The container shall be clearly marked "Bid Documentation" and shall also show on the face of the container the Proposer's name, Proposer's address, the date of submittal, the Project Number, and the County.

\section{Affidavit}

In addition to the bid documentation, an affidavit signed under oath by an individual authorized by the Proposer to execute the bid shall be included. The affidavit shall list each bid document with sufficient specificity so a comparison may be made between the list and the bid 
documentation to ensure that all of the bid documentation listed in the affidavit has been enclosed. The affidavit shall attest that the affiant has personally examined the bid documentation, that the affidavit lists all of the documents used by the Proposer to determine the bid for this project, and that all such bid documentation has been included.

\section{Verification}

Upon delivery of the bid documentation, the Department's Contract Officer and the Proposer's representative will verify the accuracy and completeness of the bid documentation compared to the affidavit. Should a discrepancy exist, the Proposer's representative shall immediately furnish the Department's Contract Officer with any other needed bid documentation. The Department's Contract Officer upon determining that the bid documentation is complete will, in the presence of the Proposer's representative, immediately place the complete bid documentation and affidavit in the container and seal it. Both parties will deliver the sealed container to a banking institution or other bonded document storage facility selected by the Department for placement in a safety deposit box, vault, or other secure accommodation.

\section{Duration and Use}

The bid documentation and affidavit shall remain in escrow until 60 calendar days from the time the Contractor receives the final estimate; or until such time as the Contractor gives written notice of intent to file a claim, files a written claim, files a written and verified claim, or initiates litigation against the Department related to the contract; or until authorized in writing by the Contractor. Upon the giving of written notice of intent to file a claim, filing a written claim, filing a written and verified claim, or the initiation of litigation by the Contractor against the Department, or receipt of a letter from the Contractor authorizing release, the Department may obtain the release and custody of the bid documentation. If the bid documentation remains in escrow sixty (60) calendar days after the time the Contractor receives the final estimate and the Contractor has not filed a written claim, filed a written and verified claim, or has not initiated litigation against the Department related to the contract, the Department shall instruct the banking institution or other bonded document storage facility to release the sealed container to the Contractor.

The Proposer certifies and agrees that the sealed container placed in escrow contains all of the bid documentation used to determine the bid and that no other bid documentation shall be relevant or material in litigation over claims brought by the Contractor arising out of this contract.

\section{Failure to Provide Bid Documentation}

The Proposer's failure to provide the original, unaltered bid documentation or a certified copy of the original, unaltered bid documentation within 10 days after the notice of award is received may be just cause for rescinding the award of the contract and may result in the removal of the Proposer from the Department's list of qualified Proposers for a period up to 180 days. Award may then be made to the next lowest responsible Proposer or the work may be readvertised and constructed under the contract or otherwise, as the Board of Transportation may decide. 


\section{Escrow Agreement}

The Proposer will be required to sign an Escrow Agreement within 10 days after receipt of the notice of award. A copy of this Escrow Agreement document will be mailed to the Proposer with the notice of award for informational purposes. The Proposer and Department will sign the Escrow Agreement at the time that the bid documentation is delivered to a Banking Institution or other facility as outlined above. The Proposer's failure to sign the Escrow Agreement at the time the bid documentation is delivered may be just cause for rescinding the award of the contract and may result in the removal of the Proposer from the Department's list of qualified Proposers for a period up to 180 days. Award may then be made to the next lowest responsible Proposer or the work may be readvertised and constructed under the contract or otherwise, as the Board of Transportation may decide.

\section{Confidentiality of Bid Documentation}

The bid documentation and affidavit in escrow are, and will remain, the property of the Proposer. The Department has no interest in, or right to, the bid documentation and affidavit other than to verify the contents and legibility of the bid documentation unless the Contractor gives written notice of intent to file a claim, files a written claim, files a written and verified claim, or initiates litigation against the Department. In the event of such written notice of intent to file a claim, filing of a written claim, filing a written and verified claim, or initiation of litigation against the Department, or receipt of a letter from the Contractor authorizing release, the bid documentation and affidavit may become the property of the Department for use in considering any claim or in litigation as the Department may deem appropriate.

Any portion or portions of the bid documentation designated by the Proposer as a "trade secret" at the time the bid documentation is delivered to the Department's Contract Officer shall be protected from disclosure as provided by General Statutes 132-1.2.

\section{Cost and Escrow Instructions}

The cost of the escrow will be borne by the Department. The Department will provide escrow instructions to the banking institution or other bonded document storage facility consistent with this provision.

\section{Payment}

There will be no separate payment for all costs of compilation of the data, container, or verification of the bid documentation. Payment at the monthly lump sum price for the project will be full compensation for all such costs.

\section{TWELVE-MONTH GUARANTEE}

The Contractor shall guarantee materials and workmanship against latent and patent defects arising from faulty materials, faulty workmanship or negligence for a period of twelve months following completion of the initial, and if applicable, second term, of the contract. The Contractor shall replace such defective materials and workmanship without cost to the Department.

Where items of equipment or material carry a manufacturer's guarantee for any period that survives the end of the contract, then the manufacturer's guarantee shall apply for that particular 
piece of equipment or material. The Department's first remedy shall be through the manufacturer although the Contractor is responsible for invoking the warranted repair work with the manufacturer. The Contractor's responsibility shall be limited to the term of the manufacturer's guarantee.

For Department contracts with others along the facilities covered by this contract, warranty requirements within those contracts shall be exhausted prior to that work becoming the responsibility of this Contractor.

This provision shall not be used as a mechanism to force the Contractor to return to the project to make repairs or perform additional work for which the Department would normally compensate the Contractor.

The Contractor may offer additional or specific warranties beyond that required by this special provision. Such additional warranties will be considered in the evaluation of the Technical Proposals.

\section{OUTSOURCING OUTSIDE THE USA}

All work on consultant contracts, services contracts, and construction contracts shall be performed in the United States of America. No work shall be outsourced outside of the United States of America.

Outsourcing for the purpose of this provision is defined as the practice of subcontracting labor, work, services, staffing, or personnel to entities located outside of the United States.

The North Carolina Secretary of Transportation shall approve exceptions to this provision in writing.

\section{BOOKS AND RECORDS}

The Contractor shall retain all books, records and other documents relative to this Contract for three (3) years after expiration of the last contract term, except that books, records and other documents relating to any items unpaid or in dispute as of the date of expiration of the Term shall be retained for three (3) years after final payment of such amounts. The Department, its authorized agents, and/or state auditors shall have full access to and the right to examine any said materials during said period.

\section{VEGETATION MANAGEMENT}

\section{Pesticides}

To ensure compliance with existing NPDES requirements and to sustain the Department's current approach to vegetation management, the Contractor shall adhere to the following requirements.

The Contractor shall submit for approval a completed "Application for Permit to Apply Pesticides along NCDOT Rights-of-Way." The form shall be submitted to the Engineer 15 
business days prior to any pesticide application. The Department shall approve in writing all tree-cutting before operations begin. In addition, for every application, a "Daily Pesticide Application Form for Contractor Applied Products" shall be completed by the Contractor and shall be maintained for the duration of the contract. These logs shall become the property of the Department at the end of the contract period.

Pesticide applicators shall be appropriately licensed by the North Carolina Department of Agriculture and Consumer Services Pesticide Section. A license holder shall be on-site during all applications. A Contractor representative shall be available within a 24-hour timeframe to respond to any questions regarding pesticide applications. The Contractor shall be responsible for all third party claims arising from pesticide applications.

The Contractor shall preserve and protect endangered and threatened species both within and beyond the right-of-way. The Contractor shall follow NCDOT policies regarding Roadside Memorials on Highway Rights-of-Way, Control of Kudzu and Undesirable Vegetation (§13618(9)), and Cutting Down Trees (§136-18.6). The control of exotic invasive plants is the Contractor's responsibility.

The use of products containing ester formulations is restricted to the period between November 15 and February 15 of each year.

No pesticide shall be used to maintain or open lines-of-sight at outdoor advertising structures or as a component of Selective Vegetation Removal unless otherwise approved in writing by the Engineer. The Department shall retain control of the Outdoor Advertising and Selective Vegetation Removal permitting processes. Any utility encroachments including vegetation removal will also be approved and permitted by the Department.

\section{Mowing}

All mowing cycles shall be clean-up cycles.

Vertical trimming shall be pre-approved by the Engineer and shall result in a neat appearance with debris disposed of properly. Proper disposal includes mulching and spreading or disposal offsite.

Vegetation management in the area of the University Research Park is excluded from this contract. Specifically, mowing, landscape plant beds, brush and trees, turf condition, seeding and mulching, and uncontrolled growth at signs/guardrail/guiderail are excluded from the contract in this area. The limits of the area are from the beginning of the southern ramps of the W. T. Harris Blvd. where they intersect with I-85 to the ends of the northern ramps at Mallard Creek Church Rd. where they intersect with I-85.

\section{NCDOT GENERAL SEED SPECIFICATIONS FOR SEED QUALITY}

Seed shall be sampled and tested by the North Carolina Department of Agriculture and Consumer Services, Seed Testing Laboratory. When said samples are collected, the vendor shall supply an independent laboratory report for each lot to be tested. Results from seed so sampled 
shall be final. Seed not meeting the specifications shall be rejected by the Department of Transportation and shall not be delivered to Department of Transportation warehouses. If seed has been delivered it shall be available for pickup and replacement at the supplier's expense.

Any re-labeling required by the North Carolina Department of Agriculture and Consumer Services, Seed Testing Laboratory, that would cause the label to reflect as otherwise specified herein shall be rejected by the North Carolina Department of Transportation.

Seed shall be free from seeds of the noxious weeds Johnsongrass, Balloonvine, Jimsonweed, Witchweed, Itchgrass, Serrated Tussock, Showy Crotalaria, Smooth Crotalaria, Sicklepod, Sandbur, Wild Onion, and Wild Garlic. Seed shall not be labeled with the above weed species on the seed analysis label. Tolerances as applied by the Association of Official Seed Analysts will NOT be allowed for the above noxious weeds except for Wild Onion and Wild Garlic.

Tolerances established by the Association of Official Seed Analysts will generally be recognized. However, for the purpose of figuring pure live seed, the found pure seed and found germination percentages as reported by the North Carolina Department of Agriculture and Consumer Services, Seed Testing Laboratory will be used. Allowances, as established by the NCDOT, will be recognized for minimum pure live seed as listed on the following pages.

The specifications for restricted noxious weed seed refers to the number per pound as follows:

\begin{tabular}{|c|c|c|c|}
\hline $\begin{array}{c}\text { Restricted Noxious } \\
\text { Weed }\end{array}$ & $\begin{array}{l}\text { Limitations per } \\
\text { Lb. Of Seed }\end{array}$ & $\begin{array}{c}\text { Restricted Noxious } \\
\text { Weed }\end{array}$ & $\begin{array}{c}\text { Limitations per } \\
\text { Lb. of Seed }\end{array}$ \\
\hline Blessed Thistle & 4 seeds & Bermudagrass & 27 seeds \\
\hline Cocklebur & 4 seeds & Cornflower (Ragged Robin) & 27 seeds \\
\hline Spurred Anoda & 4 seeds & Texas Panicum & 27 seeds \\
\hline Velvetleaf & 4 seeds & Bracted Plantain & 54 seeds \\
\hline Morning-glory & 8 seeds & Buckhorn Plantain & 54 seeds \\
\hline Corn Cockle & 10 seeds & Broadleaf Dock & 54 seeds \\
\hline Wild Radish & 12 seeds & Curly Dock & 54 seeds \\
\hline Purple Nutsedge & 27 seeds & Dodder & 54 seeds \\
\hline Yellow Nutsedge & 27 seeds & Giant Foxtail & 54 seeds \\
\hline Canada Thistle & 27 seeds & Horsenettle & 54 seeds \\
\hline Field Bindweed & 27 seeds & Quackgrass & 54 seeds \\
\hline Hedge Bindweed & 27 seeds & Wild Mustard & 54 seeds \\
\hline
\end{tabular}

Seed of Pensacola Bahiagrass shall not contain more than 7\% inert matter, Kentucky Bluegrass and Fine or Hard Fescue shall not contain more than 5\% inert matter whereas a maximum of 2\% inert matter will be allowed on all other kinds of seed. In addition, all seed shall not contain more than $2 \%$ other crop seed or more than $1 \%$ total weed seed. The germination rate as tested by the North Carolina Department of Agriculture shall not fall below 70\%, which includes both dormant and hard seed. Seed shall be labeled with not more than $7 \%, 5 \%$ or $2 \%$ inert matter (according to above specifications), $2 \%$ other crop seed and 1\% total weed seed.

Exceptions may be made for minimum pure live seed allowances when cases of seed variety shortages are verified. Pure live seed percentages will be applied in a verified shortage situation. Those purchase orders of deficient seed lots will be credited with the percentage that the seed is deficient. 


\section{FURTHER SPECIFICATIONS FOR EACH SEED GROUP ARE GIVE BELOW:}

Minimum $85 \%$ pure live seed; maximum 1\% total weed seed; maximum $2 \%$ total other crop seed; maximum 144 restricted noxious weed seed per pound. Seed less than $83 \%$ pure live seed will not be approved.

\section{Sericea Lespedeza}

Oats (seeds)

Minimum $80 \%$ pure live seed; maximum $1 \%$ total weed seed; maximum $2 \%$ total other crop; maximum 144 restricted noxious weed seed per pound. Seed less than $78 \%$ pure live seed will not be approved.

Tall Fescue (all approved varieties)

Kobe Lespedeza

Korean Lespedeza

Weeping Lovegrass

Carpetgrass
Bermudagrass

Browntop Millet

German Millet - Strain R

Centipedegrass

Clover - Red/White/Crimson

Minimum 78\% pure live seed; maximum 1\% total weed seed; maximum $2 \%$ total other crop seed; maximum 144 restricted noxious weed seed per pound. Seed less than $76 \%$ pure live seed will not be approved.

\section{Common or Sweet Sundangrass}

Minimum 76\% pure live seed; maximum 1\% total weed seed; maximum 2\% total other crop seed; maximum 144 restricted noxious weed seed per pound. Seed less than $74 \%$ pure live seed will not be approved.

Rye (grain; all varieties)

Kentucky Bluegrass (all approved varieties)

Hard Fescue (all approved varieties)

Shrub (bicolor) Lespedeza

Minimum $70 \%$ pure live seed; maximum $1 \%$ total weed seed; maximum $2 \%$ total other crop seed; maximum 144 restricted noxious weed seed per pound. Seed less than $70 \%$ pure live seed will not be approved.

\section{Crownvetch Japanese Millet \\ Reed Canary Grass}

Pensacola Bahiagrass

Switchgrass

Minimum 65\% pure live seed; maximum 1\% total weed seed; maximum $2 \%$ total other crop seed; maximum 144 restricted noxious weed seed per pound. Seed less than $60 \%$ pure live seed will not be approved.

Little Bluestem 
Switchgrass

Minimum 75\% pure live seed; maximum 1\% total weed seed; maximum 2\% total other crop seed; maximum 144 restricted noxious weed seed per pound. Seed less than $70 \%$ pure live seed will not be approved.

Big Bluestem

Minimum 78\% pure live seed; maximum 1\% total weed seed; maximum 2\% total other crop seed; maximum 144 restricted noxious weed seed per pound. Seed less than $73 \%$ pure live seed will not be approved.

Indiangrass

NCDOT seed mixtures can be found at:

www.ncdot.org/doh/operations/dp chief eng/roadside/soil water/special provisions.

Any and all seed substitutes must be pre-approved by the Division Roadside Environmental Engineer.

\section{PLANT AND PEST QUARANTINES}

\section{(Imported Fire Ant, Gypsy Moth, Witchweed, And Other Noxious Weeds)}

\section{Within quarantined area}

This project may be within a county regulated for plant and/or pests. If the project or any part of the Contractor's operations is located within a quarantined area, thoroughly clean all equipment prior to moving out of the quarantined area. Comply with federal/state regulations by obtaining a certificate or limited permit for any regulated article moving from the quarantined area.

\section{Originating in a quarantined county}

Obtain a certificate or limited permit issued by the N.C. Department of Agriculture/United States Department of Agriculture. Have the certificate or limited permit accompany the article when it arrives at the project site.

\section{Contact}

Contact the N.C. Department of Agriculture/United States Department of Agriculture at 1-800206-9333, 919-733-6932, or http://www.ncagr.com/plantind/ to determine those specific project sites located in the quarantined area or for any regulated article used on this project originating in a quarantined county. 


\section{Regulated Articles Include}

1. Soil, sand, gravel, compost, peat, humus, muck, and decomposed manure, separately or with other articles. This includes movement of articles listed above that may be associated with cut/waste, ditch pulling, and shoulder cutting.

2. Plants with roots including grass sod.

3. Plant crowns and roots.

4. Bulbs, corms, rhizomes, and tubers of ornamental plants.

5. Hay, straw, fodder, and plant litter of any kind.

6. Clearing and grubbing debris.

7. Used agricultural cultivating and harvesting equipment.

8. Used earth-moving equipment.

9. Any other products, articles, or means of conveyance, of any character, if determined by an inspector to present a hazard of spreading imported fire ant, gypsy moth, witchweed or other noxious weeds.

\section{MINIMUM WAGES}

The Contractor shall have no claim against the Department of Transportation for any changes in the minimum wage laws, State or Federal. It is the responsibility of the Contractor to keep himself fully informed of all Federal and State Laws affecting this contract.

*** Deleted Special Provision for Minority and Female Employment Requirements ***

\section{ERRATA}

Revise the Standard Specifications for Roads and Structures July 2006 on all projects as follows:

\section{Division 1}

- Page 1-1, replace AREA - American Railway Engineering Association with American Railway Engineering and Maintenance of Way Association.

a Page 1-7, remove -L- in middle of page after INVITATION TO BID and before LABORATORY.

口 Page 1-21, Article 102-11, add (A) Paper Bids under the 2nd paragraph, just prior to No bid will be considered or .....

- Page 1-22, Article 102-11, change (A) to (B)

- Page 1-25, (R) move 2nd paragraph to left margin. It is not a part of this subarticle, but part of the entire article.

\section{Division 2}

a Page 2-23, Subarticle 235(B)(9), at the end of the sentence, replace finished greater with finished grade. 


\section{Division 3}

a Page 3-13, Article 340-4, Second paragraph, change Flowable Backfill to Flowable Fill

\section{Division 4}

- Page 4-70, 442-13(B) Second sentence, change SSPC Guide 6I to SSPC Guide 6.

a Pages 4-72, 4-74, 4-76, at the top of the page, substitute the heading Section 452 with Section 450.

\ Page 4-79, at the top of the page, substitute the heading Section 450 with Section 452

- Page 4-80, change 452-7 to 452-6 at the top of the page.

ـ Page 4-80, change Pay Item___ Steel Pile Retaining Walls, to Sheet Pile Retaining Walls.

\section{Division 6}

口 Page 6-3, Article 600-9, 3rd Paragraph, replace 818-5 with 818-4.

口 Pages 6-30 and 31, Subarticle 610-3(A)(13) Move 2 paragraphs from the margin to the right under the number (13).

- Page 6-43, Article 610-8, 4th paragraph, remove the first the

a Page 6-44, 2nd full paragraph, $1^{\text {st }}$ sentence, delete the first and and add transverse just before cross-slope control.

- Page 6-51, at the top of the page, add 610-14 on the same line, and just before the heading MAINTENANCE.

- Page 6-66, title, Replace EXISTNG with EXISTING

- Page 6-67, at the top of the page, substitute the heading Section 654 with Section 657.

- Page 6-89, Add a period at the end of the last sentence at the bottom of the page.

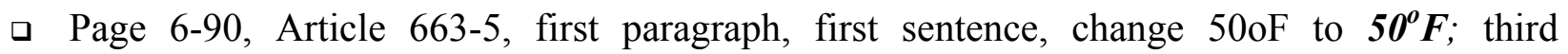
paragraph, fourth sentence change $325 \mathrm{oF}$ to $325^{\circ} \mathrm{F}$.

\section{Division 7}

- Page 7-12, at the top of the page, substitute the heading Section 710 with Section 700.

口 Page 7-15, Article 710-9, 4th paragraph, last line, change 710-11(B) to 710-10(B).

\section{Division 8}

Page 8-35, Article 848-2, Item: Replace Cncrete with Concrete

\section{Division 9}

a Page 9-2, add 901-3 just before CONSTRUCTION METHODS.

\section{Division 10}

- Page 10-12, near bottom of page add $(\boldsymbol{C})$ before Proportioning and Mixing of Modified Compositions, which should be bold type. 
a Page 10-28, at the top of the page, substitute Section 1006 for 1005.

a Pages 10-56, 10-58, 10-60 at the top of the page, substitute Section 1018 with Section 1020.

口 Page 10-100, Table 1056-1, replace on the line for Trapezoidal Tear Strength:

\begin{tabular}{|c|c|c|c|c|}
\hline Type 1 & Type 2 & \multicolumn{2}{|c|}{ Type 3 } & Type 4 \\
\hline & & Class A & Class B & Soil Stabilization \\
\hline $\mathbf{4 5} \mathbf{l b}$ & $\mathbf{7 5} \mathrm{lb}$ & -- & -- & $\mathbf{7 5} \mathrm{lb}$ \\
\hline
\end{tabular}

口 Page 10-116, Subarticle 1070-10, first paragraph, second sentence, add or just before coldforged sleeve.

a Pages 10-136 through 10-147, at the top of the page, substitute Section 1074 with Section 1072.

- Page 10-211, at the top of the page, substitute Section 1081 with Section 1082.

a Page 10-229, add 1088-6 BLANK on the line above 1088-7 TUBULAR MARKERS.

a Page 10-244, add 1089-10 BLANK and 1089-11 BLANK on the lines just above 1089-12 FLAGGER.

a Page 10-272, delete Article 1098-6 in its entirety. Renumber Articles 1098-7 through 109817 as Articles 1098-6 through 1098-16 consecutively.

\section{Division 12}

․ Page 12-21 Add 1266-2 just before the heading MATERIALS.

\section{Division 15}

a Page 15-2 add 1500-4 just before the heading WEEKEND, NIGHT AND HOLIDAY WORK.

a Page 15-5, add 1505-6 on the same line and just before the heading MEASUREMENT AND PAYMENT. (Remove the period after PAYMENT.)

a Page 15-8, add 1510-4 on the same line and just before the heading MEASUREMENT AND PAYMENT.

a Page 15-10, substitute BLANK for CONSTRUCTION REQUIREMENTS on the same line and just after 1515-4.

a Page 15-10, substitute CONSTRUCTION REQUIREMENTS for General Requirements

a Page $15-22$, add $\mathbf{1 5 4 0 - 3}$ on the same line and just before the heading CONSTRUCTION REQUIREMENTS

\section{Division 16}

a Page 16-12, Subarticle 1632-1(C) 1/4 Inch hardware cloth, change the minimum width from 24 inches to 48 inches. 


\section{*** CONTRACTOR PROPOSAL AND EVALUATION ***}

\section{GENERAL}

The Contractor shall be fully and totally responsible for the accuracy and completeness of all work performed under this contract and shall save the State harmless and shall be fully liable for any additional costs and all claims against the State which may arise due to errors, omissions and negligence of the Contractor or its subcontractors in performing the work. The Contractor shall certify any required plans, specifications, estimates and engineering data furnished by the Contractor's team.

All work by the Contractor shall be performed in a manner satisfactory to the State and in accordance with the established customs, practices, and procedures of the North Carolina Department of Transportation, and in conformity with the standards adopted by the American Association of State Highway Transportation Officials, and approved by the U.S. Secretary of Transportation as provided in Title 23, U.S. Code, Section 109 (b). The decision of the Engineer shall control in all questions regarding location, design, and similar questions.

\section{NO CONTACT CLAUSE}

To ensure that information is distributed equitably to all short-listed Proposers, all questions and requests for information shall be directed to the State Contract Officer through the Interstate Maintenance e-mail address. This procedure precludes any Contractor, subcontractor, or representative, from contacting representatives of the Department, other State Agencies or Federal Agencies either by phone, e-mail or in person concerning this Interstate Maintenance Project.

\section{DESIGN REFERENCES}

Design references may be needed during the course of this contract. Any design references developed and published by NCDOT or developed and published by other agencies and adopted for use by NCDOT may be obtained by contacting the Contract Office of the Project Services Unit. Standard prices for materials, which the Department normally sells for a fee, will be in effect. The Contractor is responsible for designing in accordance with the applicable documents and current revisions and supplements thereto.

\section{DESIGN SUBMITTALS}

The Contractor will be responsible for submitting to the Department for approval all design work necessary to make emergency repairs or collision damage repairs except for bridge elements, retaining walls, and culverts greater in size than 54". The Department will provide designs for bridge elements, retaining walls, and culverts greater in size than 54". The Contractor will be responsible for all traffic control plans and shop drawings. Traffic control submittals shall be sealed by a Professional Engineer licensed in the State of North Carolina and submitted in accordance with the document entitled "Design-Build Submittal Guidelines", which by reference is incorporated and made a part of this contract. This document is available through the following website: www.ncdot.org/ designbuild 
Design submittals will be reviewed within 10 working days from the date of receipt by NCDOT. All submittals shall be made simultaneously to the Engineer and the State Alternative Delivery Engineer.

\title{
ETHICS POLICY
}

Employees employed by the Contractor or subcontractors to provide services for this project shall comply with the Department's ethics policy. Failure to comply with the ethics policy will result in the employee's removal from the project and may result in removal of the Contractor from consideration on future Department contracts.

\section{APPROVAL OF PERSONNEL}

The Contractor shall not change team members or subcontractors identified in the Technical Proposal without written consent of the Engineer. In addition, subcontractors not identified in the Statement of Qualifications or Technical Proposal shall not perform any work without written consent of the Engineer. The Department will have the right to approve or reject any personnel assigned to the project by the Contractor.

Key Contractor team members, including prime contractor personnel and subcontractors, identified in the Statement of Qualifications shall not be modified in the Technical Proposal without written approval of the Department. Any such request should be sent to:

\author{
Randy Garris, PE \\ NCDOT-Project Services Unit \\ Century Center-Building B \\ 1020 Birch Ridge Drive \\ Raleigh, NC 27610
}

The Contractor or any subcontractor which are employed to provide services for this project shall not discuss employment opportunities or engage the services of any person or persons, now in the employment of the State during the time of this contract, without written consent of the State.

In the event of engagement, the Contractor or its subcontractors shall restrict such person or persons from working on any of the Contractor's contracted projects in which the person or persons were "formerly involved" while employed by the State. The restriction period shall be for the duration of the contracted project with which the person was involved. Former Involvement shall be defined as active participation in any of the following activities:

Drafting the contract

Defining the scope of the contract

Selection of the Contractor

Negotiation of the cost of the contract (including calculating manhours or fees); and

Administration of the contract.

An exception to these terms may be granted when recommended by the Secretary and approved by the Board of Transportation. 
Failure to comply with the terms stated above in this section may be justification for removing the Contractor from further consideration for this project and disqualification from submitting on future Department contracts.

\title{
SUBMITTAL OF TECHNICAL AND PRICE PROPOSALS
}

Price Proposals will be accepted until 4:00 P.M. Local Time on Wednesday January 24, 2007, at the office of the State Contract Officer:

\author{
Mr. Randy A. Garris, PE \\ Project Services Unit \\ 1020 Birch Ridge Drive \\ Century Center Complex Bldg. B \\ Raleigh, NC
}

No Proposals will be accepted after the time specified.

Based on the nature of the revisions in this BAFO RFP, amendments to the Technical Proposals previously submitted for the November 29, 2006 deadline are not warranted and will not be permitted.

Price Proposals shall be submitted in a sealed package. The outer wrapping will clearly indicate the following information:

\author{
Price Proposal \\ Submitted by (Contractor's Name) \\ WBS Number 40682 \\ Mecklenburg, Gaston, Cabarrus \& Cleveland Counties \\ I-85, I-77, I-485 \& I-277 Interstate Maintenance Contract
}

The Price Proposal shall be submitted by returning the Request for Proposals with the item sheets completed, and all required signatures and bonds. Failure to execute the required documents may render the proposal non-responsive. 


\section{EVALUATIONS}

Technical Proposals shall address the elements of the routine maintenance of the project. The Technical Review Committee will consider the understanding of the project, the anticipated problems and the solutions to those problems.

The Contractor's Technical Proposal shall be developed using narratives, tables, charts, plots, drawings and sketches as appropriate. The purpose of the Technical Proposal is to document the Contractor's understanding of the project, their selection of appropriate subcontractors, and their approach for completing all maintenance and repair activities.

The award of the Interstate Maintenance contract does not in any way imply that the Department accepts or approves the details of the Technical Proposal submitted by the Contractor. The Technical Proposals will be evaluated in each of the following areas:

\section{Quality Credit Evaluation Factors for Technical Proposals}

Management

Responsiveness to Request for Proposal

Maintenance of Traffic and Safety Plan

Timeliness Requirements and Tracking

Oral Interview
20

40

20

15

5

\section{TECHNICAL PROPOSAL EVALUATION CRITERIA}

\section{Management -20 points}

\section{Interstate Maintenance Management - 20 points}

- Describe the Contractor's concept of maintenance management. The proposal shall identify key positions and subordinate organizational units. The proposal shall also address overall staffing expectations to ensure that proper and timely maintenance and repair functions are completed. Provide an organizational chart that illustrates the various subcontractors and key personnel.

- Provide a description of the proposed location of the Contractor's office(s) and their respective responsibilities.

- Describe how the Contractor's team will interact with Department personnel, State Highway Patrol, Fire and Rescue, and other agencies as needed.

- Describe the overall strengths of the Contractor's organization, including subcontractors, and their ability to fulfill the requirements of this contract.

- Descriptions of those categories of work that the Contractor anticipates will be selfperformed and those categories that will be performed by subcontractors.

- Describe in general terms the resources that the Contractor's team will have or make available for this project.

\section{Responsiveness to $\mathrm{RFP}-\mathbf{4 0}$ points}

\section{General - 15 Points}

- Describe the Contractor's understanding of the major components and issues surrounding this contract. 
- Provide a brief description of the Contractor's proposed plan for performing maintenance and repairs on the project. This description shall include any items that the Contractor is responsible for that are not specifically mentioned in the RFP.

- Describe any initial condition assessment that the Contractor has performed within the project limits, highlighting those work elements that are viewed as severely below the performance targets contained herein.

- Describe innovative approaches that have been used on other projects or will be used to fulfill the maintenance needs throughout this project.

- Describe the Contractor's philosophy, abilities, and approach to assessing and collecting funds as third party claims.

\section{Quality Management - 15 Points}

- Describe how the Contractor's team will ensure achievement of the performance criteria specified herein. Include a narrative describing the Contractor's understanding of the Department's quality control philosophy.

- Include a Quality Management Plan as discussed elsewhere in this RFP.

- Describe the Contractor's approach to overall quality control and quality assurance.

- Describe how the Contractor will track and evaluate their performance.

- Describe the reporting or tracking techniques that the Contractor will use to ensure timely and quality maintenance services on this project.

- Describe the methods the Contractor will use to ensure quality across the large geographic area and diverse traffic conditions across this project.

- Describe any specific approaches, methods, or materials that will be used to provide long-term solutions to maintenance and repair problems in order to minimize the Department's cost after the period of this contract.

- Describe any additional warranties that the Contractor may offer other than those required herein.

\section{Minority \& Women's Business Enterprises and Small Businesses - 5 Points}

- Describe the Contractor's approach to ensuring that MB/WB and Small Businesses will have opportunities to participate in the various aspects of the project.

- Describe the Contractor's commitment to maintaining a high level of MB/WB and Small Business involvement throughout the life of the contract.

\section{Natural Environmental Responsibility - 5 Points}

- Describe the Contractor's approach to environmental concerns within the project.

- Describe the Contractor's understanding of the overall approach to permitting and their comfort level with obtaining any required permits.

- Describe any Notice of Violations (NOV's) or Immediate Corrective Actions (ICA's) the Contractor has received and the disposition of any NOV's or ICA's.

- Describe the Contractor's approach to Sedimentation and Erosion Control for the project. 


\section{Maintenance of Traffic and Safety Plan - 20 points}

\section{Maintenance of Traffic}

- Describe the Contractor's approach to any traffic control that will be used for each maintenance operation. Describe how traffic will be maintained as appropriate and describe the Contractor's understanding of the traffic control time restrictions noted elsewhere in the RFP.

\section{Safety Plan}

- Describe the safety considerations specific to the project.

- Discuss the Contractor 's overall approach to safety.

\section{Timeliness Requirements and Tracking -15 points}

- Describe the Contractor's approach to meeting all timeliness requirements within this contract.

- Describe the Contractor's specific approach to the timeliness of emergency response.

- Describe the Contractor's approach to tracking and addressing customer service issues.

- Describe the Contractor's approach to tracking work progress and asset conditions.

\section{Oral Interview -5 points}

- The Contractor's team shall present a brief introduction of the project team and maintenance approach.

- Introductory comments shall be held to no more than 20 minutes.

- The Department will use this interview to ask specific questions about the Contractor's background, philosophies, and approach to the project.

- Presentation, questions, and answers shall not exceed 75 minutes. No more than 10 people from the Contractor's team may attend.

- The Department will use the information presented in the oral interview to assist in the evaluation of the Technical Proposal.

\section{SELECTION PROCEDURE}

There will be a Technical Review Committee (TRC) composed of NCDOT personnel that will evaluate the Technical Proposal on the basis of the criteria provided in the Request for Proposals.

The selection of a Contractor will involve both technical quality and price. The technical proposals will be presented to the TRC for evaluation. The TRC shall first determine whether the proposals are responsive to the requirements of the Request for Proposals. Each responsive technical proposal shall be evaluated based on the rating criteria provided in the Request for Proposals. The TRC will submit an overall technical proposal score for each Contractor to the State Contract Officer. A maximum quality credit percentage will be assigned for each project, as determined by the TRC. 


\section{Quality Credit Evaluation Factors for Technical Proposals}

Management

Responsiveness to Request for Proposal

Maintenance of Traffic and Safety Plan

Timeliness Requirements and Tracking

Oral Interview
20

40

20

15

5

The State Contract Officer will use a table based on the maximum quality credit percentage to assign a Quality Credit Percentage to each proposal based on the proposal's overall technical score. The maximum percentage for this project will be $\mathbf{2 0 \%}$.

\section{Quality Credit Percentage for Technical Proposals}

\begin{tabular}{|c|c|c|c|}
\hline Technical Score & Quality Credit (\%) & Technical Score & Quality Credit (\%) \\
\hline 100 & 20 & 89 & 9 \\
\hline 99 & 19 & 88 & 8 \\
\hline 98 & 18 & 87 & 7 \\
\hline 97 & 17 & 86 & 6 \\
\hline 96 & 16 & 85 & 5 \\
\hline 95 & 15 & 84 & 4 \\
\hline 94 & 14 & 83 & 2 \\
\hline 93 & 13 & 82 & 1 \\
\hline 92 & 12 & 81 & 0 \\
\hline 91 & 11 & 80 & \\
\hline 90 & 10 & & \\
\hline
\end{tabular}

If any of the Technical Proposals were considered non-responsive, the State Contract Officer will notify those Contractors of that fact. The State Contract Officer shall publicly open the sealed Price Proposals and multiply each Contractor's Total Price Proposal for "Maintenance Services Excluding Snow and Ice Removal" by the Quality Credit Percentage earned by the Contractor's Technical Proposal to obtain the Quality Value of each Contractor's Technical Proposal. The Quality Value will then be subtracted from each Contractor's Total Price Proposal for "Maintenance Services Excluding Snow and Ice Removal" to obtain an Adjusted Price based upon Price and Quality combined. Unless all Proposals are rejected, the Department will recommend to the State Board of Transportation that the Contractor having the lowest Adjusted Price be awarded the contract. The cost of the maintenance contract will be the amount received as the Total Price Proposal. The following table shows an example of the calculations involved in this process. 


\begin{tabular}{|c|c|c|c|c|c|}
\hline Proposal & $\begin{array}{c}\text { Technical } \\
\text { Score }\end{array}$ & $\begin{array}{c}\text { Quality } \\
\text { Credit (\%) }\end{array}$ & $\begin{array}{c}\text { Price } \\
\text { Proposal }(\$)\end{array}$ & $\begin{array}{c}\text { Quality } \\
\text { Value (\$) }\end{array}$ & $\begin{array}{c}\text { Adjusted } \\
\text { Price }(\$)\end{array}$ \\
\hline A & 95 & 15 & $3,000,000$ & 450,000 & $2,550,000$ \\
\hline B & 90 & 10 & $2,900,000$ & 290,000 & $2,610,000$ \\
\hline C $*$ & 90 & 10 & $2,800,000$ & 280,000 & $2,520,000$ \\
\hline D & 80 & 0 & $2,700,000$ & 0 & $2,700,000$ \\
\hline E & 70 & 0 & $2,600,000$ & 0 & $2,600,000$ \\
\hline * Successful Contractor - Contract Cost $\$ 2,800,000$ &
\end{tabular}

\section{OPENING OF PRICE PROPOSALS}

Prior to opening of price proposals, the Contract Officer will provide to each Proposer their technical score in a sealed envelope. The sealed envelope will contain that Proposer's score only.

At the time and date specified the Contract Officer will open the price proposals and calculate the percentage difference between the price proposals submitted and the Engineer's Estimate.

Should all of the price proposals be within an acceptable range or below the Engineer's Estimate the Contract Officer will proceed to calculate the quality credit and publicly read the price proposal, technical score, and adjusted price as outlined in the selection procedure above.

Should any one or more of the price proposals be within an acceptable range or below the Engineer's Estimate and the remaining price proposals exceed an acceptable range of the Engineer's Estimate the Contract Officer will go to a separate location to calculate the quality credit and determine if the Proposer with the lowest adjusted price is within an acceptable range of the Engineer's Estimate. Should the price proposal of the Proposer with the lowest adjusted price be within an acceptable range of the Engineer's Estimate or below the Engineer's Estimate the Contract Officer will proceed to publicly read the price proposals, technical scores, and adjusted prices. Should the price proposal of the Proposer with the lowest adjusted price exceed an acceptable range of the Engineer's Estimate the Contract Officer will publicly read the price proposals only and the Department will then determine whether to proceed to request a Best and Final Offer (BAFO) as outlined below.

Should all price proposals submitted exceed an acceptable range of the Engineer's Estimate the Contract Officer will publicly read the price proposal only. The Department will then determine whether to proceed to request a Best and Final Offer (BAFO) as outlined below.

Provided the Department elects to proceed to request a BAFO, at the date and time specified, the Contract Officer will open the BAFO price proposals and proceed to publicly read all price proposals, technical scores and adjusted prices.

\section{BEST AND FINAL OFFER}

In the event initial price proposals exceed an acceptable range of the Engineer's Estimate or if the Department feels it is necessary for any reason the Department may choose to make 
amendments to the details of the RFP and request a Best and Final Offer from all of the previously shortlisted teams. Alternately, the Department may choose to redistribute to the shortlisted firms another RFP for the project with no amendments to the RFP scope.

Based on the nature of the revisions in this BAFO RFP, amendments to the Technical Proposals previously submitted for the November 29, 2006 deadline are not warranted and will not be permitted. The Technical Proposals previously submitted will not be re-evaluated.

Additional oral interviews will not be held. The Contractor shall submit a revised Price Proposal at the time, place, and date specified in the BAFO RFP. A revised Adjusted Price will then be determined. This will constitute the Contractor's Best and Final Offer. Award of the project may be made to the Proposer with the lowest adjusted price on this Best and Final Offer for the project. 


\section{*** SCOPE OF WORK ***}

\section{OVERVIEW}

The requirements of this contract apply to interstate transportation facilities within the state road right of way. The Contractor shall manage and perform maintenance and repair activities associated with roadways, drainage, structures, roadside, vegetation and aesthetics, traffic services, emergency response and as otherwise contained herein. The contractor shall also be responsible for any traffic control, design, shop drawings, and permits required to satisfy the duties required by this contract.

The scope of work for this project shall include the management and performance of maintenance and repair activities on approximately 131 center-line miles of interstate highways. The project will include management and performance of routine maintenance of, and repairs to, I-85, I-77, I-277 and I-485 in Mecklenburg, Gaston, and Cleveland Counties. In addition, the project will extend on I-85 up to the point at which the pavement section changes at the Southernmost exit in Cabarrus County. The contract will also include maintenance and repair activities for projects that are currently under construction and are all anticipated to be completed in 2006 or 2007. The requirements of this contract will become this Contractor's responsibility upon final acceptance of the construction project by the Department. These projects are as follows:

$\mathrm{R}-2248 \mathrm{BB}$

$\mathrm{R}-2248 \mathrm{C}$

$\mathrm{R}-2248 \mathrm{D}$
$2.3 \pm$ miles of new six-lane section on I-485

$4.6 \pm$ miles of new six-lane section on I-485

$5.5 \pm$ miles of new six-lane section on I-485

These activities shall be performed in accordance with the Manual of Uniform Traffic Control Devices and the North Carolina supplement thereto, NCDOT Maintenance Operations Manual, NCDOT Emergency Procedures Manual, 2006 NCDOT Standard Specifications for Roads and Structures Edition, NCDOT Construction Manual, 2006 Roadway Standard Drawings, Structure Standard Drawings, NCDOT Environmental Handbook, all Design Manuals, all AASHTO design references, NCHRP 350, Sedimentation and Erosion Control for Maintenance (and Construction) Manuals, Best Management Practices for Construction and Maintenance, Guardrail Manual, NCDOT Vegetation Management Manual, Culvert Repair Practices Manual, Drainage Manual, typical Special Provisions, and all other applicable manuals and provisions, which by reference are incorporated and made a part of this contract.

The scope of this contract is not to bring all facilities up to current design standards. However, if an asset must be replaced (e.g. guardrail end units, impact attenuators, sign structures, etc.) than that asset must be replaced in a manner such that current design standards are met. 
Areas of work required for this project shall include, but are not limited, to routine maintenance, minor repairs, collision damage repairs, and emergency repairs for the following items as detailed in the Performance Criteria contained elsewhere in this RFP:

1. Shoulder and Ditches

2. Drainage

3. Roadside

4. Roadside Appurtenances

5. Traffic

6. Pavement

7. Bridge

8. Timeliness of Performance

The Contractor shall manage all assets within the project limits that are not specifically excluded within this RFP. The Contractor shall perform routine maintenance, minor repairs, collision damage repairs and emergency repair activities as necessary. These maintenance activities will be performed at a frequency that ensures uniform and consistent compliance with the performance criteria and requirements specified herein.

The project limits are further defined as follows:

(a) All assets located within the controlled access fences of the transportation facilities, unless otherwise stated within.

(b) All interchanges, crossovers and ramps to the point at which the ramp or loop intersects the crossing facility.

(c) All overpasses that carry the interstate, including bridge superstructure and substructure.

(d) Maintenance of the substructure of all highway bridges over the interstate facilities.

(e) Repair of any portion of bridges over the interstate facilities necessitated by damage from traffic travelling on the interstates.

(f) All permanent drainage easements associated with the highway corridor including compliance with any permit requirements.

(g) All Rest Area and Weigh Station roadways to the back of curb and the roadway drainage system (from entrance ramp through the parking area to exit ramp of the Rest Area) as well as high-mast roadway lighting within the Rest Areas.

(h) Regulatory, Warning, Guide, and Facility (airport, railroad, commuter parking, rest area, welcome center) signs will be the responsibility of the Contractor.

The Department will provide a recent Maintenance Condition Assessment of the existing facilities. In addition, various as-built drawings are available for viewing at the Division 10 and 12 offices. The Department in no way guarantees the accuracy or sufficiency of these documents and the Contractor shall be fully responsible for verifying the existing asset inventory to their own satisfaction. 


\section{EXCLUSIONS}

This project specifically excludes:

(a) Frontage roads

(b) Repair or maintenance of bridges over the interstate facilities caused by anything other than damage from traffic travelling on the interstates.

(c) Repair or maintenance of Railroad bridges

(d) Fog detection, closed circuit televisions, traffic counters, signal loops, Highway Advisory Radio (HAR) and Changeable Message Signs (CMS) and associated electronics, power and communication infrastructure.

(e) Rest Area and Weigh Station Janitorial, Buildings, Equipment, and Grounds Maintenance. Mowing at rest areas to the limit of the gore areas.

(f) The installation and maintenance of LOGO signs, General Motorist Service signs, and informational safety signs for specific events (e.g. Lowe's Motor Speedway).

(g) NCDOT will perform Bridge, Culvert, roadside Sign Structure, Over Head Sign, and High Mast Light Pole Inspection in accordance with Department Standards and Specifications. NCDOT will also perform structural analyses when, as a result of routine or incident inspection, significant section loss is observed due to deterioration or damage. Nothing in this paragraph relieves the Contractor from its responsibility to make repairs deemed necessary as a result of the inspections.

(h) Maintenance activities covered by a Municipal Agreement as provided by the Department.

(i) All activities associated with Outdoor Advertising (ODA), Selective Vegetation Removal (SVR), and requests by utility companies to control vegetation with herbicides on the highway right-of-way.

(j) Facilitation of Adopt a Highway segments. The expansion or continuation of this program on any facility segments in no way relieves the Contractor of satisfying the performance criteria contained in this RFP.

(k) Wildflower Program and beds

(1) Right-of-Way Fence

(m) Incident Management Assistance Patrols

(n) All overhead sign lighting in Division 12

(o) All White on Green Guide signs will be supplied by the Department

(p) I-277 roadway lighting system as well as the lighting system on I-77 from the I-85 interchange southward to the South Carolina state line. However, in the event that the Department upgrades either of these systems during the contract period(s), the Contractor will become responsible for the lighting to the same extent they are responsible for any other existing roadway lighting.

(q) Prompt Action Notices issued for bridge repairs or rehabilitation

(r) Vegetation management in the vicinity of University Research Park. See Vegetation Management Project Special Provision.

(s) Several plant beds (map to be provided) located near the I-277/US-74 interchange are currently abandoned and only require the Contractor to control unsightly growth. During the contract, these beds may be planted by the Department at which time they will be subject to the same level of contractor maintenance as all other plant beds. 


\section{DEFINITIONS}

Routine Maintenance is defined as the restoration of an asset, including all its appurtenances, to meet acceptable performance criteria as contained herein. Routine maintenance also includes all preventative maintenance activities.

Minor repairs are defined as repairs to return an asset to a structurally sound condition (e.g., no loss of strength, functionality), but may have minor section loss, cracking, etc. Minor repairs include any activity intended to correct the effects of minor material deterioration by restoring the damaged component.

Collision Damage Repairs are defined as any repairs necessitated by collision of any type vehicle with a portion of the transportation facilities. Generally these will include third party claims to which the Contractor will be entitled as indicated elsewhere in this RFP.

Emergency Repairs are defined as those repairs necessitated by a natural disaster or as deemed necessary through exposure via a routine inspection by either the Contractor or the NCDOT. Some of these will include third party claims to which the Contractor will be entitled as indicated elsewhere in this RFP.

Typical routine maintenance activities are shown below. This list of activities is not intended to be all inclusive as other activities may be needed in order to meet the specified performance criteria.

Environmental Permitting

Engineering Duties

Asphalt Pothole Repair (Manual)

Asphalt Pothole Repair (Mechanical)

Base Repair

Pressure Grouting

Concrete Pavement Joint Repair

Concrete Slope Pavement Joint Repair

Concrete Pavement Surface Pothole

Repairing Non-Paved Shoulders, Front Slopes and Roadside Ditches (Manual)

Seeding, Fertilizing and Mulching

Reworking Non-Paved Shoulders, Front Slopes and Roadside Ditches (Mech.)

Miscellaneous Slope and Ditch Repair

Clean Drainage Structures
Unpaved Ditches - Clean and Reshape

Paved Ditches - Clean and Repair

Routine Mowing

Slope Mowing

Debris and Road Kill Removal

Pavement Markings and Markers

Roadside Vegetation Control

Tree Trimming and Removal

Landscape Area Maintenance

Erosion and Sedimentation Control

Storm Water Management

Delineators

Ground Signs and all Overhead Signs

Sign Cleaning 


$\begin{array}{ll}\begin{array}{l}\text { Repair Storm Drains, Side Drains, Cross } \\ \text { Drains }\end{array} & \text { Guardrail Repair } \\ \text { Concrete Repair } & * * * \text { Deleted "Fence Repair"*** } \\ \text { Attenuator Repair } & \text { Raised Pavement Marker Replacement } \\ \text { Graffiti Removal } & \text { Glare Screens } \\ \text { Roadside Litter Removal } & \text { Emergency Repairs } \\ \text { Road Sweeping } & \text { Barrier Wall } \\ \text { Edging and Sweeping } & \text { Noise Walls } \\ \text { Highway Lighting Maintenance } & \begin{array}{l}\text { Rest Area and Weigh Stations (roadways, } \\ \text { drainage, lighting) }\end{array} \\ \text { Overhead Sign } & \text { Bridge \& Culvert Maintenance } \\ \text { Structure Maintenance } & \text { Winter Weather Event (if Snow and Ice } \\ \text { Concrete Slab Repair and Replacement } & \text { Option is exercised by the Department) }\end{array}$

\section{WORK PLANS AND REPORTS}

The following plans are required of the Contractor at various times during the contract. Failure to submit any of the required documents listed below will result in withholding monthly payments to the Contractor until the acceptable documents are received by NCDOT.

\section{Quality Management Plan}

A Quality Management Plan shall be delivered as a part of the Technical proposal. The Quality Management Plan shall describe in detail how the Contractor shall monitor its own performance to ensure that the Performance Criteria are to be achieved. The Quality Management Plan shall define the procedures to ensure that all work meets or exceeds the Performance Criteria contained herein. The Quality Management Plan shall incorporate reporting procedures compatible with the NCDOT's Maintenance Management System (MMS) to ensure approval of proposed work, services and products.

\section{Quality Management Reports}

The Contractor shall furnish hard copy and electronic access to quality management reports prepared as a result of the Quality Management Plan monitoring.

\section{Annual Implementation Work Plan}

No later than 60 days after the Notice of Award, the Contractor shall deliver to the Department an Implementation Plan, in form and substance satisfactory to the Department, covering the first calendar year of the contract period. The Implementation Plan shall be broken down by month and by work element, and shall describe the expected work for the upcoming year. The 
Implementation Plan shall include a budget broken down by work element. In preparing the Implementation Plan, the Contractor shall consult and coordinate with appropriate Department staff, as necessary. A revised Implementation Plan shall be presented to the Department no later than the $1^{\text {st }}$ of January, each year for the duration of the contract. The revised implementation plan shall also include expenditures for each work element for the prior year. In lieu of actual dollars expended, the expenditures for each work element shall be shown as a percentage of the total expenditures for that year.

\section{Monthly Report}

No later than the $15^{\text {th }}$ of each month, the Contractor shall deliver to the Department a Monthly Report covering the prior month's activities and accomplishments. The report may be furnished as part of the monthly invoice for services. The Monthly Report shall describe all completed work for each specific asset type, reported by location, county and Division. The information shall also include unit of measure, mile marker, direction, GPS coordinates, length, size, type and resulting condition. The Contractor shall also provide monthly expenditures for $\mathrm{MB} / \mathrm{WB}$ and Small Business Enterprises. This report shall be delivered in an electronic format compatible with the NCDOT Maintenance Management System (MMS).

The Contractor is not responsible for interacting with the MMS other than to provide the above information in a format compatible with MMS. The Department will provide the typical format that shall be used upon award of the contract.

\section{Weekly Work Plan}

The Contractor shall provide a Work Plan every Wednesday to the Metrolina Regional Transportation Management Center (MRTMC) and the Engineer concurrently. The Work Plan shall designate the intended work to be performed the following week. The Contractor shall include any planned lane closures in this Work Plan.

\section{Customer Service Response Log}

The Contractor shall develop, implement and maintain a Customer Service Response Log. The log shall itemize all complaints/requests, time/date of complaint, and the disposition thereof. The customer service log shall be made available to the Department for review on the first day of each month or upon request. The Contractor may use the Department's Citizen Action Reporting System (CARS) to assist in the maintenance of this log.

\section{$* * *$ Deleted intermediate contract times and liquidated damages for customer responses and resolutions. $* * *$}

In some cases, NCDOT may direct the Contractor to respond to customer requests immediately.

\section{Emergency Response Plan}

The Contractor shall prepare and furnish to the Department for its review and approval an Emergency Response Plan within 30 days after the Notice of Award. This plan shall outline the 
Contractor's response procedures in the event of an emergency, collision damage, and adverse weather conditions including hurricanes, rain, snow, ice, flooding and fog. The plan shall address the Contractor's coordination procedures with the Department, the State Highway Patrol and other emergency personnel during emergency events.

\section{Public Information Plan}

The Contractor shall prepare and furnish to the Department for its review and approval a draft Public Information Plan within 60 days after the Notice of Award. Within 90 days after the Notice of Award, the Contractor shall coordinate with Department personnel, to finalize and implement the Public Information Plan. During this 90-Day period, all information regarding this contract and the services required herein shall be disseminated through the Department.

The Public Information Plan shall prescribe roles, responsibilities and procedures regarding public communications including:

- The dissemination of information regarding the Contractor's contracting approach.

- Procedures for providing information to the Travelers Information Management System (TIMS).

- The issuance of activity update bulletins.

The Contractor shall not issue press releases or otherwise communicate directly with the media (except as otherwise provided in the Public Information Plan) without the Department's approval.

The Contractor shall attend a TIMS/511 briefing within 60 days after Notice of Award.

\section{Snow and Ice Removal Plan}

In the event that the Department elects to exercise the option to include Snow and Ice Removal as part of this contract, the Contractor shall submit a Snow and Ice Removal Plan prior to September $1^{\text {st }}$ of each year. The plan shall address the Contractor's procedures, equipment, materials, staging areas, manpower, communication network, priorities, and other information deemed necessary.

\section{EMERGENCY PREPARATION RESPONSE}

The Contractor shall cooperate with the Department and may be required to furnish its forces (to include subcontractors) to supplement the Department in Hurricane Preparedness, Evacuation Plans and Execution of these Plans for the duration of the event within the project limits.

In the event that services or equipment are required by the Department for emergency preparation response, such services and equipment will be deemed as Extra Work and paid for in accordance with Article 104-8(A) of the Standard Specifications. 


\section{INCIDENT RESPONSE}

The Department will continue to utilize existing Incident Management Assistance Patrols during this contract. The Contractor will not be responsible for responding to abandoned vehicles, traffic accidents, or other shoulder or lane-blocking incidents except as may be set forth elsewhere in this RFP.

The Contractor shall immediately notify the Department's MRTMC and the Engineer of all traffic slowing incidents that are discovered during the course of their work or are caused by the Contractor's operations.

\section{EMERGENCY MAINTENANCE REPAIRS}

The Contractor is responsible for immediately responding to emergency situations that pose an imminent risk to the travelling public (e.g. sink holes, flooding, etc.). An intermediate contract time of 2 hours after notification or discovery will apply to initiating corrective measures for situations that pose an imminent risk to the travelling public. Initiating corrective measures includes initial response, assessment, traffic control to protect the travelling public, and the determination, coordination, and execution of corrective measures to restore traffic. In the event that the Contractor fails to initiate corrective measures within 2 hours after notification or discovery, liquidated damages in the amount of $\$ 5,000$ per hour, or portion thereof, will be deducted from the monies due to the Contractor.

The Contractor shall immediately notify the Department's MRTMC and the Engineer of all emergency situations.

\section{PERMITS}

The Contractor is responsible for preparing all documents and obtaining any and all permits, including those for navigable waterways, necessary to complete the work required in this contract.

\section{TRAFFIC CONTROL}

The Contractor shall maintain traffic in accordance with the 2006 Standard Specifications, Roadway Standard Drawings, the Manual of Uniform Traffic Control Devices (MUTCD), the NCDOT Supplement to the MUTCD, and the following provisions:

\section{Traffic Control Plan (TCP)}

Prior to commencing an activity that will restrict or divert traffic, including lane closures and detours, the Contractor shall prepare, and furnish to the Department for review and approval a Traffic Control Plan. A standard Traffic Control Plan may be prepared and pre-approved for each typical operation. The NCDOT Work Zone Traffic Control Unit website contains information necessary for the proper development of these plans. In addition, standard traffic control plans for typical operations may be available for use. 
As required by the approved TCP, the Contractor shall provide, install, maintain such temporary barrier, pavement markings, lights, signs and other devices and take such other protective measures as are necessary to prevent accidents, damage or injury to the public, and as required by the Traffic Control Plan and the Manuals, Standards and Procedures.

\section{Notification of Planned Work}

Planned lane closures shall be included in the Weekly Work Plan. In addition, the Contractor shall notify the Engineer and the MRTMC at least 8 hours before a planned lane closure is installed and notify the designated MRTMC within 30 minutes after the planned lane closure is removed. If the Contractor is found to have installed a lane closure without notifying MRTMC, NCDOT may require the Contractor to immediately remove the lane closure and may require the Contractor to refrain from installing all planned lane closures until such time as the Contractor can demonstrate to NCDOT that the Contractor can fully comply with these notification requirements.

\section{Time Restrictions}

No road closures are allowed unless authorized by the Engineer. The time restrictions listed below apply to planned lane and shoulder closures only. The Contractor shall not install, maintain or remove any traffic control device required for narrowing or closing a lane or shoulder during the times listed below. Lane closures for emergency response are not subject to these time restrictions. An intermediate contract time applies to lane narrowing, lane closing, shoulder closing, and holiday and event restrictions.

Liquidated Damages for lane narrowing, lane closing, shoulder closing, and holiday and event restrictions for $I-77, I-277, I-485$, and $I-85$ are $\$ \mathbf{1 0 , 0 0 0 . 0 0}$ per hour for this Intermediate Contract Time. In areas where a median contains guardrail or median barrier rail in close proximity to the travelway, operations that require shoulder closure will also require a lane closure and will therefore be subject to the time restrictions and liquidated damages associated with lane closures.

Road name

For Lane Closures

I-85, I-485 and I-277

$\mathrm{I}-77$

For Shoulder Closures

I-85, I-485 and I-277

I-77

\section{Time Restrictions}

6:00am to 8:00pm, Monday through Friday

9:00am to 6:00pm, Saturday and Sunday

6:00am to 9:00pm, Monday through Friday

9:00am to 6:00pm, Saturday and Sunday

6:00am to $9: 00 \mathrm{am}$ and $4: 00 \mathrm{pm}$ to $7: 00 \mathrm{pm}$, Monday through Friday

6:00am to $9: 00 \mathrm{am}$ and $4: 00 \mathrm{pm}$ to $9: 00 \mathrm{pm}$, Monday thru Friday 
The Contractor shall not close or narrow a lane of traffic, detain and/or alter the traffic flow during holidays, holiday weekends, special events, or any other time when traffic is unusually heavy on any of the roadways listed above, including the following schedules:

- For New Year's, between the hours of 6:00 a.m. December 31 $1^{\text {st }}$ to 9:00 p.m. January 2nd. If New Year's day is on a Saturday or a Sunday, then until 9:00 p.m. the following Tuesday.

- For Easter, between the hours of 6:00 a.m. Thursday and 9:00 p.m. Monday.

- For Memorial Day, between the hours of 6:00 a.m. Friday to 9:00 p.m. Tuesday.

- For Independence Day, between the hours of 6:00 a.m. the day before Independence Day and 9:00 p.m. the day after Independence Day. If Independence Day is on a Saturday or Sunday, then between the hours of 6:00 a.m. the Thursday before Independence Day and 9:00 p.m. the Tuesday after Independence Day.

- For Labor Day, between the hours of 6:00 a.m. Friday to 9:00 p.m. Tuesday.

- For Thanksgiving, between the hours of 6:00 a.m. Tuesday to 9:00 p.m. Monday.

- For Christmas, between the hours of 6:00 a.m. the Friday before the week of Christmas day and 9:00 p.m. the following Monday after the week of Christmas.

- For any NASCAR event at the Lowes Motor Speedway, between the hours of 6:00 a.m. the Thursday the week of the event until 8:00 p.m. the following Monday after the race.

- For any Carolina Panthers Football game in Charlotte and any games at the Bobcats Arena, from three hours before the game until 3 hours after the game.

- For any event which creates high traffic volumes, between the hours of 7:00 a.m. the Friday of the week of the event and 8:00 p.m. the Monday after the week of the event. Such events may be at Bank of America Stadium, Charlotte Convention Center or other arenas. The Engineer will provide guidance on what events constitute unusually high traffic volumes.

\section{HAZARDOUS WASTE REMOVAL}

The Contractor shall dispose of, or cause the disposal of dead animals, and all waste, residue, debris, materials and supplies (including paints, herbicides and chemicals), foliage clippings, and other waste materials produced or generated by the Contractor under this contract.

The Contractor shall use, contain, store and dispose of all hazardous substances employed in connection with this contract in accordance with all applicable Federal, State and Local Laws, Regulations and Ordinances.

Unknown hazardous materials that may exist with the project limits will be handled in accordance with Article 107-26 of 2006 Standard Specifications. 
With respect to Asset Maintenance Services relating to bridge structures that have existing coatings that include Hazardous Substances, such as lead, chromium and cadmium, the Contractor shall, where required, remove, handle, store, transport and dispose of such Hazardous Substances in accordance with applicable Federal, State and Local Laws, Regulations, and Ordinances.

*** Deleted statement referencing "Incident Response.” ***

\section{SNOW AND ICE CONTROL (ALTERNATE BID ITEM)}

This section applies only if the Department exercises its right to accept the Contractor's Price Proposal for the alternate bid item "Maintenance Services Including Snow and Ice Removal". Reference the Project Special Provision "Alternate Bid Item for Snow and Ice Removal" found elsewhere in this RFP.

The Contractor will be responsible for prompt removal of snow and ice throughout the project limits beginning September $1^{\text {st }}, 2007$.

Not later than July 1st of each year, the Contractor shall demonstrate to the reasonable satisfaction of the Engineer that it has sufficient resources (including equipment, materials, supplies and personnel) to fully perform Snow and Ice Control on all segments of the contracted transportation facilities for the following year. If by August $1^{\text {st }}$ the Contractor fails to satisfy the Department that it has sufficient resources to undertake snow and ice removal during the following winter season, the Department may terminate for cause this portion of the contract and monthly payments will be adjusted in accordance with the Project Special Provision "Alternate Bid Item for Snow and Ice Removal"

The Contractor shall respond and deploy resources to ensure that at least one travel lane in each direction is passable at all times. In the event that the Contractor fails to maintain, in a passable condition, at least one continuous lane in each direction, liquidated damages in the amount of $\$ 4,000$ per direction per hour, or portion thereof, will be deducted from the monies due to the Contractor.

The Contractor shall continue snow and ice removal until such time that all travel lanes are clear and passable (icy spots allowed). An intermediate contract time of 12 hours will apply from the end of the winter weather event. In the event that the Contractor fails to make clear and passable all travel lanes within this intermediate contract time, liquidated damages in the amount of $\$ 2,500$ per lane per hour, or portion thereof, will be deducted from the monies due the Contractor.

The Contractor shall continue snow and ice removal until such time that all travel lanes are 100\% free from frozen precipitation. An intermediate contract time of 24 hours will apply from the end of the winter weather event. In the event that the Contractor fails to remove all frozen precipitation within this intermediate contract time, liquidated damages in the amount of $\$ 1,000$ per lane per hour, or portion thereof, will be deducted from the monies due the Contractor. 
The Contractor shall plow all shoulders immediately following the end of the winter weather event. An intermediate contract time of $\mathbf{3 6}$ hours will apply from the end of the winter weather event. In the event that the Contractor fails to plow all shoulders within this intermediate contract time, liquidated damages of $\$ 1,000$ per shoulder mile per hour, or portion thereof, will be deducted from the monies due to the Contractor.

During winter weather conditions, the Contractor shall contact MRTMC at 7:00 am and 3:00 pm to advise of road conditions. The Contractor shall also update the MRTMC continually as conditions change. MRTMC will enter this information into TIMS.

No sand, slag, or similar material shall be used on open-graded asphalt surface course sections. 


\section{*** PERFORMANCE CRITERIA AND CONTRACT PAYMENT ***}

\section{PERFORMANCE CRITERIA}

The performance criteria and target ratings are shown in Tables $1-7$. Each table represents a "component" of the overall Maintenance Condition Assessment (MCA). Each row within each table represents an "element" of that component. Each element has associated performance criteria that will be used to determine the performance rating for that element. Next to the element name, the weight of that element within the component is shown in parentheses.

\section{EVALUATION PROCEDURES}

An initial Maintenance Condition Assessment will be performed by the Department and provided to the prospective contractors prior to the submission of Proposals.

A new condition assessment will be made by Department personnel every six months of the contract. The first assessment will begin October 1, 2007. Each assessment will be completed incrementally and will occur randomly throughout the project limits. Throughout the remainder of the contract, assessments will occur once in every 6-month period beginning each January $1^{\text {st }}$ and July $1^{\text {st }}$. The Department reserves the right to perform additional assessments for any element within the Roadside component. The results of these additional element level assessments will be used in lieu of that from the prior regularly scheduled assessment.

In addition, if the contractor is below the performance target on any element in the Roadside component, the contractor may request that the Department re-evaluate that element(s) prior to the next 6-month assessment period. The Roadside element(s) will be re-evaluated with the same performance criteria listed in Table 4. The element rating determined through any reevaluation of a Roadside element will then be used to re-calculate the partial payment. This recalculated partial payment will take effect with the next month's partial payment and will remain in effect until the next condition assessment ratings are evaluated and a new partial payment is calculated. The option for a re-evaluation of Roadside elements may not be exercised more than once a month.

Linear samples, in lengths of 0.2 miles, will be made in sufficient quantity to ensure $95 \%$ confidence that the samples represent the condition assessment throughout the entire project limits. Gross deficiencies will be brought to the Contractor's attention as soon as is practicable during or each assessment.

Upon request, specific sample data will be made available to the Contractor within 14 calendar days following notification of the condition assessment results. The Contractor may dispute element ratings only. Such dispute shall be made in writing to the Engineer within 30 calendar days of notification of the condition assessment results. The amount of the partial payment calculated in accordance with the procedures outlined herein will continue notwithstanding any time that elapses during dispute resolution. If through dispute resolution, any element rating is revised, the partial payment will be re-calculated and the amount of the change in the partial payment amount will be returned to the Contractor with the next month's partial payment. 


\section{MAINTENANCE CONDITION ASSESSMENT (MCA) RATING}

The element ratings are weighted in Tables $1-7$ to determine an overall MCA rating. The MCA targets are as follows:
Calendar Year 2007
88
Calendar Year 2008
90
Calendar Years 2009 - 2012
92

If in four consecutive assessments, the overall MCA rating is more than 5 points below the applicable overall MCA target, the Department shall have the right to declare the Contractor in default of contract.

If, in four consecutive assessments, any element is more than 15 points below the applicable target for that element, the Department shall have the right to declare the Contractor in default of contract.

\section{PHASED PERFORMANCE TARGETS}

In addition to the MCA, some elements have a performance target that increases within the first three years of the contract. These elements will be clearly indicated in the tables as a performance target followed by a calendar year in parentheses.

\section{PARTIAL PAYMENTS BASED ON PERFORMANCE}

An example of the calculation of partial payment based on performance is provided in the table following this section. This example is based on the targets for calendar year 2007.

The unit price bid is the bid per month as indicated on the Itemized Proposal Sheet for either "Maintenance Services Excluding Snow and Ice Removal" or "Maintenance Services Including Snow and Ice Removal", whichever bid alternate is exercised by the Department, and as adjusted in accordance with the Project Special Provision "Annual Price Adjustments."

Beginning with the January 2008 partial payment, the monthly partial payment will be based on the contractor's performance rating for each element during the previous assessment period. The January 2008 partial payment and that for the five subsequent months will be based on the assessment begun in October 2007. Monthly partial payments will be reflective of the most recent condition assessment and will be applied to each monthly partial payment following the assessment period. This payment amount will remain in effect until the next condition assessment ratings are evaluated and a new partial payment is calculated.

The partial payments are based solely on the performance at the element level, minus any applicable liquidated damages as outlined elsewhere in this RFP. Each partial payment will be the sum of the payments attributable to each element and its element value. Based on performance, the contractor will be paid up to the full amount of the element value for each 
element. The element value for each element is defined as the element weight multiplied by the unit price bid.

The contractor will be paid the full amount of the element value for each element where the applicable Performance Target is met. The contractor will be paid a percentage of the element value based on a graduated scale when failing to meet the applicable Performance Target. If the contractor's performance is $1-5$ points below the performance target, the payment for that element will be $75 \%$ of the element value. If the contractor's performance is $6-10$ points below the Performance Target, the payment for that element will be $50 \%$ of the element value. If the contractor's performance is greater than 10 points below the Performance Target, the contractor will receive no payment for that element. The element weights that will be used to calculate the element values are listed in Tables 1-7 and included in the sample assessment spreadsheet.

\section{TIMELINESS TARGETS}

Table 8 provides timeliness requirements for certain activities. These timeliness requirements are not used in the partial payment calculations but are enforced through liquidated damages as indicated throughout the "Scope of Work". For those activities that do not have liquidated damages, if the timeliness requirement for any one activity is not fulfilled in at least $80 \%$ of the occurrences in any 6-month assessment period, the Contractor may be deemed in default of contract. 


\section{PERFORMANCE CRITERIA AND TARGET TABLES}

\begin{tabular}{|c|c|c|c|}
\hline \multicolumn{4}{|c|}{ TABLE 1} \\
\hline $\begin{array}{l}\text { ELEMENT } \\
\text { (ELEMENT } \\
\text { WEIGHT) }\end{array}$ & OUTCOME & $\begin{array}{c}\text { PERF. } \\
\text { TARGET }(\%)\end{array}$ & TOLERANCE \& CRITERIA \\
\hline $\begin{array}{l}\text { Unpaved Shoulders } \\
\text { (Low Shoulder) } \\
(0.04)\end{array}$ & $\begin{array}{l}\text { Safe } \\
\text { Smooth }\end{array}$ & $\begin{array}{l}95(2009-2012) \\
90(2008) \\
\quad 85(2007)\end{array}$ & $\begin{array}{l}\text { - No dropoffs greater than 2" within 4' of the edge } \\
\text { of pavement }\end{array}$ \\
\hline $\begin{array}{l}\text { Unpaved Shoulders } \\
\text { (High Shoulder) } \\
(0.03)\end{array}$ & $\begin{array}{l}\text { Safe } \\
\text { Smooth }\end{array}$ & $\begin{array}{l}95(2009-2012) \\
90(2008) \\
85(2007)\end{array}$ & $\begin{array}{l}\text { - No shoulders higher than 1" within 4' of the edge } \\
\text { of pavement } \\
\text { - No shoulders that cause water to drain back } \\
\text { within the travelway }\end{array}$ \\
\hline $\begin{array}{l}\text { Lateral Ditches } \\
\text { (Includes Rip Rap } \\
\text { and Paved) (0.03) }\end{array}$ & $\begin{array}{l}\text { No blockage } \\
\text { or erosion. } \\
\text { Functioning } \\
\text { as designed }\end{array}$ & $\begin{array}{l}95(2009-2012) \\
90(2008) \\
85(2007)\end{array}$ & $\begin{array}{l}\text { - No more than } 50 \% \text { blocked } \\
\text { - No erosion greater than } 1 \text { ' below original ditch } \\
\text { line } \\
\text { - No joint separation, misalignment, or } \\
\text { undermining in paved ditches }\end{array}$ \\
\hline
\end{tabular}




\begin{tabular}{|c|c|c|c|}
\hline \multicolumn{4}{|c|}{$\begin{array}{c}\text { TABLE } 2 \\
\text { DRAINAGE (0.1) }\end{array}$} \\
\hline $\begin{array}{l}\text { ELEMENT } \\
\text { (ELEMENT } \\
\text { WEIGHT) }\end{array}$ & OUTCOME & $\begin{array}{c}\text { PERF. } \\
\text { TARGET }(\%)\end{array}$ & TOLERANCE \& CRITERIA \\
\hline $\begin{array}{l}\text { Crossline Pipes } \\
\left(<54^{\prime \prime}\right) \text { (Blocked) } \\
(0.03)\end{array}$ & $\begin{array}{l}\text { Open } \\
\text { Drains } \\
\text { No Erosion }\end{array}$ & $\begin{array}{l}95(2009-2012) \\
90(2008) \\
85(2007)\end{array}$ & $\begin{array}{l}\text { - } \text { Greater than } 75 \% \text { diameter open and/or meets } \\
\text { environmental permitting requirements } \\
\text { - } \quad \text { No evidence of flooding } \\
\text { - } \quad \text { Minimal erosion at ends } \\
\text { - } \quad \text { End protection intact. } \\
\text { - } \quad \text { No obstructions to water flow. }\end{array}$ \\
\hline $\begin{array}{l}\text { Crossline Pipes } \\
(<54 ”) \\
\text { (Damaged) (0.02) }\end{array}$ & $\begin{array}{l}\text { No pipe, } \\
\text { pavement, or } \\
\text { shoulder } \\
\text { damage }\end{array}$ & $\begin{array}{l}95(2009-2012) \\
\quad 90(2008) \\
\quad 85(2007)\end{array}$ & $\begin{array}{l}\text { - No damage due to cracking, joint failures, or } \\
\text { corrosion. } \\
\text { - No water infiltration causing pavement failures, } \\
\text { shoulder failures, or roadway settlement. }\end{array}$ \\
\hline $\begin{array}{l}\text { Drop Inlets/Catch } \\
\text { Basins/Shoulder } \\
\text { Drains/Funnel } \\
\text { Drains/etc. } \\
\text { (Blocked) (0.02) }\end{array}$ & Open Drains & $\begin{array}{l}98(2009-2012) \\
90(2008) \\
85(2007)\end{array}$ & $\begin{array}{l}\text { - } \text { Grates and Outlets not blocked greater than } 50 \% \\
\text { - } \\
\text { - } \\
\text { - Outfalls functional. }\end{array}$ \\
\hline $\begin{array}{l}\text { Drop Inlets/Catch } \\
\text { Basins/Shoulder } \\
\text { Drains/Funnel } \\
\text { Drains/etc. } \\
\text { (Damaged) (0.01) }\end{array}$ & Functional & $\begin{array}{l}98(2009-2012) \\
\quad 90(2008) \\
85(2007)\end{array}$ & $\begin{array}{l}\text { - } \text { Grates are present and not broken } \\
\text { - } \\
\text { - } \\
\text { Outlets are not damaged and are functioning } \\
\text { properly } \\
\text { - } \\
\text { End protection intact with no erosion }\end{array}$ \\
\hline $\begin{array}{l}\text { Curb \& Gutter, } \\
\text { Valley Gutter/ } \\
\text { Median Barrier } \\
\text { (Blocked) }(0.01)\end{array}$ & $\begin{array}{l}\text { No blockage, } \\
\text { No spread } \\
\text { into lane }\end{array}$ & $\begin{array}{l}95(2009-2012) \\
\quad 90(2008) \\
85(2007)\end{array}$ & $\begin{array}{l}\text { - No obstruction greater than } 2 \text { " for a length of 2' } \\
\text { - Runoff does not spread into travelway for a } \\
\text { distance of half the lane width }\end{array}$ \\
\hline $\begin{array}{l}\text { Curb \& Gutter/ } \\
\text { Valley Gutter/ } \\
\text { Median Barrier } \\
\text { (Damaged) }(0.01)\end{array}$ & Functional & $\begin{array}{l}95(2009-2012) \\
90(2008) \\
85(2007)\end{array}$ & $\begin{array}{l}\text { - No cracking, settlement, joint separation, } \\
\text { misalignment, or deterioration }\end{array}$ \\
\hline
\end{tabular}




\begin{tabular}{|c|c|c|c|}
\hline \multicolumn{4}{|c|}{$\begin{array}{c}\text { TABLE } 3 \\
\text { ROADSIDE APPURTENANCES (0.15) }\end{array}$} \\
\hline $\begin{array}{l}\text { ELEMENT } \\
\text { (ELEMENT } \\
\text { WEIGHT) }\end{array}$ & OUTCOME & $\begin{array}{c}\text { PERF. } \\
\text { TARGET (\%) }\end{array}$ & TOLERANCE \& CRITERIA \\
\hline $\begin{array}{l}\text { Guardrail/ } \\
\text { Cable Rail (0.09) }\end{array}$ & $\begin{array}{l}\text { Functional } \\
\text { Repairs per } \\
\text { current } \\
\text { Standards }\end{array}$ & $95(2007-2012)$ & $\begin{array}{l}\text { - All guardrail and cable guiderail is functional } \\
\text { - Contractor to respond to all failures, which } \\
\text { include site mitigation and repairs, and } \\
\text { immediately address unsafe conditions } \\
\text { - No dents or deterioration that decrease structural } \\
\text { integrity. }\end{array}$ \\
\hline $\begin{array}{l}\text { Concrete Median } \\
\text { Barrier }(0.015)\end{array}$ & $\begin{array}{l}\text { Structurally } \\
\text { safe/sound }\end{array}$ & $95(2007-2012)$ & $\begin{array}{ll}\text { - } & \text { Clean } \\
\text { - } & \text { Free of vegetation } \\
\text { - } & \text { Straightened } \\
\text { - } & \text { Repaired and or replaced, if damaged. }\end{array}$ \\
\hline Noise Walls $(0.015)$ & $\begin{array}{l}\text { Structurally } \\
\text { Sound } \\
\text { Clean }\end{array}$ & $95(2007-2012)$ & $\begin{array}{l}\text { - } \\
\text { - } \\
\text { - } \\
\text { - No da missing or broken pieces } \\
\text { No gritti or vegetation }\end{array}$ \\
\hline $\begin{array}{l}\text { Impact Attenuators } \\
(0.03)\end{array}$ & $\begin{array}{l}\text { Present } \\
\text { Operational }\end{array}$ & $95(2007-2012)$ & $\begin{array}{l}\text { - No missing parts, properly maintained and } \\
\text { undamaged. } \\
\text { - Contractor to respond to all failures, and } \\
\text { immediately address unsafe conditions }\end{array}$ \\
\hline
\end{tabular}




\begin{tabular}{|c|c|c|c|}
\hline \multicolumn{4}{|c|}{$\begin{array}{c}\text { TABLE } 4 \\
\text { ROADSIDE }(0.15)\end{array}$} \\
\hline $\begin{array}{l}\text { ELEMENT } \\
\text { (ELEMENT } \\
\text { WEIGHT) }\end{array}$ & OUTCOME & $\begin{array}{c}\text { PERF. } \\
\text { TARGET (\%) }\end{array}$ & TOLERANCE \& CRITERIA \\
\hline Mowing (0.03) & $\begin{array}{l}\text { Grass height } \\
\& \text { mowing } \\
\text { quality }\end{array}$ & $90(2007-2012)$ & $\begin{array}{l}\text { - For all grass species, grass height not to exceed } \\
15 \text { inches, nor less than } 6 \text { inches } \\
\text { - All mowing to be of a high quality to present a } \\
\text { neat appearance } \\
\text { - In compliance with all other Department mowing } \\
\text { specifications. }\end{array}$ \\
\hline $\begin{array}{l}\text { Landscape } \\
\text { Plant Beds }(0.0225)\end{array}$ & $\begin{array}{l}\text { Primary } \\
\text { emphasis on } \\
\text { aesthetics; } \\
\text { also environ. } \\
\text { safety factors }\end{array}$ & $\begin{array}{c}80(2008-2012) \\
70(2007)\end{array}$ & $\begin{array}{l}\text { - Overall appearance is neat and well maintained. } \\
\text { - Ornamentals and shrubs maintained for optimum } \\
\text { - } \quad \text { Pesthetics and plant health. } \\
\text { - Must follow IRVM program as established by } \\
\text { NRVMA \& as adopted by NCDOT. } \\
\text { - Contractor will utilize and be evaluated on the } \\
\text { "Roadside Environmental Landscape Plant Bed } \\
\text { Inspection Report" } \\
\text { No excessive "brown-out", pre-approval of } \\
\text { herbicides from the Engineer required }\end{array}$ \\
\hline $\begin{array}{l}\text { Brush \& Trees } \\
(0.0225)\end{array}$ & $\begin{array}{l}\text { Unobstructed } \\
\text { sight distance } \\
\& \text { vertical } \\
\text { clearance. }\end{array}$ & $\begin{array}{c}90(2008-2012) \\
85(2007)\end{array}$ & $\begin{array}{l}\text { - No sight distance or sign obstruction } \\
\text { - Vertical clearance of } 15 \text { ' over roadway and } \\
\text { shoulder to 10' back of ditch or shoulder point or } \\
\text { clear recovery area, whichever is further from the } \\
\text { edge of roadway } \\
\text { - No dead trees, or leaning trees that present a } \\
\text { hazard. } \\
\text { - A clear distance of 5' behind guardrail } \\
\text { - Must follow IRVM program as established by } \\
\text { NRVMA \& as adopted by NCDOT. } \\
\text { - No excessive "brown-out", pre-approval of } \\
\text { herbicides from the Engineer required }\end{array}$ \\
\hline
\end{tabular}




\begin{tabular}{|c|c|c|c|}
\hline $\begin{array}{l}\text { Turf Condition/ } \\
\text { Seeding \& Mulching } \\
(0.015)\end{array}$ & $\begin{array}{l}\text { Healthy } \\
\text { growing } \\
\text { Neat } \\
\text { appearance }\end{array}$ & $\begin{array}{c}90(2009-2012) \\
85(2008) \\
80(2007)\end{array}$ & $\begin{array}{l}\text { - } \begin{array}{l}\text { Unpaved shoulders, slopes, and ditch lines free of } \\
\text { bare, dead, diseased, distressed, or weedy areas }\end{array} \\
\text { - } \\
\text { - } \\
\text { MCDOT approved species and seed mixes } \\
\text { NRVMA \& as adopted by NCDOT } \\
\text { - } \quad \text { *** Deleted bullet *** } \\
\text { - No excessive "brown-out", pre-approval of } \\
\text { herbicides from Division Roadside } \\
\text { Environmental Engineer required }\end{array}$ \\
\hline $\begin{array}{l}\text { Uncontrolled } \\
\text { Growth at Signs and } \\
\text { Guardrail/Cable } \\
\text { Guiderail }(0.015)\end{array}$ & $\begin{array}{l}\text { Grass height } \\
\text { is neat and } \\
\text { uniform }\end{array}$ & $70(2007-2012)$ & $\begin{array}{l}\text { - Vegetation height should not exceed the bottom } \\
\text { of the guardrail/cablerail } \\
\text { - Vegetation around signposts should be uniform } \\
\text { with the roadside grass height } \\
\text { - Neatly trimmed around fixed objects, including } \\
\text { but not limited to signs, bridge ends \& guardrails } \\
\text { - No reduced sight distance } \\
\text { - No excessive "brown-out", pre-approval of } \\
\text { herbicides from Div. Roadside Engineer required }\end{array}$ \\
\hline \multicolumn{4}{|c|}{ *** Moved Debris and Road Kill Element to Table 8, Timeliness Performance Criteria *** } \\
\hline Slope $(0.0075)$ & $\begin{array}{l}\text { Stable } \\
\text { No erosion }\end{array}$ & $95(2007-2012)$ & $\begin{array}{l}\text { - No washouts or ruts greater than 6" deep and } 2 \mathrm{ft} \\
\text { wide } \\
\text { - No erosion showing a pattern that will endanger } \\
\text { the stability of the slope creating an unsafe } \\
\text { recovery area }\end{array}$ \\
\hline Litter $(0.0375)$ & $\begin{array}{l}\text { Neat } \\
\text { Attractive }\end{array}$ & $90(2007-2012)$ & $\begin{array}{l}\text { - } \\
\text { - } \\
\text { Leadside appears neat and clean } \\
\text { litter/debris within } 0.2 \text { miles } \\
\text { - Areas of excessive unsightly litter will fall under } \\
\text { performance criteria of debris and road kill }\end{array}$ \\
\hline
\end{tabular}




\begin{tabular}{|c|c|c|c|}
\hline \multicolumn{4}{|c|}{$\begin{array}{c}\text { TABLE } 5 \\
\text { TRAFFIC (0.15) }\end{array}$} \\
\hline $\begin{array}{l}\text { ELEMENT } \\
\text { (ELEMENT } \\
\text { WEIGHT) }\end{array}$ & OUTCOME & $\begin{array}{c}\text { PERF. } \\
\text { TARGET (\%) }\end{array}$ & TOLERANCE \& CRITERIA \\
\hline $\begin{array}{l}\text { Pavement Markings } \\
(0.03)\end{array}$ & Visible & $\begin{array}{l}95(2009-2012) \\
\quad 90(2008) \\
\quad 85(2007)\end{array}$ & $\begin{array}{l}\text { - No edgelines, centerlines, or skip lines worn, } \\
\text { missing, or obliterated } \\
\text { - } \\
\text { - Rust be present, visible, and reflective at night } \\
\text { repair or whinter weather events, regardless of who } \\
\text { performs the snow and ice removal }\end{array}$ \\
\hline $\begin{array}{l}\text { Words and Symbols } \\
(0.0075)\end{array}$ & Visible & $\begin{array}{l}95(2009-2012) \\
\quad 90(2008) \\
\quad 85(2007)\end{array}$ & $\begin{array}{l}\text { - Must be present, visible, and reflective at night } \\
\text { - Replaced when damaged/lost during pavement } \\
\text { repair or winter weather events, regardless of who } \\
\text { performs the snow and ice removal }\end{array}$ \\
\hline $\begin{array}{l}\text { Pavement Markers } \\
(0.015)\end{array}$ & $\begin{array}{l}\text { Present and } \\
\text { Reflective }\end{array}$ & $\begin{array}{c}95(2009-2012) \\
90(2008) \\
85(2007)\end{array}$ & $\begin{array}{l}\text { - Markers must be present and reflective at night } \\
\text { - Replaced when damaged/lost during pavement } \\
\text { repair or winter weather events, regardless of who } \\
\text { performs the snow and ice removal } \\
\text { - All lenses replaced or installed if missing or non- } \\
\text { functional }\end{array}$ \\
\hline $\begin{array}{l}\text { Overhead Signs } \\
(0.0375)\end{array}$ & $\begin{array}{l}\text { Present, } \\
\text { visible, } \\
\text { legible, and } \\
\text { reflective }\end{array}$ & $92(2007-2012)$ & $\begin{array}{l}\text { - Clean and flush debris from and around the base } \\
\text { support areas } \\
\text { - Clean and lubricate anchor bolts and nuts } \\
\text { - Criteria also applies to any sign that the } \\
\text { Department may install within the contract } \\
\text { period(s) }\end{array}$ \\
\hline Other Signs (0.0195) & $\begin{array}{l}\text { Present, } \\
\text { visible, } \\
\text { legible, and } \\
\text { reflective }\end{array}$ & $92(2007-2012)$ & $\begin{array}{l}\text { - Signs must be visible and legible at night } \\
\text { - Contractor to respond to all failures due to } \\
\text { incidents, accidents, etc., and includes site } \\
\text { mitigation/other repairs } \\
\text { - No damaged signs } \\
\text { - Criteria also applies to any sign that the } \\
\text { Department may install within the contract } \\
\text { period(s) }\end{array}$ \\
\hline $\begin{array}{l}\text { Overhead Sign } \\
\text { Lighting }(0.0075) \\
\text { FOR DIVISION } 10 \\
\text { ONLY }\end{array}$ & $\begin{array}{l}\text { Present } \\
\text { Functional } \\
\text { Sound } \\
\text { Clear \& } \\
\text { Clean }\end{array}$ & $90(2007-2012)$ & $\begin{array}{l}\text { - Lighting must be operational at night } \\
\text { - Contractor to replace defective lighting upon } \\
\text { notification or discovery } \\
\text { - Contractor is responsible for all components } \\
\text { above the concrete footing }\end{array}$ \\
\hline
\end{tabular}




\begin{tabular}{|c|c|c|c|}
\hline $\begin{array}{l}\text { Roadway, Bridge, } \\
\text { and Interchange } \\
\text { Lighting }(0.03)\end{array}$ & Operational & $90(2007-2012)$ & $\begin{array}{l}\text { - Lighting must be operational at night } \\
\text { - Contractor to replace defective lighting upon } \\
\text { notification or discovery } \\
\text { - Contractor is responsible for all components } \\
\text { above the concrete footing }\end{array}$ \\
\hline $\begin{array}{l}\text { Object Markers \& } \\
\text { Delineators }(0.003)\end{array}$ & $\begin{array}{l}\text { Present } \\
\text { Reflective } \\
\text { Functional }\end{array}$ & $90(2007-2012)$ & $\begin{array}{l}\text { - } \quad \text { Properly mounted. Correctly positioned. } \\
\text { - No sight distance or sign obstructions. } \\
\text { - } \quad \text { No missing posts delineators, or object markers }\end{array}$ \\
\hline \multicolumn{4}{|c|}{$* * *$ Deleted Glare Screens $* * *$} \\
\hline
\end{tabular}




\begin{tabular}{|c|c|c|c|}
\hline \multicolumn{4}{|c|}{$\begin{array}{c}\text { TABLE } 6 \\
\text { PAVEMENT (0.2) }\end{array}$} \\
\hline $\begin{array}{l}\text { ELEMENT } \\
\text { (ELEMENT } \\
\text { WEIGHT) }\end{array}$ & OUTCOME & $\begin{array}{c}\text { PERF. } \\
\text { TARGET (\%) }\end{array}$ & TOLERANCE \& CRITERIA \\
\hline $\begin{array}{l}\text { Paved Shoulders } \\
(0.02)\end{array}$ & Safe, smooth & $90(2007-2012)$ & $\begin{array}{l}\text { - Pavement failures are repaired with permanent } \\
\text { patches in kind (asphalt with asphalt, concrete } \\
\text { with concrete) as soon as weather conditions } \\
\text { permit. } \\
\text { - Rumble strips are retained or replaced when } \\
\text { damaged. } \\
\text { - Longitudinal joint separation is }<0.5 \text { " or is sealed. } \\
\text { - No unsealed cracks in asphalt shoulders larger } \\
\text { than } 0.5 \text { " } \\
\text { - Cross section allows drainage from mainline (no } \\
\text { shoulder buildup). No vegetation present. }\end{array}$ \\
\hline $\begin{array}{l}\text { Asphalt Pavement } \\
\text { Repair }(0.09)\end{array}$ & $\begin{array}{l}\text { Safe, durable, } \\
\text { smooth }\end{array}$ & $95(2007-2012)$ & $\begin{array}{l}\text { - Potholes are fixed with permanent patches as } \\
\text { soon as weather conditions permit. Patching is } \\
\text { done in a manner than maintains or improves the } \\
\text { ride quality. } \\
\text { - Rut depths }>0.75 \text { " are reduced to }<0.25 \text { ". } \\
\text { - No unsealed cracks larger than } 0.5 \text { ". }\end{array}$ \\
\hline $\begin{array}{l}\text { Concrete Pavement } \\
\text { Repair }(0.09)\end{array}$ & $\begin{array}{l}\text { Safe, durable, } \\
\text { smooth }\end{array}$ & $95(2007-2012)$ & $\begin{array}{l}\text { CRC punchouts: Permanent patches with } \\
\text { concrete and restoration of reinforcing steel as } \\
\text { soon as weather conditions permit. Patching is } \\
\text { done in a manner than maintains or improves the } \\
\text { ride quality. } \\
\text { - Jointed PCC: No slabs broken in more than } 3 \\
\text { pieces. Permanent concrete patches as soon as } \\
\text { weather conditions permit. Patching is done in a } \\
\text { manner than maintains or improves the ride } \\
\text { quality. } \\
\text { - Corner breaks and spalls are patched with asphalt } \\
\text { surface course or concrete. Patching is done in a } \\
\text { manner than maintains or improves the ride } \\
\text { quality. } \\
\text { Cracks in slabs broken into } 2 \text { or } 3 \text { pieces are } \\
\text { sealed. } \\
\text { In the event that movement is evident, the slab } \\
\text { must be repaired or replaced regardless of the } \\
\text { number of pieces the slab is broken into }\end{array}$ \\
\hline
\end{tabular}




\begin{tabular}{|c|c|c|c|}
\hline \multicolumn{4}{|c|}{ BRIDGE MAINTENANCE (0.15) } \\
\hline $\begin{array}{l}\text { ELEMENT } \\
\text { (ELEMENT } \\
\text { WEIGHT) }\end{array}$ & OUTCOME & $\begin{array}{c}\text { PERF. } \\
\text { TARGET (\%) }\end{array}$ & TOLERANCE \& CRITERIA \\
\hline $\begin{array}{l}\text { Bridge Deck }{ }^{1} \\
(0.0225)\end{array}$ & $\begin{array}{l}\text { Safe } \\
\text { Clean } \\
\text { Functional } \\
\text { Joints intact }\end{array}$ & $\begin{array}{c}90(2009-2012) \\
85(2008) \\
80(2007)\end{array}$ & $\begin{array}{l}\text { Perform all routine/ordinary maintenance including } \\
\text { sweeping, washing and cleaning. } \\
\text { The deck is free of foreign material (grass, stones, } \\
\text { limbs, trash, etc.) } \\
\text { - Riding surface has no spalls } \geq 2 \text { inches deep. } \\
\text { - Joints are clean and joint material is present and } \\
\text { functioning as designed. } \\
\text { Drainage system (drains, scuppers, trough, etc) is } \\
\text { clean and functioning as designed. Railings are intact } \\
\text { and connections are tight. } \\
\text { Routes receiving de-icing salts, each deck shall be } \\
\text { washed after the last snow fall has melted. }\end{array}$ \\
\hline $\begin{array}{l}\text { Bridge } \\
\text { Superstructure } \\
(0.045)\end{array}$ & $\begin{array}{l}\text { Safe } \\
\text { Clean } \\
\text { Functional }\end{array}$ & $\begin{array}{c}90(2009-2012) \\
85(2008) \\
80(2007)\end{array}$ & $\begin{array}{l}\text { - Perform all routine/ordinary maintenance including } \\
\text { sweeping, washing, clearing of all obstructions. } \\
\text { - No damage by vehicular impact is evident. } \\
\text { - Bridge components are free of damaging vegetation. } \\
\text { - The bearing assemblies and the end } 5 \text { feet of } \\
\text { longitudinal superstructure elements are free of } \\
\text { foreign material (grass, stones, limbs, trash, sand dirt, } \\
\text { etc.) } \\
\text { Bearing assemblies and the end } 5 \text { feet of longitudinal } \\
\text { superstructure elements shall be washed after the last } \\
\text { snow fall has melted. }\end{array}$ \\
\hline $\begin{array}{l}\text { Bridge Substructure } \\
(0.045)\end{array}$ & $\begin{array}{l}\text { Safe } \\
\text { Clean } \\
\text { Functional }\end{array}$ & $\begin{array}{c}90(2009-2012) \\
85(2008) \\
80(2007)\end{array}$ & $\begin{array}{l}\text { Perform all routine/ordinary maintenance including } \\
\text { sweeping, washing, clearing of all obstructions. } \\
\text { No damage ( } \geq 2 \text { " deep spalls) caused by vehicular } \\
\text { impact is evident. } \\
\text { - Bridge components are free of damaging vegetation. } \\
\text { Horizontal surfaces to including bridge seats and } \\
\text { bearing areas are free of foreign material (grass, } \\
\text { stones, limbs, trash, sand, dirt, etc.) } \\
\text { - Horizontal surfaces including bridge seats/bearing } \\
\text { areas washed after the last snow fall has melted. } \\
\text { Weep holes are clean and free of foreign material and } \\
\text { properly functioning. }\end{array}$ \\
\hline
\end{tabular}

\footnotetext{
${ }^{1}$ Bridge Deck includes and not limited to the bridge roadway surface, approach slabs, curbs, sidewalks, parapets, railing system, drainage system, lighting, expansion joints

${ }^{2}$ Bridge Superstructure includes and not limited to beams, girders, diaphragms, bracings, truss members, bearing devices

${ }^{3}$ Bridge Substructure includes and not limited to abutments, backwalls, seats, piers, columns, wingwalls, Weep holes
} 


\begin{tabular}{|c|c|c|c|}
\hline $\begin{array}{l}\text { Pipes and Culverts } \\
\left(>/=54^{\prime \prime}\right)(0.0225)\end{array}$ & $\begin{array}{l}\text { Safe } \\
\text { Clean } \\
\text { Functional } \\
\text { Stable }\end{array}$ & $90(2007-2012)$ & $\begin{array}{l}\text { - } \quad \text { Perform all routine/ordinary maintenance. } \\
\text { - } \text { Opening } \geq 75 \% \text { open } \\
\text { - } \quad \text { Free of debris and vegetation. } \\
\text { Any erosion and scour at inlet and outlet ends has } \\
\text { been stabilized. } \\
\text { - } \quad \begin{array}{l}\text { End walls/wing-walls are clear of vegetation and } \\
\text { debris. }\end{array} \\
\text { - Concrete elements have no spalls } \geq 2 \text { inches deep. } \\
\text { - Weep holes are clean and free of foreign material and } \\
\text { properly functioning. } \\
\text { There are no construction joints opened greater than } 1 / 4 \\
\text { inch. }\end{array}$ \\
\hline $\begin{array}{l}\text { Retaining Walls } \\
(0.0075)\end{array}$ & $\begin{array}{l}\text { Safe } \\
\text { Clean } \\
\text { Functional } \\
\text { Stable }\end{array}$ & $90(2007-2012)$ & $\begin{array}{l}\text { - Perform all routine/ordinary maintenance. } \\
\text { - } \quad \text { Concrete elements have no spalls } \geq 2 \text { inches deep. } \\
\text { properly functioning. Free of vegetation. }\end{array}$ \\
\hline $\begin{array}{l}\text { Channel and Slope } \\
\text { Protection }(0.0075)\end{array}$ & $\begin{array}{l}\text { Safe } \\
\text { Clean } \\
\text { Functional } \\
\text { Stable }\end{array}$ & $90(2007-2012)$ & $\begin{array}{l}\text { Perform all routine/ordinary maintenance to include } \\
\text { removing channel drift, stabilizing, erosion, cutting, } \\
\text { removing and disposing of vegetation, brush and trees } \\
\text { that are on, adjacent to, or under bridges } \\
\text { - Maintain bridge slope protection as designed. } \\
\text { Drainage systems are clean and functioning as } \\
\text { designed. } \\
\text { - Channel and/or Slope Protection components are free } \\
\text { of vegetation. } \\
\text { Any erosion and/or scour has been stabilized. }\end{array}$ \\
\hline
\end{tabular}




\section{TABLE 8}

\section{TIMELINESS PERFORMANCE CRITERIA}

\begin{tabular}{|c|c|c|c|}
\hline $\begin{array}{l}\text { General terms } \\
\text { and conditions } \\
\text { ELEMENT }\end{array}$ & OUTCOME & $\begin{array}{c}\text { PERF. } \\
\text { TARGET (\%) }\end{array}$ & TOLERANCE \& CRITERIA \\
\hline $\begin{array}{l}\text { Debris/Road Kill } \\
\text { Removal \&Litter } \\
\text { Removal as directed } \\
\text { by DOT or other } \\
\text { customers }\end{array}$ & $\begin{array}{l}\text { Roadway free } \\
\text { of obstruction } \\
\text { Litter Free }\end{array}$ & $100(2007-2012)$ & $\begin{array}{l}\text { - } \\
\text { - } \\
\text { - } \\
\text { - Litter compond kill and Debris promptly and properly disposed } \\
\text { Department personnel addressed promptly and } \\
\text { thoroughly }\end{array}$ \\
\hline Customer Response & $\begin{array}{l}\text { Timely } \\
\text { Efficient } \\
\text { Effective } \\
\text { Productive } \\
\text { Follow-up }\end{array}$ & $100(2007-2012)$ & $\begin{array}{l}\text { - The Contractor shall contact the customer within } 48 \\
\text { hours following initial customer inquiry. } \\
\text { - All work resulting from customer requests should be } \\
\text { scheduled within } 48 \text { hours of customer contact. } \\
\text { - The Contractor shall conduct follow-up contact with } \\
\text { the customer within } 72 \text { hours of initial inquiry. } \\
\text { - All customer concerns/requests must be resolved to } \\
\text { the Department's satisfaction within } 2 \text { weeks of the } \\
\text { initial inquiry. }\end{array}$ \\
\hline Pavement Repairs & $\begin{array}{l}\text { Timely } \\
\text { Efficient } \\
\text { Effective } \\
\text { Productive } \\
\text { Durable } \\
\text { Safe }\end{array}$ & $100(2007-2012)$ & $\begin{array}{l}\text { - All shoulder failures }>1 \mathrm{sq} \mathrm{ft} \times 1.5 \text { ", all asphalt } \\
\text { pavement potholes or failures greater than } 1 \mathrm{sq} \mathrm{ft} x \\
1.5 \text { x, all CRC punchouts, and all concrete slabs } \\
\text { broken into } 4 \text { or more pieces are repaired in a } \\
\text { temporary manner within } 2 \text { days of notification or } \\
\text { discovery. } \\
\text { - All shoulder failures }>1 \mathrm{sq} \mathrm{ft} x 1.5 \text { ", all asphalt } \\
\text { pavement potholes or failures greater than } 1 \mathrm{sq} \mathrm{ft} x \\
1.5 \text { ", all CRC punchouts, and all concrete slabs } \\
\text { broken into } 4 \text { or more pieces, and slabs with } \\
\text { movement are repaired in a permanent manner within } \\
60 \text { days of notification or discovery. }\end{array}$ \\
\hline $\begin{array}{l}\text { Guardrail/Guiderail/ } \\
\text { Impact Attenuators }\end{array}$ & $\begin{array}{l}\text { Timely } \\
\text { Efficient } \\
\text { Effective } \\
\text { Safe }\end{array}$ & $100(2007-2012)$ & $\begin{array}{l}\text { Damaged impact attenuators and damaged, non- } \\
\text { functional guardrail, and guiderail must be repaired } \\
\text { within } 7 \text { days following notification or discovery. } \\
\text { - Damaged impact attenuators must be replaced within } \\
30 \text { days following notification or discovery. } \\
\text { - Damaged but functional guardrail must be } \\
\text { repaired/replaced within } 30 \text { days following } \\
\text { notification or discovery. }\end{array}$ \\
\hline
\end{tabular}




\begin{tabular}{|c|c|c|c|}
\hline Signs & $\begin{array}{l}\text { Timely } \\
\text { Efficient } \\
\text { Effective } \\
\text { Safe }\end{array}$ & $100(2007-2012)$ & $\begin{array}{l}\text { - Damaged overhead signs and sign structures that pose } \\
\text { imminent risk to the public must be mitigated } \\
\text { immediately. } \\
\text { - Damaged but functional overhead signs } \\
\text { repaired/replaced within } 60 \text { days following } \\
\text { notification or discovery. } \\
\text { - Non-functional Stop, Do Not Enter, Wrong Way and } \\
\text { Yield signs must be repaired/replaced within } 8 \text { hours } \\
\text { following notification or discovery. } \\
\text { - All other signs, including posts, that are damaged or } \\
\text { missing must be repaired/replaced within five (5) days } \\
\text { following notification or discovery. }\end{array}$ \\
\hline $\begin{array}{l}\text { Frozen Inclement } \\
\text { Weather Pavement } \\
\text { Management } \\
\text { Winter Weather } \\
\text { Events }\end{array}$ & $\begin{array}{l}\text { Open } \\
\text { Free of frozen } \\
\text { precipitation } \\
\text { Safe }\end{array}$ & $100(2007-2012)$ & $\begin{array}{l}\text { - At least one travel lane in each direction shall be kept } \\
\text { open and free of frozen precipitation so that traffic can } \\
\text { proceed in a safe and orderly manner throughout the } \\
\text { inclement weather occurrence } \\
\text { - Frozen precipitation removal activities shall continue } \\
\text { in full force from the onset of a snow or ice event } \\
\text { until such time as all pavement travel lanes are clear } \\
\text { and passable (icy spots allowed) by no later than } 12 \\
\text { hours after the end of a winter weather event. } \\
\text { - Frozen precipitation removal activities shall continue } \\
\text { in full force from the onset of a snow or ice event } \\
\text { until such time as all pavement travel lanes are } 100 \% \\
\text { free of frozen precipitation and any other frozen } \\
\text { accumulations by no later than } 24 \text { hours after the end } \\
\text { of a winter weather event. } \\
\text { All shoulders shall be plowed (pushed back) within } 36 \\
\text { hours of the cessation of falling precipitation. }\end{array}$ \\
\hline $\begin{array}{c}\text { Emergency } \\
\text { Maintenance } \\
\text { Repairs }\end{array}$ & $\begin{array}{l}\text { Timely } \\
\text { Efficient } \\
\text { Effective } \\
\text { Safe }\end{array}$ & $100(2007-2012)$ & $\begin{array}{l}\text { The Contractor shall initiate corrective measures } \\
\text { within } 2 \text { hours after notification or discovery, } \\
\text { liquidated damages in the amount of } \$ 5,000 \text { per hour, } \\
\text { or portion thereof, will be deducted from the monies } \\
\text { due to the Contractor. }\end{array}$ \\
\hline
\end{tabular}


EXAMPLE OF CONTRACTOR PAYMENT

$\$ 100,000.00$ MONTHLY UNIT BID AMOUNT

\begin{tabular}{l} 
Element Value equals Element Weight X Unit Price \\
Bid (Monthly Bid Amount) \\
Ex. Asphalt Pavement Repair \\
Element Weight $=.09$ \\
Unit Price Bid $=\$ 100,000.00$ \\
Element Value $=\$ 9,000.00$ \\
\hline
\end{tabular}

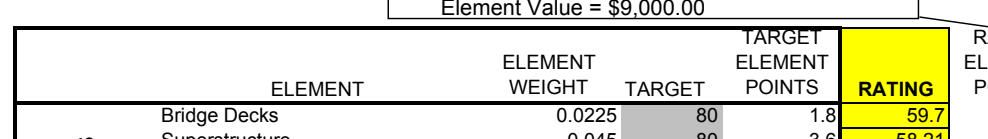




\section{ITEMIZED PROPOSAL FOR WBS ELEMENT 40682}

Counties: $\quad$ Mecklenburg, Gaston, Cleveland, \& Carbarrus

\begin{tabular}{|c|c|c|c|c|c|c|}
\hline $\begin{array}{l}\text { Line } \\
\text { \# }\end{array}$ & $\begin{array}{c}\text { Item Number } \\
\#\end{array}$ & $\begin{array}{c}\text { Sec } \\
\#\end{array}$ & Description & Quantity & Unit Price & Amount \\
\hline 0001 & 0000900000-N & $\mathrm{SP}$ & $\begin{array}{l}\text { MAINTENANCE SERVICES EXCLUDING } \\
\text { SNOW AND ICE REMOVAL }\end{array}$ & 60 & & \\
\hline
\end{tabular}

(for entire 60 month contract period)

*****SNOW AND ICE CONTROL ALTERNATE ITEMS *****

(Reference Alternate Bid for Snow and Ice Removal Project Special Provision)

\begin{tabular}{|c|c|c|c|c|c|}
\hline 0002 & $0000900000-\mathrm{N}$ & SP & $\begin{array}{l}\text { MAINTENANCE SERVICES INCLUDING } \\
\text { SNOW AND ICE REMOVAL }\end{array}$ & 60 & \\
\hline 0003 & 0000900000-N & SP & $\begin{array}{l}\text { MOBILIZATION (INCLUDING SNOW } \\
\text { AND ICE REMOVAL) }\end{array}$ & Lump Sum & L. \\
\hline
\end{tabular}

Total Price Proposal for Maintenance Services Including Snow and Ice Removal: (for the entire 60 month contract period plus mobilization) 


\begin{tabular}{|l|c|c|l|l|l|}
\hline \multicolumn{6}{|c|}{ LISTING OF MB \& WB SUBCONTRACTORS } \\
\hline $\begin{array}{c}\text { FIRM NAME AND } \\
\text { ADDRESS }\end{array}$ & $\begin{array}{c}\text { MB } \\
\text { or } \\
\text { WB }\end{array}$ & $\begin{array}{l}\text { ITEM } \\
\text { NO. }\end{array}$ & ITEM DESCRIPTION & $\begin{array}{c}\text { AGRED UPON } \\
\text { UNIT PRICE }\end{array}$ & $\begin{array}{c}\text { DOLLAR VOLUME } \\
\text { OF ITEM }\end{array}$ \\
\hline & & & & & \\
\hline & & & & & \\
\hline & & & & & \\
\hline & & & & & \\
\hline & & & & & \\
\hline & & & & & \\
\hline & & & & & \\
\hline & & & & & \\
\hline & & & & & \\
\hline & & & & & \\
\hline & & & & & \\
\hline & & & & & \\
\hline & & & & & \\
\hline
\end{tabular}




\begin{tabular}{|c|c|c|c|c|c|}
\hline \multicolumn{6}{|c|}{ LISTING OF MB \& WB SUBCONTRACTORS } \\
\hline FIRM NAME AND ADDRESS & $\begin{array}{l}\text { MB } \\
\text { OR } \\
\text { WB }\end{array}$ & $\begin{array}{c}\text { ITEM } \\
\text { NO. }\end{array}$ & ITEM DESCRIPTION & $\begin{array}{c}\left(^{(*)}\right. \\
\text { AGREED UPON } \\
\text { UNIT PRICE }\end{array}$ & $\begin{array}{c}\text { DOLLAR VOLUME } \\
\text { OF ITEM }\end{array}$ \\
\hline & & & & & \\
\hline & & & & & \\
\hline & & & & & \\
\hline & & & & & \\
\hline & & & & & \\
\hline & & & & & \\
\hline & & & & & \\
\hline & & & & & \\
\hline & & & & & \\
\hline & & & & & \\
\hline & & & & & \\
\hline & & & & & \\
\hline & & & & & \\
\hline & & & & & \\
\hline & & & & & \\
\hline CONTRACT NO. & & COUN? & & FIRM & \\
\hline
\end{tabular}




\begin{tabular}{|l|c|c|c|c|c|}
\hline \multicolumn{7}{|c|}{ LISTING OF MB \& WB SUBCONTRACTORS } \\
\hline FIRM NAME AND ADDRESS & $\begin{array}{c}\text { MB } \\
\text { OR } \\
\text { WB }\end{array}$ & $\begin{array}{c}\text { ITEM } \\
\text { NO. }\end{array}$ & ITEM DESCRIPTION & $\begin{array}{c}\text { AGRED UPON } \\
\text { UNIT PRICE }\end{array}$ & $\begin{array}{c}\text { DOLLAR VOLUME } \\
\text { OF ITEM }\end{array}$ \\
\hline & & & & & \\
\hline & & & & & \\
\hline & & & & & \\
\hline & & & & & \\
\hline & & & & & \\
\hline & & & & & \\
\hline & & & & & \\
\hline & & & & & \\
\hline & & & & & \\
\hline & & & & & \\
\hline & & & & & \\
\hline
\end{tabular}




\begin{tabular}{|c|c|c|c|c|c|}
\hline \multicolumn{6}{|c|}{ LISTING OF MB \& WB SUBCONTRACTORS } \\
\hline FIRM NAME AND ADDRESS & \begin{tabular}{l|}
$\mathrm{MB}$ \\
$\mathrm{OR}$ \\
$\mathrm{WB}$
\end{tabular} & $\begin{array}{l}\text { ITEM } \\
\text { NO. }\end{array}$ & ITEM DESCRIPTION & $\begin{array}{c}{ }^{(*)} \\
\text { AGREED UPON } \\
\text { UNIT PRICE }\end{array}$ & $\begin{array}{c}\text { DOLLAR VOLUME } \\
\text { OF ITEM }\end{array}$ \\
\hline & & & & & \\
\hline & & & & & \\
\hline & & & & & \\
\hline & & & & & \\
\hline & & & & & \\
\hline & & & & & \\
\hline & & & & & \\
\hline & & & & & \\
\hline & & & & & \\
\hline & & & & & \\
\hline & & & & & \\
\hline & & & & & \\
\hline
\end{tabular}

\section{COST OF CONSTRUCTION WORK ONLY:}

(*) The Dollar Volume Shown in this Column Shall be Shall be Actual Price Agreed Upon by the Prime Contractor and the MB and/or WB Subcontractor, and These Prices will be Used to Determine the Percentage of the MB and/or WB Participation in the Contract.

\section{$\$$}

Dollar Volume of MB Subcontractor MB Percentage of Total Contract Cost Dollar Volume of WB Subcontractor WB Percentage of Total Contract Cost
$\$$

$\$$ 


\section{EXECUTION OF BID, NONCOLLUSION AFFIDAVIT AND DEBARMENT CERTIFICATION}

The person executing the bid, on behalf of the Bidder, being duly sworn, solemnly swears (or affirms) that neither he, nor any official, agent or employee of the bidder has entered into any agreement, participated in any collusion, or otherwise taken any action which is in restraint of free competitive bidding in connection with this bid, and that the Bidder intends to do the work with its own bonafide employees or subcontractors and is not bidding for the benefit of another contractor.

In addition, execution of this bid in the proper manner also constitutes the Bidder's certification of "Status" under penalty of perjury under the laws of the United States in accordance with the Debarment Certification included elsewhere in the proposal form, provided that the Debarment Certification also includes any required statements concerning exceptions that are applicable.

SIGNATURE OF CONTRACTOR

(If a corporation uses this sheet)

(Print full name of corporation)

\section{(Address as Prequalified)}

Attest

(Secretary) (Assistant Secretary)
Delete inappropriate title

Delete inappropriate title

Print Signer's Name
By

(President) (Vice President)
(Asst. Vice President)
Delete inappropriate title

Print Signer's Name

\section{NOTE - AFFIDAVIT MUST BE NOTARIZED}

Subscribed and sworn to before me this the

day of , 20

of County.

State of

My Commission Expires:

Signature Sheet 1 (Bid) - Corporation 


\section{EXECUTION OF BID, NONCOLLUSION AFFIDAVIT, AND DEBARMENT CERTIFICATION}

The person executing the bid, on behalf of the Bidder, being duly sworn, solemnly swears (or affirms) that neither he, nor any official, agent or employee of the bidder has entered into any agreement, participated in any collusion, or otherwise taken any action which is in restraint of free competitive bidding in connection with this bid, and that the Bidder intends to do the work with its own bonafide employees or subcontractors and is not bidding for the benefit of another contractor.

In addition, execution of this bid in the proper manner also constitutes the Bidder's certification of "Status" under penalty of perjury under the laws of the United States in accordance with the Debarment Certification included elsewhere in the proposal form, provided that the Debarment Certification also includes any required statements concerning exceptions that are applicable.

\section{SIGNATURE OF CONTRACTOR}

(If a joint venture, use this sheet)

Instructions to Bidders: On Line (1), print the name of each contractor. On Line (2), print the name of one of the joint venturers and execute below in the appropriate manner and furnish in the following lines all information required by Article 102-8 of the Specifications. On Line (3), print the name of the other joint venturer and execute below in the appropriate manner and furnish all information required by said article of the Specifications. For correct form of execution and information required for execution of this sheet by an individual, see Signature Sheets 3 and 4; for a corporation, see Signature Sheet 1; and for a partnership, see Signature Sheet 5.

(1) and

A Joint Venture

(2)

(Name of Contractor)

Witness or Attest

By

\begin{tabular}{l}
\hline Witness or Attest \\
\hline Print Signer's Name
\end{tabular}

and

(3)

If a corporation, affix corporate seal:

(Name of Contractor)

(Seal)

(Address as Prequalified)

By

Witness or Attest

Print Signer's Name

Print Signer's Name

If a corporation, affix corporate seal:

NOTE - AFFIDAVIT MUST BE NOTARIZED For Line (2) NOTE - AFFIDAVIT MUST BE NOTARIZED For Line (3)

Subscribed and sworn to before me

this the day of , 20

(Signature of Notary Public \& Seal)

of County.

State of

My Commission Expires:

Signature Sheet 2 (Bid) - $\underline{\text { Joint Venture }}$
Subscribed and sworn to before me

this the day of , 20
(Signature of Notary Public \& Seal)

of County.

State of

My Commission Expires 


\section{EXECUTION OF BID, NONCOLLUSION AFFIDAVIT, AND DEBARMENT CERTIFICATION}

The person executing the bid, on behalf of the Bidder, being duly sworn, solemnly swears (or affirms) that neither he, nor any official, agent or employee of the bidder has entered into any agreement, participated in any collusion, or otherwise taken any action which is in restraint of free competitive bidding in connection with this bid, and that the Bidder intends to do the work with its own bonafide employees or subcontractors and is not bidding for the benefit of another contractor.

In addition, execution of this bid in the proper manner also constitutes the Bidder's certification of "Status" under penalty of perjury under the laws of the United States in accordance with the Debarment Certification included elsewhere in the proposal form, provided that the Debarment Certification also includes any required statements concerning exceptions that are applicable.

\section{SIGNATURE OF CONTRACTOR}

(If an individual doing business under a

firm name, use this sheet)

Name of Contractor trading

(Print individual name)

\section{Witness}

Print Signer's Name and doing business as

(Print firm name)
(Address as Prequalified)

Signature of Contractor

Print Signer's Name

NOTE - AFFIDAVIT MUST BE NOTARIZED

Subscribed and sworn to before me this the

NOTARY SEAL

day of , 20

(Signature of Notary Public)

of County.

State of

My Commission Expires:

Signature Sheet 3 (Bid) - INDIVIDUAL WITH FIRM NAME 


\section{EXECUTION OF BID, NONCOLLUSION AFFIDAVIT, AND DEBARMENT CERTIFICATION}

The person executing the bid, on behalf of the Bidder, being duly sworn, solemnly swears (or affirms) that neither he, nor any official, agent or employee of the bidder has entered into any agreement, participated in any collusion, or otherwise taken any action which is in restraint of free competitive bidding in connection with this bid, and that the Bidder intends to do the work with its own bonafide employees or subcontractors and is not bidding for the benefit of another contractor.

In addition, execution of this bid in the proper manner also constitutes the Bidder's certification of "Status" under penalty of perjury under the laws of the United States in accordance with the Debarment Certification included elsewhere in the proposal form, provided that the Debarment Certification also includes any required statements concerning exceptions that are applicable.

\section{SIGNATURE OF CONTRACTOR}

(If an individual doing business in

his own name, use this sheet)

Name of Contractor

(Print)

(Address as Prequalified)

Witness

Print Signer's Name
Signature of Contractor

(Individually)

Print Signer's Name

\section{NOTE - AFFIDAVIT MUST BE NOTARIZED}

Subscribed and sworn to before me this the

NOTARY SEAL

day of , 20

(Signature of Notary Public)

of County.

State of

My Commission Expires:

Signature Sheet 4 (Bid) - Individual Name 


\section{EXECUTION OF BID, NONCOLLUSION AFFIDAVIT, AND DEBARMENT CERTIFICATION}

The person executing the bid, on behalf of the Bidder, being duly sworn, solemnly swears (or affirms) that neither he, nor any official, agent or employee of the bidder has entered into any agreement, participated in any collusion, or otherwise taken any action which is in restraint of free competitive bidding in connection with this bid, and that the bidder intends to do the work with its own bonafide employees or subcontractors and is not bidding for the benefit of another contractor.

In addition, execution of this bid in the proper manner also constitutes the bidder's certification of "Status" under penalty of perjury under the laws of the United States in accordance with the Debarment Certification included elsewhere in the proposal form, provided that the Debarment Certification also includes any required statements concerning exceptions that are applicable.

\section{SIGNATURE OF CONTRACTOR}

(If a partnership, use this sheet)

(Print Name of Partnership)

(Address as Prequalified)

Witness

Print Signer's Name
By

Partner

Print Signer's Name

\section{NOTE - AFFIDAVIT MUST BE NOTARIZED}

Subscribed and sworn to before me this the

NOTARY SEAL

day of

, 20

(Signature of Notary Public)

of

County.

State of

My Commission Expires:

Signature Sheet 5 (Bid) - Partnership 


\section{EXECUTION OF BID, NONCOLLUSION AFFIDAVIT, AND DEBARMENT CERTIFICATION}

The person executing the bid, on behalf of the Bidder, being duly sworn, solemnly swears (or affirms) that neither he, nor any official, agent or employee of the bidder has entered into any agreement, participated in any collusion, or otherwise taken any action which is in restraint of free competitive bidding in connection with this bid, and that the Bidder intends to do the work with its own bonafide employees or subcontractors and is not bidding for the benefit of another contractor.

In addition, execution of this bid in the proper manner also constitutes the Bidder's certification of "Status" under penalty of perjury under the laws of the United States in accordance with the Debarment Certification included elsewhere in the proposal form, provided that the Debarment Certification also includes any required statements concerning exceptions that are applicable.

\section{SIGNATURE OF CONTRACTOR}

(Limited Liability Company, use this sheet)

Name of Contractor

(Print firm name)

(Address as Prequalified)

Signature of Manager

(Individually)

Print Signer's Name

$\underline{\text { NOTE - AFFIDAVIT MUST BE NOTARIZED }}$

Subscribed and sworn to before me this the

day of , 20

NOTARY SEAL

\section{(Signature of Notary Public)}

of

County.

State of

My Commission Expires:

Signature Sheet 6 (Bid) - LIMITED LIABILITY COMPANY 
WBS Element: $\underline{40682}$

Counties: Mecklenburg, Gaston, Cabarrus \& Cleveland Counties

ACCEPTED BY THE

DEPARTMENT OF TRANSPORTATION

Contract Officer

Date

Execution of Contract and Bonds

Approved as to Form:

Attorney General

Signature Sheet 7 (Bid - Acceptance by Department) 


\section{DEBARMENT CERTIFICATION OF BIDDERS}

Instructions \& conditions for certification

1. By signing and submitting this proposal, the bidder is providing the certification set out below.

2. The inability of a bidder to provide the certification required below will not necessarily result in denial of participation in this contract. If the certification is not provided, the bidder must submit an explanation (exception) of why it cannot provide the certification set out below. The certification or explanation (exception) will be considered in connection with the Department's determination whether to award the contract. However, failure of the prospective bidder to furnish a certification or an explanation (exception) may be grounds for rejection of the bid.

3. The certification in this provision is a material representation of fact upon which reliance is placed when the Department determines whether or not to award the contract. If it is later determined that the bidder knowingly rendered an erroneous certification, in addition to other remedies available to the Federal Government, the Department may terminate this contract for cause of default.

4. The prospective bidder shall provide immediate written notice to the Department if at any time the bidder learns that its certification was erroneous when submitted or has become erroneous by reason of changed circumstances.

5. The terms "covered transaction," "debarred," "suspended," "ineligible," "lower tier covered transaction," "participant," "person," "primary covered transaction," "principal," "proposal," and "voluntarily excluded," as used in this provision, have the meanings set out in the Definitions and Coverage sections of the rules implementing Executive Order 12540. A copy of the Federal Rules requiring this certification and detailing the definitions and coverages may be obtained from the Contract Officer of the Department.

6. The bidder agrees by submitting this bid that, should the contract be awarded, it shall not knowingly enter into any lower tier covered transaction with a person who is debarred, suspended, declared ineligible, or voluntarily excluded from participation in this contract, unless authorized by the Department.

7. The prospective bidder further agrees by submitting this proposal that it will include the Federal-Aid Provision titled "Required Contract Provisions Federal-Aid Construction Contract" (Form FHWA PR 1273) provided by the Department, without subsequent modification, in all lower tier covered transactions. 
8. The prospective bidder may rely upon a certification of a prospective participant in a lower tier covered transaction that it is not debarred, suspended, ineligible, or voluntarily excluded from the covered transaction, unless it knows that the certification is erroneous. A participant may decide the method and frequency by which it determines the eligibility of its principals.

9. Nothing contained in the foregoing shall be construed to require establishment of a system of records in order to render in good faith the certification required by this provision. The knowledge and information of a participant is not required to exceed that which is normally possessed by a prudent person in the ordinary course of business dealings.

10. Except for transactions authorized under paragraph 6 of these instructions, if the successful bidder knowingly enters into a lower tier covered transaction with a person who is suspended, debarred, ineligible, or voluntarily excluded from participation in this transaction, in addition to other remedies available to the Federal Government, the Department may terminate this transaction for cause of default. 


\section{DEBARMENT CERTIFICATION}

The bidder certifies to the best of its knowledge and belief, that it and its principals:

a. Are not presently debarred, suspended, proposed for debarment, declared ineligible, or voluntarily excluded from covered transactions by any Federal department or agency;

b. Have not within a three-year period preceding this proposal been convicted of or had a civil judgment rendered against them for commission of fraud or a criminal offense in connection with obtaining, attempting to obtain, or performing a public (Federal, State or local) transaction or contract under a public transaction; violation of Federal or State antitrust statutes or commission of embezzlement, theft, forgery, bribery, falsification or destruction of records; making false statements; or receiving stolen property;

c. Are not presently indicted for or otherwise criminally or civilly charged by a governmental entity (Federal, State or local) with commission of any of the offenses enumerated in paragraph $b$. of this certification; and

d. Have not within a three-year period preceding this proposal had one or more public transactions (Federal, State or local) terminated for cause or default.

Where the prospective bidder is unable to certify to any of the statements in this certification, it shall attach an explanation to this proposal. BOX SHOWN BELOW:

An explanation has been attached to the proposal. 
Appendix I

VDOT TAMS Contract 


\section{VIRGINIA DEPARTMENT OF TRANSPORTATION INVITATION FOR BID}

Commodity: Turnkey Asset Maintenance Services (TAMS) on: I-95, I-295, I-64, SR \# 288, I-195, SR\#195, SR \# 76, SR \# 150, SR \# 146

\section{Authorized User: $\quad$ VDOT Richmond \& Hampton Roads Districts}

Initial Period of Contract: From July 1, 2007 to June 30, 2012 (11:59:59 PM)

\section{Purpose:}

The Virginia Department of Transportation is submitting this Invitation for Bid - COMBINED TWO STEP SEALED BID - to establish a contract with qualified Vendors (Bidders) for Turnkey Asset Maintenance Services (TAMS) on the roadway sections as describes herein. The services to be provided to/for the Virginia Department of Transportation, herein referred to as the "Department" are outlined in the attached specifications.

\section{General}

For the purpose of clarification, each firm receiving this invitation for bid is referred to as a "Bidder" and the Bidder awarded the contract to supply the goods or services is referred to as a "contractor". This invitation for bid states the instructions for submitting bids, the procedures and criteria by which a contract may be awarded, and the contractual terms which will exclusively govern the contract between VDOT and the Contractor.

\section{Technical Proposal Due Date:}

Sealed Proposals, one unpriced technical proposal and bid price in a separate sealed envelope will be received until 2:00 P.M. December 27, 2006 For Furnishing the Services Described Herein. Mail bid proposals to:

Commonwealth of Virginia

Virginia Department of Transportation (VDOT)

Administrative Services Division (Bid Tab)

1401 East Broad Street, Richmond, Virginia 23219.

Or Hand deliver (FedX, UPS, etc.) proposals to: Administrative Services Division (Bid Tab), 1201 East Broad St, Richmond, VA, Memorial Hospital $1^{\mathrm{ST}}$ Floor Reception Desk.

All Inquiries for Information shall be directed to: Rachel Turner at Rachel.turner@vdot.virginia.gov All inquiries must be received by December 11, 2006.

A Non-Mandatory Question and Answer Session will be held at

10:00 A.M. December 11, 2006 - Vendors may attend in Richmond at VDOT - Monroe Building, 101 North 14th. Broad St., $1^{\text {st }}$ floor Conference Room D

\section{Instruction to Bidders:}

Bidders who respond to the solicitation are to furnish an unpriced technical proposal in one sealed envelope and their bid prices in a second sealed envelope at the same time. Bidders are responsible to identify these envelopes marked "Technical Proposal" and the other "Bid Price". It is the bidders responsibility to ensure that sealed bids in response to this Invitation for Bid are received at the Department's designated receipt location prior to the due date and hour shown below, at which time they will be publicly opened and the names of the bidders read. Bids must be sealed, with commodity, bid 
number and opening date shown on face of envelope, including any special delivery envelopes. This bid is a re-issue of IFB 149-RT. All of the supporting documents issued in conjunction with that previous IFB are still applicable to this solicitation. Copies of those items will be made available upon request.

The technical proposals will be opened and evaluated. Only the price envelopes for those technical proposals selected as acceptable will be opened and the award made to the lowest responsive and responsible bidder. "Acceptable” is deemed a score of $\mathbf{8 0}$ points or higher. There is no negotiation in the procurement process (except as herein); however, the Commonwealth at its option may request information from a bidder to clarify material contained within the technical proposal to determine responsiveness. The award document will incorporate the terms and conditions of the solicitation and include the bidder's technical proposal and their bid price. The price envelopes for those technical proposals determined to be not acceptable will be returned unopened.

\section{Negotiation with the lowest bidder}

Unless all bids are cancelled or rejected, the Commonwealth reserves the right granted by 2.2-4318 of the Code of Virginia to negotiate with the lowest responsive, responsible bidder to obtain a contract price within the funds available to the agency whenever such low bid exceeds the Agency's available funds. For the purpose of determining when such negotiations may take place, the Term "available funds" shall mean those funds, which were budgeted by the agency for this contract prior to the issuance of the written Invitation for Bids. Negotiations with the low bidder may include a change in requirements including price. The agency shall initiate such negotiations by written notice to the lowest responsive, responsible bidder that its bid exceeds the available funds and that the agency wishes to negotiate a lower contract price. The times, places, and manner of negotiating shall be agreed to by the agency and the lowest responsive, responsible bidder.

\section{Technical Proposal Requirements}

Please submit the person or persons that will be VDOT's contact during the bid evaluation process:

Name Email address

Phone number

This sheet must be signed and returned with proposal. Do not put in sealed cost proposal envelope.

Name and Address of Firm:

Date:

By:

(Signature in Ink)

Name:

Title:

FEI/FIN NO:

Telephone\#: (

e-mail:

Fax \#: 


\section{TABLE OF CONTENTS}

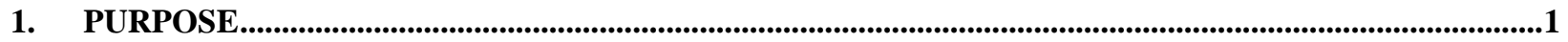

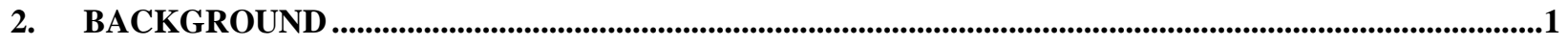

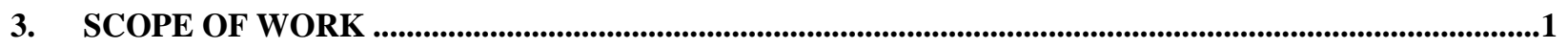

4. TECHNICAL PROPOSAL PREPARATION AND SUBMISSION INSTRUCTIONS..................................2

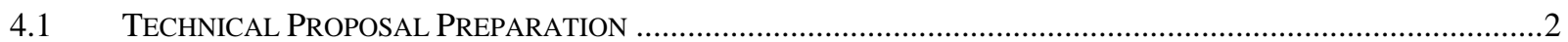

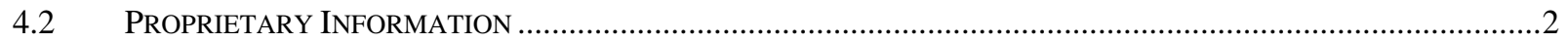

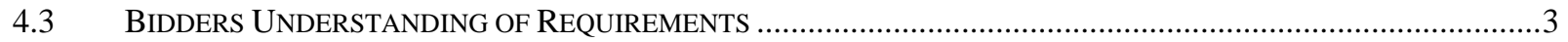

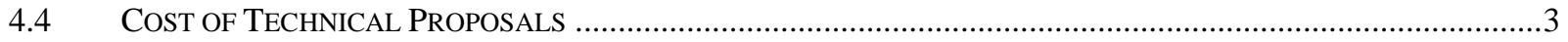

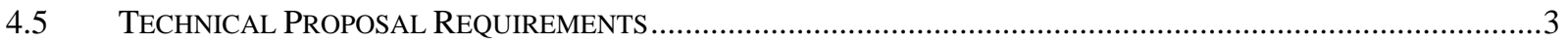

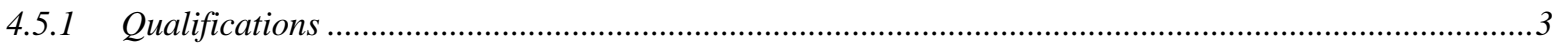

4.5.1.1 Organizational Structure, History and Key Personnel..................................................................................... 3

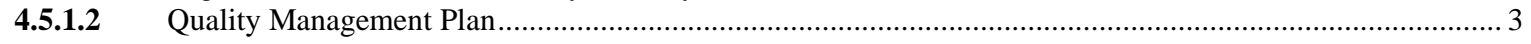

4.5.1.3 Routine Maintenance Operations Plan ...................................................................................................... 3

4.5.1.4 Emergency Operations \& Incident Management ............................................................................................. 4

4.5.1.5 Customer Service, Timeliness Requirements \& Tracking Plan ......................................................................... 4

4.5.2 Third Party Damages....................................................................................................................

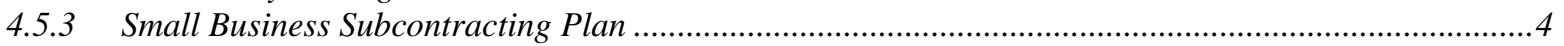

4.5.3.1 Subcontracting Restrictions ....................................................................................................... 5

5. TECHNICAL EVALUATION CRITERIA ….............................................................................................

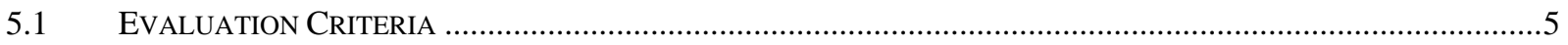

Organizational Structure, History and Key Personnel .................................................................................... 5

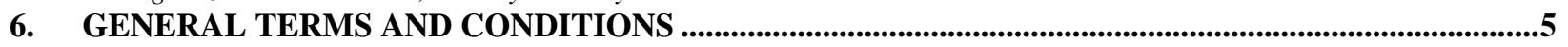

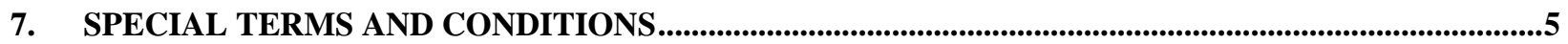

EXHIBIT A - SCOPE OF SERVICES ............................................................................................................6

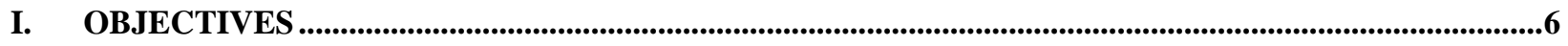

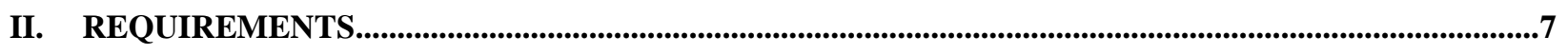

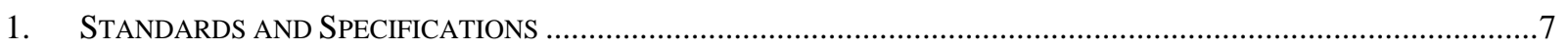

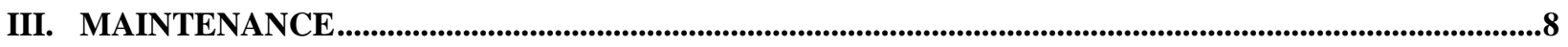

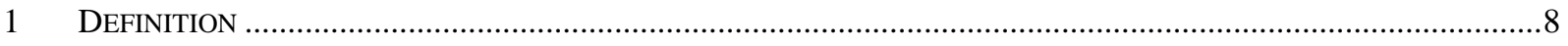

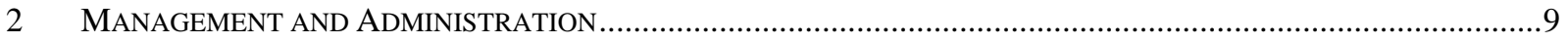

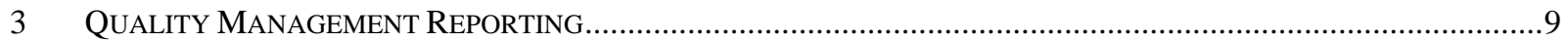

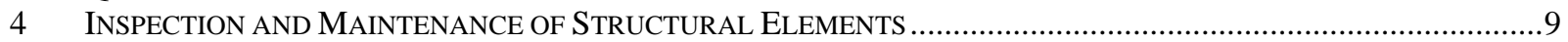

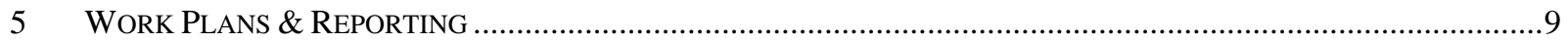

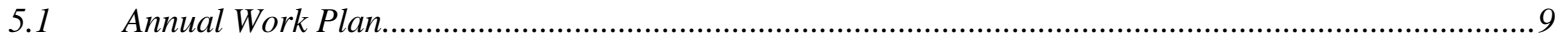

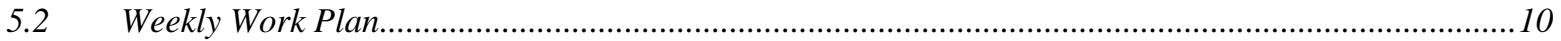

5.3 Traffic Control Plan ....................................................................................................................10

5.4 Incident and Emergency Response Plan ..........................................................................................10

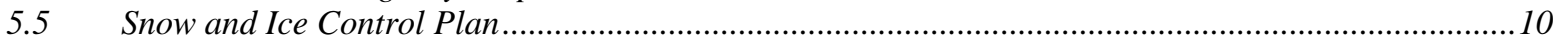

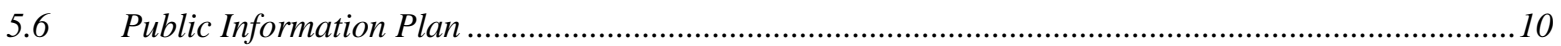

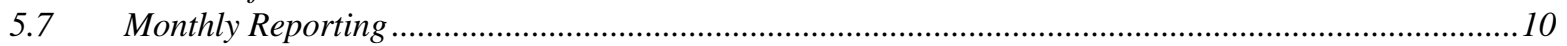

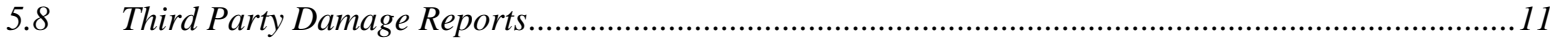

6 SNOW AND ICE CONTROL ………………………..........................................................................11

7 OPERATIONS, SAFETy MANAGEMENT AND TRAFFIC CONTROL ................................................................12

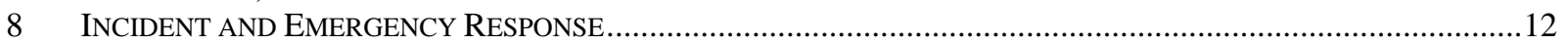

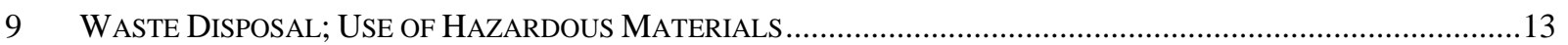

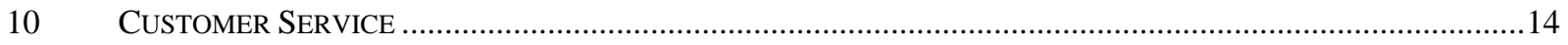

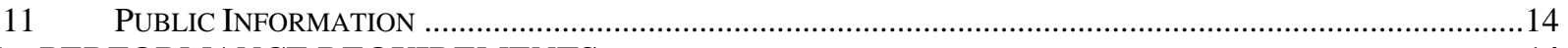

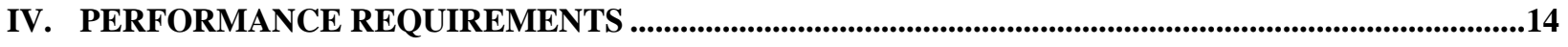

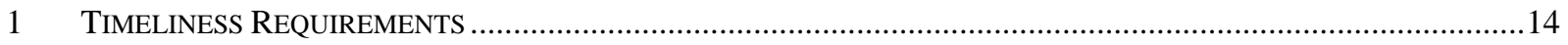

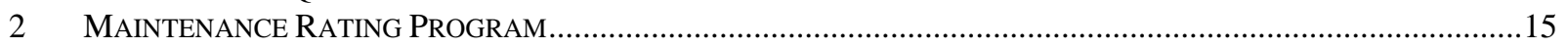




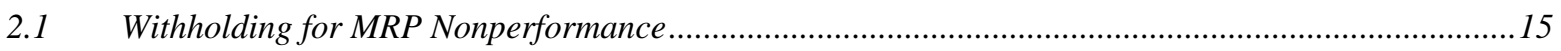

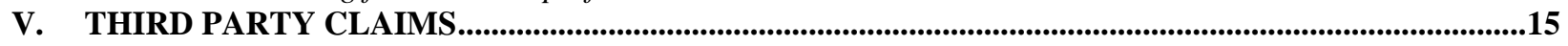

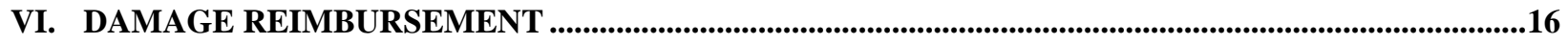

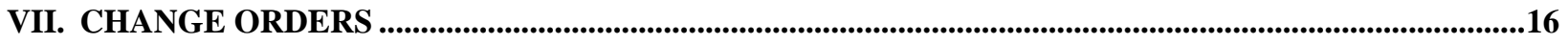

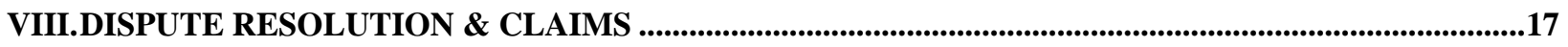

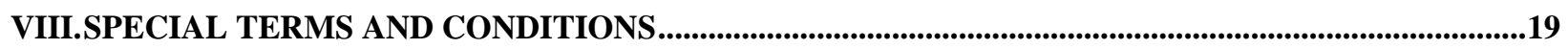

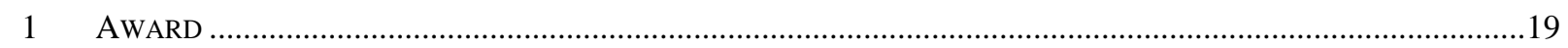

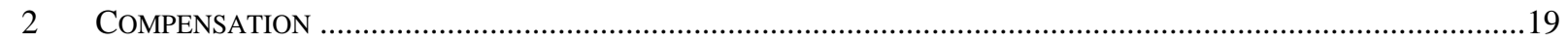

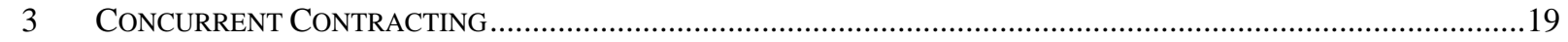

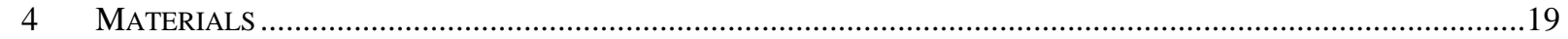

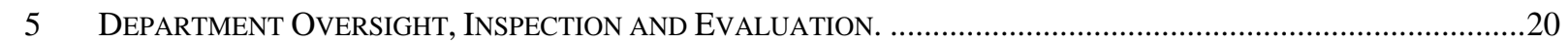

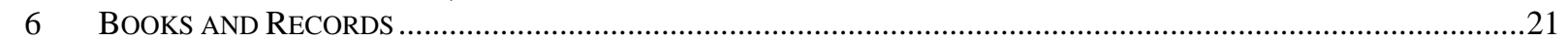

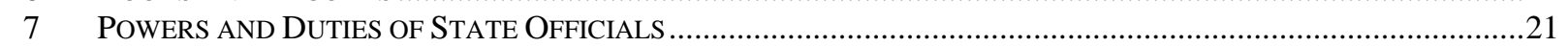

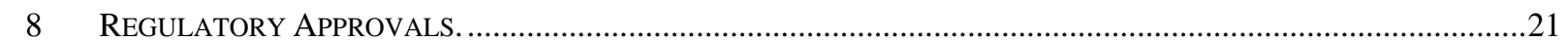

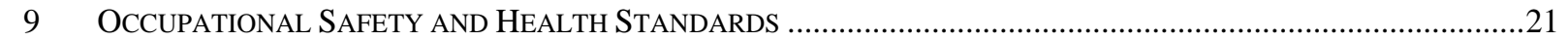

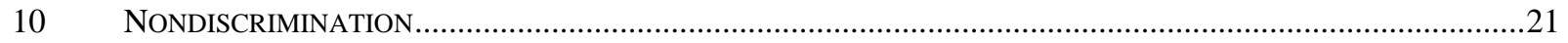

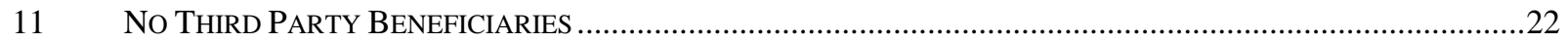

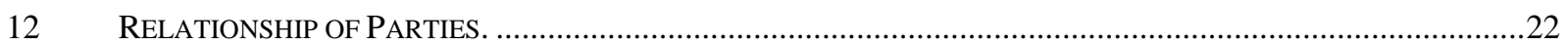

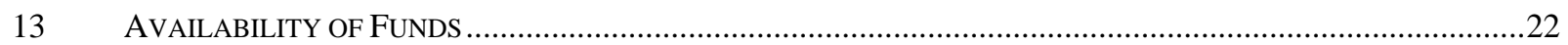

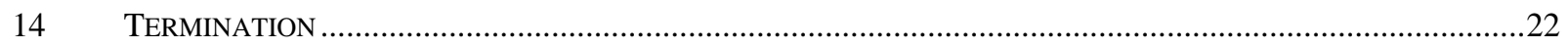

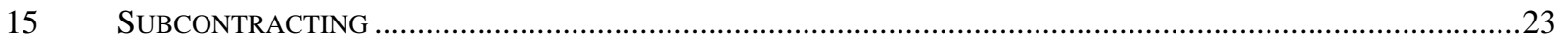

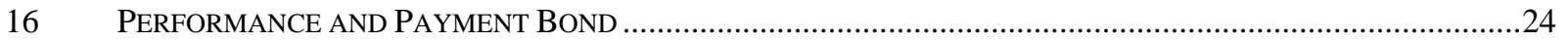

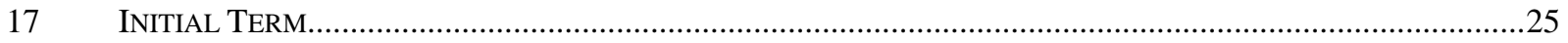

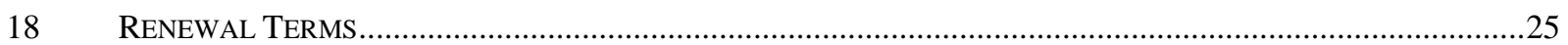

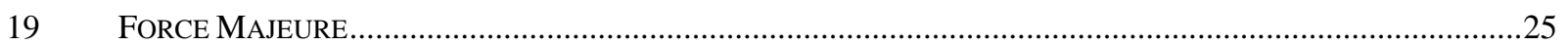

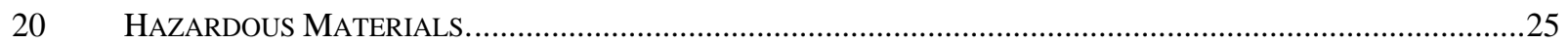

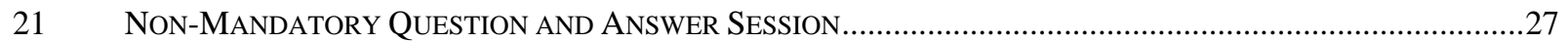

22 VA BUSINESS-TO GOVERNMENT CONTRACTS AND ORDERS:.................................................27

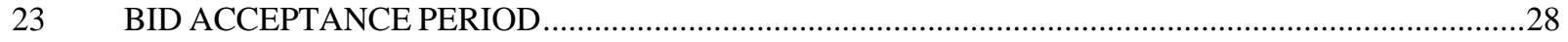

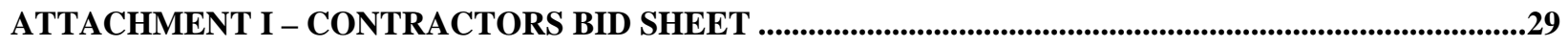

ATTACHMENT II - ROUTINE MAINTENANCE ACTIVITIES ..............................................................30

ATTACHMENT III - PERFORMANCE CRITERIA ...................................................................................

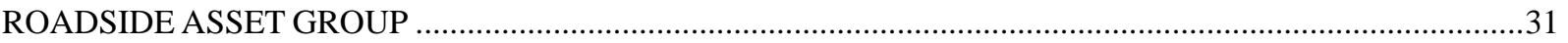

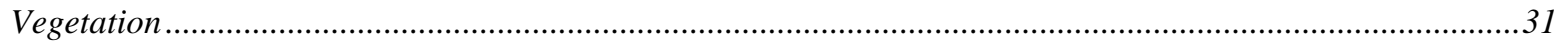

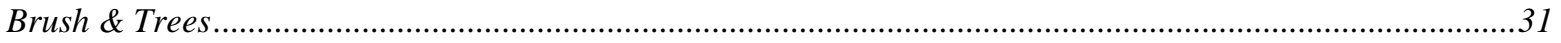

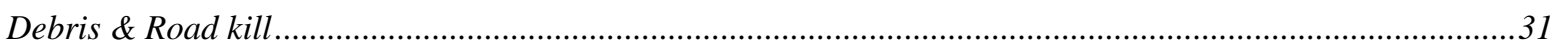

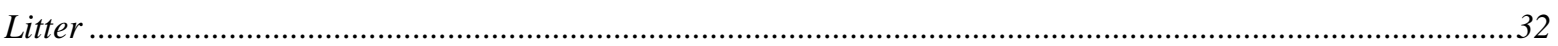

Landscaping, Wildflowers Beds, Bulb Beds, Ornamental Shrub Beds ............................................................32

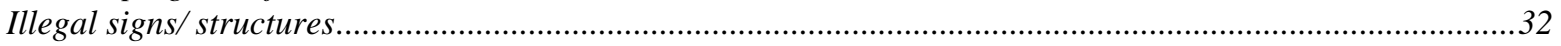

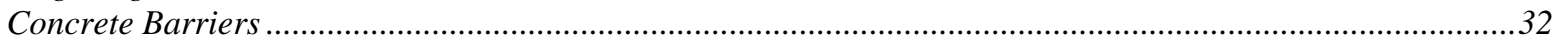

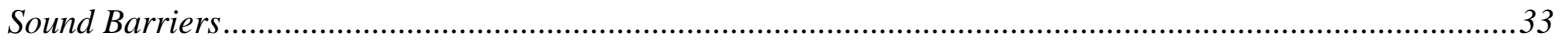

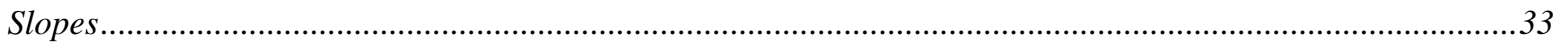

Fence

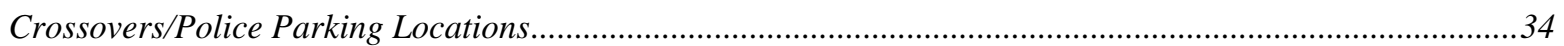

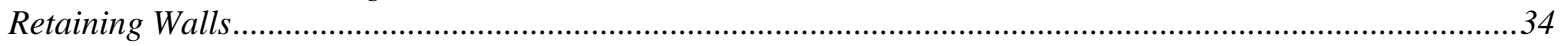

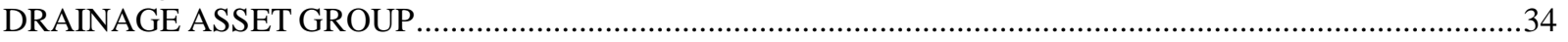

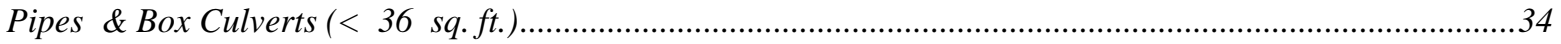

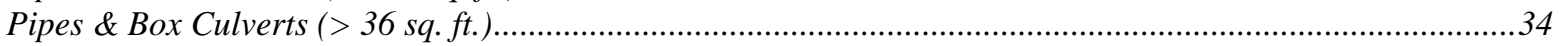

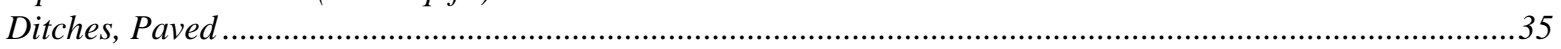

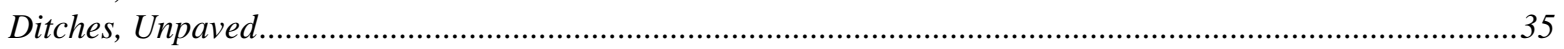

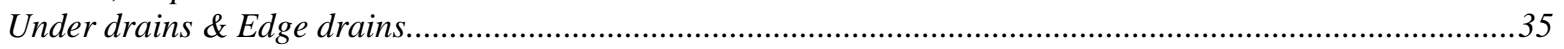

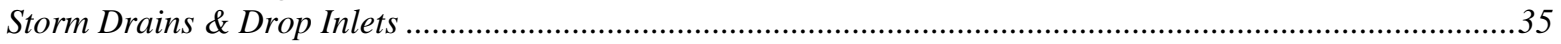

Curb \& Gutter, Curbing Raised, Concrete Median ........................................................................................36 


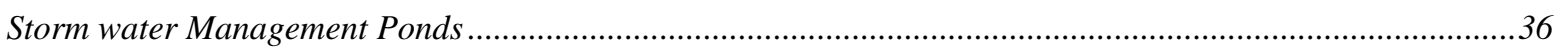

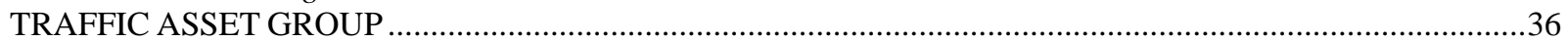

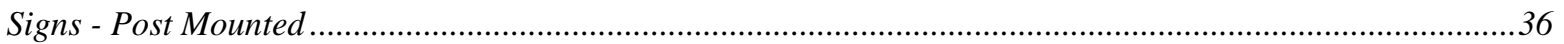

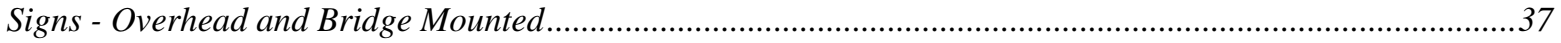

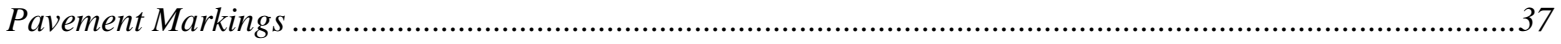

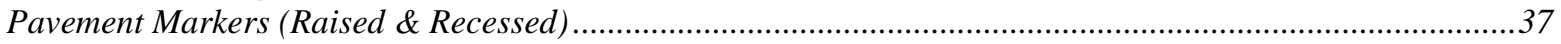

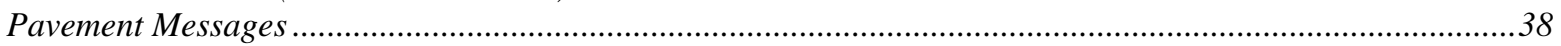

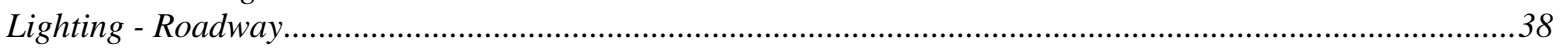

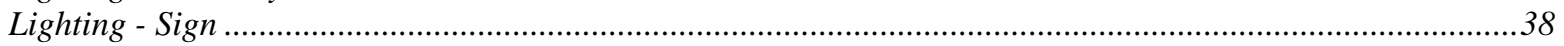

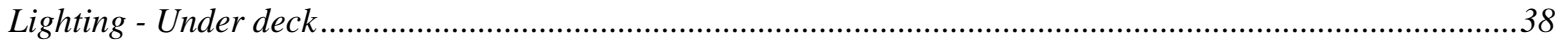

Lights - Warning, Bridge Mounted Navigation, anti-collision ................................................................38

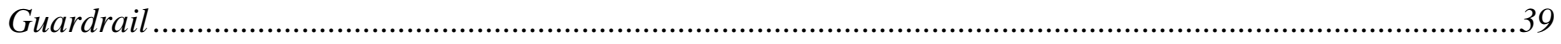

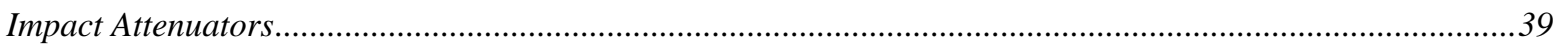

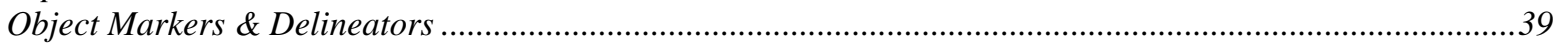

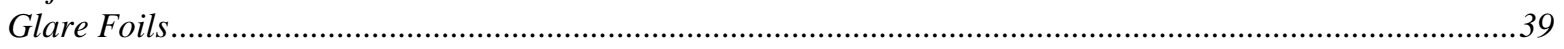

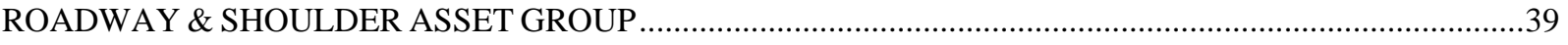

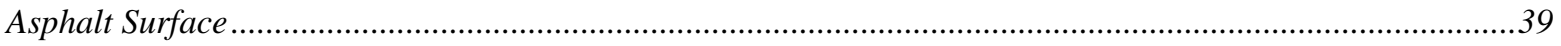

Paved Shoulders and Rumble Strips (Asphalt) ..................................................................................40

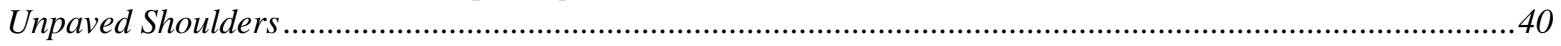

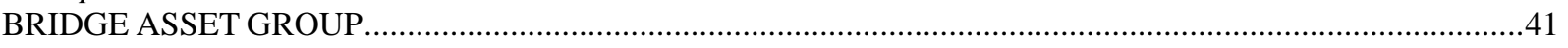

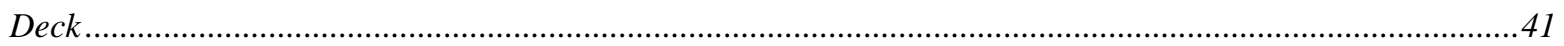

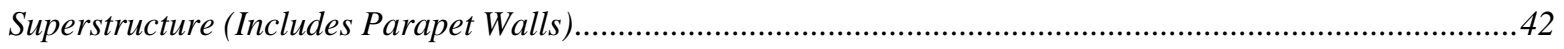

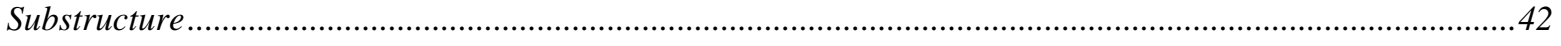

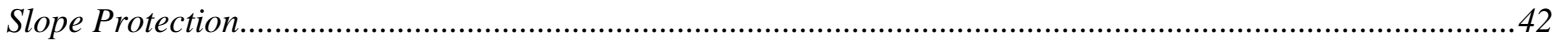

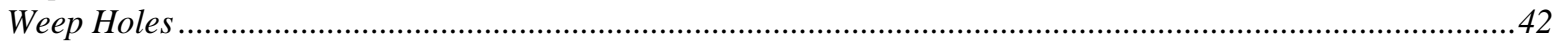

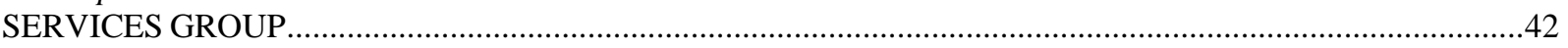

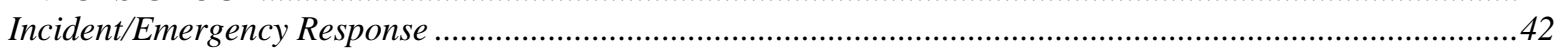

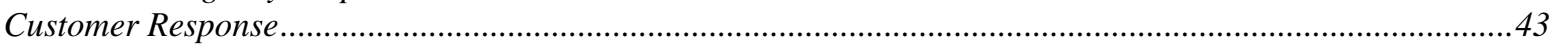

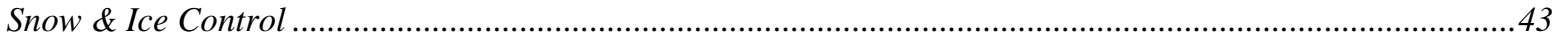

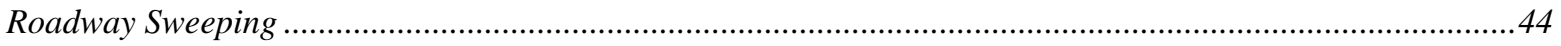

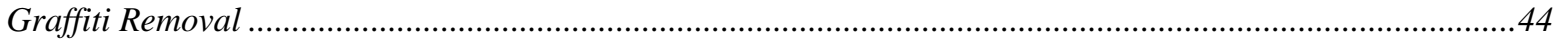

ATTACHMENT IV - SPECIAL TERMS AND CONDITION NOTES ....................................................45

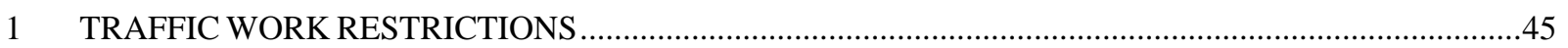

2 ADDITIONAL ASSETS - PERFORMANCE REQUIREMENTS ...................................................45

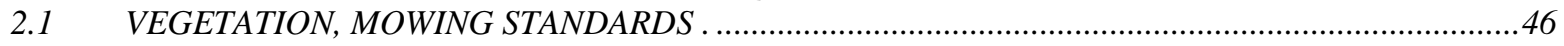

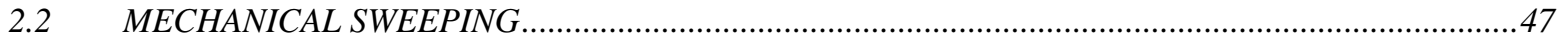

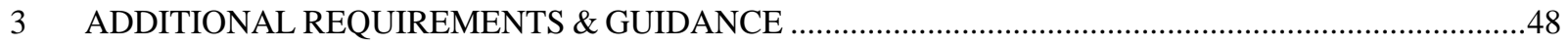

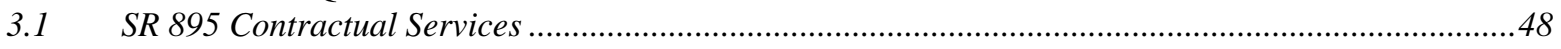

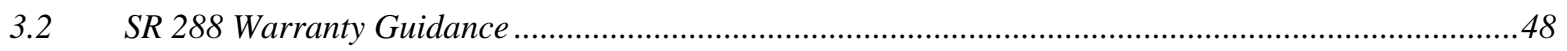

ATTACHMENT V - SMALL BUSINESS SUBCONTRACTING PLAN ....................................................50

ATTACHMENT VI - FREQUENTLY ASKED QUESTIONS AND ANSWERS .......................................55

EXHIBIT B - GENERAL TERMS AND CONDITIONS ........................................................................60 


\section{PURPOSE}

The Virginia Department of Transportation is submitting this Invitation for Bid to solicit sealed proposals from qualified vendors (the "Bidders") to establish a contract through competitive two-step sealed bidding for Turnkey Asset Maintenance Services (TAMS) on the routes described herein.

\begin{tabular}{|c|l|l|l|l|l|l|}
\hline Route & \multicolumn{1}{|c|}{ County } & \multicolumn{1}{|c|}{ Begin } & \multicolumn{1}{c|}{ MP } & \multicolumn{1}{c|}{ MP } & $\begin{array}{c}\text { Length } \\
\text { (Miles) }\end{array}$ \\
\hline I-95 & $\begin{array}{l}\text { City Colonial } \\
\text { Heights \& } \\
\text { Chesterfield County }\end{array}$ & I-85/I-95 Int. & 53.01 & $\begin{array}{l}\text { Hanover/Caroline } \\
\text { Co. Line }\end{array}$ & 101.3 & 48.29 \\
\hline \multirow{2}{*}{ I-295 } & $\begin{array}{l}\text { Chesterfield \& } \\
\text { Henrico }\end{array}$ & X-over N. Rte \# 10 int. & 16.24 & Henrico Co.@ I-64 & 52.62 & 36.38 \\
\hline \multirow{2}{*}{ I-64 } & Goochland & SR \# 288 & 175.06 & Henrico CL & 175.7 & 0.64 \\
\cline { 2 - 7 } & Henrico & Goochland CL & 175.7 & I-95 & 186.82 & 11.76 \\
\cline { 2 - 7 } & Henrico & I-95 E & 191.75 & I-295 & 202.87 & 11.12 \\
\hline \multirow{2}{*}{ SR \# 288 } & Chesterfield & I-95 & 0 & Powhatan CL & 22.62 & 21.83 \\
\cline { 2 - 7 } & Powhatan & Chesterfield CL & 22.62 & Goochland CL & 26.03 & 3.41 \\
\cline { 2 - 7 } & Goochland & Powhatan CL & 26.03 & I-64 & 32.56 & 6.53 \\
\hline I-195 & City Richmond & Sign @Meadow St. OP & 0 & End @ I-64 / I-95 & 4.18 & 4.18 \\
\hline SR\#195 & $\begin{array}{l}\text { City Limits } \\
\text { Richmond }\end{array}$ & Meadow St. OP & 0 & I-95 @ N/S @ JRB & 2.49 & 2.49 \\
\hline \multirow{2}{*}{ SR \# 76 } & Chesterfield & $\begin{array}{l}\text { From 0.69 mi. N Rte. \# } \\
\text { 652 }\end{array}$ & 0 & $\begin{array}{l}\text { To OP I-195 S To } \\
\text { SR. \# 195 }\end{array}$ & 11.44 & 11.44 \\
\hline SR \# 150 & Chesterfield & @ I-95 N/S & 0 & $\begin{array}{l}\text { Henrico Co. @ } \\
\text { River Rd. Int. }\end{array}$ & 11.7 & 11.7 \\
\hline SR \# 146 & City Richmond & $\begin{array}{l}\text { From 0.09 mi. N } \\
\text { Sheppard St. OP }\end{array}$ & 0 & End SR \# 76 tie-in & 0.93 & 0.93 \\
\hline & & \multicolumn{2}{|c|}{ Total Center Line Miles } & & & 170.7 \\
\hline
\end{tabular}

All mileage is approximate.

\section{BACKGROUND}

In an effort to provide the traveling public of the Commonwealth of Virginia a cost effective, high quality, transportation infrastructure, the Virginia Department of Transportation (hereinafter referred to as the "Department") has adopted an innovative highway asset management program whereby the Department will contract with a private entity for the management, and maintenance of certain assets located within the right-of-way for an entire geographical area as described herein

Once the contract is executed, the Department will monitor the Contractor's maintenance management program and conduct evaluations based upon the contract performance specifications. The use of performance specifications, effectively transfers day-to-day managerial and administrative responsibility to the Contractor, with oversight by the Department.

\section{SCOPE OF WORK}

The Contractor will manage and perform all routine maintenance and minor repair activities as described herein, that are associated with roadway, drainage, structures, roadside, vegetation and aesthetics, traffic services, and incident management and snow and ice control.

The scope of this project includes management and performance of routine, ordinary maintenance on components of the transportation facility currently maintained by the Department or the Department Designee within, or associated with; the state road right-of-ways (Scope of Services, Exhibit A) 


\section{TECHNICAL PROPOSAL PREPARATION AND SUBMISSION INSTRUCTIONS}

In order to be considered for selection, Bidders must submit a complete response to this IFB. One (1) marked original and five (5) copies of each technical proposal shall be submitted to VDOT. The Bidder shall make no other distribution of the proposal. Proposals will not be accepted by facsimile transmission or by electronic mail. Any proposals received after the deadline will not be considered. It is the Bidder's responsibility to assure that proposal packages are received by the time and date indicated. Proposals submitted elsewhere, including to other state or federal agencies, will not be accepted. Refer to the first page of this document for the deadline and for the address.

\subsection{Technical Proposal Preparation}

An authorized representative of the Bidder shall sign proposals. All required information must be submitted. Proposals should be prepared simply and economically, providing a straightforward, concise description of capabilities to satisfy the requirements of the IFB. An omission of any of the following requirements from the bidder's technical proposal will cause the bidder to be considered non-responsive, to more easily evaluate proposals, please tab your submittal in the order of the required information:

\section{Qualifications}

a. Organizational Structure, History and Key Personnel

b. Quality Management Plan

c. Routine Maintenance Operations Plan

d. Emergency Operations \& Incident Management

e. Customer Service, Timeliness Requirements \& Tracking Plan

2. Third Party Damages - Accounts Receivable Claims Process and Reporting.

3. Small Business Utilization

4. Complete IFB Copy

Emphasis should be placed on completeness and clarity of content. Each copy of the proposal should be bound or contained in a single volume where practical. All documentation submitted with the proposal should be contained in that single volume. The entire proposal shall be limited to 100 typed sheets (excluding résumés, IFB copy and addendums, if issued) on $8 \frac{1}{2}$ x 11 inch page size (larger pages are allowed for figures or tables, but they must be folded into the overall proposal and used sparingly) with no font smaller than 11 point.

\subsection{Proprietary Information}

All source code, executables, user data, materials, meeting minutes, progress reports and documentation shall be submitted to VDOT and shall belong exclusively to VDOT, and shall be subject to public inspection in accordance with the Virginia Freedom of Information Act. Trade secrets or proprietary information submitted by a Bidder shall not be subject to public disclosure under the Virginia Freedom of Information Act provided the Bidder invokes the protections of Section 2.2-4342F of the Virginia Public Procurement Act, which provides that:

"Trade secrets or proprietary information submitted by a Bidder, or subsequently the Contractor, in connection with a procurement transaction, shall not be subject to public disclosure under the Virginia Freedom of Information Act. However, the Bidder or Contractor must invoke the protection of this Section prior to, or upon submission of the data or other materials. The Contractor must identify the data or other materials to be protected and justify in writing the explicit reasons that such protection is necessary. Failure to mark the data or other materials as proprietary or otherwise classified, will result in the data or other materials being released to Bidders or to the public as provided in the Virginia Freedom of Information Act.” 
The classification of the entire proposal document and total bid price as proprietary or trade secrets is not acceptable.

\subsection{Bidders Understanding of Requirements}

Bidders are responsible to inquire about and clarify any requirement of this IFB that is not understood.

NO ORAL REQUESTS FOR INFORMATION WILL BE ACCEPTED. Questions should reference specific page number and section. All inquiries related to this IFB must be submitted by e-mail to Rachel Turner at Rachel.turner@VDOT.Virginia.gov . Please include this IFB \# in the title of the message in subject line.

The issuing office must receive all written inquiries by December 11, 2006. NO FURTHER WRITTEN INQUIRIES WILL BE ACCEPTED AFTER 4:00 P.M. ON THAT DAY. Any change in this solicitation will be made through an addendum that will be mailed to the list of IFB recipients, posted on eVA and ASD posting website.

\subsection{Cost of Technical Proposals}

The Bidder is responsible for all costs of proposal preparation. The Commonwealth of Virginia is not liable for any costs incurred in response to the IFB.

\subsection{Technical Proposal Requirements}

Proposals should be as thorough and detailed as possible so that VDOT may properly evaluate your capabilities to provide the required services. Bidders are required to submit a copy of the complete IFB within the proposal.

The Bidders technical proposal shall include a detailed description how the contractor will address accomplishing the tasks noted herein

Technical proposal and required submittals submitted by the Bidders shall become an enforceable part of this contract, but should there be a contractual conflict, the IFB as advertised or as amended by the Department shall govern.

\subsubsection{Qualifications}

4.5.1.1 Organizational Structure, History and Key Personnel:

Provide a description of the firm's organizational structure and history. Identify key personnel to be assigned to this project and their relevant experience in the management of transportation asset maintenance services. Describe the firm’s experience with similar asset maintenance contracts.

\subsubsection{Quality Management Plan}

The contractor shall provide a detailed self monitoring plan to ensure all contract performance measures are meet or exceeded including reporting procedures. The plan must include all internal control methods used to insure quality throughout all of the contractor's operations.

The Quality Management Plan shall also define reporting procedures to VDOT to ensure approval of proposed work, services and products. The Contractor shall furnish electronic access to reports produced from the results of the Quality Management monitoring in format acceptable to the Department.

\subsubsection{Routine Maintenance Operations Plan}

The Contractor shall provide a detailed work effort planned to meet the contract performance requirements for all assets and all activities, including snow and ice removal. The contractor's plan shall present the contractor's intended response to the snow \& ice events listed herein, including type and number of equipment, type of proposed chemical applications: 
0 "-4” accumulation including ICE storms

$>4$ "-12" accumulation

$>12$ "- 18" accumulation

$>18$ " accumulation

\subsubsection{Emergency Operations \& Incident Management}

The Contractor shall provide a detailed plan as to how emergency events will be handled. The plan should include the contractor's initial response efforts, and demonstrate the Contractor's understanding of the processes and timeframes used for reimbursement submittals to FEMA, FHWA. The Contractor shall also provide a detailed approach to incident response and incident management.

\subsubsection{Customer Service, Timeliness Requirements \& Tracking Plan}

Describe in detail the system or method that will be employed in order to track, monitor and ensure compliance with all customer service and timeliness requirements of this IFB.

\subsubsection{Third Party Damages}

Accounts Receivable Claims Process and Reporting: Describe in detail the process for handling and executing the recovery of monetary amounts due to $3^{\text {rd }}$ party damages.

\subsubsection{Small Business Subcontracting Plan}

The Commonwealth of Virginia has a commitment to maximizing the participation of its citizens in the vast array of commercial opportunities in state procurement. All state agencies are required to monitor the use of Virginia Department of Minority Business Enterprise (DMBE) certified small business participation in its procurement process. All potential bidders are required to complete Section A, B, or C of the Small Business Subcontracting Plan (Attachment V) to ensure DMBE certified small business participation. Failure to complete Section A, B or C shall result in your bid being declared nonresponsive. A Bidder's response of not applicable, none or N/A in Section C of the Small Business Subcontracting Plan will result in the bid being declared non-responsive if the Bidder is not a DMBEcertified small business and does not plan to subcontract part of the work to a DMBE-certified small business.

If your company is interested in becoming certified through DMBE, confirming certification status of a firm or identifying DMBE certified small businesses, please contact the DMBE certification office at 804786-5560 or by visiting http://www.dmbe.virginia.gov.sn

If the offeror is a DMBE-certified small business, the offeror shall indicate such in Section A of Attachment V, and shall receive $100 \%$ of the points assigned to this evaluation criterion. If the offeror is not a DMBE-certified small business, the offeror is required to identify which portions of the requirement is planned to subcontract to DMBE-certified small businesses by completing and returning Section B of Attachment V. The maximum number of points available if the offeror is not a DMBEcertified small business is $75 \%$ of the points assigned to this evaluation criterion. Failure to meet the planned small business participation levels as documented in Section B of Attachment V, however, will not alone be the basis for determination of non-compliance. If the offeror is not a DMBE-certified small business and cannot practicably subcontract any portion of the requirement being solicited, in order to be eligible to receive points for this evaluation criterion, the offeror must document past efforts made to provide subcontracting opportunities to DMBE-certified small businesses for other contracts within the past 24 months. The documentation may include any good faith efforts made regarding the procurement. This shall be done by the offeror completing and returning Section $\mathrm{C}$ of Attachment $\mathbf{V}$. The maximum number of points an offeror may receive for completing Section $C$ is $50 \%$ of the points assigned to this evaluation criterion. 


\subsubsection{Subcontracting Restrictions}

The Prime Contractor shall perform or exercise responsibility for this contract with its own work force for at least $30 \%$ of the total dollar value of the contract

\section{TECHNICAL EVALUATION CRITERIA}

The Proposal Evaluation Team will review all proposals received by the deadline. Proposals must be complete and responsive to all sections of the IFB. Firms whose technical score is less than 80 will not be considered for project award.

\subsection{Evaluation Criteria}

Factors upon which proposals will be evaluated are as listed:

Qualifications

Organizational Structure, History and Key Personnel

\section{Scoring}

Quality Management Plan

10

Routine Maintenance Operations Plan 20

Emergency Operations \& Incident Management 20

\section{Third Party Damage} Customer Service, Timeliness Requirements \& Tracking Plan 10

\section{Small Business Utilization}

Accounts Receivable Claims Process and Reporting 5

Use of Small Business

\section{GENERAL TERMS AND CONDITIONS}

For a listing of the General Terms and Conditions, please see Exhibit B. If there is a conflict between the General Terms and Conditions and the Special Terms and Conditions, the Special Terms and Conditions shall govern.

\section{SPECIAL TERMS AND CONDITIONS}

If there is a conflict between the General Terms and Conditions and the Special Terms and Conditions, the Special Terms and Conditions shall govern. The following Special Terms and Conditions will apply to this procurement (Exhibit A).

\section{Attachments}

1. Exhibit A: Scope of Services

Attachment I: Bid Sheet

Attachment II: Routine Maintenance Activities

Attachment III: Performance Criteria

Attachment IV: Special Provision Copy Notes

Attachment V: Small Business Subcontracting Plan

Attachment VI: Questions and Answers

2. Exhibit B: General Terms and Conditions 


\section{EXHIBIT A - SCOPE OF SERVICES Virginia Department of Transportation TURNKEY ASSET MAINTENANCE SERVICES}

July 1, 2007 to June 30, 2012 (11:59:59 PM)

\section{OBJECTIVES}

The Contractor shall manage and perform all maintenance activities (as stated within) associated with roadway, drainage, structures, roadside, vegetation and aesthetics, traffic services, incident management, and emergency response.

The scope of this project includes management and performance of routine, ordinary maintenance components of the transportation facility currently maintained by the Department within, or associated with, the state road right-of-ways.

\section{Assets shall include:}

(a) All assets located within and including the limited access fences of the Transportation Facilities, unless otherwise stated within.

(b) All interchanges, crossovers and ramps, collectors to the point at which the right-of-way terminates or as shown by the Department through supplemental description.

(c) All mainline bridge structures within the transportation facilities to the limits of the right-ofway, to include bridge superstructure and substructure. All overhead bridge substructures to the limits of the right-of-way (substructure is defined as from the top of the seat down)

(d) All waterway and intermittent waterways to the right-of-way line including compliance with any permit requirements.

(e) All storm water management and mitigation areas associated with the highway corridor including compliance with any permit requirements.

(f) Highway lighting, including roadway and weigh stations (mainline only), All bridge mounted navigation waterway and anti-collision lighting.

(g) All weigh stations, according to DMV/VDOT Memorandum of Understanding. All weigh station drive troughs and parking areas within the transportation facility right-of-way. To repair and maintain ramps, parking facility, roadways leading up to a weigh station, and turn out lanes and undeveloped rest areas being used by DMV in the operation of a weigh station program as mutually agreed. Maintain roadway lighting (main line). Maintain the condition and location of right-of-way fences located at a weigh station site, turnout lanes and undeveloped rest areas. Provide snow clearing service to vehicular access areas for aprons and bypass lanes of all real property used to operate the truck weigh station program and parking areas upon request on a secondary basis.

(h) All rest area drive through's only (from entrance ramp through the parking area to exit ramp of the rest area). Contractor shall be responsible for snow and ice removal for the entrance and exit ramps only. Contractor shall provide traffic control for all emergency closures for all rest areas under this contract.

\section{Assets shall exclude unless otherwise noted herein:}


(a) Frontage roads

(b) Superstructures of overhead bridge structures over the transportation facility

(c) Environmental Sensor Stations (ESS) to include Roadway Weather Information Stations (RWIS), Fog Detection, Closed Circuit Televisions, Traffic Counters, Highway Advisory Radio (HAR) and Changeable Message Signs (CMS) and associated electronics, power and communication infrastructure.

(d) Weigh Stations and weigh in motion stations (Buildings and supporting ancillary assets)

(e) All rest areas (except as identified above)

(f) Tunnels (unless otherwise noted herein)

\title{
II. REQUIREMENTS
}

\section{Standards and Specifications}

It is the intent of the Department for all work to be performed to current Standards and Specifications throughout the contract duration, as may be updated throughout the life of the contract. The Contractor shall manage all assets within the project limits and shall perform work that produces end results in accordance with all Department Specifications as noted in the following Manuals, Standards and Procedures. The Contractor shall comply with all current versions as updated throughout the life of the contract. It shall be the contractor's responsibility to be aware of these updates.

\section{CONSTRUCTION DIVISION}

* Construction Manual

* Road and Bridge Specifications, and Special Provisions and Copied Notes (As updated)

\section{CIVIL RIGHTS DIVISION}

* DBE Directory (Published Monthly)

\section{ENVIRONMENTAL DIVISION}

* Environmental Permit Manual

* Environmental Document Handbook

\section{LOCATION AND DESIGN DIVISION \\ * Drainage Manual \\ * Instructional and Informational Memoranda \\ * Public Involvement Policy and Procedures Manual \\ * Road Design Manual, Volumes I and II \\ * Road and Bridge Standards - Volumes I and II \\ * VDOT Erosion and Sediment Control and Stormwater Management Program Manual}

\author{
ASSET MANAGEMENT DIVISION \\ * Maintenance Policy Manual \\ * Culvert Repair Practices Manual, Volumes I and II (FHWA) \\ * Bridge Maintenance Training Manual (FHWA) \\ * Maintenance Rating Program Manual (MRP) \\ * Asset Management “Best Practices” Manual \\ * VDOT Tree Trimming Policy \\ * VDOT Asset Management Performance Based Tree Trimming Specification \\ * AASHTO Maintenance Manual
}




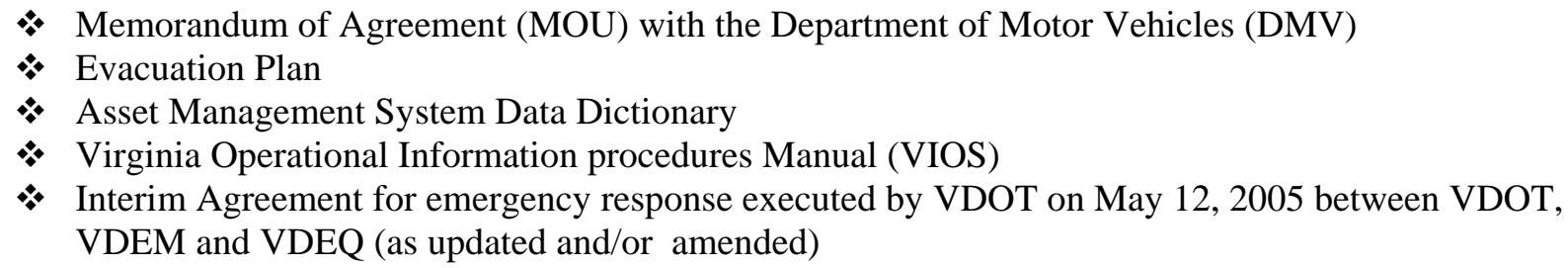

\section{LOCAL ASSISTANCE DIVISION}

* Land Use Permit Manual (Current Edition)

\section{MATERIALS DIVISION}

* Material Manual of Instructions

\section{RIGHT OF WAY DIVISION}

* Right of Way Manual of Instructions - Volumes I and II

\section{STRUCTURE AND BRIDGE DIVISION \\ * AASHTO Standard Specifications for Highway Bridges \\ * Virginia Modifications to the AASHTO Standard Specifications for Highway Bridges \\ * Road and Bridge Standards (Volumes I and II) \\ * Condition Evaluation of Bridges \\ * Structure and Bridge Instructional and Information Memos \\ * AASHTO Standard Specifications for Structural Support for Highway Signs, Luminaries and Traffic Signals}

\section{TRAFFIC ENGINEERING DIVISION}

* Virginia Work Area Protection Manual

* Manual on Uniform Traffic Control Devices

* Traffic Engineering Division Memoranda

\section{MAINTENANCE}

The Contractor shall manage the routine ordinary maintenance and perform minor repair activities as necessary on all assets within the project limits. These maintenance and repair activities will be performed at a frequency that ensures uniform and consistent compliance with the performance measures and requirements specified herein.

\section{Definition}

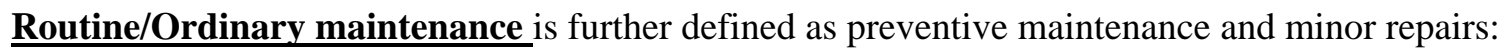

Preventive Maintenance: Any planned activity performed in advance of a need for repair or in advance of accumulated deterioration, so as to avoid such occurrences and reduce or arrest the rate of future deterioration. The activities may correct minor defects as a secondary benefit. Preventive maintenance is: 1) planned, 2) cyclical, 3) not conditioned-based, and 4) for pavements only, does not add structural capacity to the pavement structure.

Minor Maintenance Repair and Replacement: The restoration of an asset, including all its appurtenances, to its original condition (or as subsequently improved) insofar as practical. Minor repairs include any activity intended to correct the effects of minor material deterioration by restoring the damaged component. Minor repairs are generally defined as repairs to assets that are structurally sound (i.e., no loss of strength, functionality), but may have minor section loss, cracking, etc. The contractor shall be responsible for replacement of assets that are damaged due to incident, accidents and or inclement weather. 
The installation and maintenance of TODS, Supplemental, and LOGO and General Motorist Service signs are the responsibility of others. Regulatory, Warning, Informational and Facility (airport, railroad, commuter parking, rest area, welcome center) signs on the interstate mainline will be the responsibility of the Contractor. The Contractor shall maintain any flashing signs that are not covered by a maintenance agreement with a city or county. Typical routine and ordinary maintenance activities are listed in Attachment II. The List of activities presented in Attachment II is not intended to be all inclusive as other activities may be needed in order to meet the specified performance criteria.

\section{Management and Administration}

The Contractor shall have designated and appropriate staff throughout the life of the contract. The Contractor shall submit a management plan to include staffing levels and an organizational chart depicting responsibilities. The staff shall have the authority and responsibilities set forth in the contract. The Contractor shall ensure that any employee replacement meets or exceeds the qualifications set forth in the Contractor's Management Plans.

\section{Quality Management Reporting}

The Contractor shall submit a Quality Management Plan as a part of the Technical proposal. The Quality Management Plan shall describe in detail how the Contractor shall monitor its own performance to ensure that all of the requirements of this contract including the Performance Criteria and Outcomes are to be achieved.

The Quality Management Plan shall also define reporting procedures to VDOT to ensure approval of proposed work, services and products. The Contractor shall furnish electronic access to reports produced from the results of the Quality Management monitoring in format acceptable to the Department.

\section{$4 \quad$ Inspection and Maintenance of Structural Elements}

VDOT will perform Bridge, Culvert, roadside Sign Structure, Overhead Sign, and High Mast Light Pole Inspection in accordance with Department Standards and Specifications. VDOT will also perform structural analyses when, as a result of routine or incident inspection, significant section loss is observed due to deterioration or damage. The Contractor shall perform routine maintenance minor repair and replacement on such assets including collision damage repair, on the state right-of-way. The Contractor is not responsible for total replacement of Bridge and Overhead Sign Structures that are damaged due to collision. The Department reserves the right to request that the Contractor perform such replacement activities of Bridge and Overhead Sign Structures; however such activities will be handled under the change/task order provision of this contract.

\section{$5 \quad$ Work Plans \& Reporting}

All Plans and Reports have to be in a form and substance satisfactory to the Department. The Contractor shall consult and coordinate with appropriate Department staff, as necessary in preparing all plans and reports as well as to establish submittal dates if those dates and times are not specified herein.

\subsection{Annual Work Plan}

Not later than 30 Days prior to the Start Date, the Contractor shall deliver to the Department an Annual Work Plan, in form and substance satisfactory to the Department, covering the initial 12 months of the contract. The Work Plan shall describe the initial and proposed work efforts and manner in which the Contractor shall achieve the work. Work activities shall at a minimum be reported by asset, county and by district. The Contractor shall develop an associated budget to ensure the desired maintenance outcome is allocated and performed. The budget shall be incorporated as part of the work plan submission(s).

The Contractor shall manage the maintenance program including the performance of work needs determinations, location of resources, work assignments and management of resources. A revised 
Work Plan and associated budget shall be presented to the Department no later than the June $1^{\text {st }}$, each year for the duration of the contract.

\subsection{Weekly Work Plan}

The Contractor shall produce a Weekly Work Plan to the designated Smart Traffic Center and VDOT Project Manager. The Weekly Work Plan shall include the asset, activity, and the location of where work is to be performed, time of work operation, as well as indicate the use of any lane closures including the type of lane closure.

\subsection{Traffic Control Plan}

The contractor shall submit 30 days prior to the start of the contract a Traffic Control Plan, which shall outline in-depth the methods the Contractor intends to use for traffic control while carrying out all general asset maintenance services. Prior to commencing any specific activity, that is not covered in the Traffic Control Plan, which will require restriction or diversion of traffic, including lane closures and detours, the Contractor shall prepare, and furnish to the Department for review and approval a site specific traffic control plan for all affected portions of the Transportation Facilities

\subsection{Incident and Emergency Response Plan}

The Contractor shall develop and submit no later than 30 days prior to the start of the contract an Incident and Emergency Response Plan. The plan shall include a detailed account of public/agency notifications, incident management, how the safety of motorists will be ensured, handling of hazardous waste, coordination with the Department, the State Police and other emergency personnel with respect to emergency incidents and occurrences including vehicle accidents, hazardous materials spills or releases, and adverse weather conditions including rain, snow, ice, flooding and fog, .submission of "Incident" reports, the establishment and maintenance of detour routes when needed for closure of the interstate and primary roads, emergency repairs, removal of debris and evacuation response.

\subsection{Snow and Ice Control Plan}

Not later than June 1 of each Fiscal Year, the Contractor shall furnish to Department its Snow and Ice Control Plan for the following Fiscal Year, which starts on July 1. Contractor shall demonstrate to the reasonable satisfaction of the Department that it has sufficient resources under contract (including equipment, materials, supplies and personnel) to fully perform Snow and Ice Control on all segments of the contracted Transportation Facilities, covered under this agreement, for the following Fiscal Year.

\subsection{Public Information Plan}

Within 30 Days prior to the contract start, the Department and the Contractor shall jointly develop and implement a Public Information Plan. The Public Information Plan shall prescribe roles, responsibilities and procedures regarding public communications, including the dissemination of information regarding the Contractor's contracting approach, providing information to the Virginia Operations Information System, and the issuance of activity update bulletins.

\subsection{Monthly Reporting}

No later than the $15^{\text {th }}$ calendar day after the start of each month, the Contractor shall deliver to the Department a Monthly Report covering the prior month's activities and accomplishments, including response to incidents, routine maintenance activities, asset replacements, compliance with timeliness requirements of the contract. All of this information shall be delivered in an electronic format. 
The Monthly Report shall describe all completed work for each specific asset type, reported by location, county and by district. The information shall also include UOM, mile marker, direction, GPS, length, size, type condition. The Contractor shall also provide a rolling monthly budget and expenditure report against each asset type to include activity. Expenditures shall include in-house and contract services.

The Contractor is required to report monthly, through the Department's Civil Rights Division actual payments, retainage, minority status, and the work type of all subcontractors and suppliers. Information necessary for reporting DBE utilization and SWAM's may be obtained from the Department's Civil Rights Office. The Contractor shall maintain records and documents of payments to SWAM and DBE's for three years following close out of the of the contract records

\subsection{Third Party Damage Reports}

The Contractor shall submit a summary of $3^{\text {rd }}$ party damage repairs, the present stage in the Contractor defined process, and the amount billed and collected. The Contract shall provide the initial report within 60 days of the start of the contract and update the report every month thereafter throughout the life of the agreement.

\section{Snow and Ice Control}

(a) If the Contractor fails to present a plan satisfactory to Department demonstrating that it has resources to undertake Snow and Ice Control by July 1 of each Fiscal Year, the Department, at its sole and absolute discretion, may terminate the Contractor's right to perform Snow and Ice Control for such Fiscal Year and take the actions set forth below, or declare the Contractor to be in Default of the entire Contract.

(1) In the event that the Department terminates the Contractor's right to conduct Snow and Ice Control in any Fiscal Year, the Department may do the following:

i. Perform or cause to be performed such work, spend such sums as the Department deems necessary and reasonable to employ and pay employees of the Department or contractors and obtain necessary materials and equipment as may be required for the purpose of undertaking such work, and take any and all other actions which it may in its sole and absolute discretion consider necessary to complete the work, including redeployment of other resources of the Department.

ii. Require the Contractor to reimburse the Department upon presentation of the Department's invoice for all costs and expenses it reasonably incurs in connection with the performance of any authorized action, including but not limited to all fees paid by Department to any person the Department retains to perform Snow and Ice Control, including but not limited to the reasonably allocated wages, salaries, compensation and allocated overhead of the Department staff and its employees performing any work on behalf of the Department for Snow and Ice Control, and interest on all the foregoing sums not paid within 30 days from the date of the invoice at the judgment rate permitted by law.

(b) If the Contractor fails to perform in accordance with the outcomes and performance measures set forth, the following will apply:

(1) During the Snow \& Ice Event

i. In the event any/all pavement travel lanes are not kept open for use during an event, a Road User Costs of \$ 4,700.00 per lane/hour will be applied and deducted from the payment to the Contractor, until opened and safe to travel.

(2) After the Cessation of precipitation 
i. In the event the Contractor fails to meet the established deadlines as required in the Outcomes and Performance Targets Attachment III, Liquidated Damages of $\$ 1,500.00$ per $1 / 2$ hour will be assessed until met.

(c) During inclement weather, the Contractor shall enter current roadway condition information into VDOT's VOIS system, updating information as necessary.

\section{Operations, Safety Management and Traffic Control}

(a) The Contractor shall perform all work in accordance with the Virginia Work Area Protection Manual (current edition and any subsequent revision or updates throughout the term of the contract) and shall comply with District lane closure restrictions/requirements as updated. Lane closures for planned work shall be performed at night, unless otherwise authorized by the Department.

(b) The Contractor shall notify the designated Smart Traffic Center (STC) $1 \frac{1}{2}$ hour before a planned lane closure is installed and notify the designated STC within $1 / 2$ hour after the planned lane closure is removed. If the Contractor is found to have installed a lane closure without notifying the designated STC, VDOT may require the Contractor (including Contractor's sub-contractors) to immediately remove the lane closure and may require the Contractor to refrain from installing all planned lane closures until such time as the Contractor can demonstrate to VDOT that the Contractor (and the Contractor's subcontractors), can fully comply with the requirements of lane closure notifications of this contract.

(c) The Contractor shall be responsible for providing a safe travel way for the public during the performance of all work under control of the Contractor, its Agents or employees or subcontractors. Whenever the Contractor's operations require, the Contractor shall cause to be furnished, erected and maintained such fences, temporary railing, barricades, lights, signs and other devices and take such other protective measures as are necessary to prevent accidents, damage or injury to the public, and as required by the Traffic Control Plan and the Manuals, Standards and Procedures.

(d) The Contractor shall perform its Asset Maintenance Services in a manner that keeps the Transportation Facilities fully open to the public 24 hours per day, every day, subject only to closures permitted by the District Limits of Operations, Traffic Control Plan, emergency closures and detours due to Force Majeure. The Contractor shall also comply with VDOT Holiday and Event Traffic Restrictions.

(e) In the event that the Contractor or it's subcontractors is found to have installed traffic control measures/ work zones that do not meet the requirements of the Virginia Work Area Protection Manual, and/or the District lane closure restrictions/requirements or such measures have not been properly maintained, an assessment of $\$ 500.00$ per occurrence will be deducted from the Contractor's monthly invoice.

(f) If the contractor is found to have installed traffic control measures/ work zones that are deemed to be an immediate threat to life or property, VDOT may require the contractor (including the Contractor's sub-contractors) to immediately remove lane closures and refrain from installing all planned lane closures until such time that the Contractor can demonstrate to VDOT that the Contractor (and the Contractor's sub-contractors) can fully comply with all requirements.

\section{Incident and Emergency Response}

(a) The Contractor shall respond 24 hours per day, 7 days per week, including holidays, to any emergency occurring on the roadway. The Contractor shall arrive on-site, prepared to take 
appropriate action with necessary manpower, materials and equipment within a maximum time of 30 minutes during work hours and 60 minutes after work hours from initial notification of the incident.

(b) The Contractor shall be responsible for all aspects of traffic control related to an incident, including, but not limited to, the entire detour route off the corridor(s) covered by this contract onto other state roads or non-state roads.

(c) The Contractor shall cooperate with the Department and may be required to furnish its forces (to include subcontractors) to supplement the Department in Hurricane Preparedness, Evacuation Plans and Execution of the Plans, for the duration of the event

(d) The Contractor shall immediately notify the Department's designated Smart Traffic Center (STC) and the VDOT Project Manager or designee, of all roadway closures and re-openings, or major incidents upon occurrence. The Contractor shall enter the event into the Department's VOIS system, unless otherwise instructed. A summary of incident responses, by the Contractor, shall be submitted to the Department with the monthly invoice. VDOT may require weekly meetings after roadway closures and responses to identify deficiencies and correct them. These meetings may include, but are not limited to State Police, County or City Police, Fire and Rescue Division Heads, Contract Project Manager and the Contractor and Sub-contractors of the Contractor that are involved.

(e) The Contractor shall have incident response procedures in place to ensure proper response timeliness and ensure proper coordination of the handling of hazardous (or potentially hazardous) materials abandoned within the right-of way in accordance with the terms outlined in the VDOT, VDEQ, VDEM interim agreement for emergency response (executed by VDOT May 12, 2005) and any subsequent agreements that substantially reflect the terms outline in the interim agreement. The Contractor shall comply with all Local, State, and Federal Laws, Department policy and agreements dealing with incident, evacuation, handling and disposal of hazardous (or potentially hazardous) materials. The contractor will communicate with hazardous materials mitigation contractors to protect VDOT interest. The contractor will reestablish damaged areas not affected by the hazardous materials clean-up operations.

(f) If the Contractor does not arrive on-site, prepared to take necessary action within the specified time periods from initial notification of an incident, $\$ 1,000.00$ per hour or portion thereof, per incident, will be deducted from the Contractor's monthly payment. If VDOT must respond, due to Contractor unresponsiveness, the Contractor shall be responsible for all cost incurred by VDOT and such costs will be deduced from the Contractor's monthly payment.

\section{Waste Disposal; Use of Hazardous Materials}

(a) The Contractor shall dispose of, or cause the disposal of, all waste, residue, debris, materials and supplies (including paints, herbicides and chemicals), grass and foliage clippings, dead animals and all other waste materials produced or generated by the Contractor under this contract and in accordance with all applicable Federal, State and Local Laws, Regulations and Ordinances.

(b) The Contractor shall use, contain, store and dispose of all Hazardous Materials employed in connection with this contract in accordance with all applicable Federal, State and Local Laws, Regulations and Ordinances.

(c) Except for releases as stated in this agreement the Contractor's responsibility for clean up, containment, removal, transportation, storage or disposal of any such Hazardous Materials shall be limited to its responsibilities set forth in the Emergency Response Plan and to providing and 
removing sand used to soak up fuel spills upon request of any Person duly authorized to conduct clean up activities.

\section{Customer Service}

The Contractor shall maintain a customer service log, which shall detail complaints or requests, and the disposition of the items contained in the log. The customer service log shall be made available to the Department for review on the first day of each month and or upon request. The Contractor shall contact the customer within forty-eight (48) hours and have resolution of the customer service request within two (2) weeks. In some cases, VDOT may direct the Contractor to respond immediately due to the urgency or in the best interest of the Department. The Contractor shall develop and implement a Customer Service Resolution Plan. A Copy to be provided to the Department before July $1^{\text {st }}$ of each year.

\section{Public Information}

All information regarding this contract and the Asset Maintenance Services shall be disseminated through the Department. The Contractor shall not issue press releases or otherwise communicate directly with the media (except as otherwise provided in the Public Information Plan) without the Department's approval.

\section{PERFORMANCE REQUIREMENTS}

Contractor performance will be measured by achievement of Outcomes and Performance Targets as specified in Attachment III of this document. These outcomes include both Asset Outcomes and Timeliness Requirements. The Contractor's Performance will be assessed for each route separately. Timeliness performance measurement will be independent of annual Maintenance Rating Program evaluations.

Failure to meet any of the performance requirements as described herein may result in deductions from the Contractor's payment. The Department reserves the right not to assess any monetary deduction or withholding if in the Departments opinion the circumstances surrounding the assessment warrant that no monetary deduction is made. The waiver of any deduction shall not impair the Departments right to assess any future monetary deductions or withholdings.

\section{Timeliness Requirements}

(a) Instances where a timeliness of response has been mandated as part of this contract will result in the timeliness of response being measured. Recording of the measurement shall be the responsibility of the Contractor. Timeliness Requirement Criteria not met will result in deductions from the Contractors monthly payment as set forth herein.

(b) Validation of the measurement of Timeliness requirements will be the responsibility of VDOT or an agency designee. The Department reserves the right to measure timeliness performance in accordance with the tolerances and criteria at any time. The Contractor is required to submit a timeliness report as part of the monthly reporting requirements.

(c) The Department or designee shall continue to have the right to inspect any and all timeliness records at any time. Falsification of timeliness compliance may cause the contractor to be found in default of this contract.

(d) Quarterly Timeliness Review for overall compliance. The monthly timeliness reports will be compiled and analyzed quarterly to determine the Contractor's overall compliance with timeliness requirements. The Contractor is required to achieve $100 \%$ compliance on Timelines requirements; however for the purpose of this review a quarterly compliance rating of $<90 \%$ is consider poor performance. Continued poor timeliness performance is defined as more than 2 
consecutive quarterly evaluations, or more than 3 total quarterly evaluations less than $90 \%$ compliance within any 2-year period is cause for the Department to declare the Contractor in default of the contract

\section{Maintenance Rating Program}

(a.) The Contractor shall achieve and maintain a Maintenance Rating Program (MRP) rating of $90 \%$ or above for all assets for each route unless otherwise noted. The Contractor shall use the criteria established in Attachment III to establish the level of maintenance attained to ensure a uniform consistent level of Maintenance at all times. All Asset Groups (roadway \& shoulder, roadside, traffic services, drainage, and bridge) shall have a minimum rating of $90 \%$ unless otherwise noted herein. Each Route Covered under this agreement will be treated as a separate entity for MRP compliance

(b.) VDOT or an agency designee will annually conduct at least 1 training session every year for all raters before the inspections in the field take place. For its own purposes and in the best interest of the Department, VDOT reserves the exclusive right to examine and analyze any specific asset component independent of routine MRP evaluations.

(c.) Performance evaluations will be conducted on an annual basis, beginning approximately one (1) year after the start of this contract. A Third Party (VDOT Designee) will perform the MRP evaluation and provide the data and summary of its findings to VDOT.

(d.) The Department may declare the contractor in default of this agreement if continued poor performance as defined as 2 consecutive evaluations, or more than 3 total evaluations throughout the life of this contract of an overall rating of less than $90 \%$.

\subsection{Withholding for MRP Nonperformance}

(a) Beginning with the first year's MRP evaluation, the Department will assess a nonperformance withholding equal to one percent (1\%) of the annual contract value for each point below an maintenance rating of 90 for each Asset Group (roadway \& shoulders, roadside, traffic services, drainage, and bridge). The Department will assess an additional nonperformance withholding equal to one half of one percent (.50\%) of the cumulative amount for each point below 80 on any Asset item.

(b) The Total Nonperformance withholding amount will be deducted from the Contractor's monthly invoices over a six (6) month period. The Department will continue to hold the nonperformance withholding until the Third Party completes the next annual evaluation and the results have been compiled. The new MRP results will be compared to the previous year's results for compliance. Where the new assessment indicates that the Contractor has achieved the contract requirements then the corresponding nonperformance withholding will be paid to the Contractor. Where the new assessment indicates that he contractor has not achieved the contract requirements the nonperformance withholding will be permanently deducted from the contractor.

(c) The new MRP Nonperformance withholding will be calculated by the process as described above and shall continue for the life of the contract.

\section{THIRD PARTY CLAIMS}

The Contractor shall promptly notify Department of damage caused by third parties to real or personal property included in the Transportation Facilities. When an event occurs, causing damage to any of the Department's facilities that falls within the Contractors responsibility, the Department authorizes the Contractor to pursue claims against any responsible party for reimbursement of actual expenses incurred in making such repairs. The Contactor shall cooperate with Department in providing all necessary 
information to the Department with respect to the cost of such repairs, regardless of whether any separate or additional compensation is owed to the Contractor in connection with undertaking any such repair. The Contractor shall submit a summary of $3^{\text {rd }}$ party damage repairs, the present stage in the Contractor defined process, and the amount billed and collected. The Contract shall provide the initial report within 60 days of the start of the contract and update the report every month thereafter throughout the life of the agreement.

\section{DAMAGE REIMBURSEMENT}

(a) Advance preparation, response, inspection, engineering services, repairs, and replacement, required as a result of natural disaster, catastrophic or emergency response event will be considered part of the contract responsibilities and the Contractor will not receive any additional compensation from the Department, other than qualifying FEMA or FHWA funds the Department receives as a result of the Contractor seeking qualifying FEMA or FHWA reimbursement. The Department authorizes the Contractor to pursue claims of any emergency reimbursement in response to the disaster. It is the Contractor's responsibility to provide all information needed to pursue such claims in a timely manner.

(b) For all FEMA or FHWA qualifying reimbursements, it is the Contractor's responsibility to generate and keep the necessary documentation for the qualifying reimbursement. The Department will assist in this reimbursement process by processing and forwarding to FEMA or the FHWA all necessary documentation paperwork as provided by the Contractor

(c) The sequence of reimbursement for damages will be as follows:

1. Pursuit of claims against the individual or entity which caused damages, or their insurers

2. If eligible, compensation from FEMA or FHWA for qualifying reimbursements

\section{Contractor's own insurance coverage}

(d) In the event the Department chooses to take responsibility for system restoration, the amount of reimbursements obtained in items 1 and 2 above will be retained by the Department.

(e) In the event of an act that is officially declared by the Commonwealth of Virginia or appropriate Federal Entity as an "act of terrorism" the Contractor will not be liable for damage beyond the extent of the amounts obtained in items 1 and 2 above.

(f) The Contractor's responsibility to make damage repairs at its own expense, in each 12 month period beginning with the date of the original contract, shall be limited to $20 \%$ of the annual contract amount for that year. Such $20 \%$ of the annual contract amount cap shall be in addition to any amounts reasonably obtainable under items 1, 2 and 3 above, and any damage repairs caused by the Contractor's negligence. Failure to provide timely and detailed information for the pursuit of eligible compensation from FEMA or FHWA shall result in the Contractor bearing all cost for the damage repairs at its own expense and will not apply toward the annual Cap. The Contractor shall diligently pursue all such claims and company insurance coverage before making any such claim for reimbursement from the Department. The annual contract amount as used above means each 12-month period beginning with the date of the original contract and each annual anniversary date thereafter.

\section{CHANGE ORDERS}

(a) A written instruction signed by the Department requiring changes in the Asset Maintenance Services is called a Change Order. A Change Order may be initiated only by the Department, either issued unilaterally or based on the Contractor's response to a Request for Quotation. 
Upon the Department's approval of the matters set forth in the Change Order form, the Department shall sign such Change Order form indicating approval by the Department. Each Change Order shall contain the terms and amount of any adjustment to the Asset Maintenance Fee, or the Outcomes and Performance Targets or, an additional Single Payment or, at Department's sole discretion, may direct the Contractor to proceed with the work under a unilateral or directed change order with the amount of any such adjustment to be determined in the future.

(b) Before starting to work on any item for which a Change Order is necessary, the Contractor shall have received a Change Order for such work signed by the Department. In the absence of such Change Order, the Contractor shall not be required to perform the extra work or be entitled to payment for such extra work.

(c) In accordance with the procedures set forth herein, the Department may, at any time and from time to time, without notice to any surety or guarantor, authorize and/or require changes in the Asset Maintenance Services within the general scope of this Agreement, including without limitation:

(1) changing the Outcomes and Performance Targets

(2) changing the type or location of Assets included under this Agreement

(3) adding additional segments of a highway system to the contracted Transportation Facilities

(4) temporarily or permanently removing or adding segments of highways (or certain Assets within such segments) from the contracted Transportation Facilities

(5) Requiring work within the scope of Asset Maintenance Services to be performed on other highways during emergencies or otherwise determined.

(d) If the Department desires to initiate a change in the Asset Maintenance Services (including changes in any Assets, or Outcomes and Performance Targets set forth in Attachment III, or to evaluate whether to initiate a change, the Department may at its discretion issue a Request for Quotation. Within seven (7) days after the Contractor's receipt of a Request for Quotation, Department and the Contractor shall consult (at no charge to the Department) concerning the estimated cost and time impacts. At the Department's request, the Contractor shall provide to the Department up to three (3) options for modifying the Asset Maintenance Services so that the total Asset Maintenance Fee will not be increased as a result of the Change Order under consideration including data related to the value of any change in the Outcomes and Performance Targets. In the event of a Change order request regarding the removal of any Asset, roadway segment or any reduction is the contractor's liability, exposure and or responsibility, the Contractor's Asset Maintenance fee shall be reduced accordingly.

(e) In the event that damage occurs to an Asset not maintained by the Contractor, but within the project limits of the Contract, the Department may request that the Contractor assess the damage, and submit an estimate for the repair of the damage (Request for Quotation). The Department will review the estimate, and make a determination whether or not it is advantageous to have the Contractor repair the damage under a Change Order.

\section{DISPUTE RESOLUTION \& CLAIMS}

\section{DISPUTE RESOLUTION}


(a) All dispute and claim submittals shall be presented in accordance with Section 105.16 of the VDOT Road and Bridge Specifications, and will be resolved in accordance with conditions contained in this document. Any dispute, which may arise between the Department and the Contractor, shall be mutually resolved through best efforts and good faith negotiations between the authorized representatives of the Department and the Contractor.

(b) In conducting such negotiations, the Department and the Contractor recognize that in drafting this Agreement, it is impracticable to make provisions for every contingency that may arise during its term. Accordingly, in order to achieve the resolution of any dispute concerning matters for which the Agreement provides no clear guidance, the Department and the Contractor concur in the principle that this Agreement is intended to operate between them in fairness.

(c) If, despite best efforts and good faith negotiations and the application of the principle of fairness in the disputes/claims process set forth above, and the dispute is not resolved to the mutual satisfaction of both parties within Thirty (30) days after written notification by one party to the other of a dispute arising that remains unresolved, (or such longer time as is mutually agreed), then such dispute shall be submitted administratively as set forth herein.

(i) Dispute submittal is to the District Administrator/Residency Administrator through the Contract Administrator (30 day resolution)

(ii)If the Contractor is not satisfied by the resolution in (i) he may request a review and recommendation by the Asset Management Division. The Asset Management Division will respond within 30-days of receipt of dispute resolution request.

If, after all good faith efforts, a mutual agreement can not be obtained by the Contractor and the Contract Administrator (up to the District level), the dispute may become a formal claim, and shall be handled as set forth in Claims section of this contract.

\section{CLAIMS}

(a) At the end of any Fiscal Year, the Contractor may within 60 Days, submit to the Asset Management Division (AMD) a written claim (an original and three legible copies) for any unresolved disputes, for the amount it deems it is entitled to under the Agreement.

i. The claim shall set forth the facts upon which the claim is based. The Contractor shall include all pertinent data and correspondence that may substantiate the claim, including any and all information submitted under the dispute resolution process for the claim.

ii. Within 30 Days from the receipt of the claim, the AMD will make an investigation and notify the Contractor by registered mail of its decision. However, by mutual agreement, the Department and the Contractor may extend the 30-day period for another 30 Days.

iii. If the Contractor is dissatisfied with the decision, they shall notify the Commissioner in writing, within 30 Days from the receipt of the Departments decision, that it desires to appear before him, whether in person or through counsel, to present additional facts and arguments in support of this claim.

(b) The Commissioner will schedule and meet with the Contractor within 30 Days after receiving the request. However, the Commissioner and the Contractor, by mutual agreement, may schedule the meeting to be held after 30 Days but before the 60th day from the receipt of the Contractor's written request. Within 45 Days from the date of the meeting, the Commissioner will investigate the claim, including the additional facts presented, and notify the Contractor in writing of his decision. However, the Commissioner and the Contractor, by mutual agreement, may extend the 45-day period for another 30 Days. If the Commissioner deems that all or any portion of a claim is valid, he shall have the authority to negotiate a settlement with the Contractor subject to the provision of Section 2.1.127 of the Code of Virginia 1950 as amended. 
* Any moneys that become payable as the result of claim settlement after final payment for that contract year will not be subject to payment of interest unless such payment is specified as a condition of the claim settlement. If the Contractor is dissatisfied with the decision of the Commissioner may institute a civil action as to such portion of the claim as is denied by the Commissioner pursuant to Section 33.1-387 of the Code of Virginia

\section{SPECIAL TERMS AND CONDITIONS}

\section{Award}

The Department intends to recommend award to the lowest responsive and responsible bidder to the Commonwealth Transportation Board. The State reserves the right to reject any and all bids in whole or in part, to waive any informality, or to delete items prior to making an award. The lowest responsible, responsible bidder shall submit to VDOT detailed bid documents as a prerequisite to the award recommendation. The Bidder is referred to Section 4.2 Proprietary Information for protection of Trade Secrets and Proprietary information.

\section{Compensation}

(a) The Contract award will be made per a lump sum.

(b) The Contractor will be compensated according to the bid price of the Contractors Bid sheet (Attachment I). The Contractor will invoice the Department monthly. The Contractor will include with the monthly invoice a breakdown of all work completed within the limits of the facility, by the appropriate activity designation as determined by the Department. Penalties, assessments, Liquidated Damages and Road User Costs fees will be deducted from the monthly invoice total as determined herein.

(c) The Contractor and agents are required to pay all tolls, permit fees and taxes as applicable by law. The Department will pay all highway lighting electric bills.

(d) The Department will consider claims for additional compensation on an annual basis when compliance with a VDOT initiated change to any components of this contract causes a substantial documented economic impact on the Contractor exceeding five (5\%) percent of the annual contract amount. The five percent (5\%) is not cumulative year to year. The Contractor will not receive any additional compensation for maintenance of projects currently scheduled in the Department's Work Program at the time of the proposal due date.

\section{Concurrent Contracting}

The Department may award separate contracts for services that are not covered under this agreement (e.g. bridge and pavement rehabilitation projects). When separate contracts are awarded within the limits of this project, the contractor shall not hinder the work being performed by other contractors. The Contractor is encouraged to make all reasonable efforts to coordinate asset maintenance services with other contract services that are being provided along the roadway to limit the impact of traffic disruptions. Unless otherwise stated, the contractor shall continue to be responsible for all asset maintenance services that are covered in this agreement.

\section{$4 \quad$ Materials}

(a) The Department will not provide materials used for routine/ordinary maintenance. It is the Contractor's sole responsibility to furnish, supply, install, maintain, and manage all materials in accordance with governing VDOT Standards and Specifications. 
(b) Upon receipt of a written request from the Contractor, the Department may, in its sole discretion, make available for purchase by the Contractor certain materials and supplies (including salt, sand and signs) for use in carrying out contractual mandates. Such materials and supplies shall be sold to the Contractor at such price or prices and on such terms as shall be mutually agreeable.

(c) Except as stated in the preceding paragraph, the Department shall have no obligation to sell or otherwise furnish any items to the Contractor. Similarly, the Contractor shall have no obligation to purchase or otherwise acquire from the Department, any materials, supplies or equipment required to carry out the contract.

\section{Department Oversight, Inspection and Evaluation.}

(a) The Department shall at all times retain the right to oversee, inspect and test all materials and each detail of the work performed under this Agreement and to determine the Contractor's compliance with the terms hereof, including without limitation the requirements and specifications set forth in the Manuals, Standards and Procedures.

(b) The Contractor shall remedy or re-perform at its expense and within the time periods specified in subsection-(c) below, work that does not conform to the requirements of this Agreement so that it meets the requirements of this Agreement and shall promptly take all action necessary to prevent similar deficiencies from occurring in the future. The fact that the Department may not have discovered the nonconforming work shall not constitute an acceptance of such nonconforming work.

(c) The Contractor shall cure any such (or commence meaningful steps to cure the deficiency, if curing the deficiency cannot reasonably be completed within ten days) any nonconforming work within ten days of receipt of written notice from the Department requesting correction or immediately upon written or oral notice if needed to remove an immediate or present threat to the safety of persons or property unless the nonconforming work cannot be reasonably cured within such period. In such event, the Contractor shall commence meaningful steps to cure such nonconforming work within such period and shall diligently prosecute such cure to completion as soon thereafter as is practicable.

(d) If the Contractor fails to cure any such non-performing work (or timeliness issues) as required by subsection (c) above, in addition to any other remedies it may have under this Agreement, the Department may cause the nonconforming work (or lack of response by the Contractor) to be remedied or removed and replaced; or perform any work that may be needed to met the performance requirements of this contract and may deduct the cost of doing so from any moneys due; or to become due the Contractor, and/or to obtain reimbursement from the Contractor for such cost.

(e) The Department may require the Contractor to remove or uncover such portions of any finished work as directed by Department. After examination by the Department, the Contractor shall restore the work to the standards required by this Agreement. If the work exposed or examined is not in conformance with the requirements of this Agreement, then uncovering, removing and restoring the work shall be at the Contractor's expense. If the work exposed or examined is in conformance with the requirements of this Agreement, then the Contractor shall be entitled to a Change Order under Article VII with respect to such efforts. 
(f) The performance of the Contractor's obligations under this Agreement will be subject to periodic review by the Department in accordance with the terms of the Evaluation Program.

(g) No action taken by the Department under the Evaluation Program (MRP) will be, or will be deemed to be, a waiver of any of the Department's rights to oversee the work, to make inspections or to conduct tests, to require remedial work or to exercise any other remedy for the Contractor's failure to comply with the terms of this Agreement.

\section{Books and Records}

The Contractor hereby agrees to retain all books, records and other documents relative to this Contract for Five (5) years after expiration of the Term, except that books, records and other documents relating to any items unpaid or in dispute as of the date of expiration of the Term shall be retained for Five (5) years after final payment of such amounts. The Department, its authorized agents, and/or state auditors shall have full access to and the right to examine any said materials during said period.

\section{$7 \quad$ Powers and Duties of State Officials}

Nothing contained in this Agreement shall in any way limit the constitutional and statutory powers, duties and rights of elected state officials, including the independent rights of the Auditor of Public Accounts in carrying out his or her legal authority.

\section{Regulatory Approvals.}

(a) Prior to performing any Asset Maintenance Services activities, the Contractor shall identify in the Work Plan all Regulatory Approvals necessary for the particular maintenance type activities to be performed, and request in writing that the Department obtain any such Regulatory Approvals in the Department's name.

(b) The Contractor shall, at its sole cost and expense, assist the Department in preparing and presenting materials required to obtain any Regulatory Approvals required to undertake the Asset Maintenance Services, including the preparation of any required site surveys and the collection of relevant data.

(c) The Contractor shall pay all charges and fees incident to obtaining Regulatory Approvals.

\section{$9 \quad$ Occupational Safety and Health Standards}

(a) The Contractor shall not require any individual employed in the performance of this Agreement to work in or under working conditions that are in violation of the Occupational Safety and Health Standards promulgated by the United States Secretary of Labor.

(b) The Contractor shall abide by the duties imposed under Section 40.1-51.1 of the Code of Virginia (the Virginia Occupational Safety and Health Standards). Any violation of the aforementioned requirements or duties which are brought to the attention of the Contractor by the Department shall be immediately abated in accordance with all provisions of the Memorandum of Understanding between the Department and the Virginia Department of Labor and Industries, the enforcement agency identified under Section 40.1-51.1 of the Code of Virginia.

\section{Nondiscrimination}

(a) The Contractor hereby certifies to the Department that it will conform to the applicable provisions of the Federal Civil Rights Act of 1964, as amended, the Virginia Fair Employment 
Contracting Act of the 1975, as amended, the Virginians With Disability Act and Section 11.51 of the Virginia Public Procurement Act.

(b) The Contractor shall not discriminate against any employee or applicant for employment because of race, religion, color, sex or national original, or disabilities except where religion, sex, or national origin is a bona fide occupational qualification reasonably necessary to the normal operation of the Contractor. The Contractor agrees to post in conspicuous places, available to employees and applicants for employment, notices setting forth the provisions of this nondiscrimination clause. The Contractor shall state that it is an equal opportunity employer. Notices, advertisements and solicitations placed in accordance with Federal law, rule or regulation shall be deemed sufficient for the purpose of meeting the requirements of this IFB.

(c) The Contractor shall include the provisions of subsection (a) above in every subcontract or purchase order over $\$ 10,000$ so that the provisions will be binding upon each subcontractor or vendor.

\section{No Third Party Beneficiaries}

Nothing contained in this Agreement is intended or shall be construed as creating or conferring any rights, benefits or remedies upon, or creating any obligations of the parties hereto toward, any person or entity not a party to this Agreement.

\section{Relationship of Parties.}

The relationship of the Contractor to the Department shall be one of an independent contractor, not an agent, partner, joint venture or employee, and the Department shall have no rights to direct or control the activities of the Contractor or any Contractor Party except as provided herein.

Officials, employees and agents of the Department, including the Department's Agent, shall in no event be considered employees, agents, partners or representatives of the Contractor.

\section{Availability of Funds}

The obligation of Department to make any payment under this contract is subject to the availability of funds, including the annual appropriation of sufficient funds to Department by the Virginia General Assembly. Department shall provide reasonable notice to the Contractor in the event that sufficient funds are not available to make any payment under this Agreement.

No user fees for use of the Transportation Facilities shall be established or collected by the Contractor under this contract.

\section{Termination}

(a) The Department may at any time in its sole and absolute discretion terminate this Agreement when the Department determines that such termination is in the best interests of the Commonwealth. In the event of termination, the following shall apply: The Department's exercise of its right to terminate shall be made by written notice to the Contractor setting forth an effective date for termination, which shall not be less than 60 Days after the date of delivery of such notice. As compensation for a termination for public convenience, the Contractor may be entitled to receive compensation for its termination costs, including, but not limited to any reasonable cancellation charges and prepayment of long-term obligations reasonably incurred by the Contractor. If the Contractor disputes the adequacy of the amount of, and does not accept, the compensation offered by the Department, the Contractor may proceed under the Dispute Resolution an Claims section to resolve the dispute as to the proper amount of compensation owing to the Contractor. 
(b) No termination for public convenience shall result in forfeiture by the Contractor of damages it may be entitled to due to preceding Department Default to the extent such damages is not subsumed by the compensation owing upon the termination for public convenience. The Contractor is expected to maintain the road system uniformly and consistently throughout the contract period by meeting performance specifications.

(c) Performance, or lack of performance resulting in a threat to the public safety and/or continued poor performance (more than 2 consecutive evaluations, or more than 3 total) of work or failure to perform (including timeliness requirements) in accordance with the Contractor's proposal, will cause the Contractor to be declared in default of the contract and subject to termination.

(d) The Contractor shall have the right to terminate this agreement only in the event of a material default by the Department. The Contractor shall have no other ability to terminate this agreement.

1. Material Default by the Department is defined as: Failure by the Department to pay the Contractor for valid, undisputed work, performed under this agreement.

\section{Subcontracting}

(a) Each Subcontract that the Contractor executes at a minimum:

i shall set forth a standard of professional responsibility or a standard for commercial practice equal to prudent industry standards for work of similar scope and scale and shall set forth effective procedures for claims and change orders;

ii shall require the subcontractor to carry out its scope of work in accordance with all applicable Laws, Regulations and Ordinances and the Manuals, Standards and Procedures;

iii shall set forth warranties, guaranties and liability provisions of the contracting party in accordance with good commercial practice for work of similar scope and scale;

iv with respect to any subcontract which, when aggregated with all subcontracts between the Contractor and such subcontractor for the same Fiscal Year, is in excess of $\$ 50,000$, subcontractor shall indemnify against any and all claims, losses, costs, damages, expenses and liabilities arising out of the subcontractor's contractual breach or the willful misconduct or negligence of the subcontractor or any of its officers, employees, agents or representatives;

$\mathrm{v} \quad$ shall be fully assignable to the Department, such assignability to include the benefit of all subcontractor warranties, indemnities, guarantees and professional responsibility and include express requirements that, if the Department succeeds to subcontractor's rights under the subject contract (by assignment or otherwise), then the subcontractor agrees that (a) it will maintain usual and customary books and records for the type and scope of operations -of business in which it is engaged (e.g., constructor, equipment supplier, designer, service provider), (b) permit audit thereof by the Contractor, and provide progress reports to the Contractor appropriate for the type of subcontract it is performing sufficient to enable the Contractor to provide the reports it is required to furnish the Department under this contract, and (c) allow the Department to assume the benefit of the Contractor's subcontract rights and the work performed thereunder with liability only for those remaining obligations accruing after the date of assumption; 
vi shall not be assignable by the subcontractor without the Contractor 's prior written consent;

vii with respect to any subcontract which, when aggregated with all subcontracts between the Contractor and such subcontractor for the same Fiscal Year, is in excess of $\$ 50,000$, shall be terminable by the subcontractor only for cause;

viii shall expressly require the subcontractor to participate in meetings between the Contractor and the Department, upon Department's reasonable request, concerning matters pertaining to such subcontractor or its work, provided that all direction to such subcontractor shall be provided by the Contractor, and provided further that nothing in this subsection

ix shall limit the authority of a Department Agent to give such direction or take such action which in the opinion of such Agent is necessary to remove an immediate and present threat to the safety of life or property;

$\mathrm{x} \quad$ shall expressly provide that all liens, claims and charges of the subcontractor and its subcontractors at any time shall not attach to any interest of the Department in the Transportation Facilities; and

$\mathrm{xi}$ shall be consistent in all other respects with the terms and conditions of this Agreement to the extent such terms and conditions are applicable to the scope of work or such subcontractors.

(b) The Contractor shall not amend any subcontract with respect to any of the foregoing matters without the prior written consent of the Department.

(c) The Contractor shall not enter into any subcontracts with any Person then debarred or suspended from submitting bids by any agency of the State.

(d) The Contractor shall include a provision in each subcontract requiring the subcontractor to maintain all licenses required by applicable Laws, Regulations and Ordinances.

(e) The appointment of subcontractors by the Contractor will not relieve the Contractor of its responsibility hereunder or for the quality of work, materials and services provided by it. The Contractor will at all times be held fully responsible to the Department for the acts and omissions of its subcontractors and persons employed by them and no subcontract entered into by the Contractor will impose any obligation or liability upon the Department to any such subcontractor or any of its employees. Nothing in this contract will create any contractual relationship between the Department and a subcontractor of the Contractor.

(f) All subcontracts with Affiliates shall be arm's-length, and on terms no less favorable to the Contractor than to non-Affiliates of the subcontractor.

\section{Performance and Payment Bond}

(a) The successful Contractor shall provide to Department concurrently with the execution hereof and shall maintain at all times during the Term of this Agreement/Contract an annualrenewable performance and payment bond which shall guarantee the performance of the Work and shall also guarantee payment to Persons performing work for the Contractor under this contract. The surety of the bond shall be a surety company authorized to transact business in the 
State of Virginia and shall have a current A.M. Best unit rating not less than "A-." The payment and performance bond shall be cancelable only for non-payment of premium.

(b) On or before 45 days prior to the end of each subsequent year, the contractor shall provide a renewed performance and payment bond effective for an additional year. The face value of the performance and payment bonds shall be as identified in below. In the event the performance and payment bond is executed, the Surety will only be responsible for a single face value payment or relief. The Surety will then be released from further obligation.

(c) In lieu of performance and payment bonds, the Contractor may furnish a certified check or cash escrow in the face amount required for the bonds, which will be held for the full statutory period as applicable. Failure to provide the Department with a performance and payment bond shall be cause for immediate contract cancellation and the Contractor will be declared in a state of default. The Contractor shall be excluded from any further VDOT bidding and contracting for a period of two years, from date of default.

(d) The penal amount of the bond for any Fiscal Year shall be not less than the non-cumulative amount of $50 \%$ of the Annual Contract Value.

\section{Initial Term.}

The initial Term of this Agreement shall be the period commencing on the Agreement Date and ending July 1, 2012 subject to earlier termination in accordance with the terms hereof.

\section{Renewal Terms}

The duration of the contract will be five (5) years with a renewal option for two (2) additional two (2) year terms. If the renewal option is exercised, price may be increased/decreased by no more than the percentage increase/decrease of the Services Category of the CPI-W section, Table 4 of the Consumer Price Index of the United States Bureau of Labor Statistics for the latest twelve months from which statistics are available. The option shall be exercisable by the Department's delivery to the Contractor of written notice of its intent to renew this Agreement not less than 90 Days prior to expiration of the then current Term.

\section{Force Majeure}

The term "Force Majeure" shall mean any event or occurrence arising out of circumstances which:

(a) are beyond the control of the Contractor ;

(b) constitute an imminent threat to life or property;

(c) give rise to a declaration of a state of emergency by the Governor of the Commonwealth;

\section{In no event shall any occurrence involving Snow and Ice Control constitute Force Majeure.}

\section{Hazardous Materials.}

(a) The liabilities of Department and the Contractor with respect to Hazardous Materials are as follows:

(i) Notwithstanding any other provision of this Agreement, or statutory or case law provisions that would govern in the absence of an agreement between the parties, the Contractor shall bear the responsibilities set forth in this subsection (a) with respect to any Hazardous Materials (including but not limited to that present in the soil, 
groundwater or soil vapor) found in, on or under the Transportation Facilities to the extent they result from any act or omission of the Contractor under this' Agreement. under no circumstances shall the Contractor be responsible or liable for any such Hazardous Materials found in, on or under the Transportation Facilities on or before the Agreement Date, whether known or unknown; provided, however, that the Contractor Party shall be relieved of any responsibility or liability for any such Hazardous Materials which are found in the soil, groundwater or soil vapor as a result of any act or omission of the Contractor Party occurring prior to the Agreement Date.

(ii) If Hazardous Materials for which the Contractor is responsible under this agreement are discovered (in circumstances, concentrations and amounts required by applicable Laws, Regulations and Ordinances to be remediated) in, on or under real property within the Transportation Facilities right of way, the Contractor shall, at its sole cost and expense, cause any such Hazardous Materials to be remediated, as required by applicable Laws, Regulations and Ordinances or otherwise addressed by a method approved by the Virginia Department of Environmental Quality, Virginia Water Control Board or other appropriate agency of the State, and shall cause such real property to be restored to its condition existing prior to such remedial action or other methodology (except for the absence of the Hazardous Materials), including, to the extent required, any grading and reinforcement necessary to restore the weight-bearing capacity of the Transportation Facilities right of way.

(iii) If within a reasonable time after discovery of a Hazardous Substance for which the Contractor is responsible under subsection (a)(i) above, taking into consideration the nature and extent of the contamination and the type and extent of remedial action required the Contractor has not undertaken remedial action required under subsection (a)(ii) above, the Department may provide the Contractor with written notice that it, will undertake the remedial action itself. The Department thereafter may-undertake remedial action if it assumes in writing all responsibility to remediate in compliance with a remediation plan approved by applicable regulatory authorities and reasonably approved by the Contractor and in compliance with. Applicable Laws, Regulations and Ordinances. The Contractor shall reimburse to the Department on a current basis the reasonable costs the Department pays in carrying out such remediation plan. Notwithstanding the foregoing, if either party notifies the other that it desires to preserve claims against other potentially responsible parties, then the party undertaking the remedial act shall do so consistently with either the National Contingency Plan or comparable regulations and standards of the Virginia Department of Environmental Quality and a reasonable period of time for the Contractor to perform the remedial work shall include a sufficient period for the Contractor to comply with the National Contingency Plan or such comparable State regulations and standards.

(b) The Contractor shall indemnify, protect, defend and hold harmless the Department Indemnities from all Claims (including but not limited to response costs, administrative costs, fines, charges, penalties and cost recovery or similar actions brought by a governmental or private party and including third party tort liability) arising, directly or indirectly, from any presence, "threat of release" placement, use, generation, manufacture, encapsulation, storage, treatment, disposal, discharge, burial, repair, cleanup, detoxification, removal or remediation of any Hazardous Substance for which any the Contractor Party bears responsibility pursuant to subsection (a) above. 
(c) Department shall indemnify, protect, defend and hold harmless the Contractor Indemnities from all Claims (including but not limited to response costs, administrative costs, fines, charges, penalties and cost recovery or similar actions brought by a governmental or private party and including third party tort liability) arising, directly or indirectly, from any presence, release, threat of release, placement, use, generation, manufacture, encapsulation, storage, treatment, disposal, discharge, burial, repair, cleanup, detoxification', removal or remediation of any Hazardous Substance except that for which any the Contractor Party bears responsibility pursuant to subsection (a) above.

(d) Without limiting their generality, the indemnities under subsection (b) and (c.) above are intended to operate as agreements pursuant to Section 107(e) of CERCLA, 42 U.S.C. Section 9607(e) to insure, protect, hold harmless and indemnify the indemnified parties from any liability pursuant thereto.

(e) The provisions apply with equal force and effect to the indemnifications under subsections (b) and (c) above.

(f) The Department and the Contractor shall cooperate with each other in the prosecution of any Claims against or defense of any Claims made by third. parties in connection with Hazardous Materials present in, or under the Transportation Facilities right of way. In addition, each party not responsible hereunder for remediation of Hazardous Materials shall accommodate any reasonable needs and requests of the responsible party hereunder and cooperate with the responsible party in connection with the responsible party's investigation, analysis of alternatives and conduct of remedial action. Without limiting the foregoing, the party not responsible hereunder shall cooperate in order to preserve and protect the responsible party's right to recover costs from other potentially responsible parties, including but not limited to cooperating in maintaining consistency with the National Contingency Plan or any other regulations of the U.S. Environmental Protection Agency, or cooperating in the responsible party's conduct of a remediation substantially equivalent to one which would be conducted under the supervision of the Virginia Department of Environmental Quality.

(g) All references in this to remediation, remedial action, remedial work and similar terminology include, without limitation, removal and disposal, if elected by or required of the party responsible to remediate.

21 Non-Mandatory Question and Answer Session:

10:00 A.M. December 11, 2006 - Vendors may attend in Richmond at VDOT - Monroe Building, 101 North 14th. Broad St., $1^{\text {st }}$ floor Conference Room D

Bring a copy of the solicitation with you. Any changes resulting from this session will be issued in a written addendum to the solicitation

\section{VA BUSINESS-TO GOVERNMENT CONTRACTS AND ORDERS:}

The solicitation/contract will result in one purchase order per year with the eVA transaction fee specified below assessed to each order.

a. For orders issued prior to August 16, 2006, the Vendor Transaction Fee is $1 \%$ capped at a maximum of $\$ 500$ per order. 
b. For orders issued after August 16, 2006 and after, the Vendor Transaction Fee is:

(i) DMBE-certified small, women, minority owned businesses: 1\% Capped at \$500 per order.

(ii) Business other than those listed above: 1\% Capped at \$1,500 per order

\section{BID ACCEPTANCE PERIOD}

Any bid in response to this solicitation shall be valid for 90 days. At the end of the 90 days the bid may be withdrawn at the written request of the Bidder. If the bid is not withdrawn at that time it remains in effect until an award is made or the solicitation is canceled. 


\section{ATTACHMENT I - CONTRACTORS BID SHEET}

(To be removed from contract and placed in a separate envelope marked as BID PRICE. Bids must be sealed, with commodity, bid number and opening date shown on the face of the envelope.

MONTHLY Bid price for Turnkey Asset Maintenance Services:

$\$$

Total Lump Sum Bid Price (Monthly bid price X 60 months)

$\$$ 


\section{ATTACHMENT II - ROUTINE MAINTENANCE ACTIVITIES}

ㅁ Environmental Work

ㅁngineering Duties

ㅁ Asphalt Pothole Repair (Manual)

口 Asphalt Pothole Repair (Mechanical)

ㅁ Base Repair

口 Pressure Grouting

- Concrete Pavement Joint Repair

- Concrete Slope Pavement Joint Repair

- Concrete Pavement Surface Pothole Repair

- Repairing Non-Paved Shoulders, Front

Slopes and Roadside Ditches (Manual)

口 Seeding, Fertilizing and Mulching

- Reworking Non-Paved Shoulders, Front

Slopes and Roadside Ditches (Mechanical)

- Miscellaneous Slope and Ditch Repair

- Clean Drainage Structures

- Repair Storm Drains, Side Drains, Cross

Drains

- Concrete Repair

ㅁ Concrete Sidewalk Repair

- Unpaved Ditches - Clean and Reshape

$\quad$ Paved Ditches - Clean and Repair

ㄴ Large Machine Mowing

ㅇ Slope mowing

- Intermediate Machine Mowing

Small Machine Mowing

ㄴ Weed Control (Manual)

口 Wildflowers

ㅁertilizing

ㅁ Tree Trimming and Removal

- Landscape Area Maintenance

- Chemical Weed and Grass Control

- Chemical Weed and Grass Control

Selective Weeding

ㄱ Storm Water Management

ㅁ Delineators
- Signs (Ground Signs 30 square Feet or Less)

- Signs (Ground Signs Over 30 Square Feet and All Overlane Signs)

ㄱign Cleaning

口 Guardrail Repair

口 Fence Repair

口 Attenuator Repair

口 Raised Pavement Marker Replacement

口 Graffiti Removal

口 Roadside Litter Removal

ㅁ Road Sweeping (Manual)

口 Road Sweeping (Mechanical)

Edging and Sweeping

- Highway Lighting Maintenance

․ Overhead Sign Structure Maintenance

口 Supervision, Inspection and/or Engineering of Roadway Maintenance

- Contract Maintenance Supervision, Engineering and Inspection

ㅁ Emergency Maintenance

口 Glare Foil

- Maintenance Support Services

口 Barrier Wall

- Bridge \& Culvert Maintenance

Rumble Strip Sealing

口 Winter Weather Events

口 Incident Management 
ATTACHMENT III - PERFORMANCE CRITERIA

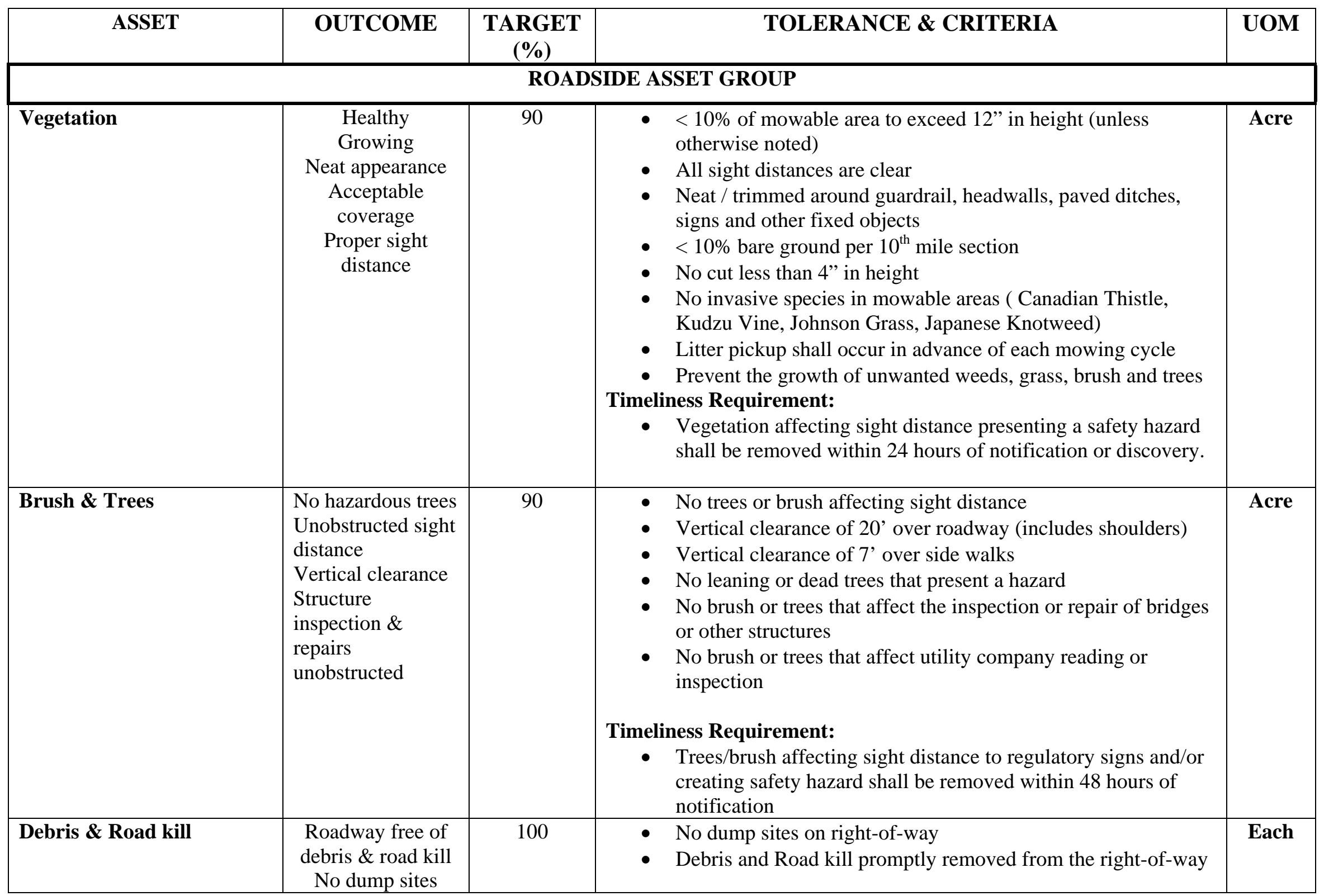




\begin{tabular}{|c|c|c|c|c|}
\hline ASSET & OUTCOME & $\begin{array}{c}\text { TARGET } \\
(\%)\end{array}$ & TOLERANCE \& CRITERIA & UOM \\
\hline & & & $\begin{array}{l}\text { and properly disposed } \\
\text { - Owner of household pets to be notified if identification is } \\
\text { available } \\
\text { Timeliness Requirement: } \\
\text { - Contractor shall respond immediately upon notification or } \\
\text { discovery, } 30 \text { minute response time during normal work hours } \\
\text { and } 60 \text { minute response time outside normal work hours }\end{array}$ & \\
\hline $\begin{array}{l}\text { Landscaping, Wildflowers } \\
\text { Beds, Bulb Beds, } \\
\text { Ornamental Shrub Beds }\end{array}$ & $\begin{array}{c}\text { Neat } \\
\text { Attractive } \\
\text { Growing }\end{array}$ & 90 & $\begin{array}{l}\text { Bulb beds } \\
\text { - } \quad<10 \% \text { of bed contains weeds } \\
\text { - } \text { Bed is mulched } \\
\text { - }<10 \% \text { of bed not growing } \\
\text { Ornamental / Shrub beds } \\
\text { - neat appearance and pruned } \\
\text { Wildflower beds } \\
\text { - } \quad<10 \% \text { of bed contains weeds } \\
\text { - }<10 \% \text { of bed not growing }\end{array}$ & Acre \\
\hline Illegal signs/ structures & $\begin{array}{l}\text { Right-of-way free } \\
\text { of illegal signs or } \\
\text { structures }\end{array}$ & 100 & $\begin{array}{l}\text { - No illegal signs on the right-of-way } \\
\text { Timeliness Requirement } \\
\text { - Contractor shall remove illegal signs/structures within } 72 \text { hours } \\
\text { of notification or discovery. }\end{array}$ & Each \\
\hline Concrete Barriers & $\begin{array}{c}\text { Safe } \\
\text { Structurally sound }\end{array}$ & 90 & $\begin{array}{l}\text { - Free of vegetation } \\
\text { - } \quad<10 \% \text { joint material damaged or missing } \\
\text { - Weep Holes } \geq 90 \% \text { free of obstruction } \\
\text { Timeliness Requirement: } \\
\text { - } \quad \text { Damaged or misaligned barriers due to accidents/ incidents } \\
\quad \text { shall be mitigated immediately upon notification or discovery }\end{array}$ & Each \\
\hline
\end{tabular}




\begin{tabular}{|c|c|c|c|c|}
\hline ASSET & OUTCOME & $\begin{array}{c}\text { TARGET } \\
(\%) \\
\end{array}$ & TOLERANCE \& CRITERIA & UOM \\
\hline & & & $\begin{array}{l}\text { or before accident scene is cleared } \\
\text { - Repairs to barriers shall be completed within } 10 \text { days of } \\
\text { notification or discovery }\end{array}$ & \\
\hline Sound Barriers & $\begin{array}{l}\text { Structurally sound } \\
\text { Functional }\end{array}$ & 90 & $\begin{array}{l}\text { - Free of damaging vegetation } \\
\text { - } \quad \text { 10\% damage to surface materials } \\
\text { Timeliness Requirement: } \\
\text { - Damaged or misaligned barriers due to accidents/ incidents } \\
\text { shall be mitigated immediately upon notification or discovery } \\
\text { or before accident scene is cleared. } \\
\text { - A plan for repairs to barriers shall be completed within } 10 \\
\text { days of notification or discovery }\end{array}$ & LFT \\
\hline Slopes & $\begin{array}{c}\text { Stable } \\
\text { No erosion }\end{array}$ & 90 & $\begin{array}{l}\text { - } \quad<\text { 8” deep erosion } \\
\text { - } \quad \text { No pattern of erosion that endangers the stability of the slope } \\
\text { - } \quad \text { 105 feet greater than 2" lower than paved shoulder within .1 } \\
\text { mile sample unit } \\
\text { - } \quad \text { 105 feet greater than 2" higher than paved shoulder within .1 } \\
\text { mile sample unit } \\
\text { Timeliness Requirement: } \\
\text { - Any safety hazard that results from a sink hole, slide, high slope } \\
\text { or low slope areas shall be mitigated immediately. } \\
\text { - } \quad \text { Repairs to sink holes and slides shall be completed within in } 7 \\
\text { days of notification or Discovery. } \\
\text { High and or low slope areas shall be repaired within } 30 \text { days. }\end{array}$ & LFT \\
\hline Fence & $\begin{array}{l}\text { Functional } \\
\text { Structurally sound }\end{array}$ & 90 & $\begin{array}{l}\text { - } \quad<10 \% \text { fence in need of repair } \\
\text { - No damage that allows access } \\
\text { - }<10 \% \text { vegetation on fence } \\
\text { Timeliness Requirement: } \\
\text { - Any damaged or fallen fencing holding livestock must be } \\
\text { replaced/repaired with in } 24 \text { hours after notification or discovery. }\end{array}$ & LFT \\
\hline
\end{tabular}




\begin{tabular}{|c|c|c|c|c|}
\hline ASSET & OUTCOME & $\begin{array}{l}\text { TARGET } \\
(\%)\end{array}$ & TOLERANCE \& CRITERIA & UOM \\
\hline $\begin{array}{l}\text { Crossovers/Police Parking } \\
\text { Locations }\end{array}$ & $\begin{array}{c}\text { Safe } \\
\text { Functional }\end{array}$ & 95 & $\begin{array}{ll}\text { - } & \text { Properly signed if open } \\
\text { - } & \text { Properly signed / blocked if restricted access } \\
\text { - } & \text { Free of potholes } \\
\text { - } & \text { Properly maintained driving surface (as constructed) }\end{array}$ & Each \\
\hline Retaining Walls & $\begin{array}{l}\text { Structurally sound } \\
\text { Safe } \\
\text { Clean } \\
\text { Stable }\end{array}$ & 90 & $\begin{array}{l}\text { - Free of vegetation } \\
\text { - Weep holes open } \\
\text { - No damaged or missing parts } \\
\text { - Jotal components free of rust } \\
\end{array}$ & Each \\
\hline \multicolumn{5}{|c|}{ DRAINAGE ASSET GROUP } \\
\hline $\begin{array}{l}\text { Pipes \& Box Culverts }(\leq \\
36 \text { sq. ft.) }\end{array}$ & $\begin{array}{l}\text { Structurally Sound } \\
\text { Open \& Drains } \\
\text { Joints intact } \\
\text { Functional } \\
\text { Free of damage }\end{array}$ & 90 & $\begin{array}{l}\text { - } \quad \text { < } 10 \% \text { diameter closed } \\
\text { - No separated joints } \\
\text { - No missing joint material } \\
\text { - } \quad \text { End deep erosion at ends } \\
\text { load carrying grates) } \\
\text { Timeliness Requirement: } \\
\text { - Culverts or structures beyond } 50 \% \text { diameter closed shall be } \\
\text { - cleaned and opened within 30days } \\
\text { Culverts/structures structurally near collapse as determined by } \\
\text { the VDOT Structure \& Bridge Engineer shall be mitigated } \\
\text { immediately }\end{array}$ & Each \\
\hline $\begin{array}{l}\text { Pipes \& Box Culverts (> } 36 \\
\text { sq. ft.) }\end{array}$ & $\begin{array}{l}\text { Structurally Sound } \\
\text { Open \& Drains } \\
\text { Joints intact } \\
\text { Functional } \\
\text { Free of damage }\end{array}$ & 90 & $\begin{array}{l}\text { - } \quad<10 \% \text { diameter closed } \\
\text { - No missing joints material } \\
\text { - } \quad<1 \text { ' deep erosion at ends } \\
\text { - } \text { Free of damaging vegetation } \\
\text { End walls \& end sections intact and free of damage (includes } \\
\text { Timelinesd carrying grates) } \\
\text { - Culverts or structures beyond 50\% diameter closed shall be } \\
\quad \text { cleaned within 30days }\end{array}$ & Each \\
\hline
\end{tabular}




\begin{tabular}{|c|c|c|c|c|}
\hline ASSET & OUTCOME & $\begin{array}{c}\text { TARGET } \\
(\%) \\
\end{array}$ & TOLERANCE \& CRITERIA & UOM \\
\hline & & & $\begin{array}{l}\text { - Culverts/structures structurally near collapse as determined by } \\
\text { the VDOT Structure \& Bridge Engineer shall be mitigated } \\
\text { immediately }\end{array}$ & \\
\hline Ditches, Paved & $\begin{array}{l}\text { Structurally sound } \\
\text { Joints intact } \\
\text { Open \& Drains }\end{array}$ & 90 & $\begin{array}{l}\text { - } \quad<2 \text { inches settlement } \& \text { joints intact. } \\
\text { - No undermining or undercutting } \\
\text { - } \quad<25 \% \text { obstructions impeding the flow of water } \\
\text { - } \quad<10 \% \text { surface area cracking }>1 / 4 \text { ” wide } \\
\text { - No damaged or missing sections (includes energy dissipaters) } \\
\text { Timeliness Requirement: } \\
\text { - Open complete blockages and abate significant erosion } \\
\text { - } \quad \text { immediately upon discovery or notification } \\
\text { - lines within } 90 \text { days from notification or discovery } \\
\text { Damage to paved ditch should be repaired within } 180 \text { days of } \\
\text { notification or discovery unless flow is impaired refer to the } \\
\text { above for timeframes }\end{array}$ & LFT \\
\hline Ditches, Unpaved & $\begin{array}{l}\text { Open \& Drains } \\
\text { Minimal Erosion }\end{array}$ & 90 & $\begin{array}{l}\text { - No water ponding } \\
\text { - No erosion > 6" deep } \\
\text { Timeliness Requirement: } \\
\text { - Open complete blockages and abate significant eroision } \\
\text { - Clean debris or remove vegetation to clear flow lines within } 90 \\
\quad \text { days from notification or discovery }\end{array}$ & LFT \\
\hline $\begin{array}{l}\text { Under drains \& Edge } \\
\text { drains }\end{array}$ & $\begin{array}{l}\text { Structurally Sound } \\
\text { Functional }\end{array}$ & 90 & $\begin{array}{ll} & <10 \% \text { damage or deterioration to outlet pipe } \\
\text { - } & <10 \% \text { blockage of pipe or end protection } \\
\text { - } & \text { No damaged or missing end protection (includes rodent } \\
\text { screen) }\end{array}$ & Each \\
\hline
\end{tabular}




\begin{tabular}{|c|c|c|c|c|}
\hline ASSET & OUTCOME & $\begin{array}{c}\text { TARGET } \\
(\%)\end{array}$ & TOLERANCE \& CRITERIA & UOM \\
\hline Inlets & Functional & & $\begin{array}{l}\text { throat) } \\
\text { - No obstructions ( }<10 \% \text { of opening) (includes top, throat \& } \\
\text { drop inlet) } \\
\text { Timeliness Requirement: } \\
\text { - Storm Drains and Drop Inlets beyond } 50 \% \text { closed shall be } \\
\text { cleaned within } 30 \text { days } \\
\text { - Safety issues shall be mitigated immediately }\end{array}$ & \\
\hline $\begin{array}{l}\text { Curb \& Gutter, Curbing } \\
\text { Raised, Concrete Median }\end{array}$ & $\begin{array}{c}\text { In line } \\
\text { Draining } \\
\text { Structurally sound }\end{array}$ & 90 & $\begin{array}{ll}\text { - } & \text { No obstruction which impedes the flow of water } \\
\text { - } & <25 \% \text { of surface area spalling } \\
\text { - No damaged or missing section } \\
\text { - No separation }>1 / 2 \text { ” from asphalt surface } \\
\text { - Joints and joint material intact }\end{array}$ & LFT \\
\hline $\begin{array}{l}\text { Storm water Management } \\
\text { Ponds }\end{array}$ & $\begin{array}{c}\text { Safe } \\
\text { Structurally sound } \\
\text { Functional }\end{array}$ & 90 & $\begin{array}{l}\text { - No damage to stem pipes, weirs, grates, drainage tubing or } \\
\text { debris racks } \\
\text { - } \\
\text { - dree of debris (stem pipes, weirs, grates, drainage tubing \& } \\
\text { - No vegetation that affects the function (mowed, sprayed) } \\
\text { - } \text { No fence missing or damaged (if present at start of contract) } \\
\text { Timeliness Requirement: } \\
\text { - Inspection once every six months and after every significant } \\
\text { storm event (documentation shall be maintained according to } \\
\text { applicable state regulations) } \\
\text { All deficiencies reported or discovered shall be corrected } \\
\text { within } 45 \text { days. }\end{array}$ & Each \\
\hline \multicolumn{5}{|c|}{ TRAFFIC ASSET GROUP } \\
\hline Signs - Post Mounted & $\begin{array}{c}\text { Meets Reflectivity } \\
\text { Standards } \\
\text { Clean \& Clear } \\
\text { Free of Damage }\end{array}$ & 95 & $\begin{array}{l}\text { - } \quad \text { Meets current reflectivity standards, as updated (replacements) } \\
\text { - } \quad \text { Reflective at } 120 \text { ' day or night } \\
\text { - } \quad \text { Surface clean \& legible } \\
\text { - holes) } \\
\text { - No down or missing signs }\end{array}$ & Each \\
\hline
\end{tabular}




\begin{tabular}{|c|c|c|c|c|}
\hline ASSET & OUTCOME & $\begin{array}{l}\text { TARGET } \\
(\%)\end{array}$ & TOLERANCE \& CRITERIA & UOM \\
\hline & & & $\begin{array}{l}\text { • Mile markers are at least 60’ to achieve uniform appearance } \\
\text { Timeliness Requirement: } \\
\text { - Damaged Regulatory / Warning signs shall be mitigated } \\
\text { immediately upon notification or discovery } \\
\text { - Damaged Regulatory / Warning signs shall be repaired or } \\
\text { replaced within } 2 \text { days of notification or discovery. } \\
\text { - All other signs repaired or replaced within } 30 \text { days of } \\
\text { notification or discovery. }\end{array}$ & \\
\hline $\begin{array}{l}\text { Signs - Overhead and } \\
\text { Bridge Mounted }\end{array}$ & $\begin{array}{l}\text { Structurally Sound } \\
\text { Meets Reflectivity } \\
\text { standards } \\
\text { Free of Damage }\end{array}$ & 90 & $\begin{array}{l}\text { - Meets current reflectivity standards, as updated (replacements) } \\
\text { - Reflective at } 120 \text { ' day or night } \\
\text { - } \quad \text { Surface clean \& legible } \\
\text { - holes) } \\
\text { - No damage to surface of sign (scratches, dents, bullet } \\
\text { - Structure \& support areas kept free of dirt \& debris... (clean \& } \\
\text { - } \text { flush) } \\
\text { TDOT Structure Report shall be used for other maintenance } \\
\text { Timeliness Requirement: } \\
\text { - Damaged sign structures shall be mitigated immediately upon } \\
\text { - notification or discovery } \\
\text { - Damaged sign structures shall be repaired within } 60 \text { days of } \\
\text { notification or discovery } \\
\text { Damaged signs shall be repaired or replaced within } 60 \text { days }\end{array}$ & Each \\
\hline Pavement Markings & $\begin{array}{c}\text { Present } \\
\text { Reflective }\end{array}$ & 90 & $\begin{array}{l}\text { - } \quad<10 \% \text { damaged or missing due to incidents, patching } \\
\text { operations, or snow removal operations } \\
\text { - } \quad<10 \% \text { covered by debris } \\
\text { - All markings to be VDOT approved durable, high quality } \\
\text { materials }\end{array}$ & LFT \\
\hline $\begin{array}{l}\text { Pavement Markers (Raised } \\
\text { \& Recessed) }\end{array}$ & $\begin{array}{c}\text { Present } \\
\text { Reflective }\end{array}$ & 90 & $\begin{array}{l}\text { - } \quad<30 \% \text { missing or damaged within a tenth mile section } \\
\text { - Meets reflectivity standards } \\
\text { - Missing pavement marker lenses shall be repaired or replaced } \\
\text { Timeliness Requirement } \\
\text { - Pavement markers that present a hazard shall be removed }\end{array}$ & Each \\
\hline
\end{tabular}




\begin{tabular}{|c|c|c|c|c|}
\hline ASSET & OUTCOME & $\begin{array}{c}\text { TARGET } \\
(\%)\end{array}$ & TOLERANCE \& CRITERIA & UOM \\
\hline & & & immediately & \\
\hline Pavement Messages & $\begin{array}{l}\text { Present } \\
\text { Reflective }\end{array}$ & 90 & $\begin{array}{ll}\text { - } & <10 \% \text { damaged } \\
\text { - } & <10 \% \text { covered by debris } \\
\text { - } & \text { Meets reflectivity standards }\end{array}$ & Each \\
\hline Lighting - Roadway & $\begin{array}{c}\text { Operational } \\
\text { Structurally sound }\end{array}$ & 90 & $\begin{array}{l}\text { - Conventional Lighting (single bulb structure): Working at all } \\
\text { times } \\
\text { - High Mast Lighting: }>50 \% \text { of bulbs per structure working at } \\
\text { all times } \\
\text { - No damaged or missing parts } \\
\text { - } \text { VDOT Structure Report shall be used for other maintenance } \\
\text { needs } \\
\text { Timeliness Requirement: } \\
\text { - Damaged or non - functional lights/ structures shall be } \\
\text { repaired or replaced within } 7 \text { days of notification or discovery }\end{array}$ & Each \\
\hline Lighting - Under deck & $\begin{array}{l}\text { Operational } \\
\text { Safe }\end{array}$ & 90 & $\begin{array}{l}\text { - No damaged or missing parts } \\
\text { - } \quad \text { Properly working at all times, with no more than } 30 \% \text { of the } \\
\text { bulbs, per structure in non-functional condition. } \\
\text { Timeliness Requirement: } \\
\text { - Non- functional lights shall be repaired or replaced within } 7 \\
\text { days of notification or discovery }\end{array}$ & Each \\
\hline $\begin{array}{l}\text { Lights - Warning, Bridge } \\
\text { Mounted Navigation, anti- } \\
\text { collision }\end{array}$ & $\begin{array}{c}\text { Operational } \\
\text { Structurally sound }\end{array}$ & 100 & $\begin{array}{l}\text { - Functional at all times } \\
\text { - No damaged or missing parts } \\
\text { Timeliness Requirement: } \\
\text { - Repair or replace within } 24 \text { hours of notification or discovery }\end{array}$ & Each \\
\hline
\end{tabular}




\begin{tabular}{|c|c|c|c|c|}
\hline ASSET & OUTCOME & $\begin{array}{c}\text { TARGET } \\
(\%)\end{array}$ & TOLERANCE \& CRITERIA & UOM \\
\hline Guardrail & $\begin{array}{l}\text { Functional } \\
\text { Undamaged }\end{array}$ & 100 & $\begin{array}{l}\text { - No damage or rust that affects the structural integrity, no } \\
\text { - } \text { missing damaged post } \\
\text { - No loose or missing parts } \\
\text { - No graffiti } \\
\text { - Meets NCHRP } 350 \text { standards } \\
\text { Timeliness Requirement: } \\
\text { - Badly damaged guardrail shall be mitigated immediately upon } \\
\text { - } \text { notification or discovery } \\
\text { - } \text { dadly damaged guardrail shall be repaired or replaced within } 3 \\
\text { Damaged but functional guardrail shall be repaired or replaced } \\
\text { within } 7 \text { days of notification or discovery }\end{array}$ & LFT \\
\hline Impact Attenuators & $\begin{array}{l}\text { Functional } \\
\text { Undamaged }\end{array}$ & 100 & 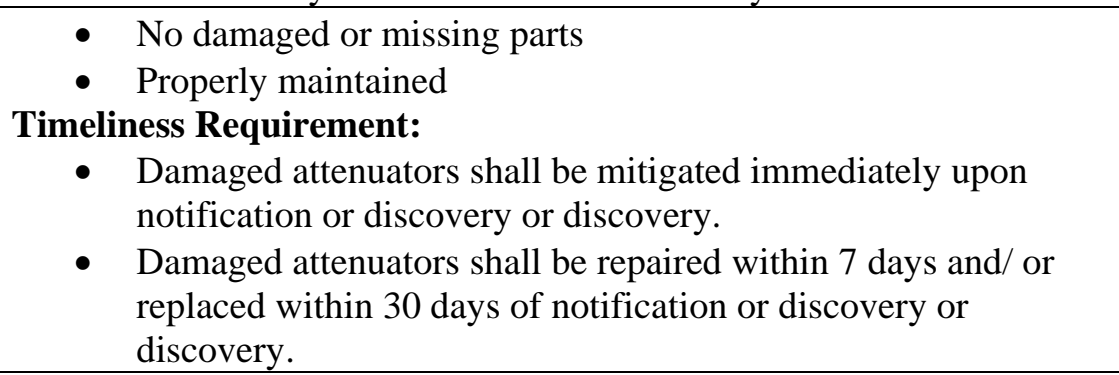 & Each \\
\hline $\begin{array}{l}\text { Object Markers \& } \\
\text { Delineators }\end{array}$ & $\begin{array}{c}\text { Present } \\
\text { Reflective } \\
\text { Functional }\end{array}$ & 90 & $\begin{array}{l}\text { - } \quad<10 \% \text { missing or damaged parts } \\
\text { - Post mounted delineator height } 4 \text { foot (+/- } 6 \text { inches to achieve } \\
\text { uniform appearance) mileage markers are at least } 60 \text { " to } \\
\text { achieve uniform appearance. } \\
\text { - Meets reflectivity standards }\end{array}$ & Each \\
\hline Glare Foils & $\begin{array}{c}\text { Present } \\
\text { Functional }\end{array}$ & 90 & $\begin{array}{ll} & <10 \% \text { missing or damaged } \\
\text { - } & \text { Properly mounted } \\
\text { - } & \text { Uniform in appearance } \\
\end{array}$ & Each \\
\hline
\end{tabular}




\begin{tabular}{|c|c|c|c|c|}
\hline ASSET & OUTCOME & $\begin{array}{l}\text { TARGET } \\
(\%)\end{array}$ & TOLERANCE \& CRITERIA & UOM \\
\hline & Smooth & & $\begin{array}{l}\text { • No pavement obstructions that present a safety hazard } \\
\text { Timeliness Requirement } \\
\text { - Temporary repairs to potholes } 6 \text { ” x 6” x } 1 \text { 1/2” deep or larger } \\
\text { shall be repaired immediately upon notification or discovery. } \\
\text { All others within } 2 \text { days of notification or discovery } \\
\text { - Permanent repairs to potholes/ pavement failures shall be } \\
\text { completed within } 30 \text { days of notification or discovery during } \\
\text { seasons when asphalt plants are operating or within } 30 \text { days of } \\
\text { asphalt plants opening for the season } \\
\text { - Pavement obstructions that present a safety hazard shall be } \\
\text { mitigated immediately }\end{array}$ & \\
\hline $\begin{array}{l}\text { Paved Shoulders and } \\
\text { Rumble Strips (Asphalt) }\end{array}$ & $\begin{array}{c}\text { Safe } \\
\text { Smooth } \\
\text { Functional }\end{array}$ & 90 & 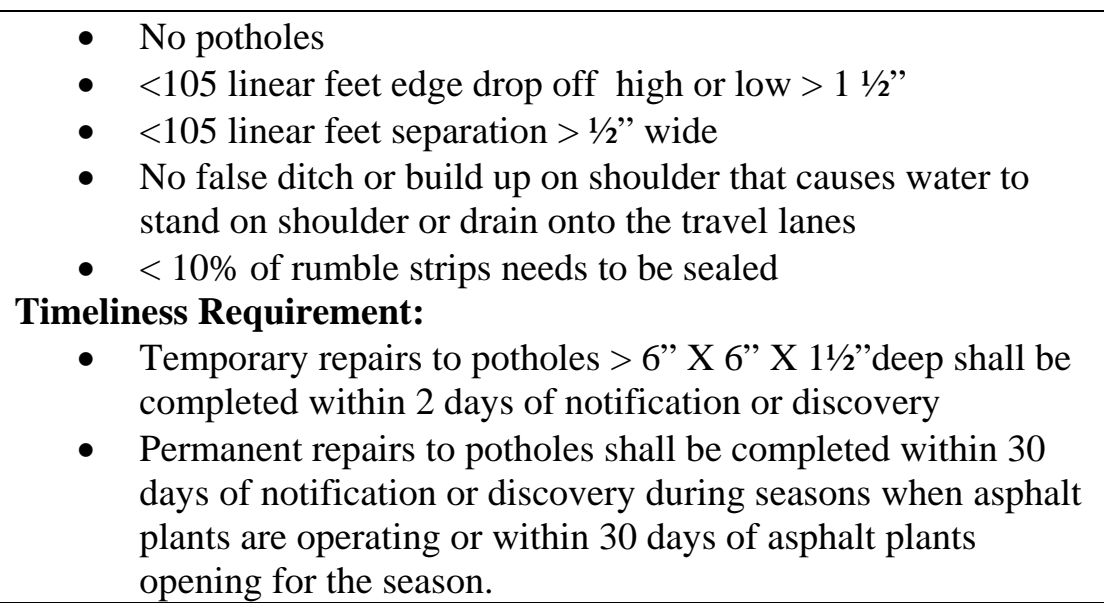 & Sq. Ft. \\
\hline Unpaved Shoulders & $\begin{array}{c}\text { Safe } \\
\text { Smooth }\end{array}$ & 90 & $\begin{array}{l}\text { - No potholes } \\
\text { - } \quad \text { No linear feet edge drop off high or low }>11 / 2 \text { " ditch or build up on shoulder that causes water to } \\
\text { - stand on shoulder or drain onto the travel lanes } \\
\text { - No erosion }>2 \text { " deep } \\
\text { Timeliness Requirement: } \\
\text { - All potholes shall be repaired within } 7 \text { days of notification or } \\
\text { - } \text { discovery } \\
\text { Erosion }>2 \text { " deep shall be repaired within } 7 \text { days of }\end{array}$ & Sq. Ft \\
\hline
\end{tabular}




\begin{tabular}{|c|c|c|c|c|}
\hline ASSET & OUTCOME & $\begin{array}{c}\text { TARGET } \\
(\%)\end{array}$ & TOLERANCE \& CRITERIA & UOM \\
\hline Concrete Surface & $\begin{array}{c}\text { Safe } \\
\text { Durable } \\
\text { Smooth }\end{array}$ & 95 & 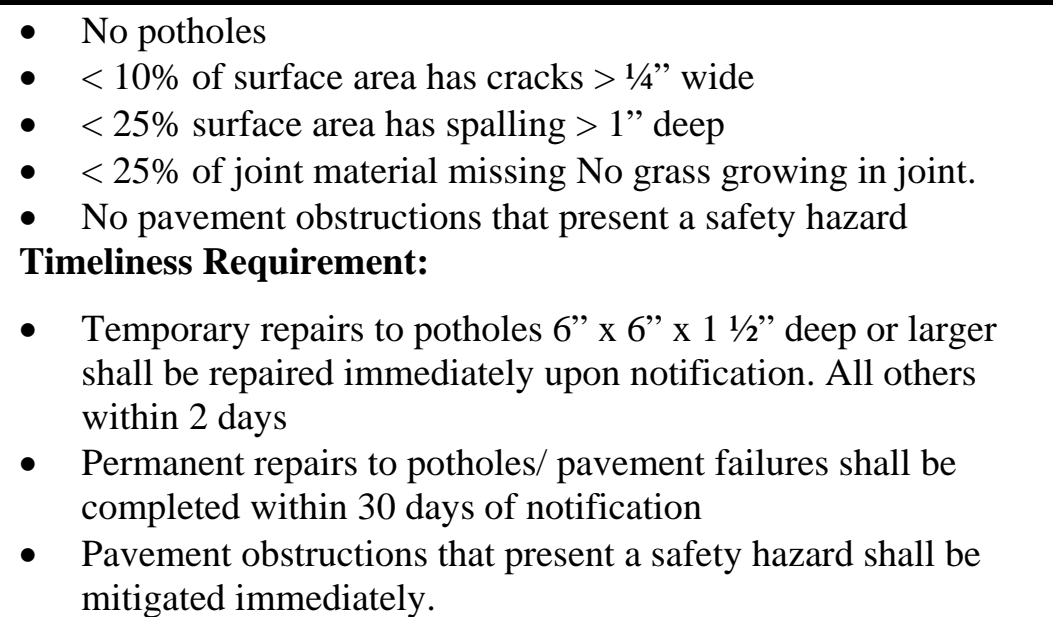 & $\begin{array}{l}\text { Sq. } \\
\text { Ft }\end{array}$ \\
\hline
\end{tabular}




\begin{tabular}{|c|c|c|c|c|}
\hline ASSET & OUTCOME & $\begin{array}{c}\text { TARGET } \\
(\%)\end{array}$ & TOLERANCE \& CRITERIA & UOM \\
\hline & & & $\begin{array}{l}\text { Timeliness Requirement: } \\
\text { - Temporary repairs to potholes 6” x 6” x } 1 \text { 1/2” deep or larger } \\
\text { shall be repaired immediately upon notification or discovery. } \\
\text { All others within } 2 \text { days of notification or discovery } \\
\text { - Permanent repairs to potholes shall be completed within } 30 \\
\text { days of notification or discovery and flush with surrounding } \\
\text { surface } \\
\text { - Damaged/ missing bridge railing shall be mitigated } \\
\text { immediately upon notification or discovery } \\
\text { - Damaged/ missing railing shall be repaired or replaced within } \\
30 \text { days }\end{array}$ & \\
\hline $\begin{array}{l}\text { Superstructure (Includes } \\
\text { Parapet Walls) }\end{array}$ & $\begin{array}{l}\text { Structurally Sound } \\
\text { Free of Debris }\end{array}$ & 90 & $\begin{array}{l}\text { - } \quad \text { Perform all routine/ordinary maintenance including sweeping, } \\
\text { - } \quad \text { Noshing, clearing of all obstructions. } \\
\text { - } \quad \text { Bearing assemblies clean and free of debris } \\
\text { - } \quad \text { No damaged or missing parts } \\
\text { - Bridge components are free of damaging vegetation. } \\
\text { - VDOT Structure Report shall be reference for other routine } \\
\text { maintenance and minor repair needs }\end{array}$ & Sq. Ft \\
\hline Substructure & $\begin{array}{l}\text { Structurally Sound } \\
\text { Free of debris }\end{array}$ & 90 & $\begin{array}{l}\text { - Seats clean and free of debris } \\
\text { - VDOT Structure Report shall be reference for other routine } \\
\text { maintenance and minor repair needs }\end{array}$ & Sq. Ft \\
\hline Slope Protection & $\begin{array}{l}\text { Structurally Sound } \\
\text { Minimal Erosion }\end{array}$ & 90 & $\begin{array}{ll}- & \text { No trend or pattern of erosion }>2 \text { " deep } \\
\text { - } & \text { No settlement }>\text { "” } \\
\text { - } & \text { No damaging vegetation }\end{array}$ & Sq. Ft \\
\hline Weep Holes & Functional & 90 & - $\quad \geq 90 \%$ of diameter open & Each \\
\hline \multicolumn{5}{|c|}{ SERVICES GROUP } \\
\hline $\begin{array}{l}\text { Incident/Emergency } \\
\text { Response }\end{array}$ & $\begin{array}{l}\text { Timely } \\
\text { Efficient } \\
\text { Safe } \\
\text { Effective }\end{array}$ & 100 & $\begin{array}{l}\text { - The contractor shall provide equipment/ personnel as } \\
\text { necessary to support EMS operations } 24 \text { hours, } 7 \text { days a week. } \\
\text { - The contractor after arriving on site shall take necessary action } \\
\text { using appropriate resources to handle any and all traffic } \\
\text { control needs to insure the safety of the incident scene and }\end{array}$ & Each \\
\hline
\end{tabular}




\begin{tabular}{|c|c|c|c|c|}
\hline ASSET & OUTCOME & $\begin{array}{c}\text { TARGET } \\
(\%)\end{array}$ & TOLERANCE \& CRITERIA & UOM \\
\hline & & & $\begin{array}{l}\text { - } \text { traveling public } \\
\text { The Contractor shall provide proper notification of all } \\
\text { incidents to the Smart Traffic Center } \\
\text { Timeliness Requirement: } \\
\text { - On site response during normal business hours within } 30 \\
\text { minutes of notification or discovery } \\
\text { - On site response after normal business hours, and on } \\
\text { weekends and holidays within } 60 \text { minutes of notification or } \\
\text { discovery } \\
\text { - Temporary lane closures if needed, shall installed immediately } \\
\text { upon arrival on scene } \\
\text { Permanent lane closures if needed shall be installed within } 60 \\
\text { minutes of arrival on scene }\end{array}$ & \\
\hline Customer Response & $\begin{array}{c}\text { Timely } \\
\text { Efficient } \\
\text { Effective } \\
\text { Productive }\end{array}$ & 100 & $\begin{array}{l}\text { - All customer concerns/ requests shall be resolved to the } \\
\text { Department's satisfaction } \\
\text { Timeliness Requirement: } \\
\text { - Contact the customer within } 2 \text { days following the initial } \\
\text { customer inquiry } \\
\text { - Work resulting from request shall be scheduled within } 2 \text { days } \\
\text { of the initial customer contact } \\
\text { - Follow - up contact within } 3 \text { days of the completion of work }\end{array}$ & Each \\
\hline Snow \& Ice Control & $\begin{array}{c}\text { Safe } \\
\text { Effective } \\
\text { Efficient }\end{array}$ & 100 & 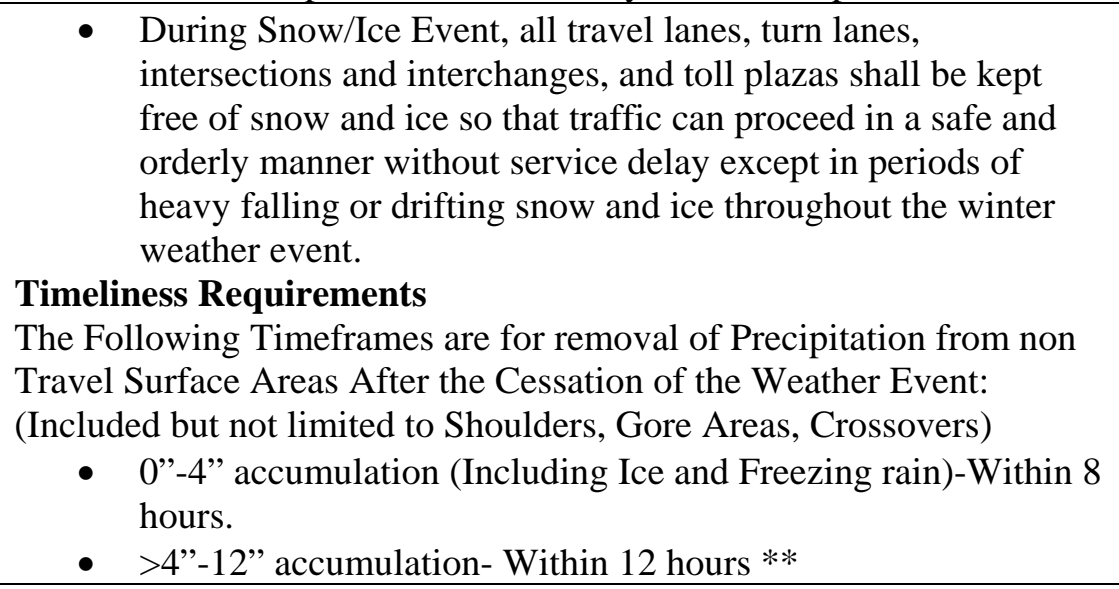 & Each \\
\hline
\end{tabular}




\begin{tabular}{|c|c|c|c|c|}
\hline ASSET & OUTCOME & $\begin{array}{c}\text { TARGET } \\
(\%) \\
\end{array}$ & TOLERANCE \& CRITERIA & UOM \\
\hline Roadway Sweeping & $\begin{array}{l}\text { Neat, Clean } \\
\text { appearance } \\
\text { Free of Debris }\end{array}$ & 90 & $\begin{array}{l}\text { No debris (sand, gravel, dirt) at barrier walls, retaining walls, } \\
\text { sidewalks, or curb and gutter } \\
\text { - Contractor to provide schedule of planned sweeping } \\
\text { operations. }\end{array}$ & Each \\
\hline Graffiti Removal & None present & 90 & $\begin{array}{l}\text { Timeliness Requirements } \\
\text { - Graffiti to be removed within } 48 \text { hours from notification } \\
\text { or discovery. }\end{array}$ & Each \\
\hline
\end{tabular}




\section{ATTACHMENT IV - SPECIAL TERMS AND CONDITION NOTES}

This section is reserved for special provisions, additional information and additional requirements that are unique to the locations covered under this contract.

\section{TRAFFIC WORK RESTRICTIONS}

Traffic work restrictions are listed in the following table

\begin{tabular}{|c|c|c|c|c|c|c|}
\hline $\begin{array}{l}\text { Route } \\
\text { ID }\end{array}$ & County & $\begin{array}{l}\text { From } \\
\text { _MP }\end{array}$ & $\begin{array}{l}\text { To } \\
\_ \text {MP }\end{array}$ & Description & $\begin{array}{l}\text { Volume } \\
\text { Range }\end{array}$ & $\begin{array}{l}\text { Week Day Work } \\
\text { Only }\end{array}$ \\
\hline I-64 & $\begin{array}{l}\text { Lousia, Goochland, } \\
\text { Henrico \& New Kent }\end{array}$ & 147.71 & 204.62 & $\begin{array}{l}\text { Louisa CL to James } \\
\text { City CL }\end{array}$ & $\begin{array}{c}16000 \text { to } \\
69000\end{array}$ & $\begin{array}{l}\text { 9:30 PM to 5:30 } \\
\text { AM }\end{array}$ \\
\hline I-95 & $\begin{array}{l}\text { Colonial Heights, } \\
\text { Chesterfield, Richmond, }\end{array}$ & 48.59 & 73.00 & $\begin{array}{l}\text { From Wagner Rd to } \\
\text { Maury Street }\end{array}$ & $\begin{array}{l}20000 \text { to } \\
52000\end{array}$ & $\begin{array}{l}\text { 9AM-3 PM and } \\
\text { 6:30PM-5:30 AM }\end{array}$ \\
\hline I-95 & Richmond, Henrico & 73.00 & 83.00 & $\begin{array}{l}\text { Maury Street to } \\
\text { Parham Road }\end{array}$ & $\begin{array}{l}20000 \text { to } \\
52000\end{array}$ & $\begin{array}{c}\text { 9:30 PM to 5:30 } \\
\text { AM }\end{array}$ \\
\hline I-95 & Henrico, Hanover & 83.00 & 101.30 & $\begin{array}{l}\text { Parham Road to } \\
\text { Caroline CL }\end{array}$ & $\begin{array}{l}20000 \text { to } \\
52000\end{array}$ & $\begin{array}{l}\text { 9AM-3 PM and } \\
\text { 6:30PM-5:30 AM }\end{array}$ \\
\hline I-195 & Henrico & 0.00 & 3.50 & $\begin{array}{c}\text { SR-00195S to IS- } \\
00095 \mathrm{~S}\end{array}$ & $\begin{array}{c}15000 \text { to } \\
39000\end{array}$ & $\begin{array}{c}\text { 9:30 PM to 5:30 } \\
\text { AM }\end{array}$ \\
\hline $\mathrm{I}-295$ & Henrico, Hanover & 0.00 & 27.64 & From I-64 to Rt 895 & $\begin{array}{c}20000 \text { to } \\
45000\end{array}$ & $\begin{array}{c}\text { 9:30 PM to 5:30 } \\
\text { AM }\end{array}$ \\
\hline I-295 & $\begin{array}{l}\text { Henrico, Chesterfield, } \\
\text { Prince George }\end{array}$ & 27.64 & 52.62 & From Rt 895 to I-95S & $\begin{array}{l}20000 \text { to } \\
8600\end{array}$ & $\begin{array}{l}\text { 9AM-3 PM and } \\
\text { 6:30PM-5:30 AM }\end{array}$ \\
\hline SR00076 & Chesterfield & 1.13 & 9.60 & $\begin{array}{l}\text { From Rt. } 288 \text { to } \\
\text { WCL Richmond }\end{array}$ & 34000 & $\begin{array}{c}\text { 9:30 PM to 5:30 } \\
\text { AM }\end{array}$ \\
\hline SR00076 & Henrico & 11.44 & 13.04 & $\begin{array}{c}\text { Henrico Maint. } \\
\text { Chesterfield CL to I- } \\
\text { 195S }\end{array}$ & 70029 & $\begin{array}{c}\text { 9:30 PM to 5:30 } \\
\text { AM }\end{array}$ \\
\hline SR00150 & Chesterfield & 4.58 & 15.19 & $\begin{array}{l}\text { From ECL } \\
\text { Richmond to I-95 }\end{array}$ & 58204 & $\begin{array}{c}\text { 9:30 PM to 5:30 } \\
\text { AM }\end{array}$ \\
\hline SR00288 & Chesterfield & 0.00 & 28.24 & $\begin{array}{l}\text { From I-95 to } \\
\text { Goochland CL }\end{array}$ & 35166 & $\begin{array}{c}\text { 9:30 PM to 5:30 } \\
\text { AM } \\
\end{array}$ \\
\hline SR00288 & Goochland & 28.24 & 32.56 & $\begin{array}{l}\text { Goochland CL to I- } \\
64\end{array}$ & 23394 & $\begin{array}{c}\text { 9:30 PM to 5:30 } \\
\text { AM }\end{array}$ \\
\hline SR00195 & Henrico & 0.00 & 2.50 & $\begin{array}{c}\text { James River Bridge } \\
\text { to } 2.50 \mathrm{mi} \mathrm{N} \text { of I-95 } \\
\text { tie in }\end{array}$ & - & $\begin{array}{c}\text { 9:30 PM to 5:30 } \\
\text { AM }\end{array}$ \\
\hline SR00146 & City of Richmond & 0.00 & 0.86 & $\begin{array}{c}\text { Rt. } 76 \text { NB to } \\
\text { Sheppard St. } \\
\text { overpass }\end{array}$ & - & $\begin{array}{c}\text { 9:30 PM to 5:30 } \\
\text { AM }\end{array}$ \\
\hline
\end{tabular}

\section{ADDITIONAL ASSETS - PERFORMANCE REQUIREMENTS}

Additional Assets to be considered under this agreement include the following 


\subsection{VEGETATION, MOWING STANDARDS .}

LISTED BELOW ARE SELECTED AREAS ON ALL ROUTS UNDER THIS CONTRACT THAT WILL REQUIRE AN URBAN MOWING STANDARD.

URBAN MOWING STANDARD IS DEFINED AS AREA THAT REQUIRES MOWING EITHER BY HAND OR SMALL TRACTOR MOWING TO THE RIGHT-OF- WAY LINE. THESE AREAS CONTAIN STEEP FILL AND CUT SLOPES IN THE HIGHLY VISIBLE METROPOLITAN RICHMOND AREA AND WILL BE MOWED EVERY MOWING CYCLE. THE AREAS LISTED BELOW WITH AN * INDICATE GRASS NOT TO EXCEED 8” IN HEIGHT (FOLLOW EXISTING MOW LINES)

\begin{tabular}{|c|c|c|}
\hline Route Number & Termini From & Termini To \\
\hline $\begin{array}{l}\text { I-64 EAST } \\
\text { HENRICO }\end{array}$ & $\begin{array}{l}\text { MM \# } 191.00 \text { E \& W FROM }{ }^{\mathrm{TH}} \text {. ST. } \\
\text { EXIT TO I-95 S \& H }\end{array}$ & $\begin{array}{l}\text { MM \# 191.93 XOVER AT END MB. WALL. } \\
\text { (overlap I-95) }\end{array}$ \\
\hline $\begin{array}{l}\text { I-64 WEST } \\
\text { HENRICO }\end{array}$ & MM \# 181.17 E \& W & $\begin{array}{l}\text { MM \# 191.93 RAMP TO DOWN TOWN } \\
\text { EXPWY. \& @ I-95 RAMP N \& S (overlap I- } \\
\text { 95) }\end{array}$ \\
\hline $\begin{array}{l}\text { I-95 CITY OF } \\
\text { RICHMOND }\end{array}$ & MM \# $73.0 \mathrm{~N} \& \mathrm{~S}$ & MM \# 82.0 N \& S \\
\hline $\begin{array}{l}\text { * I-195 NB CITY OF } \\
\text { RICHMOND }\end{array}$ & $\begin{array}{l}\text { MM \# 00 SIGN@ MEADOW ST.O.P } \\
\text { (END SR.195 }\end{array}$ & END @ I-64 WB TIE-IN MM \# 4.20 \\
\hline $\begin{array}{l}\text { * I-195 SB CITY OF } \\
\text { RICHMOND }\end{array}$ & MM \# 4.16 @ I-64 EB & $\begin{array}{l}\text { END @ MEADOW ST.O.P (BEG.SR. } 195 \text { MM } \\
\# 00\end{array}$ \\
\hline $\begin{array}{l}\text { * I-195 NB CITH OF } \\
\text { RICHMOND }\end{array}$ & MM \# 00 @ MEADOW ST. RAMP & TO I-64 EB/I-95 SB MM \# 0.44 RAMP \\
\hline $\begin{array}{l}* \text { I-195 NB CITY OF } \\
\text { RICHMOND }\end{array}$ & $\begin{array}{l}\text { FROM MM \# } 00 @ \text { MEADOW ST. } \\
\text { RAMP }\end{array}$ & I-95 NB MM \# 0.74 RAMP \\
\hline $\begin{array}{l}\text { * I-195 SB CITY OF } \\
\text { RICHMOND }\end{array}$ & FROM I-64 WB MM \# 00 RAMP & TO I-195 SB MM \# 0.38 RAMP \\
\hline $\begin{array}{l}\text { SR \# } 150 \\
\text { CHESTERFIELD }\end{array}$ & FROM MM \# 150 RICHMOND C.L. & TO MM \# 10.91 RAMP TIE-IN TO I-95 N/S \\
\hline $\begin{array}{l}\text { SR \# } 150 \\
\text { HENRICO }\end{array}$ & FROM N END WILLEY BR.MM \# 00 & TO MM \# 1.28 INT. RIVER ROAD. \\
\hline $\begin{array}{l}\text { * SR \# } 195 \text { NB CITY } \\
\text { OF RICHMOND }\end{array}$ & MM \# 00 FROM I-95 NB @ JRB & MM \# 0.29 @ TIE-IN \\
\hline $\begin{array}{l}\text { * SR \# } 195 \text { SB CITY } \\
\text { OF RICHMOND }\end{array}$ & FROM MEADOW ST. O.P & END @ I-95 NB TIE-IN MM \# 2.50 \\
\hline $\begin{array}{l}\text { * SR \# } 195 \text { SB CITY } \\
\text { OF RICHMOND }\end{array}$ & FROM TIE-IN MM \#00 & END @ I-95 SB TIE-IN MM \# 0.17 \\
\hline $\begin{array}{l}\text { * SR \# } 146 \text { NB CITY } \\
\text { OF RICHMOND }\end{array}$ & FROM SR \# 76 NB MM \# 00 & END @ SHEPPARD ST. O.P MM \# 0.86 \\
\hline $\begin{array}{l}\text { * SR \# } 146 \text { SB CITY } \\
\text { OF RICHMOND }\end{array}$ & $\begin{array}{l}\text { FROM } 0.09 \text { MI. N SHEPPARD ST. O.P } \\
\text { MM \# } 00\end{array}$ & END @ SR. 76 SB TIE-IN MM \# 1.00 \\
\hline SR \# 76 TOLL & MM \# 00 SOUTH END JAMES RIVER & MM \# 1.45 OP FROM I-195 SBL TO SR 195 \\
\hline
\end{tabular}




\begin{tabular}{|l|l|l|}
\hline \multicolumn{1}{|c|}{ Route Number } & \multicolumn{1}{|c|}{ Termini From } & \multicolumn{1}{c|}{ Termini To } \\
\hline ROAD. HENRICO & BR. EBL & DOWNTOWN EXPWAY. \\
\hline $\begin{array}{l}\text { SR \#76 TOLL } \\
\text { ROAD } \\
\text { CHESTERFIELD }\end{array}$ & $\begin{array}{l}\text { MM \# 00 S. END JAMES RIVER } \\
\text { BR.WBL }\end{array}$ & $\begin{array}{l}\text { MM \# 1.60 OP FROM I-195SBL TO SR 195 } \\
\text { DOWNTOWN EXPWAY. }\end{array}$ \\
\hline $\begin{array}{l}\text { SR\# 76 TOLL } \\
\text { ROAD } \\
\text { CHESTERFIELD }\end{array}$ & MM \# 00 INT. RT. \# 652 N \& S & MM \# 11.44 S. END JAMES RIVER BR. \\
\hline
\end{tabular}

\subsection{MECHANICAL SWEEPING}

Listed below are the routes and sections, by mile marker, that will require sweeping on a regular scheduled cycle.

This does not relieve the contractor from normal sweeping activities on all other areas of these routes on an as needed basis. Each section will require sweeping in both direction of the route and include left and right shoulder area.

\begin{tabular}{|c|c|c|c|c|c|c|}
\hline Route & From: mm & $\begin{array}{l}\text { To: } \\
\text { mm }\end{array}$ & Direction & $\begin{array}{c}\text { Collector } \\
\text { Rd./Ramp's }\end{array}$ & $\begin{array}{c}\text { Cycle } 2 \\
\text { mo. }\end{array}$ & $\begin{array}{c}\text { Cycle } 4 \\
\text { mo. }\end{array}$ \\
\hline $\begin{array}{l}\text { I-64 west } \\
\text { end }\end{array}$ & 181.17 (overlap I-95) & 191.93 & $\mathrm{e} / \mathrm{w}$ & $\mathrm{n} / \mathrm{a}$ & $\mathrm{x}$ & \\
\hline $\begin{array}{l}\text { I-64 east } \\
\text { end }\end{array}$ & 191.15 (overlap I-95) & 191.93 & $\mathrm{e} / \mathrm{w}$ & $\mathrm{n} / \mathrm{a}$ & $\mathrm{x}$ & \\
\hline I-95 & 53.01 & 82.20 & $\mathrm{n} / \mathrm{s}$ & $\mathrm{x}$ & $\mathrm{x}$ & \\
\hline I-95 & 86.10 & 86.89 & $\mathrm{n} / \mathrm{s}$ & $\mathrm{n} / \mathrm{a}$ & & $\mathrm{x}$ \\
\hline I-95 & 86.65 & 87.45 & $\mathrm{n} / \mathrm{s}$ & $\mathrm{x}$ & & $\mathrm{x}$ \\
\hline $\mathrm{I}-195$ & 1.00 & 1.18 & $\mathrm{n}$ & & & $\mathrm{x}$ \\
\hline $\mathrm{I}-195$ & 1.36 & 1.58 & $\mathrm{n}$ & & & $\mathrm{x}$ \\
\hline $\mathrm{I}-195$ & 1.58 & 3.83 & $\mathrm{n}$ & & & $\mathrm{x}$ \\
\hline $\mathrm{I}-195$ & 1.69 & 3.85 & $\mathrm{~s}$ & & & $\mathrm{x}$ \\
\hline $\mathrm{I}-195$ & 1.0 & 1.21 & $\mathrm{~s}$ & & & $\mathrm{x}$ \\
\hline $\mathrm{I}-295$ & 16.90 & 19.27 & $\mathrm{n} / \mathrm{s}$ & $\mathrm{n} / \mathrm{a}$ & & $\mathrm{x}$ \\
\hline Rte. 76 & 3.22 & 3.72 & $\mathrm{n}$ & $\mathrm{x}$ & & $\mathrm{x}$ \\
\hline Rte.76 & 4.05 & 4.29 & $\mathrm{n}$ & $\mathrm{x}$ & & $\mathrm{x}$ \\
\hline Rte.76 & 5.52 & 9.35 & $\mathrm{n} / \mathrm{s}$ & $\mathrm{n} / \mathrm{a}$ & & $\mathrm{x}$ \\
\hline Rte.76 & 6.56 & 7.42 & $\mathrm{n}$ & $\mathrm{x}$ & & $\mathrm{X}$ \\
\hline Rte. 76 & 10.58 & 11.44 & $\mathrm{n} / \mathrm{s}$ & Toll plaza & & $\mathrm{x}$ \\
\hline Rte. 76 & 6.19 & 7.20 & $\mathrm{~s}$ & $\mathrm{X}$ and toll plaza & & $\mathrm{x}$ \\
\hline Rte. 76 & 3.82 & 4.10 & $\mathrm{~s}$ & $\mathrm{X}$ and toll plaza & & $\mathrm{x}$ \\
\hline
\end{tabular}




\begin{tabular}{|l|l|l|c|c|c|c|}
\hline Route & From: mm & $\begin{array}{l}\text { To: } \\
\text { mm }\end{array}$ & Direction & $\begin{array}{c}\text { Collector } \\
\text { Rd./Ramp's }\end{array}$ & $\begin{array}{c}\text { Cycle 2 } \\
\text { mo. }\end{array}$ & $\begin{array}{c}\text { Cycle 4 } \\
\text { mo. }\end{array}$ \\
\hline Rte. 76 & 3.10 & 3.50 & $\mathrm{~s}$ & Toll plaza & & $\mathrm{x}$ \\
\hline Rte.146 & 0.21 & 0.59 & $\mathrm{n}$ & & $\mathrm{x}$ \\
\hline Rte. 146 & 0.37 & 0.75 & $\mathrm{~s}$ & & $\mathrm{x}$ \\
\hline Rte. 150 & 00 & 10.61 & $\mathrm{n} / \mathrm{s}$ & $\begin{array}{c}\text { Tie-in to I-95 n/s } \\
\text { ramps. }\end{array}$ & $\mathrm{x}$ \\
\hline Rte.195 & 0.41 & 0.89 & $\mathrm{~s}$ & & $\mathrm{x}$ \\
\hline Rte. 195 & 0.56 & 1.00 & $\mathrm{~s}$ & $\mathrm{x}$ & $\mathrm{x}$ \\
\hline Rte.288 & 12.33 & 12.65 & $\mathrm{n}$ & $\mathrm{x}$ & $\mathrm{x}$ \\
\hline Rte.288 & 15.06 & 16.82 & $\mathrm{n}$ & $\mathrm{x}$ & $\mathrm{x}$ \\
\hline Rte.288 & 19.90 & 20.95 & $\mathrm{n}$ & $\mathrm{x}$ & $\mathrm{x}$ \\
\hline Rte.288 & 19.88 & 20.87 & $\mathrm{~s}$ & $\mathrm{x}$ & & $\mathrm{x}$ \\
\hline Rte.288 & 15.10 & 16.26 & $\mathrm{~s}$ & $\mathrm{x}$ & & $\mathrm{x}$ \\
\hline Rte.288 & 11.92 & 12.60 & $\mathrm{~s}$ & $\mathrm{x}$ & & \\
\hline
\end{tabular}

\section{ADDITIONAL REQUIREMENTS \& GUIDANCE}

\subsection{SR 895 Contractual Services}

The following provision is applicable to the Richmond Regional North TAMS Contract.

\section{Section 8.15 Contract Services}

If at any time the Department procures a contract for snow and ice removal or other maintenance services for the State Highways on a regional or network basis in the are of the Project, the Department shall require the contractor, so long as it is under contract with the Department, at the Operator's request, to offer comparable services to the Operator on comparable terms and conditions, subject to the contractor's reasonable approval Operator's ability to pay. The Department shall have no obligation to provide any such services to Operator and shall have no liability with respect to the contractor's performance or failure to perform. The Department shall have full discretion to establish priorities for its contractors regarding the timing and location of the services, materials, and equipment, without liability of Operator.

\subsection{SR 288 Warranty Guidance}

Guidance for the 288 Warranty requirements as to what the maintenance responsibility will be for the TAMS contractor and Warranty Contractor.

The Route 288 Warranty will continue to be administered by VDOT. TAMS contractor will not be responsible for items under this warranty until warranty expires. The Pavement warranty may expire at a date earlier than listed below. The dates listed are to serve as a guide. The TAMS Contractor is not 
responsible for normal pot hole repair on the sections under warrantee except for those caused by the items listed in the warranty exclusions.

The Warranty Covers: From Chesterfield/Powhatan County Line to Route I- 64

Pavement Warranty duration

Segment "A" From Powhatan County Line to Va Rt 6 - Aug. 27, 2024

Segment "B" From Va Rt 6 to Va Rt 250 - May 10, 2024

Segment "C" Form VA Rt 250 to Route I-64

Exclusions to Warranty Coverage

Damage to pavement due to accidents, disasters, vandalism, heavy equipment, drainage, pipe or structure collapses and damage to shoulders due to diversion of traffic to shoulders are not covered under the warranty and will be the responsibility of the TAMS Contractor.

Design, workmanship, materials and equipment Warranty duration

Segment "A" - Aug 27, 2009

Segment "B" - May 10, 2009

Segment "C" - Dec 22, 2008

Pavement Markings Thermoplastic and Epoxy Resin duration

Segment "A" - Aug 27, 2010

Segment "B" - May 10,2010

Segment "C" - Dec 22,2009 


\section{ATTACHMENT V - SMALL BUSINESS SUBCONTRACTING PLAN}

\section{Definitions}

Small Business: "Small business " means an independently owned and operated business which, together with affiliates, has 250 or fewer employees, or average annual gross receipts of $\$ 10$ million or less averaged over the previous three years. Note: DMBE-certified women- and minority-owned businesses shall also be considered small businesses when they have received DMBE small business certification.

Women-Owned Business: Women-owned business means a business concern that is at least $51 \%$ owned by one or more women who are citizens of the United States or non-citizens who are in full compliance with United States immigration law, or in the case of a corporation, partnership or limited liability company or other entity, at least $51 \%$ of the equity ownership interest is owned by one or more women who are citizens of the United States or non-citizens who are in full compliance with United States immigration law, and both the management and daily business operations are controlled by one or more women who are citizens of the United States or non-citizens who are in full compliance with the United States immigration law.

Minority-Owned Business: Minority-owned business means a business concern that is at least 51\% owned by one or more minority individuals or in the case of a corporation, partnership or limited liability company or other entity, at least $51 \%$ of the equity ownership interest in the corporation, partnership, or limited liability company or other entity is owned by one or more minority individuals and both the management and daily business operations are controlled by one or more minority individuals.

All small businesses must be certified by the Commonwealth of Virginia, Department of Minority Business Enterprise (DMBE) to participate in the SWAM program. Certification applications are available through DMBE online at www.dmbe.virginia.gov (Customer Service).

Bidder/Offeror Name:

Preparer Name:

Date:

\section{Instructions}

A. If you are certified by the Department of Minority Business Enterprise (DMBE) as a small business, complete only Section A of this form. This shall include DMBE-certified women-owned and minority-owned businesses when they have received DMBE small business certification.

B. If you are not certified by DMBE as a small business and plan to subcontract part of this contract with a DMBE certified business, complete only Section B of this form.

C. If you are not certified by DMBE as a small business and cannot identify any subcontracting opportunities to subcontract part of this contract with a DMBE-certified business, only provide the information requested in Section $\mathrm{C}$ of this form. 


\section{Section A}

If your firm is certified by the Department of Minority Business Enterprise (DMBE), are you certified as a (check only one below):

_ Small Business

__ Small and Women-owned Business

__ Small and Minority-owned Business

Certification number:

Certification date: 


\section{Section B}

Populate the table below to show your firm's plans for utilization of DMBE-certified small businesses in the performance of this contract. This shall include DMBE-certified women-owned and minority-owned businesses that meet the small business definition and have received the DMBE small business certification. Include plans to utilize small businesses as part of joint ventures, partnerships, subcontractors, suppliers, etc.

B. Plans for Utilization of DMBE-Certified Small Businesses for this Procurement

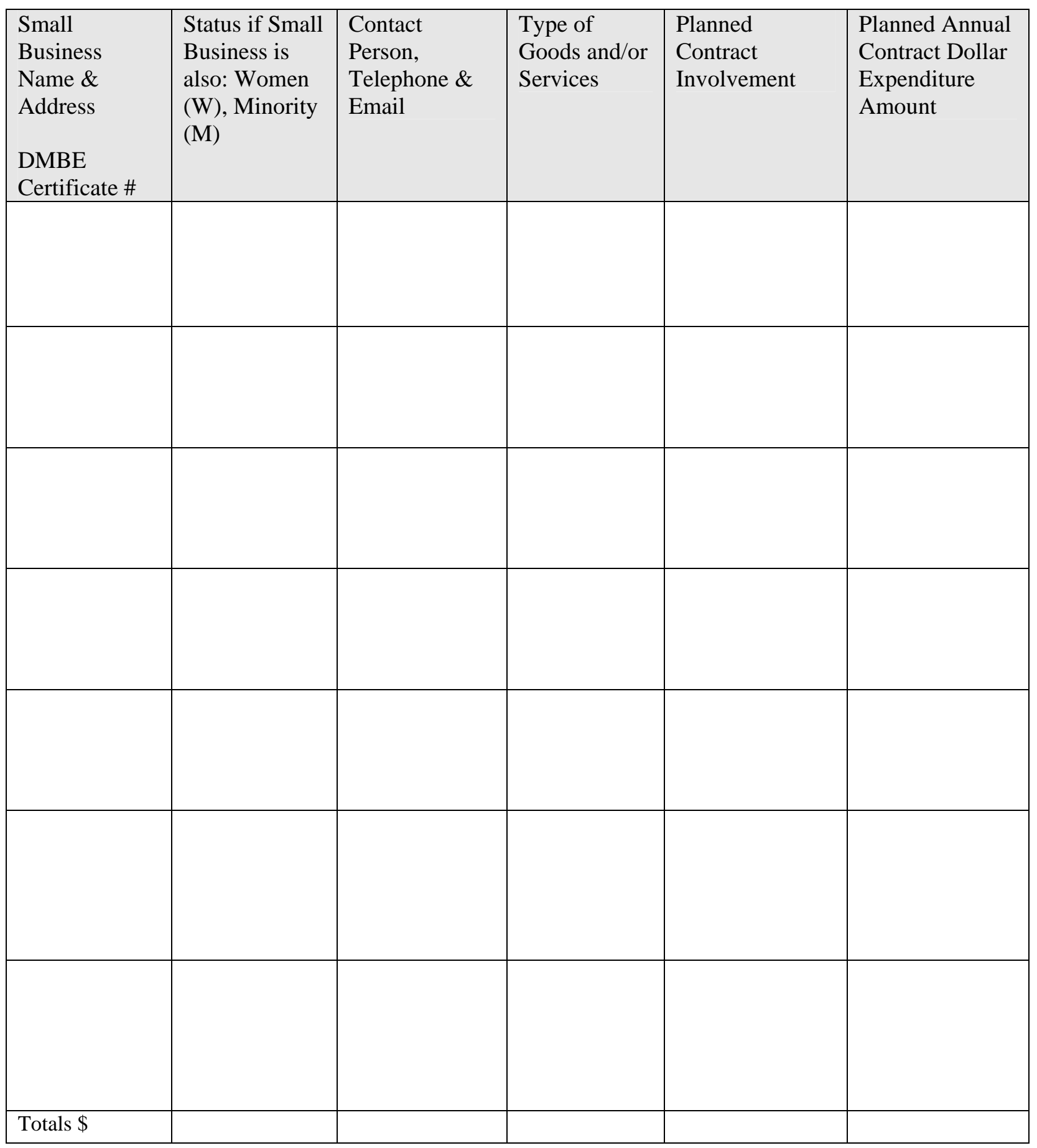




\section{Section C}

Respond to how your business has met or exceeded at least two of the following indicators within the past 24 months. Your response may include any good faith efforts made regarding this procurement.

C. Good Faith Effort Indicators by the Bidder/Offeror

1. Identify areas of work your business has subcontracted to DMBE-certified small businesses for other contracts. Include company names, dates, dollar amounts, and percentages on a per contract basis.

2. List research efforts conducted by your business in the past to locate DMBE-certified small businesses by advertising in publications or in the classified section of the newspaper where small businesses are likely to see it. List specific publications and dates.

3. List small business outreach meetings, conferences, or workshops conducted by your firm to locate DMBE-certified small businesses_-including the dates, participation numbers, and results.

4. Provide documented correspondence (i.e., certified mail, email, receipt of fax transmissions, etc.) to small businesses from the lists provided by DMBE and other outreach agencies and organizations which indicates your solicitation of such for utilization of subcontracting opportunities on other contracts for which your business has competed.

5. List areas of work which your business has subcontracted with DMBE-certified small businesses for upcoming contracts - including the name of the business, certification number, dates, dollar amounts, and percentages on a per contract basis. 
6. Provide documentation of any assistance offered to interested small businesses in obtaining bonds, lines of credit, and/or insurance for any present or past contracts your business has in place.

7. Provide documentation of follow-up on initial contacts with DMBE-certified small businesses (e.g., telephone call logs, emails, certified letters, etc.). Be sure to list the small business name and dates of contact. 


\section{ATTACHMENT VI - FREQUENTLY ASKED QUESTIONS AND ANSWERS}

The following list of frequently asked questions and answers are provided to provide guidance on the requirements of this IFB.

\section{Is TAMS vendor expected to inventory all assets?}

No, only when assets are repaired. GPS required at that time

2. Litter - Define size it items. Is $<20$ items per $10^{\text {th }}$ mile section correct?

The intent of this performance measure is to maintain the roadside in a safe manner, neat in appearance. The standard is 20 fist size items that are visible from the right-of-way, within a tenth mile section. Please note that ramps, regardless of length, will be treated as separate sample units (e.g. any ramp will be equivalent to a $10^{\text {th }}$ mile section). In some cases excessive accumulation of litter that are smaller than "fist size" will have to be removed from the right-of-way.

3. Litter Requirement - Will there be an exception to the timeliness requirement during events?

No exceptions will be considered at this time.

4. Out-Cropping/Rock Cuts - What is the definition of "mitigated" immediately?

Make area safe to the extent possible to allow free flowing of traffic and to create a condition where no further damage can occur.

\section{Clarify "Environmental Work".}

Any work necessary to locate, define limits and acquire necessary environmental clearances prior to commencing maintenance activities. The Contractor is also referred to Section X, Subsection 8 Regulatory Approvals.

6. Does VDOT have any approved waste sites for Debris coming off the interstate? Will VDOT need to approve Contractors Waste Site?

The Department does not have any approved debris sites that are available for use with this contract. The Department does not approve waste sites. The Contractor must comply with all applicable standards (e.g. Federal, State) in the location, installation and use of any waste site. The Contractor must seek and obtain review and comment from the VDOT Contract Administrator and the District Environmental Section for all such activities.

\section{Are Stream permits required to clean Box Culverts?}

The Contractor shall consult with the VDOT Contract Administrator and District Environmental Section prior to commencing any work that may require regulatory approvals.

8. If two barrels of a quad box are $60 \%$ full and two barrels clear does this mean it must be cleared in $\mathbf{3 0}$ days? Permits if required will take longer? If regulatory permits are required for any repair or replacement work, will VDOT consider extending the timeliness requirements? 
The entire structure is evaluated with regard to the $50 \%$ open performance criteria. In this scenario the $50 \%$ timeliness requirement may not be applicable depending on the condition of the other barrels. If regulatory approvals are required the timeliness criteria would go into effect after the permit is obtained, provided that the Contractor meets their responsibility with regard to obtaining regulatory approvals. The Contractor is expected to mitigate any safety issues immediately.

\section{What are the vendor's Rest Area responsibilities for lighting and snow removal?}

Primary contractor will be responsible for lighting along the deceleration lane to the point of the gore entering the rest area and from the point of the gore leaving the rest area along the acceleration lane. Some lighting within the rest area may be on the same circuit.

The primary contractor is responsible for snow removal of the rest area drive through. Rest area contractor is responsible for the remainder. Drive through is defined as one lane into, through, and out of the rest area. Rest areas with separate truck and passenger vehicle parking will have two drive through.

10. What are the vendor's Weight Station responsibilities for lighting, snow removal and mowing?

\section{General Responsibilities}

The memorandum of understanding defines the responsibilities between VDOT \& DMV in Duties of DMV. The following is a summary that describes those responsibilities and includes some of the activities that the TAMS Contractor will be responsible for.

VDOT retains the ownership of and limited access rights to all real property.

DMV is responsible for (but not limited to) the maintenance of the real property (i.e.) facility, automated equipment \& scale signs, scales, lighting (not considered roadway lighting) and grounds maintenance. That would be the grass and plant beds in close proximity to the building that is (aesthetically) maintained more frequently than standard roadside assets.

The TAMS Contractor Responsibility includes but is not limited to the following;

Roadway, and parking area Lighting

ROW Fencing

Repair and Maintain Ramps, Parking facilities, Roadways leading up to the weigh station, Turnout lanes.

Snow removal...to vehicular access areas for aprons and bypass lanes.

Maintenance of grass and plant beds that are not in close proximity to the building and is maintenance at the same level as the mainline roadside areas.

11. What is the definition of an unpaved shoulder? (i.e., on the current contract, an unpaved shoulder exists only where no paved shoulder is present.) 
Definition: Unpaved shoulders are defined as shoulders, or portions of shoulders, that do not contain an asphalt concrete or Portland cement concrete surface. Unpaved shoulders typically consist of unbound, dense-graded aggregate, stabilized soil, or turf. There cannot be any unpaved shoulder on the mainline. Ramps can have unpaved shoulders. The standard shoulder design is from the edge of the paved travel way to the break of the fill or cut slope.

12. Is it VDOT's intent to utilize the MRP of 90 as the overall evaluation or will VDOT have the ability to inspect the road and identify any and all deficiencies and utilize the timeliness performance standard, understanding that in the latter case, VDOT will have the option of 100 percent of the assets being at an MRP of 100?

The overall performance target for the annual evaluation is $90 \%$ all assets. It is not the intent to have an MRP of $100 \%$, one hundred percent of the time. The intent of timeliness performance standards is to have a tool to address immediate safety hazards or to protect the integrity of the roadway asset by preventing further damage.

13. Will permanent repairs as a result of a declared emergency be paid by VDOT or will the contractor have to absorb?

The Contractor is referred to Exhibit A, Section VII. Damage Reimbursement, subsection (f). The Contractor out of pocket expense, not including any pending reimbursement from FEMA, FHWA, or its own insurance coverage, is capped at $20 \%$ of the annual contract value in any given year.

14. For snow and ice control, can VDOT please clarify what defines "heavy falling or drifting snow and ice”? Ex: 2" an hour, etc.?

Heavy Falling snow is defined at 2" of accumulation per hour.

The Department realizes that every possible scenario can not be specifically addressed in the Contract Document however the Department is committed to working with the Contractor in a spirit of partnership to resolve such issues; however it is incumbent on the Contractor to show that ALL necessary steps and precautions were taken to avoid and/or mitigate the roadway effects of inclement weather event. The contractor must also continue in full force from the start of the weather event to its conclusion.

15. Traffic Control - Is it VDOT's intent that every intersection during an event be manned during the road closure?

The general intent is not to have every intersection manned during a road closure; however the contractor may be required to do so, on a case by case basis, in order to meet the requirements of this IFB.

The Contractor is referred to Exhibit A, Section VI, Section 8, Incident and Emergency Response, subsection (b):

The Contractor shall be responsible for all aspects of traffic control related to an incident, including, but not limited to, the entire detour route off the corridor(s) covered by this contract onto other state roads or non-state roads. 


\section{Are lane closures for repair to be performed at night?}

Work zone and lane closure restrictions have been provided. Exceptions to this will be on a case by case basis.

\section{Will there be any changes to the traffic restrictions in the next 5 years?}

Changes in traffic restrictions may occur throughout the life of this contract. The contractor must comply with the current traffic work restrictions for each district or region as updated.

\section{What does emergency response entail?}

Emergency Response shall be interpreted to mean when the Contractor is notified by the Department or any Emergency Management Official, or when the Contractor discovers an incident or accident that impedes the flow of traffic and presents a safety hazard to the traveling public. It is not the intent of this contract to have the contractor continuously respond to "fender benders." The Contractor is referred to applicable portions of the IFB for further clarification on emergency response.

\section{Is the TAMS Contractor responsible for replacing damaged signs?}

The Contractor is responsible for replacement of signs that have been damaged by incident, accident, emergency, inclimate weather, and or by the Contractor's own operations (including sub contractors). The Contractor is not responsible for replacing signs that are non reflective due to normal environmental degradation.

\section{Is pavement marking a part of this project?}

Annual striping is not included. Pavement marking repairs are required only on portions that have been damaged due incident, accident, inclimate weather, emergency operations, as well as any damage that is caused by the contractors own operations, including all subcontractors.

\section{Does guardrail have to be upgraded?}

The Contractor is not expected to uniformly upgrade guardrail due to change in standards; however the contractor is expected to repair or replace guardrail that are damaged. Guardrail terminal end sections when damaged will be repaired to current standards. If a W Beam guardrail (GR-2, GR-8) run is more than $60 \%$ damaged the Contractor shall upgrade the entire run to current standards. If less than $60 \%$ of the entire run is damaged, the damaged section should be replaced with current standards. All fixed object attachments (FOA'S) when damaged will be repaired with current standards.

See Memorandum MM 327

\section{Can recycled material be used for guardrail repairs?}

The Contractor may request the use of recycled materials for guardrail components; however the approval for use of such materials will be on a case by case basis.

\section{What is the definition under striping for "high quality" material?}


Thermoplastic, B-6 Tape, or epoxy resin.

\section{Is vendor responsible for crack sealer?}

The Contractor is not responsible for wholesale cracking sealing, unless required as part of a permanent pothole repair. The Contractor may wish to perform crack sealing to reduce the occurrence of pothole patching on a particular portion of roadway, in such cases the contractor shall obtain approval from the appropriate District.

\section{Is TAMS contractor allowed to bid any additional work not included in TAMS contract?}

The TAMS Contractor is allowed to bid on additional work advertised by the Department.

\section{Is the Contractor required to perform underdeck spall repairs?}

Yes, the contractor is responsible for maintenance of the underdeck which may repair of spalled areas, to the extent required to meet the requirements of this IFB.

27. How do we determine when a structure or any asset needs rehabilitation, as opposed to minor repairs? Example:

(a) Substructure Repair - 5 SF substructure repair may be visible but when sounding would show 100 SF would this then be considered rehabilitation and it be completed under another contract?

The Contractor is responsible for maintaining the travel way open for use at all times. The rehabilitation of bridge substructure repair is the responsibility of the Department and will be carried out either by another contract or a change order to the TAMS contract. The Contractor shall continue to maintain the structure to ensure that the travel way is safe and open for use at all times. The Department will make the determination on a case by case basis as to what level of damage (SF) constitutes rehabilitation. The contractor shall immediately consult with the Department if the contractor encounters the situation described in the question. 


\title{
EXHIBIT B - GENERAL TERMS AND CONDITIONS
}

\author{
VIRGINIA DEPARTMENT OF TRANSPORTATION \\ ADMINISTRATIVE SERVICES DIVISION
}

1. VENDOR'S MANUAL: This solicitation is subject to the provisions of the Commonwealth of Virginia Vendors Manual and any revisions thereto, which are hereby incorporated into this contract in their entirety. A copy of the manual is normally available for review at the purchasing office and in addition, a copy can be obtained by calling the Division of Purchases and Supply (804) 786-3842.

2. CONTRACTUAL DISPUTES: Contractual claims arising after final payment shall be governed by Section 2.2-4363A of the Code of Virginia. This claim shall be submitted to the Commissioner of VDOT who will render a decision within 30 days. Contractual disputes arising during the course of performance shall be submitted to the Administrative Services Administrator who will make a decision in 30 working days, which will be final. Vendors will not be precluded from filing a claim at the conclusion of performance as a result of the decision made during the course of contract performance.

3. APPLICABLE LAW AND COURTS: This solicitation and any resulting contract shall be governed in all respects by the laws of the Commonwealth of Virginia and any litigation with respect thereto shall be brought in the courts of the Commonwealth. The Contractor shall comply with applicable Federal, State and local laws, rules and regulations.

4. ANTI-DISCRIMINATION: By submitting their (bids/proposals), (Bidders/Offerors) certify to the Commonwealth that they will conform to the provisions of the Federal Civil Rights Act of 1964, as amended, as well as the Virginia Fair Employment Contracting Act of 1975, as amended, where applicable, the Virginians With Disabilities Act, the Americans with Disabilities Act and 2.2-4311 of the Virginia Public Procurement Act. If the award is made to a faith-based organization, the organization shall not discriminate against any recipient of goods, services, or disbursements made pursuant to the contract on the basis of the recipient's religion, religious belief, refusal to participate in a religious practice, or on the basis of race, age, color, gender or national origin and shall be subject to the same rules as other organizations that contract with public bodies to account for the use of the funds provided; however, if the faith-based organization segregates public funds into separate accounts, only the accounts and programs funded with public funds shall be subject to audit by the public body (Code of Virginia, 2.2-4343.1E). In every contract over $\$ 10,000$ the provisions in (A) and (B) below apply:

(A) During the performance of this contract, the Contractor agrees as follows:

1. The Contractor will not discriminate against any employee or applicant for employment because of race, religion, color, sex, national origin, age, disability, or any other basis prohibited by state law relating to discrimination in employment, except where there is a bona-fide occupational qualification reasonably necessary to the normal operation of the Contractor. The Contractor agrees to post in conspicuous places, available to employees 
and applicants for employment, notices setting forth the provisions of this nondiscrimination clause.

2. The Contractor, in all solicitations or advertisements for employees placed by or on behalf of the Contractor, will state that such Contractor is an equal opportunity employer.

3. Notices, advertisements and solicitations placed in accordance with federal law, rule or regulation shall be deemed sufficient for the purpose of meeting these requirements.

(B) The Contractor will include the provisions of (A) above in every sub-contract or purchase order over $\$ 10,000$ so that the provisions will be binding upon each Sub-Contractor or Vendor.

5. ETHICS IN PUBLIC CONTRACTING: By submitting their bids or proposals, Bidders or Offerors certify their bids or proposals are made without collusion or fraud and they have not offered or received any kickbacks or inducements from any other Bidder or Offeror, supplier, manufacturer or SubContractor in connection with their bid or proposal, and they have not conferred on any public employee having official responsibility for this procurement transaction any payment, loan, subscription, advance, deposit of money, services or anything of more than nominal value, present or promised, unless consideration of substantially equal or greater value was exchanged.

6. IMMIGRATION REFORM AND CONTROL ACT OF 1986: By signing their bids or proposals, the Bidders or Offerors certify that they do not and will not during the performance of this contract employ illegal alien workers or otherwise violate the provisions of the Federal Immigration Reform and Control Act of 1986.

7. DEBARMENT STATUS: By submitting their (bids/proposals), (Bidders/Offerors) certify that they are not currently debarred by the Commonwealth of Virginia from submitting bids or proposals on contracts for the type of goods and/or services covered by this solicitation, nor are they an agent of any person or entity that is currently so debarred.

8. ANTI-TRUST: By entering into a contract, the Contractor conveys, sells and transfers to the Commonwealth of Virginia all rights, title and interest have in and to all causes of the action it may now or hereafter acquire under the antitrust laws of the United States and the Commonwealth of Virginia, relating to the particular goods purchased or acquired by the Commonwealth of Virginia under said contract.

9. MANDATORY USE OF STATE FORM AND TERMS AND CONDITIONS: Failure to submit a bid on the official State form provided for that purpose shall be a cause for rejection of the bid.

Modification of or additions to any portion of the invitation for bids may be cause for rejection of the bid; however, VDOT reserves the right to decide, on a case by case basis, in its sole discretion, whether or not to reject such a bid as non-responsive. As a precondition to its acceptance, VDOT may, in its sole discretion, request that the Bidder withdraw or modify non-responsive portions to a bid which do not affect quality, quantity, price or delivery. No modification of or addition to the provisions of the contract 
shall be effective unless reduced to writing and signed by the parties. Failure to submit a proposal on the official State form provided for that purpose may be a cause for rejection of the proposal. Modification of or additions to the General Terms and Conditions of the solicitation may be cause for rejection of the proposal; however VDOT reserves the right to decide, on a case-by-case basis, in its sole discretion, whether to reject such a proposal.

10. CLARIFICATION OF TERMS: If any prospective Bidder or Offeror has questions about the specifications or other bid documents, the prospective Bidder or Offeror should submit a written request to the buyer whose name appears on the face of the solicitation, no later than 5 days before the due date. Any revisions to the solicitation will be made only by addendum issued by the buyer.

11. PAYMENT TO PRIME CONTRACTORS: Invoices for items ordered, delivered and accepted by VDOT shall be submitted by the Contractor direct to the payment address shown on purchase order/contract. All invoices shall show the VDOT contract number and/or purchase order number; social security number (for individual Contractors) or the federal employer identification number' (for proprietorships, partnerships, and corporations).

12. PAYMENT TERMS: Any payment terms requiring payment in less than 30 days will be regarded as requiring payment 30 days after delivery of an accepted invoice. This, however, shall not affect offers of discounts for prompt payment in less than 30 days. All goods or services provided under this contract or purchase order, that are to be paid with public funds, shall be billed by the Contractor at the contract price, regardless of which public agency is being billed. The following shall be deemed to be the date of payment: the date of postmark in all cases where payment is made by mail, or the date of offset when offset proceedings have been instituted as authorized under the Virginia Debt Collection Act.

13. PAYMENT TO SUB-CONTRACTOR: A Contractor awarded a contract under this solicitation is hereby obligated:

A. To pay the Sub-Contractors within seven (7) days of the Contractor's receipt of payment from VDOT for the proportionate share of the payment received for work performed by the SubContractor under the contract; or

B. To notify VDOT and the Sub-Contractor, in writing, of the Contractor's intention to withhold payment and the reason. The Contractor is obligated to pay the Sub-Contractor interest at the rate of one percent per month (unless otherwise provided under the terms of the contract) on all amounts owed by the Contractor that remain unpaid seven (7) days following receipt of payment from VDOT, except for amounts withheld as stated in B. above. The date of mailing of any payment by US Mail is deemed to be payment to the addressee. These provisions apply to each sub-tier Contractor performing under the primary contract. A Contractor's obligation to pay an interest charge to a Sub-Contractor may not be construed to be an obligation of VDOT.

14. PROTEST OF AWARD: A Bidder or Offeror wishing to protest an award or a decision to award a contract must submit a written protest to the Administrative Services Administrator, VDOT 1401 East Broad Street, Richmond, Virginia 23219, no later than ten (10) days after public notice of award or 
announcement of the decision to award whichever occurs first. The public notice will be in the area designated for solicitation/proposal and award notices. The protest must include the basis for the protest and the relief sought. Within ten (10) days after receipt of the protest the Administrative Services Administrator will issue a written decision stating the reasons for the action taken. This decision is final unless within ten (10) days after receipt of such decision, the Bidder or Offeror institutes legal action as provided in the Code of Virginia.

15. PRECEDENCE OF TERMS: Paragraphs 1-14 of these General Terms and Conditions shall apply in all instances. In the event there is a conflict between any of the other General Terms and Conditions and any Special Terms and Conditions in this solicitation, the Special Terms and Conditions shall apply.

16. SPECIFICATIONS: The material shall strictly conform to all specifications, plans, etc. and current VDOT Road and Bridge Specifications unless otherwise stated herein.

17. QUALIFICATIONS OF BIDDERS OR OFFERORS: VDOT may make such reasonable investigations as deemed proper and necessary to determine the ability of the Bidder or Offeror to perform the contract. Such investigations may include but are not limited to fingerprint-based criminal history background checks, credit checks, legal residence checks, or proof of US citizenship. The Bidder or Offeror shall furnish to VDOT all such information and data for this purpose as may be requested. VDOT further reserves the right to reject any bid or proposal if the evidence submitted by, or investigations of, such Bidder or Offeror fails to satisfy VDOT that such Bidder or Offeror is properly qualified to carry out the obligations of the contract and to complete the work/furnish the item(s) contemplated therein.

18. TESTING AND INSPECTION: VDOT reserves the right to conduct any test/inspection it may deem advisable to assure goods and services conform to the specifications.

19. ASSIGNMENT OF CONTRACT: A contract shall not be assignable by the Contractor in whole or in part without the written consent of the VDOT Contract Officer indicated in this solicitation.

20. DEFAULT: In case of failure to deliver goods or services in accordance with the contract terms and conditions, VDOT, after due oral or written notice, may procure them from other sources and hold the Contractor responsible for any resulting additional purchase and administrative costs. This remedy shall be in addition to any other remedies which VDOT may have.

21. TAXES: Sales to the Commonwealth of Virginia are normally exempt from state sales tax. State sales and use tax certificates of exemption, Form ST-12, will be issued upon request. Deliveries against this contract shall be free of federal excise and transportation taxes. The Commonwealth's excise tax exemption registration number is $54-73-0076 \mathrm{~K}$.

22. TRANSPORTATION AND PACKAGING: By submitting their bids or proposals, all Bidders or Offerors certify and warrant that the price offered for F.O.B. destination includes only the actual freight 
rate costs at the lowest and best rate and is based upon the actual weight of the goods to be shipped. Except as otherwise specified herein, standard commercial packaging, and shipping containers shall be used. All shipping containers shall be legibly marked or labeled on the outside with the purchase order number or the contract number, commodity description and quantity.

23. DELIVERY POINT: Except when otherwise specified herein, all items shall be F.O.B. delivered to any of the locations specified herein.

24. AUDIT: The Contractor hereby agrees to retain all books, records and other documents relative to this contract for five (5) years after final payment, or until audited by VDOT, whichever is sooner. VDOT, its authorized agents, and/or state auditors shall have full access to and the right to examine any of said materials during said period.

25. ADDITIONAL INFORMATION: VDOT reserves the right to ask any Bidder/Offeror to submit information missing from its bid/offer, to clarify its bid/offer, and to submit additional information which VDOT deems desirable, and does not affect quality, quantity, price or delivery.

26. MATERIAL SAFETY DATA SHEETS (MSDS): Prior to award of this contract, the successful Bidder or Offeror shall provide to this print office, within 10 calendar days of the verbal or written request, copies of MSDS for each hazardous chemical/compound offered. Failure to provide such MSDS within the required time frame will be cause for declaring such bid as non-responsive.

27. CANCELLATION OF CONTRACT: VDOT reserves the right to cancel and terminate any resulting contract, in part or in whole, without penalty, upon 60 days written notice to the Contractor. In the event the initial contract period is for more than 12 months, the resulting contract may be terminated by either party, without penalty, after the initial 12 months of the contract period upon 60 days written notice to the other party. Any contract cancellation notice shall not relieve the Contractor of the obligation to deliver any outstanding orders issued prior to the effective date of cancellation.

28. CHANGES TO THE CONTRACT: Changes can be made to the contract in any one of the following ways:

A. The parties may agree in writing to modify the scope of the contract. An increase or decrease in the price of the contract resulting from such modification shall be agreed to by the parties as a part of their written agreement to modify the scope of the contract.

B. VDOT may order changes within the general scope of the contract at any time by written notice to Contractor. Changes within the scope of the contract include, but are not limited to, things such as the method of packing or shipment and the place of delivery or installation. The Contractor shall comply with the notice upon receipt. The Contractor shall be compensated for any additional costs incurred as the result of such order and shall give VDOT a credit for any savings. Said compensation shall be determined by one of the following methods: 
1. By mutual agreement between the parties in writing; or

2. By agreeing upon a unit price or using a unit price set forth in the contract, if the work to be done can be expressed in units, and the Contractor accounts for the number of units of work performed, subject to VDOT's right to audit the Contractor's records and/or to determine the correct number of units independently; or

3. By ordering the Contractor to proceed with the work and to keep a record of all costs incurred and savings realized. A markup for overhead and profit may be allowed if provided by the contract. The same markup shall be used for determining a decrease in price as the result of savings realized. The Contractor shall present VDOT with all vouchers and records of expenses incurred and savings realized. VDOT shall have the right to audit the records of the Contractor as it deems necessary to determine costs or savings. Any claim for an adjustment in price under this provision must be asserted by written notice to VDOT within thirty (30) days from the date of receipt of the written order from VDOT. If the parties fail to agree on an amount of adjustment, the question of an increase or decrease in the contract price or time for performance shall be resolved in accordance with the procedures for resolving disputes provided by the Disputes Clause of this contract or, if there is none, in accordance with the disputes provisions of the Commonwealth of Virginia's Vendors Manual. Neither the existence of a claim or a dispute resolution process, litigation or any other provision of this contract shall excuse the Contractor from promptly complying with the changes ordered by VDOT with the performance of the contract generally.

29. AVAILABILITY OF FUNDS: By signing this bid the Bidder agrees that VDOT shall be bound only to the extent of the funds available or budgeted for the particular function or which may hereafter become available for the purpose of any resultant contract.

30. SPECIAL DISCOUNTS: (A) During the contract period, if the Contractor offers promotional discounts as a general practice for items available under this contract, with the result that those prices are lower than the prices available under this contract, then the promotional discounts shall be made available to VDOT under this contract. (B) The effective date for price changes/discounts will be the date that the lower prices/discounts were made available to the Contractor's customers generally.

31. DELAYS IN AWARD: Delays in award of a contract beyond the anticipated starting date may result in a change in the contract period indicated in the solicitation. If this situation occurs, VDOT reserves the right to award a contract covering the period equal to or less than the initial term indicated in the solicitation.

32. RECYCLED PRODUCTS: VDOT encourages the use of products which contain recycled materials. Please indicate as a percentage the amount and type of recycled materials contained in each of the products offered.

33. USE OF BRAND NAMES: Unless otherwise provided in this solicitation, the name of a certain brand, make or manufacturer does not restrict Bidders or Offerors to the specific brand, make or manufacturer named but conveys the general style, type, character, and quality of the article desired. Any article which the public body in its sole discretion determines to be the equal of that specified, considering 
quality, workmanship, economy of operation, and suitability for the purpose intended, shall be accepted. The Bidder or Offeror is responsible to clearly and specifically indicate the product being offered and to provide sufficient descriptive literature, catalog cuts and technical detail to enable VDOT to determine if the product offered meets the requirements of the solicitation. This is required even if offering the exact brand, make or manufacturer specified. Normally in competitive sealed bidding only the information furnished with the bid will be considered in the evaluation. Failure to furnish adequate data for evaluation purposes may result in declaring a bid non-responsive. Unless the Bidder/Offeror clearly indicates in its bid/proposal that the product offered is an "equal" product, such bid/proposal will be considered to offer the brand name product referenced in the solicitation.

34. INSURANCE: By signing and submitting a bid or proposal under this solicitation, the Bidder or Offeror certifies that if awarded the contract, it will have the following insurance coverage at the time the contract is awarded. VDOT reserves the right to request a copy of the Certificate of Insurance. The Bidder or Offeror further certifies that the Contractor and any Sub-Contractors will maintain these insurance coverage during the entire term of the contract and that all insurance coverage will be provided by insurance companies authorized to sell insurance in Virginia by the Virginia State Corporation Commission.

\section{INSURANCE COVERAGES AND LIMITS REQUIRED:}

1. Worker's Compensation: Statutory requirements and benefits.

2. Employer's Liability: $\$ 100,000$.

3. Commercial General Liability: $\$ 1,000,000$ per occurrence. Commercial General Liability is to include Premises/Operations Liability, Products and Completed Operations Coverage, and Independent Contractor's Liability or Owner's and Contractor's Protective Liability. The Commonwealth of Virginia must be named as an additional insured when requiring a Contractor to obtain Commercial General Liability coverage.

4. Automobile Liability: $\$ 1,000,000$ per occurrence. (Only used if motor vehicle is to be used in the contract.)

35. DRUG-FREE WORKPLACE: During the performance of this contract, the Contractor agrees to (i) provide a drug-free workplace for the Contractor's employees; (ii) post in conspicuous places, available to employees and applicants for employment, a statement notifying employees that the unlawful manufacture, sale, distribution, dispensation, possession, or use of a controlled substance or marijuana is prohibited in the Contractor's workplace and specifying the actions that will be taken against employees for violations of such prohibition; (iii) state in all solicitations or advertisements for employees placed by or on behalf of the Contractor that the Contractor maintains a drug-free workplace; and (iv) include the provisions of the foregoing clauses in every subcontract or purchase order of over $\$ 10,000$, so that the provisions will be binding upon each Sub-Contractor or vendor. For the purposes of this section, "drugfree workplace" means a site for the performance of work done in connection with a specific contract awarded to a Contractor, the employees of who are prohibited from engaging in the unlawful manufacture, sale, distribution, dispensation, possession or use of any controlled substance or marijuana during the performance of the contract. 
36. SAFETY AND HEALTH STANDARDS: It is a condition of the contract, and shall be made a condition of each subcontract entered into pursuant to the contract, that the Contractor and any SubContractor shall not require any worker employed in performance of the contract to work in surroundings or under working conditions that are unsanitary, hazardous, or dangerous to their health or safety, as determined under construction safety and health standards promulgated by the US Secretary of Labor in accordance with Section 107 of the Contract Work Hours and Safety Standards Act. The Contractor shall comply with the Virginia Occupational Safety and Health Standards adopted under Section 40.1-22 of the Code of Virginia and the duties imposed under Section 40.1-51.1 of the Code. Any violation of the requirements or duties that is brought to the attention of the Contractor shall be immediately abated. Additionally at a minimum, all Contractor personnel shall comply with the following, unless otherwise determined unsafe or inappropriate in accordance with OSHA regulations: Hardhats shall be worn while participating in or observing all types of field work when outside of a building or outside of the cab of a vehicle, and exposed to, participating in or supervising construction. Respiratory protective equipment shall be worn whenever an individual is exposed to any item listed in the OSHA Standards as needing such protection unless it is shown the employee is protected by engineering controls. Adequate eye protection shall be worn in the proximity of the grinding, breaking of rock and/or concrete, while using brush chippers, striking metal against metal or when working in situations where the eyesight may be in jeopardy. Safety vests shall be worn by all exposed to vehicular traffic and construction equipment. Standards and guidelines of the current Virginia Work Area Protection Manual shall be used when setting, reviewing and removing traffic controls. Flag persons shall be certified according to the Virginia Flagger Certification Program. No person shall be permitted to position themselves under any raised load or between hinge points of equipment without first taking steps to support the load by the placing of a safety bar or blocking. Explosives shall be purchased, transported, stored, used and disposed of by a Virginia Certified Blaster in possession of a current criminal history record check and a commercial driver's license with hazardous materials endorsement and a valid medical examiner's certificate. All federal, state and local regulations pertaining to explosives shall be strictly followed. All electrical tools shall be adequately grounded or double-insulated. Ground fault Circuit Interrupter (GFCI) protection must be installed in accordance with the National Electrical Code (NEC) and current Virginia Occupational Safety and Health Agency (VOSH) regulations. No person shall enter a confined space without training, permits and authorization. Fall protection is required whenever an employee is exposed to a fall six feet or greater.

37. NON-DISCRIMINATION OF CONTRACTORS: A Bidder, Offeror, or Contractor shall not be discriminated against in the solicitation or award of this contract because of race, religion, color, sex, national origin, age, disability, faith-based organizational status, any other basis prohibited by state law relating to discrimination in employment or because the Bidder or Offeror employs ex-offenders unless the state agency, department or institution has made a written determination that employing ex-offenders on the specific contract is not in its best interest. If the award of this contract is made to a faith-based organization and an individual, who applies for or receives goods, services, or disbursements provided pursuant to this contract objects to the religious character of the faith-based organization from which the individual receives or would receive goods, services, or disbursements, the public body shall offer the individual, within a reasonable period of time after the date of his objection, access to equivalent goods, services, or disbursements from an alternative provider.

38. eVA Business-To-Government Vendor Registration: The eVA Internet electronic procurement solution, web site portal www.eVA.virginia.gov streamlines and automates government purchasing activities in the Commonwealth. The eVA portal is the gateway for 
vendors to conduct business with state agencies and public bodies. All vendors desiring to provide goods and/or services to the Commonwealth shall participate in the eVA Internet eprocurement solution either through the eVA Basic Vendor Registration Service or eVA Premium Vendor Registration Service. All bidders or offerors must register in eVA; failure to register will result in the bid/proposal being rejected.

a. eVA Basic Vendor Registration Service: \$25 Annual Registration Fee plus the appropriate order Transaction Fee specified below. eVA Basic Vendor Registration Service includes electronic order receipt, vendor catalog posting, on-line registration, electronic bidding, and the ability to research historical procurement data available in the eVA purchase transaction data warehouse.

b. eVA Premium Vendor Registration Service: \$25 Annual Registration Fee plus the appropriate order Transaction Fee specified below. eVA Premium Vendor Registration Service includes all benefits of the eVA Basic Vendor Registration Service plus automatic email or fax notification of solicitations and amendments,

c. For orders issued prior to August 16, 2006, the Vendor Transaction Fee is 1\%, capped at a maximum of $\$ 500$ per order,

d. For orders issued August 16, 2006 and after, the Vendor Transaction Fee is:

(i) DMBE-certified Small Business: 1\%, capped at \$500 per order.

(ii) Businesses that are not DMBE-certified Small Business: 1\% capped at \$1500 per order. 


\section{APPENDIX J}

NCDOT Snow and Ice Subcontract 


\section{PURCHASE ORDER CONTRACT General Provisions}

\section{GENERAL}

This contract is for providing fully operated equipment necessary for snow and ice control activities in Mecklenburg County. All work and materials shall be in accordance with the provisions of the General Guidelines of this contract, the Project Special Provisions, the North Carolina Department of Transportation Standard Specifications for Roads and Structures, the North Carolina Department of Transportation Roadway Standards Drawings, and the current edition of the Manual of Uniform Traffic Control Devices (MUTCD).

The Contractor shall keep himself fully informed of all Federal, State and local laws, ordinances, and regulations, and shall comply with the provisions of Section 107 of the Standard Specifications.

\section{AUTHORITY OF THE ENGINEER}

The Engineer for this project shall be the Division Engineer, Division 10, Division of Highways, North Carolina Department of Transportation, acting directly or through his duly authorized representatives.

The Engineer will decide all questions which may arise as to the quality and acceptability of work performed and as to the rate of progress of the work; all questions which may arise as to the interpretation of the contract, and all questions as to the acceptable fulfilment of the contract on the part of the Contractor. His decision shall be final and he shall have executive authority to enforce and make effective such decisions and orders as the Contractor(s) fails to carry out promptly. In addition the Engineer and/or his representatives will decide the areas or roads within the county, at which the Contractor(s) will be astigned. But these work areas could vary at different times.

\section{AVAILABILITY OF FUNDS - CONTRACT TERMINATION}

Payments on this contract are subject to availability of funds as allocated by the General Assembly. If the General Assembly fails to allocate adequate funds, the Department reserves the right to terminate this contract.

In the event of termination, the Contractor shall be given a written notice of termination at least 60 days before completion of scheduled work for which funds are available. In the event of termination, the Contractor shall be paid for the work already performed in accordance with the contract specifications. 


\section{PURCHASE ORDER CONTRACT General Provisions}

\section{BANKRUPTCY}

The Department of Transportation, at its option, may terminate the contract upon filing by the Contractor of any petition for protection under the provisions of the Federal Bankruptcy Act.

\section{DEFAULT OF CONTRACT}

The Department of Transportation shall have the right to declare default of contract for breach by the Contractor of any material term or condition of the contract. Default of contract shall be in accordance with the terms, conditions, and procedures of Article 108-9 of the Standard Specifications.

\section{SUBLETTING OF CONTRACT}

The Contractor shall not sublet, sell, transfer, assign or otherwise dispose of this contract or any portion thereof, or his right, title, or interest therein; without written consent of the Engineer. Subletting of this contract or any portion of the contract shall conform to the requirements of Article of $108-6$ of the Standard Specifications. The Contractor, with the consent of the Engineer, may sublet up to $50 \%$ of the equipment provided under this contract.

\section{SAFETY AND ACCIDENT PROTECTION}

In accordance with Article 107-22 of the Standard Specifications, the Contractor shall comply with all applicable Federal, State, and local laws, ordinances, and regulations governing safety, hcalth, and sanitation, and shall provide all safeguards, safety devices, and protective equipment, and shall take any other needed actions, on his own responsibility that are reasonably necessary to protect the life and health of employees on the job and the safety of the public, and to protect property in connection with the performance of the work covered by the contract.

\section{INSPECTION}

All work shall be subject to inspection by the Engineer at any time. Routinely, the Engineer will make periodic inspections of the completed work. It will be the responsibility of the Contractor to keep the Engineer informed of his wark efforts and when work is considered accomplished. 


\section{PURCHASE ORDER CONTRACT General Provisions}

\section{SUPERVISION BY CONTRACTOR}

At all times during the life of the project the Contractor shall provide one permanent emoployee who shall have the authority and capability for overall responsibility or the project and who shall be personally available 24 hours a day while the work is in progress: Such exaployee shail be fully authorized to conduct all business with the subtethtrictors, to negotiate and execute all supplemental agreements, and to execute the ordens or, directions, af the Engincer. .

At all times that work is actually being performed, the Contractor shall have aygilghtegnge competent individual who is authorized to act in a supervisory capacity aver all work on the project, including work subcontracted. The individual who has been so authorized should be experienced in the type of work being performed and shall be fully capable of managing, dixecting, and coordinating the work; of reading and thoroughly understanding the contract; and receiving and carrying out directions from the Engineer or his authorized representatives. He shall be an employee of the Contractor unless otherwise approved by the Engineer.

The Contractor may, at his option, designate one employee to meet the requirements of both positions. However, whenever the designated employee is absent from the work site, an authorized individual qualified to act in a supervisory capacity on the project shall be present.

\section{LIABILITY INSURANCE}

The Contractor shall obtain from an insurance company, duly authorized to do business in North Carolina, Public Liability and Property Damage Insurance to protect his company and subcontractors pertorming work covered under this contract from claims which may arise from operations under this contract. Insurance coverage shall be maintained during the life of this contract and shall extend to operations performed by the Contractor or his subcontractors, and by anyone employed directly or indirectly by either of them.

Public Liability Insurance shall be in an amount not less than seven hundred fifty thousand dollars $(\$ 750,000.00)$ for injuries, including accidental death, to any one person, and subject to the same limit for each person, in an amount not less than seven hundred fifty thousand dollars $(\$ 750,000.00)$ on account of one accident.

Property Damage Insurance shall be in an amount not less than seven hundred fifty thousand dollars $(\$ 750,000.00)$

Proof of insurance shall be furnished to the Engineer prior to beginning work. 


\section{PURCHASE ORDER CONTRACT General Provisions}

\section{INDEMNIFICATION}

The Contractor shall defend, indemnify and hold harmless the North Carolina Department of Transportation, its officers and employees from any claim, demand, suit, liability, judgment and expense (including attorney's fees and other costs of litigation) arising out of or relating to injury, disease, or death of persons or damage to or loss of property resulting from or in connection with the negligent performance of this contract by the Contractor, its agents, employees, and subcontractors or any one for whom the Contractor may be responsible. The obligations, indemnities and liabilities assumed by the Contractor under this paragraph shall not extend to any liability caused by the negligence of the Department of Transportation or its employees. The Contractor's liability shall not be limited by any provisions or limits of insurance set forth in this contract.

The Contractor shall indemnify and hold harmless the Department of Transportation from any claim, demand, suit, liability, judgment, and expense involving damage or loss to the Contractor's equipment (including vandalism, theft, fre, and acts of God) arising out of or relating to work performed under this agreement. The obligations, indernnities and liabilities assumed by the Contractor under this paragraph shall not extend to any liability caused by the negligence of the Department of Transportation or its employees. The Contractor's liability shall not be limited by any provisions or limits of insurance set forth in this contract.

The Contractor further agrees to indemnify the Department of Transportation for any damages to the roadway, highway signs, highway equipment and other property owned or in possession of the Department of Transportation, brought about by reason of the negligent operation of the equipment. The Contractor further agrees to indemnify and save harmless the Department of Transportation, its officers and employees from any claims or amounts recovered by any of the Contractor's employees under the Workmen's Compensation Act.

\section{POSTED WEIGHT LIMITS}

The Contractor's attention is directed to the fact that many primary and secondary roads and bridges are posted with weight limits less than the legal limit. The Contractor will not be allowed to exceed the posted weight limits in transporting materials or equipment to the project.

\section{NON-EXCLUSIVE CONTRACT}

The Contractor agrees and understands by signature on this contract that this agreement does not constitute an exclusive contract. The Department of Transportation reserves the right to employ as many Contractors as necessary to effectively and efficiently fulfill the need for fully operated rental equipment. 


\section{PURCHASE ORDER CONTRACT Special Provisions}

\section{SCOPE OF WORK}

The Contractor shall furnish to the Department of Transportation the fully operated equipment described in this contract as needed during inclement weather to perform snow and ice control activities at such time, and at such locations as directed by the Engineer.

The Contractor shall turnish equipment in good operating condition and operated by properly trained and qualified personnel. The personnel operating the equipment shall be employees of the Contractor and the Contractor shall be responsible for employees during the performance of the contract. The personnel shall be subject to the directions of the Department of Transportation. The Department of Transportation may refuse delivery or may return any equipment found to be defective and/or inadequately operated.

The Contractor shall conform to the guidelines as set forth in the Department of Transportation's Snow and Ice Control Plans, policies, operational practices, use of designated chemical/abrasive storage sites, etc. Copies of this infomation will be provided upon request

\section{PROSECUTION OF WORK}

The Contractor will be required to prosecute the work in a continuous and uninternupted manner from the time he begins the work until completion and final acceptance. The Contractor will not be permitted to suspend his operations except for reasons beyond his control or except where the Engineer has authorized a suspension of the Contractor's operations. The Contractor shall not perform snow and ice control activities for other entities until released from the work under this contract for any particular winter weather event by the Engineer.

\section{COOPERATION WITH STATE FORCES AND OTHER CONTRACTORS}

This contract is for storm related recovery work, and is not an exclusive contract. The Contractor must cooperate with State forces and other Contractors working within the limits of this project as directed by the Engineer.

\section{PRESERVATION OF PROPERTY}

The Contractor shall exercise care to avoid damage to all public and private property and facilities. Any danage to properties, such as mailboxes, fences, gates, vehicles, driveways, etc. shall immediately be restored to the previously existing condition. No payment will be made to the Contractor for such restorative work. 


\section{PURCHASE ORDER CONTRACT \\ Special Provisions}

\section{CONTRACT TIME AND RENEWAL}

This agreement shall commence on the date the Department of Transportation issues a purchase order and shall be effective for a period of one (1) year. At the option of the Department of Transportation, based on the Contractor's satisfactory performance of the terms contained herein, this agreement may be extended additional periods of one (1) year each up to a maximum total contract time of five (5) years, with the same terms and conditions. Each renewal year, the Equipment Operating Rate, defined elsewhere in this contract, will be increased by three (3) percent. Only the Equipment Operating Rate will be adjusted; no adjustment will be applied to the Outfitting Fee item, or to the payment rate for training sessions outlined elsewhere in this contract.

\section{EQUIPMENT}

The Contractor shall provide the following types of equipment:

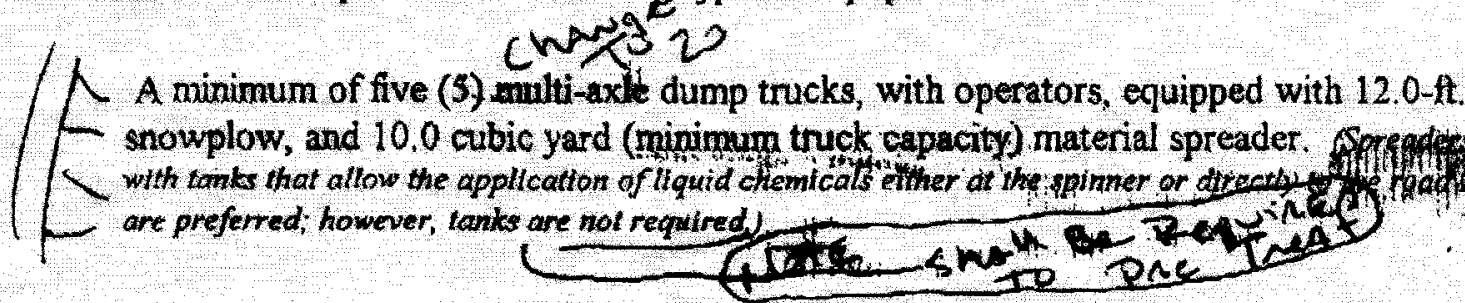

All snowplows provided under this agreement should be hydraulic powered, reversible, hydraulic angling, moldboard type plows, with a dual trip spring assembly, which will automatically return the plow to the normal plowing position. The trip spring asserably is intended to reduce the potential for damage to the plowing equipment resulting from collision with roadway structures, such as, but not limited to, manholes and valve boxes. The Department will not be responsible for damage to the Contractor's equipment resulting from collisions with such structures.

All material spreaders provided under this agreement should be truck engine driven, hydraulic punp powered, in-body style spreaders with a calibrated, adjustable, locking feed gate which controls the amount of material being discharged.

A copy of the DOT specifications for snowplows and material spreaders will be made available to the Contractor upon request.

Operators of all trucks shall have a Commercial Driver's License. The Contractor shall provide enough operators, per piece of equipment provided under this agreenent, to operate 24 hours per day during a storm event. Operators are limited to a maximum 12-hour shift within a 24-hour period. 


\section{PURCHASE ORDER CONTRACT Special Provisions}

\section{MOBILIZATION AND DEMOBILIZATION}

There is no separate payment for mobilization, or for demobilization, in this contract. The Contractor will be paid for three (3) hours at the Equipment Operating Rate for these purposes. These three hours will be paid as additional operating hours for each piece of fully operated equipment provided under this contract. These three additional hours shall be considered full compensation for all costs to mobilize and demobilize the equipment provided under this contract. Mobilization shall include rigging the dump truck with the specified appurtenances and having the trucks ready for operation (loading and plowing) at the designated Department facility.

Demobilization shall include the cleanup of the trucks and appurtenances at the conclusion of the current storm event and unrigging the specified appurtenances from the dump trucks.

\section{CONTRACTORJOPERATOR PREPARATION}

The Department of Transportation shall provide training session(s) and dry run(s) to familiarize all of the Contractor's personnel (both operators and supervisors) with snow removal and ice control methods, equipment, and assigned routes. Training session(s) and dry run(s) will be scheduled and completed as determined by the Engineer. Typically, dry run(s) are held during the months of October and November each year. The Department will provide the Contractor with a minimum two (2) weeks notice of scheduled training sessions and dry runs.

Training sessions consist of classroom style instruction on snow removal and ice control methods and materials, snowplow and spreader operation, calibration and safety issues. Dry runs include the use of equipment. At a dry run, equipment is inspected, calibrated and plowing routes are reviewed and driven for operators to note potential plowing patterns and changes.

Payment for training session(s) shall be at the rate of $\$ 25.00$ per hour for each person in attendance. The Department will pay the Contractor for a maximum of two (2) operatgef pe piece of equipment provided under this agreement and for a maximum of one (1)htuther or supervipr. Payment will only be made for regularly scheduled training sessions provided by the Department of Transportation. No payment will be made for training provided to the Contractor's personael due to operator or supervisor tumover or absence from regularly scheduled training.

Payment for dry run(s) shall be at the hourly operating rate for each piece of fully operated equpment used in the dry run(s). The Contractor will also receive compensation for mobilization/demobilization as described in this contract. 


\section{PURCHASE ORDER CONTRACT Special Provisions}

\section{OUTFITTING FEE}

An Outfitting Fee for investment costs associated with the purchase and installation of the equipment appurtenances (spreaders, snow plows, plow blades, etc.) specified herein will be paid to the Contractor. The unit price bid will be spread over the total, optional, renewable five (5) year term of the contract. One payment in an amount of Fifty percent $(50 \%)$ of the unit price bid will be made to the Contractor on the First year, Thirty $(30 \%)$ on theThird year and Twenty (20\%) on the Fifth year, during the term of this contract for each piece of equipment provided under this contract. Payments for this iten will be made upon satisfactory inspection, and the completion of all scheduled training sessions and dry runs established by the Engineer. The snowplows and material spreaders will be inspected and approved by the Engineer during the scheduled dry run(s). The Engineer will also periodically inspect all equipment provided. If, at any time, the Engineer finds that the equipment is not satisfactory, or has not been maintained in operating condition, the Contractor will repair or replace the unsatisfactory equipment at the Contractor's cost. If the Contractor does not repair or replace the equipment within a reasonable timeframe, as established by the Engineer, this shall constitute grounds for termination of the contract and the Contractor may be invoiced for a portion of, or all, outfiting fees paid for said equipment. All equipment covered by this pay item will remain the property of the Contractor upon the expiration or termination of the contract. Costs associated with the maintenance and repair of the equipment and appurtenances shall be considered incidental to the operating costs of the equipment.

\section{WORK NOTIFICATION}

The Engineer will notify the Contractor when inpending inclement weather is forecast, and when timing of precipitation is forecast to mobilize equipment in preparation for work. Once the timing of precipitation is forecast, the Engineer will notify the Contractor a minimum of two (2) hours before equipment is needed for operation.

\section{DEICING CHEMICAL SUPPLIES}

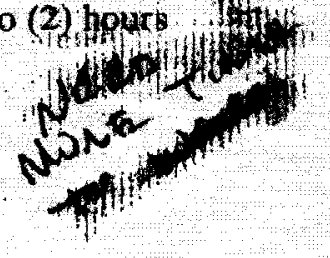

The Department of Transportation shall provide all necessary deicing chemical materials and/or abrasives necessary for snow and ice control operations. The Contractor's equipment will be loaded with deicing materials/abrasives in the same manner, and at the same locations as the Deparment of Transportation's equipment. 


\section{MNORITY AND WOMEN BUSINESS ENTERPRISES}

\section{Policy}

It is the policy of the North Carolina Deparment of Transportation that minority and women business enterprises shall have the maximum opportunity to participate in the performance of contracts financed by Non-Federal Funds.

\section{Oblieation}

The Contractor and any subsequent Subcontractor shall ensure that minority and women business enterprises have the maximum opportunity to participate in the performance of the work included in this contract. The Contractor and any subsequent contractor shall take all necessary and teasonable steps to ensure that minority and business enterprises have the maximum opportunity to compete for and perform a portion of the work included in the contract. Failure on the part of the Contractor to carry out the requirements set forth herein shall constitute a breach of contract and after proper notification, may result

in award disqualification, termination of the contract, disqualification from bidding, or other appropriate remedy.

\section{Goals}

Pursuant to the requirements of North Carolina General Statute 136-28.4, the following goals are established for this contract:

Minimum Minority Business $\quad 0 \quad \%$
Minimum Women Business

The Contractor shall exercise all necessary and reasonable steps to ensure that Minority Businesses (MB) and Women Businesses (WB) participate in at least the percents of the contract as set forth above as goals for this contract.

\section{Listine of MB and WB Subcontractors}

All bidders, at the time the bid proposal is submitted, must also submit a listing of MB and WB participation on the appropriate form (or facsimile thereot) contained in this proposal in order for the bid to be considered responsive.

Only those MB and WB firms with current certification by the Department will be considered acceptable for listing in the bidder's submittal of $M B 8$ and WB participation.

A listing of Minority Businesses (MB) and Women Businesses (WB) which have been certified as such by the Department will be available from the Division Engineer upon request. 
In the event the bidder has no MB and WB participation, he is still required to indicate this on the forms by entering the word or number zero in order for the bid to be considered responsive.

The listing of an individual frm certified by the Department shall not be construed as an endorsement of the firm's capability to perform certain work.

A. The Contractor shall indicate on the form for the listing of MB and WB Subcontractors the following required information:

\section{Required Information}

1) The names of MB and WB firms committed to participate in the contract;

2) The contract item mumbers and agreed upon unit prices of work to be performed by each MB and WB firm; and

3) The total dollar amount to be paid to each MB and WB based on the agreed upon unit prices.

Falure to indicate the required information on the specified form may cause the bid to be considered non-responsive and it may be rejected.

The Department will not allow any substitutions, deletions, or other alterations to the listing of firms committed for MB and WB participation and/or the respective listed contract item numbers after the opening of bids. The Department will not allow adjustments to the total dollar amount of $\mathrm{MB}$ and $\mathrm{WB}$ participation after the opening of bids which would result in the MB and WB participation being less than the contract goal. The only exceptions to the requirements of this paragraph will be: (1) to allow replacenent of a MB or WB fim that had been decertified after opening of bids, and (2) to allow alteration of the listed contract item numbers subject to the Bidder subtritting sufficient documentation to verify an obvious errot in the initial submittal.

B. If the MB and WB participation submitted does not meet or exceed the MB and WB contract goals, the apparent lowest responsive bidder must submit information to satisfy the North Carolina Department of Transportation that sufficient reasonable efforts have been made to meet the contract goals. This information must be received in the office of the Division Engineer no later than 12:00 noon of the sixth day following the opening of the bids. Where the bidder fails to provide this information by the deadline, the Department may impose the following sanetions.

1) Disqualify the Contractor and any affiliated companies from further bidding for a period of no more than 90 days from the date of disqualification as established in notification by certified mail.

2) Disqualify the Contractor and any affiliated companies for award of all contracts for which bids have been received and opened. 
The following factors are what the Department will consider in judging whether or not the bidder has made adequate good faith effort:

1) Whether the bidder attended any pre-bid meetings that were scheduled by the Department to inform MBs and WBs of subcontracting opportunities.

2) Whether the bidder provided written notice to a reasonable number of specific MBs and WBs that their interest in the contract is being solicited, and whether the firms solicited could have reasonably been expected to quote the work in the contract.

3) Whether the bidder followed up initial solicitations of interests by contacting MBs and WBs to determine with certainty whether they were interested.

4) Whether the bidder selected portions of the work to be performed by MBs and WBs in order to increase the likelihood of meeting the contract goals.

5) Whether the bidder provided interested MBs and WBs with adequate information about the plans, specifications and requirements of the contract.

6) Whether the bidder excluded interested MBs and WBs from the bidding process, not rejecting them as unqualified without sound reasons based on a thorough investigation of their capabilities.

7) Whether quotations were received from interested MB and WB firms but rejected as unacceptable without sound reasons why the quotations were considered unacceptable.

8) Whether the bidder made efforts to assist interested MBs and WBs in obtaining any required insurance or bonding that may be required by the bid proposal or by the bidder.

9) Whether the bidder specifically negotiated with Subcontractors to assume part of the responsibility to meet the contract $\mathrm{MB}$ and WB goal when the work to be sublet includes potential for $\mathrm{MB}$ and WB participation.

Where the apparent lowest responsive bidder fails to submit sufficient participation by MB and WB firms to meet the contract goal, and upan a determination by the Engineer based upon the information submitted that the apparent lowest responsive bidder failed to make adequate good faith efforts to meet the contract goal, the Department may reject the bid.

In the event that the Department does not award the contract to the apparent lowest responsive bidder, the Department reserves the right to award the contract to the next lowest responsive bidder that can satisfy the Department that the contract goal can be met or that adequate good faith efforts have been made to meet the goal. 


\section{Replacement of MBs and WBs}

If any MB or WB Subcontractor indicated on the form for listing of MB and WB Subcontractors and contained elsewhere in this proposal form does not perform satisfactorily to the extent indicated or anticipated, the Contractor shall take all necessary, reasonable steps to replace the MB Subcontractor with another MB Subcontractor and/or the Contractor shall take all necessaty, reasonable steps to replace the WB Subcontractor with another WB Subcontractor.

Any substitutions of MB or WB firms after award of the contract shall be approved by the Department. The Contractor shall submit any requests for substitutions in writing to the Engineer and the request must provide a valid basis or reason for the proposed substitution.

Failure of the Contractor to demonstrate reasonable efforts to replace a MB or WB firm that does not perform as intended or anticipated, shall be just cause to disqualify the Contractor from further bidding for a period of up to 6 months after notification by certified mail.

\section{Counting MBNBB Participation Toward Meetine MBAWB Goal}

MB and WB participation shall be counted toward meeting the MB and WB goal in this contract as follows:

1) If a firm is determined to be an eligible MB or WB finn and certified by the Department, the total dollar value of the participation by the MB or WB will be counted toward the appropriate MB or WB goal. The total dollar value of certified MB or WB will be based upon unit prices agreed upon by the Prime Contractor and $M B$ or WB Subcontractor.

2) A Contractor may count toward its MB or WB goal 60 percent of its expenditures for materials and supplies required to complete the contract and obtained from $\mathrm{MB}$ or WB regular dealer, and 100 percent of such expenditures to a MB or WB manufacturer.

\section{Reports}

The Contractor shall submit a statement with the final invoice to report all MB and WB participation on the project. In the event the Contractor had no MB or WB participation on the project, he is still required to submit a statement with the final invoice reporting no participation. Where participation is from MB and WB Material Suppliers or Manufacturers, the statement shall indicate the appropriate percentage ( $60 \%$ for regular dealers and $100 \%$ for manufacturers) of expenditures to be reported.

THE CONTRACTOR'S STATEMENT OF MB AND WB PARTICIPATION MUST BE DEUIVERED TO THE DEPARTMENT IN ORDER FOR THE FINAL INVOICE TO BE PROCESSED FOR PAXMENT. 


\section{FORM W-9}

$120 v, 1-92$, Bev. 10,94

for Divition Contrat Use]

Pursuant to Internal Revenue Service Regulations, vendors must furnish their Taxpayer Identifieation Number (IIV) to the State. If this number is not orovided, you mav be subject to a $31 \%$ withholding on each payment. To avoid this $31 \%$ witholding and to insure that accurate tax information is reported to the Internal Revenue Service and the State, please use this form to provide the requested information exactly as it appears on file with the IRS.

Legal Business Name

Address

9 Digit Taxpayer Identification Number

Social Security Number

Federal Employer Identification Number

Business Designation (Check One)

Individual (Soc.Sec. \#)

Sole Proprietorship (Soc.Sec. \#)

Partnership (Fed. ID)

Estate/Trust (Fed. D)

Corporation (Fed. ID)

Public Service Corporation (Fed. ID)

GovernmentalNon-Profit (Fed. ID)

Under penalties of perjury, I declare that I have examined this request and to the best of my knowledge and belief, it is true, correct, and complete. I have not been notified by the IRS that I am subject to backup witholding for failure to report income.

Name (Print or Type name of individual-not company)

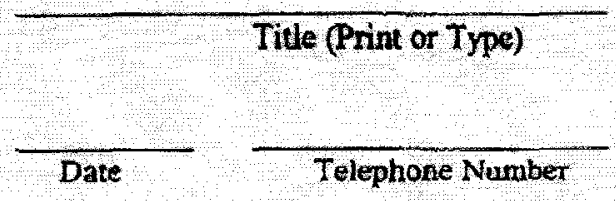




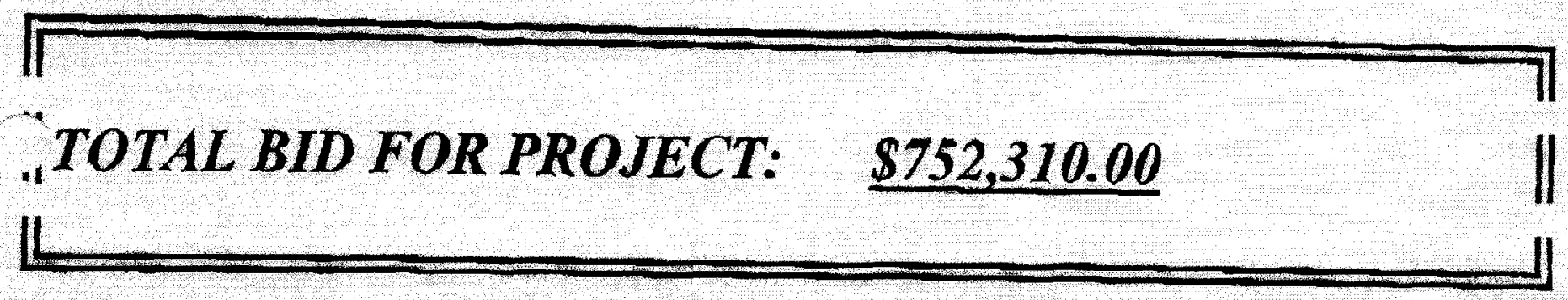

CONTRACTOR

ADDRESS

Federal Identification Number Contractors License Number

Authorized Agent Title

Ignature Date

Witness Title

Signature Dale

\section{THS SECTION TO BE COMPL ETCD BY NORTH CAROLNA DEPARTMENT OE TRANSPORTATION}

This hid has been reviewed in aceordance with Article 103-1 of the Standard Specifications for Roads and Structures 2002

Revienved by (date)

tecepred by

NCDOT

Drivion Engineer 


\section{PURCHASE ORDER CONTRACT Special Provisions.}

\section{EQUIPMENT (continued)}

All trucks provided by the Contractor shall be equipped with warning lights similar to those used by the Department All dump trucks shall have headlights mounted to provide forward lighting over the snowplow. Communication devices shall be available in each piece of equipment so the operators can communicate with the Contractor's designated supervisor. All equipment shall also be equipped with reverse gear warning devices.

The Contractor shall be responsible for all costs or charges incurred in the operation and maintenance of the equipment during the term of the contract including, but not limited to, fuel, oil, snow plow blades, tire chains, equipment repairs, communication equipment, etc. The Contractor will be compensated for equipment operation and incidentals at the Equipment Operating Rate define elsewhere in this contract.

The Contractor shall be responsible for the equipment provided in this contract at all times and at all lecations during the term of the contract. The Contractor shall have no claim against the Department of Transportation for any expense involving damage or loss to the Contractor's equipment (including vandalism, thef, fre and acts of God) arising out of, or relating to, work performed under this agreement.

\section{EQUIPMENT OPERATING RATE}

The unit price of ninety dollars (\$90.00) per hour, for each piece of fully operated equipment provided under this contract, will be the Equipment Operating Rate paid to the Contractor. This operating rate shall be full compensation for labor, equipment, and incidentals necessary to complete the work. As stated in the Contract Time and Renewal provision of this contract, the Equipment Operating Rate will be increased three (3) percent each renewal period. The Equipment Operating Rates during each year will be:

\begin{tabular}{|c|c|}
\hline Year 1 & $\$ 90.00$ \\
\hline Year 2 & $\$ 92.70$ \\
\hline Year 3 & $\$ 95.48$ \\
\hline Year 4 & $\$ 98.34$ \\
\hline Year 5 & $\$ 101.29$ \\
\hline
\end{tabular}

Payment for fully operated equipment provided in this contract shall be on an hourly basis. All charges shall be determined to the nearest one-quarter (1/4) hour based upon the time the equipment was in actual productive operation. The Contractor will not be paid for downtime due to meals, equipment fallure, accidents, or other conditions. 


\section{North Carolina Department of Transportation BID FORM}

Work Order Number: Various

Description: Fully Operated Equipment for Snow and Ice Control

Mecklenburg County

\begin{tabular}{|c|c|c|c|c|c|c|}
\hline ITEM & SECT & DLSCRUPTION & QUANTITY & UNIT & UNTT PRICE & AMOUNT BID \\
\hline 1 & & Maximuge No of Trucles ovnilable & 50 & Total & N/A & N/A \\
\hline 2 & & $\begin{array}{l}\text { Ourfiting Fee-for snow removal } \\
\text { equipmeit for eacb multi-axle dump } \\
\text { truck ( } 50 \% \text { of } \$ 27,000.00 \text { 1\%, Year.) }\end{array}$ & 10 & 2A & $(513,500.00)$ & $(\$ 135,000.00)$ \\
\hline 3 & & $\begin{array}{l}\text { Outfiting Fee-for snow removal } \\
\text { equipment for each multi-axle dump } \\
\text { truck }\left(30 \% \text { of } 527,000.003^{\text {ri. }} \text {. Year.) }\right.\end{array}$ & 10 & EA & $(\$ 8,100,00)$ & $(581,000.00)$ \\
\hline 4 & & $\begin{array}{l}\text { Outriting fee-for saow remeval } \\
\text { equipment for ench multi-arle dumg } \\
\text { truck }\left(20 \% \text { of } \$ 27,000,005^{\text {th }} \text {. Year.) }\right.\end{array}$ & 10 & $\mathbf{E A}$ & $(\$ 5,400.00)$ & $(554,000,00)$ \\
\hline 5 & & Truck w/Driver $1^{2}$ Year $2003-04$ & 1000 & Ar. & $\$ 90.00$ & $\$ 90,000,00$ \\
\hline 6 & & Truck w/Driver $2^{\text {th }}$ Year 2004-05 & 1000 & Er. & $\$ 92.70$ & $\$ 92,700,00$ \\
\hline & & & & & & \\
\hline 7 & & Truck w/Driver ${ }^{3 \pi d}$ Year $2005-06$ & 1000 & Fir. & $\$ 95.48$ & $\$ 95,480.00$ \\
\hline 8 & & Truek w/Driver ${ }^{\text {Stb }}$ Year 200607 & 1000 & Hr. & 598.34 & 598340.00 \\
\hline & & & & & & \\
\hline 9 & & Truck womriver ${ }^{36}$ Year $2007-08$ & 1000 & He. & $\$ 101.29$ & $\$ 101290.00$ \\
\hline 10 & & Mourdy Training Contractor's Forces & 180 & Br. & $\$ 25.00$ & $\$ 4,500,00$ \\
\hline & & & & & & \\
\hline & & & & & & \\
\hline & & & & & & \\
\hline & & & & & & \\
\hline 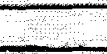 & & & & & & \\
\hline & & & & & & \\
\hline & & & & & & \\
\hline & & & & & & \\
\hline & & & & & & \\
\hline
\end{tabular}

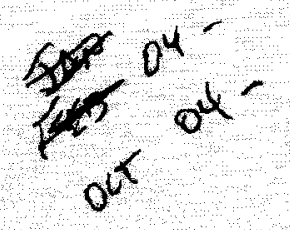


Appendix K FDOT MRP 


\title{
FLORIDA DEPARTMENT OF TRANSPORTATION MAINTENANCE RATING PROGRAM HANDBOOK
}

\author{
DATA COLLECTION \\ FOR \\ MAINTENANCE RATING PROGRAM \\ Prepared by \\ Office of Maintenance \\ 2007 Edition
}

Additional copies of this handbook may be obtained from:

Office of Maintenance or

Maps and Publications Office

605 Suwannee Street

Mail Station 12

Tallahassee, Florida 32399-0450

or

Phone: (850) 414-4050 


\section{ACKNOWLEDGMENTS}

The development of this program was conducted by the Office of Maintenance, Florida Department of Transportation, in cooperation with Maintenance representatives from all Districts within the State. Acknowledgment to: Maintenance Levels-of-Service Guidelines, National Cooperative Highway Research Program Report 223, Transportation Research Board, National Research Council, Washington, D.C., June 1980, for guidelines in developing our Maintenance Rating Program and in providing some verbiage in this manual. Any ongoing revisions are the result of continuous review by a team established by the District Maintenance Engineers for that purpose. The team consists of a representative from each district. Our thanks and appreciation goes to those members for many long hours of meetings, research and study in the continuing development and refinement to this program. 


\section{TABLE OF CONTENTS}

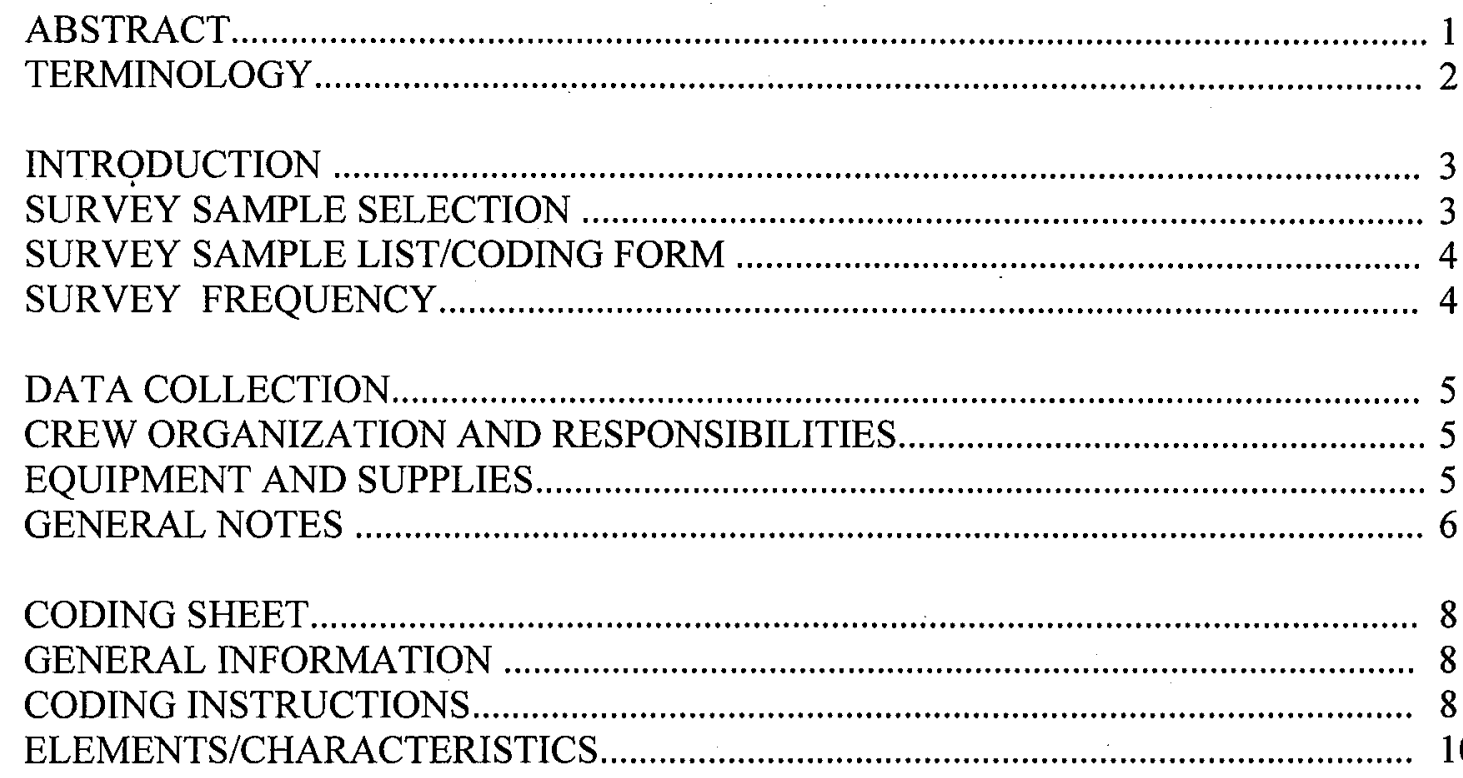

MAINTENANCE RATING PROGRAM STANDARDS

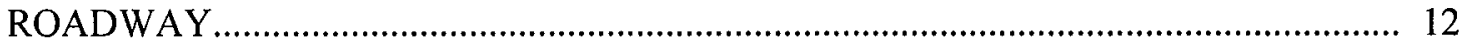

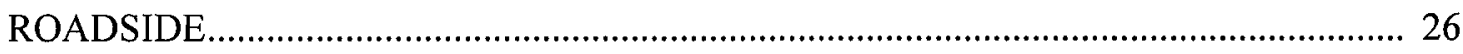

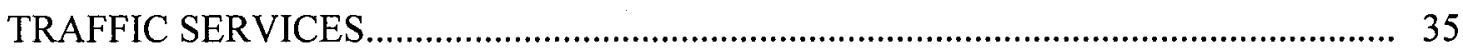

DRAINAGE

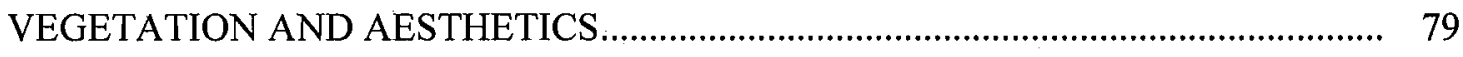

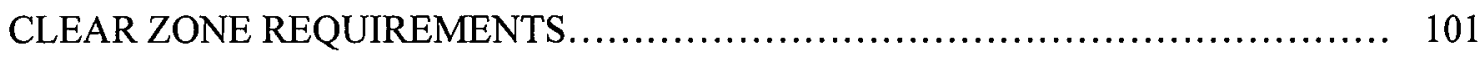

CRITICAL ELEMENT CONSISTENCY CHECK FORM.......................... 103

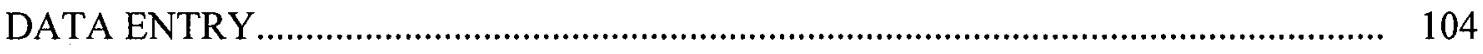




\begin{abstract}
The information contained in this handbook defines a method of conducting a visual and mechanical evaluation of routine highway maintenance conditions. The purpose of this evaluation is to provide information that should be used to schedule and prioritize routine maintenance activities and provide uniform maintenance conditions that meet established Departmental objectives. General program requirements are outlined in the Maintenance Rating Program procedure, Topic No. 850-065-002.

This handbook is, primarily, for the use of personnel responsible for conducting the Maintenance Rating Program Survey. Training for conducting the survey was provided to initiate the program and additional training will be provided as required. The survey is being conducted on all types of highway facilities. The type of maintenance required determines the classification of a particular facility. The current facility type classifications are as follows:
\end{abstract}

\title{
1. Rural Limited Access \\ 2. Rural Arterial \\ 3. Urban Limited Access \\ 4. Urban Arterial
}

Each of the highway facility types is divided into 5 elements:

\section{Pavement \\ 2. Roadside \\ 3. Traffic Service \\ 4. Drainage \\ 5. Vegetation/Aesthetics}

Further divisions of these elements include those features that are characteristic to an individual element. For example, the Roadside element is composed of the following characteristics:
A. Unpaved Shoulder
B. Front Slope
C. Slope Pavement
D. Sidewalk
E. Fence

The field worksheet/data processing input coding forms list all characteristics that are to be evaluated in the survey. A sample form is included in the CODING SHEET section of this manual. 


\section{TERMINOLOGY}

FACILITY TYPE - Classification is determined by the type of maintenance applied to the facility (rural or urban) and the access to and from the facility (e.g., Limited Access).

MAINTENANCE ELEMENT - A part of the highway system that requires maintenance (e.g., pavement, traffic services, aesthetics).

CHARACTERISTIC - A part or parts of a maintenance element that, combined with other characteristics, compose the maintenance element (e.g., Roadside is composed of: unpaved shoulder, front slope, slope pavement, sidewalk and fence).

MAINTENANCE CONDITION - That condition of an element characteristic that requires routine maintenance to prevent deficiencies or that need to be repaired or corrected.

LEVEL-OF-MAINTENANCE - That point or level of a maintenance condition in relation to a desired level of maintenance.

EDGE OF PAVEMENT - Is the outside edge of pavement where it meets the curb or unpaved shoulder.

FUNCTION AS INTENDED - Characteristics that meet the desired maintenance conditions as determined by the applicable Design Standards, or Maintenance Rating Program guidelines. 


\section{INTRODUCTION}

The Department is responsible for maintaining the highways in a safe and comfortable condition for the users and for protecting the public investment in these facilities. Field supervisors are assisted in maintaining desired conditions by recommended levels of service prepared by maintenance engineers for various highway elements (pavement, roadside, traffic services, drainage, and vegetation). These desired maintenance conditions are neither a minimum or a maximum condition but rather a level of service influenced by a number of considerations, such as safety, protection of public investment, comfort, economics, environmental impact, aesthetics and not least, money constraints on available resources (personnel, equipment and materials). The decision of which elements should be maintained at a desired level of service and which should be allowed to regress were, generally, made informally by maintenance personnel (e.g., field supervisors). Consequently, because of these many and complicated factors, inconsistent decisions were made that result in unintended lower levels of maintenance.

Because of these inconsistencies and resulting lower levels of maintenance, a systematic and formal method of making policy decisions for desired levels of maintenance was developed. This method, now called the Maintenance Rating Program, was implemented in April 1985. This program considers of those factors talked about previously and allows different levels of service for varying maintenance elements and highway classifications.

This handbook does not address the steps involved in the development of the program. Instead, it is produced as guidelines for those responsible for gathering the data needed to implement and maintain the program. This edition of the handbook still does not address every situation or answer every question encountered in conducting the survey or maintaining the MRP, but, as experience is gained, it will be applied to these instructions for further expansion and refinement. Classroom and on-the-job training will supplement this handbook in the continuance of the program.

\section{SURVEY SAMPLE SELECTION}

The Maintenance Rating Program uses the Department's data processing system to store information collected. This data is grouped and compared to desired levels or conditions of maintenance. Data processing is also used to produce those samples of highways to be surveyed. These samples are selected from the Department's Roadway Characteristics Inventory, by listing all facilities by length and classification (e.g. Urban Limited Access) and then applying a random number generator program to produce locations to be surveyed. Versatility of the random number generator allows selection by facility type, by county, by maintenance area (yard), by district or on a statewide level. A sample sheet listing the district, maintenance area, county section and subsection, location by mile and other pertinent information is explained in the SURVEY SAMPLE LIST section of this handbook. 
The complete list contains the number of samples required for each facility type based upon the available mileage.

\section{SURVEY SAMPLE LIST/CODING FORM}

The Survey Sample List (a sample copy is provided at the end of this section) is a computer printout listing the maintenance area, facility type number, county section and subsection, state road number and location of sample by milepost. The number of samples for each Maintenance Area will normally be 30 per facility type or a minimum of 3 samples per available mile. If the mileage for any facility type is less than 3, no samples will be generated for evaluation. Alternate samples are provided for use when a primary sample is unacceptable for evaluation. This is explained later in this section of the handbook. The maintenance area number is the FLORIDA DEPARTMENT OF TRANSPORTATION designation and is three digits of 1 thru 9. The next column on the list is the facility type number. The county section number is the FDOT county numbering system of five digits between 00000 and 99999 . The state road number is then listed for each sample. The next column on the list is the mile point at the CENTER of the selected sample.

\section{SURVEY FREQUENCY}

A listing of samples required to be surveyed will be provided to each District by the State Maintenance Office on the following frequency:

Scheduled Sample Period - The District will be responsible for completing the survey of those samples in the District not later than the last working day of the scheduled period. The District will assure that all data is verified as correct and entered in the appropriate place in the Department's data processing system no later than the last day of the rating period.

It is recommended that the data collected be entered into the data processing system on a regular basis. The computer file will provide a safe storage place with means of quick retrieval, if necessary. Statistically, partial data cannot be used until all samples have been completed and entered, however, interim and preliminary reports may be required for planning, current status or interpolated information.

As Required - Occasionally, a survey of a particular section of roadway (e.g., a roadway adjacent or leading to a popular tourist attraction) will be requested. Other occasions will require surveys for a particular facility type (e.g., URBAN LIMITED ACCESS), by individual section, by a grouping of sections, by county, by maintenance area or any combination of facility types by sections, counties, maintenance areas, districts or statewide. In most instances, priorities and completion dates will be assigned to these additional requests, possibly requiring some adjustment to existing and other workloads. 


\section{DATA COLLECTION}

The data must be collected accurately and completely to maintain credibility of the program and because ratings may be used by other sections and divisions within the Department, other State of Florida Agencies, and possibly by other states and federal agencies.

\section{CREW ORGANIZATION AND RESPONSIBILITIES}

A Maintenance Rating Program survey team will be composed of a minimum of two persons. Each district will be responsible for implementing and maintaining the Maintenance Rating Program.

It is mandatory that the MRP survey team's first responsibility be the safety of the pedestrian and motoring public and themselves. On occasions, it may be necessary to schedule the survey of those samples with high traffic density during low traffic periods to provide proper safety. It may become necessary to request a safety crew (flag persons, cones, signs, flashing directional arrow) from the maintenance area in which the survey is taking place. The survey team shall walk together, facing traffic, as they evaluate each sample. Facing traffic is for safety of the survey team, and walking together to prevent missing items that might be overlooked by one person and to permit accurate measurements.

\section{EQUIPMENT AND SUPPLIES}

The following is a list of equipment and supplies for the efficient and safe collection of the survey data:

- Copy of Maintenance Rating Program Handbook

- FDOT approved safety vest

- Flashing amber lights for vehicle roof

- Vehicle with installed Distance Measuring Instrument (DMI) (calibrated before each rating period)

- Current copy of Straight-line diagram maps for those sections to be sampled

- Maintenance Rating Program coding sheets

- Measuring wheel

- Measuring tape $(50 \mathrm{ft}$. or more)

- Small measuring rule (6") or small roll up metal tape

- Straightedge (5' to $\left.8^{\prime}\right)$ (metal or wood)

- Leveling device (carpenter's level or string level)

- String line $\left(100^{\prime}\right)$ or more

- Hammer

- Hand held optical level

$>$ Nails $-12 \mathrm{D}$ or larger

$>$ Legal size writing clipboard 
Pocket type calculator

$>$ Paper clips

$>$ Pencils

$>$ Pencil erasers

$>$ Metal pry bar

$>$ Probing rod

$>$ Small box to hold supplies and coding forms

$>$ Appropriate size box(es) for measuring litter

$>$ Other publication (e.g., Design Standards, Uniform Traffic Control Devices) (MUTCD)

$>$ Roadway Characteristics Inventory printouts:

Location of Vehicle impact attenuators

Location of outfall ditches

Location of landscaped areas

- Mandatory Items

$>$ Optional Items 
Some items on the list are necessary for proper collection of the data. Other items or supplies that will make collection of the survey data safer or more efficient may be included. Straightline diagrams should be available from the District Planning Section and should also be available in each maintenance area.

General Notes:

- Any feature or characteristic that is included in your RCI inventory shall be rated under the MRP criteria. If necessary, verify inventoried limits with your respective MMS/RCI Manager.

- At interchange ramps project the right-of-way limits across the ramp and rate for normal maintenance criteria.

- If the sample point falls within the gore limits of a rest area, weight station, inspection station, etc. project the right-of-way limits across the ramp and rate for normal maintenance criteria.

- Rate only those items maintained by the district being evaluated.

- A sample is $1 / 10$ mile or 528 feet in length. 


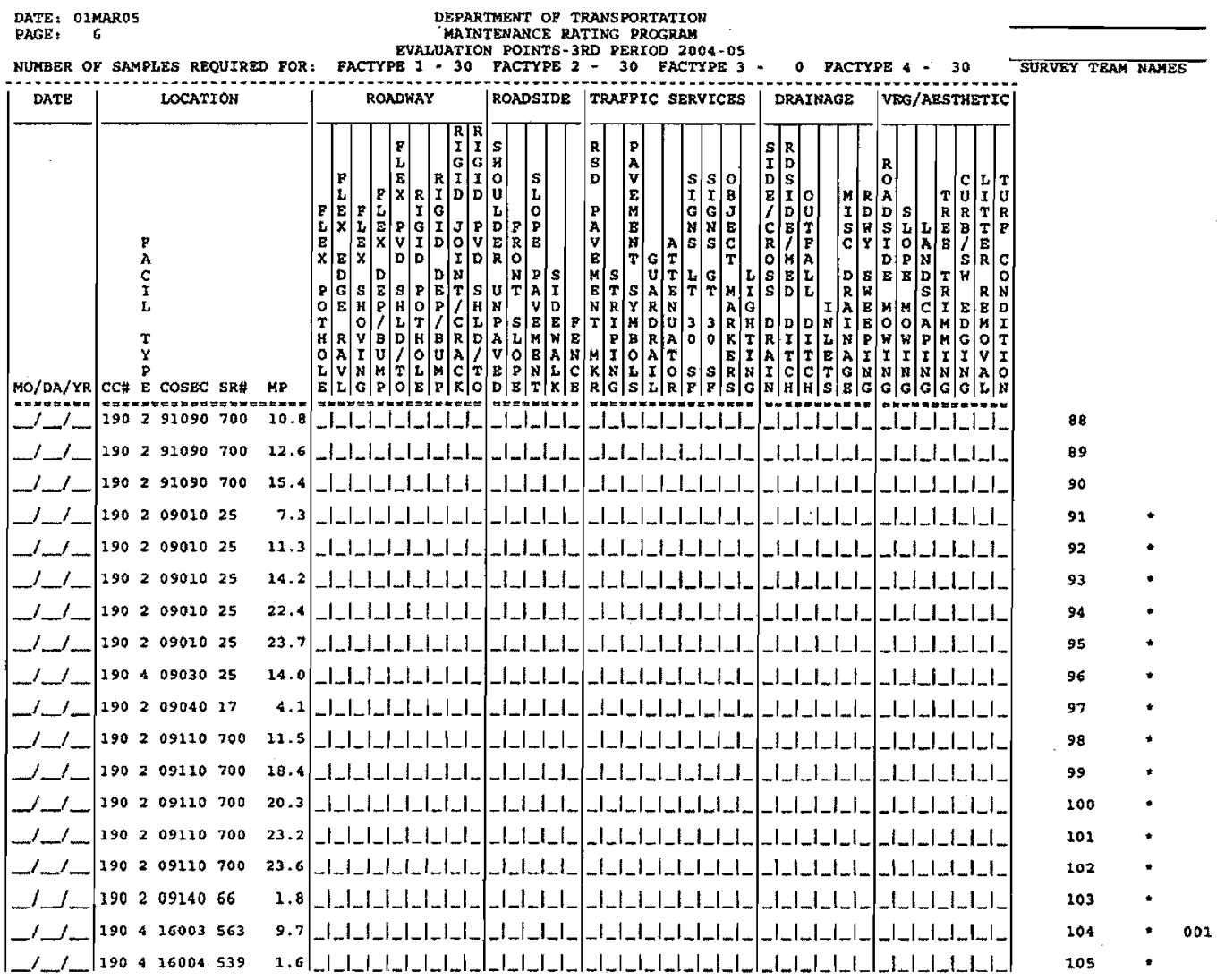




\section{CODING SHEETS}

\section{GENERAL INFORMATION}

There are several versions of the coding sheets used to record survey data but the Random Sample Program produces a combination SAMPLE LIST and CODING SHEET. The top section of the sheet is for survey team names. The body of the form is used to list the characteristics being surveyed and whether or not they meet the Maintenance Rating Program Standards. When entering information on the field coding sheets, place a dash line in those columns under characteristics that are not present in the section being surveyed. Pencil entries are recommended so that a rating may be changed if it does not meet desired nighttime conditions. Block type numbers and letters should be used for coding rather than those of a cursive, fancy or rounded type. Keep the sheet clean, neat and clear of stray marks and figures in any coding fields since this data may be entered into the computer by those not familiar with the survey or the coding sheets.

\section{CODING INSTRUCTIONS (PRECODED FORM)}

SURVEY TEAM - These spaces are for the team member's names conducting the survey. This information is not entered into the computer, but must be on the coding sheet since these sheets should be considered as "source" documents that could be used for auditing purposes.

DATE OF SURVEY - (card columns 1 thru 8) - This field is used to record the date the actual daytime survey was accomplished for a sample.

COST CENTER NO. - (card columns 9 thru 11) - This number is a FDOT cost center number and should be the maintenance area number in which the survey is being taken. This number is precoded.

FACILITY TYPE - (card column 12) - This column is precoded and is the facility type (1 through 4) of the sample being surveyed. Facility type number assignments are as follows: 1 for RURAL LIMITED, 2 for RURAL ARTERIAL, 3 for URBAN LIMITED ACCESS and 4 for URBAN ARTERIAL. A brief explanation of each FACILITY TYPE is listed below:

RURAL LIMITED ACCESS - Interstate, toll and other limited access roadways that have adjacent property unimproved, agricultural, low-density population, industrial and light commercial development. 
RURAL ARTERIAL - All other rural roadways not covered above that have adjacent property unimproved, agricultural, low density population, industrial and light commercial development.

URBAN LIMITED ACCESS - Interstate, toll and other limited access roadways that have adjacent property of high-density population, industrial and heavy commercial development.

URBAN ARTERIAL - All other urban roadways not covered above that have adjacent property of high-density population, industrial and heavy commercial development.

The above definitions are used to classify the type of maintenance for all roadways currently maintained by the FDOT.

COUNTY SECTION NO. - (card columns 14 thru 18) - This field is precoded and is the county and section number as assigned by the FDOT's Office of Planning. It is the same as used on straight-line diagrams and other official FDOT identifications of roadways.

STATE ROAD NO. - (card columns 20 thru 24) - This number indicates the state road number of the section on which the sample is to be surveyed. U.S. Highway number designations are not listed. This number is precoded beginning at the left and leaves unused columns blank.

MILE POST STATION - (card columns 26 thru 28) - This number is precoded on the Random Sample Selection List. A sample is $1 / 10$ mile or 528 feet in length. The milepost location is the mid point of the sample. The survey should be conducted in opposite directions along the roadway(s) for 264 feet from the designated center point and includes all area within the FDOT's right of way or authorized boundaries.

SUB-SECTION NUMBER - This number, if greater than 000, is shown as three digits in the right margin of the Random Sample Selection List. This number is not to be coded. It is provided for proper location of those roadways that have been assigned a unique identification.

RECENTLY COMPLETED CONSTRUCTION PROJECTS: - The system will automatically identify all random sample selections that fall inside the limits of any construction project completed within the last year to date. The Maintenance Rating Program Team will evaluate the sample for all characteristics. 
ELEMENTS/CHARACTERISTICS - The remaining portion of the form lists each element and its associated characteristics. Each characteristic should be coded: $Y=Y E S-m e e t s$ desired conditions, $\mathrm{N}=\mathrm{NO}$-does not meet desired conditions or left blank when the characteristic is not present in the sample.

The MRP team shall be responsible for locating and marking the sample mid point and limits. The sample points must be surveyed by the MRP team at the time they are being marked. Each sample shall be marked in a manner (e.g., paints, reflective tapes) so it can be located at night or by verification teams, auditors or others that may be required to evaluate the samples. The beginning and end of the sample shall be marked on inside and outside lane of multi-lane roadways. The marking should remain in place for the scheduled sample period.

The vehicle assigned is required to have Distance Measuring Equipment installed to assure accurate location of the selected center point. The team shall use a current straight-line diagram to determine the SLD milepost of the nearest roadway feature (bridge, intersection, side road) and use this known location as a reference to locate the selected point. Actual field conditions will override obvious SLD errors. Most DMI's will measure stations or miles ascending or descending and will allow programming of a desired station or milepost. If the DMI becomes inoperative or unavailable due to vehicle maintenance, then the replacement vehicle must be equipped with DMI as well.

The Random Sample Program should automatically exclude bridges. If any portion of a sample falls on a bridge, the team should select the end (abutment) of the bridge nearest the sample milepost and begin the evaluation from that end of the bridge. Should a sample mid point fall on a bridge, the team should select an alternate point, of the same facility type, provided on the Survey Sample List and notify the Office of Maintenance of this situation. Notification should include County-Section and subsection and mile point of the sample. Many multi-lane or median divided facilities are constructed with individual travel way bridges. When a portion of a sample falls on a facility of this type it will be necessary to consider all bridges for the proper begin or end bridge point (use abutment) since some structure locations may be staggered or one may be longer than the other.

PROJECTS UNDER CONSTRUCTION - The Random Sample Program currently does not eliminate projects let to bid or under construction. Roads under construction that affect two or more characteristics throughout the sample should not be surveyed. The survey team should evaluate one of the available alternate samples of the same facility type.

Samples that have a characteristic under construction (e.g., guardrail, minor shoulder repair, turnout/turn storage installation, intersection upgrade, utility work*) may be surveyed but omit the portion(s) of the characteristic(s) that is/are affected by the construction.

*(Utility cuts to install buried pipeline, cables and so forth.) 
Note:

Listed below are six characteristics that should be evaluated for all samples.

\section{ROADWAY (BOTH TYPES)}

1. Pothole

2. Depression

TRAFFIC SERVICES

\section{Raised Pavement Markers}

4. Striping

\section{VEGETATION/AESTHETIC}

\section{Tree Trimming \\ 6. Litter Removal}

Further, there are characteristics that should be evaluated only for a particular pavement type:

\section{ROADWAY (RIGID)}

\section{Joint/Cracking}

\section{ROADWAY (FLEXIBLE)}

2. Edge Raveling (Not with curb \& gutter, or paved shoulders)

3. Shoving

As a check, the total of any RIGID ROADWAY characteristic PLUS the total of any FLEXIBLE ROADWAY characteristic should be equal to or greater than the total number of points surveyed. To further assure that the mandatory data is coded, a review of coding forms prior to entering the data into the computer should be made. 
-BLANK PAGE- 


\section{FLORIDA DEPARTMENT OF TRANSPORTATION \\ MAINTENANCE RATING PROGRAM STANDARDS}

\section{ROADWAY}

\section{THE FOLLOWING CHARACTERISTICS MEET THE DESIRED MAINTENANCE CONDITIONS WHEN:}

FLEXIBLE POTHOLE: No defect is greater than $1 / 2$ square foot in area and $1-1 / 2$ inches deep. No pervious base is exposed in any hole.

FLEXIBLE EDGE

RAVELING:

FLEXIBLE SHOVING: The shoved area does not exceed a cumulative 25 square feet.

FLEXIBLE

DEPRESSION/BUMP: No deviation exceeds more than $\underline{1 / 2 \text { inch for any area greater than } 1}$ square foot. No single measurement shall exceed 2 inches.

FLEXIBLE PAVED

SHOULDER/TURNOUT: Rate flexible paved shoulder for pothole, edge raveling and depression/bump. Rate flexible turnout for pothole only.

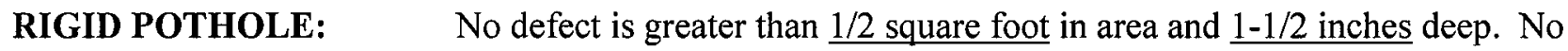
pervious base is exposed in any hole.

RIGID DEPRESSION/

BUMP:

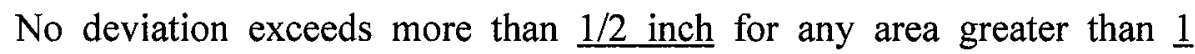
square foot. No single measurement shall exceed 2 inches.

RIGID JOINT/

CRACKING:

$\underline{85 \%}$ of the length of transverse and longitudinal joint material appears to function as intended and $\underline{90 \%}$ of the roadway slabs have no unsealed cracks wider than $\underline{1 / 8}$ inch.

RIGID PAVED

SHOULDER/TURNOUT: Rate rigid paved shoulder for pothole, depression/bump and joint/cracking. Rigid turnout rated for potholes and cracking only. 


\section{NOTES:}

1) All pavement characteristics are to be rated as last constructed. (Rigid pavement overlaid with asphalt should be rated under the flexible pavement characteristic).

2) When a railroad crossing falls within the sample point, the following shall apply: The area to

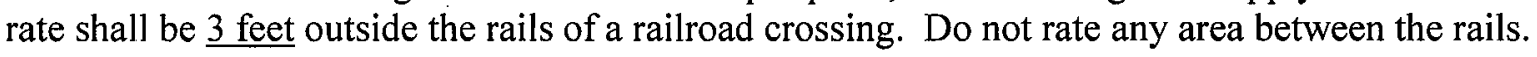

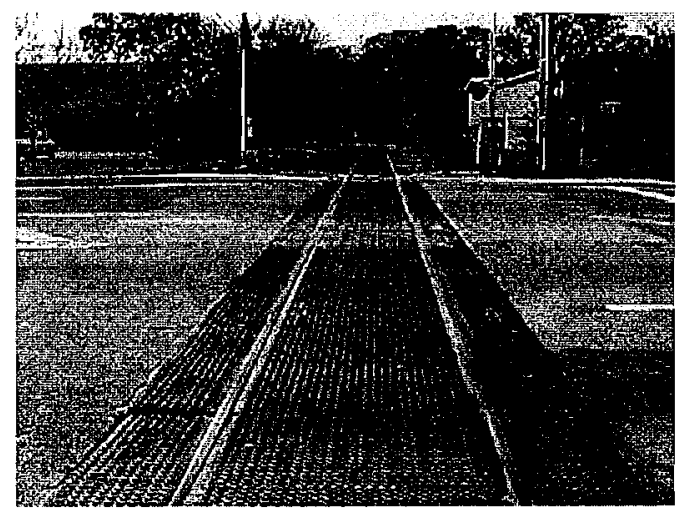

3) In non-curb and gutter sections, all paved areas adjacent to the travel way are evaluated as paved shoulders. For MRP purposes do not rate tapers on paved shoulders. Within curb and gutter sections, all pavement is evaluated as roadway pavement. This includes bus turnouts. Edge widening less than 2 feet in width from the travel lane edge does not meet desired conditions for paved shoulders.

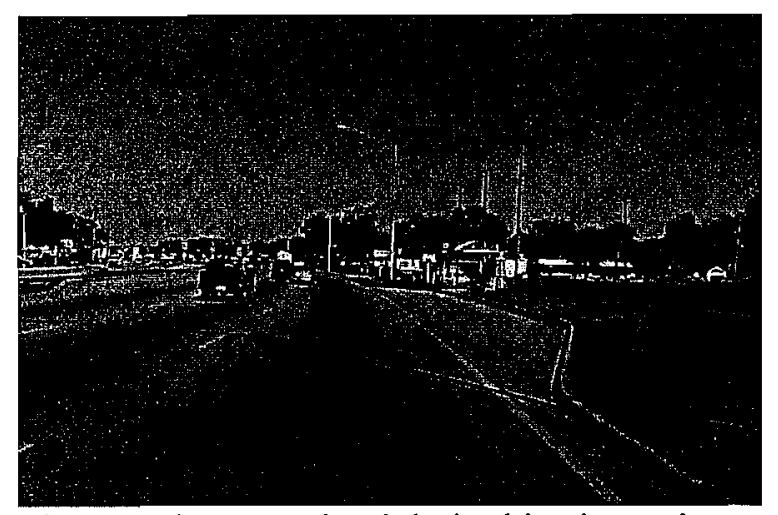

The paved area to the right in this picture is a bus turnout. The pavement in this bus turnout should be evaluated as roadway pavement.

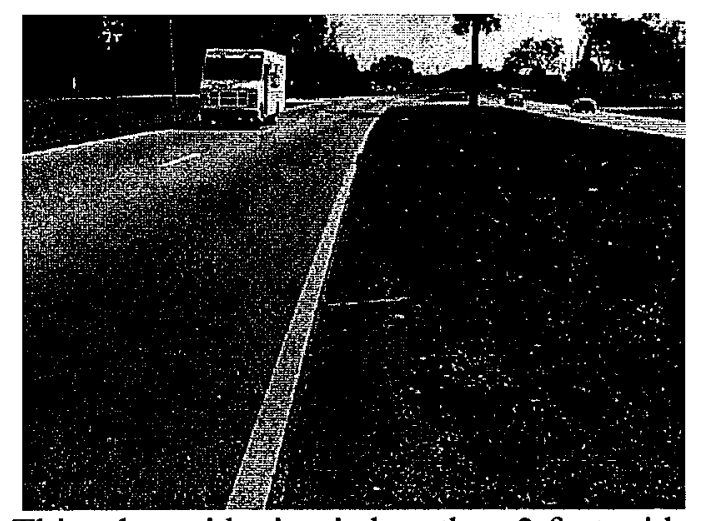

This edge widening is less than 2 feet wide therefore, does not meet MRP standards for. paved shoulders. 


\section{FLEXIBLE ROADWAY}

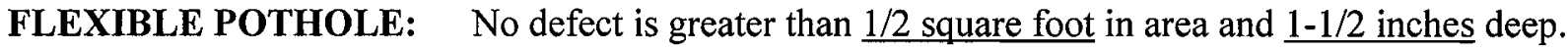

No pervious base is exposed in any hole.

Flexible Pothole - Potholes are normally bowl-shaped holes in the pavement that usually form in low areas, such as wheel paths and utility trenches. They are caused by pavement weaknesses, which may result from poor quality materials, thin pavement surface, poor drainage on the pavement surface or within the base, or a loss of load support by either the base or sub grade.

Evaluation: Measure the size of the pothole. To measure the size of a pothole, place a straightedge across the defective area and determine if the defective area is deeper than that listed in the standard. To determine the area of a defect, measure the area as a square or rectangle. Use of a straightedge and a marker to outline the area may be helpful. In a non-curb and gutter section, do not rate the first 4 inches from the actual edge of pavement for pothole criteria (see edge raveling).

\section{Flexible pothole does not meet MRP standards when any of the following exist:}

1) If BOTH depth and area are greater than the standard limits.

2) If pervious base is exposed in any hole.

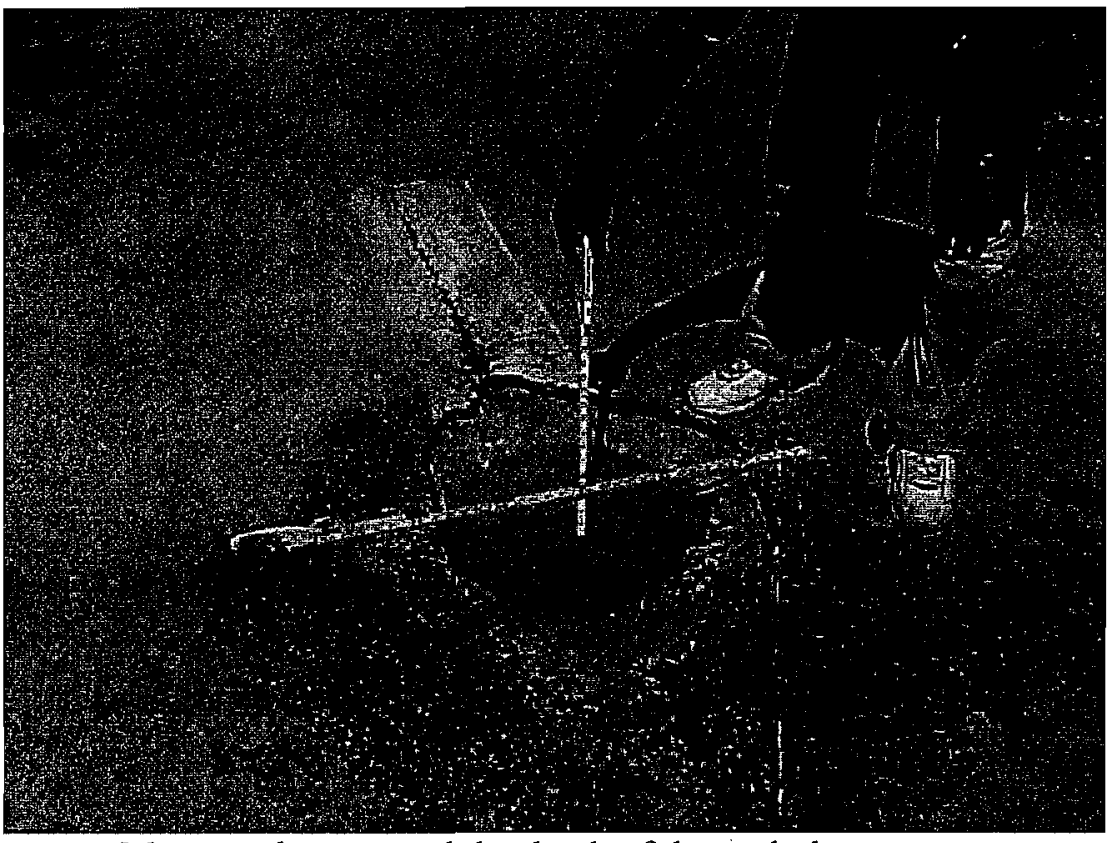

Measure the area and the depth of the pothole. 


\section{FLEXIBLE EDGE \\ RAVELING:}

$\underline{90 \%}$ of the total roadway edge is free of raveling.

No continuous section of edge raveling $\underline{4 \text { inches }}$ or wider exceeds $\underline{25 \text { feet }}$ in length.

Flexible Edge Raveling - Edge raveling is the progressive separation of aggregate particles in a pavement from the surface downward or from the edges inward.

Evaluation: Determine if edge raveling exists within the sample by reviewing the edge of pavement. If the pavement edge is missing or separated within 4 inches of the edge of pavement, then edge raveling exists. Measure the length of the edge raveling that is 4 inches or wider.

Two lane roadway samples with no paved shoulders can have a maximum pavement edge of 1,056 feet (528 ft. length X 2 roadway edges). A divided roadway with no paved shoulders can have a maximum pavement edge of 2,112 feet (528 ft. length $\mathrm{X} 4$ roadway edges). Measurements are made from the actual edge of pavement. At least $90 \%$ of the total roadway edge should be free of raveling or this characteristic does not meet the desired maintenance conditions.

Roadway edge raveling should not be evaluated when paved shoulders, any type of curb, curb and gutter, or any permanent construction is installed that will protect the pavement edge.

Flexible edge raveling does not meet MRP standards when any of the following exist:

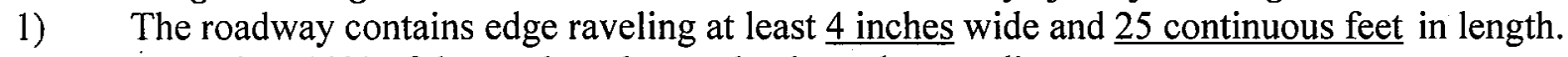

2) More than $10 \%$ of the total roadway edge has edge raveling.

\section{ROADWAY EDGE RAVELING TABLE}

\begin{tabular}{|c|c|r|r|}
\hline $\begin{array}{l}\text { \# Non-Paved } \\
\text { Shoulder Edges }\end{array}$ & $\begin{array}{l}\text { Total Non-Paved } \\
\text { Shoulder Edge }\end{array}$ & $90 \%$ & $10 \%$ \\
\hline 1 & 528 & 475.2 & 52.8 \\
\hline 2 & 1,056 & 950.4 & 105.6 \\
\hline 3 & 1,584 & 1425.6 & 158.4 \\
\hline 4 & 2,112 & 1900.8 & 211.2 \\
\hline
\end{tabular}

FLEXIBLE SHOVING: The shoved area does not exceed a cumulative 25 square feet.

Flexible Shoving - Flexible shoving is the lateral or longitudinal movement of flexible roadway surface most often caused by the acceleration or deceleration of vehicular traffic. Severe movement will result in cracking or breaking of the riding surface exposing the underlying roadway course or the base material.

Evaluation: Measure the length and width of the shoved area. If more than 25 square feet of roadway, in a sample, is displaced by pushing or shoving, then this characteristic does not meet the desired maintenance condition. Base failure and rutting are not to be considered as shoving but can cause shoving. 
Flexible Shoving does not meet MRP standards when any of the following exist:

1) More than 25 cumulative square feet of roadway, in a sample, is displaced by pushing or shoving.
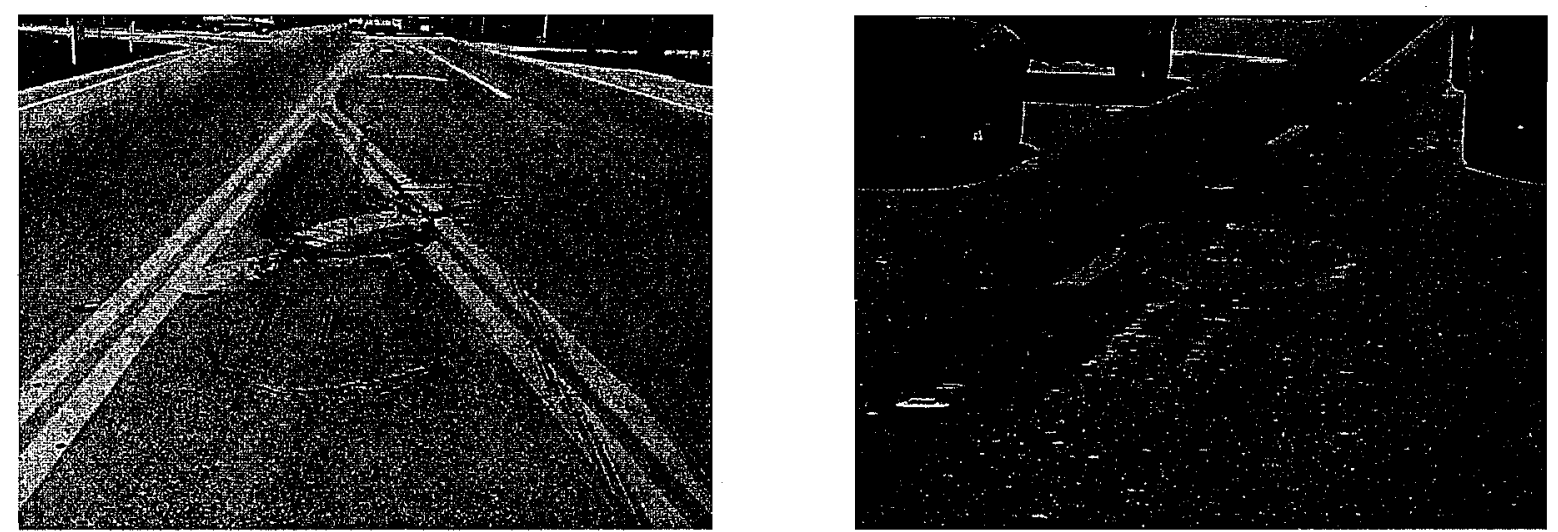

These are pictures of shoving. Measure the length and width to determine the shoving area. If the shoving area is more than 25 cumulative square feet, then this would not meet conditions for shoving.

\section{FLEXIBLE}

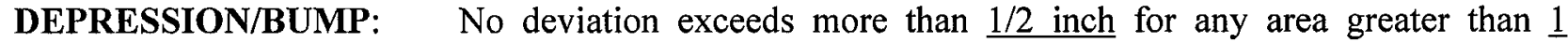
square foot.

No single measurement shall exceed 2 inches.

Flexible Depression/Bump - A pavement depression or bump is a deviation from design grade. It may be an area close to or caused by an inlet, manhole or underground utility installation.

Evaluation: To determine if there is a depression or bump within the sample area, survey the roadway pavement. Many depressions or bumps are located near inlets, manholes or underground utility installations. Vehicles traversing the sample can give an indication if a depression or bump is present. Include parking lanes and bus turnouts in the evaluation.

If there is an indication of a depression or bump within the sample area, measure the area. If the area is greater than the standard, then measure the height or depth of the depression or bump. If the height or depth and area are greater than the standard, then this characteristic does not meet desired maintenance conditions.

Flexible depression/bump does not meet MRP standards when any of the following exist:

1) A deviation from design grade greater than $1 / 2$ inch for any area greater than 1 square foot.

2) Concrete and/or asphalt spills which exceed $1 / 2$ inch and 1 square foot.

3) Any single measurement of a depression or bump exceeding $\underline{2}$ inches. 


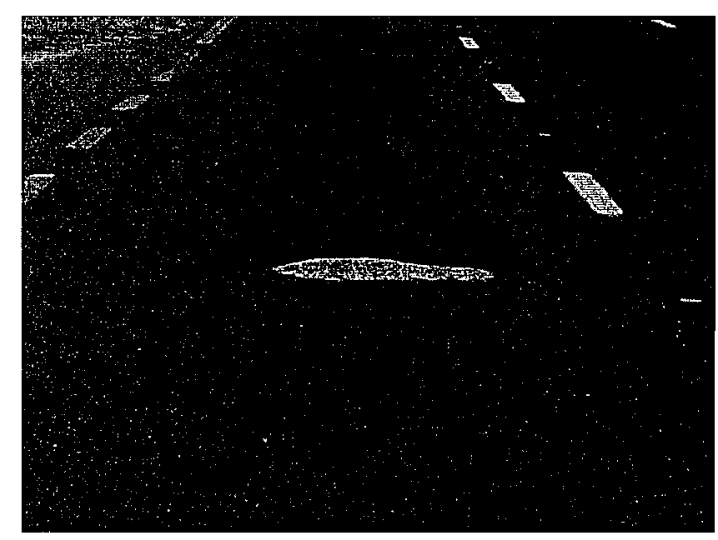

Concrete spill, rate as a bump.

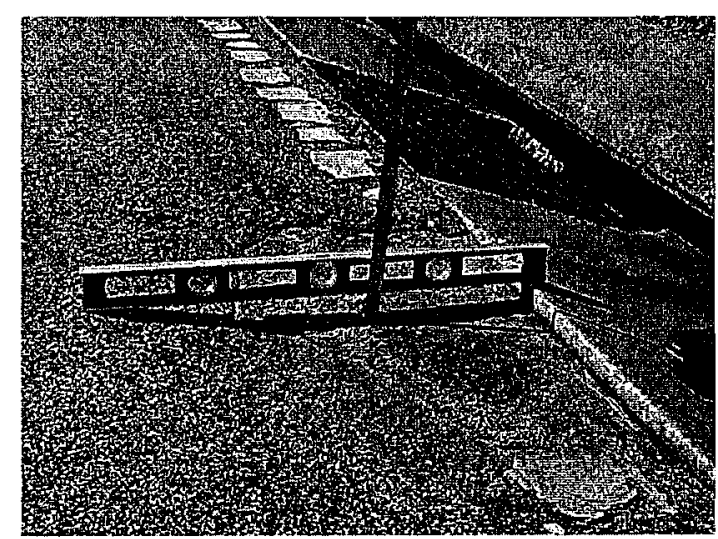

Depression next to a curb inlet.

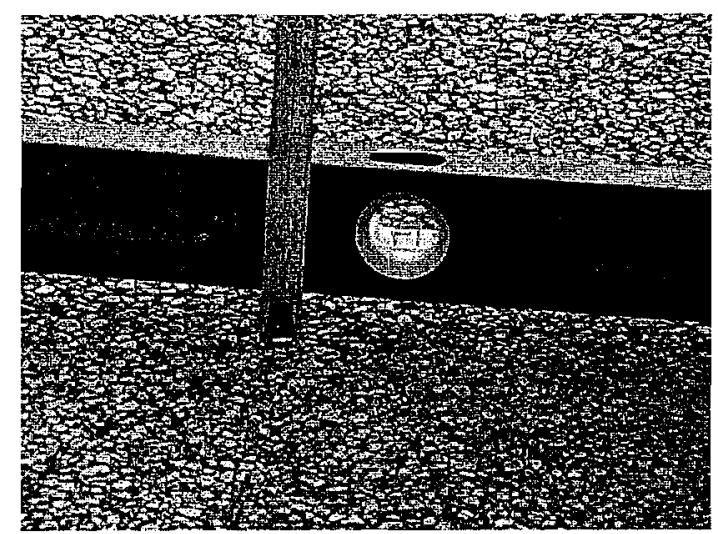

Measuring the depth of a depression.

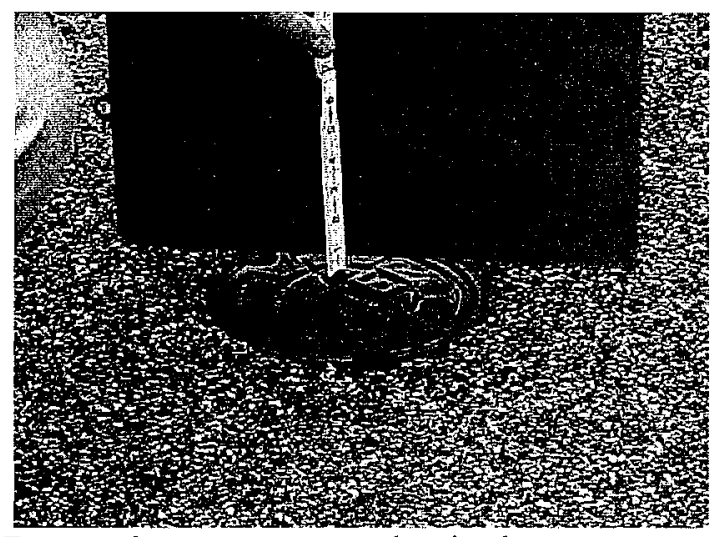

Depression at a water valve in the pavement.

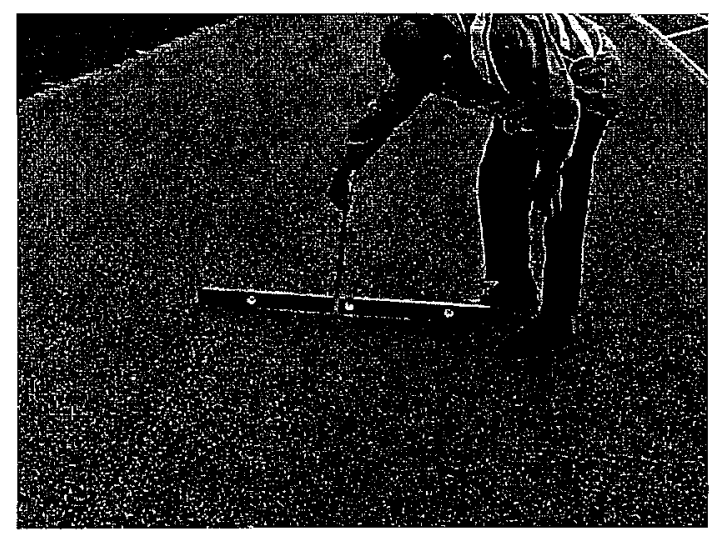

Measuring the depth of a depression.

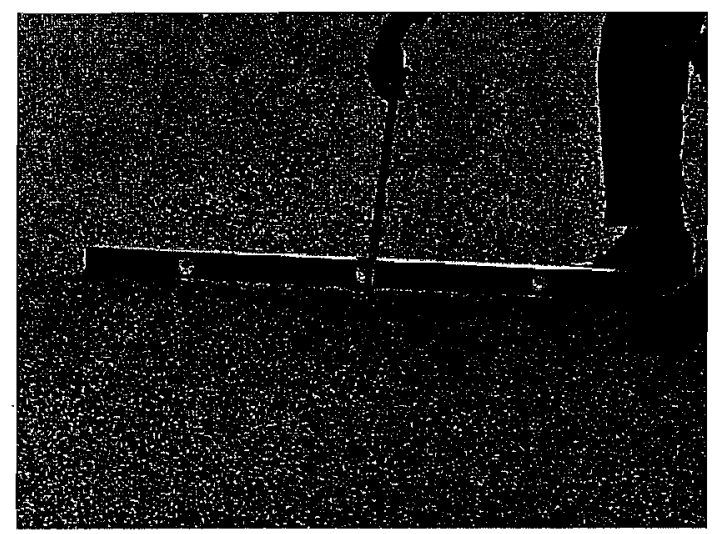

Measuring the depth of a depression. 


\section{FLEXIBLE PAVED SHOULDER/TURNOUT}

NOTE: Many roadways have combinations of paved and unpaved shoulder widths. The measurements for evaluation of the PAVED SHOULDER characteristic are different than those for ROADWAY. The methods for measuring or evaluating will be the same as for ROADWAY. Paved shoulder evaluation includes edge widening.

FLEXIBLE PAVED

SHOULDER/TURNOUT: Rate flexible paved shoulder for pothole, edge raveling and depression/bump.

Rate flexible turnout for pothole only.

\section{FLEXIBLE PAVED SHOULDER:}

Pothole

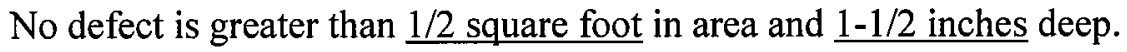

No pervious base is exposed in any hole.

Flexible pothole does not meet MRP standards when any of the following exist:

1) If BOTH depth and area are greater than the standard limits.

2) If pervious base is exposed in any pothole.

Edge Raveling $\quad \underline{75 \%}$ of the total shoulder edge is free of raveling.

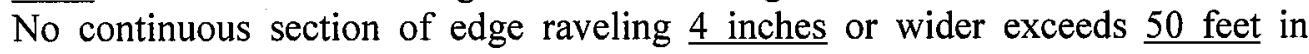
length.

Edge raveling does not meet MRP standards when any of the following exist:

1) If more than $25 \%$ of the shoulder edge contains edge raveling.

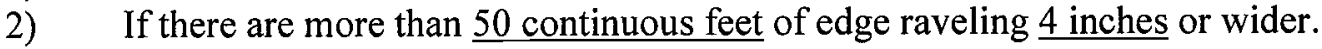

PAVED SHOULDER EDGE RAVELING TABLE

\begin{tabular}{|c|c|c|c|}
\hline 1 & 528 & 396 & 132 \\
\hline 2 & 1056 & 792 & 264 \\
\hline 3 & 1584 & 1188 & 396 \\
\hline 4 & 2112 & 1584 & 528 \\
\hline
\end{tabular}

Depression/Bump No deviation exceeds 1 inch for any area greater than 1 square foot.

No single measurement shall exceed $\underline{3 \text { inches. }}$

Depression/Bump does not meet MRP standards when any of the following exist:

1) A deviation from design grade greater than 1 inch for any area greater than 1 square foot.

2) Concrete and/or asphalt spills which exceed 1 inch and 1 square foot.

3) Any single measurement of a depression or bump exceeding 3 inches. 


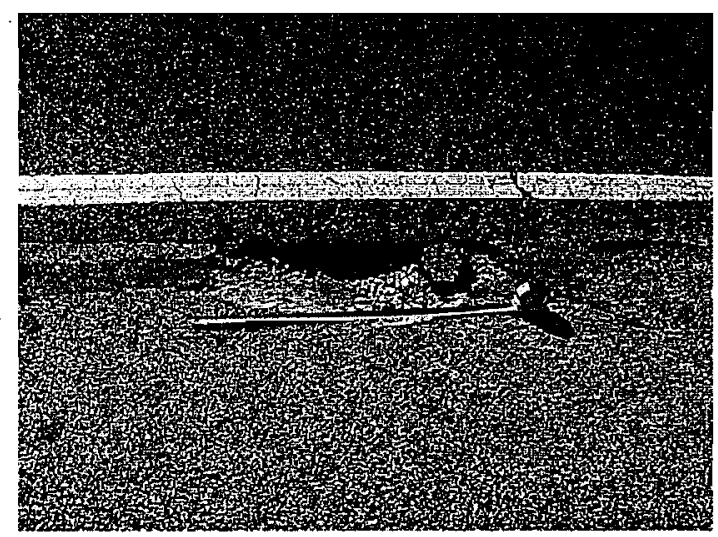

Pothole in paved shoulder. Measurements should be taken to determine if this meets MRP Standards.

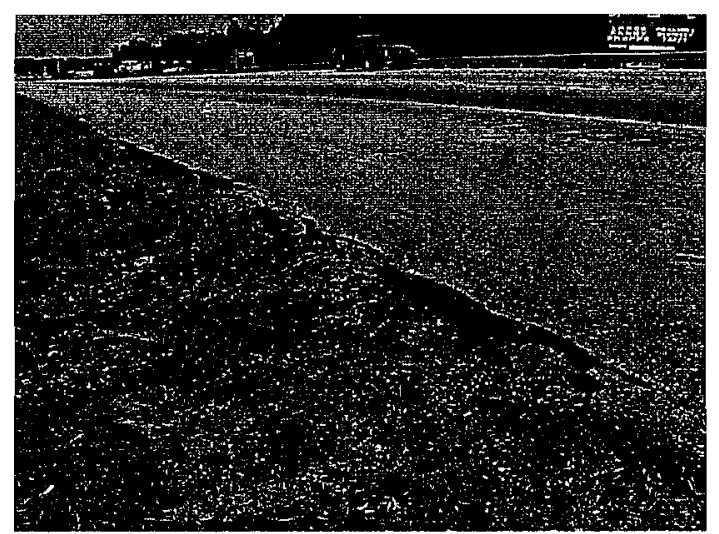

Edge raveling on paved shoulder. Measurements should be taken to determine if this meets MRP Standards.

\section{FLEXIBLE TURNOUT:}

Pothole

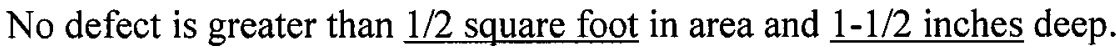

No pervious base is exposed in any hole.

Flexible Turnout - Paved aprons in highway section turnouts (no curb and gutter) should extend out $\underline{5}$ feet from the edge of the pavement or to the limits of paved shoulders. Turnouts in paved shoulder sections should be rated as paved shoulders. If there is no requirement for a paved apron as specified in Standard Index 515, rural turnout construction (less than 20 trips/day), rate as non-paved shoulder. The area outside the apron on an unpaved turnout should be rated as shoulder and front slope, if present.

Paved aprons in curb and gutter section turnouts may be of rigid or flexible construction. Unpaved turnouts in curb and gutter sections shall be rated as curb and sidewalk edging. Evaluation of urban flared turnouts shall extend out to the right-of-way or two feet back of sidewalk, whichever distance is less (See Index 515).

DO NOT evaluate dedicated streets and roads (normally should have a street sign) for paved aprons.

Flexible turnout does not meet MRP standards when any of the following exist:

1) If BOTH depth and area are greater than the standard limit.

2) Any exposed pervious base. 


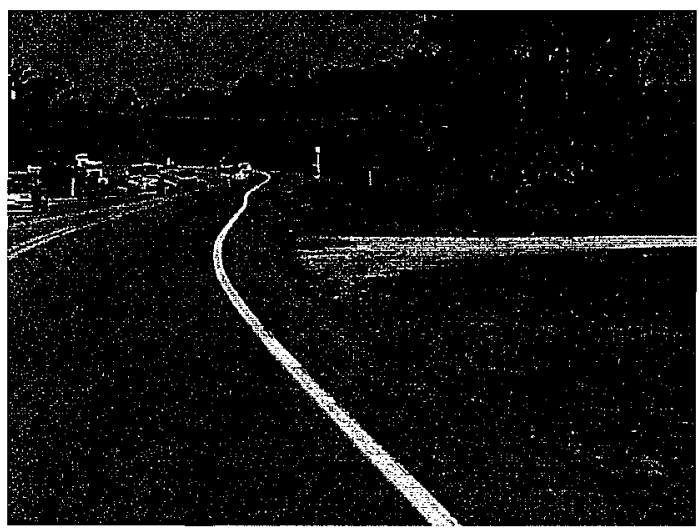

This is an example of a turnout in a paved shoulder section. This should be rated as paved shoulder only. 
CASE 1

Assume there are less than 20 trips per day. Do Nor rate ag turnout. Rate as unpaved shoulder and fxont slope.

CASE 2

Rate $5^{\prime}$ of paved apron as turnoute. Rate the rest of the diriveway as unpaved shoulder and front silope.

CASE 3

Onzy rate $5^{\circ}$ next to roadway within drivoway as turmout. DO NOT rate the rest of the paved driveway.

CASE 4

Rate as paved shoulder. DO NOT rate the regt of the paved driveway. If unpaved, rate az unpaved shoulder and front slope.
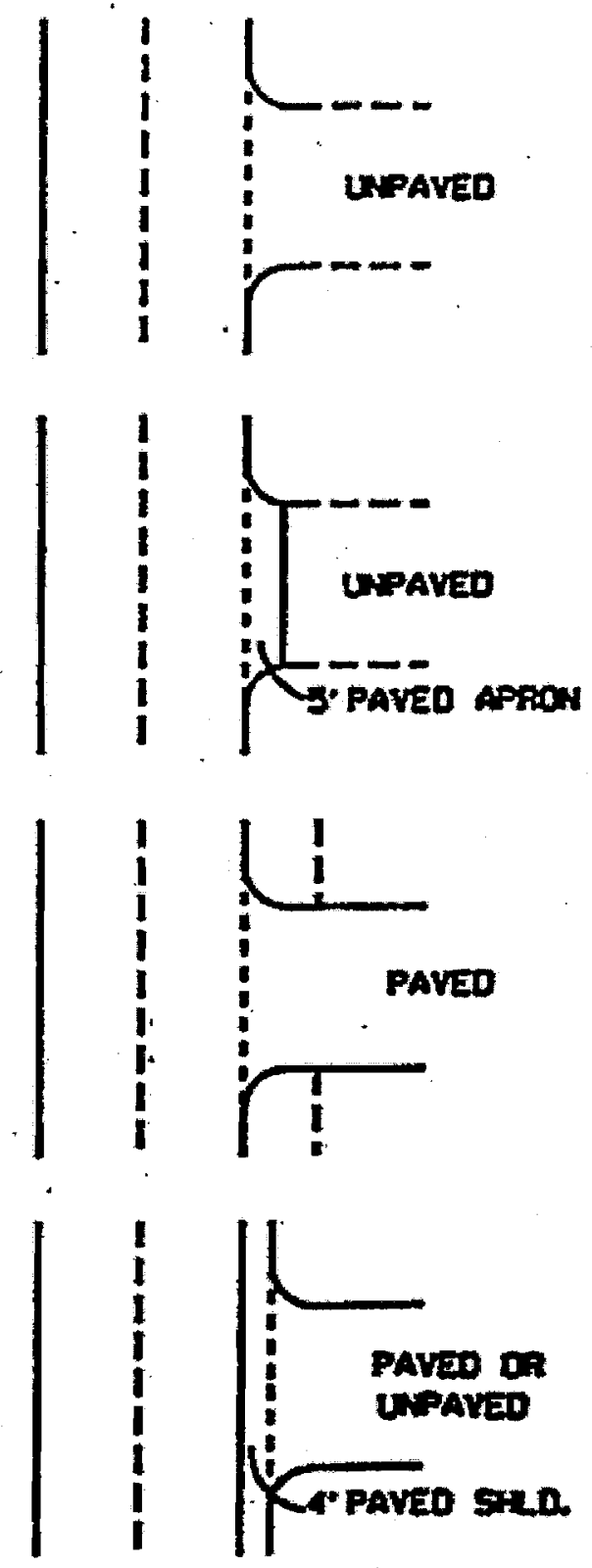


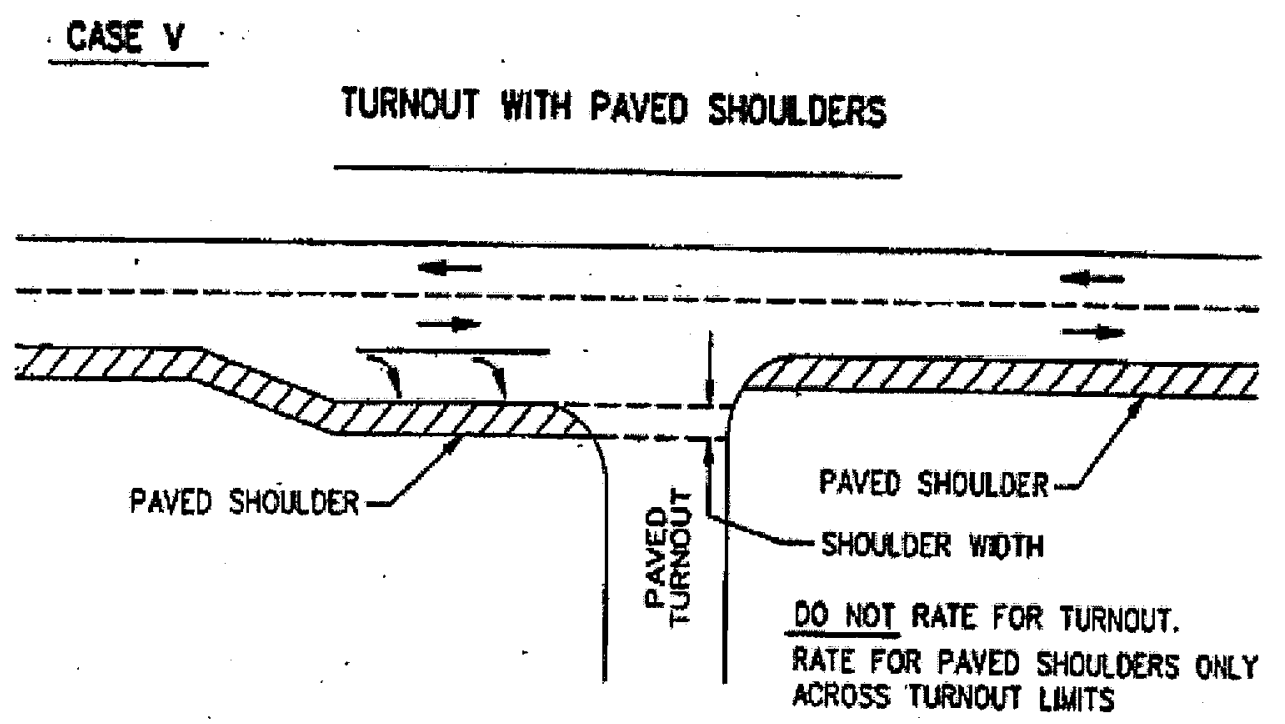

\section{TUPADOUT WITH TAPER ONLY}

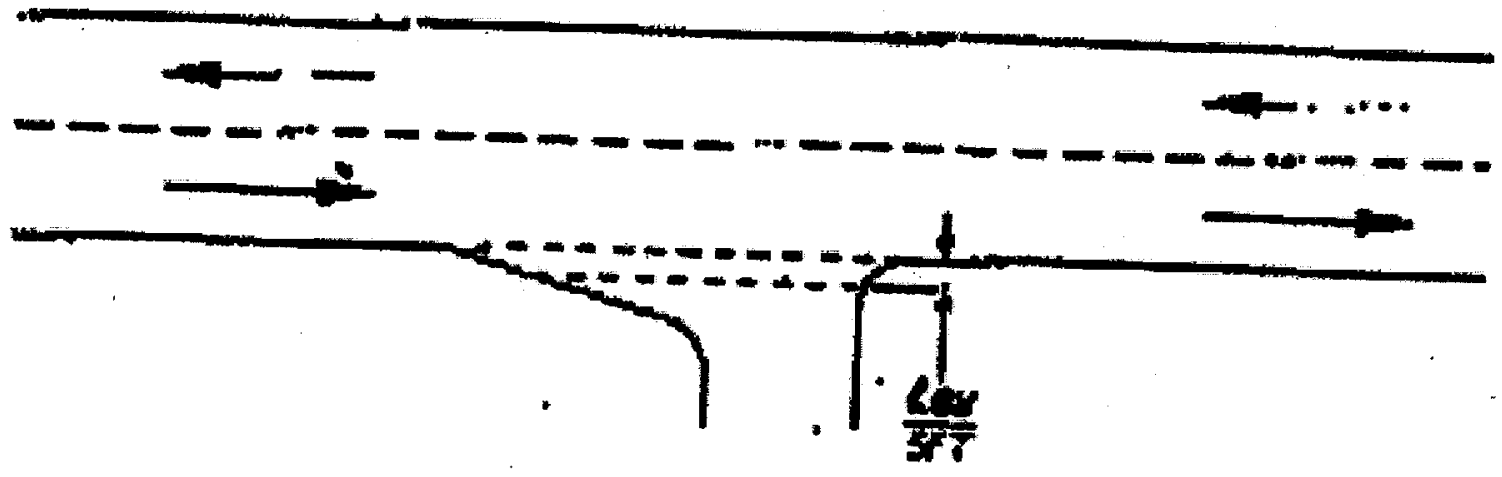

Rate $1.5 \mathrm{~m}$ ( 5 feet ) throughout taper and turnout. 


\section{RIGID ROADWAY}

NOTE: $\quad$ The methodology used for evaluating potholes and depression/bump will be the same for both flexible and rigid pavements.

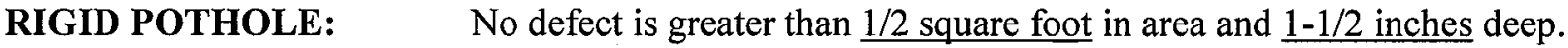

No pervious base is exposed in any hole.

Rigid Pothole - Potholes are normally bowl-shaped holes in the pavement that usually form in low areas, such as wheel paths and utility trenches. They are caused by pavement weaknesses, which may result from poor quality materials, thin pavement surface, poor drainage on the pavement surface or within the base, or a loss of load support by either the base or sub grade.

Evaluation: Measure the size of the pothole. Place a straightedge across the defective area and determine if any single measurement of the defective area is deeper than that listed in the standard. To determine the area of a defect, measure the area as a square or rectangle. Use of a straightedge and a marker to outline the area may be helpful. Do not rate the first four inches from the actual edge of pavement for pothole criteria.

\section{Rigid pothole does not meet MRP standards when any of the following exist:}

1) If BOTH depth and area are greater than the standard limits.

2) If pervious base is exposed in any hole.
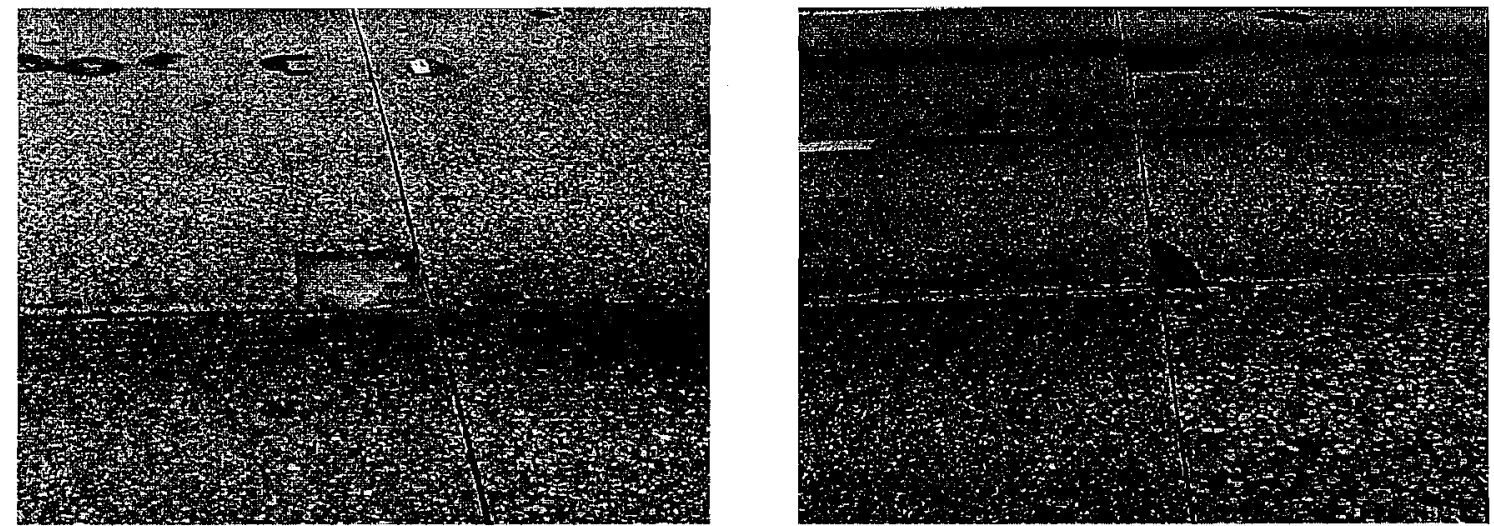

These are pictures of defects in rigid pavement. Calculate the area to determine if it is greater than $1 / 2$ square foot and measure the depth of the defect. If both the area and depth are greater than the standard limits than the areas do not meet MRP standards. 


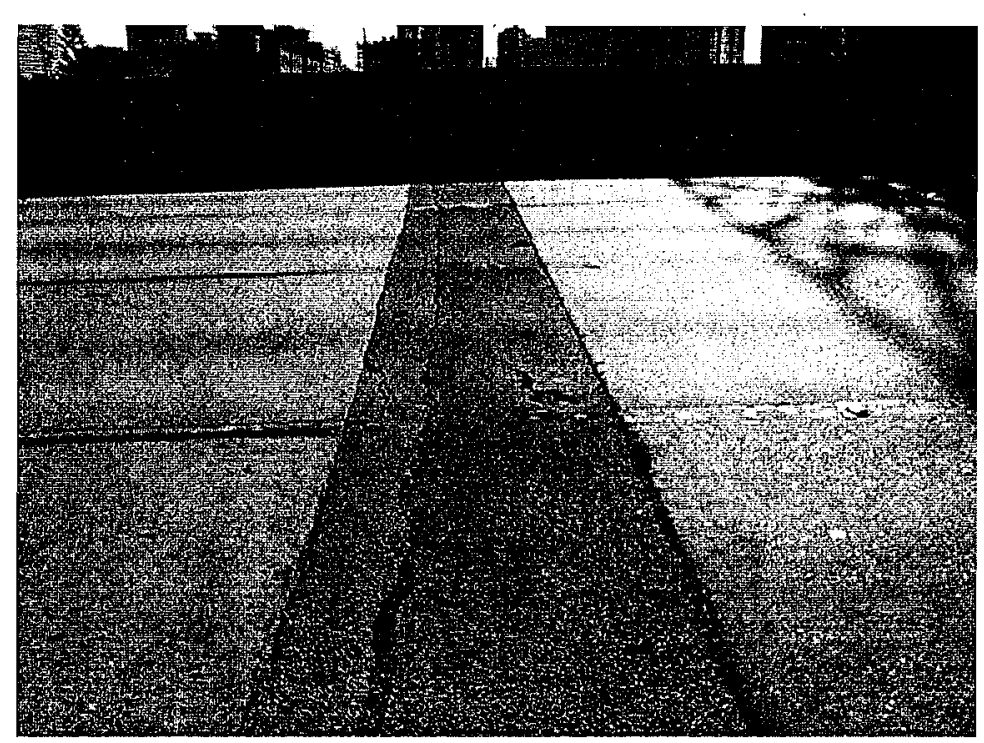

This is a picture of rigid pavement with an asphalt utility cut patch.

This area should be rated for rigid and flexible pavement. Pavement characteristics should be rated as last constructed.

\section{RIGID DEPRESSION/ BUMP:}

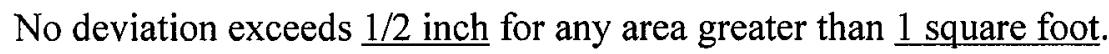
No single measurement shall exceed $\underline{2 \text { inches. }}$

Rigid Depression/Bump - A pavement depression or bump is a deviation from design grade. It may be an area close to or caused by an inlet, manhole or underground utility installation. This characteristic also includes parking lanes.

Evaluation: To measure the size of a depression or bump, first measure the area. If the area of the depressed or elevated area is less than 1 square foot, then no further measurements are necessary because it is not rated as a depression /bump unless a single measurement exceeds 2 inches. If the area is greater than 1 square foot, then measure the depression by putting a straightedge across the depression and measuring the distances from the straightedge to the lowest area in the depression. If this distance

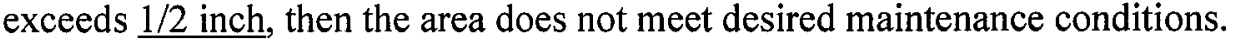

\section{A Rigid Depression/Bump does not meet MRP standards when any of the following exist:}

1) A depression more than $1 / 2$ inch exists with an area greater than 1 square foot.

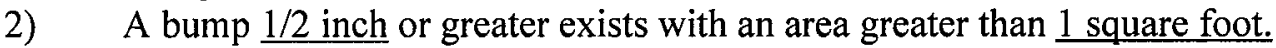

3) Any depression or bump greater than 2 inches. 


\section{RIGID JOINT/ CRACKING:}

RIGID JOINT: $\quad \underline{85 \%}$ of the length of transverse and longitudinal joint material appears to function as intended.

Rigid Joints - Joints are placed in rigid pavement to control cracking and to allow for year-round contraction and expansion. Joints should be sealed to restrict the intrusion of water and incompressibles into the joint. Sealed joints extend the life of the rigid pavement.

Evaluation: To determine if this characteristic meets MRP standards, you must first calculate the total length of transverse and longitudinal joints in the sample. This can be accomplished by computation or actual measurement.

Transverse joints are generally about 20 feet apart but an on-site verification should be done. Count the number of transverse joints and multiply by the width of the road. Count the number of longitudinal joints and multiply by the length of the joints. To obtain the total length of joint material, add the length of transverse and longitudinal joints together. Generally, it is easier to multiply the total joint length to be evaluated by $0.15(15 \%)$ to determine what length is allowed below the desired maintenance condition and then measure those joints that do not function as intended. A cumulative length greater than $15 \%$ of the total does not meet the desired maintenance condition.

On multi-lane divided sections, with paved shoulders, BOTH the paved median shoulder and paved outside shoulder joints are to be evaluated. DO NOT rate the longitudinal joint between the rigid pavement and asphalt shoulder if it was never sealed.

Rigid Joints do not meet MRP standards when the following exist:

1) More than $\underline{15 \%}$ of the total transverse and longitudinal joint length is missing.

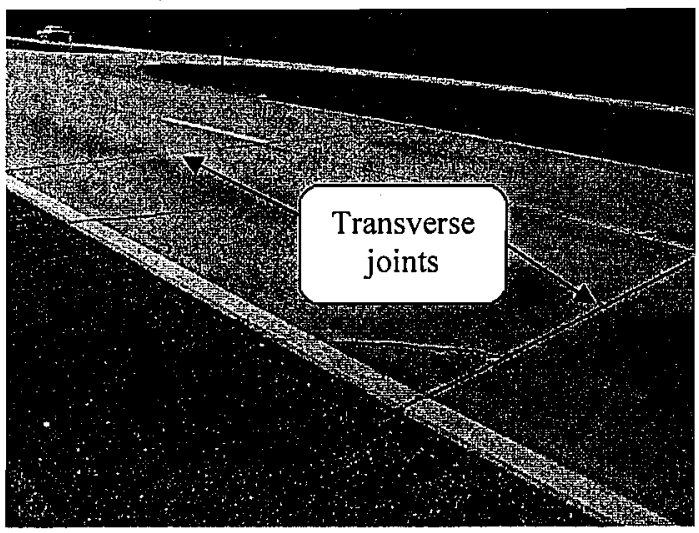

This picture shows two traverse joints and a slab that has two unsealed cracks.

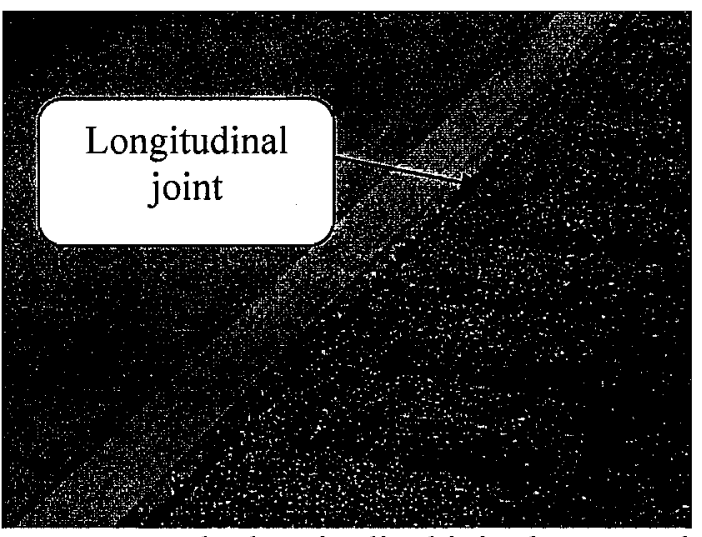

Do not rate the longitudinal joint between the Rigid pavement and the asphalt shoulder if it was never sealed. 
RIGID CRACKING: $\quad \underline{90 \%}$ of the roadway slabs have no unsealed cracks wider than $\underline{1 / 8}$ inch.

Rigid Cracking - A slab is defined as that area within the existing control joints. Do not include the control joints in the evaluation.

Evaluation: Determine the total number of slabs within the evaluation area. Then determine the number of slabs that have unsealed cracks wider than $1 / 8$ inch. Divide the number of slabs with unsealed cracks wider than $1 / 8$ inch by the total number of slabs within the evaluation area to determine the percentage of slabs with unsealed cracks wider than $1 / 8 \mathrm{inch}$. If this percentage is more than $10 \%$, then this characteristic does not meet desired conditions.

Rigid Cracking does not meet MRP standards when the following exist:

1) More than $\underline{10 \%}$ of the slabs have unsealed cracks greater than $\underline{1 / 8}$ inch.
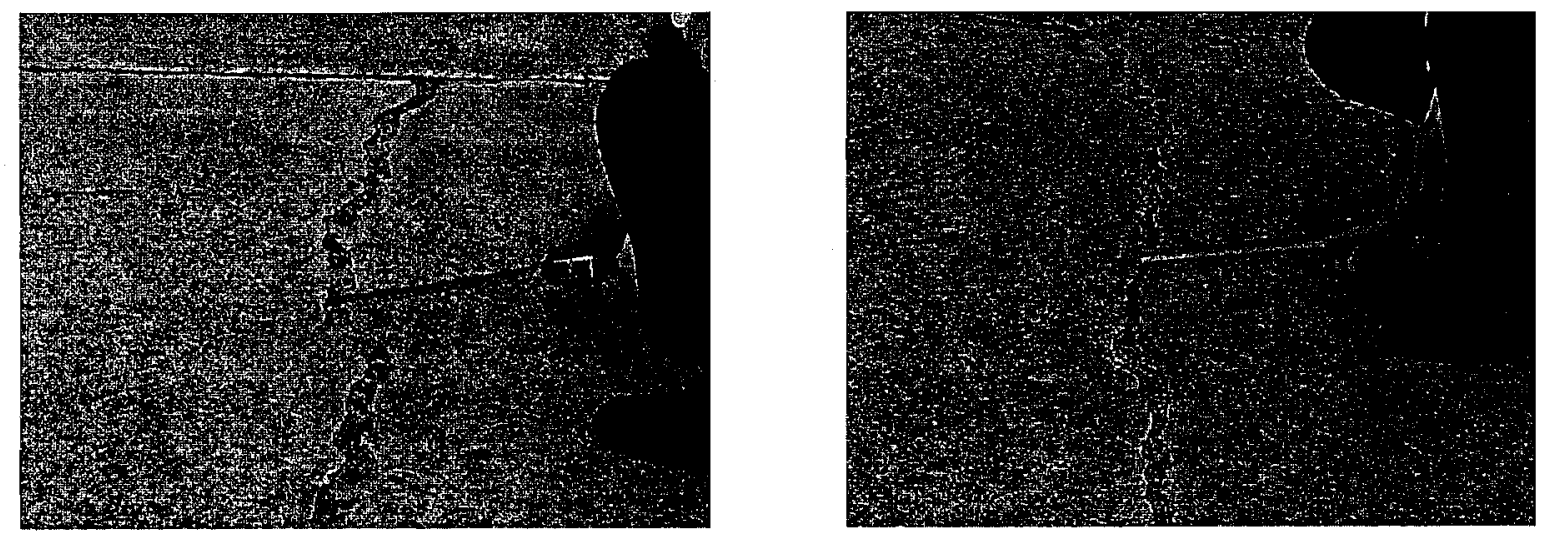

These pictures show an unsealed crack wider than $1 / 8$ inch in rigid pavement. 


\section{RIGID PAVED SHOULDER/TURNOUT}

NOTE: $\quad$ Rate rigid shoulder for pothole, depression/bump and joint/cracking. Rate rigid turnout for potholes and cracking only.

RIGID PAVED

SHOULDER:

Pothole:
Rate rigid paved shoulder for pothole, depression/bump and joint/cracking.

No defect is greater than $1 / 2$ square foot and $1-1 / 2$ inches deep.

No pervious base is exposed in any hole.

Rigid Paved Shoulder does not meet MRP standards for Pothole when any of the following exist:

1) If pervious base is exposed in any hole.

2) If BOTH depth and area are greater than the standard limits.

Depression/Bump: No deviation exceeds 1 inch for any area greater than 1 square foot. No single measurement shall exceed $\underline{3 \text { inches. }}$

Rigid Paved Shoulder does not meet MRP standards for Depression/Bump when any of the following exist:

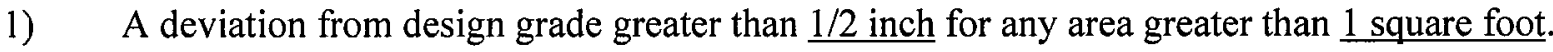

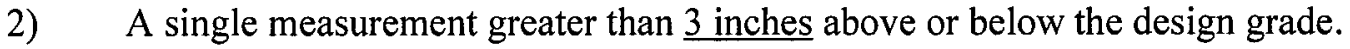

Joint: $\quad \underline{75 \%}$ of the joints appear to function as intended by restricting the intrusion of water and incompressibles.

Rigid Paved Shoulder does not meet MRP standards for Joints when any of the following exist:

1) More than $\underline{25 \%}$ of the joints do not function as intended.

Cracking: $\quad \underline{80 \%}$ of the paved shoulder cumulative areas have no unsealed cracks wider than $\underline{3 / 4 \text { inch. }}$

Rigid Paved Shoulder does not meet MRP standards for Cracking when any of the following exist:

1) More than $\underline{20 \%}$ of the slabs have unsealed cracks greater than $\underline{3 / 4 \mathrm{inch}}$.

RIGID TURNOUT: $\quad$ Rate rigid paved turnout for potholes and cracking only.

Pothole: $\quad$ No defect is greater than $1 / 2$ square foot in area and $1-1 / 2$ inches deep.

No pervious base is exposed in any hole.

Rigid Turnout does not meet MRP standards for Pothole when any of the following exist:

1) If BOTH depth and area are greater than the standard limits.

2) If pervious base is exposed in any hole.

Cracking: $\quad \underline{80 \%}$ of paved turnout cumulative area has no unsealed cracks wider than $\underline{3 / 4}$ inch.

Rigid Turnout does not meet MRP standards for Cracking when any of the following exist:

1) More than $\underline{20 \%}$ of the cumulative turnout area has unsealed cracks wider than $\underline{3 / 4}$ inch. 


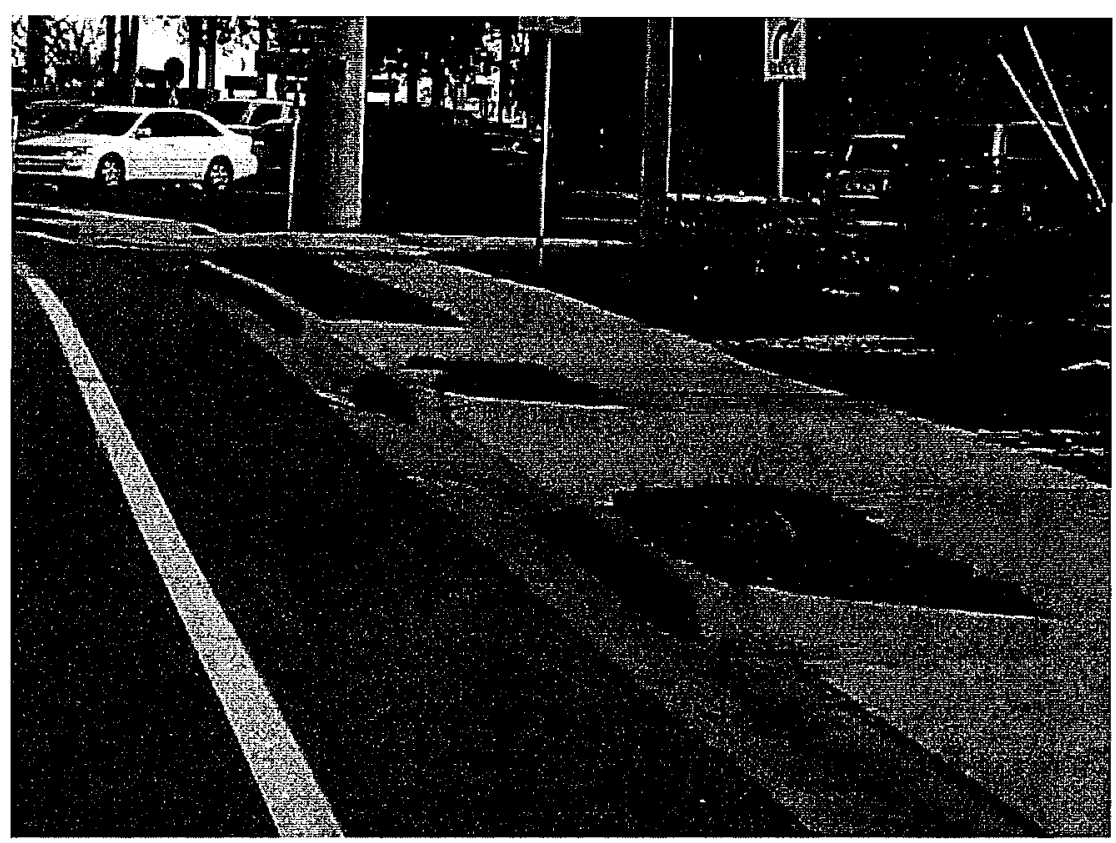

These are urban flared turnouts. The area from the back of curb to the front of the sidewalk is to be rated as turnout. 
-BLANK PAGE- 
FLORIDA DEPARTMENT OF TRANSPORTATION

MAINTENANCE RATING PROGRAM STANDARDS

ROADSIDE

\section{THE FOLLOWING CHARACTERISTICS MEET THE DESIRED MAINTENANCE CONDITIONS WHEN:}

UNPAVED SHOULDER: No deviation exists across the shoulder width greater than 5 inches above or below the design template.

No shoulder build-up exceeds $\underline{2}$ inches anywhere across the design template for a continuous $\underline{25 \text { feet. }}$.

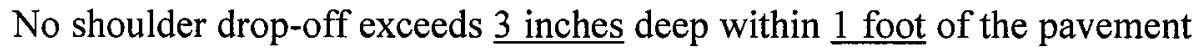
edge for a continuous 25 feet.

No washboard areas exist having a total differential greater than $\underline{5 \text { inches }}$ from the low spot to the high spot.

FRONT SLOPE: $\quad$ No deviations exist greater than 6 inches in depth or height.

SLOPE PAVEMENT: $\quad$ No single area of missing, settled or misaligned areas exist greater than 10 square feet.

SIDEWALK:

$99.5 \%$ of sidewalk area is free of vertical misalignments or horizontal cracks greater than $\underline{3 / 4 \text { inch. }}$

FENCE: $\quad$ No unrestrained entry is allowed. 


\section{ROADSIDE}

UNPAVED SHOULDER: No deviation exists across the shoulder width greater than 5 inches above or below the design template.

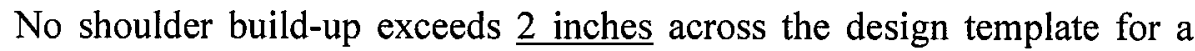
continuous 25 feet.

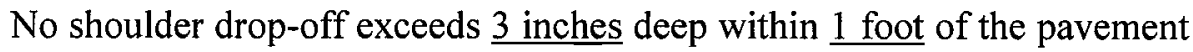
edge for a continuous $\underline{25 \text { feet. }}$

No washboard areas exist having a total differential greater than $\underline{5 \text { inches }}$ from the low spot to the high spot.

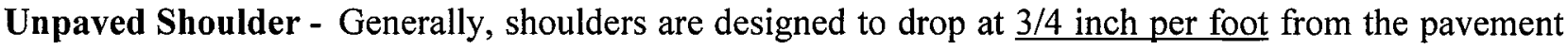
edge except in super elevated curves.

Evaluation: To measure a shoulder drop-off, place a straightedge on the pavement and measure down. If the straight-line diagrams (SLD's) do not indicate an unpaved shoulder in conjunction with a paved shoulder, the first two feet adjacent to the paved shoulder should be rated as unpaved shoulder. This applies to the inside and outside paved shoulder.

Unpaved shoulder does not meet desired maintenance conditions when any of the following exist:

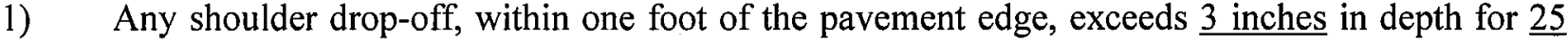
continuous feet.

2) Any deviation of shoulder elevation, including the radius at paved turnouts, is greater than $\underline{5}$ inches above or below the design template.

3) Any shoulder build-up exceeds 2 inches across the design template for 25 continuous feet.

4) Any washboard areas having a total differential greater than 5 inches from the low spot to the high spot.

NOTE: Utility strips will be evaluated using the CURB/SIDEWALK EDGING characteristic

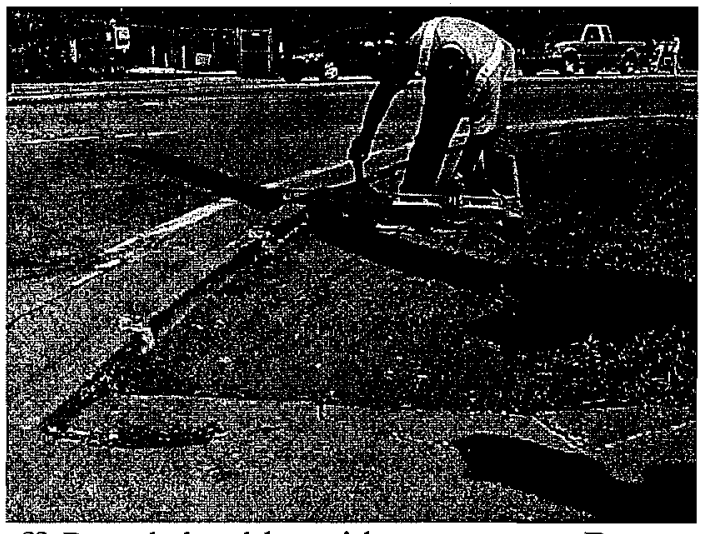

Shoulder drop-off. Paved shoulder with soil shoulder. See SLD for dimensions.
Drop-off behind curb. Since this road has curb \& gutter this would be evaluated under curb \& sidewalk edging. 


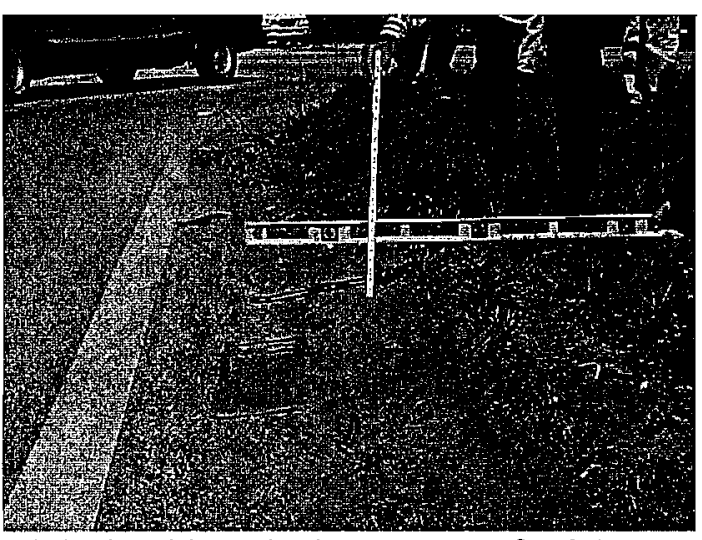

High shoulder 2 inches or more for 25 continuous feet does not meet MRP Standards.

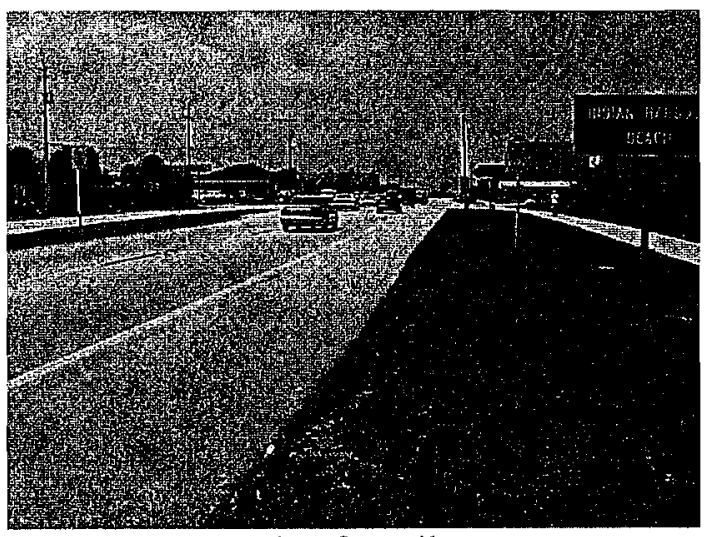

This is an example of a soil shoulder that meets MRP standards.

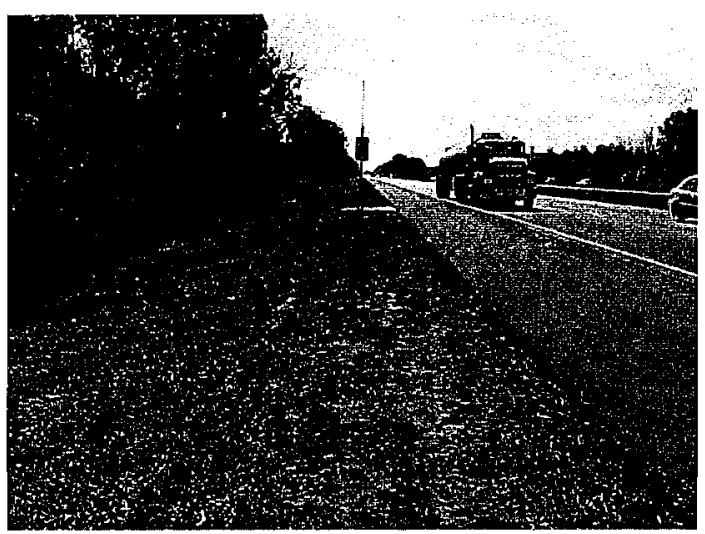

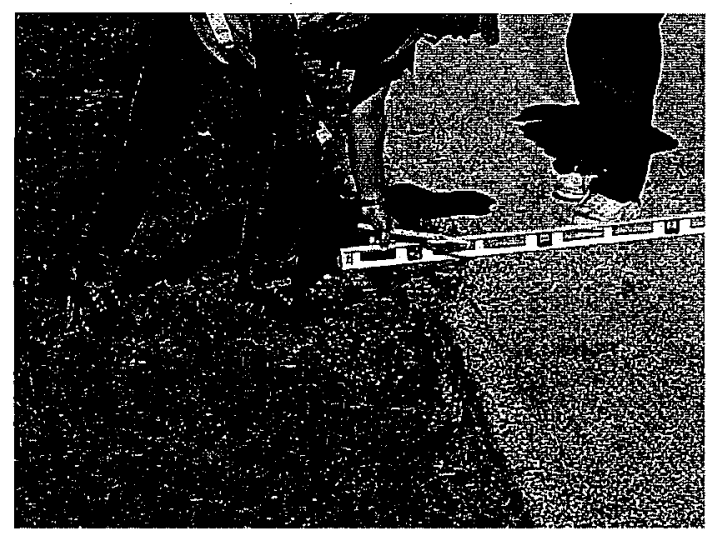

Shoulder drop off greater than 5 inches does not meet MRP Standards.

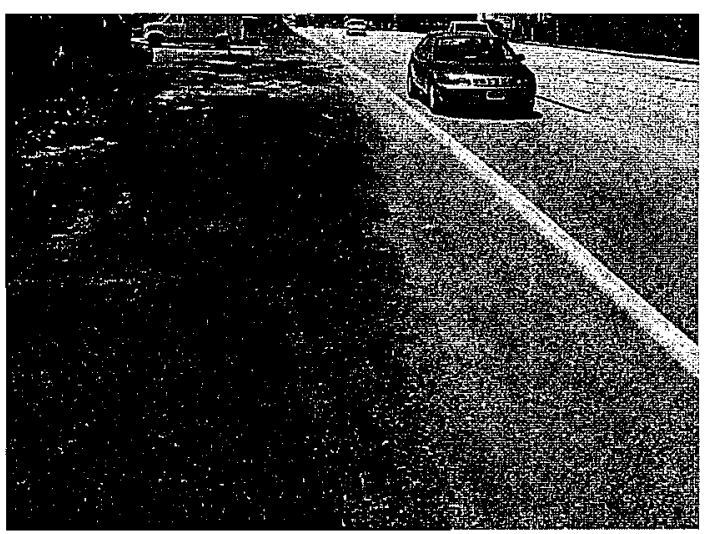

High soil shoulder adjacent to a paved shoulder. Measurements should be taken to determine if this soil shoulder meets MRP standards.

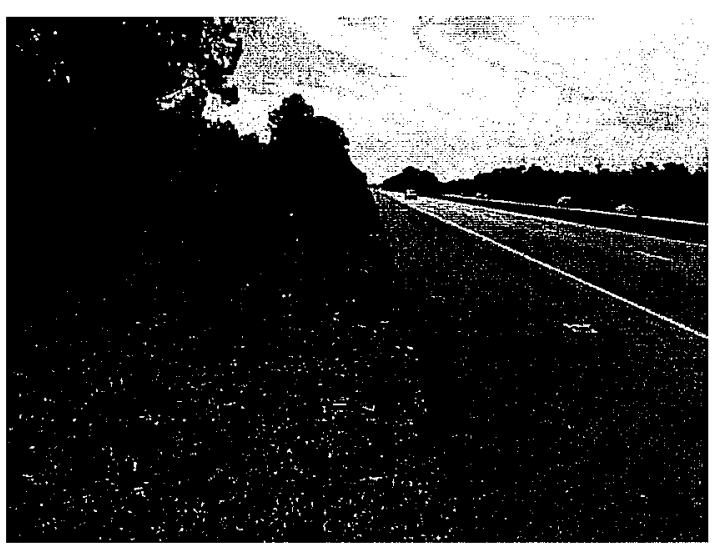

These pictures are examples of a roadway with a paved shoulder. If the SLD's do not indicate an unpaved shoulder in conjunction with a paved shoulder, the first two feet adjacent to the paved shoulder should be rated as unpaved shoulder. 


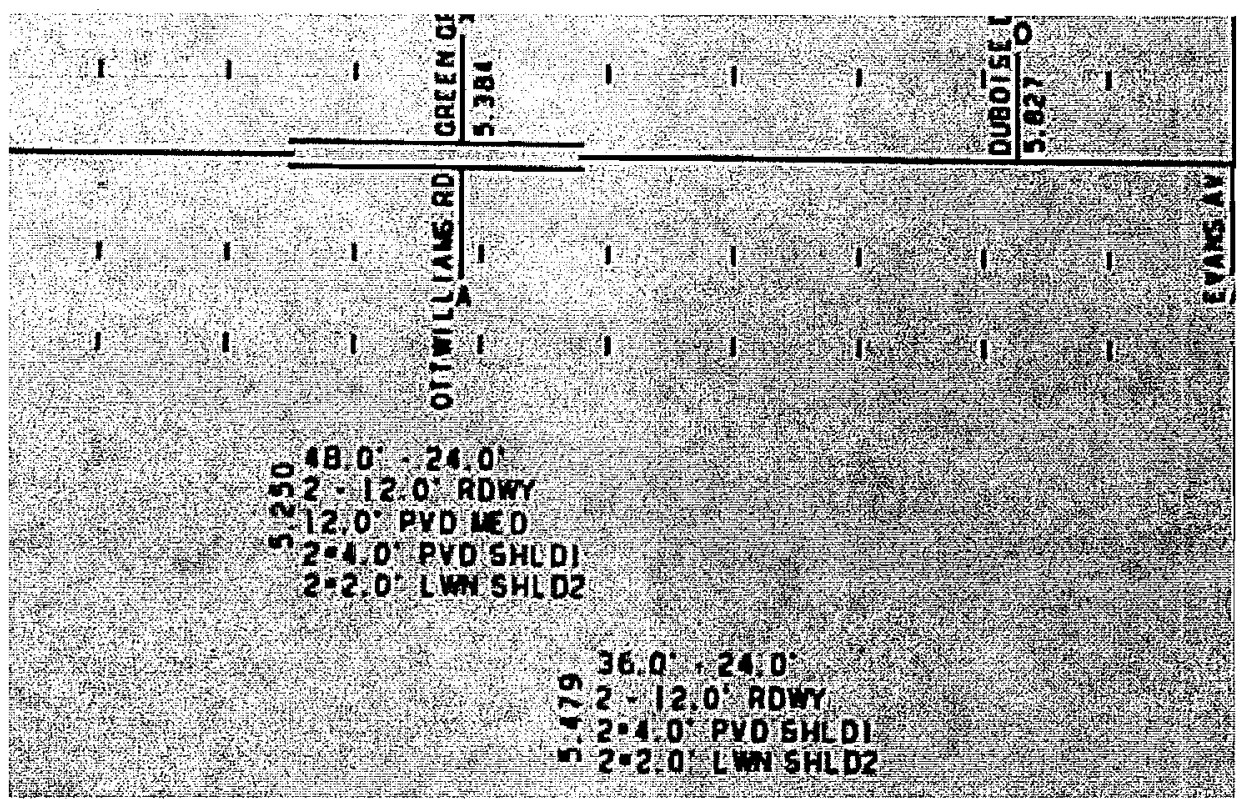

This is an example of a Straight line diagram (SLD) that shows 2-4.0' paved shoulders and 2-2.0' lawn shoulders. In this case FLEXIBLE PAVED SHOULDER/TURNOUT and UNPAVED SHOULDER characteristics should be rated. 
FRONT SLOPE: No deviations exist greater than $\underline{6 \text { inches }}$ in depth or height.

Front slope - Front slopes provide a gradual and contoured transition from the shoulder edge to the roadside ditch or toe of slope in a fill section.

Evaluation - Survey the sample point for deviations which may include ruts, washouts and/or buildups.

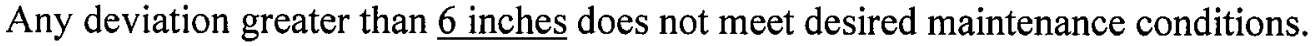

When rating front slope washouts in a turnout area, project the roadway toe of front slope across the turnout. Do not rate beyond the toe of slope for washouts in a turnout. Front slopes are evaluated from the shoulder edge to the roadside ditch bottom, to edge of slope in a fill section or to the limits of the right-of-way.

\section{Front slope does not meet MRP standards when any of the following exist:}

1) Any deviation greater than 6 inches in depth or height.

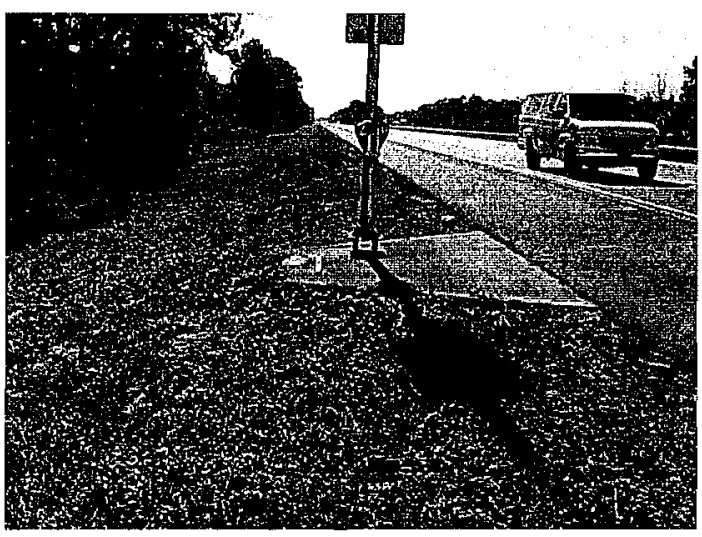

This is a call box and pad constructed on the shoulder and front slope.

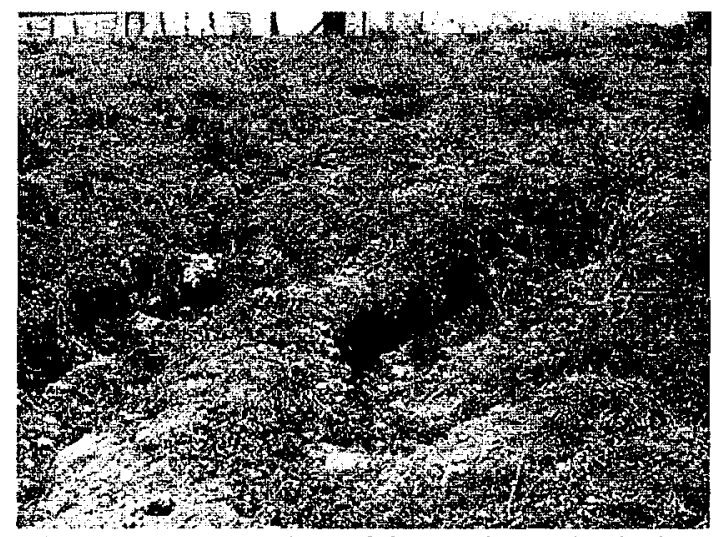

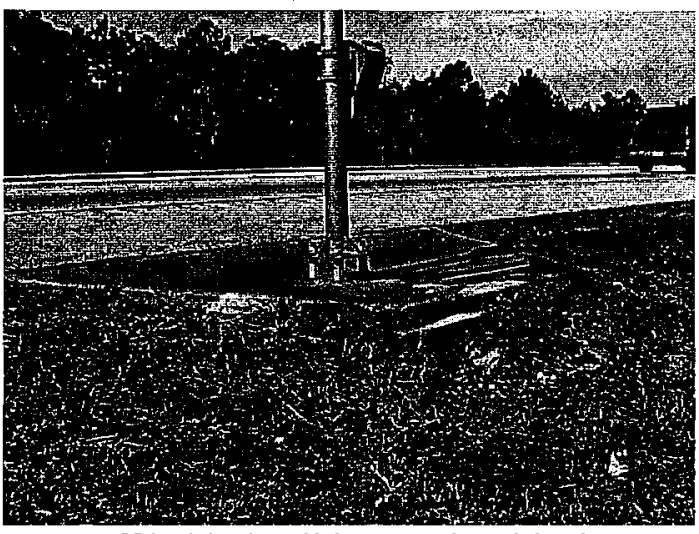

Drop off behind call box pad. This does not meet MRP Standards for Front Slope.

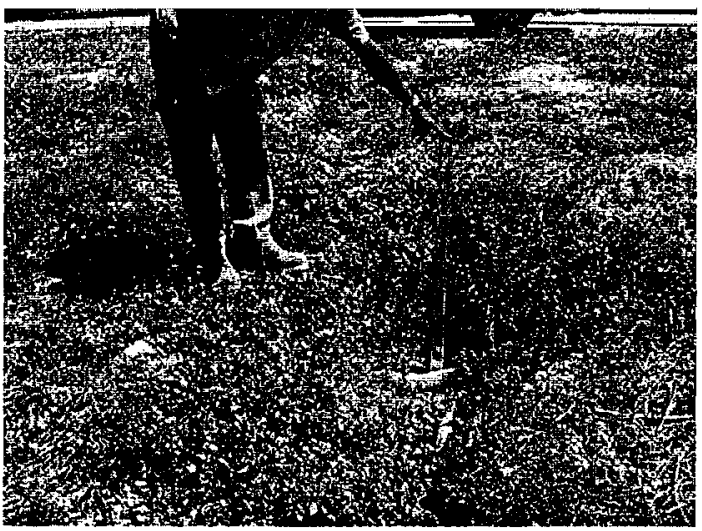

These are examples of front slope deviations greater than 6 inches. These conditions do not meet MRP standards. 


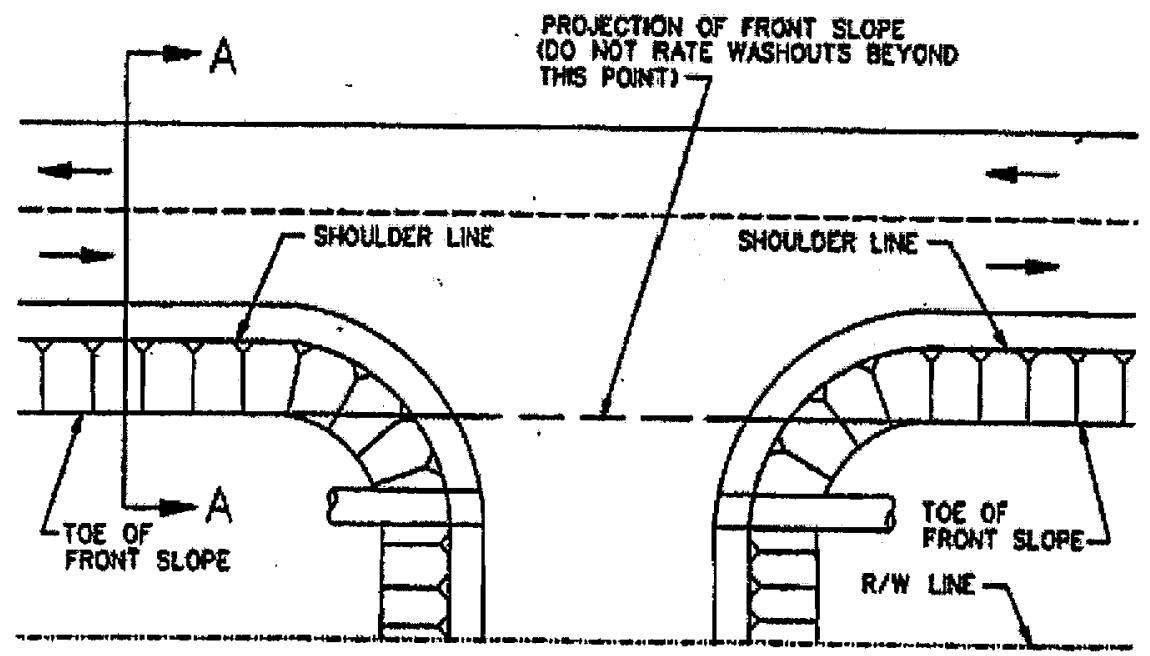

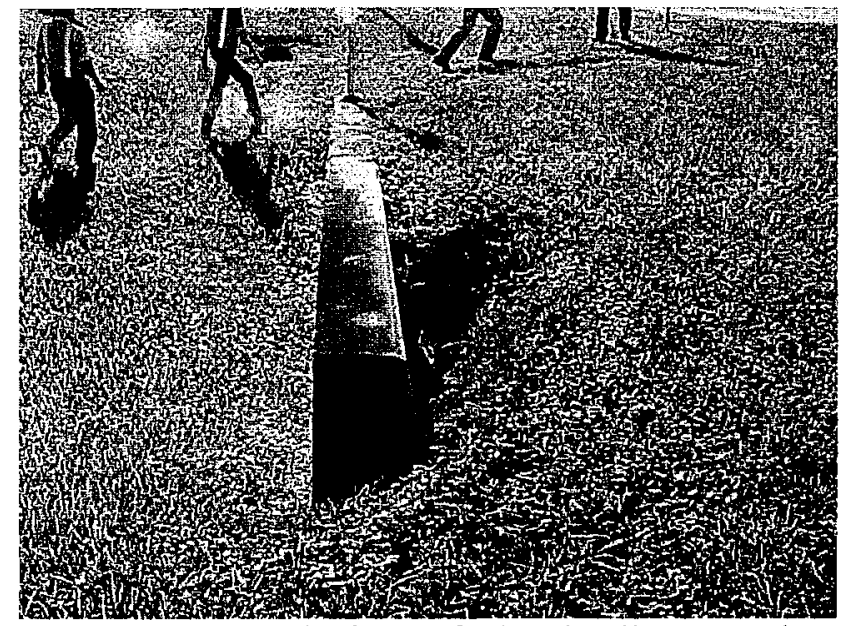

This is a washout in front of a headwall greater than 6 inches in depth. This would not meet MRP maintenance standards.

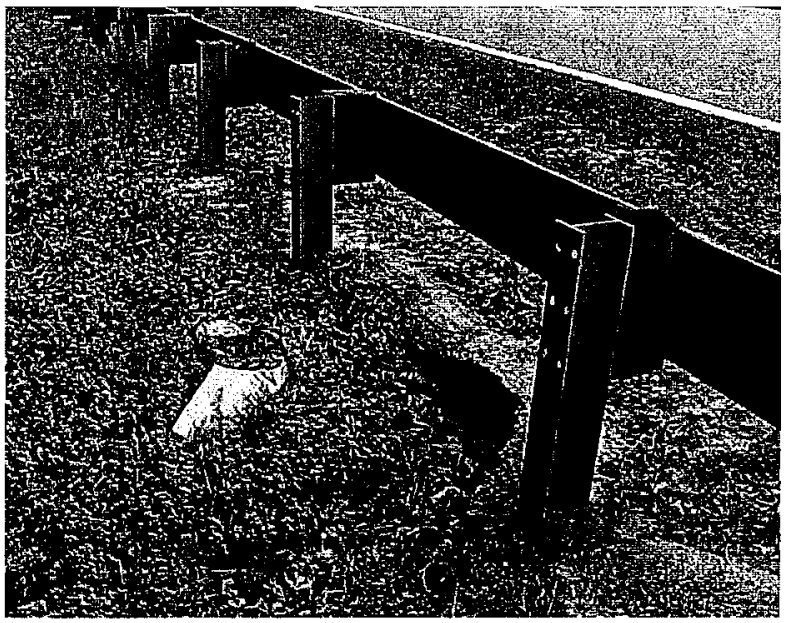

The asphalt under the guardrail has washed out. The guardrail meets desired maintenance standards, However, unpaved shoulder or front slope would not meet desired MRP standards. 
No missing, settled or misaligned areas exist greater than 10 square feet.

Slope Pavement - Any single area of missing, settled or misaligned area of paved slope (includes any paved slope treatment) greater than 10 square feet does not meet desired maintenance conditions (This includes sand cement riprap slopes).

Evaluation: Review the existing slope pavement within the sample area. Measure any missing, settled or misaligned areas.

\section{Slope Pavement does not meet MRP standards when any of the following exist:}

1) There is missing slope pavement greater than 10 square feet.

2) There is settled slope pavement greater than 10 square feet.

3) There is misaligned slope pavement greater than 10 square feet.
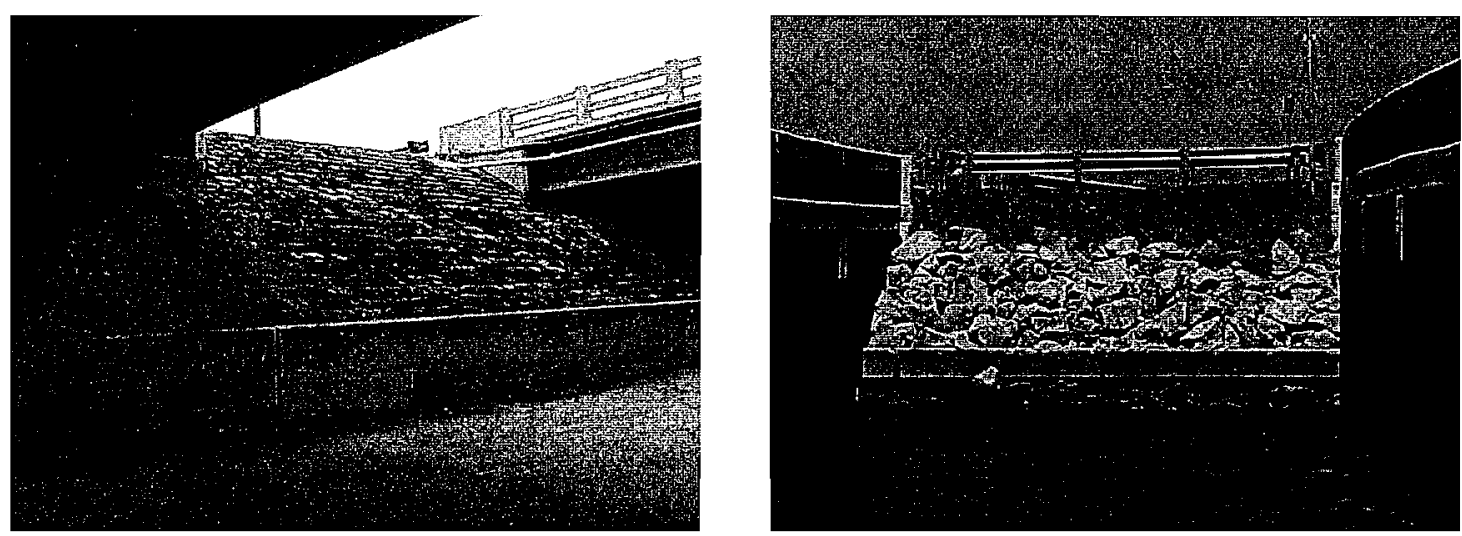

This is an example of rip-rap slope pavement. This is an example of rubble slope pavement.

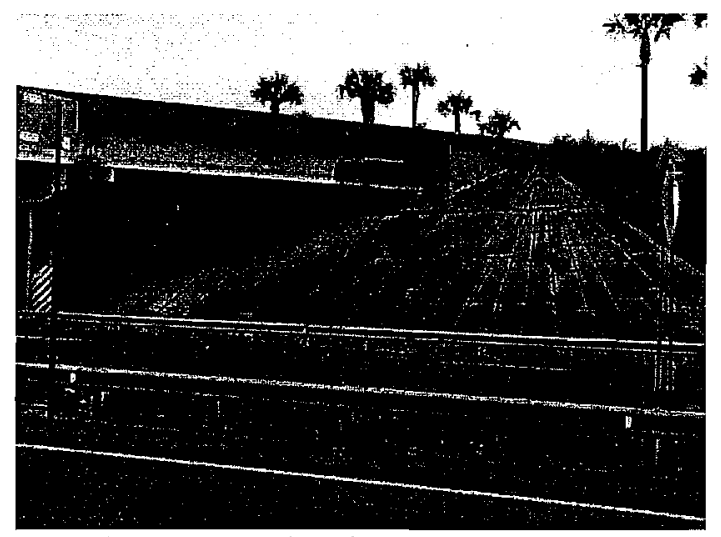

This is an example of concrete slope pavement. 
SIDEWALK:

$99.5 \%$ of sidewalk area is free of vertical misalignments or horizontal cracks greater than $\underline{3 / 4 \text { inch. }}$

Sidewalk - Sidewalk is constructed of various materials and is subject to misalignments caused by growing tree roots, settling or deterioration. This measurement includes the normal sidewalk joint and the sidewalk to curb joint. Sidewalk should be projected across an urban flared paved turnout and that area evaluated as sidewalk. Any bike path located outside the roadway pavement area will be evaluated as sidewalk. Paved utility strips are evaluated as sidewalk if they are intended to be used as sidewalk.

Sidewalk shall not be evaluated across dedicated streets. Spalled areas greater than $3 / 4$ inch in depth do not meet desired conditions. Uniform deviation from original grade that does not have vertical misalignments or cracks greater than $\underline{3 / 4}$ inch do not meet desired maintenance conditions. For purposes of evaluating this characteristic, one linear foot of misalignment or cracking not meeting desired conditions equals one square foot of sidewalk area. Do not exceed one linear foot of cracking in a one

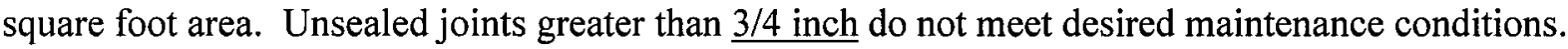

For MRP purposes if an entire slab is missing in a continuous section of sidewalk, multiply the length of the missing section by the width to get the area missing. For example, if a $5 \mathrm{ft}$. section of sidewalk $5 \mathrm{ft}$. wide is missing the area would be $25 \mathrm{sq}$. $\mathrm{ft}$. If the area missing combined with the total area of cracking is greater than that allowed for the standard then sidewalk does not meet MRP standards.

Evaluation: Measure the length of sidewalk and multiply by the width of sidewalk to determine the total area. Then multiply the total area by 0.005 to determine the maximum area that can have vertical misalignments or horizontal cracks greater than $3 / 4$ inch.

Sidewalk does not meet MRP standards when the following exist:

1) More than $\underline{0.5 \%}$ of the sidewalk area has vertical misalignments or horizontal cracks greater than $\underline{3 / 4}$ inch.

SIDEWALK TABLE

\begin{tabular}{|c|c|c|c|c|}
\hline $\begin{array}{c}\text { Length } \\
(\mathrm{ft})\end{array}$ & $\begin{array}{c}\text { Width } \\
(\mathrm{ft} .)\end{array}$ & $\begin{array}{c}\text { Area } \\
(\mathrm{LxW})\end{array}$ & $\begin{array}{c}99.5 \\
(\%)\end{array}$ & $\begin{array}{c}0.5 \\
(\%)\end{array}$ \\
\hline 528 & 5 & 2640 & 2626.8 & 13.2 \\
\hline 1056 & 5 & 5280 & 5253.6 & 26.4 \\
\hline 528 & 4 & 2112 & 2101.4 & 10.6 \\
\hline 1056 & 4 & 4224 & 4202.9 & 21.1 \\
\hline
\end{tabular}



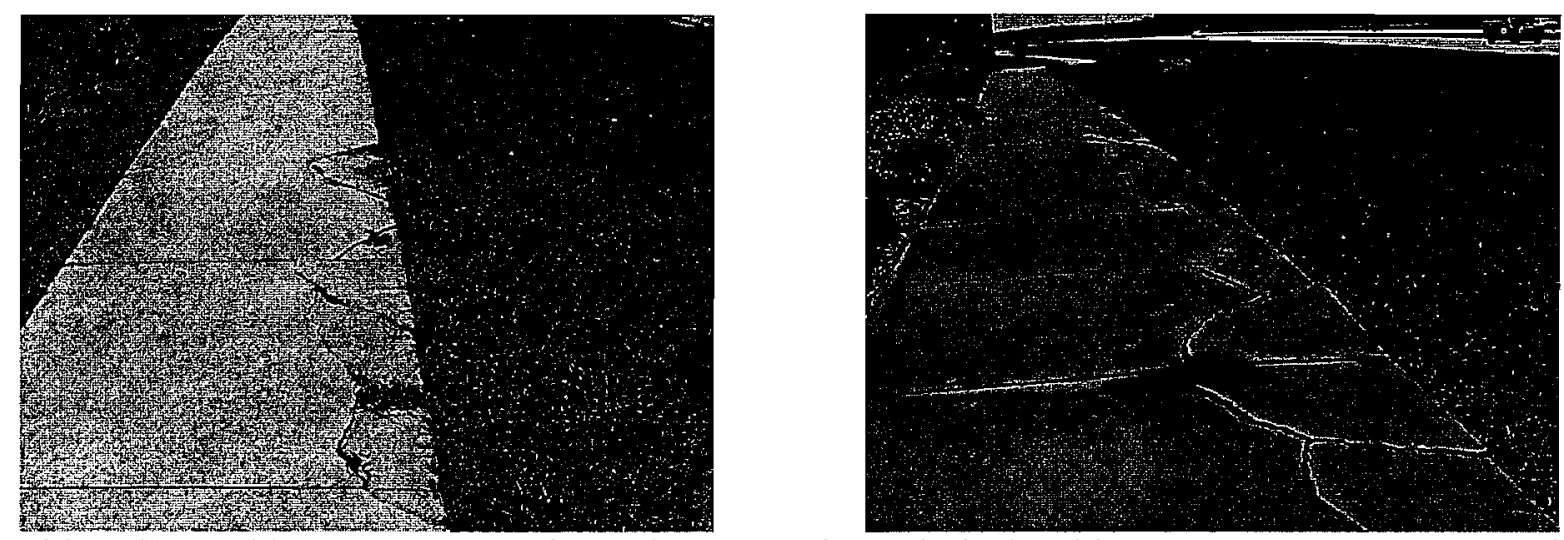

Sidewalk cracking. Measure each crack greater than 3/4 inch wide. For MRP purposes, each crack greater than $3 / 4$ inch equals $1 \mathrm{sq}$. $\mathrm{ft}$. of crack area.

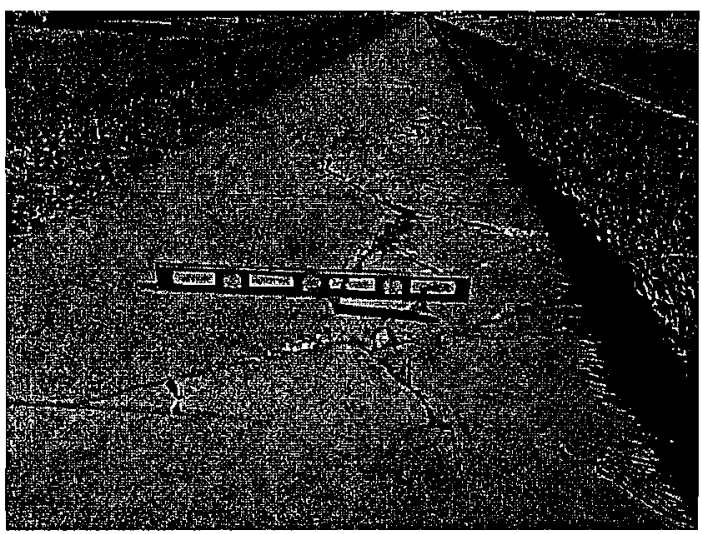

Sidewalk cracking. Measure each crack greater than $3 / 4$ inch wide. For MRP purposes, each crack greater than $3 / 4$ inch equals 1 sq. $\mathrm{ft}$. of crack area.

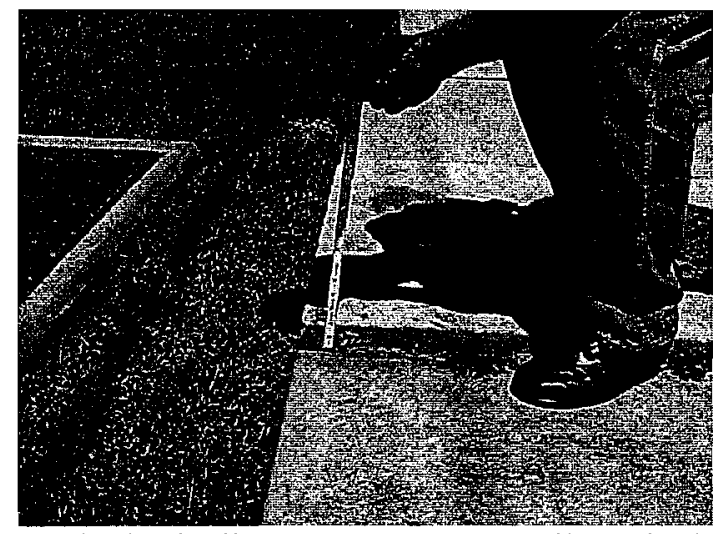

Vertical misalignment. Measure all vertical misalignments greater than $3 / 4 "$ ". For MRP purposes, one foot of $3 / 4$ inch vertical misalignment equals 1 sq. ft. of crack area.
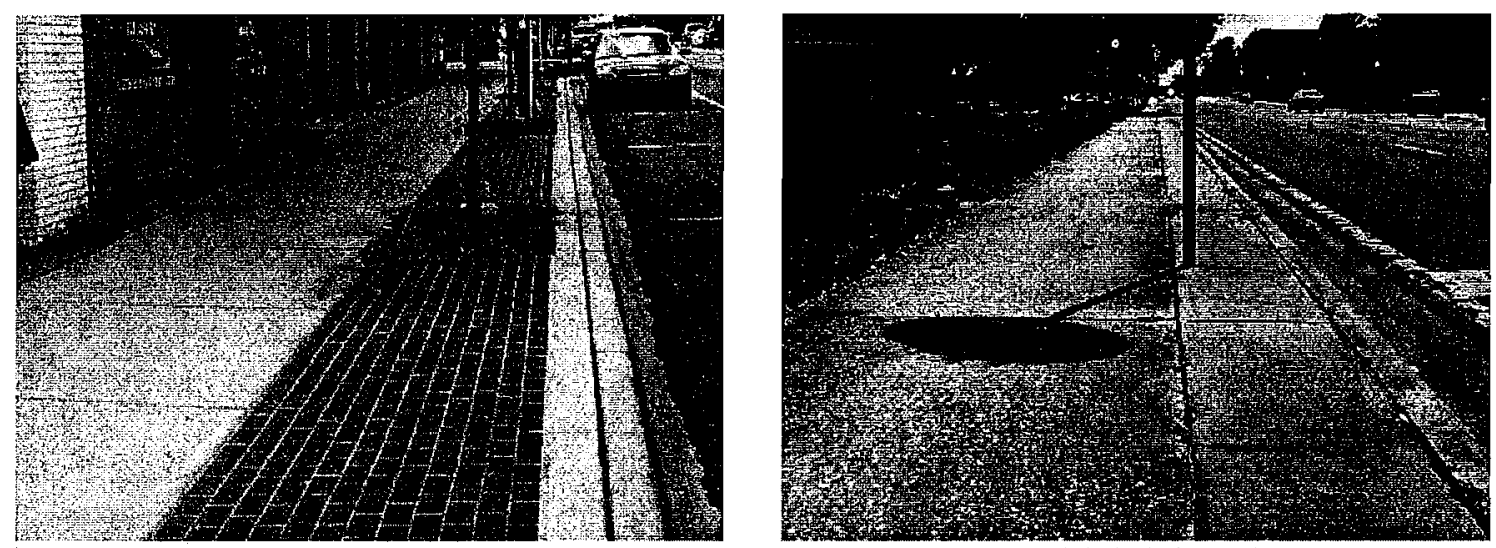

These pictures are examples of utility strips that have been paved with brick and concrete. For MRP purposes these areas should be evaluated as sidewalk. 


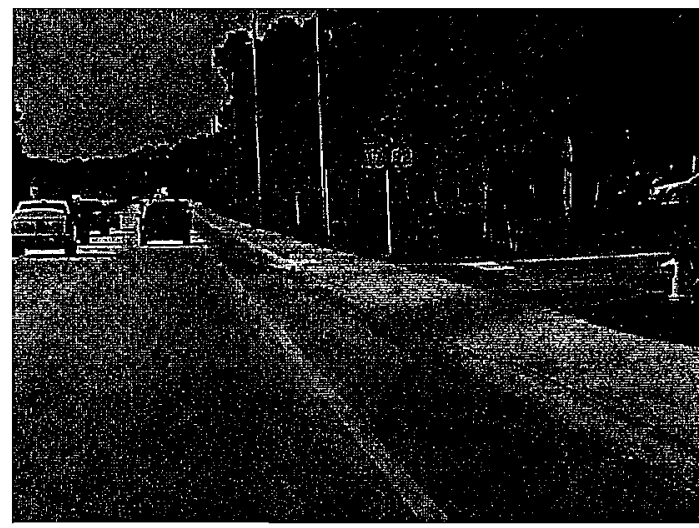

This is an urban flared turnout. The sidewalk should be projected across the turnout and evaluated as sidewalk. 
FENCE: No unrestrained entry is allowed.

Fence - Fences are constructed on limited access facilities and restricted areas to discourage people, animals and vehicles from entering the right-of-way at unauthorized locations.

Evaluation: Inspect the fence within the sample area. Any unauthorized opening in the fence line within the Department's right-of-way that allows unrestrained access causes this characteristic not to meet the desired maintenance conditions. Unrestrained access is defined as less than $2 / 3(67 \%)$ of its original height as measured from natural ground to the top of the fence fabric or any opening in the fence fabric greater than 2 square feet.

Rate fence across an outfall ditch as installed.

Washouts under the fence are not rated in the FENCE characteristic.

If any part of the fence can be reached, then that portion of the fence should be evaluated.

If after a reasonable effort, no portion of the fence can be inspected, do not rate FENCE. The coding sheet will be coded as "--.".

Fences are to be evaluated according to the Design Standard that the fence was installed.

Fence does not meet MRP standards when any of the following exist:

1) If there is an opening in the fence greater than $\underline{1 / 3}$ of its original height as measured from the natural ground, to the top of the fence fabric.

2) If there is an opening in the fence fabric greater than 2 square feet.

3) Any open gate in the limited access fence within the sample point.

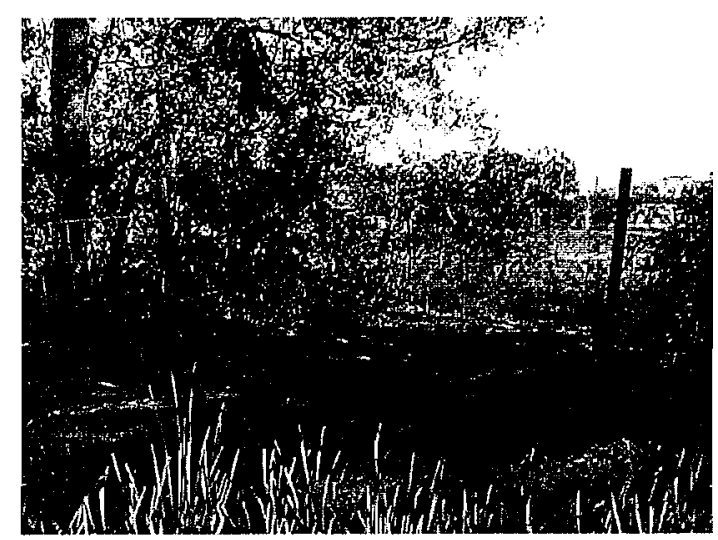

This fence has been cut and is open. This does not meet MRP standards.

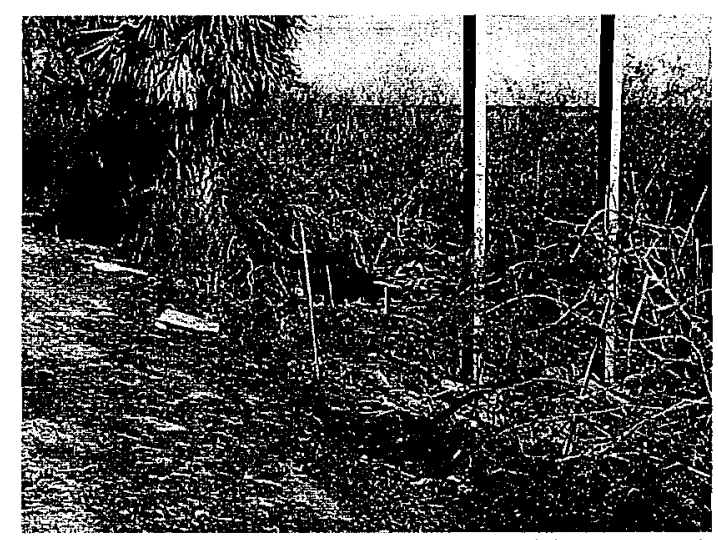

This fence has been damaged and is not at the correct height. This does not meet MRP standards. 


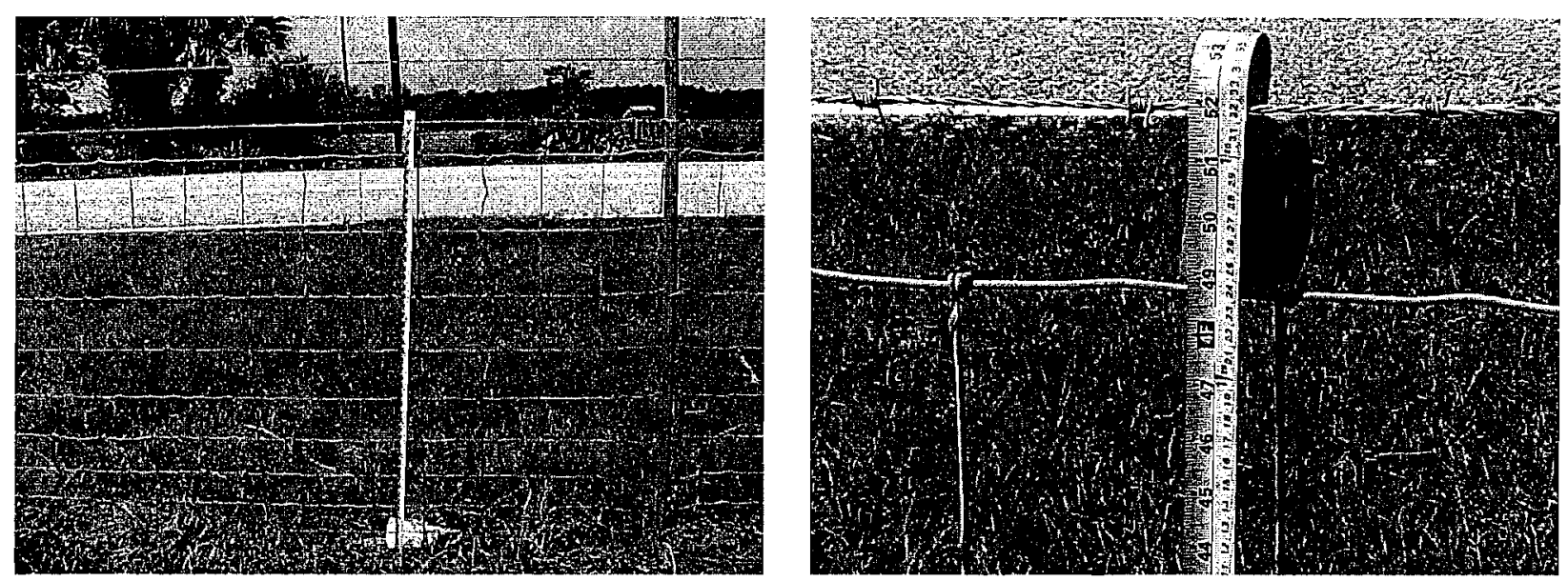

Measure the height of the fence from the natural ground to the top of the fence fabric. On the pictures above that height is about 49 inches.

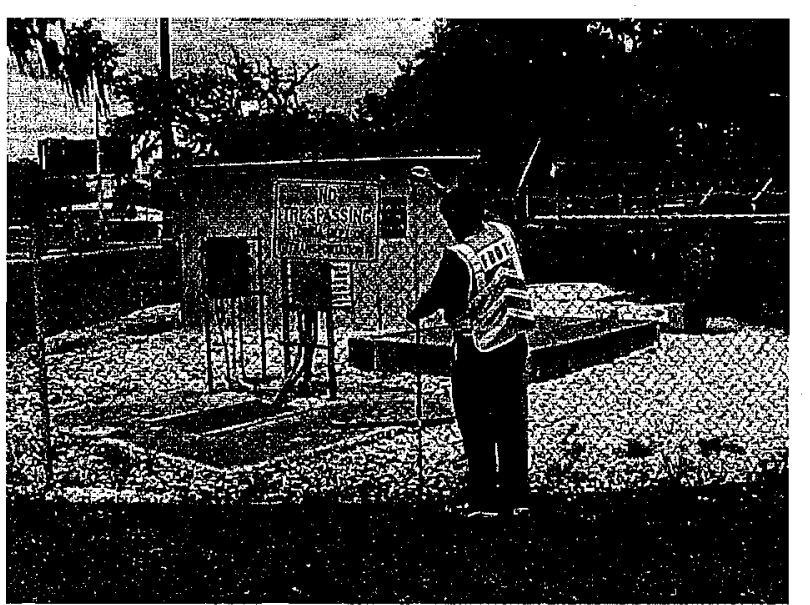

Measure the height of the fence from natural ground to the top of the fence fabric. 


\section{FLORIDA DEPARTMENT OF TRANSPORTATION}

MAINTENANCE RATING PROGRAM STANDARDS

\section{TRAFFIC SERVICES}

\section{THE FOLLOWING CHARACTERISTICS MEET THE DESIRED MAINTENANCE CONDITIONS WHEN:}

RAISED PAVEMENT

MARKERS:

STRIPING:
$70 \%$ of the required markers are functional (reflective).

No more than 100 feet of continuous centerline or lane line is without a reflective marker.

PAVEMENT SYMBOLS: $\underline{70 \%}$ of existing symbols function as intended.

GUARDRAIL: $\quad$ Each single run functions as intended.

ATTENUATOR: $\quad$ Each device functions as intended.

SIGNS LESS THAN OR

EQUAL TO 30 SQ. FT.: $\quad \underline{95 \%}$ of the signs are functioning as intended.

SIGNS GREATER

THAN 30 SQ. FT.:

OBJECT MARKERS

\& DELINEATORS:

LIGHTING: $\underline{90 \%}$ of the length and width of each line functions as intended.

$\underline{85 \%}$ of the signs are functioning as intended.

$\underline{80 \%}$ of the markers are functioning as intended.

$90 \%$ of the total luminaires of the combined sign and highway lighting are functioning as intended. 


\section{TRAFFIC SERVICES}

\section{RAISED PAVEMENT MARKERS:}

$\underline{70 \%}$ of the required markers are functional (reflective). No more than 100 feet of continuous centerline or lane line is without a reflective marker.

Raised Pavement Marker - Raised pavement markers are reflective white, amber or red. Some markers are designed with a reflector on one side only. Raised pavement markers are effective aids for night driving, especially on wet pavement. They are required on ALL FDOT highways to delineate centerline, some curbs, traffic islands and for the transition of roadway or lane width changes.

Evaluation: Daytime - Check to make sure the correct number of markers are installed. Count all the markers that should be present. Then count the number of missing markers. Determine the percentage of markers missing by dividing the number missing by the total number that should be present.

No more than 100 feet of continuous centerline or lane line should be without a reflective marker.

If RPM's are required on edge lines, they should be rated.

Nighttime - Conduct nighttime reflectivity checks using LOW BEAM headlights only. Ride the same roadway in both directions to check the reflectivity of the RPM's.

The survey vehicle headlights should be adjusted periodically.

The nighttime reflectivity check should be conducted when the pavement is dry.

At least $70 \%$ of the required markers should be functional (reflective) at a distance of 528 feet.

Refer to Design Standard Indices 17345, 17346 and 17352 for Raised Pavement Marker placement.

Designed breaks in pavement lines (crossovers, intersections) shall not be included in the 100 feet.

\section{Raised Pavement Markers do not meet MRP standards when any of the following exist:}

1) If more than $30 \%$ of the required raised pavement markers are missing.

2) If more than $\underline{30 \%}$ of the required markers are not functional (reflective) at a distance of 528 feet.

3) If more than 100 continuous feet of centerline or lane line is without a reflective marker.

4) If the raised pavement markers are installed incorrectly (Index 17352). 
STRIPING: $\underline{90 \%}$ of the length and width of each line is reflective and functions as intended.

Striping - Pavement striping is a $\underline{6 \text { inch }}$ wide centerline; skip line or edge line.

Evaluation: Daylight and nighttime inspections shall be done. Each line is evaluated independently.

Solid lines - Determine the length and width of each solid line in the sample point. A minimum of 5.4 inches of each line width should be present, visible and reflective at night with low beam headlights. Determine if the lines are reflective at night for a distance of 160 feet. Due to changes in design standards, striping may have been installed at certain locations on some roadways where no striping is installed at similar locations on other roadways. Do not evaluate striping at locations where it has not been installed.

Skip lines - Determine the length and width of each skip line in the sample point. A minimum of 5.4 inches of each line width should be present, visible and reflective at night with low beam headlights. Only evaluate the stripe and not the skip. Black lines are used for contrast only and should not be evaluated for reflectivity.

Refer to Design Standard Indices 17345 and 17346 for Interchange markings and special marking areas.

\section{Striping does not meet MRP standards when any of the following exist:}

1) If more that $10 \%$ of the length of any line is less than 5.4 inches wide during daylight inspection.

2) If more than $10 \%$ of the length and width of any line is not visible for a distance of 160 feet at night.

3) If more than $10 \%$ of the length of any line is missing.

4) If more than $\underline{10 \%}$ of the length of any line is covered by soil, grass or debris.

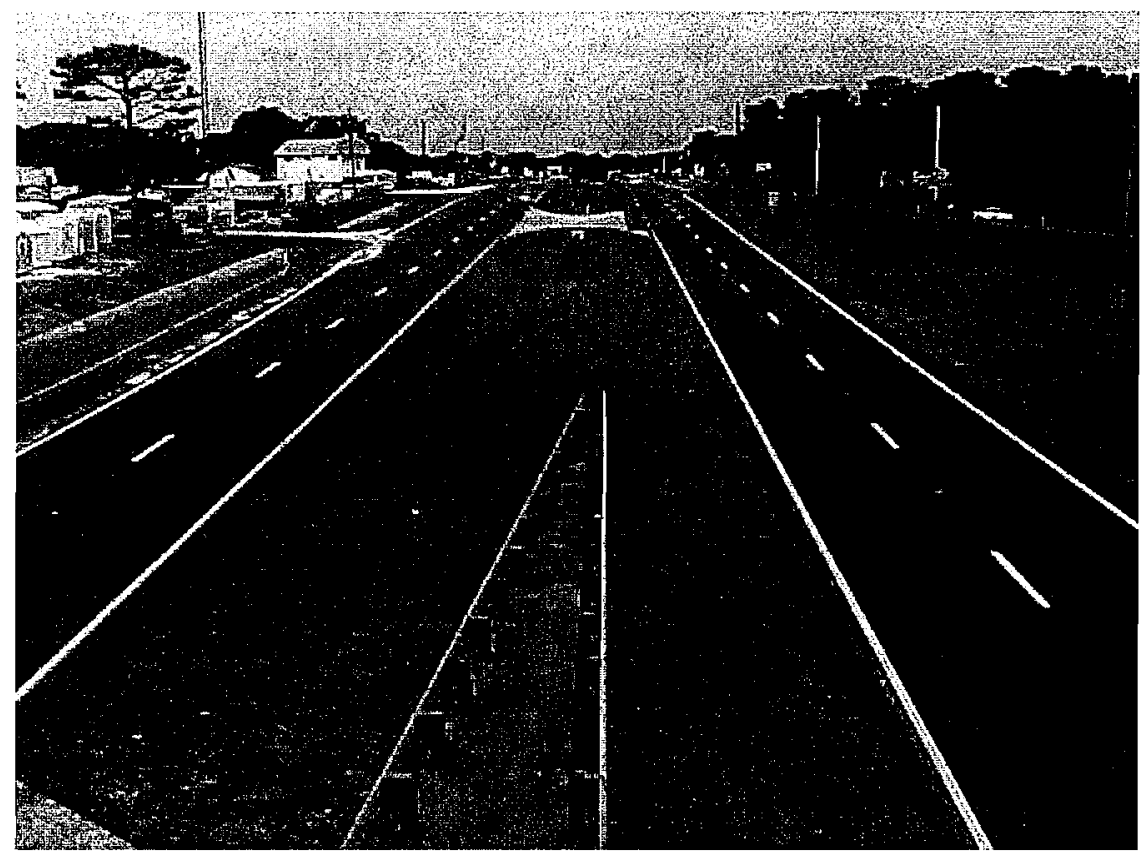

Striping on a typical four lane divided highway. 

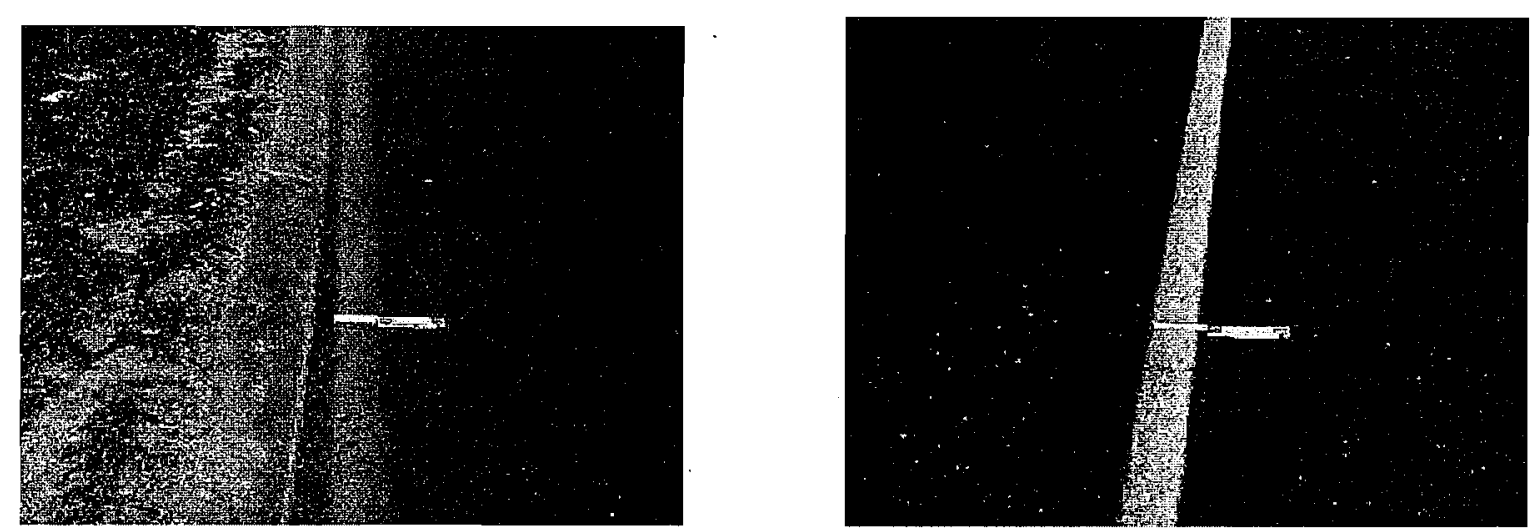

These pictures show painted yellow and white edgelines installed on a newly constructed or resurfaced roadway. Evaluate according to the striping characteristic.

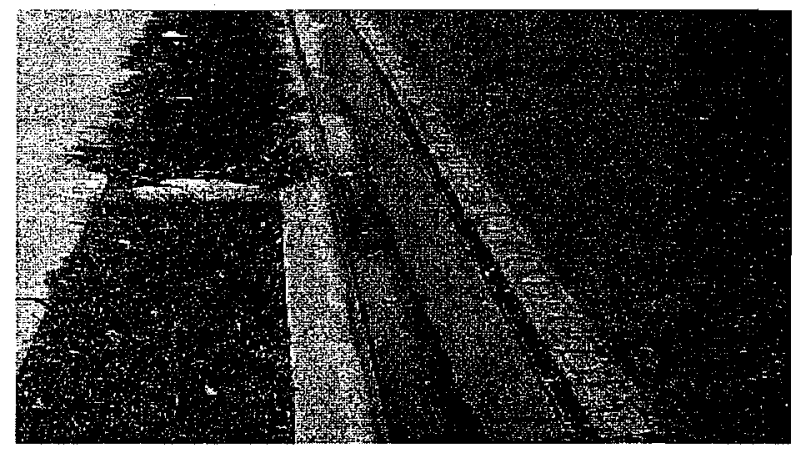

Worn out edgeline does not meet MRP standards.

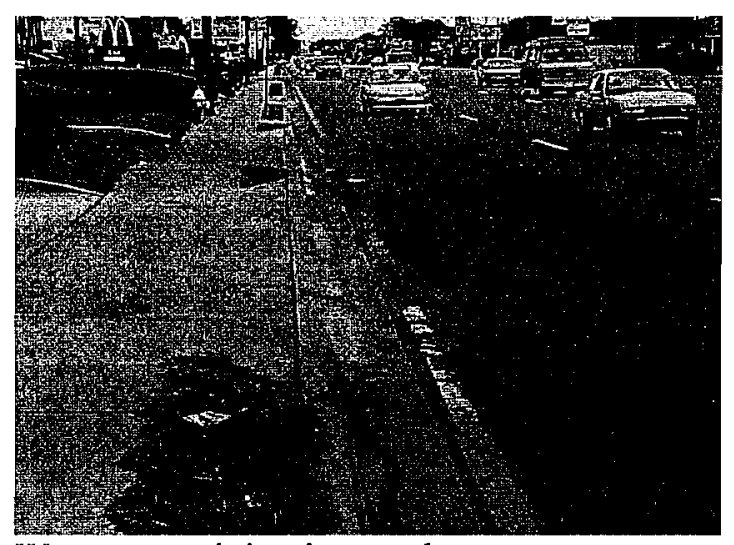

Worn out striping in an urban area. does not meet MRP standards.

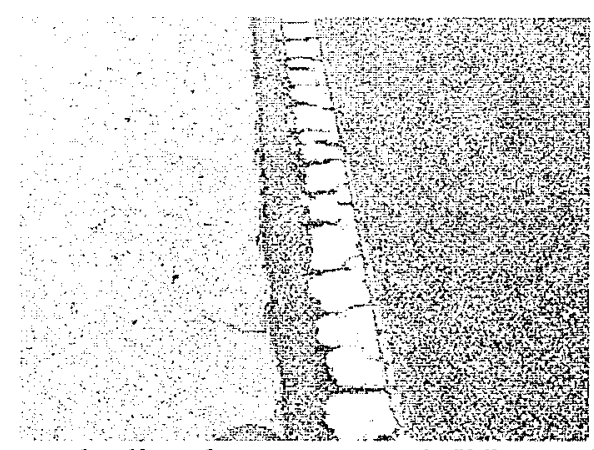

Worn out edgeline does not meet MRP standards

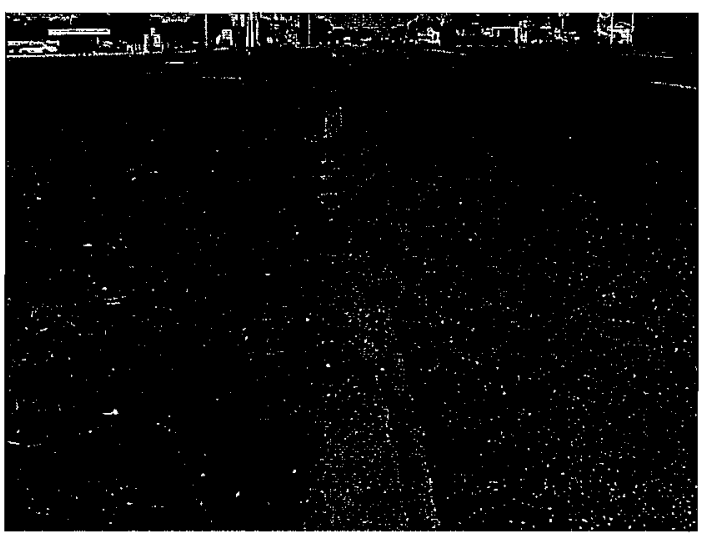

Edge line obscured by soil or other debris does not meet MRP standards 


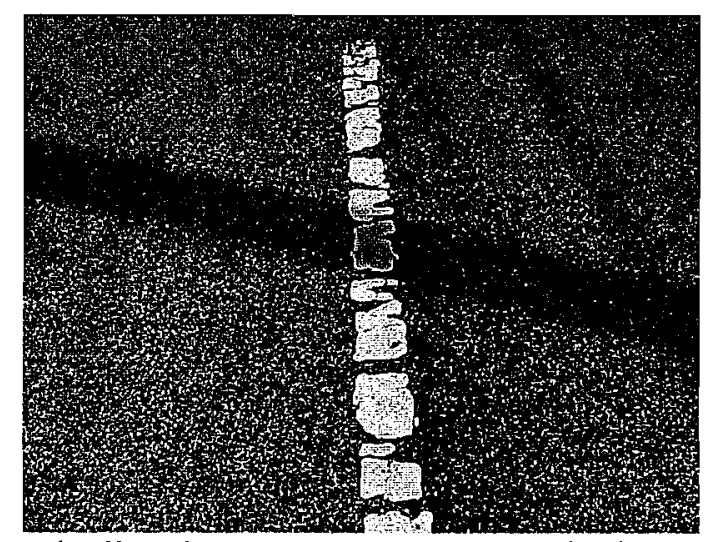

Edgeline does not meet MRP standards

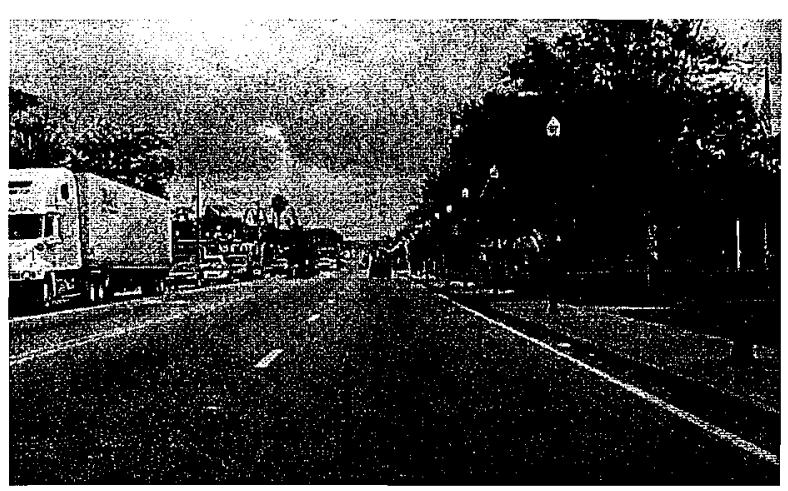

Existing white edgeline on an urban curb \& gutter section. This meets desired MRP standards.

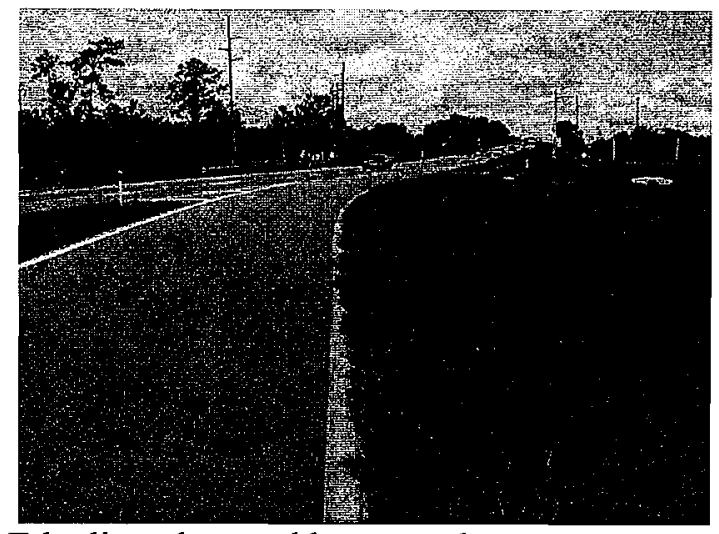

Edgeline obscured by grass does not meet MRP standards

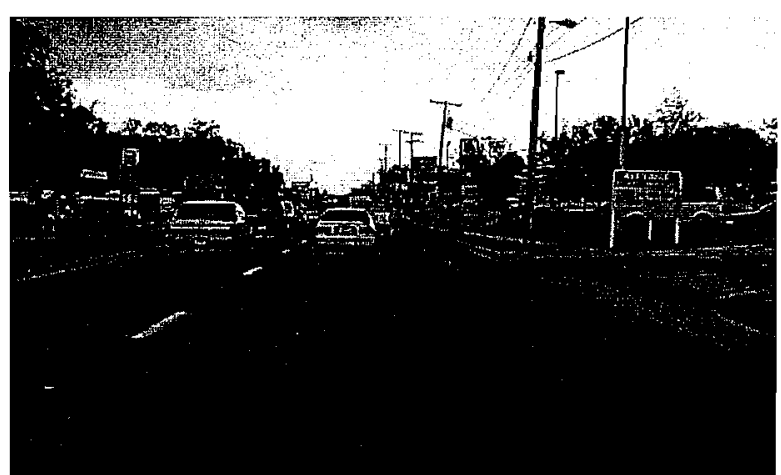

No white edgeline on this urban curb \& gutter section. This meets desired MRP standards.

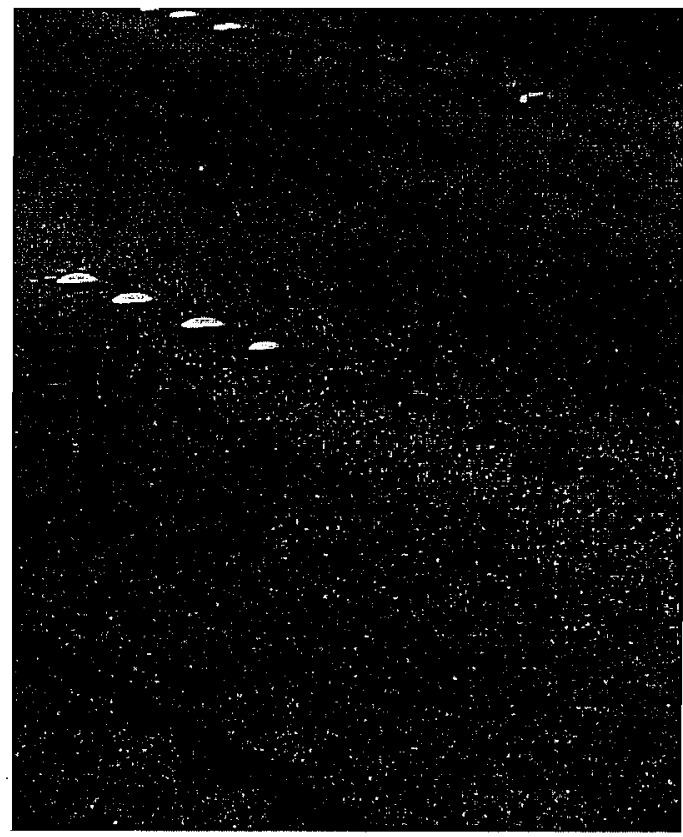

Non-reflective ceramic pavement markers should be evaluated as striping. 
PAVEMENT SYMBOL: $\quad \underline{70 \%}$ of existing symbols function as intended.

Pavement Symbol - Pavement symbols are used to communicate certain meanings at specific locations. Included in this characteristic are gore area markings, shoulder markings, word and symbol markings, stop bars, all crosswalk lines within the $\mathrm{R} / \mathrm{W}$, parking space markings (does not include edgelines that delineate parking), curb markings, painted medians, radius markings and others.

Evaluation: Determine the total square footage of all symbols within the sample point. Symbols that appear to be abandoned should be verified as such with the area engineer and not be evaluated if determined to be abandoned. Curb markings and crosswalks on connecting side streets are not to be evaluated for nighttime reflectivity. Standard Index 17346 or the MMS Handbook can be referenced to determine the square footage of symbols.

\section{Pavement Symbols do not meet MRP standards when any of the following exist:}

1) If more than $\underline{30 \%}$ of the cumulative symbol area is not functioning as intended during daylight observation.

2) If more than $\underline{30 \%}$ of cumulative symbol area is not reflective for a distance of 160 feet using low beam headlights during nighttime observation.

3) If symbols are not installed according to Index 17346.

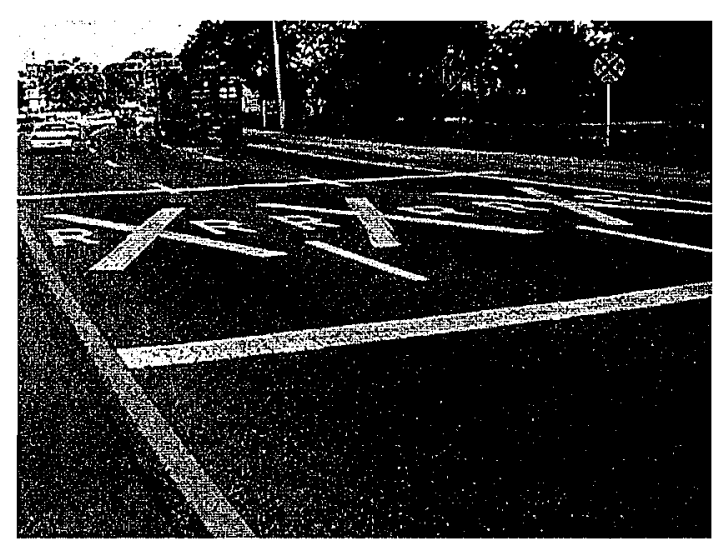

Pavement symbols, good condition meets desired MRP standards.

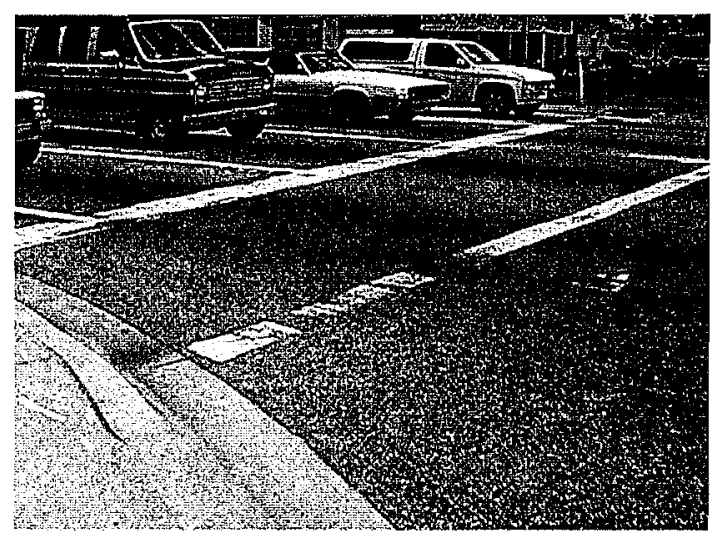

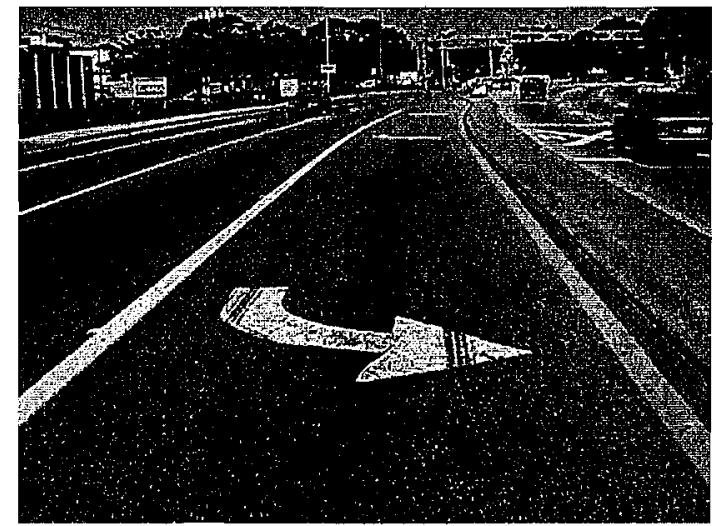

Pavement symbols, good condition meets desired MRP standards.

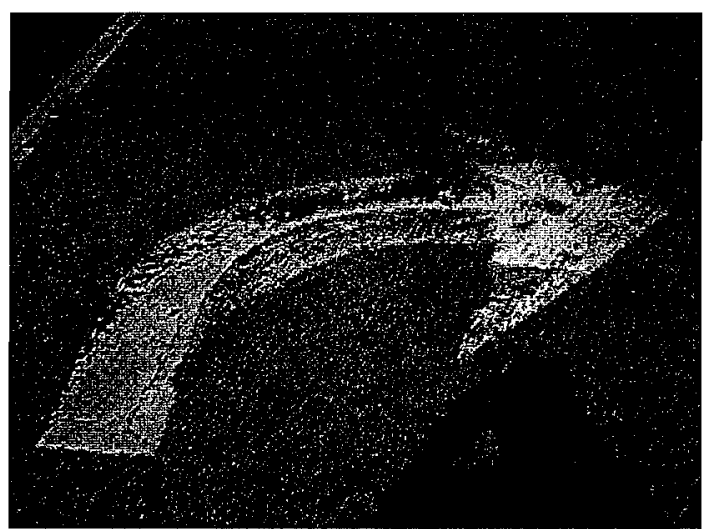

These pictures are examples of worn out symbols. If more than $30 \%$ of the cumulative symbol area Is not functioning as intended then this would not meet desired maintenance conditions. 


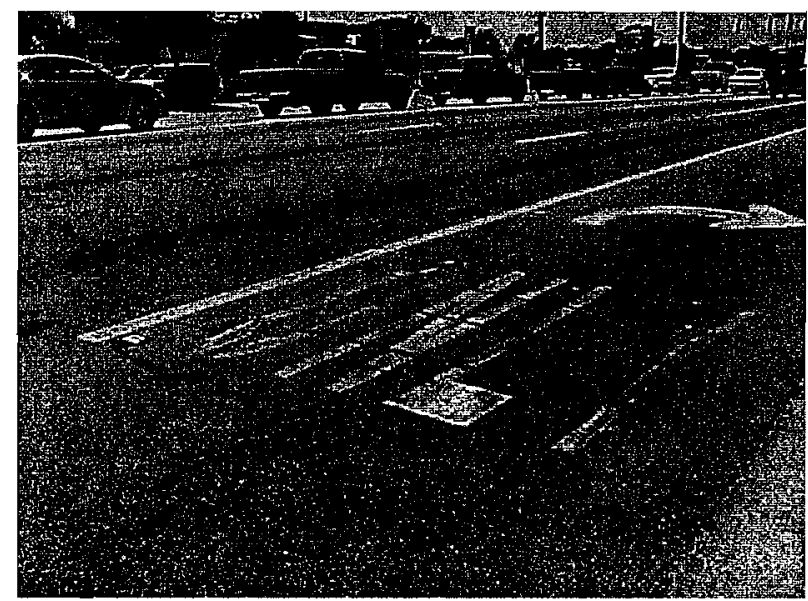

Worn and faded pavement symbol, does not meet desired maintenance conditions.

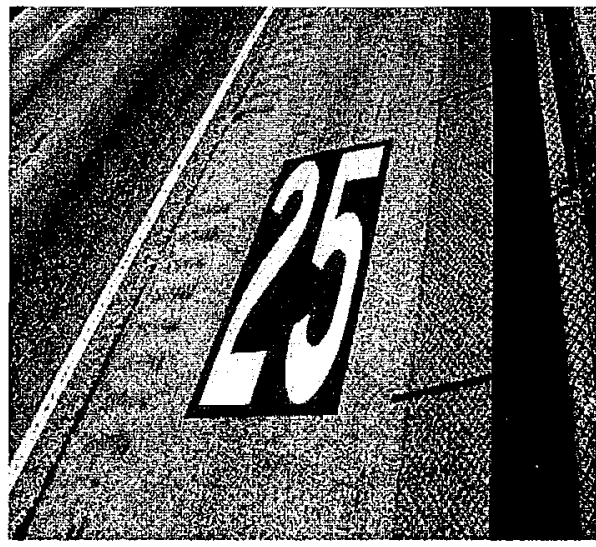

Interstate Exit marking symbol.

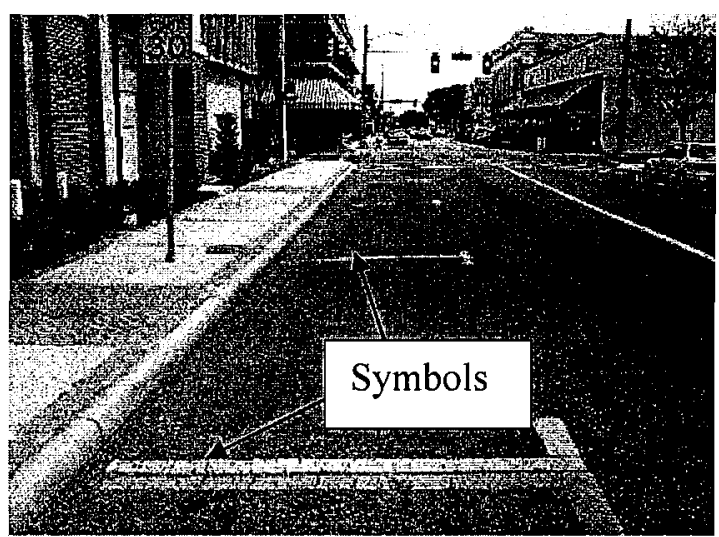

Perpendicular lines marking parking spaces are rated as symbols.

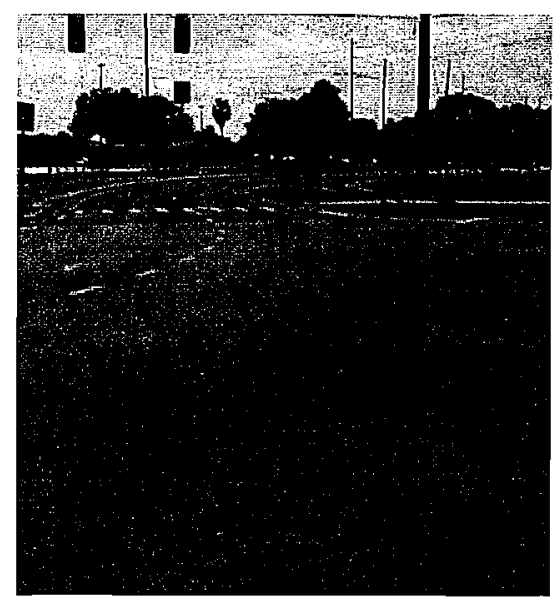

These skip lines are an example of radius markings.

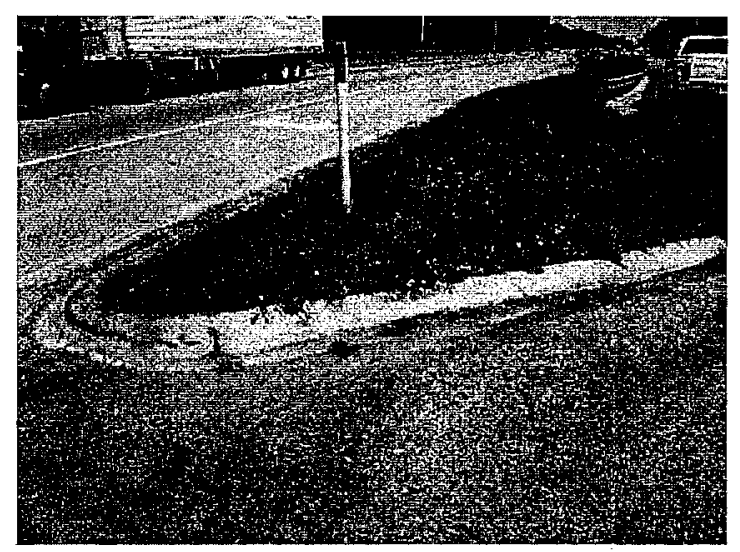

Painted curb markings are rated as symbols. Do not rate curb markings for nighttime reflectivity.

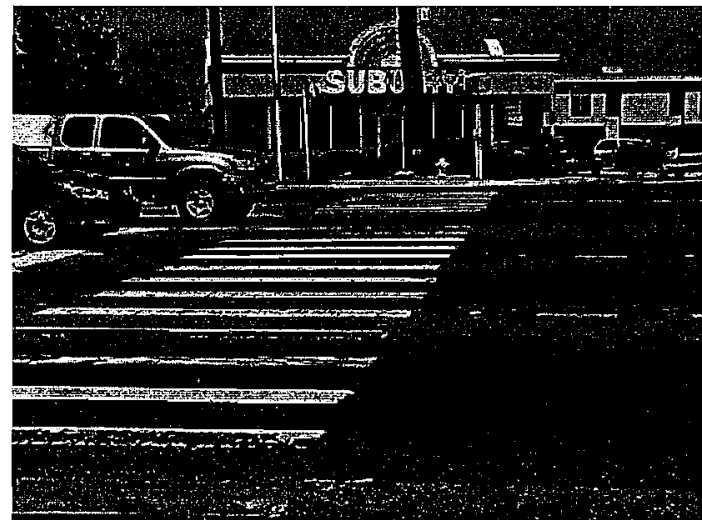

This is an example of a crosswalk symbol. 


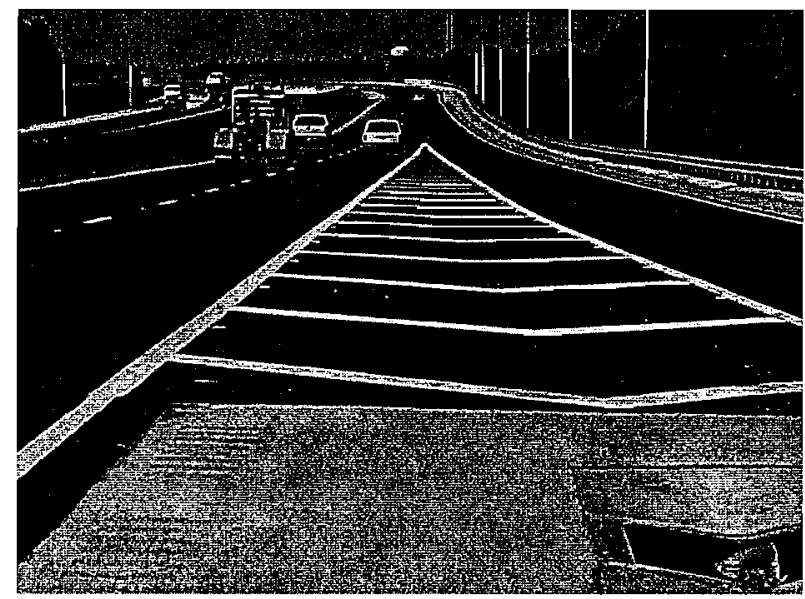

This is an example of gore area markings.

GUARDRAIL:

Each single run functions as intended.

Guardrail - Guardrail is installed to guide a vehicle away from various hazards in and adjacent to the travel way and, in most cases, where fill slopes exceed 3:1.

Evaluation: Determine the general condition of the guardrail. Check the guardrail height. Check for damaged rail, missing or damaged posts or blocks, connecting hardware and end sections. Check to make sure guardrail is lapped correctly.

If there is less than 25 feet of guardrail in a sample, then $50 \%$ or more of the guardrail must meet the height requirement for this sample point to meet maintenance conditions. All other guardrail criteria shall be rated no matter what the length.

Consideration should be given to what Design Standards were used during original construction of guardrail.

A previous minor collision may not prevent a guardrail system from functioning as designed and would not cause failure. Installations may vary from roadway to roadway because of design standard changes and should be evaluated using the appropriate design standard.

\section{Each single run of guardrail does not meet MRP standards when any of the following exist:}

1) Any missing posts, offset blocks, panels or connection hardware.

2) Nuts fully threaded within 1 inch of the anchor plate on end treatment cables and anchor rods (measurements should be checked with end treatment cable taunt).

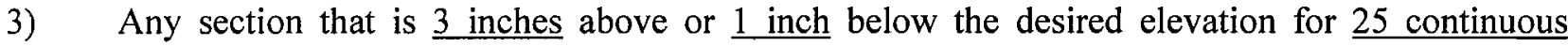
feet.

4) The backup plate does not fit snugly behind the rail. There should be some point of contact.

5) Damaged end sections.

6) The rail has been penetrated.

7) More than $10 \%$ of the guardrail blocks are twisted.

8) More than $10 \%$ of the wooden posts or blocks are rotten or deteriorated.

9) Any panel lapped incorrectly. 
This evaluation will include handrail. Refer to Design Standards.

\section{Each single run of handrail does not meet MRP standards when any of the following exist:}

1) The handrail is bent or misaligned and does not function as intended.

2) One or more anchor bolts, nuts, or neoprene/resilient pads are missing on the base plate.

3) If fence is attached to the handrail, the fence must be in place and securely fastened to the handrail.

4) It is obvious that handrail was installed but is now missing.

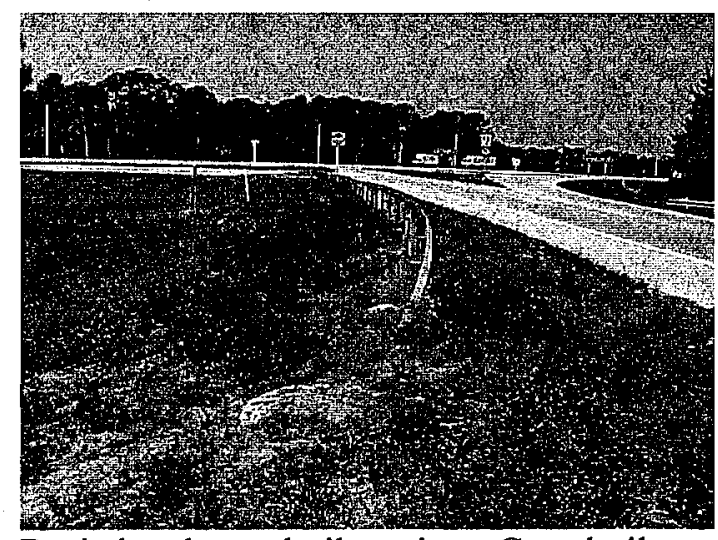

Buried end guardrail section. Guardrail shall be evaluated according to the index it was installed under. This meets desired maintenance conditions.

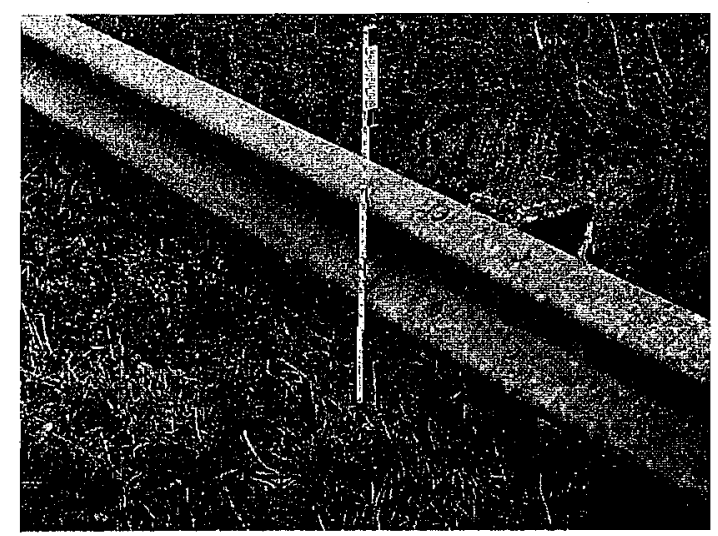

This guardrail section does not meet desired maintenance conditions because the height above the ground is incorrect.

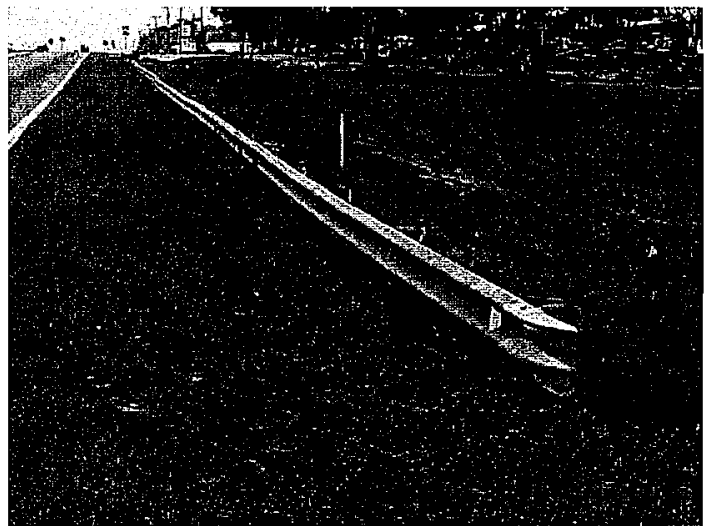

This guardrail section is low and should be measured to determine if it meets desired maintenance conditions.

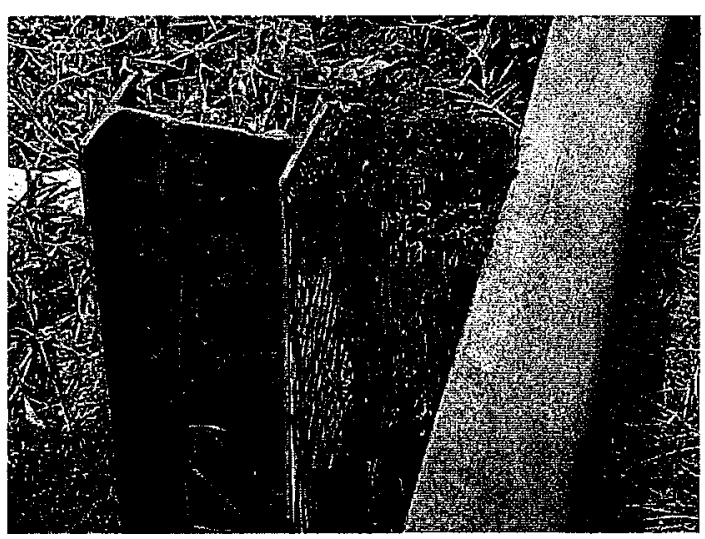

This is a rotten and deteriorated guardrail offset block. It does not meet desired maintenance conditions if more than $10 \%$ of the blocks are rotten and deteriorated. 


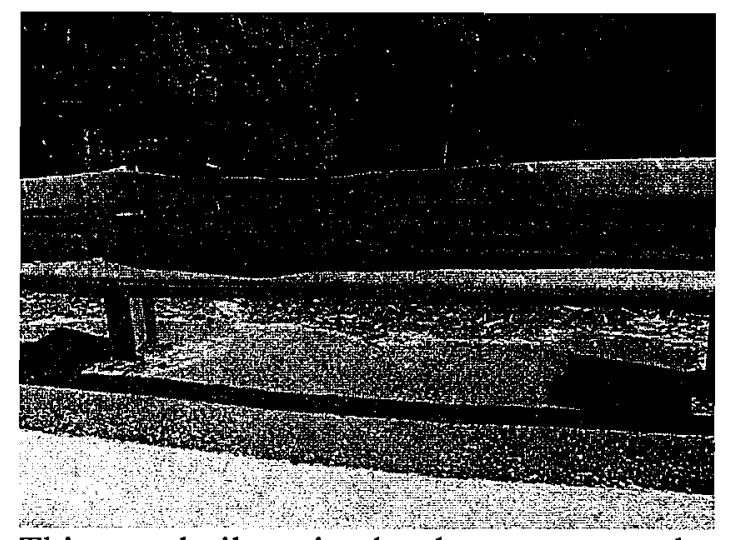

This guardrail section has been penetrated due to a crash. This does not meet desired maintenance conditions.

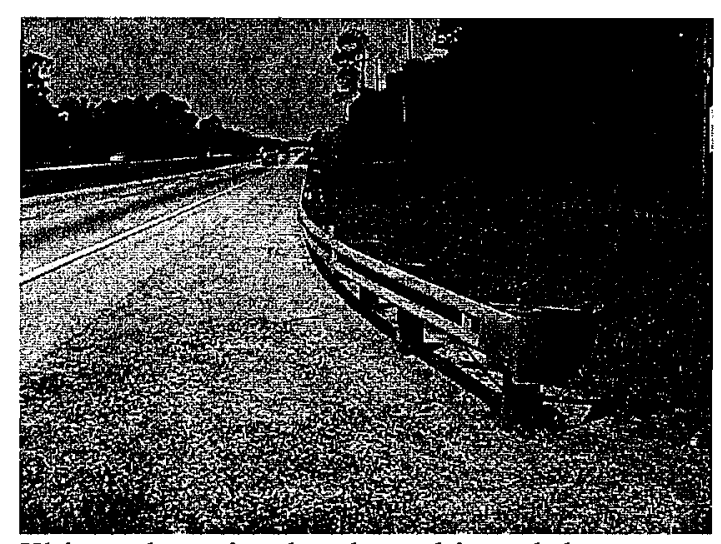

This end section has been hit and does not meet desired maintenance conditions.

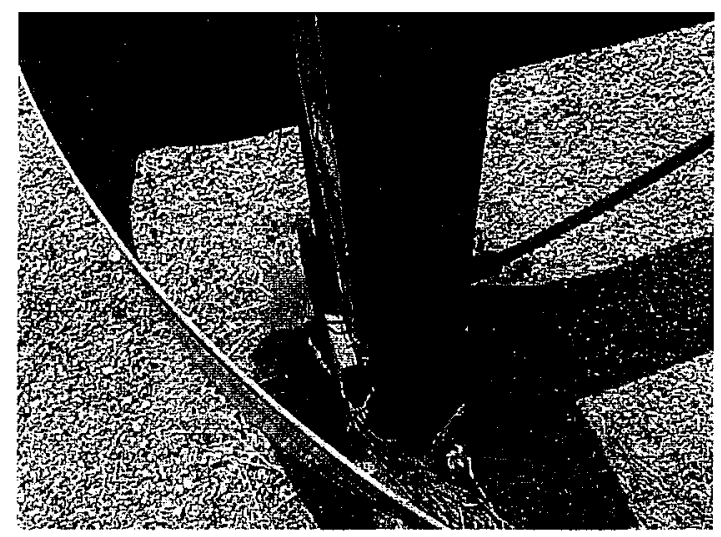

Damaged end section does not meet desired maintenance conditions.

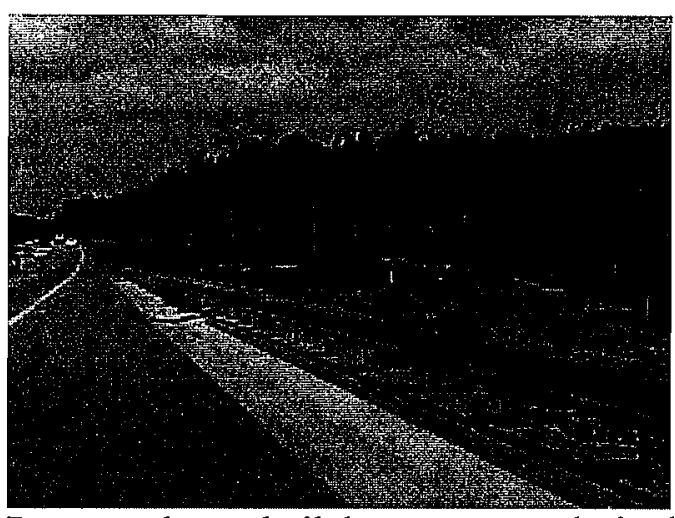

Penetrated guardrail does not meet desired maintenance conditions.

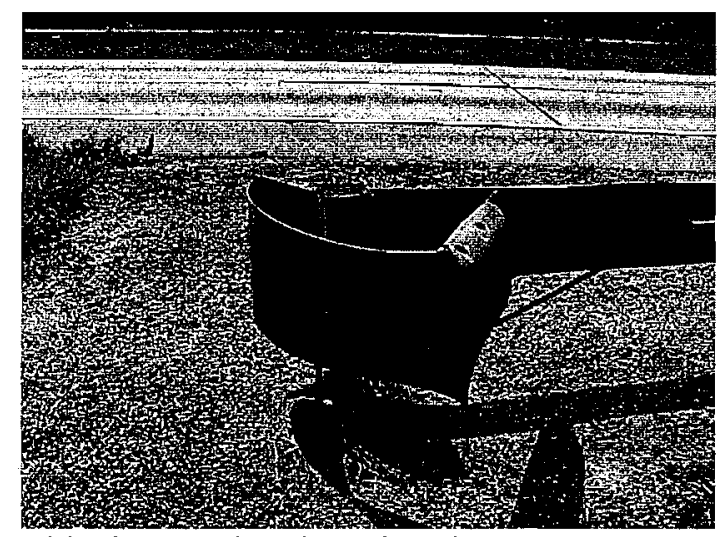

This damaged end section does not meet desired maintenance conditions.

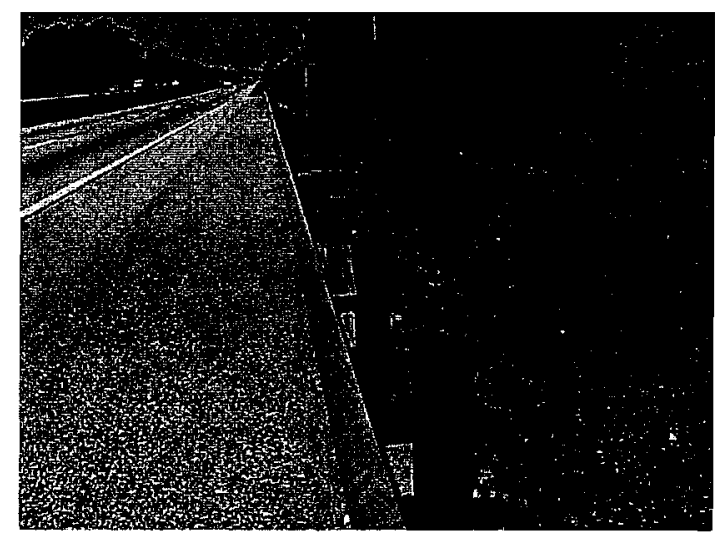

Guardrail offset blocks are not aligned properly. This condition would not meet desired maintenance conditions if more than $10 \%$ are twisted. 


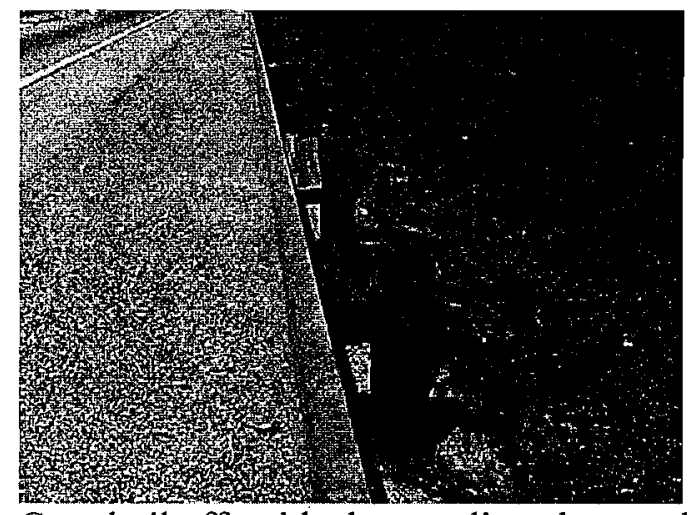

Guardrail offset blocks not aligned properly. This does not meet desired maintenance conditions if more than $10 \%$ are twisted.

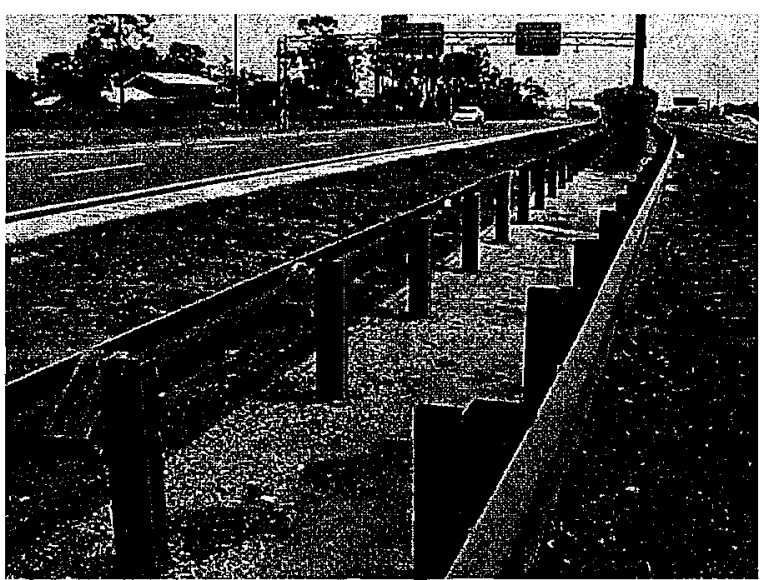

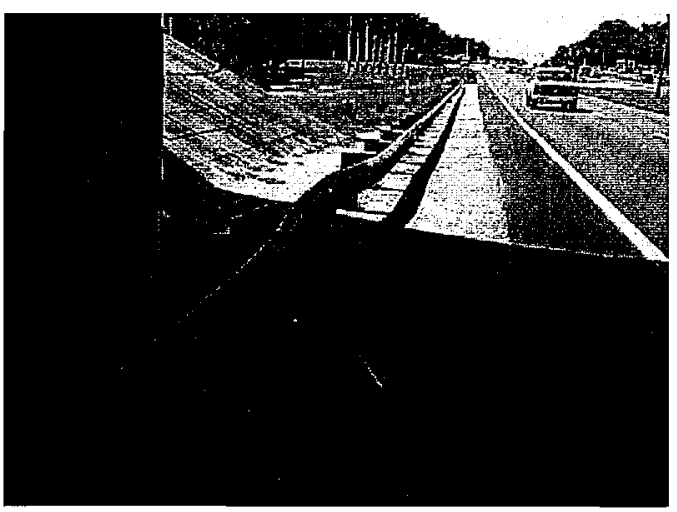

This guardrail has been damaged by a crash. Several posts are damaged. This does not meet desired maintenance conditions.

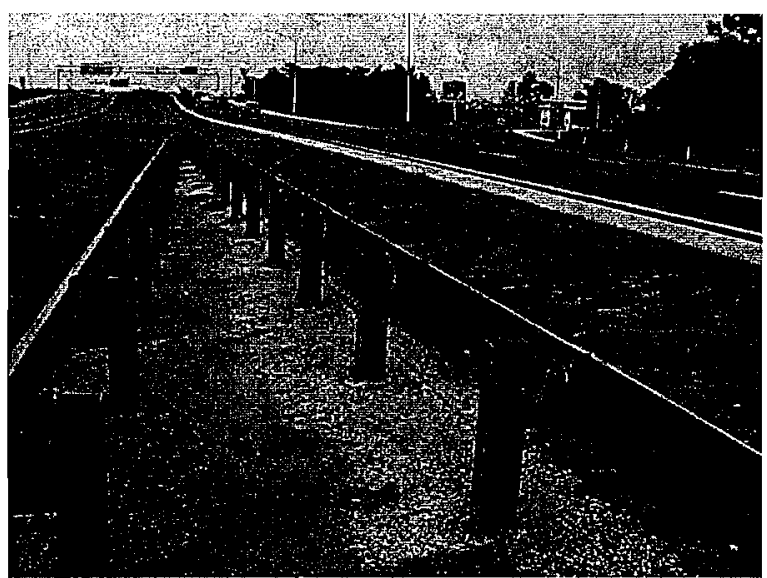

The offset blocks in these pictures are not aligned properly. If more than $10 \%$ of the blocks in a guardrail run are twisted it would not meet MRP standards.

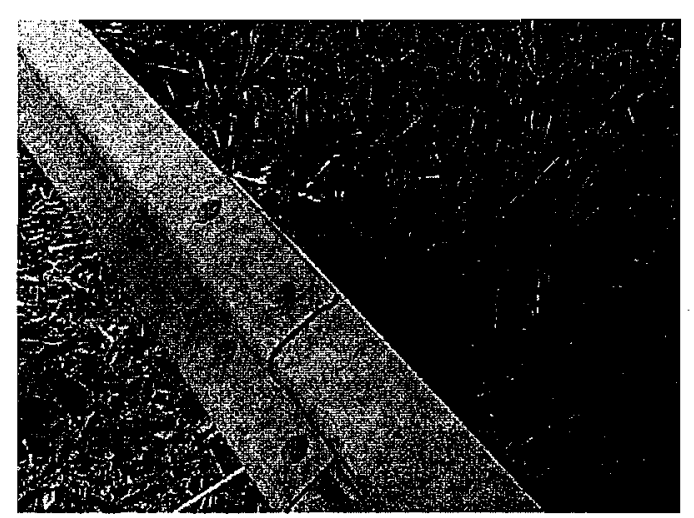

This guardrail section has several problems. The offset block is deteriorated and the rail is lapped incorrectly. This does not meet desired maintenance conditions.

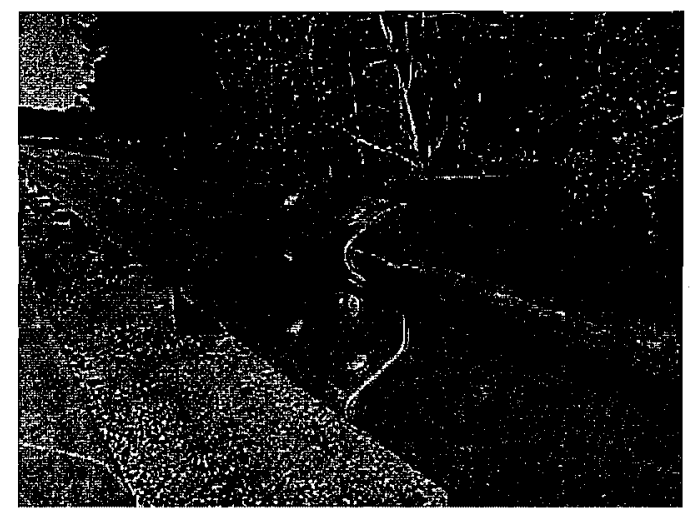

This guardrail section is lapped incorrectly. If hit by a vehicle, the rail would not function as designed. This does not meet desired maintenance conditions. 


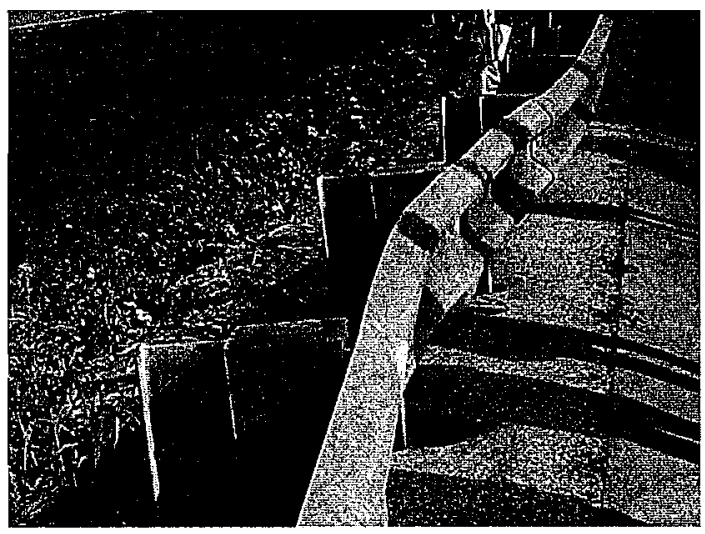

This guardrail has been hit by a vehicle. The guardrail posts have been knocked out of alignment and may not function as designed in the future. This guardrail does not meet desired maintenance conditions.

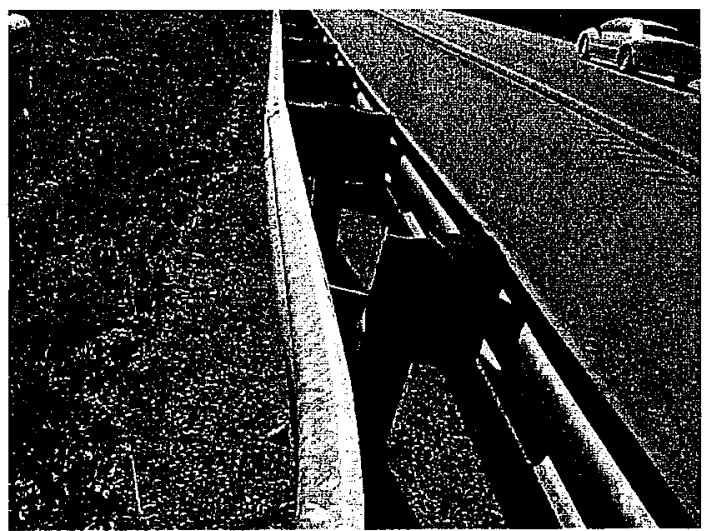

This guardrail has minor damage to the rail and a missing offset block. This would not meet desired maintenance conditions.

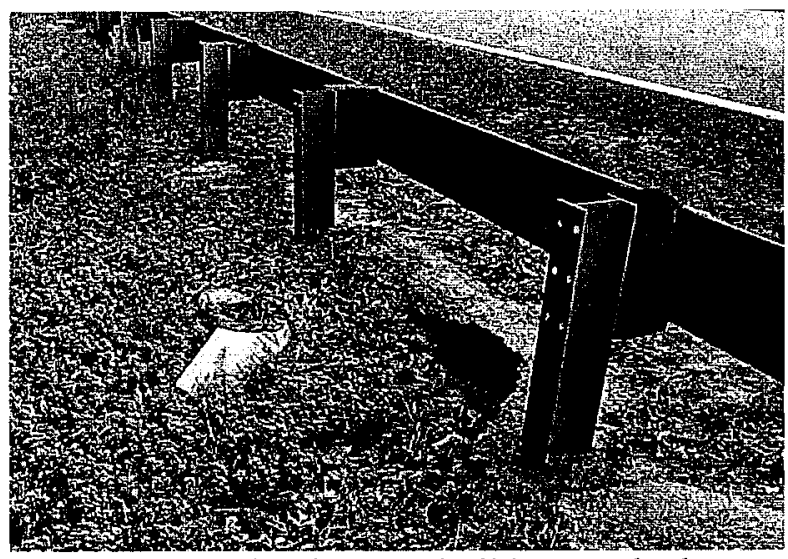

The asphalt under the guardrail has washed out. The guardrail meets desired maintenance conditions, however, unpaved shoulder or front slope would not meet desired MRP conditions.

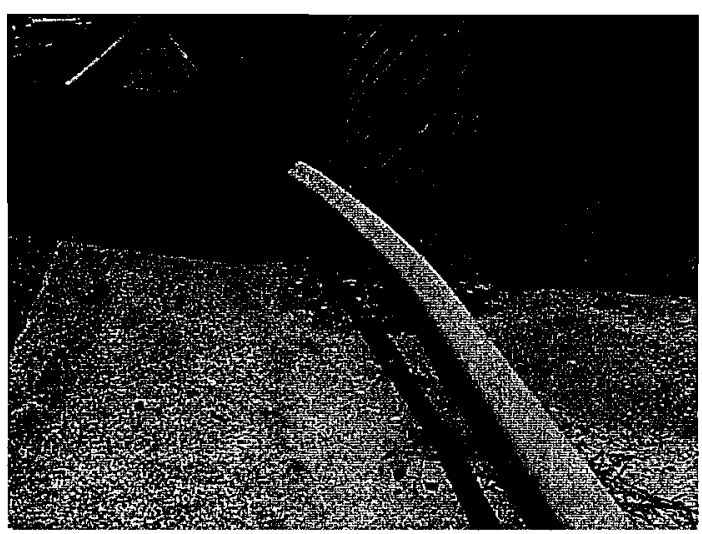

This guardrail has been hit and several posts are missing. This guardrail does not meet desired maintenance conditions.

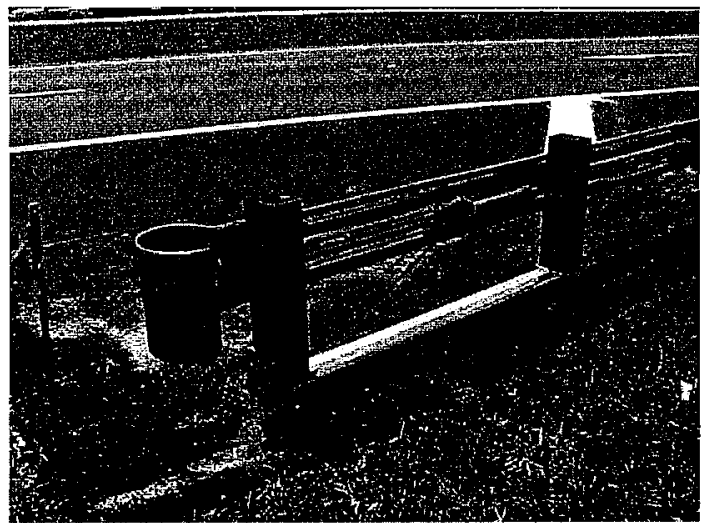

This is an approach end guardrail end section. Check to make sure all connecting hardware is in place.

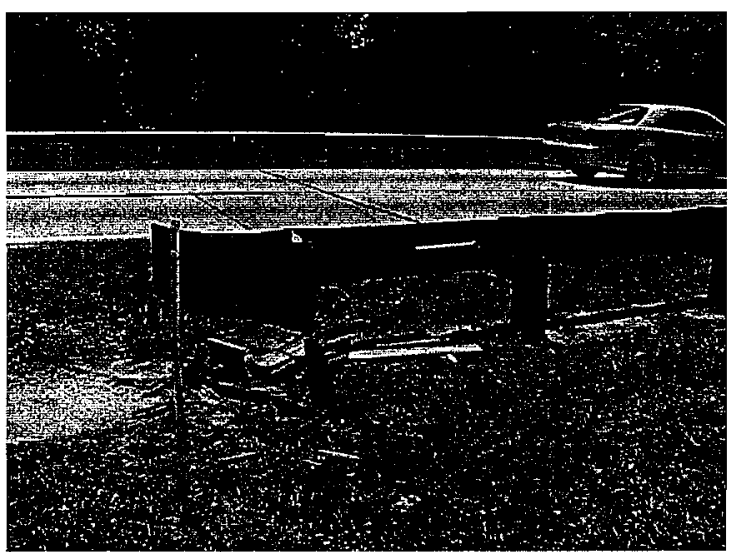

Damaged guardrail end section. This site does not meet desired maintenance conditions. 


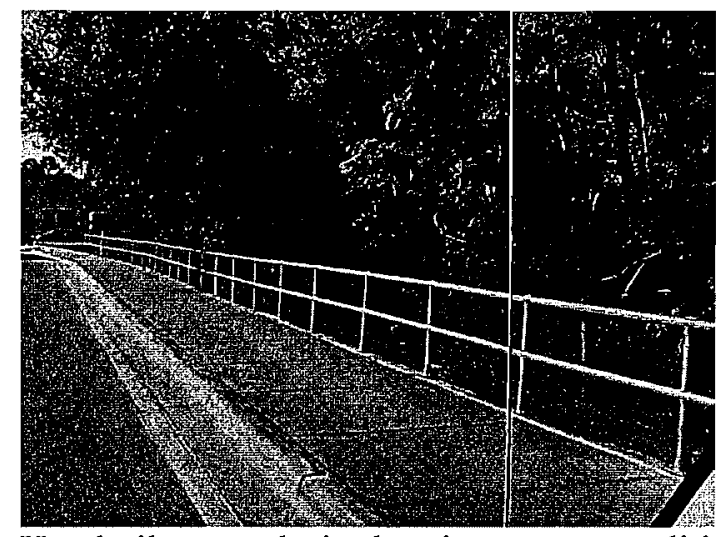

Handrail meets desired maintenance conditions.

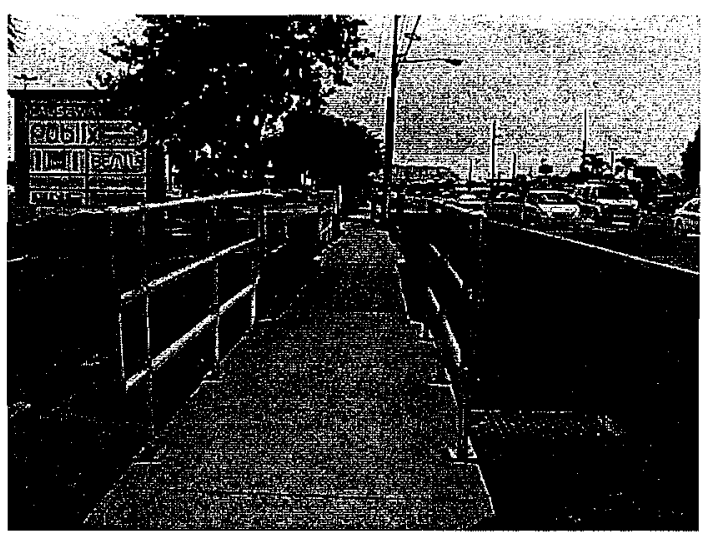

Handrail meets desired maintenance conditions.

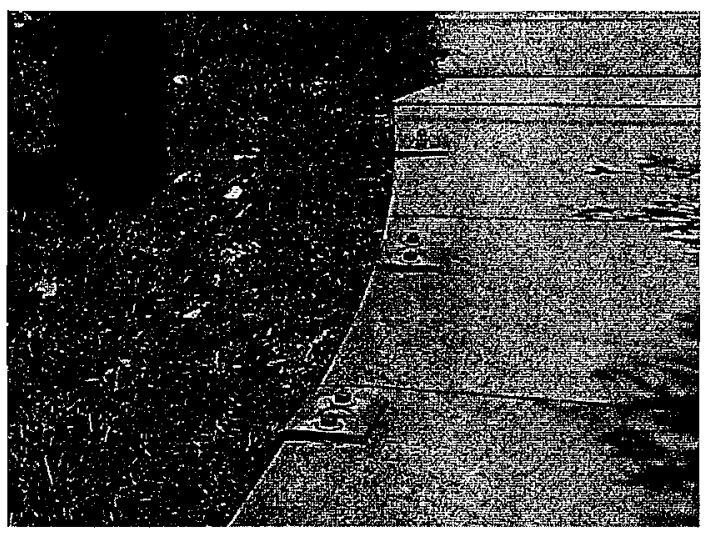

Missing handrail. This does not meet desired maintenance conditions. 


\section{ATTENUATOR: $\quad$ Each device functions as intended.}

Attenuator - Vehicle impact attenuators are of various configurations and are designed for different roadway conditions. They are generally constructed of modules containing cells of different types of energy absorption materials. Attenuators are intended to provide a motor vehicle with a cushioned impact area prior to solid obstructions such as; parapet walls, bridge columns, sign structures and signal poles.

Evaluation: Determine the general condition of the attenuator. When there is no apparent damage, the survey team will utilize the latest inspection rating. When damage to an attenuator system is discovered that may compromise its function, the responsible maintenance area should be promptly notified.

A computer printout of attenuator devices, by county-section number and milepost, can be obtained from the Department's Roadway Characteristics Inventory file. This listing should be obtained at the beginning of each survey period.

\section{Attenuators do not meet MRP standards when any of the following exist:}

1) Obvious malfunctions, such as water or sand containers that are split, compression of the device, misalignment, etc.

2) Any inspection rating less than GOOD.

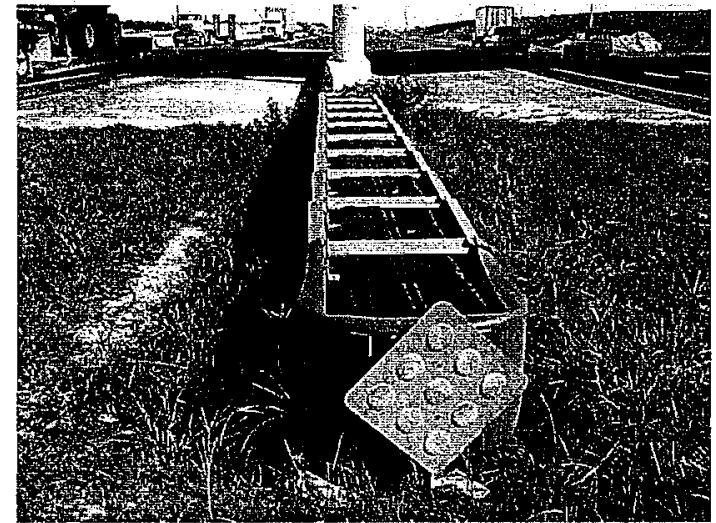

QuadGuard attenuator in the median.

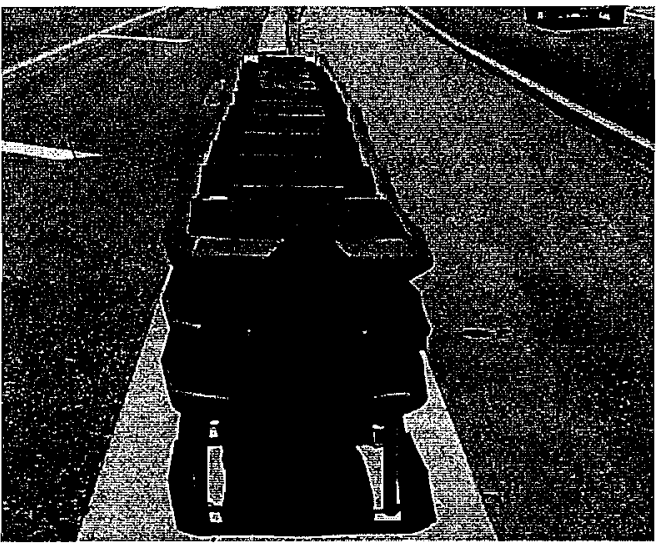

GREAT attenuator in the median. 


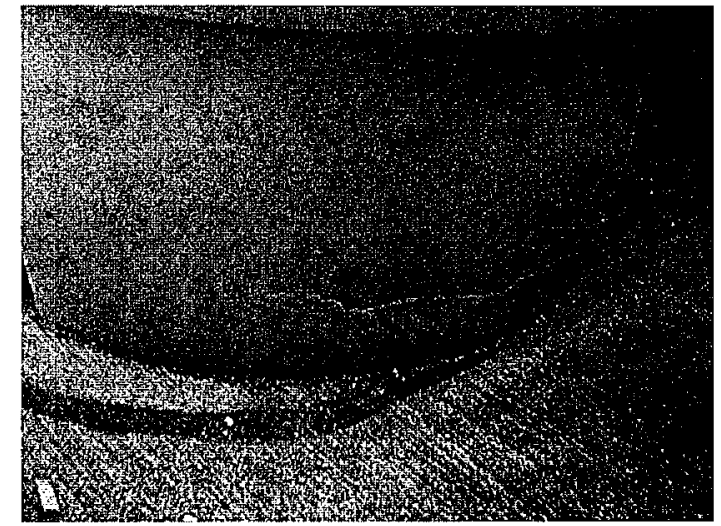

Energite sand filled attenuator with damage. This would not meet desired maintenance conditions.

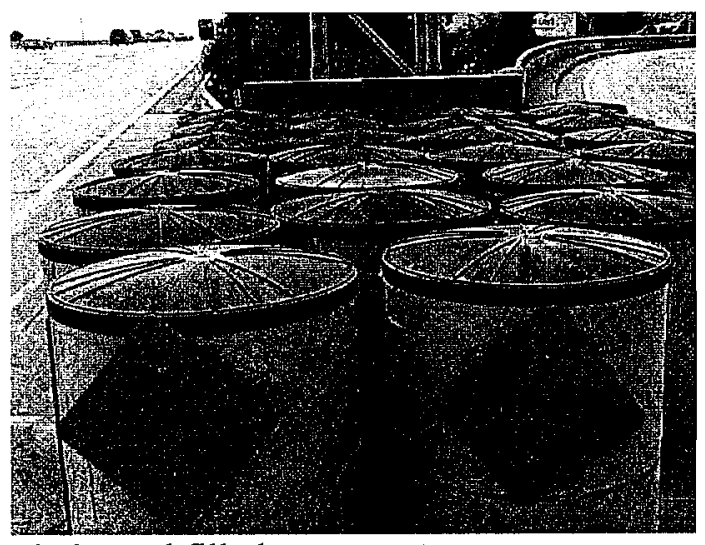

Fitch sand filled attenuator system.

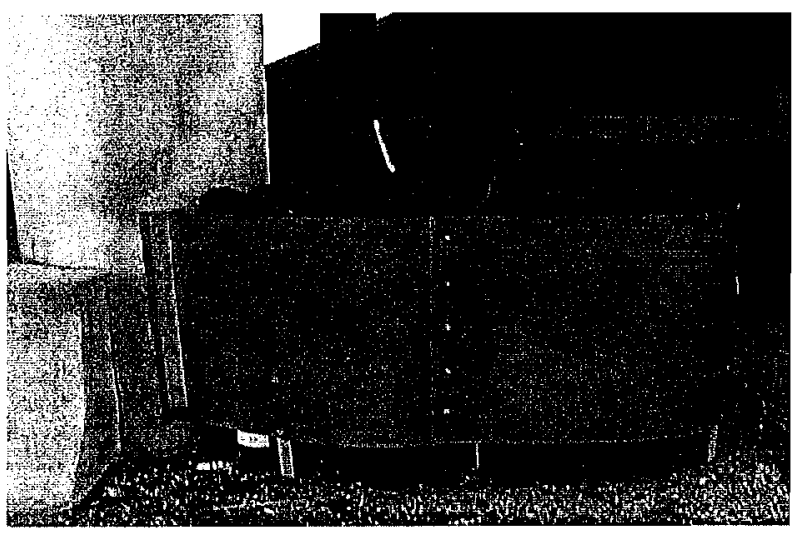

Hi-Dro cell cluster unit.

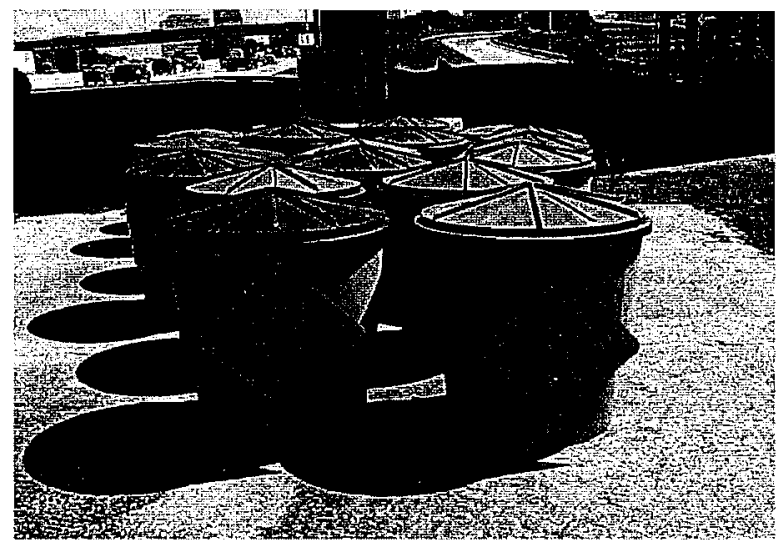

Energite sand filled attenuator system.

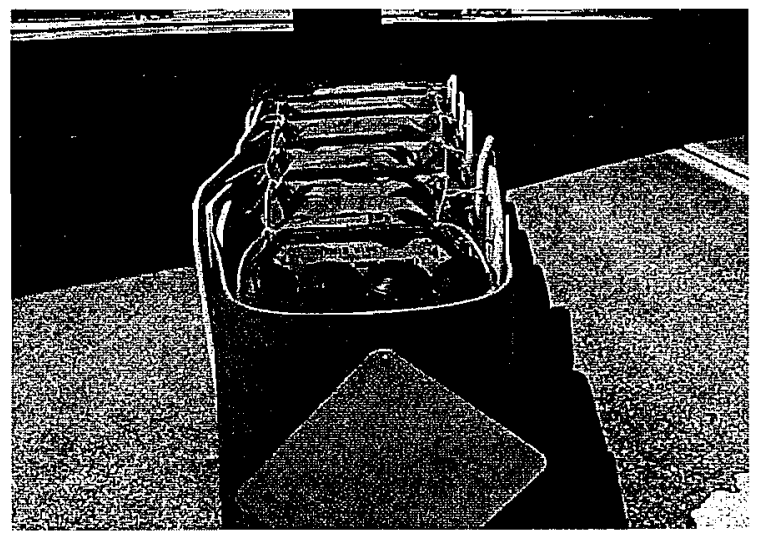

Hi-Dro Sandwich system in the median.

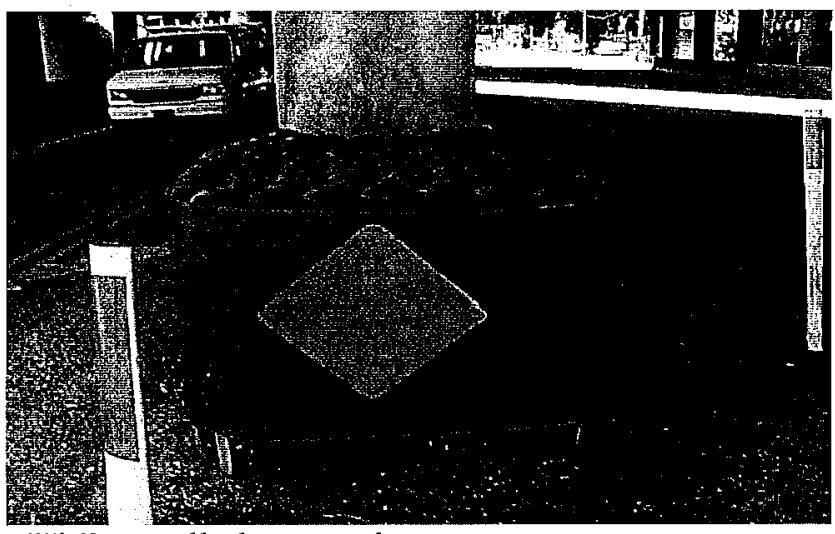

Hi-Dro cell cluster unit. 


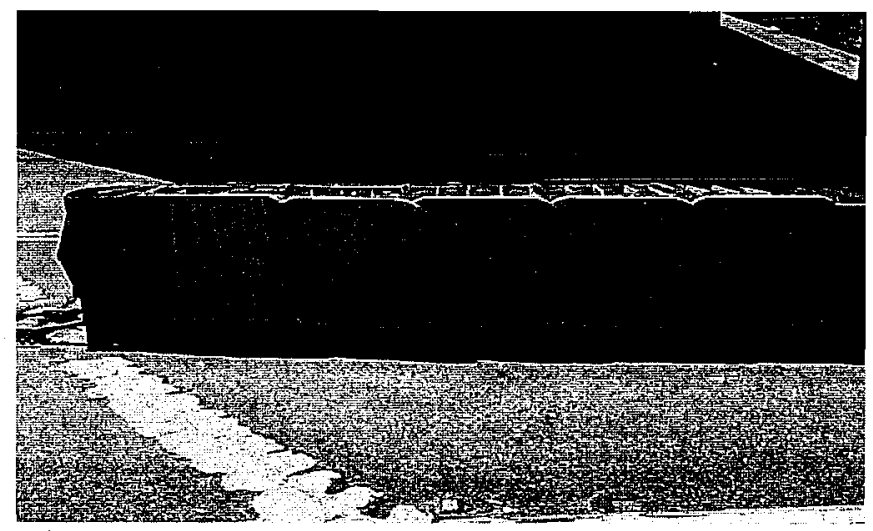

Hi-Dro Sandwich System.

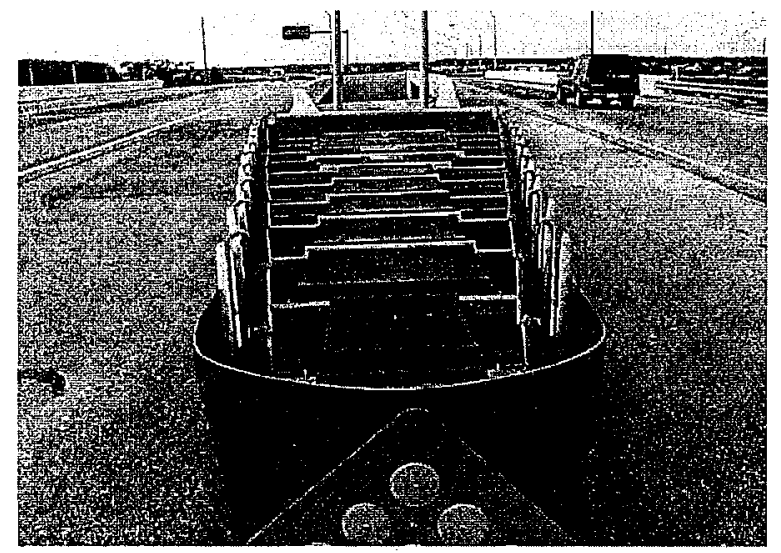

Hex-Foam Sandwich System.

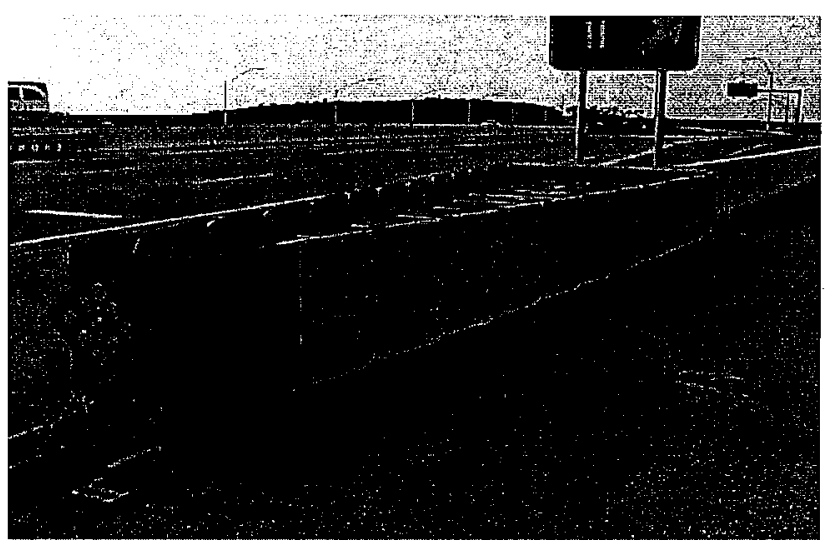

Hex-Foam Sandwich System.

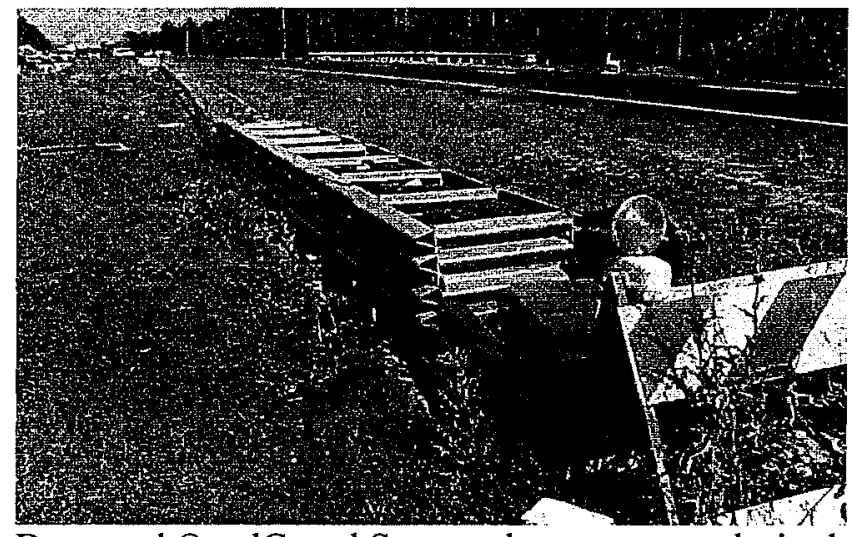

Damaged QuadGuard System does not meet desired maintenance conditions.

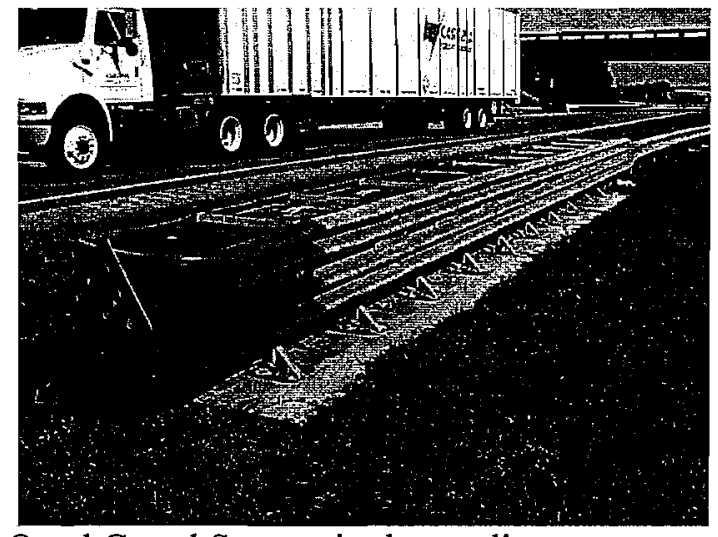

Quad Guard System in the median. 


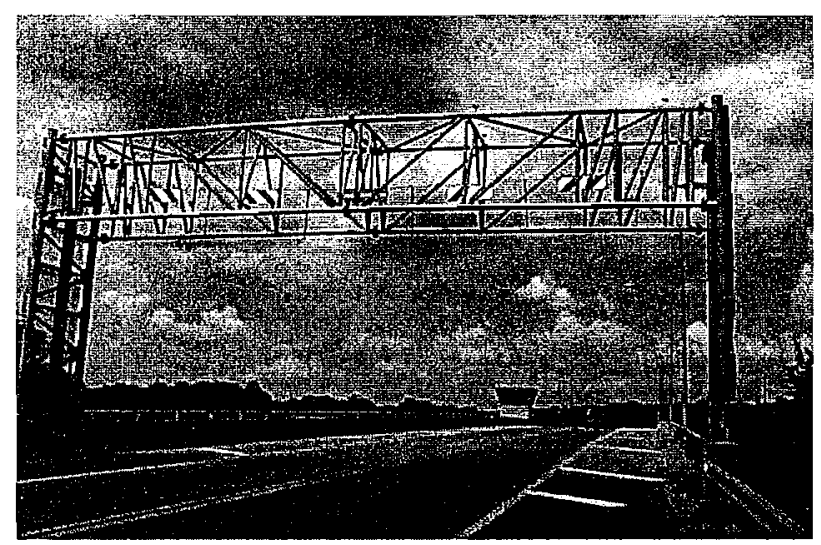

DRAGNET attenuator system.

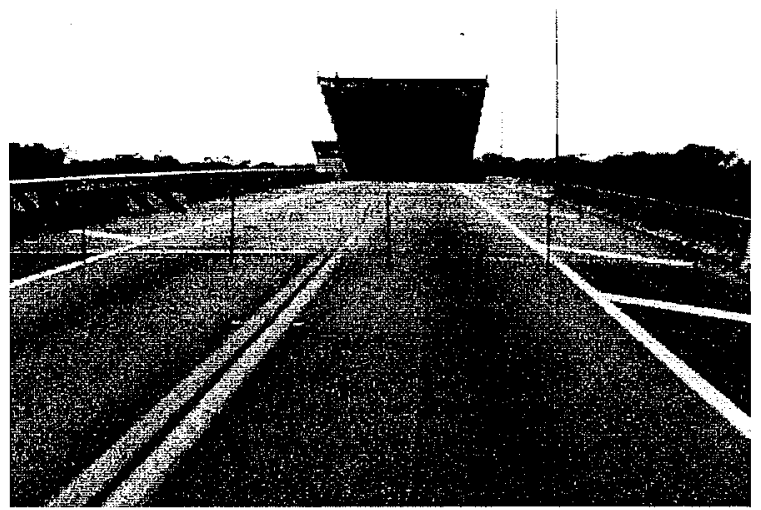

Deployed DRAGNET attenuator system. 


\section{SIGNS LESS THAN OR}

EQUAL TO 30 SQ. FT. $\quad \underline{95 \%}$ of the signs are functioning as intended.

\section{SIGNS GREATER THAN}

30 SQ. FT.

$\underline{85 \%}$ of the signs are functioning as intended.

Signs - Signs are used to convey information to the motorist so they can travel safely and efficiently on the highway.

According to the Manual on Uniform Traffic Control Devices, "Placement of a traffic control device should be within the road user's view so that maximum visual acuity is provided. To aid in conveying the proper meaning, the traffic control device should be appropriately positioned with respect to the location, object, or situation to which it applies. The location and legibility of the traffic control device should be such that a road user has adequate time to make the proper response in both day and night conditions."

Evaluation: Determine the number of signs within the sample point. Inspect the signs and determine the number of signs that do not meet desired MRP conditions. Divide the number of signs that meet MRP conditions by the total number of signs in the sample point. Multiply by 100 to get the percentage of signs that function as intended. If the percent is less than the standard, then the signs do not meet MRP standards.

For the purposes of evaluating individual sign installations, the following criteria shall apply:

\section{Sign Height:}

1. Roads with curb and gutter:

7 feet minimum height measured from top of curb to bottom of sign (measure from sidewalk, if present).

2. Roads without curb and gutter:

5 feet minimum height measured from edge of driving lane to bottom of sign.

3. Limited access ramps:

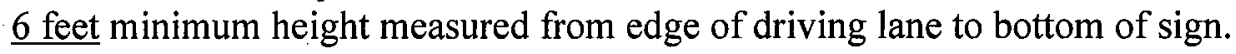

4. Limited access medians:

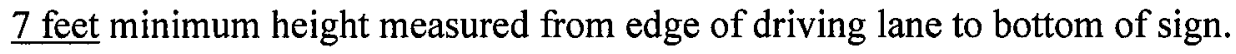

5. Limited access roads:

7 feet minimum height measured from edge of driving lane to bottom of sign.

\section{Sign Lateral Clearance:}

1. Rural roads and limited access ramps:

12 feet minimum offset from edge of driving lane and where 12 feet cannot be met. 6 feet minimum from edge of paved shoulder to edge of sign.

2. Limited access mainline:

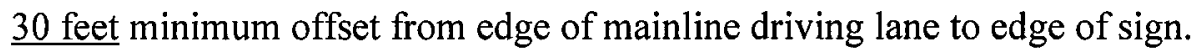


3. Roads with curb and gutter:

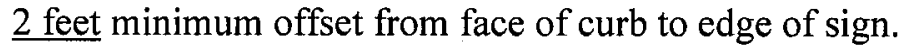

4. $\quad$ Signs behind guardrail:

2 feet minimum from the face of the rail to the edge of sign.

\section{Sign Tolerances:}

1. Height Tolerance:

A. $\quad \underline{3 \text { inch }}$ tolerance for all signs except signs over sidewalk.

B. $\quad 12$ inch tolerance for Type 1 and III object markers.

2. Lateral Clearance Tolerance:

A. $\quad 3$ inches in curb and gutter sections and behind the guardrail.

B. 6 inches on limited access ramps and arterial roads.

C. $\quad 12$ inches on limited access mainline.

The Department's Design Standards contain information on installation and placement of signs. The following standard indices may be used as guides when evaluating sign installations for the Maintenance Rating Program:

1) Index 11200 - Standard Roadside Sign Break-Away Post Details

2) Index 11037 - Aluminum \& Steel Overhead Sign Structures

3) Index 11860 - Single Column Ground Signs

4) Index 11861 - Single Column Ground Signs (60 MPH Wind Loading)

5) Index 11862 - Single Column Ground Signs (70 MPH Wind Loading)

6) Index 11863 - Single Column Ground Signs (80 MPH Wind Loading)

7) Index 11864 - Single Column Ground Signs (90 MPH Wind Loading)

8) Index 11865 - Single Column Ground Signs (Height=14' Max. all wind zones)

9) Index 13417 - Mounting Exit Numbering Panels to Highway Signs

10) Index 17302 - Typical Sections for Placement of Single \& Multi-Column Signs

The evaluation of signs greater than $30 \mathrm{sq}$. $\mathrm{ft}$. includes all over-lane signs with the exception of overhead school signs and county/city signs on signal cables.

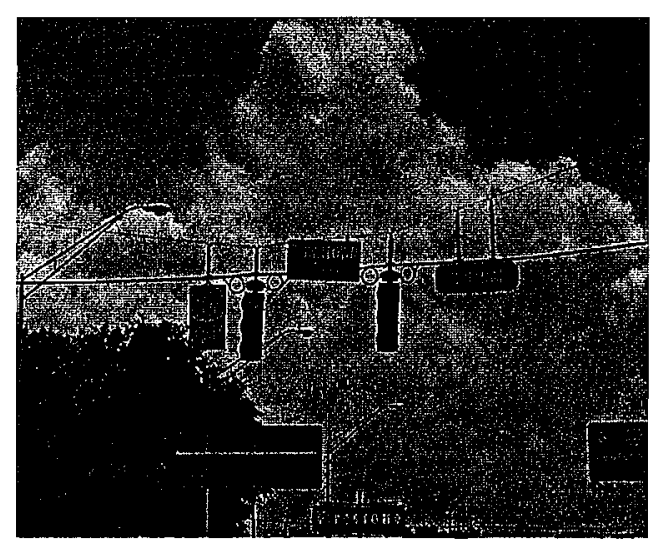

Do not rate county/city signs on signal cables. The US 17 route marker would be rated as a sign $>30$ sq. $\mathrm{ft}$. because it is an over-lane sign. 
Many cities and counties and some state and federal agencies install traffic signs and devices adjacent to or on FDOT right-of-way. Warning, Regulatory and Information signs and devices installed and maintained by FDOT are normally identified (front and back) as property of the Florida Department of Transportation and should have an installation date painted on or attached to the sign. Evaluate only FDOT signs and devices.

\section{NOTES:}

1) Highway signs shall be evaluated using two characteristics:

- Ground signs greater than 30 square feet (including all over-lane signs).

- Ground signs 30 square feet or less.

2) MRP definition of a secondary sign: A secondary sign is mounted below a primary sign and its message is not related to the primary sign message. Example: A "Do Not Block Intersection" sign mounted with a no u-turn sign below it.

3) The height to the bottom of a secondary sign mounted below another sign may be one foot less than the appropriate height except where signs are over sidewalks (a route marking assembly consisting of a route marker with an auxiliary plate is treated as a single sign).

4) Do not rate overhead school signs or county/city signs on signal cables.

5) Do not rate logo signs or signs on call boxes.

6) Do not rate wildflower signs.

7) For purposes of these guidelines, a turn lane will be considered a driving lane. Merge, rest area, signs on islands and exit gore signs shall be evaluated under Design Standard Index No. 17302.

8) If it is obvious the minimum lateral clearance cannot be met, the sign shall be considered to meet acceptable maintenance conditions. The presence of sidewalk by itself shall not be considered a reason a sign cannot meet the minimum lateral clearance.

9) A sign less than 30 square feet mounted to a sign greater than 30 square feet is evaluated as part of the sign greater than 30 square feet.

10) For MRP purposes, two post installations with round aluminum tubing less than or equal to $3-1 / 2$ inches meets maintenance conditions.

11) Signs in the median, as outlined in Index 17346 are not evaluated for lateral clearance.

\section{Signs do not meet desired maintenance conditions when any of the following exist:}

\section{NOTE: See above for all tolerances.}

1) Sign installations including panels and posts leaning more than 1 inch per foot.

2) There is missing connecting hardware, nuts and bolts.

3) Sign panels are attached to columns below a fuse cut (Index 11200).

4) Bottom of sign panel is installed more than 1 inch above or below the fuse cut (Index 11200).

5) Aluminum " $\mathrm{C}$ " clamps are used to attach a sign panel to a post.

6) Cantilever signs are not installed according to Index 11860.

7) Brackets are installed improperly.

8) A cantilever sign is wider than 4 feet.

9) Sign rotation causes the sign message to become unreadable. (Note: In urban areas, "NO PARKING" signs may be rated $30^{\circ}$ to $40^{\circ}$ toward traffic).

10) Signs fail to convey the intended message due to lack of reflectivity, fading or surface accumulations. (Note: All signs shall be reflectorized or illuminated to show the same shape and color in day and night conditions). 
11) Height and offset of mile markers are not according to Case IX of Index 17302. (Note: For MRP purposes, a height tolerance of up to 3 inches and an offset tolerance of up to 12 inches are permitted).

12) Aluminum posts greater than $\underline{3-1 / 2}$ inches in diameter are not installed on a slip base (Indices 11861 to 11864 ).

13) A slip base or breakaway support is covered with soil.

14) A slip base or breakaway support more than 4 inches above the finished ground as measured at the center (Index 11860).

15) A single post installation is prohibited by Index 11860. (Note: Details found on Sheet 3 of Index 11860 shall not be considered during MRP evaluations).

16) Single post installations of a sign wider than 48 inches unless specifically allowed by Index 11860 .

17) A sign on a slip base is installed without a concrete footing.

18) The edge of a sign panel is installed less than 2 feet from the face of guardrail.

19) The height and lateral offset of a sign panel is not installed according to Index 17302.

20) Damage to a sign column that compromises its function.

21) U-channel steel posts heavier than 3 pounds per foot have no breakaway support.

22) Steel post support stubs protrude more than 4 inches above the ground. 
Miscellaneous sign information

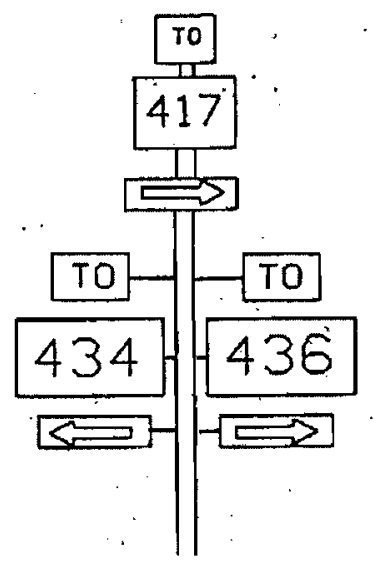

This sign assembly has three(3) messages and therfore should be rated as three (3) signs. If the SR 434 Route marker is bad then one sifn message is bad which is $33 \%$ and would not meet desired maintenance conditions

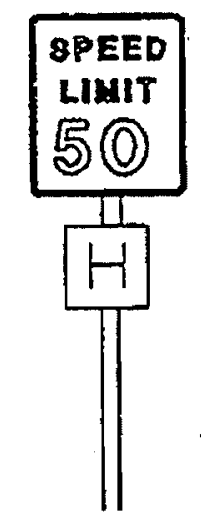

This is a regulatory sign with a hospital sign below it. The hospital sign is considered a secondary sign because its message is not related to the regulatory sign message. 


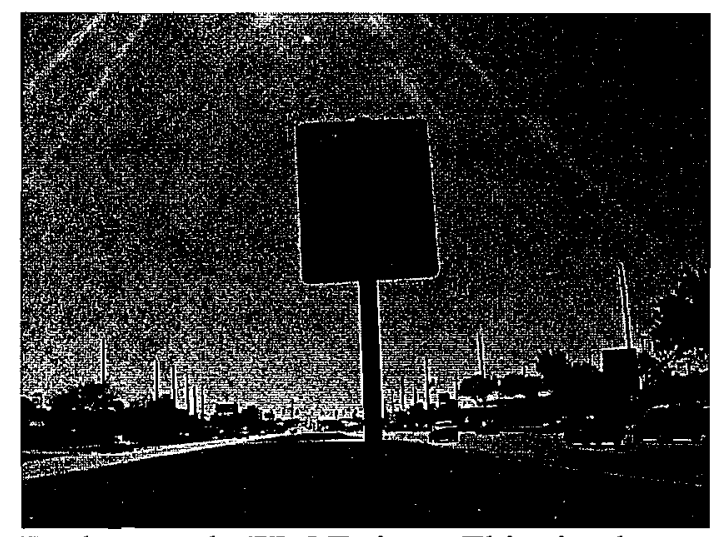

Evaluate only FDOT signs. This sign has the proper label indicating when it was installed and that it is property of FDOT.

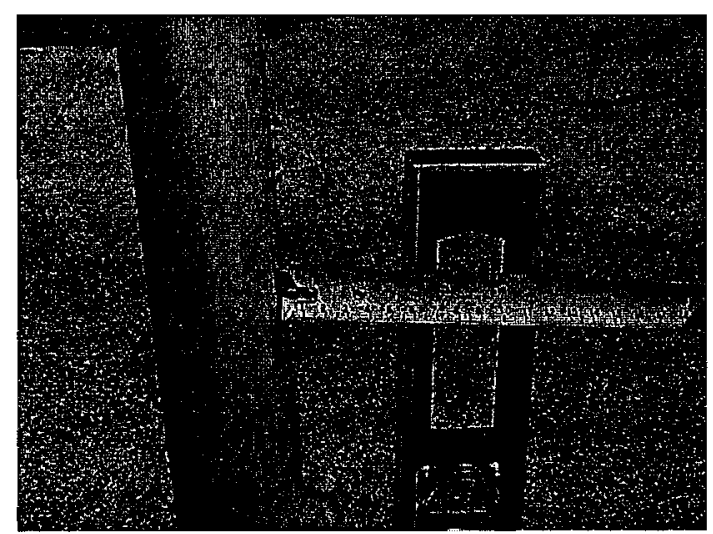

Measuring a sign that is leaning more than 1 inch per foot. This sign does not meet desired maintenance conditions.

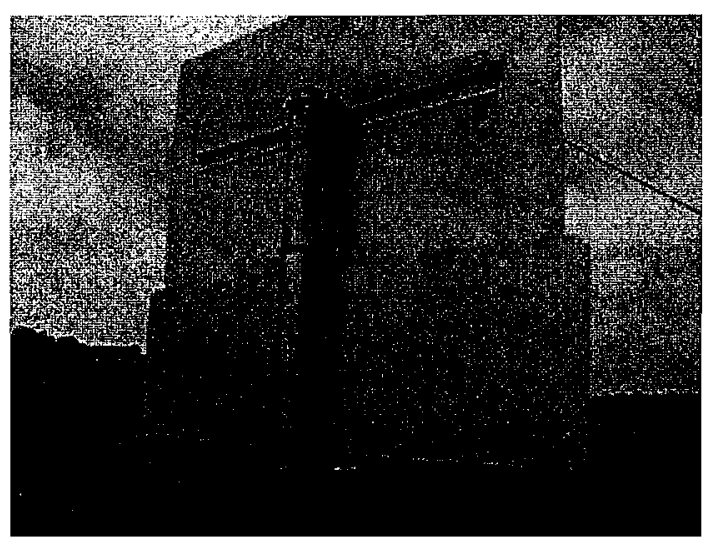

Incorrect bracket installation.

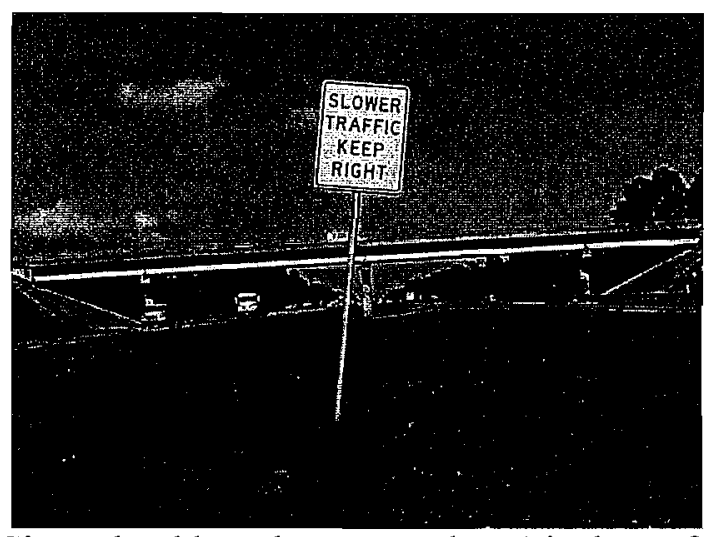

Signs should not lean more than 1 inch per foot.

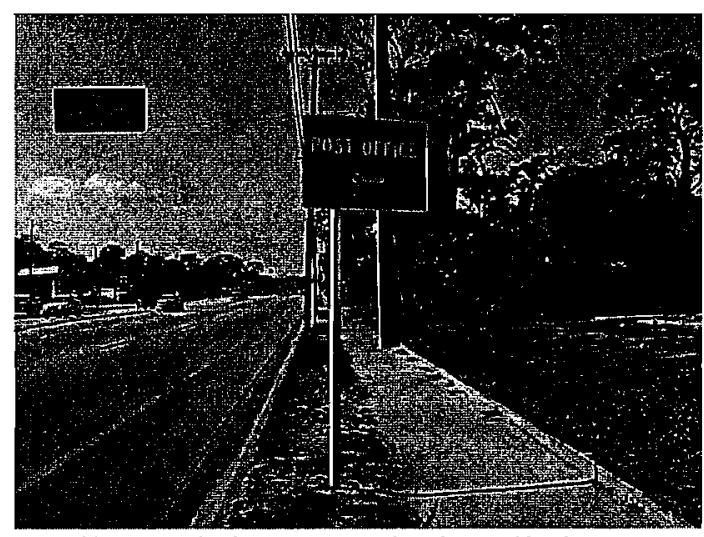

Cantilevered signs must be installed on a breakaway device and have a concrete foundation. Design standard index 11860. This sign does not meet desired maintenance conditions.

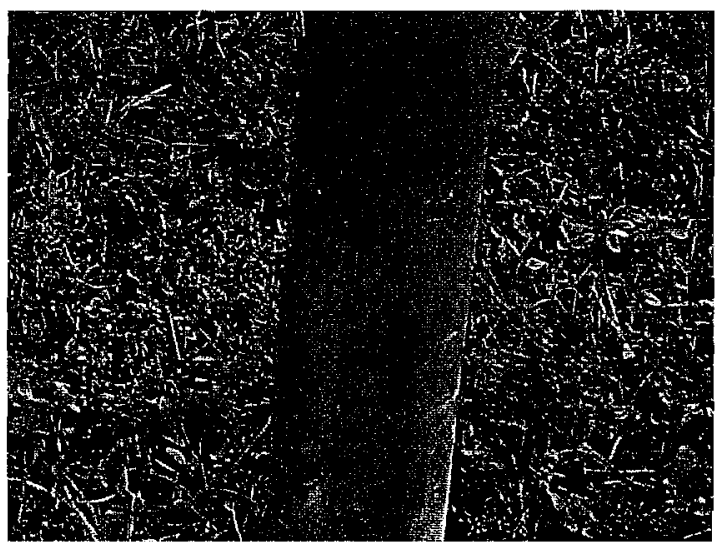

This sign column has been damaged and does not meet desired maintenance conditions. 


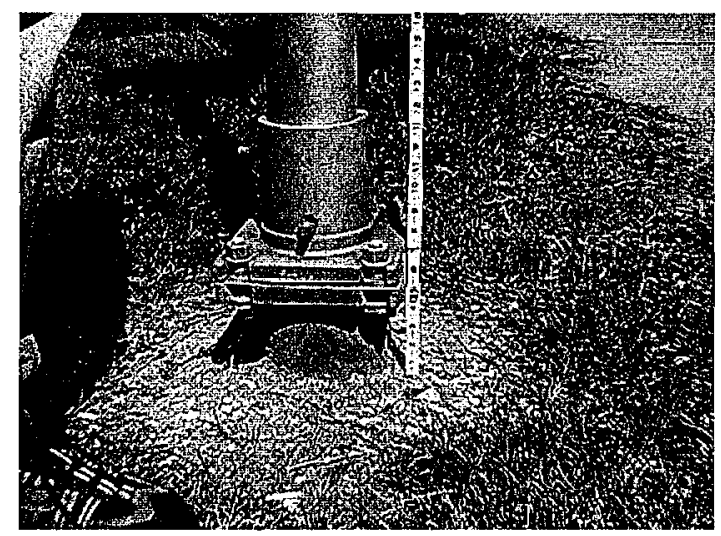

Slip base more than 4 inches above the ground. This does not meet desired maintenance conditions. This does not meet desired maintenance conditions.

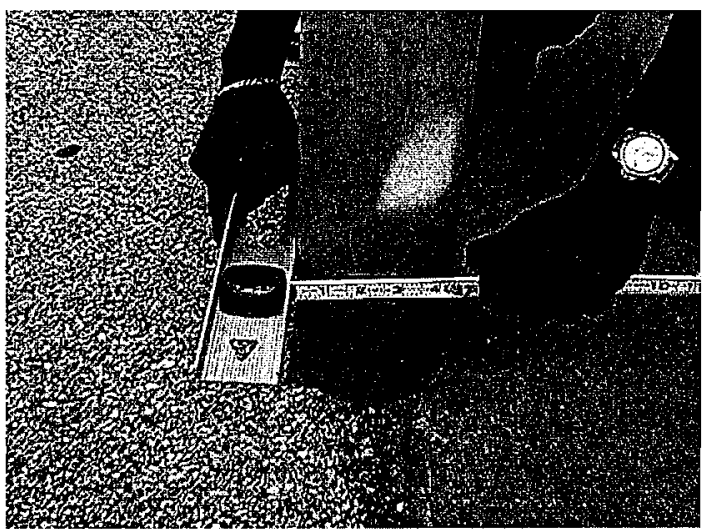

Measuring a sign post. This post is 4 inches and should be installed with a concrete foundation and breakaway assembly. This Sign installation does not meet desired maintenance conditions.

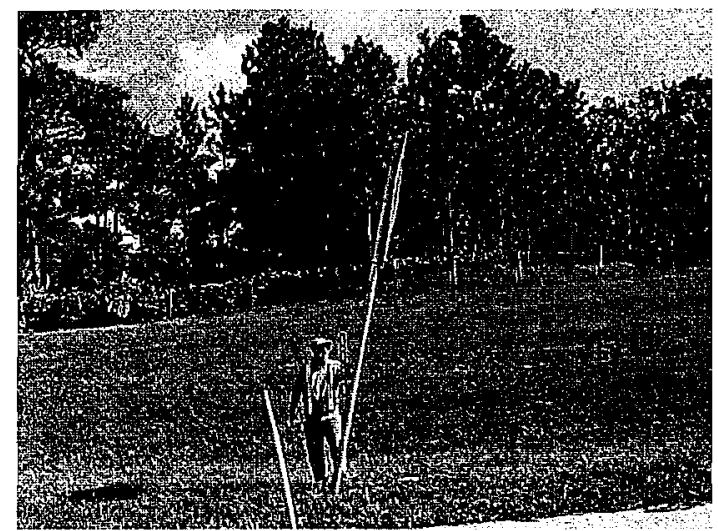

This sign installation is leaning more than 1 inch per foot and does not meet desired maintenance conditions.

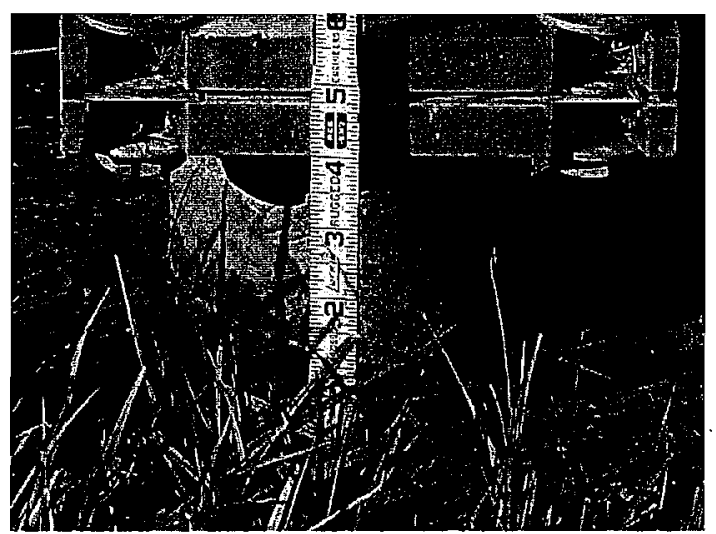

Slip base more than 4 inches above the ground.

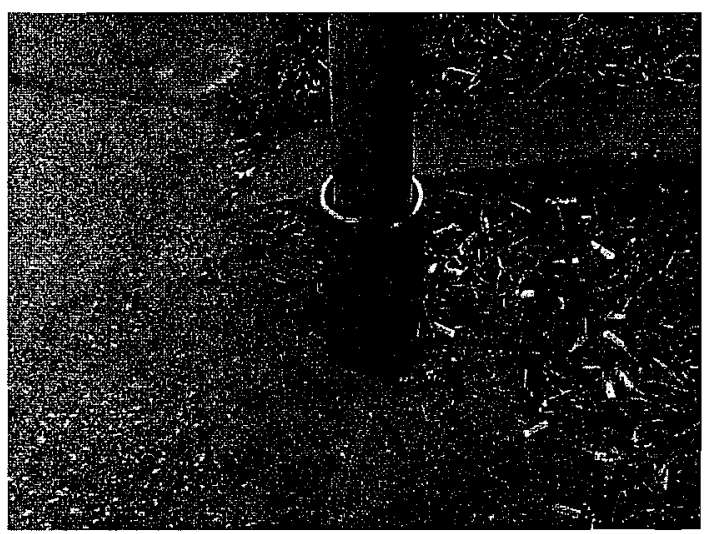

This sign foundation is non-standard and, therefore, does not meet desired maintenance conditions.

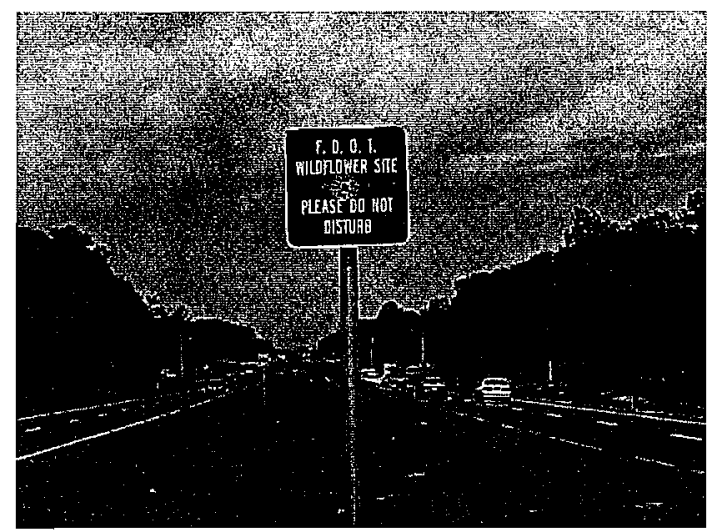

Do not rate wildflower signs. 


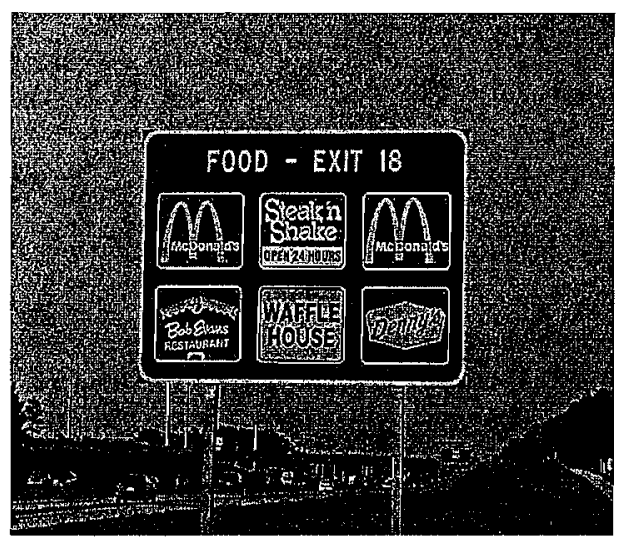

Do not rate logo signs.

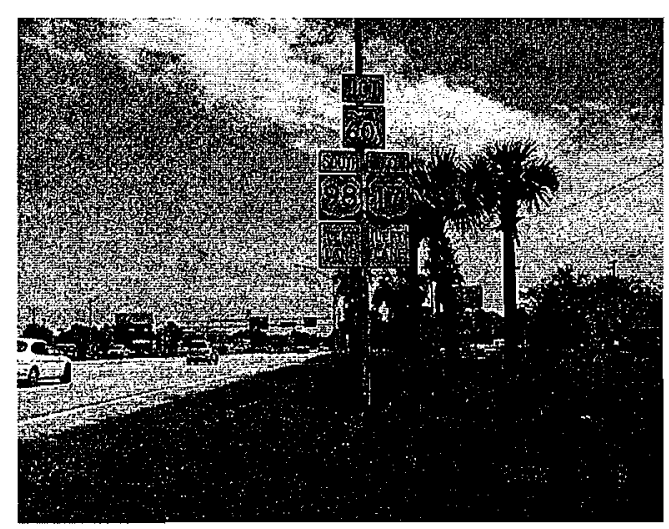

This sign assembly has 3 messages and and should be rated as 3 signs.

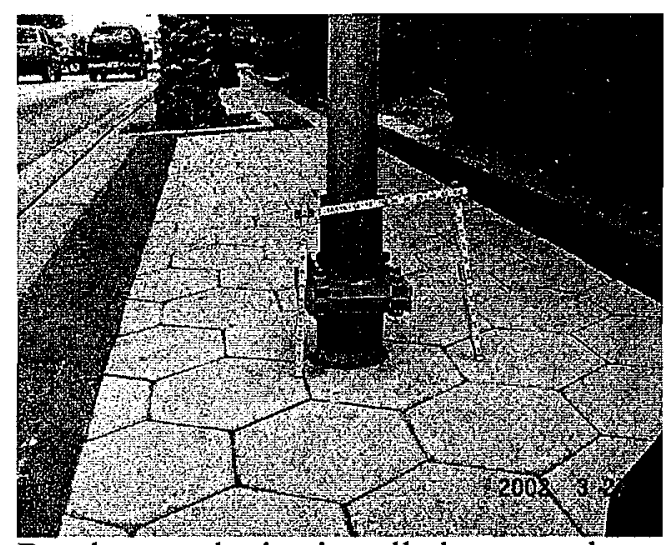

Breakaway device installed greater than 43 inches above the ground. This installation does not meet desired maintenance conditions.

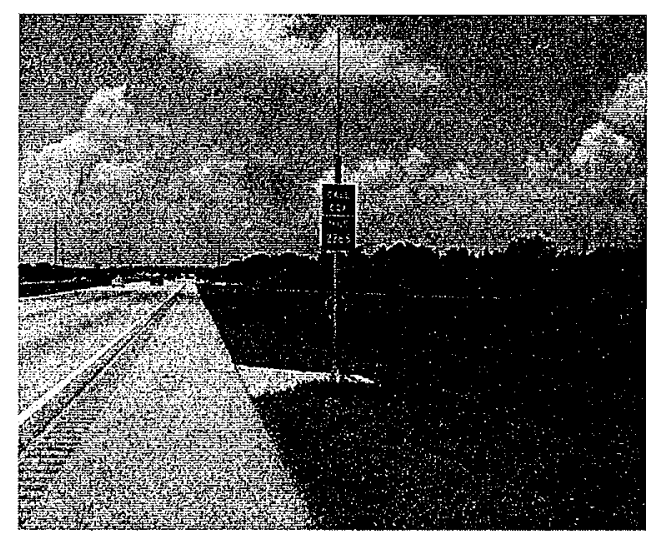

Do not rate signs on call boxes.

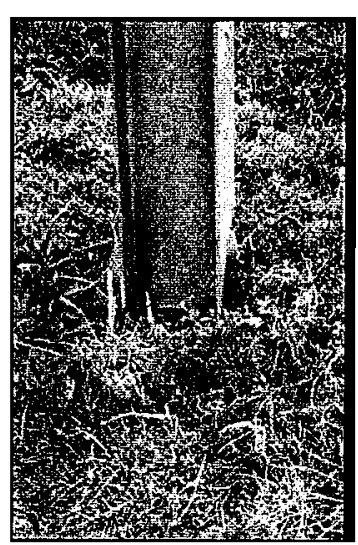

This breakaway device is covered with sand and grass and does not meet desired maintenance conditions.

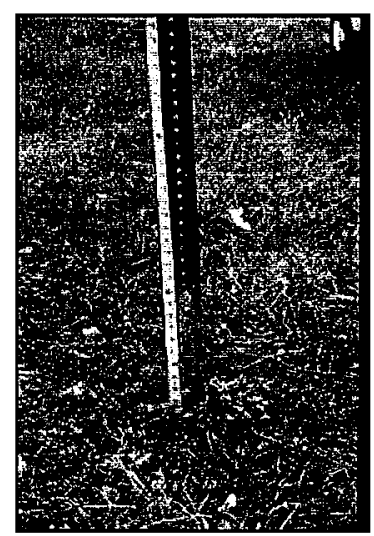

This steel flanged channel post is installed greater than 4 inches above the ground (Index 11865 ) and does not meet desired maintenance conditions. 


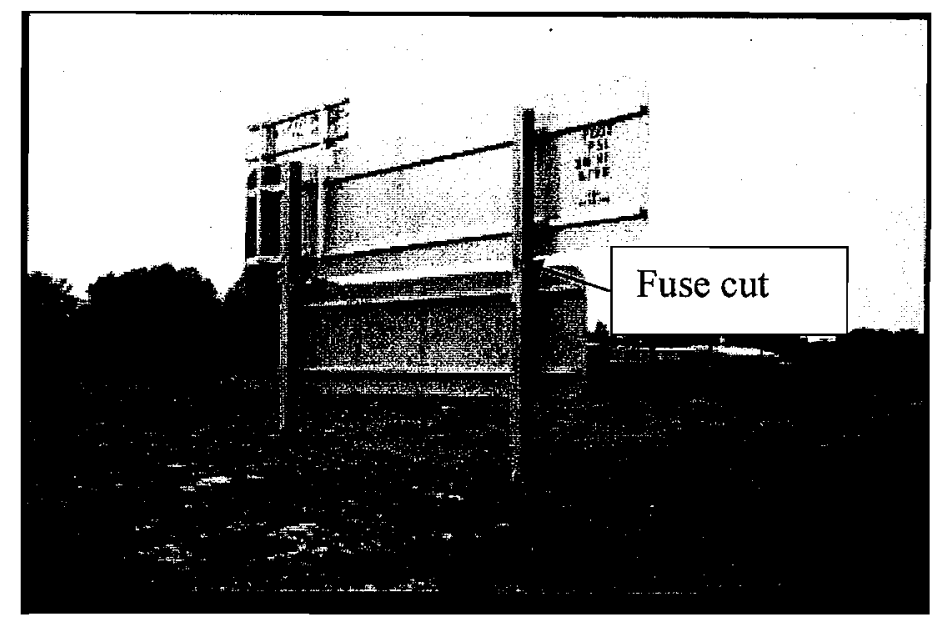

Signs installed below the fuse cut do not meet desired maintenance conditions.

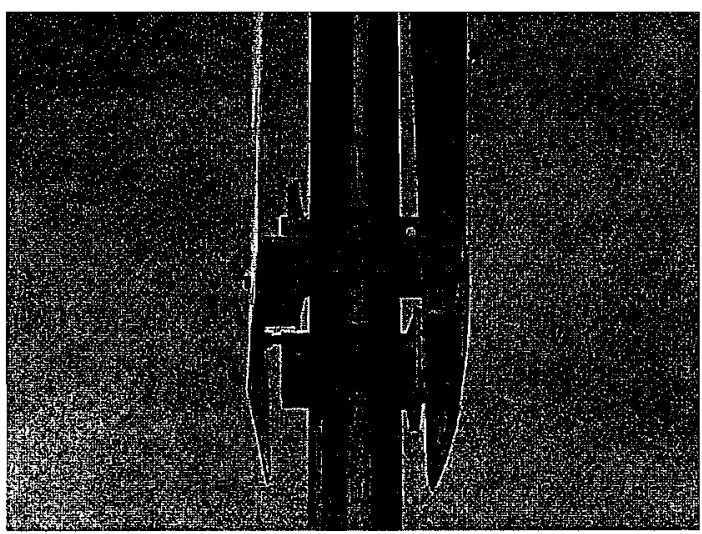

These signs are installed using "C" clamps. This does not meet desired maintenance conditions.

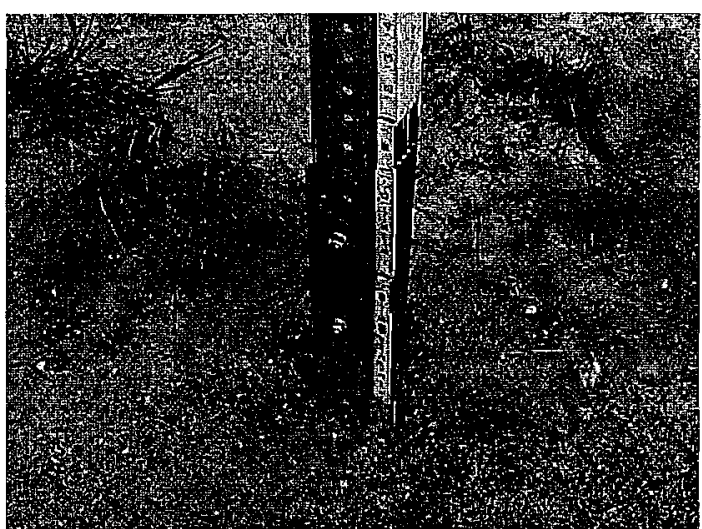

This steel flanged channel post is installed greater than 4 inches above the ground (Index 11865 ) and does not meet desired maintenance conditions.

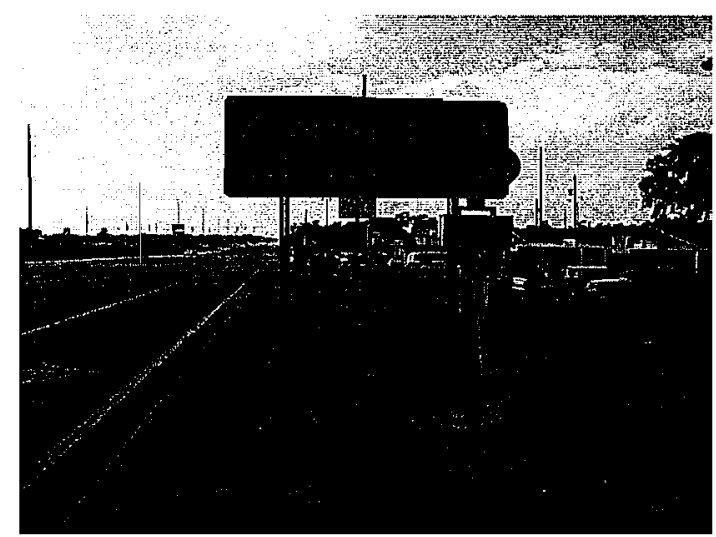

Multi-post sign installed using steel flanged channel post.

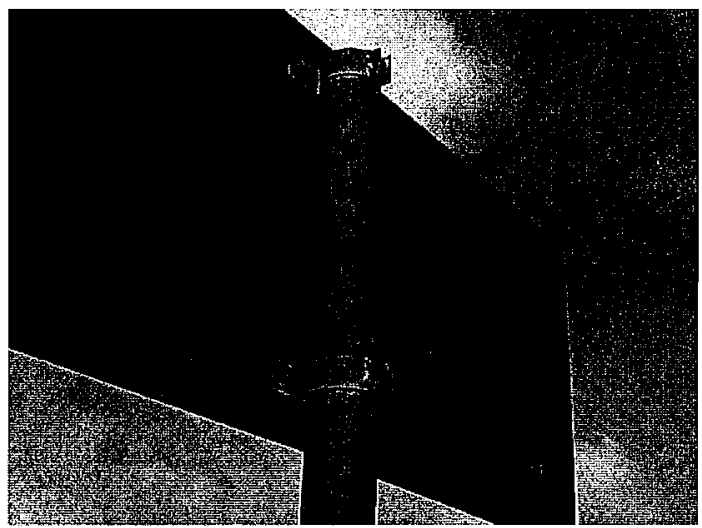

This sign was installed using " $\mathrm{C}$ clamps and does not meet desired maintenance conditions. 


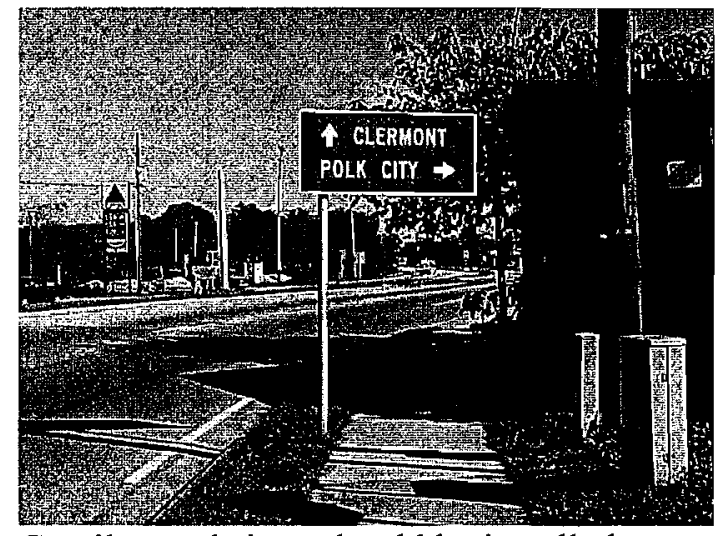

Cantilevered signs should be installed according to Index No. 11860.

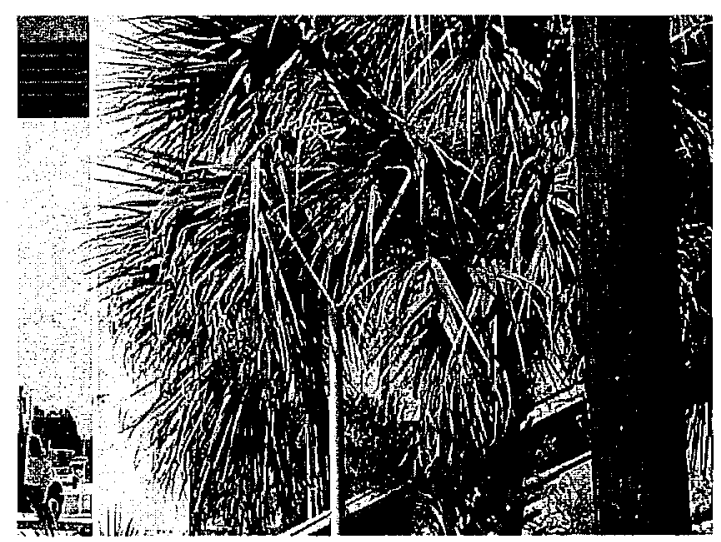

This sign is in good condition but cannot be seen because of a palm tree. The sign meets MRP standards, however tree trimming would not meet desired maintenance conditions.

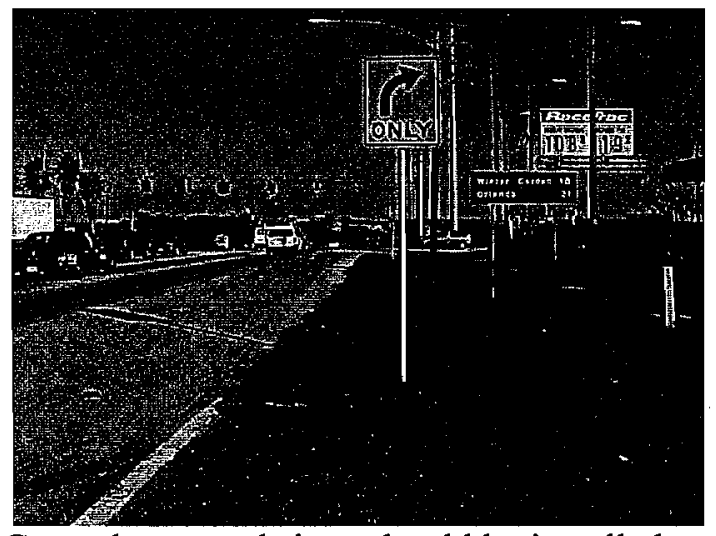

Ground mounted signs should be installed according to Index No. 17302.

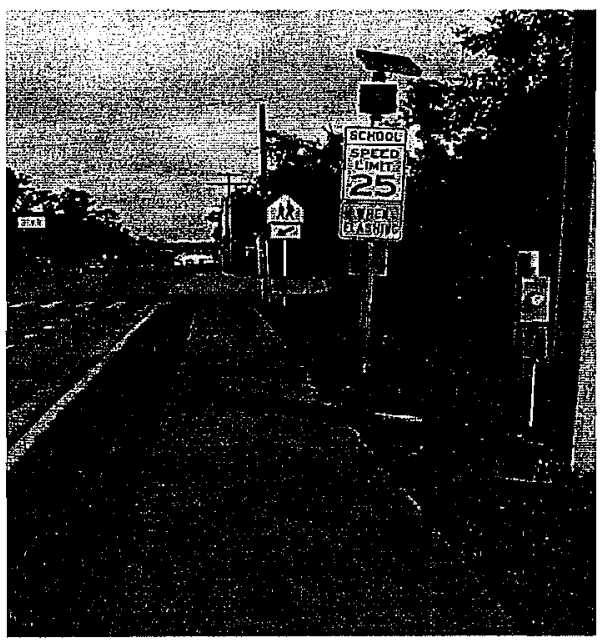

This is a flashing school sign. This sign is not rated in MRP because it is maintained by the county. 
OBJECT MARKERS

AND DELINEATORS: $\quad \underline{80 \%}$ of the markers are functioning as intended.

Object Markers - According to the MUTCD, "Object markers are used to mark obstructions within or adjacent to the roadway." Section 3C.01

Delineators - The MUTCD states, "Delineators are particularly beneficial at locations where the alignment might be confusing or unexpected, such as at lane reduction transitions and curves. Delineators are effective guidance devices at night and during adverse weather. An important advantage of delineators in certain locations is that they remain visible when the roadway is wet or snow covered." Section 3D.01

Evaluation: For MRP purposes, Type 2 Object Markers and Delineators are used to mark Department maintained objects or to delineate roadway alignment. This characteristic will include clear or amber "button" type reflectors installed on guardrail and barrier wall systems, button or combination button and reflective sheeting markers used at crossovers and other applications where object or guide marking is used.

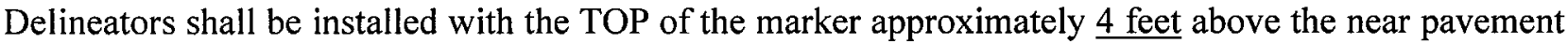
elevation.

When used for marking objects in the roadway or 8 feet or less from the shoulder or curb, the mounting height to the bottom of the object marker should normally be 4 feet above the surface of the nearest travel lane. When used to mark the objects more than 8 feet from the shoulder or curb, the mounting height to the bottom of the object marker may be 4 feet above the ground.

Except for post mounted delineators on entrance and exit ramps at interchanges all post mounted object

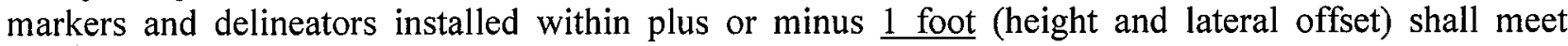
desired maintenance conditions.

Post-mounted delineators on ramps (see Index 17345) shall be installed at a uniform distance from the travel lane with a tolerance of $\underline{3 \text { inches. The height shall be uniform with a tolerance of } 3 \text { inches. }}$

Rate all post-mounted markers except those installed to prohibit unauthorized traffic movements (offtracking, median crossing, shoulder parking, etc.). Rate post-mounted delineators at major/minor intersections, if installed.

The horizontal placement of post-mounted delineators at crossovers shall be 6 feet with a tolerance of plus or minus 1 foot- 6 inches in accordance with Index 17346. This index shows the edge of pavement as the standard reference point. If curb and gutter is present measure from the top face of the curb. If no curb is present measure from the edge of pavement.

Both day and night observations should have at least $\underline{80 \%}$ of the required markers present, at the recommended height and offset and functioning as intended to meet desired maintenance conditions.

Post-mounted delineators at median crossovers and major and minor roads shall be installed according to Index 17346. Yellow delineators should be located on sides facing the crossover and green delineators should be located on sides facing away from the crossover. All connecting hardware, nuts 
and bolts should be installed. Delineators shall not be used as Type 2 object markers (see Section 3C and 3D, MUTCD).

Each run of guardrail shall have reflectors according to standard index 400. A continuous run of adhesive markers and a continuous run of post mounted markers on guardrail meet desired conditions. However, adhesive and post mounted guardrail markers shall not be intermixed (see index 400 ) in a continuous run. For MRP purpoșes, an intermixed marker will be counted the same as a missing marker.

\section{Object Markers and Delineators do not meet MRP standards when more than 20\% of the following} exist:

1) The horizontal placement of post-mounted delineators at cross-overs are installed more than plus or minus 1 foot- 6 inches from the edge of pavement or top face of curb.

2) If in the roadway or $\underline{8 \text { feet }}$ or less from the shoulder or back of curb the marker is not installed $\underline{4}$ feet plus or minus 1 foot above the edge of the nearest travel lane.

3) If the bottom of the marker is not installed 4 feet plus or minus 1 foot above the ground when marking objects more than 8 feet from the shoulder or back of curb.

4) Markers are not offset 4 feet plus or minus 3 inches from the shoulder break and installed at a uniform height on interchange ramps as shown in Index 17345.

5) Markers or delineators lean more than 1 inch per foot of post length.

6) Required markers are missing.

7) Required markers are not reflective at night.

8) Adhesive and post-mounted reflectors are mixed in a continuous run of guardrail as cited in Index 400.

9) Reflectors are not installed as shown in Index 400, Detail M.

10) Color of post-mounted delineators are installed facing the wrong way.

11) Missing connecting hardware, nuts and bolts.

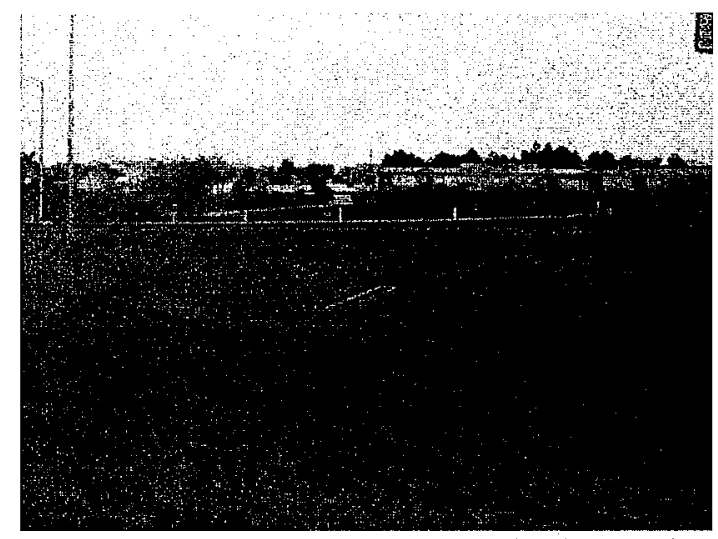

Object markers are used to mark obstructions within or adjacent to the roadway. These object markers are marking a manhole, headwall and U-endwall.

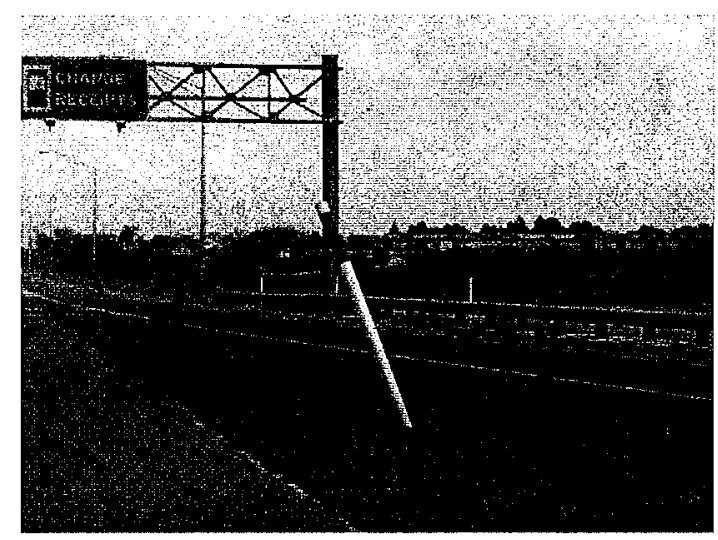

This object marker is for fiber optic cable. It would not be rated since this is not a Department maintained object. 


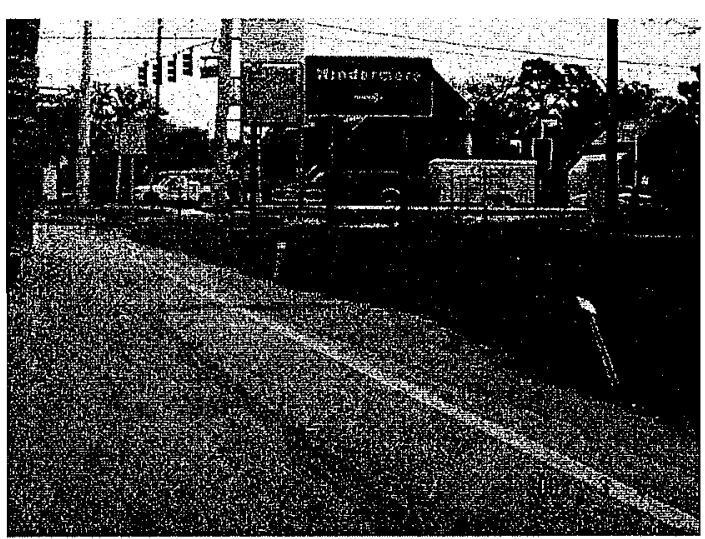

These post-mounted delineators would not be rated because they are being used to prohibit unauthorized traffic movements.

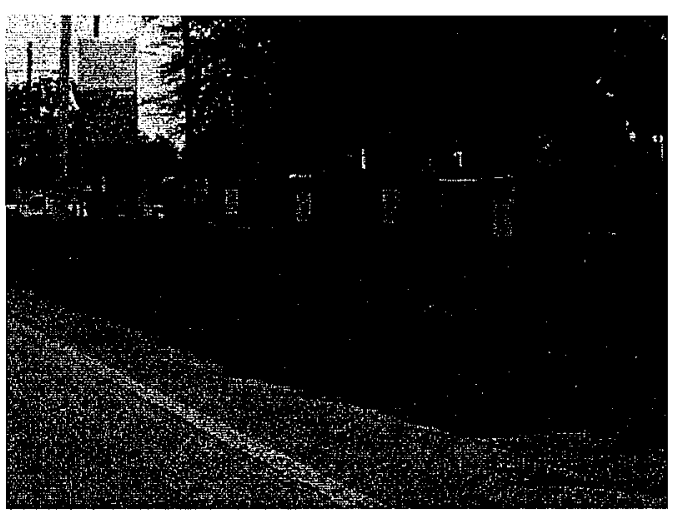

Do not rate post-mounted markers installed to prohibit unauthorized traffic movements (offtracking, median crossing, shoulder parking, etc.)

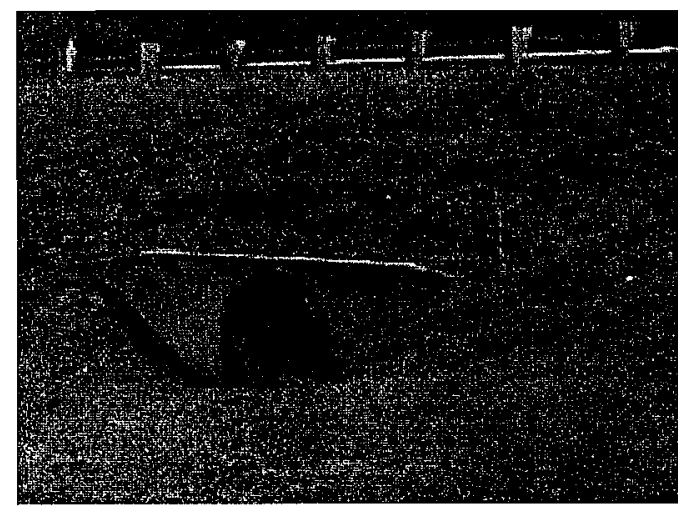

This object marker was installed but is not needed because the headwall is behind guardrail. Since the object marker is installed, it will be rated. The object marker is installed 2 feet 6 inches from the ground to the bottom of the marker. It should be installed no less than 4 feet plus or minus 1 foot from the ground to the bottom of the marker. This marker does not meet desired maintenance conditions.

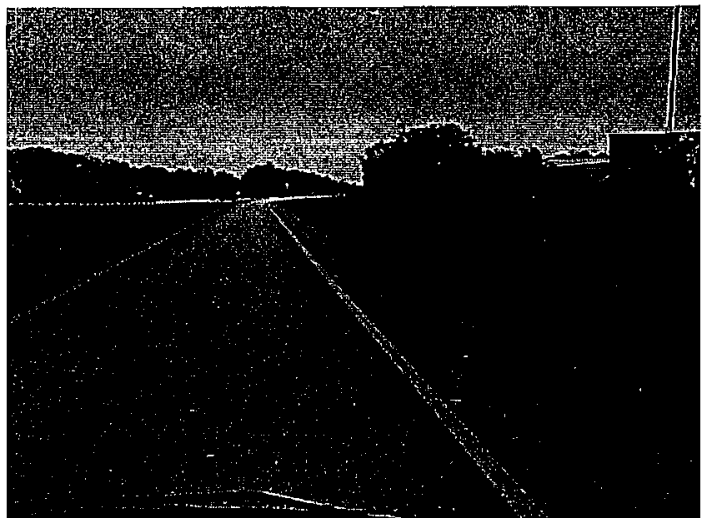

These post mounted delineators are installed on a ramp according to Index No. 17345.

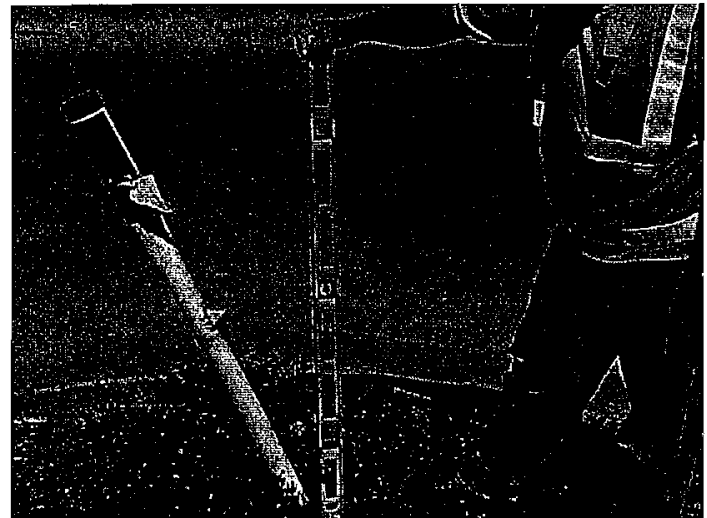

This post mounted delineator is leaning more than 1 inch per foot and does not meet desired maintenance conditions. 

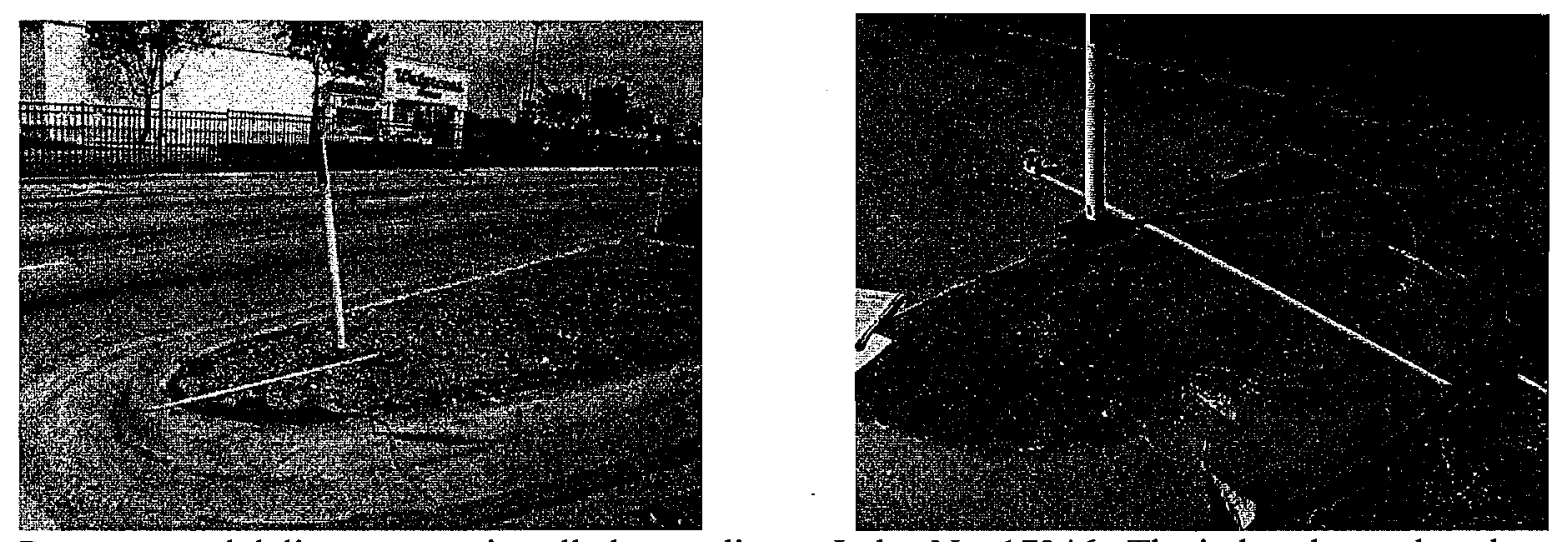

Post mounted delineators are installed according to Index No. 17346. The index shows the edge of pavement as the standard reference point. If curb and gutter is present measure from the top face of curb. At a curb without a gutter or traffic separator, the face is the edge of pavement (picture on right).

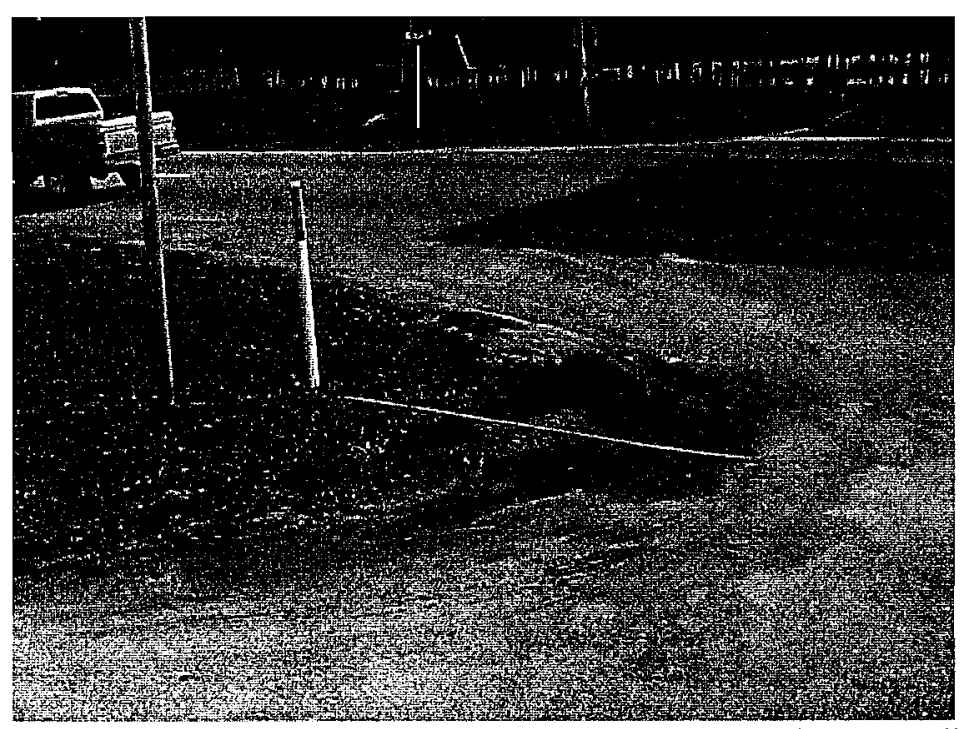

This is a rural crossover with a post mounted delineator installed. According to index 17346 the delineator should be installed $6 \mathrm{ft}$. from the edge of pavement to the delineator. MRP has a tolerance of $1 \mathrm{ft} .6$ inches. This delineator is installed $8 \mathrm{ft} .6$ inches from the edge of pavement. This installation does not meet MRP standards. 


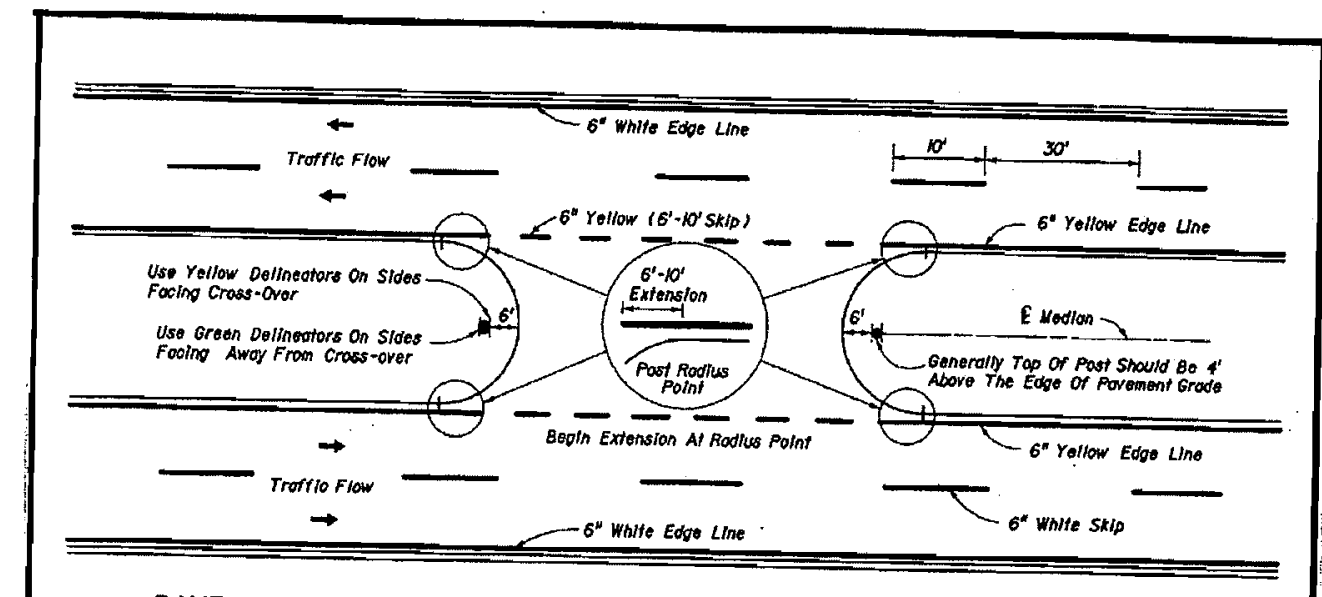

PAVENENT MARKINES AND DELUNEATORS FOR MEDIAN CROSS-OVER

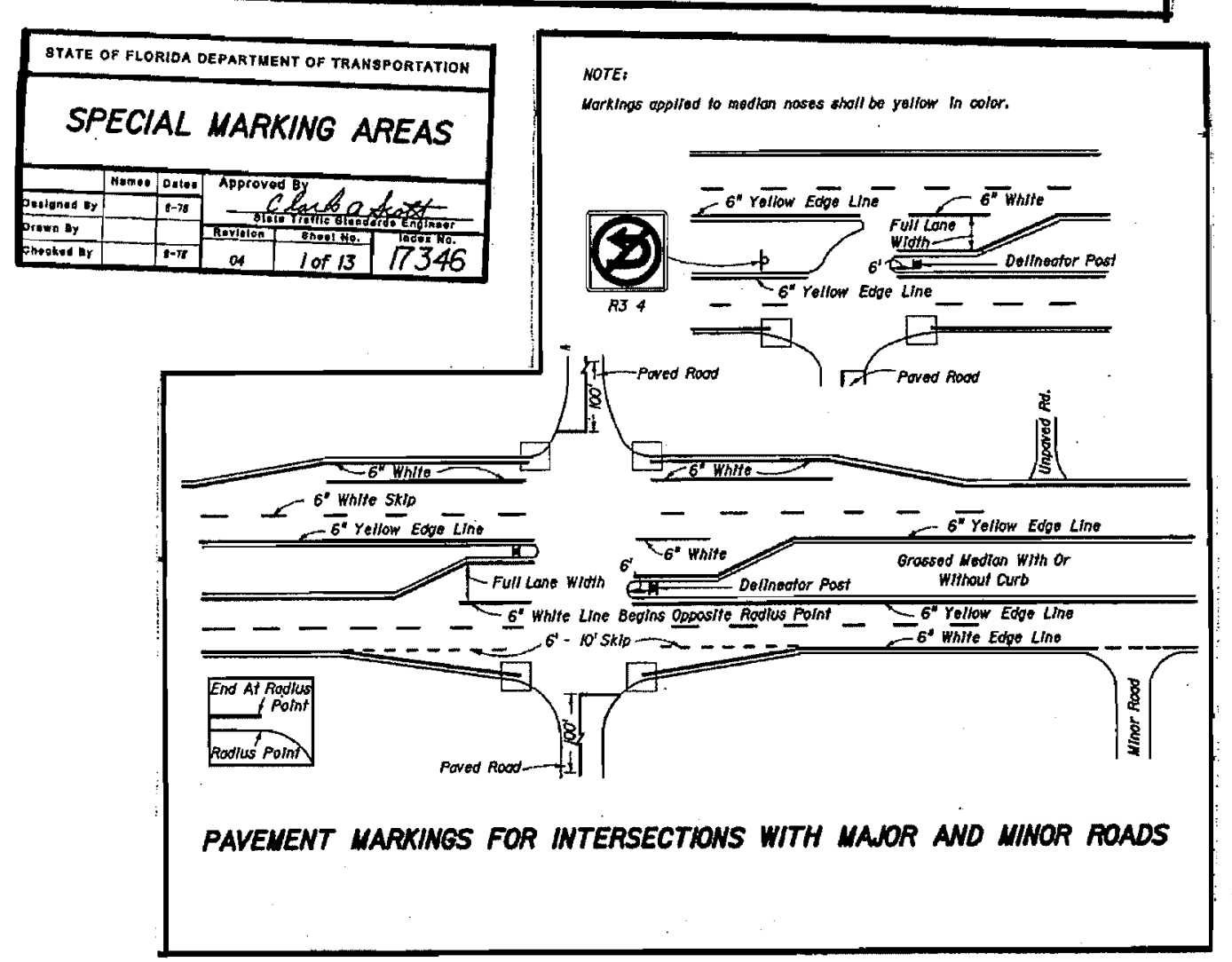

Design Standard Index 17346 shows the proper placement of delineator posts for median cross-overs and intersections. The horizontal placement of post-mounted delineators at crossovers shall be installed within plus or minus 1 foot 6 inches in accordance with Index 17346. This index shows the edge of pavement as the standard reference point. 

functioning as intended.

Sign Lighting - Illumination of overhead roadway signs may be by means of: a light illuminating the message through translucent material, a source that illuminates the entire face of the sign or some other source such as illuminated tubing or incandescent panels that make the message visible at night. Sign illumination that is present but not functioning should be verified as officially out of service. The area engineer can provide this information.

Highway Lighting - All highway lighting MAINTAINED by the Department (DOT forces or contract maintenance) is to be included in the survey. The daytime evaluation should be for missing or damaged poles and missing or damaged luminaries. ANY electrical inspection plate, access panel cover or pull box cover that is not properly secured in place will also cause this characteristic not to meet the desired maintenance conditions. If this characteristic meets the desired daytime conditions, then a nighttime evaluation shall be made.

Evaluation: Determine the total number of luminaries in the sample point. By inspection, determine the number of luminaries that do not meet desired maintenance conditions. Subtract that number from the total number of luminaries. This is the number of luminaries in the sample that meet MRP conditions. Divide this number by the total number of luminaries then multiply by 100 to get the percent of luminaries that meet desired maintenance conditions. If this percentage is equal to greater than the standard, then the point meets conditions for lighting.

\section{Lighting does not meet MRP standards when any of the following exist:}

1) Any electrical inspection plate, access panel cover, exposed electrical wire or pull box cover are not properly secured in place.

2) If more than $10 \%$ of the total luminaries are not functioning.

3) If more than $\underline{10 \%}$ of the poles are damaged or missing.
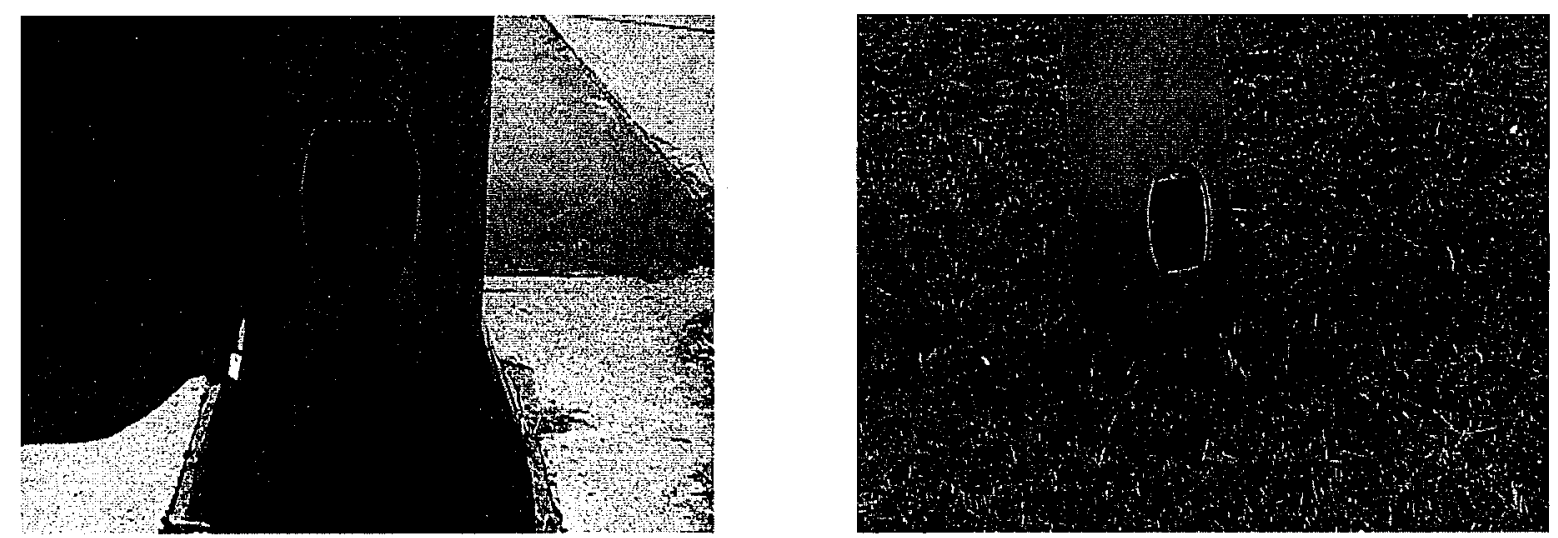

Any electrical inspection plate, access panel cover or pull box cover that is not properly secured in place will cause this characteristic not to meet the desired maintenance conditions. The light poles shown above are missing the access panel cover and, therefore, do not meet desired maintenance conditions. 


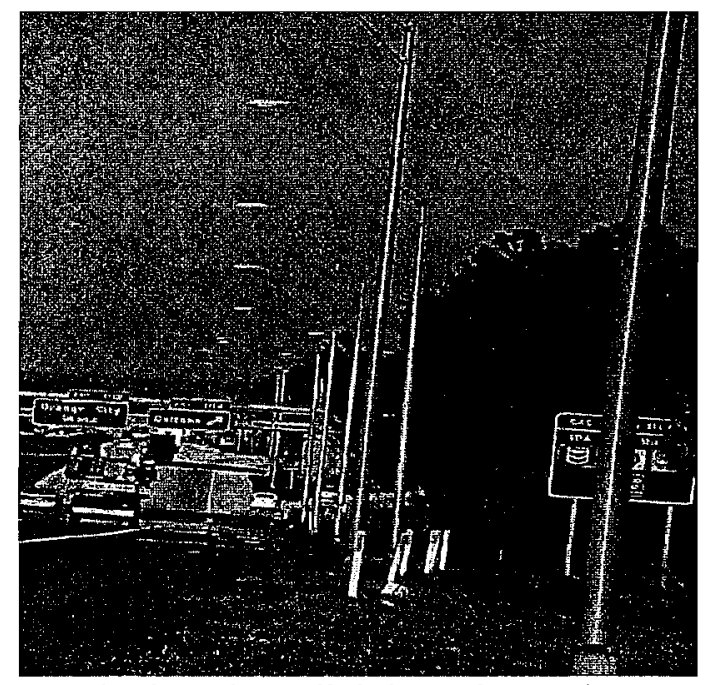

Standard roadway lighting. Count the Number of luminaries within the sample.

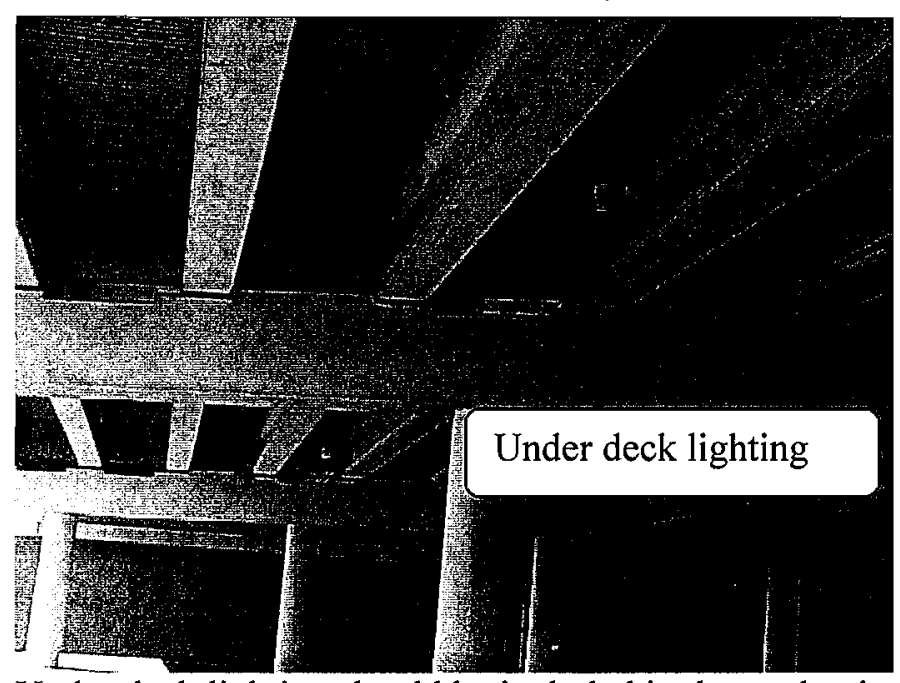

Under deck lighting should be included in the evaluation of lighting.

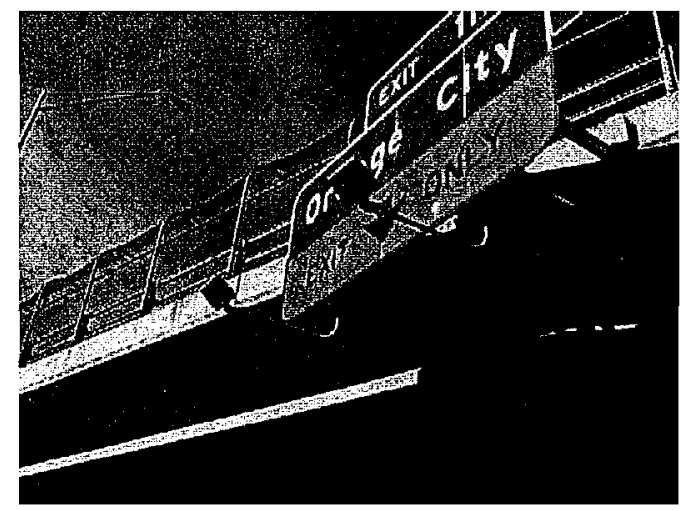

Overhead sign lighting 


\section{FLORIDA DEPARTMENT OF TRANSPORTATION \\ MAINTENANCE RATING PROGRAM STANDARDS}

\section{DRAINAGE}

\section{THE FOLLOWING CHARACTERISTICS MEET THE DESIRED MAINTENANCE CONDITIONS WHEN:}

SIDE/CROSS DRAIN: $\quad \underline{60 \%}$ of the cross-sectional area of each pipe is free of obstructions and functions as intended.

\section{ROADSIDE/MEDIAN}

DITCH:

OUTFALL DITCH:

INLETS:

MISC. DRAINAGE

STRUCTURE:

ROADWAY SWEEPING:
The ditch bottom elevation shall not vary from the ditch design elevation more than $1 / 4$ of the difference between the edge of pavement elevation and the ditch design elevation.

The ditch bottom elevation shall not vary from the ditch design elevation more than $1 / 3$ of the difference between natural ground and the ditch design flow line.

$\underline{85 \%}$ of the opening is not obstructed.

$\underline{90 \%}$ of each structure functions as intended.

\footnotetext{
Material accumulation is not greater than $3 / 4$ inch deep for more than a depth for more than a continuous 1 foot in any gutter.
} 


\section{DRAINAGE}

SIDE/CROSS DRAIN: $\quad \underline{60 \%}$ of the cross sectional area of each pipe is free of obstructions and functions as intended.

Side Drain - Side drains normally occur under turnouts.

Cross Drain - Cross drains will normally run under a roadway(s) at a perpendicular angle and begin or end in an open roadside ditch. Drains crossing under a roadway that connect to an inlet at both ends shall not be rated.

If a box culvert of any length and less than $20 \mathrm{ft}$. in width falls within a sample, evaluate as normal and rate the culvert as a cross drain. Box culverts wider than $20 \mathrm{ft}$. are classified as bridges and should not be evaluated in MRP.

Evaluation: Determine the cross sectional area of each pipe. A table is provided listing most diameters of pipe used on the FDOT's roadways and includes a measurement to assist in determining whether a pipe is obstructed more than the desired maintenance condition. The measurement will be taken at the deepest point of obstruction within the limits of the pipe including mitered ends. The percent of open area desired for SIDE/CROSS DRAIN is listed at the top of the table. Determine the pipe diameter, select the diameter in the table and move to the right along that line until under the desired percent open area and read that figure. EXAMPLE: Given an 18 inch diameter SIDE DRAIN pipe, move to the right under $60 \%$ open area and read 10.1 inches. Measure the open area of the pipe being surveyed. If the measurement is less than the table value 10.1 inches, then less than $60 \%$ of this pipe area is open and does not meet the desired maintenance condition.

Grates on pipe end sections must be the correct size and in place to meet maintenance conditions. Grates that are broken will not meet maintenance conditions. In place is defined as properly seated in design cradle and cannot be unseated by normal pedestrian or vehicular traffic. For MRP evaluation purposes, a cross drain must have at least one end open within the sample point. 
SIDE/CROSS DRAIN \& MISC. DRAINAGE DESIRED \% OPEN

\begin{tabular}{|c|c|c|c|c|}
\hline $\begin{array}{c}\text { PIPE I.D.* } \\
\text { (Inches) }\end{array}$ & $\begin{array}{c}\mathbf{9 0 \%} \\
\text { (Inches) }\end{array}$ & $\begin{array}{c}\mathbf{8 5 \%} \\
\text { (Inches) }\end{array}$ & $\begin{array}{c}\mathbf{8 0 \%} \\
\text { (Inches) }\end{array}$ & $\begin{array}{c}\mathbf{6 0 \%} \\
\text { (Inches) }\end{array}$ \\
\hline 12 & 10.1 & 9.5 & 9.0 & 6.7 \\
\hline 15 & 12.7 & 11.9 & 11.2 & 8.4 \\
\hline 18 & 15.2 & 14.3 & 13.4 & 10.1 \\
\hline 21 & 17.7 & 16.7 & 15.7 & 11.8 \\
\hline 24 & 20.3 & 19.3 & 17.9 & 13.4 \\
\hline 27 & 22.8 & 21.4 & 20.1 & 15.1 \\
\hline 30 & 25.3 & 23.8 & 22.4 & 16.8 \\
\hline 36 & 30.4 & 28.5 & 26.9 & 20.2 \\
\hline 42 & 35.4 & 33.3 & 31.3 & 23.5 \\
\hline 48 & 40.5 & 38.1 & 35.8 & 26.9 \\
\hline 54 & 45.6 & 42.8 & 40.3 & 30.2 \\
\hline 60 & 50.6 & 47.6 & 44.8 & 33.6 \\
\hline 66 & 55.7 & 52.3 & 49.2 & 37.0 \\
\hline 72 & 60.8 & 57.1 & 53.7 & 40.3 \\
\hline
\end{tabular}

*Based on inside diameter

Side/Cross Drain does not meet MRP standards when the following exist:

1) More than $\underline{40 \%}$ of the cross sectional area of the pipe is obstructed.

2) The grates are not the correct type.

3) The grates are not the correct size.

4) The grates are broken.

5) The grates are not in place.

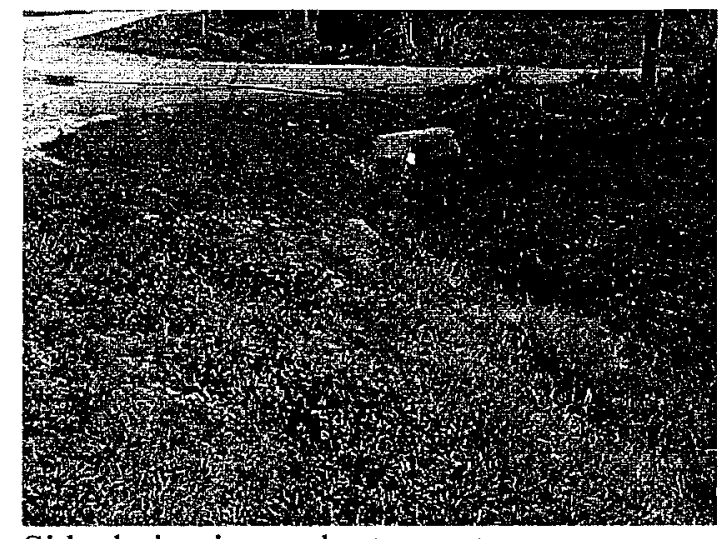

Side drain pipe under turnout.

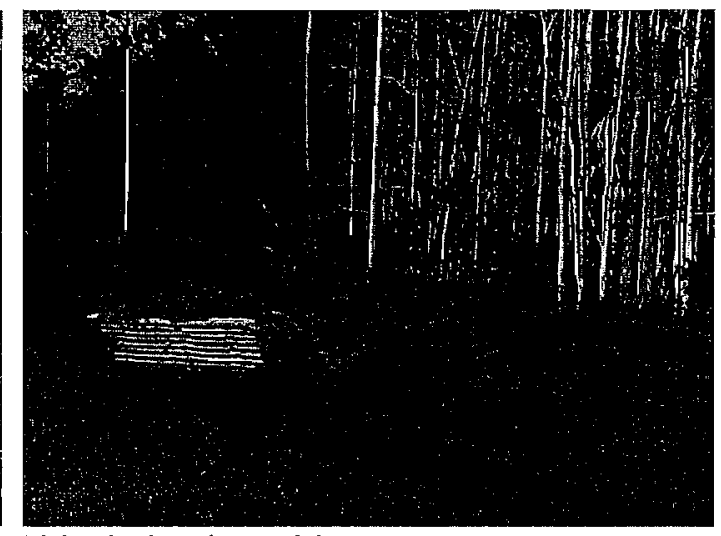

Side drain pipe with grates. 


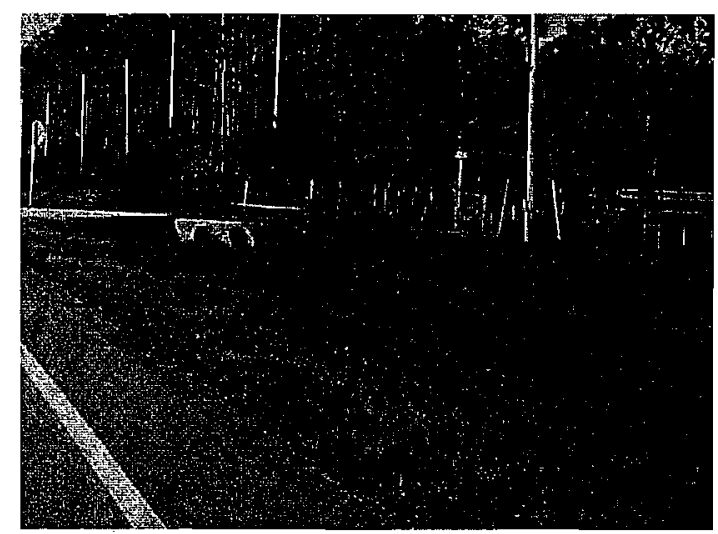

Side drain

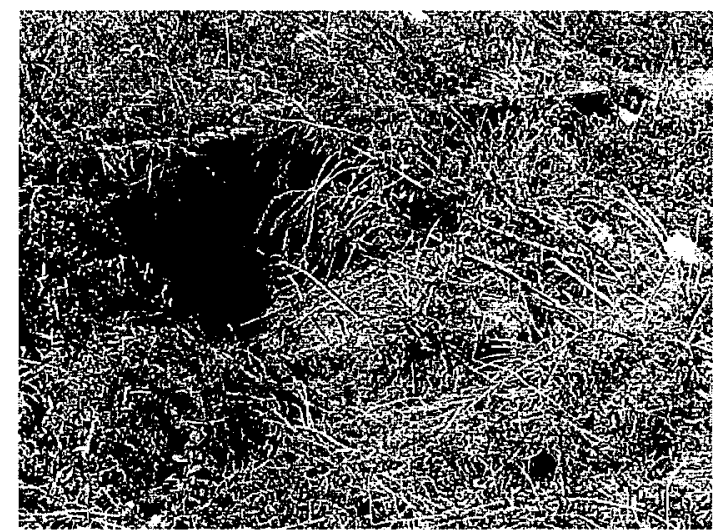

Cross drain

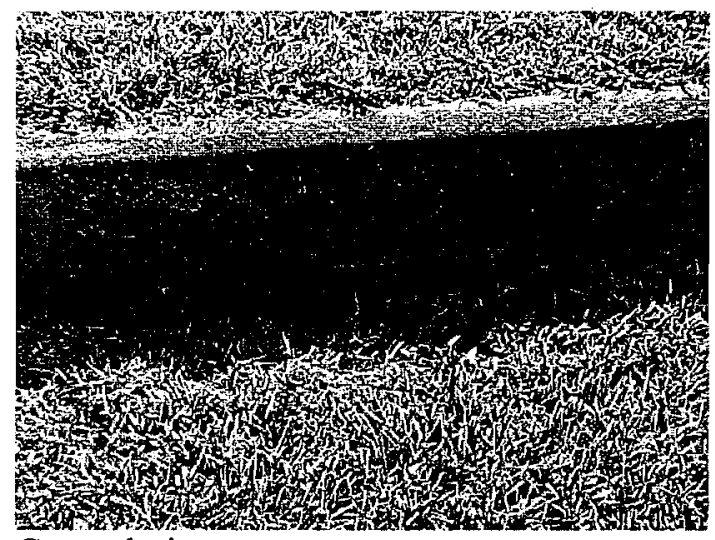

Cross drain

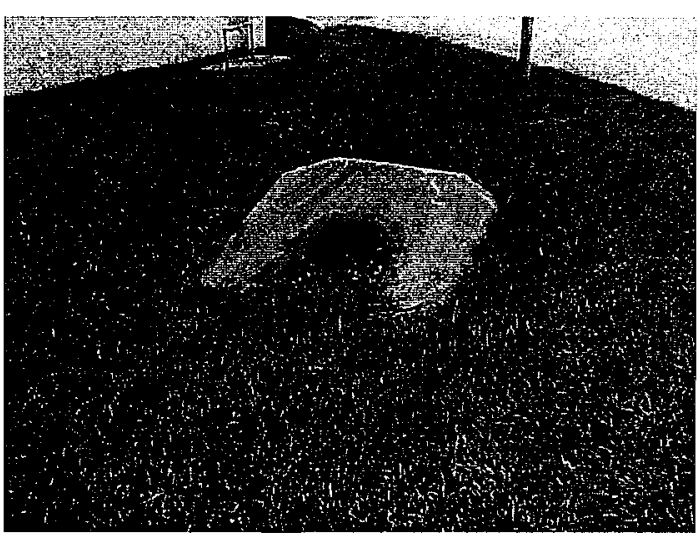

Side drain

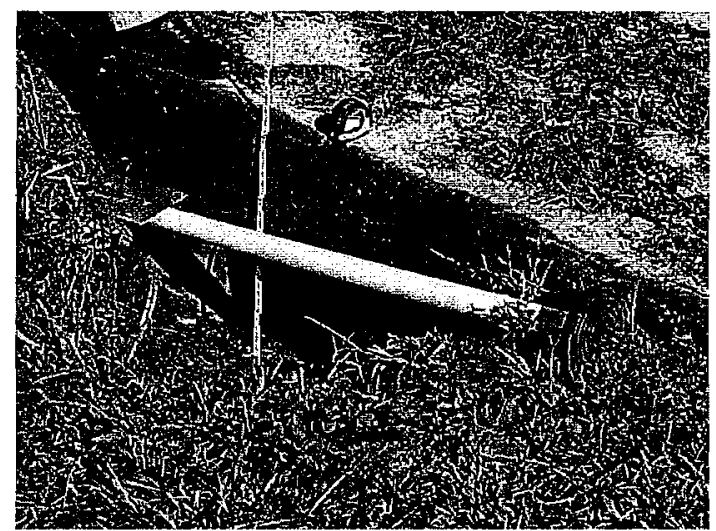

Cross drain

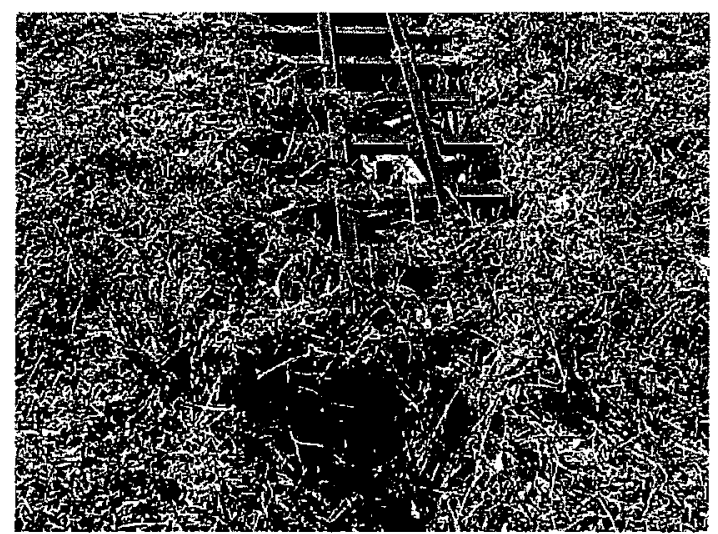

Cross drain 

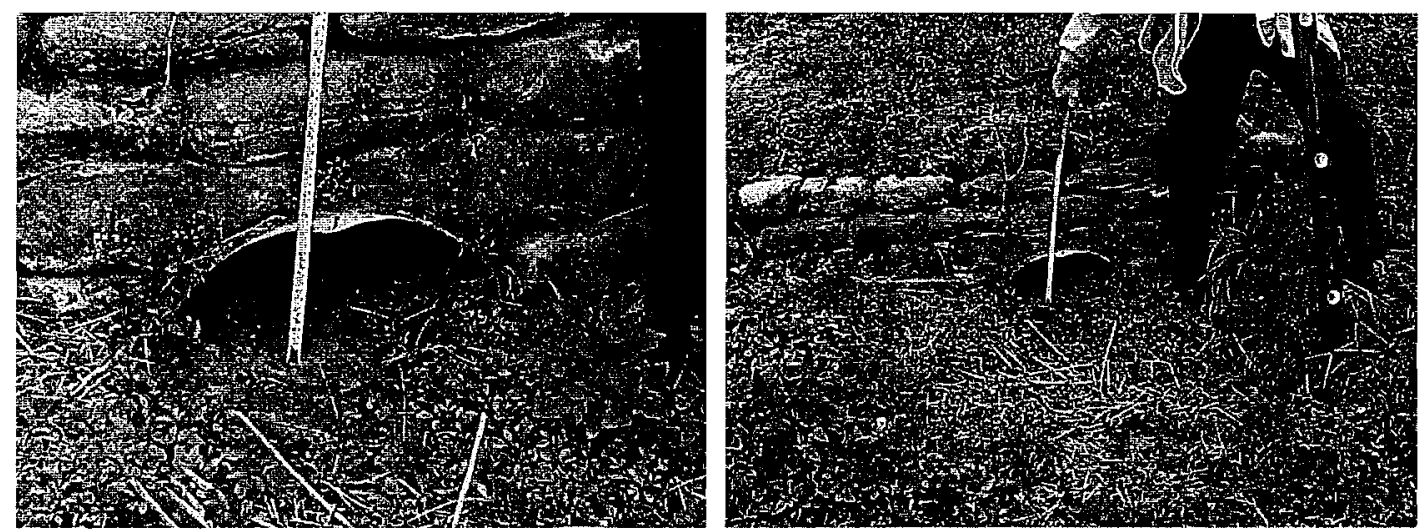

These two pictures show a typical side drain pipe in a roadside ditch. Determine the cross sectional area of the pipe that is not obstructed and functions as intended. If more than $40 \%$ of the pipe cross sectional area is obstructed or does not function as intended, then CROSS/SIDE DRAIN does not meet desired maintenance conditions.

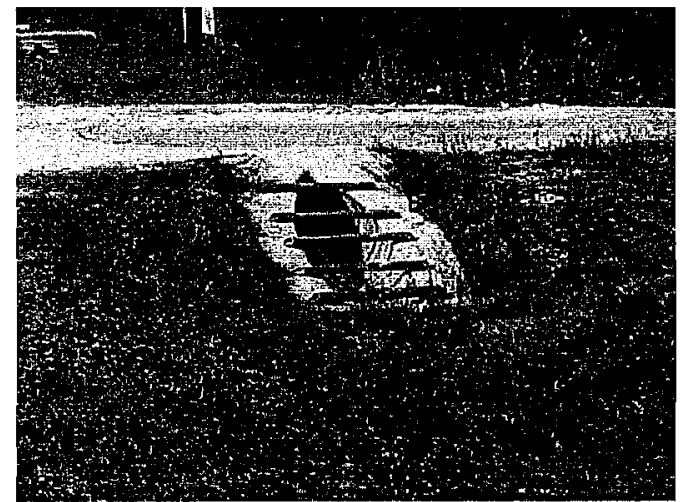

This is a side drain pipe with grates. This meets desired maintenance conditions

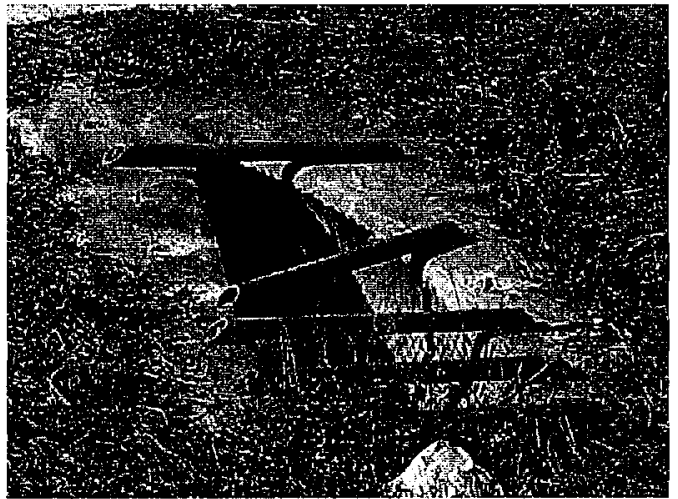

This is a side drain pipe with missing and damaged grates. This does not meet desired maintenance conditions. 
ROADSIDE /MEDIAN DITCH:
The ditch bottom elevation shall not vary from the ditch design elevation more than $1 / 4$ of the difference between the edge of pavement elevation and the ditch design elevation.

Roadside/Median Ditch (Non-Paved) - In general, a standard roadside ditch (not to include ditch paving) is designed to a minimum depth below the roadway; although, there will occur special ditches or exceptions on some older roadways. A roadside ditch must have a front slope and at least a 6 inch back slope to be considered a ditch. Some roadside canals serve as roadside ditches and have a flat berm on one or both sides. For purposes of this survey, these flat areas will be considered to be front/back slopes. Generally, if the side drain or cross drain does not meet desired maintenance conditions due to siltation buildup, then the ditch will also not meet desired maintenance conditions.

Evaluation: Determine if the ditch has a front slope and at least a 6 inch back slope. If it does, then you would rate the sample for roadside/median ditch. Observation of the ditches throughout the section should provide insight as to the original design of the ditches. If all ditches are the same elevation and provide proper drainage, then they are probably functioning as intended. A check of construction plans will provide an answer when a field determination is not possible. The elevation of the outside edge of roadway (not paved shoulder) will be used to determine the depth of the ditch. A surveyor's handheld level and folding rule or string line level can be used to make measurements along the sample. The construction plans or structures in and adjacent to the ditch can be used to determine the design flow line.

Roadside/Median Ditch does not meet MRP standards when any of the following exist:

1) The ditch bottom elevation varies more than $1 / 4$ of the difference between the edge of pavement elevation and the ditch design elevation.

2) There are erosions, washouts, or buildups that adversely affect the flow of water.

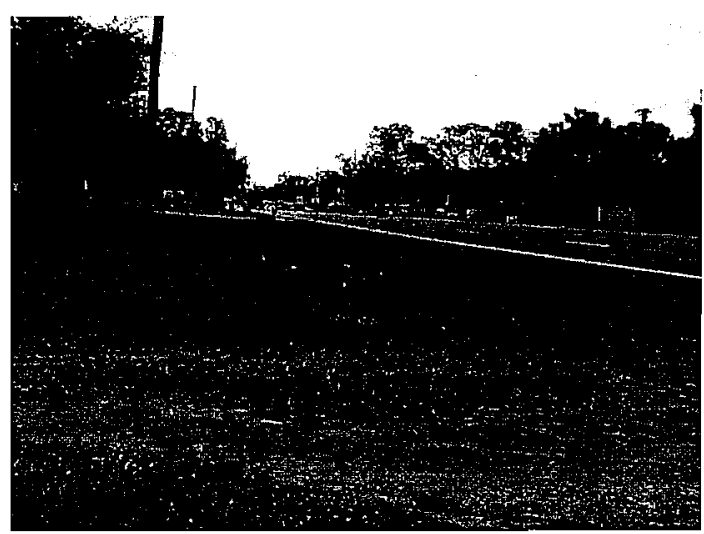

Roadside ditch 
OUTFALL DITCH:

The ditch bottom elevation shall not vary from the ditch design elevation more than $1 / 3$ of the difference between natural ground and the design flow line. Only those areas listed in the RCI as outfall will be evaluated.

Outfall Ditch - Initial observation of the ditch system, as a whole, can provide an answer as to whether actual measurements of the ditch bottom elevation shall be made. If the ditch grade appears to be higher than constructed, then actual measurements should be made. Structures included in and adjacent to the ditch or construction plans can be used to determine design flow line. After determination of designed ditch elevation, a distance from that elevation to natural ground can be calculated. If any part of the existing ditch grade is above the bottom of the calculated distance, then this characteristic does not meet the desired maintenance condition.

Evaluation: Piped outfall ditches will be evaluated using the SIDE/CROSS DRAIN characteristic. The " $60 \%$ of the cross sectional area shall be unobstructed" criteria will apply. Paved outfall ditches will be evaluated using the criteria from "miscellaneous drainage structure" (rate as outfall only).

Outfall Ditch does not meet MRP standards when any of the following exist:

1) The ditch bottom elevation varies more than $\underline{1 / 3}$ of the difference between natural ground and the design flow line.

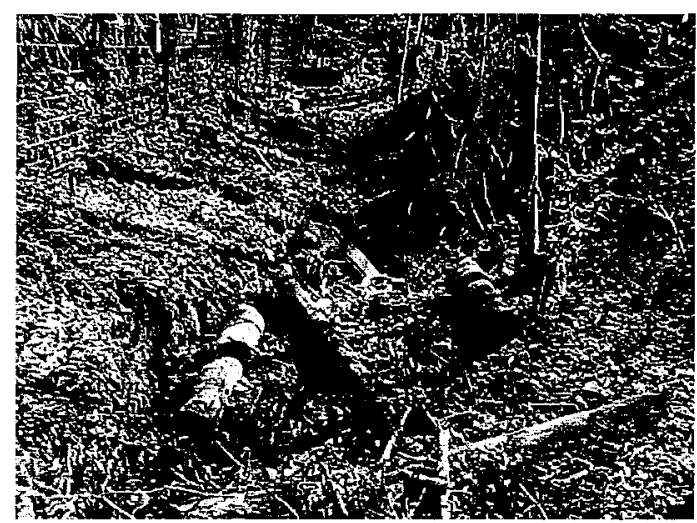

If the ditch bottom elevation of an outfall ditch is more than $1 / 3$ of the difference between natural ground and the design flow line the outfall ditch does not meet MRP standards.

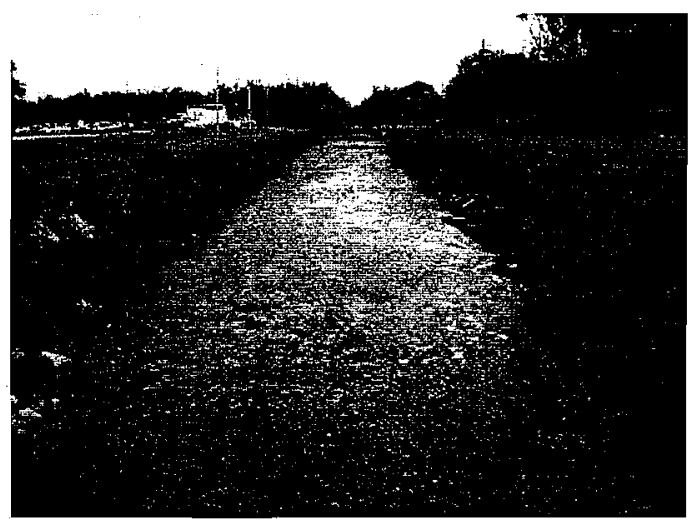

This outfall ditch appears to meet MRP standards. 
INLETS:

$85 \%$ of the opening area is not obstructed.

Inlets - This characteristic includes all inlets and enclosed junction boxes (manholes). Inlets may be found in curbs, ditches with or without ditch paving, in valley gutters and at other locations that are designed to collect water runoff.

Evaluation: Measure the opening to determine the area. When any inlet structure is unslotted then the grate is the collection area to be measured. Grates must be the correct size and in place to meet maintenance conditions. Grates that are broken will not meet conditions. In place is defined as properly seated in design cradle and cannot be unseated by normal pedestrian or vehicular traffic.

Manhole lids are required to be fastened by an acceptable method except for the Standard 212\# lid. The Standard 212\#, or similar, lid does not require fastening. Inlets with exposed steel, or surface damage $1 / 2$ square foot or more, or any deformation of the inlet that creates a hazard, will also cause this characteristic not to meet desired conditions.

Gutter grates or gutter cover plates on slotted curb inlets are installed as cleaning or maintenance access and are not to be considered as part of the opening area.

Refer to the Standard Indices to determine if the area around the inlet was designed as part of the inlet. If it was, then include it with the inlet evaluation, not as miscellaneous drainage.

\section{Inlets do not meet MRP standards when any of the following exist:}

1) More than $15 \%$ of the opening area is obstructed.

2) The grate is broken.

3) Grates are not the correct size and are not in place.

4) Manhole lids are not fastened by an acceptable method.

5) Exposed steel or any deformation of the inlet that creates a hazard.

6) Surface damage $1 / 2$ square foot or more. 


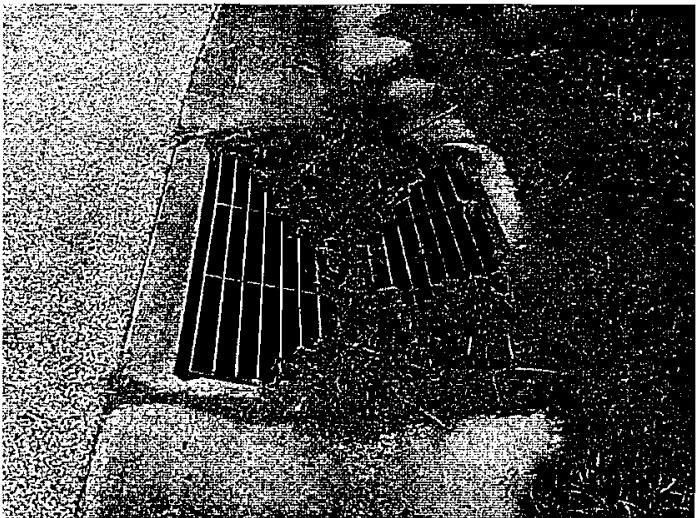

Grass covering inlet grate. Determine the percentage of opening area obstructed. If more than the standard, it would not meet desired maintenance conditions.

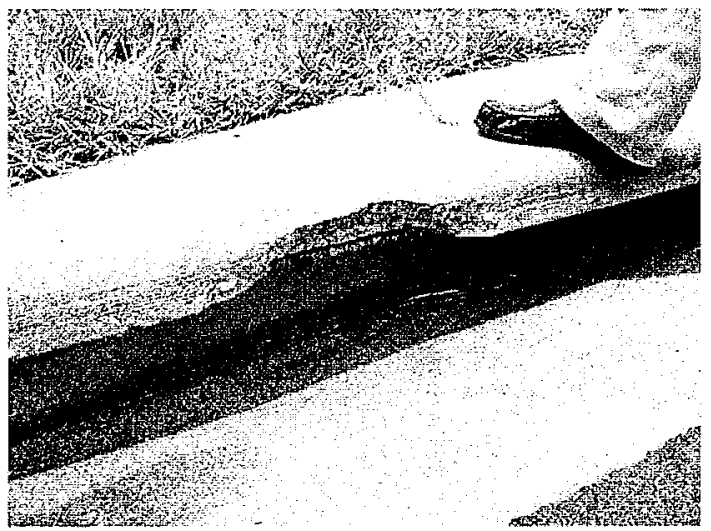

Exposed steel in this curb inlet. This does not meet MRP conditions for INLETS.

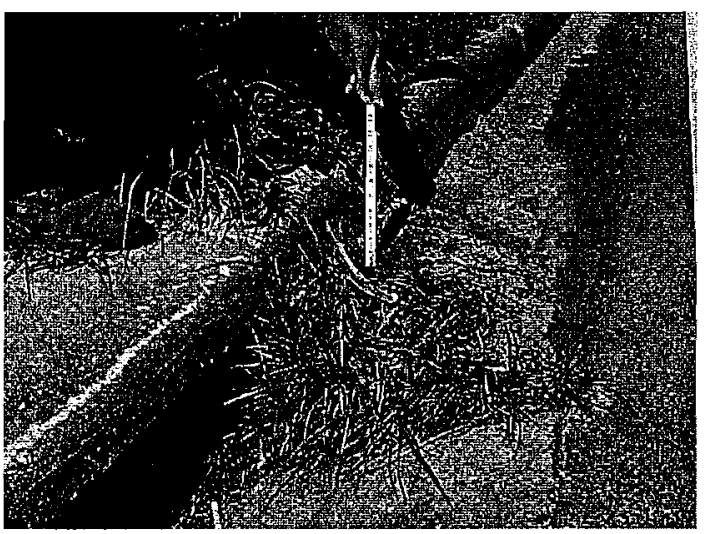

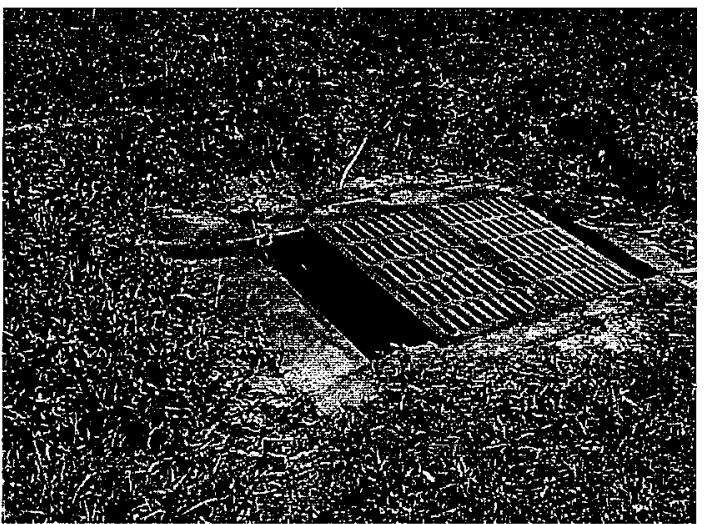

Ditch bottom inlet in good condition. This meets desired maintenance conditions.

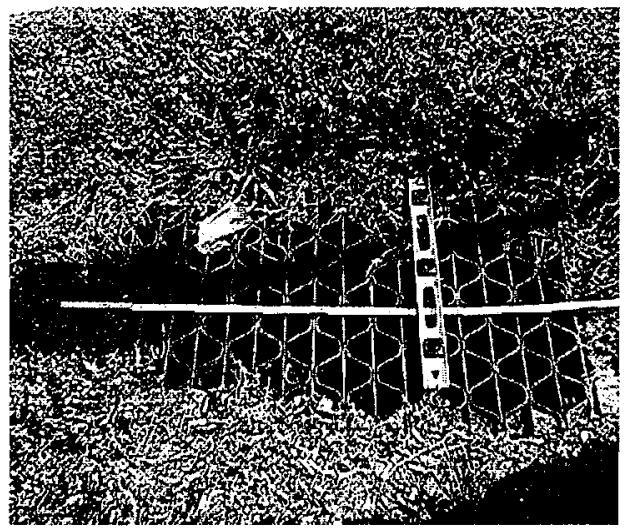

This is an obstructed inlet grate. If the Opening is obstructed more than the MRP standard, then it would not meet desired MRP conditions for INLETS.

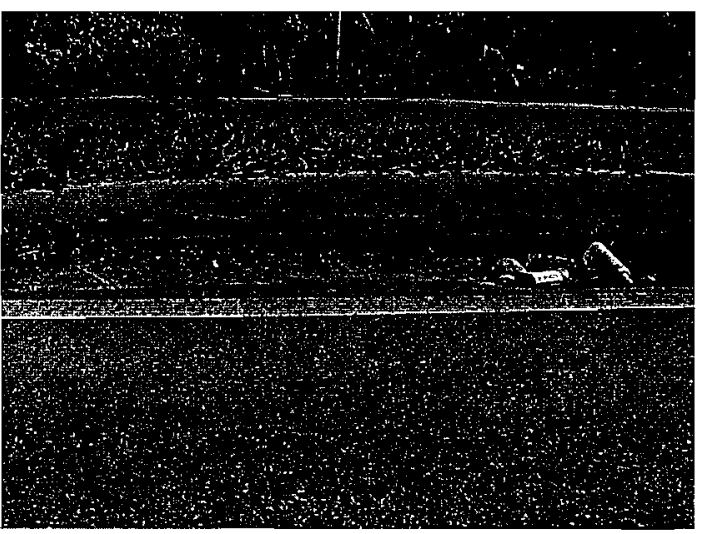

Soil buildup at curb inlet. Determine the percentage of opening area obstructed and compare to the standard. 


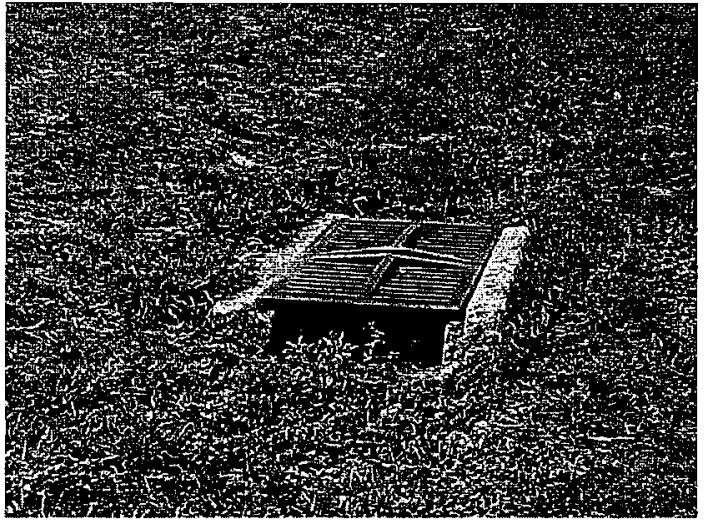

These inlet grates are installed backwards. This would not meet MRP standards.

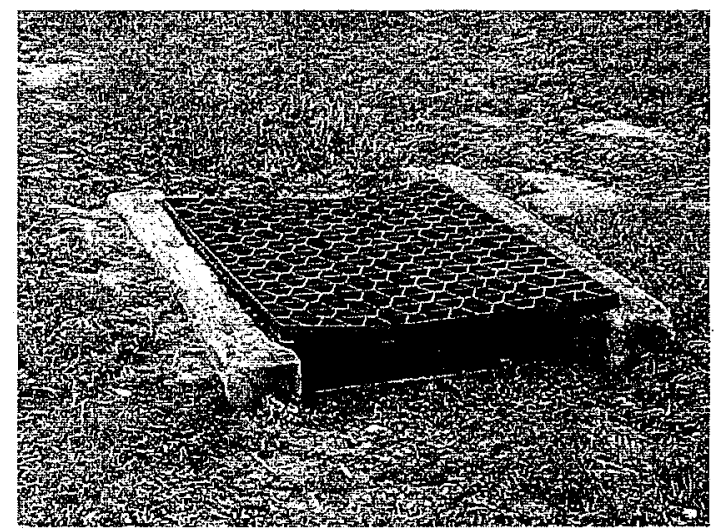

This grate is not seated correctly in the design cradle. This does not meet MRP standards.

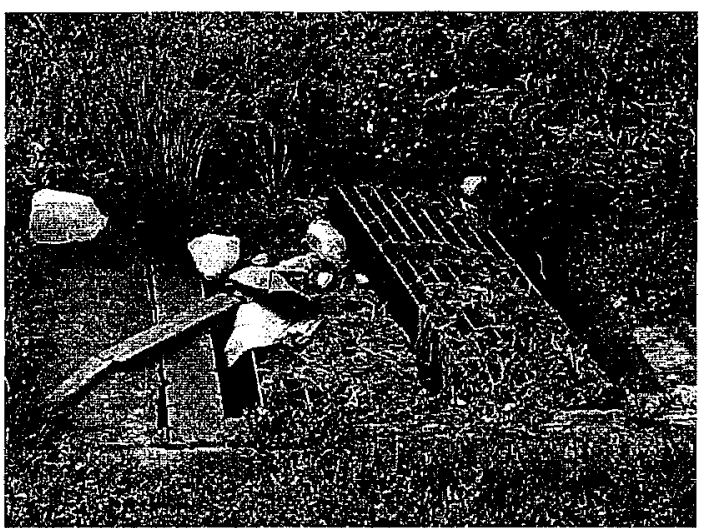

Grate out of cradle. Does not meet MRP standards.

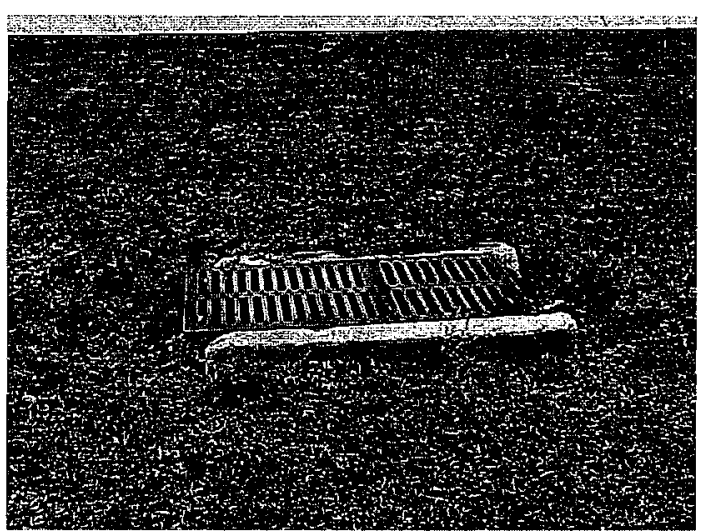

The grate on the left is the wrong size. This would not meet MRP standards.

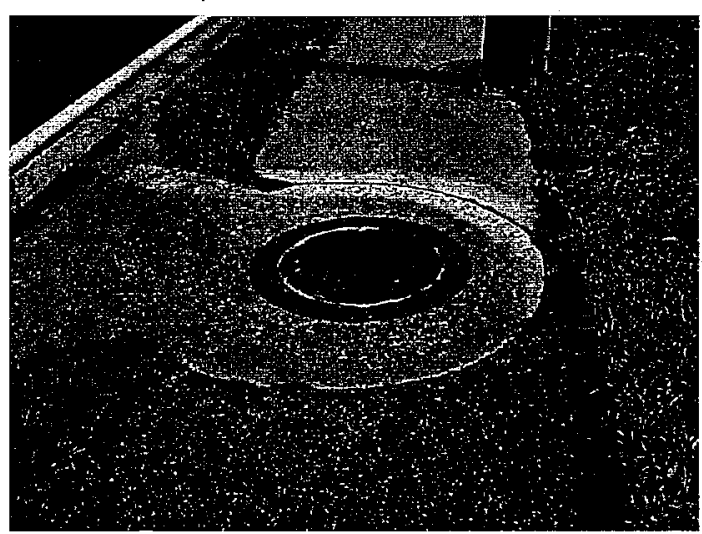

This manhole lid is seated correctly in the design cradle. This meets MRP standards.

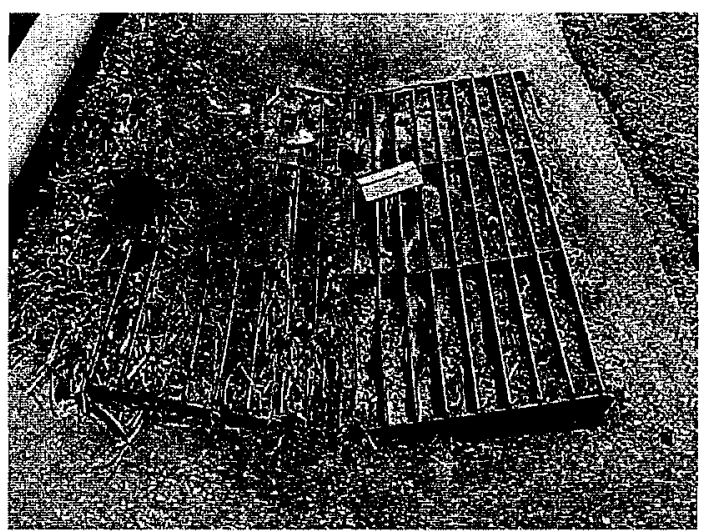

Blocked inlet. Does not meet MRP standards. 

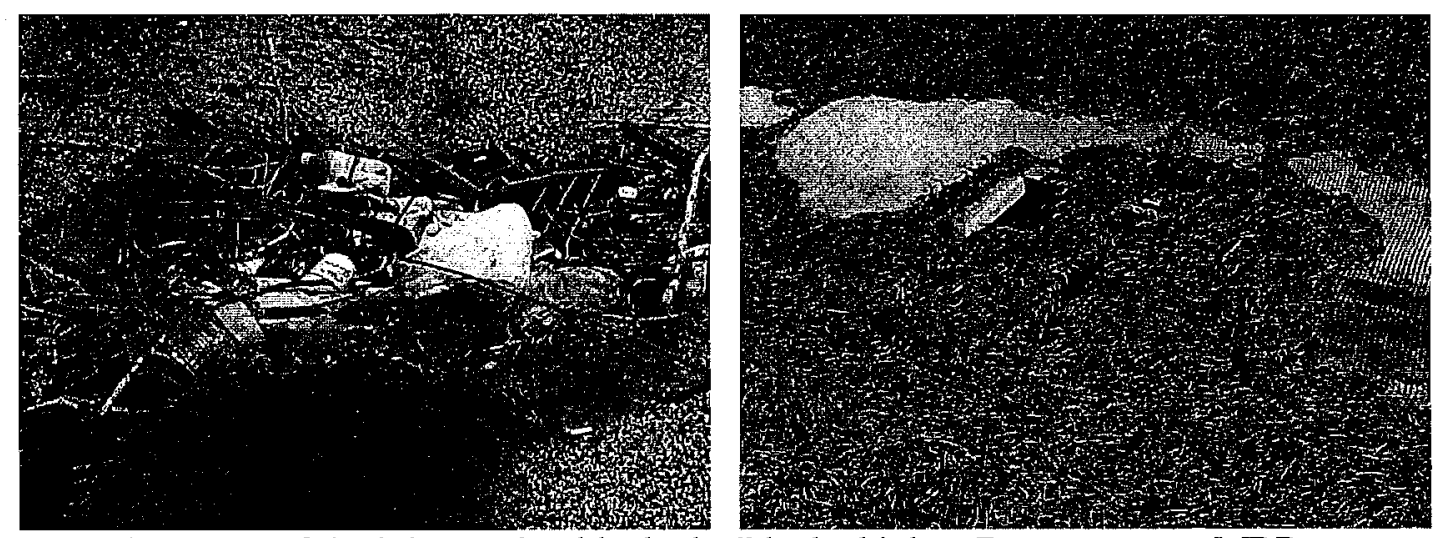

More than $15 \%$ of the inlet grating blocked. Blocked inlet. Does not meet MRP Does not meet MRP standards. standards. 


\section{MISCELLANEOUS DRAINAGE}

STRUCTURE: $\quad \underline{90 \%}$ of each structure functions as intended.

Miscellaneous Drainage Structure - This characteristic includes ditch paving, shoulder gutters, flumes, valley gutters (36 inches or greater), spillways, trench drains, French drains, edge drains, piped slope drains and other miscellaneous drainage structures that are used to enhance or control the flow of runoff or storm drain water, but does not include curb and gutter, retention/detention ponds or siltation devices. Any grates encountered on miscellaneous drainage structures or manhole covers will be rated under the inlet characteristic. A piped slope drain that is connected to a side/cross drain is evaluated as side/cross drain. U-type end walls are not to be evaluated as miscellaneous drainage unless they have baffles or some installed method of slowing the water velocity.

Edge drains shall have galvanized hardware cloth installed according to Index 287.

All miscellaneous drainage and inlets that are in RCI will be evaluated. This could involve locations outside the normal right-of-way limits.

Evaluation: To meet the desired maintenance condition, each structure must function at no less than $90 \%$ ( $90 \%$ of the length and $90 \%$ of the depth). The miscellaneous drainage structure does not meet desired conditions, when it has deteriorations, erosions, washouts or buildups which adversely affect the natural flow of water.

Siltation or other debris built up in shoulder gutter (less than 36 inches in width) shall be evaluated under roadway sweeping.

Miscellaneous drainage structures do not meet MRP standards when any of the following exist:

1) More than $10 \%$ of the structure (length and depth) does not function as intended.

2) There is edge drain with no hardware cloth on the end of the pipe.

3) Deteriorations, erosions, washouts or buildups adversely affect the natural flow of water. 


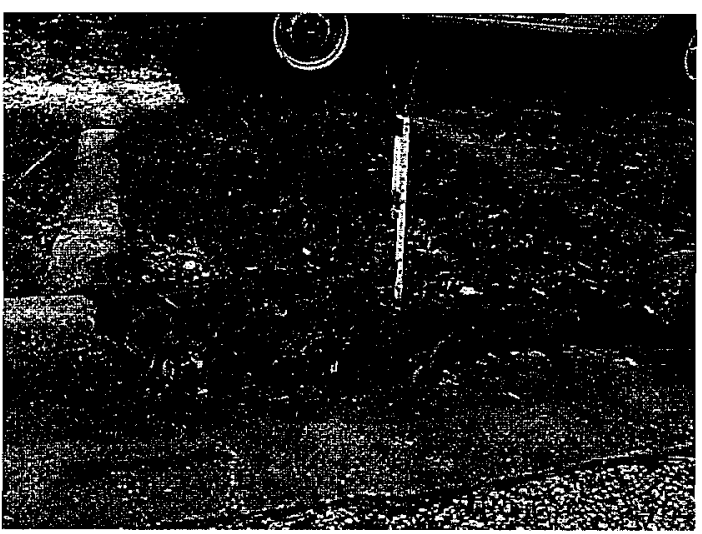

Soil buildup in a miscellaneous drainage structure. This does not meet desired MRP conditions for miscellaneous drainage.

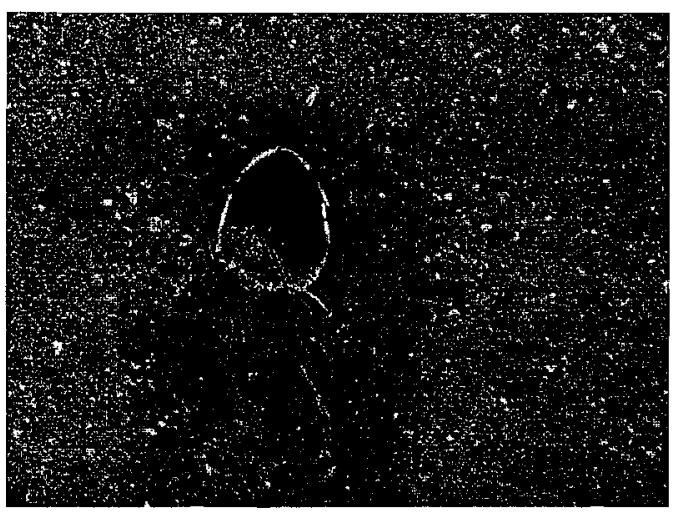

These pictures are of edge drains. The edge drain hardware cloth must be in place and functioning as intended to meet MRP conditions. These edge drains do not meet MRP conditions.

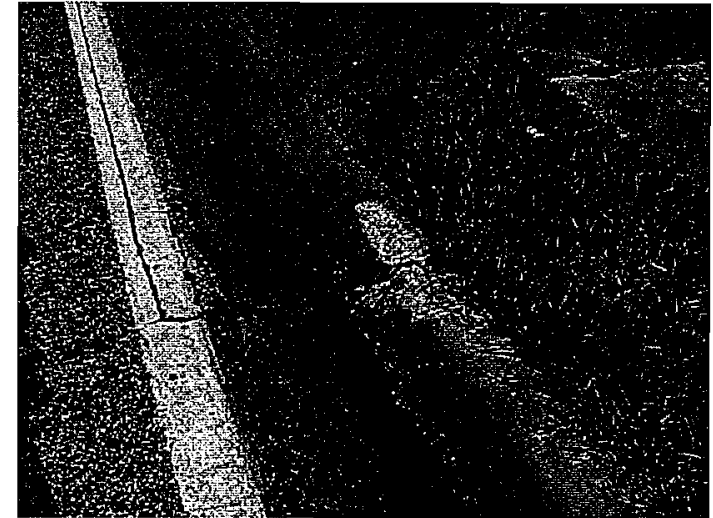

This type ' $F$ ' curb has been damaged. For MRP purposes, type ' $F$ ' curb is not evaluated. This is not rated in MRP.

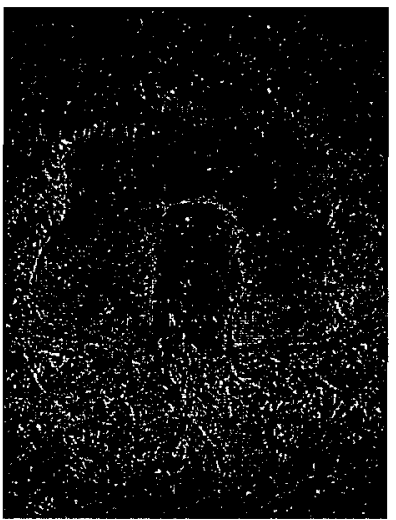


ROADWAY SWEEPING: Material accumulation is not greater than $\underline{3 / 4 \text { inch deep for }}$ more than 1 continuous foot in the travel way or shall not exceed 2-1/4 inches in depth for more than 1 continuous foot in any gutter.

Roadway Sweeping - This characteristic applies to: all urban limited access roadways and paved shoulders on urban limited access roadways. It also applies to all curb and gutter, shoulder gutter, barrier wall and intersections of State Roads.

Do not rate curb inlet throats for sweeping.

In areas with curb and gutter and sidewalk, rate sweeping around the returns to the back of the sidewalk. In areas with curb and gutter and no sidewalk, do not rate sweeping around the returns.

Items evaluated as litter will not be included in the sweeping evaluation.

Evaluation: Review urban limited access roadways, and paved shoulders on urban limited access roadways, all curb and gutter, all shoulder gutter, all barrier wall and all intersections of State Roads to determine the debris buildup. Measure the depth and length of any buildup. If the debris buildup is more than allowed by the standard, it does not meet desired maintenance conditions.

\section{Roadway Sweeping does not meet MRP standards when any of the following exist:}

1) The accumulation of material is greater than $\underline{3 / 4 \text { inch deep for more than } 1}$ continuous foot in the travel way.

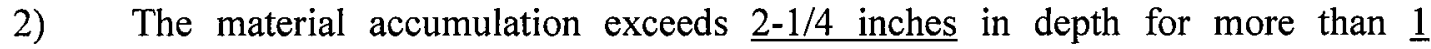
continuous foot in any gutter.

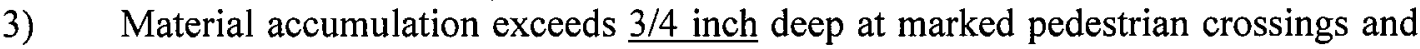
curb ramps.
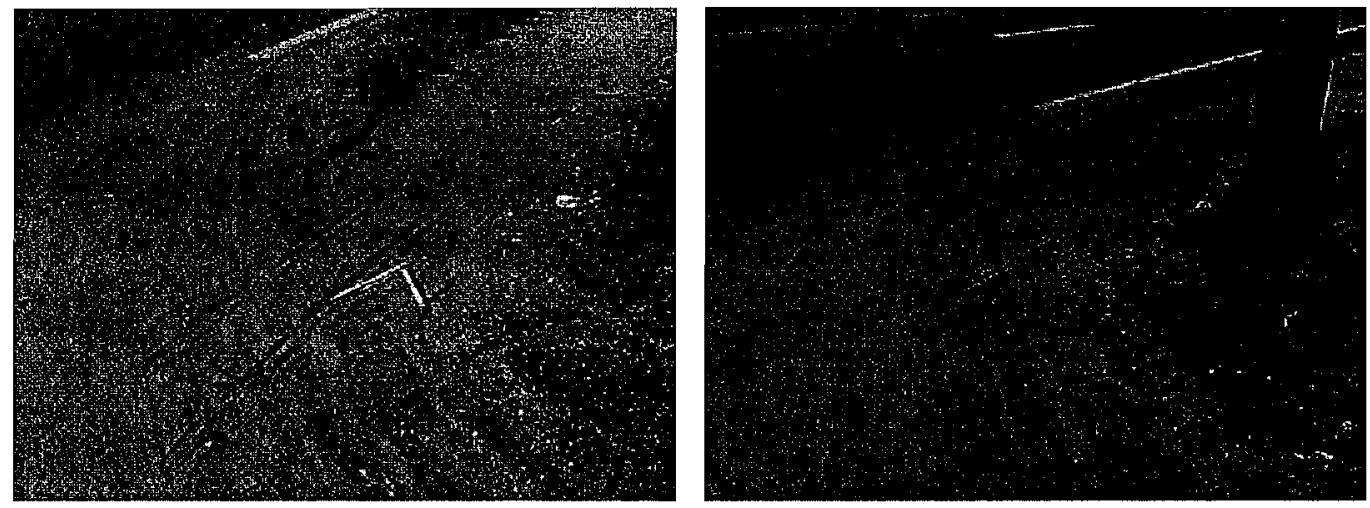

These pictures show an example of sand buildup in an area with curb and gutter and sidewalk. Sweeping should be rated around the returns to the back of the sidewalk. 


\section{FLORIDA DEPARTMENT OF TRANSPORTATION \\ MAINTENANCE RATING PROGRAM STANDARDS}

VEGETATION AND AESTHETICS

\section{THE FOLLOWING CHARACTERISTICS MEET THE DESIRED MAINTENANCE CONDITIONS WHEN:}

ROADSIDE MOWING: Not more than $1 \%$ of vegetation exceeds (varies) inches high. This excludes allowable seed stalks and decorative flowers allowed to remain for aesthetics.

$\begin{array}{ll}\text { RURAL LIMITED ACCESS } & \frac{5 \text { inches }-18 \text { inches }}{5 \text { inches }-12 \text { inches }} \\ \text { RURAL ARTERIAL } & \underline{5 \text { inches }-12 \text { inches }} \\ \text { URBAN LIMITED ACCESS } & \underline{9 \text { inches maximum }} \\ \text { URBAN ARTERIAL } & \end{array}$

SLOPE MOWING: $\quad$ Not more than $2 \%$ of vegetation exceeds 24 inches high. This excludes allowable seed stalks and decorative flowers allowed to remain for aesthetics. The area shall be evaluated in accordance with the mowing guide as a minimum.

LANDSCAPING: Vegetation is maintained in a healthy, attractive condition.

TREE TRIMMING: There is no encroachment of trees, tree limbs or vegetation in or over travel way or clear zone, lower than 14-1/2 feet or lower than 10 feet over sidewalks. There shall be no vegetation that violates the horizontal clearance as defined by this standard.

CURB/SIDEWALK EDGE:

There is no encroachment of vegetation or debris onto the curb or sidewalk for more than $\underline{6 \text { inches for more than } \underline{10}}$ continuous feet.

No deviation of soil of more than $\underline{4}$ inches above or $\underline{2}$ inches below the top of curb or sidewalk for more than 10 continuous feet.

LITTER REMOVAL: The volume of litter does not exceed $\underline{3 \text { cubic feet per } 1 \text { acre }}$ excluding all travel way pavement.

TURF CONDITION: Turf in the mowing area is $\underline{75 \%}$ free of undesired vegetation. 


\section{VEGETATION AND AESTHETICS}

ROADSIDE MOWING: Not more than $1 \%$ of vegetation exceeds (varies) inches high. This excludes allowable seed stalks and decorative flowers allowed to remain for aesthetics.

\begin{tabular}{c} 
FACILITY TYPE \\
\hline 1 \\
2 \\
3 \\
4
\end{tabular}

\section{CLASSIFICATION}

Rural Limited Access

Rural Arterial

Urban Limited Access

Urban Arterial
DESIRED HEIGHT

5 inches -18 inches

5 inches -12 inches

5 inches -12 inches

9 inches maximum

Roadside Mowing - This characteristic is the control of planted or natural grasses and vegetation for protection of soil shoulders and slopes, safety and aesthetics purposes.

Evaluation: Determine the mowing area in the sample point. Measurements with a rule or stick marked at the appropriate heights should be made throughout the sample. Determine the area of the vegetation that does not meet the standards. If more than $1 \%$ of vegetation, EXCLUDING allowable seed stalks and decorative flowers which have been allowed to remain for aesthetics, exceeds the appropriate measurement as listed in the standard, then this characteristic does not meet the desired maintenance condition. Allowable is defined as any vegetation not listed as undesirable in turf condition standard. Except for turf mowed by adjoining property owner, turf mowed at less than 5 inches on Facility Types 1,2 and 3 does not meet desired maintenance conditions.

Do not evaluate mowing areas where wet conditions prevent mowing.

Calculate the percentage of vegetation that does not meet the standard by dividing the area of vegetation that does not meet the standards by the total mowing area in the sample and multiplying by 100 .

Roadside Mowing does not meet MRP standards when any of the following exist:

1) More than $1 \%$ of the vegetation varies from the standard height.

2) The turf is mowed less than $\underline{5}$ inches on facility types 1,2 and 3, except turf mowed by adjoining property owner. 


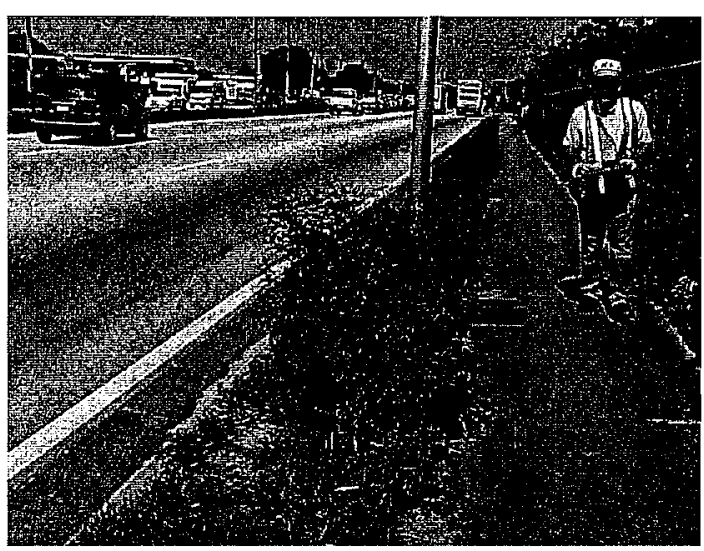

This is a Facility Type 4 (Urban Arterial). The desired roadside mowing height is 9 inches maximum. If the height of vegetation exceeds 9 inches, calculate the area. If more than $1 \%$ of the vegetation is over 9 inches high, then this would not meet desired maintenance conditions for Roadside Mowing. 
SLOPE MOWING:

Not more than $2 \%$ of vegetation is less than 5 inches or more than 24 inches in height. This excludes allowable seed stalks and decorative flowers allowed to remain for aesthetics. The area shall be maintained in accordance with the mowing guide.

Slope Mowing - This characteristic is the control of planted or natural grasses and vegetation for protection of soil slopes, safety and aesthetic purposes.

Evaluation: Only evaluate the slope mowing areas as shown in the FDOT Guide to Roadside Mowing. Measurements should be made throughout the sample. Slope mowing shall not be evaluated if vegetation has been planted to eliminate the need for slope mowing. Allowable is defined as any vegetation not listed as undesirable in turf condition standard. Except for turf mowed by adjoining property owner, turf mowed at less than 5 inches, on all facility types does not meet desired maintenance conditions.

Determine the slope mowing area in the sample point. Calculate the area of vegetation that does not meet the standard. Determine the percentage of vegetation that does not meet the standard by dividing the area of vegetation that does not meet standards by the total slope mowing area in the sample and multiplying by 100 .

Slope Mowing does not meet MRP standards when the following exist:

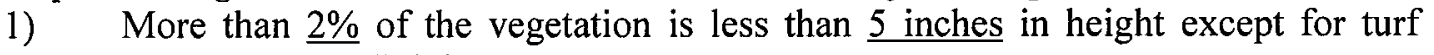
mowed by an adjoining property owner.

2) More than $\underline{2 \%}$ of the vegetation is more than 24 inches in height, except allowable seed stalks and decorative flowers allowed to remain for aesthetics. 
Figure 5

Slope mowing limits:

Rural arterial and all limited access

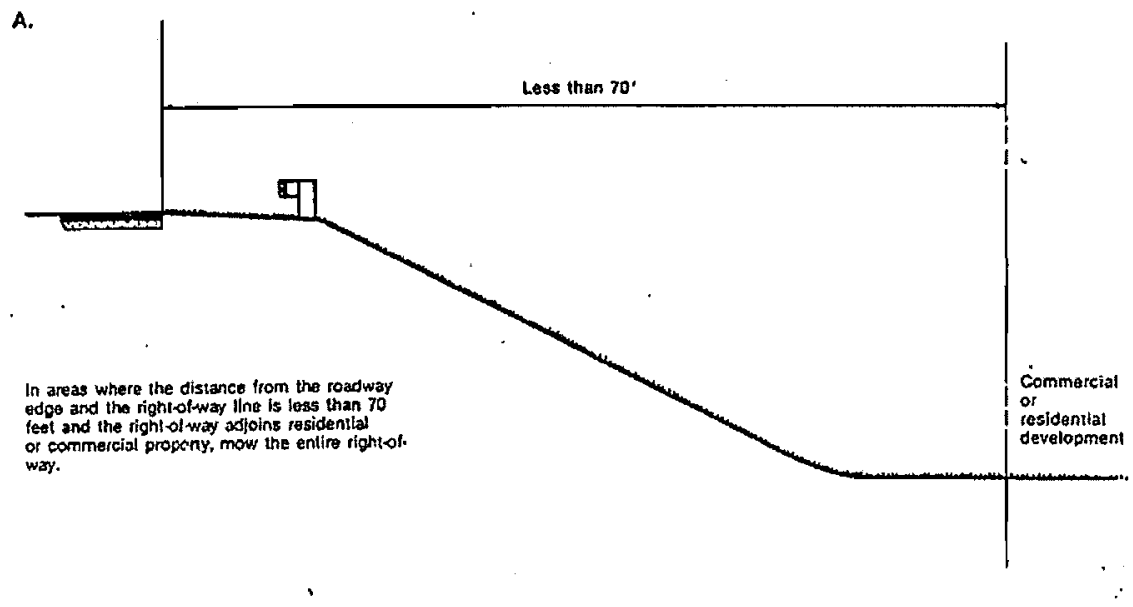

B.

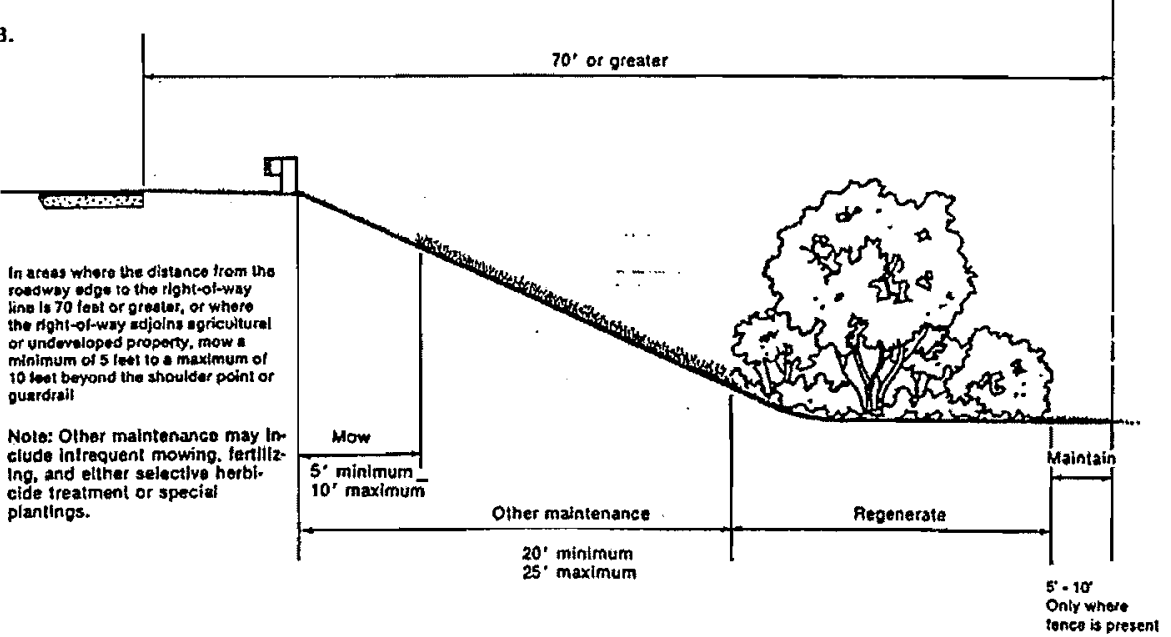


LANDSCAPING: Vegetation is maintained in a healthy, attractive condition.

Landscaping - Landscaping is defined as those areas that have been changed by the placing of ornamental bushes, shrubs, flowers or plants that require maintenance such as weeding, mulching, trimming, pruning, replacing, fertilizing, insect spraying or edging.

Evaluation: Inspect the landscaped areas. Determine if the plants are being maintained in a healthy attractive condition. Landscaped areas that appear unhealthy or unattractive due to apparent lack of maintenance (presence of weeds, dead or dying plants or overgrown appearance) cause this characteristic not to meet the desired maintenance condition. For MRP purposes, the presence of weeds in more than $10 \%$ of the landscaped area is considered undesirable. Only those areas listed in the RCI as landscaping will be evaluated.

\section{Landscaping does not meet MRP standards when any of the following exist:}

1) If more than $10 \%$ of the landscaping areas appear unhealthy or unattractive due to the apparent lack of maintenance (presence of weeds, dead or dying plants or overgrown appearance).

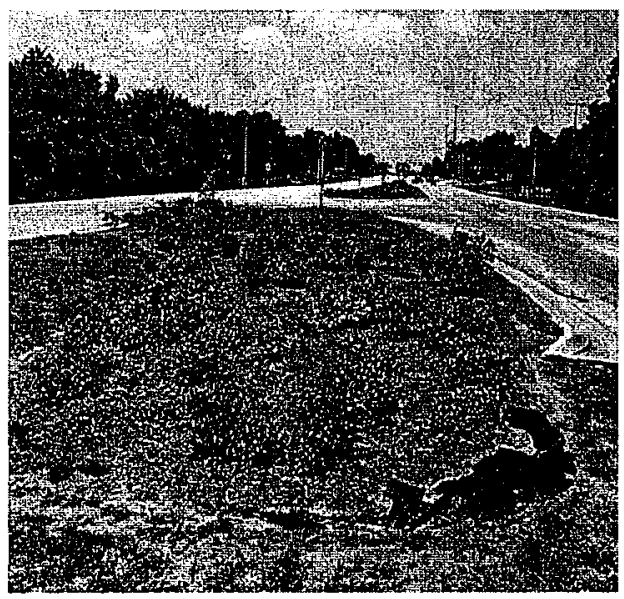

This is an example of landscaping that does not meet desired maintenance conditions. 
TREE TRIMMING: $\quad$ There is no encroachment of trees, tree limbs or vegetation lower than 14-1/2 feet onto or beyond the shoulder point, face of curb, face of guardrail or back of shoulder gutter. There is no encroachment of trees, tree limbs or vegetation lower than 10 feet over sidewalk. There shall be no vegetation that violates the horizontal clearance (clear zone).

Note: For MRP purposes the tree trimming clear zone on limited access facilities is 36 feet (see index 700).

Tree Trimming - This characteristic is the encroachment control of trees, tree limbs or brush within the right-of-way.

Evaluation: All samples are to be evaluated for tree trimming.

Dead or dying trees within the right-of-way that could fall in the clear zone or present a hazard to vehicles, adjacent property owners or pedestrians does not meet desired conditions.

For MRP purposes, trees to be evaluated should have a diameter greater than 4 inches as measured 6 inches above the ground. Also evaluated for tree trimming, are tree limbs

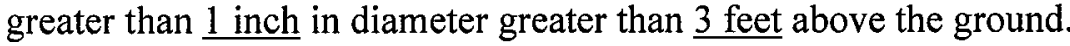

In areas with curb and gutter, there should be no vegetation over the roadway lower than 14-1/2 feet from the face of curb to the face of curb.

In areas without curb and gutter, there should be no vegetation over the roadway and shoulder lower than 14-1/2 feet.

In cases where guardrail is present, there should be no vegetation over the roadway and shoulder lower than 14-1/2 feet from the face of guardrail. See detail on page 98 .

In areas with sidewalk, there should be no encroachment of trees, tree limbs or vegetation over the sidewalk lower than 10 feet.

In an area with a bike path, there should be no encroachment of trees, tree limbs or vegetation over the bike path lower than 10 feet. 
Tree trimming does not meet MRP standards when any of the following exist:

1) In curb and gutter areas, vegetation is lower than $14-1 / 2$ feet over the roadway from the face of curb to the face of curb.

2) In areas without curb and gutter, vegetation over the roadway and shoulder is lower than 14.5 feet.

3) In areas with guardrail, vegetation over the roadway and shoulder is lower than 14.5 feet from face of guardrail.

4) Vegetation encroachment of trees, tree limbs or vegetation over the sidewalk is lower than 10 feet.

5) Dead or dying trees within the right-of-way that could fall in the clear zone or present a hazard to vehicles, adjacent property owners or pedestrians.

6) Trees and/or vegetation that obscure the message of a sign.

7) Encroachment of trees, tree limbs or vegetation over a bike path lower than 10 feet.
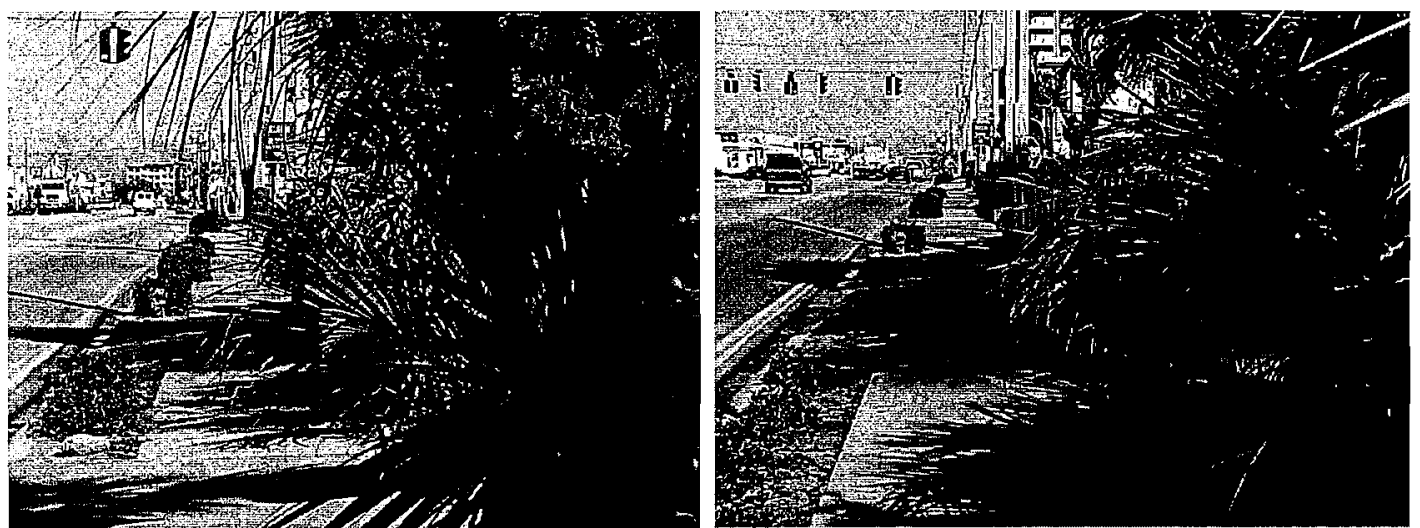

These pictures are examples of vegetation growing over the sidewalk. This obstructs the use of the sidewalk by pedestrians. If there is encroachment of trees, tree limbs or vegetation onto the sidewalk, it does not meet MRP conditions.

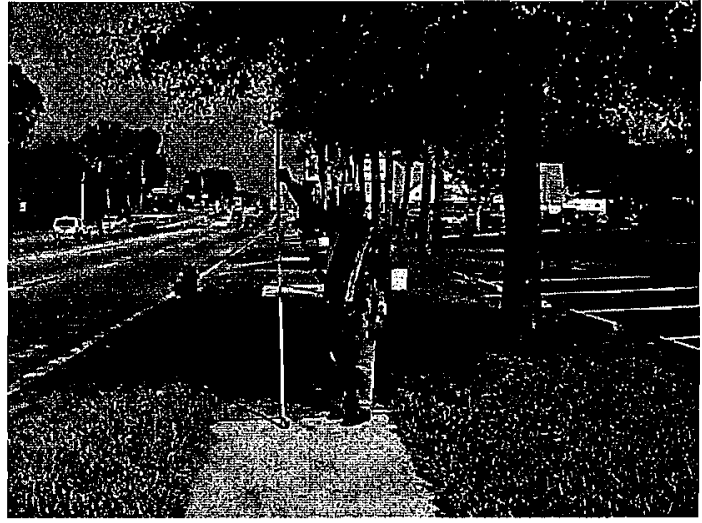

Trees, tree limbs or vegetation should be no lower than 10 feet over sidewalk. This does not meet desired maintenance conditions.

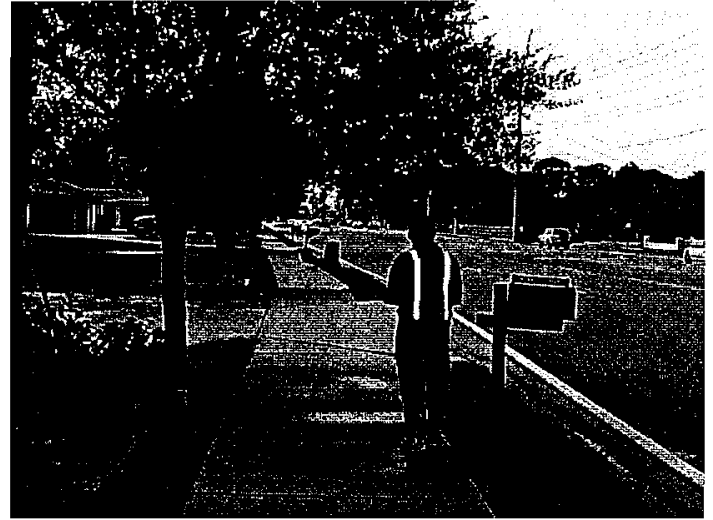

This tree limb appears lower than 10 feet over the sidewalk. This would not meet desired maintenance conditions. 

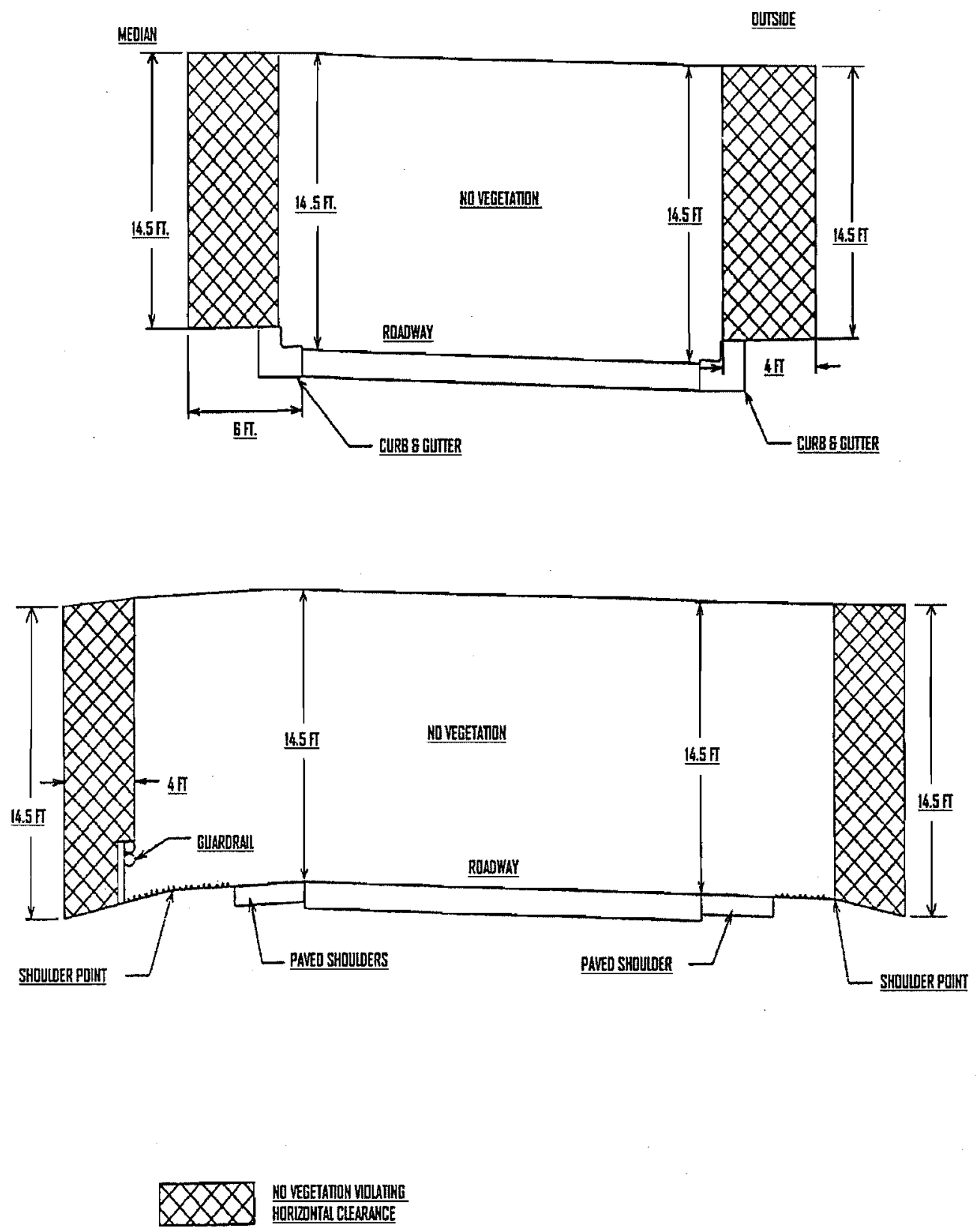

1. Vegetation shall not block signs

2. Sidewalk to be clear of vegetation.

3. In areas with shoulder gutter and no soil shoulder behind it, the back of the shoulder gutter is to be considered the shoulder point. 


\section{CURB/SIDEWALK} EDGE:
There is no encroachment of vegetation or debris for more than 6 inches onto the curb or sidewalk for more than $\underline{10}$ continuous feet.

There is no deviation of soil more than 4 inches above or 2 inches below the top of curb or sidewalk for more than $\underline{10}$ continuous feet.

Curb/Sidewalk Edging - Curb and sidewalk edging, including median curb is performed for safety and aesthetic reasons. Encroachment of vegetation or debris on the sidewalk could cause a hazard. Edging control may be accomplished by mechanical control (cutting or trimming by machine) or by chemical control.

Evaluation: Review the curb and sidewalk areas within the sample point. Only evaluate 2 feet behind all curbs and sidewalks within the right-of-way.

Dead or dying vegetation at a curb or sidewalk edge is an indication that a chemical control program is the method being used. In this case, an evaluation must be made to determine if the soil remaining, after the vegetation is gone, will still cause an encroachment. Encroachment of vegetation or debris on sidewalks could cause a hazard.

A utility strip is generally considered to be that unpaved area between the back of a curb and a sidewalk.

In areas with curb and gutter and sidewalk, rate curb/sidewalk edging around the returns to the back of the sidewalk. In areas with curb and gutter and no sidewalk, do not rate curb/sidewalk edging around the returns. In curb and gutter sections, unpaved turnouts will be evaluated by this characteristic. For MRP purposes in evaluating this characteristic, continuous encroachment may not necessarily be solid encroachment.

Any bike paths located outside the roadway pavement area will be included in the evaluation for curb/sidewalk edging.

For MRP purposes, do not rate areas outside the right-of-way. 
Curb/Sidewalk Edging does not meet MRP standards when any of the following exist:

1) Any encroachment of vegetation or debris for more than 6 inches onto the curb or sidewalk for more than 10 continuous feet.

2) Any deviation of soil of more than 4 inches above the top of curb or sidewalk for more than 10 continuous feet.

3) Any deviation of soil more than 2 inches below the top of curb or sidewalk for more than 10 continuous feet.

4) Any defect (not covered by another characteristic) within the clear zone or to the front edge of sidewalk, whichever is greater, and more than $1 / 2$ square foot in area with a depth of $\underline{6 \text { inches }}$ or greater.

5) Any encroachment of vegetation or debris for more than 6 inches onto a bike path for more than 10 continuous feet.

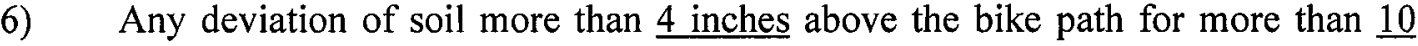
continuous feet.

7) Any deviation of soil more than $\underline{2}$ inches below the bike path for more than $\underline{10}$ continuous feet.

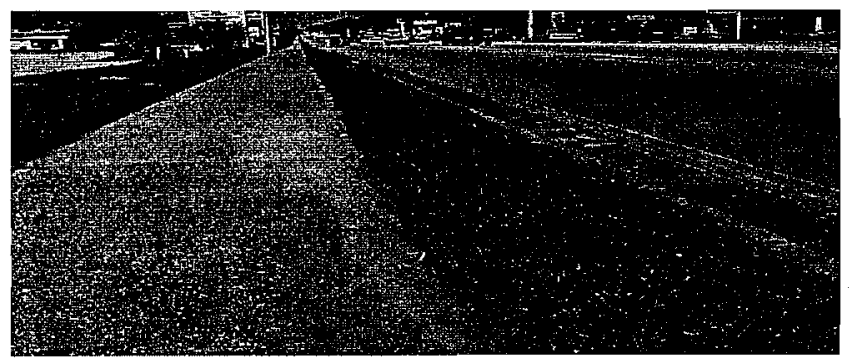

This is an example of a sidewalk that meets desired maintenance conditions for curb/sidewalk edging.

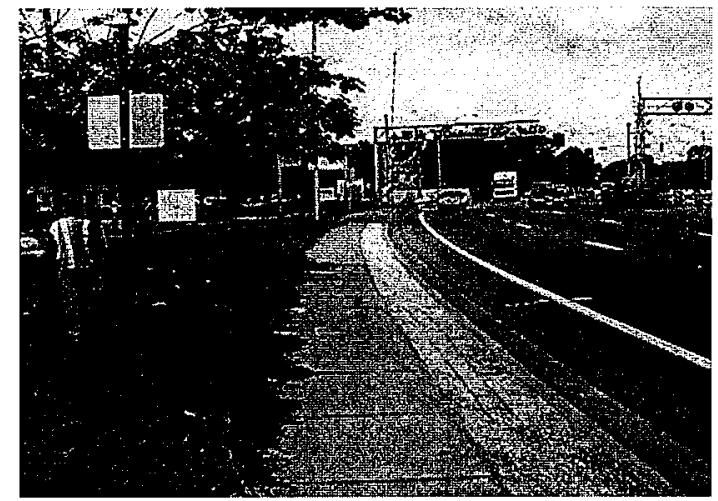

This vegetation is encroaching onto the sidewalk more than 6 inches for a continuous 10 feet. This does not meet desired maintenance conditions for curb/ sidewalk edging.

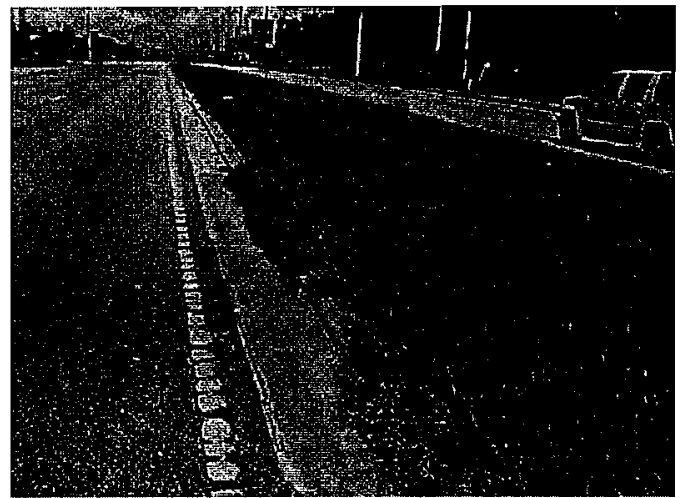

This vegetation is encroaching the curb more than 6 inches for more than 10 feet. This does not meet desired maintenance conditions for curb/sidewalk edging. 


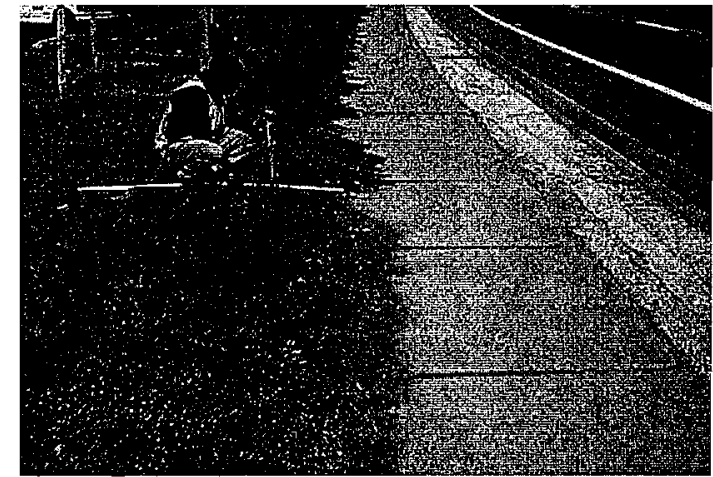

This vegetation encroachment on the sidewalk. This does not meet desired maintenance conditions for curb/sidewalk edging.

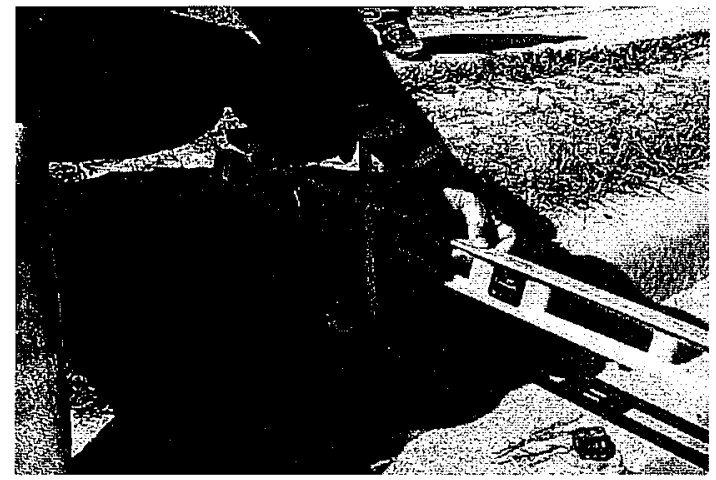

This is a soil buildup great than 4 inches in the utility strip. It is built up more than 10 continuous feet and, therefore, does not meet desired maintenance conditions for curb/ sidewalk edging. 
LITTER REMOVAL: The volume of litter does not exceed 3 cubic feet per 1 acre excluding all travel way pavement.

Litter Removal - Removal of litter from roadway and roadside areas is performed for aesthetic and safety reasons. It is desired to present a pleasing appearance to the motoring and pedestrian traffic, but is more important to provide safety. Litter on roadsides during mowing operations presents an increased possibility of hazard to the motorist, pedestrian and mower operator.

Evaluation: The evaluation area includes the mowing areas, parking areas, paved shoulders, crossovers, all medians, sidewalks, bike paths, driveways, traffic separators, gutters and drainage structures. Limbs greater than 1 inch in thickness will be included in the computation of litter in the sample point if they are present in the litter pickup area.

Determine the number of acres in the mowing area within the sample point. Calculate the number of cubic yards of litter in the sample. If the volume of litter exceed $\underline{3}$ cubic feet per acre, then the sample point does not meet MRP standards for Litter Removal.

Exclude the travel way pavement which includes through lanes, turn lanes and bidirectional lanes. Do not evaluate the portion of the right-of-way that is continually under water. Fallen trees, landscaping timbers or similar items within the clear zone may be examples of hazards that do not meet desired maintenance conditions. Items (leaves, bagged trash, tree-trimming residue) that appear to be those which will be picked up during the normal waste collection process will not be considered as litter.

\section{Litter Removal does not meet MRP standards when any of the following exist:}

1) There is more than 3 cubic feet of litter per acre within the sample point.

2) Any litter exists within the sample that creates a hazard to motorist or pedestrian traffic.

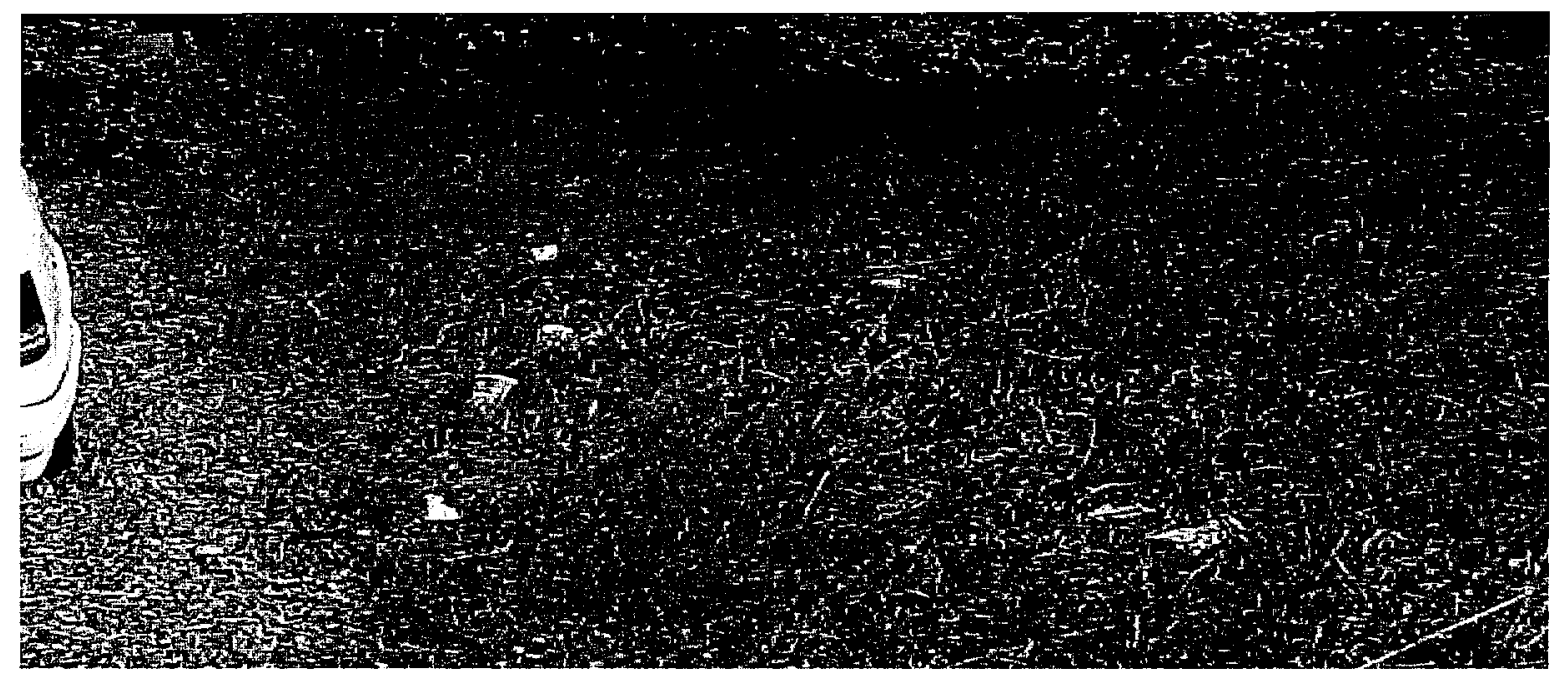

Litter within the mowing area. 

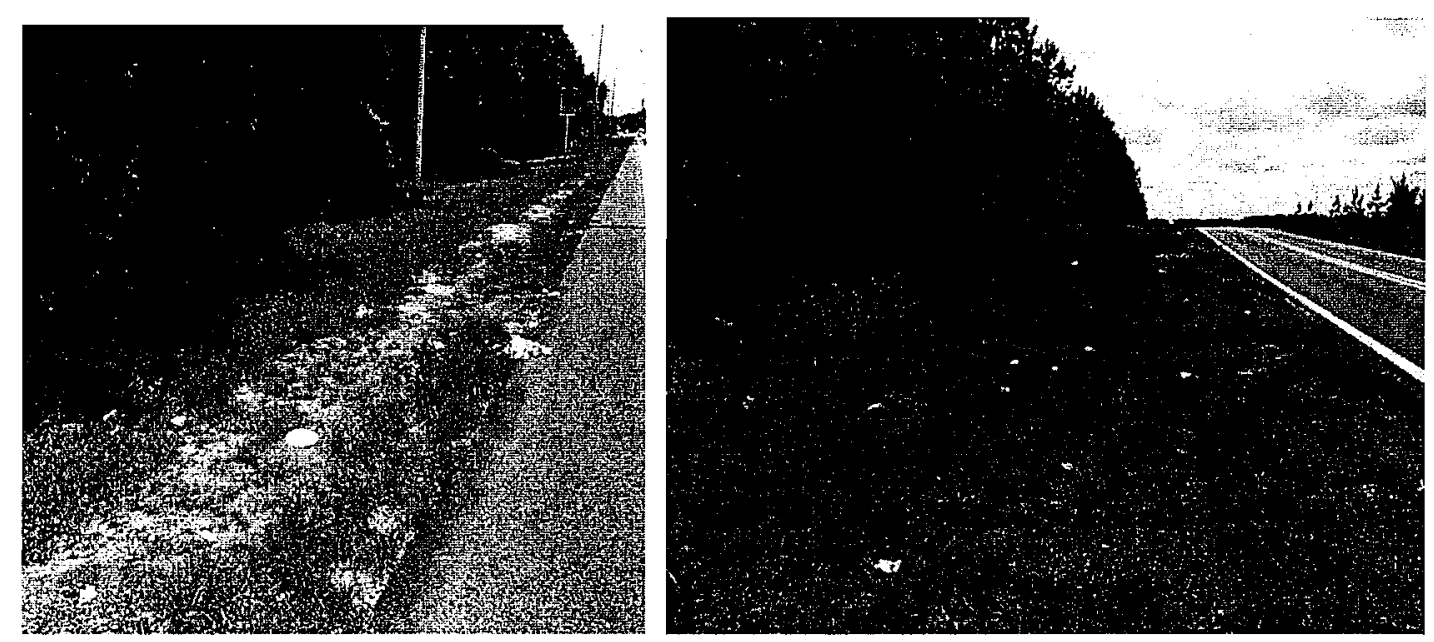

Litter Area. Determine the number of acres in the mowing area within the sample point. Calculate the cubic feet of litter within the sample. If there is more than 3 cubic feet of litter per acre, then this would not meet desired maintenance conditions.

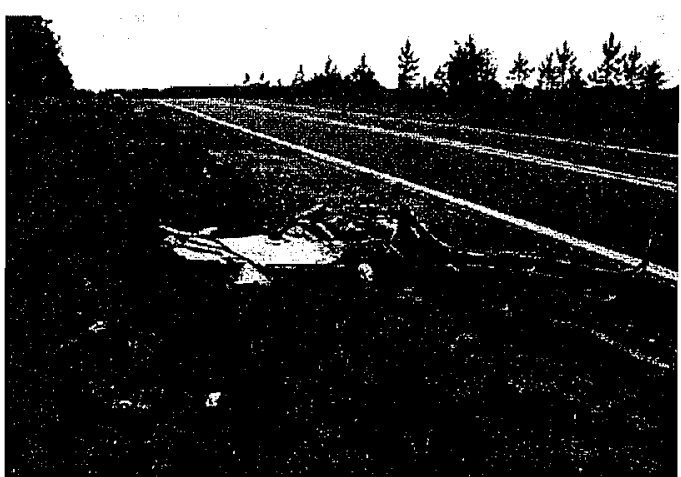

Any litter that creates a hazard to motorists or pedestrians does not meet desired MRP conditions.

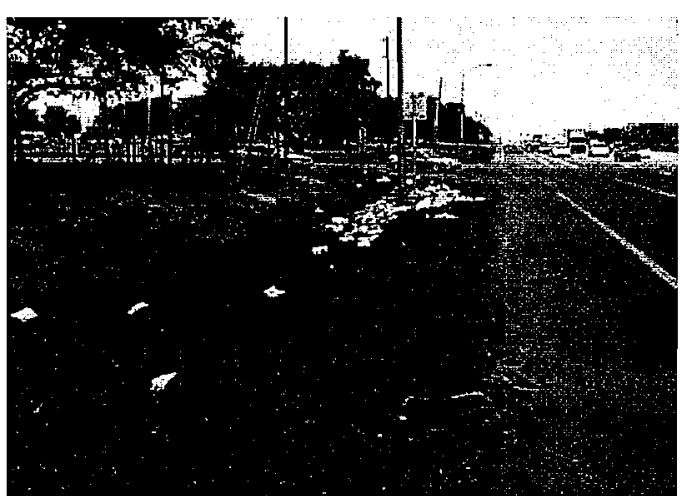

Litter in the mowing area. 
TURF CONDITION: Turf in the mowing area is $\underline{75 \%}$ free of undesired vegetation.

Turf Condition - Turf is grass or other vegetation considered desirable for the particular roadside location. Properly maintained and desired vegetation provides a pleasing appearance but, primarily, it presents less chance of shoulder and slope defects (ruts, washouts, wash boarding), thereby, providing a safe recovery area for motoring traffic.

Evaluation: Determine the mowing area within the sample point. Turf condition will normally be evaluated within the established mowing limits. Occasionally, mowing limits are changed and areas are left to regenerate. These areas, in the first stages of regeneration, will appear to be within mowing limits and probably will contain undesirable vegetation.

When mowing limits have been extended due to adjoining property improvement or new development, a transition period (one rating period) is required to establish desirable turf conditions. Considerations should be given when these situations are encountered

Turf in the mowing area should be $\underline{75 \%}$ free of the following undesired vegetation alone or in combination:

$\begin{array}{llllll}\text { 1. } & \text { Cogon grass } & 6 . & \text { Ragweed } & 11 . & \text { Sandspur } \\ \text { 2. } & \text { Vaseygrass } & 7 . & \text { Castor Bean } & 12 . & \text { Spanish Needle } \\ \text { 3. } & \text { Johnsongrass } & 8 . & \text { Maiden Cane } & 13 . & \text { Crowsfoot } \\ \text { 4. } & \text { Broomsedge } & 9 . & \text { Rhodesgrass } & 14 . & \text { Tropical Soda Apple } \\ \text { 5. } & \text { Dogfennel } & 10 . & \text { Goosegrass } & & \end{array}$

Bare ground is defined as any single area (5 square feet) $95 \%$ free of vegetation. Purposely stabilized areas (lime rock, shell, etc.) shall not be considered as bare ground and not included in the turf evaluation.

Turf grasses that appear to be dead may actually be dormant and shall be considered to meet desired maintenance conditions, if in dormant stage.

Calculate the mowing area. Determine the area of undesirable vegetation within the mowing area. Divide the undesirable vegetation area by the total mowing area and multiply by 100 . If the resulting percentage is greater than $25 \%$, then the sample does not meet desired maintenance conditions for Turf Condition.

\section{Turf condition does not meet MRP standards when any of the following exist:}

1) If more than $25 \%$ of the undesirable vegetation is present within the mowing limits of the sample.

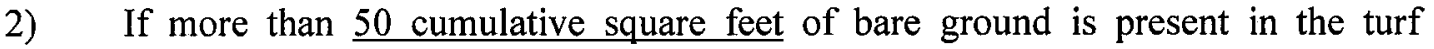
evaluation area. 


\section{UNDESIRABLE VEGETATION}

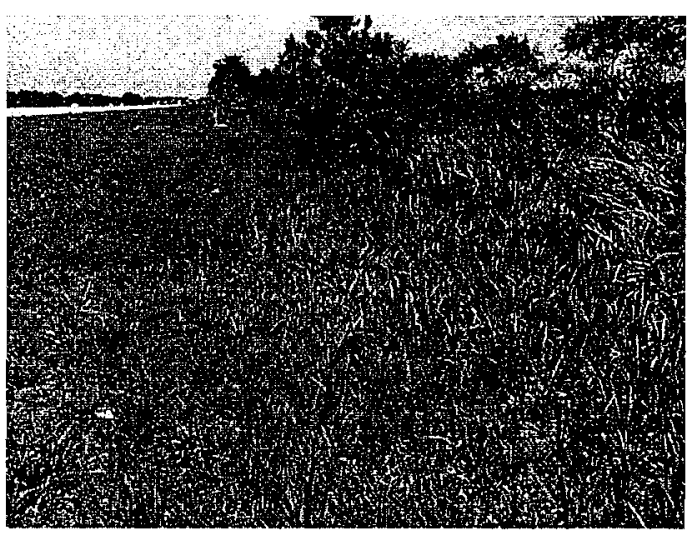

Cogon grass / Imperata cylindrica

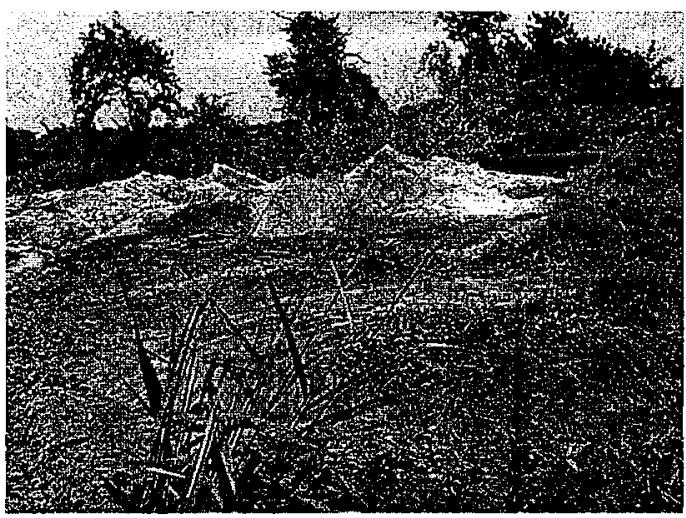

Johnsongrass / Sorghum halpense

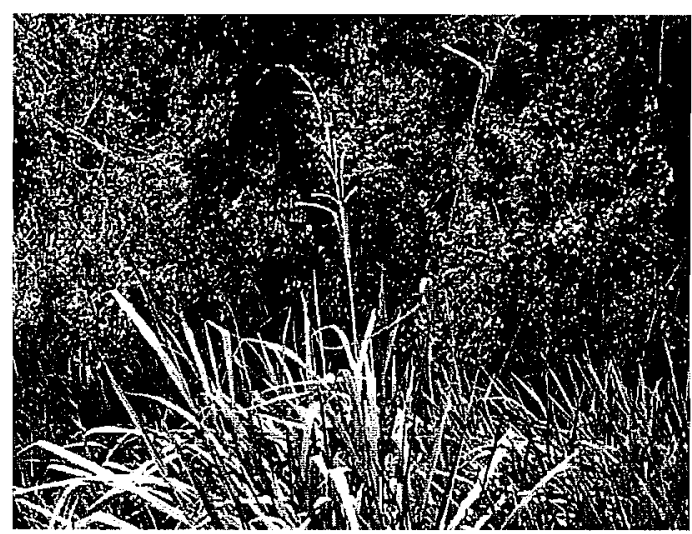

Vaseygrass / Paspalum urvillei

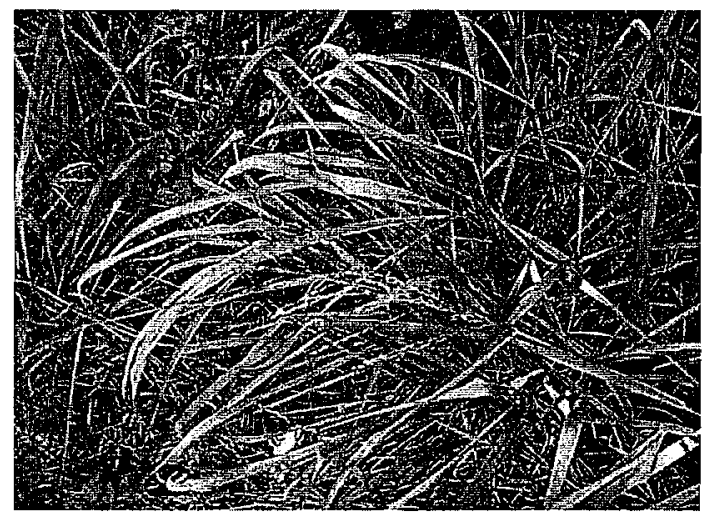

Johnsongrass

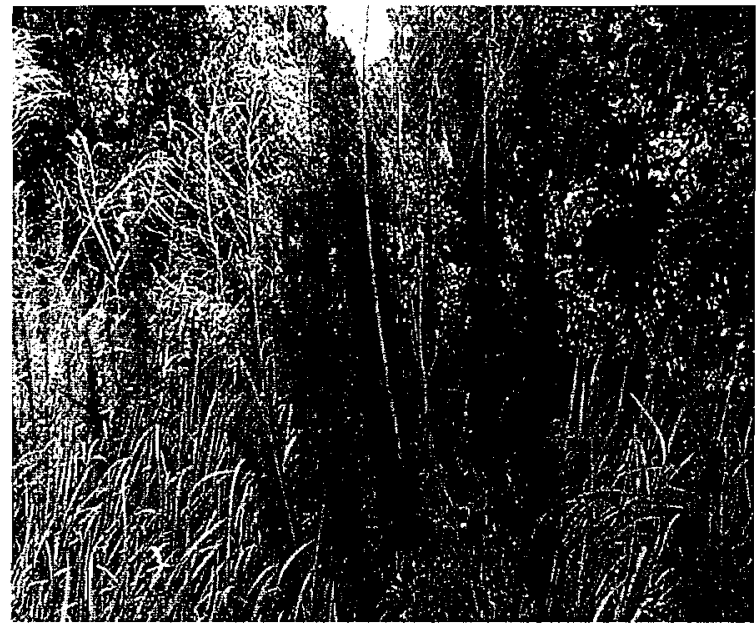

Dogfennel / Eupatorium capillifolium 


\section{UNDESIRABLE VEGETATION}

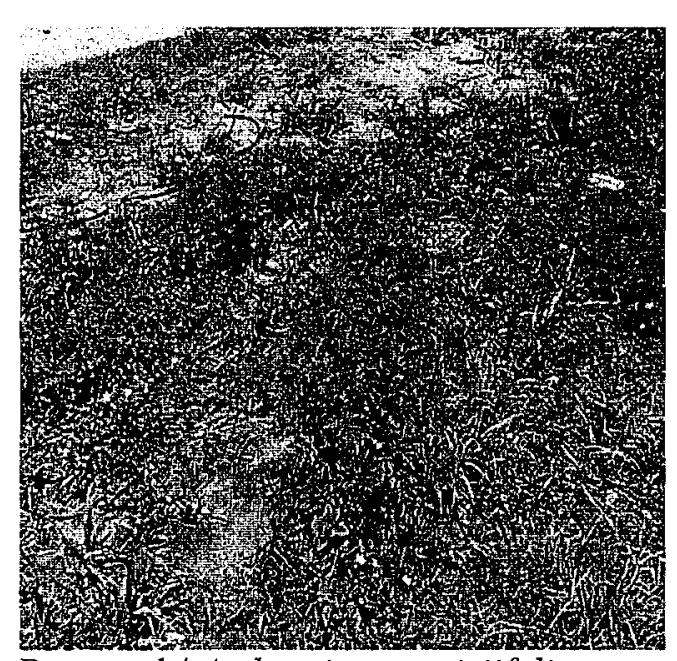

Ragweed / Ambrosia artemisiifolia

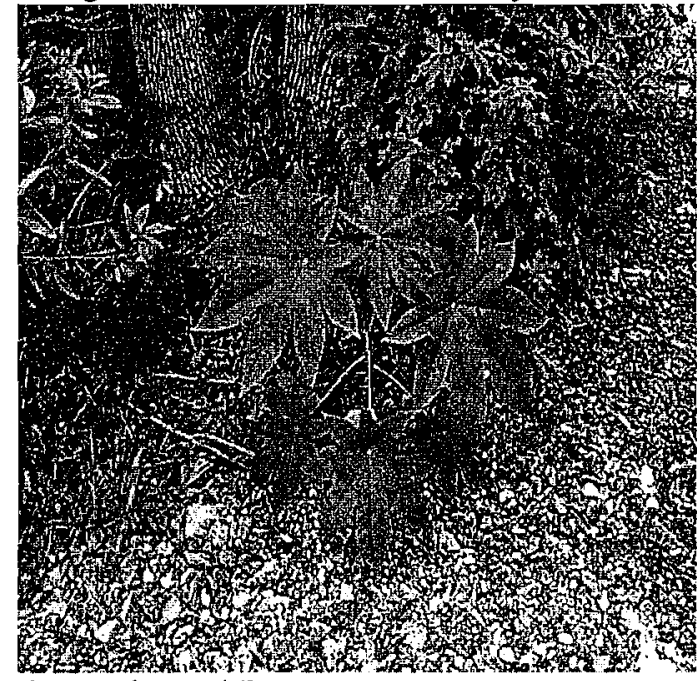

Castor bean / Ricinus communis

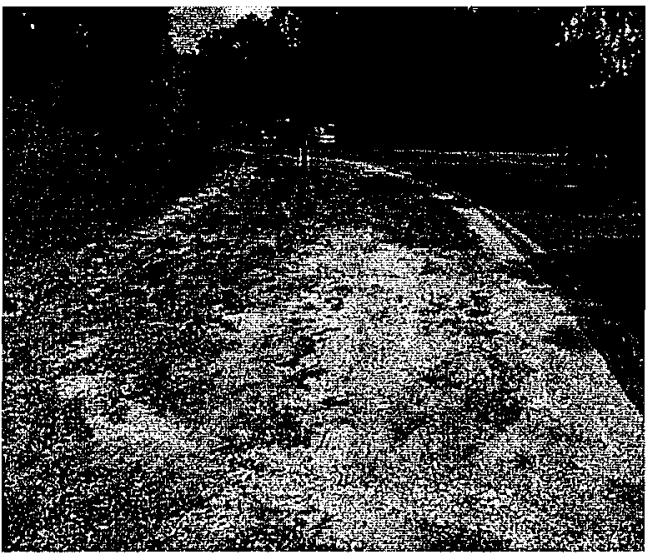

Bare ground

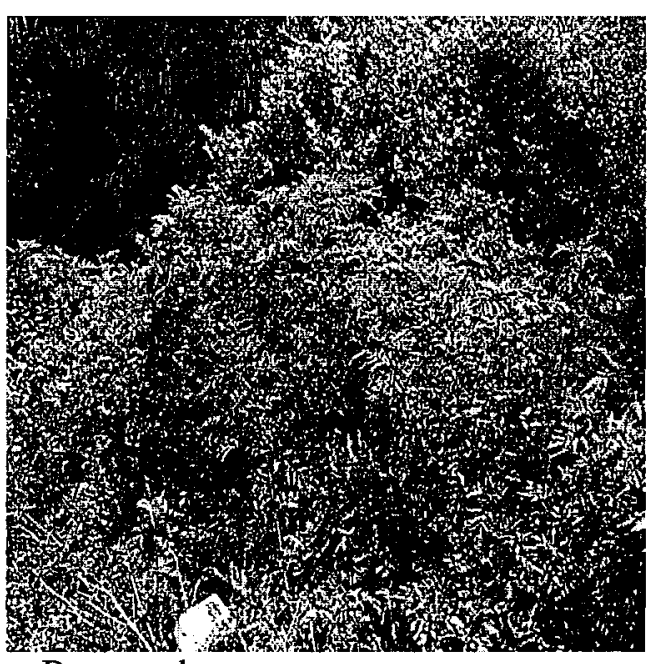

Ragweed

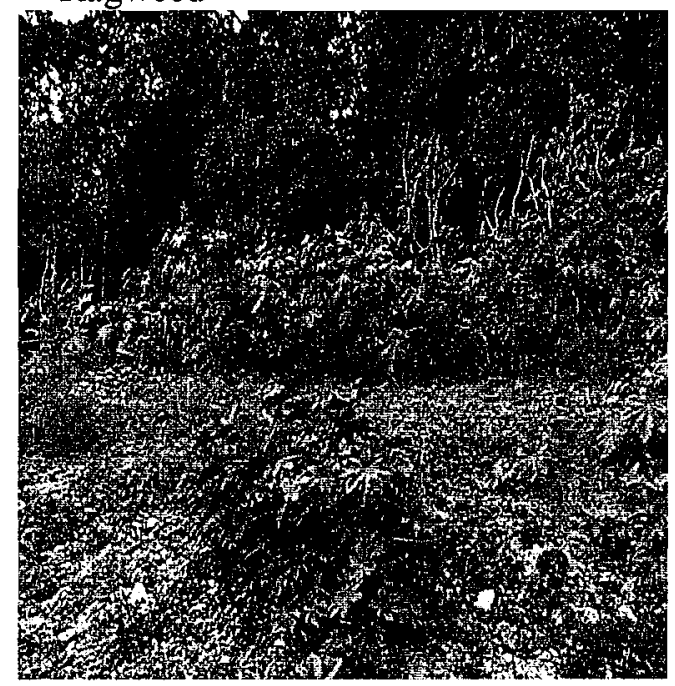

Castor bean

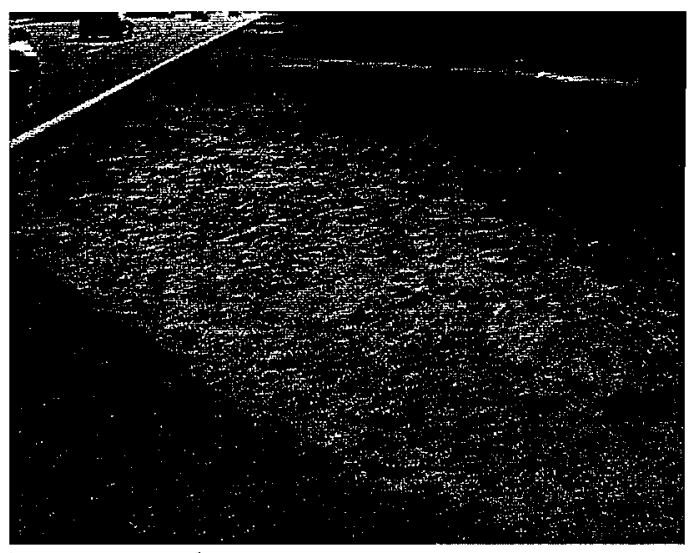

Bare ground 


\section{UNDESIRABLE VEGETATION}

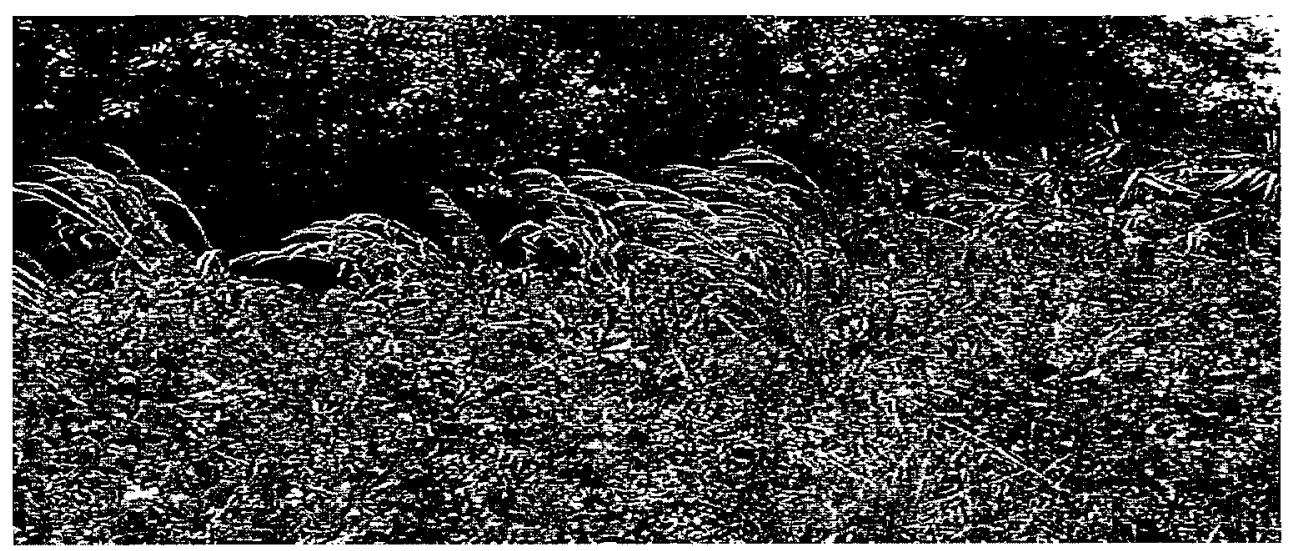

Broomsedge / Andropogon virginicus

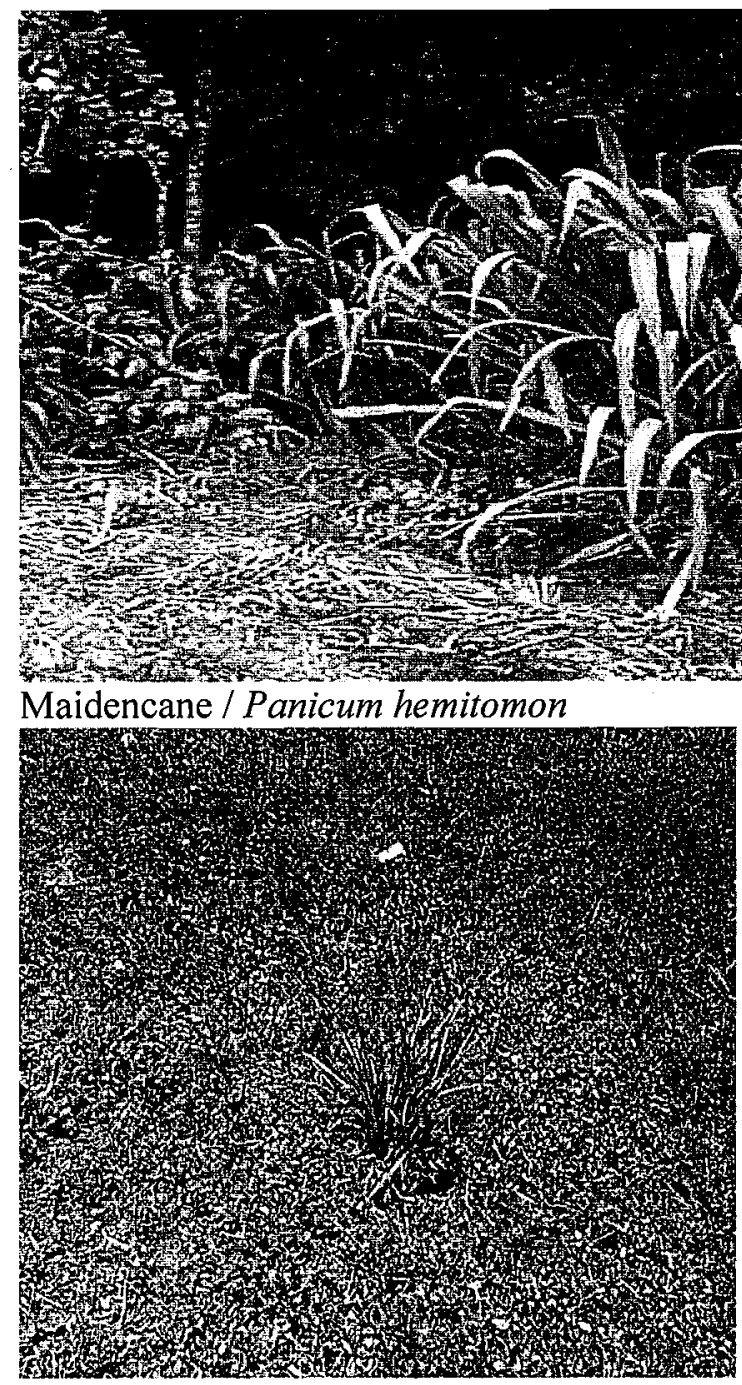

Rhodesgrass / Chloris gayana

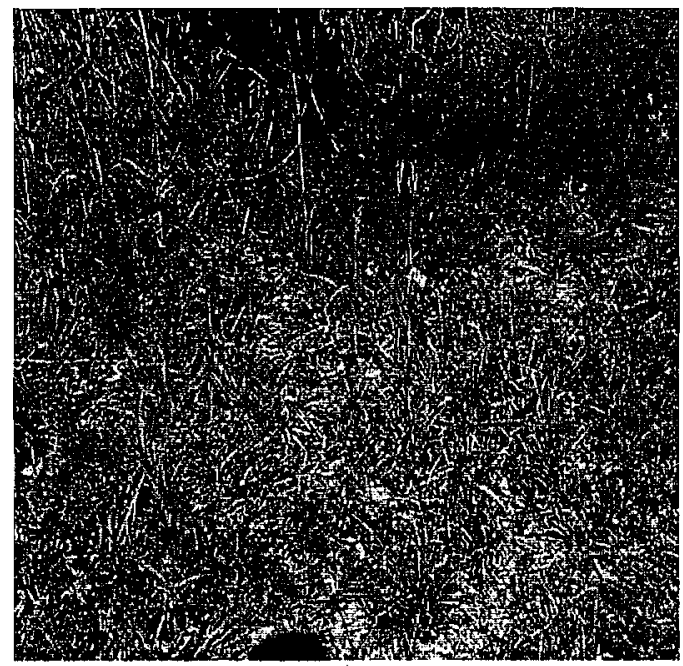

Rhodesgrass 


\section{UNDESIRABLE VEGETATION}

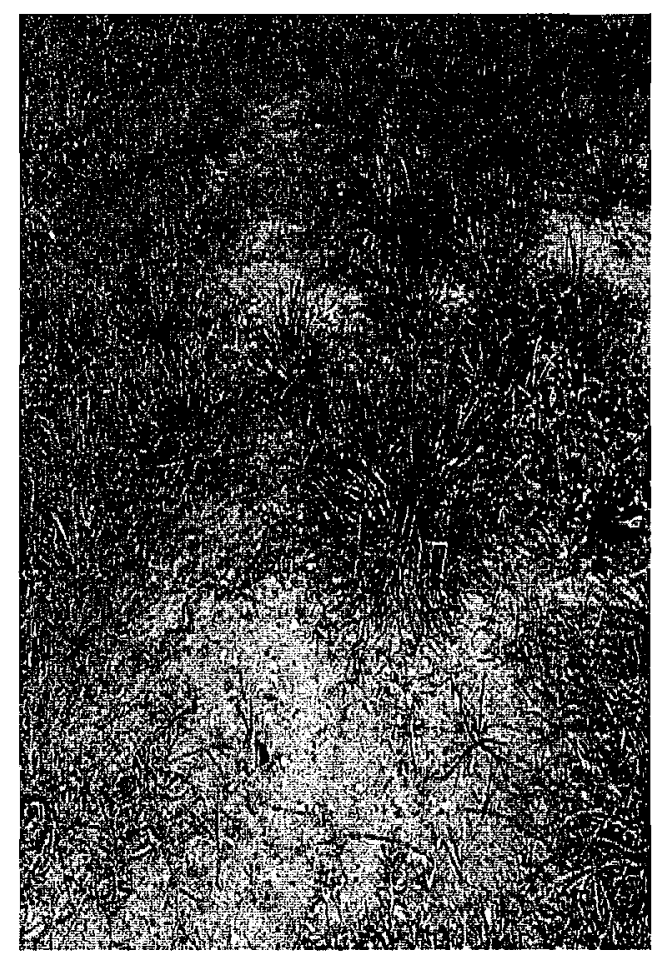

Goosegrass / Eleusine indica

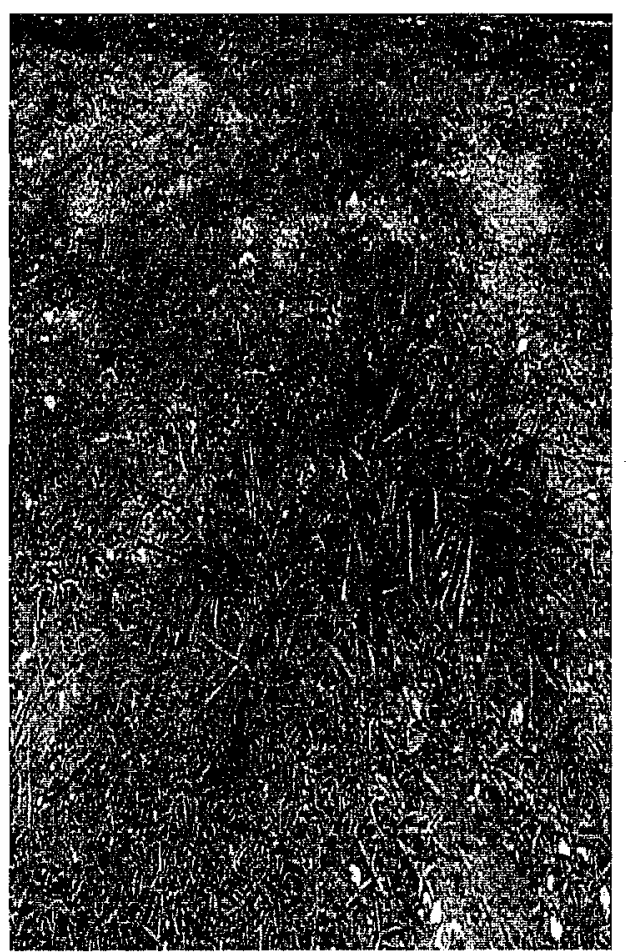

Goosegrass

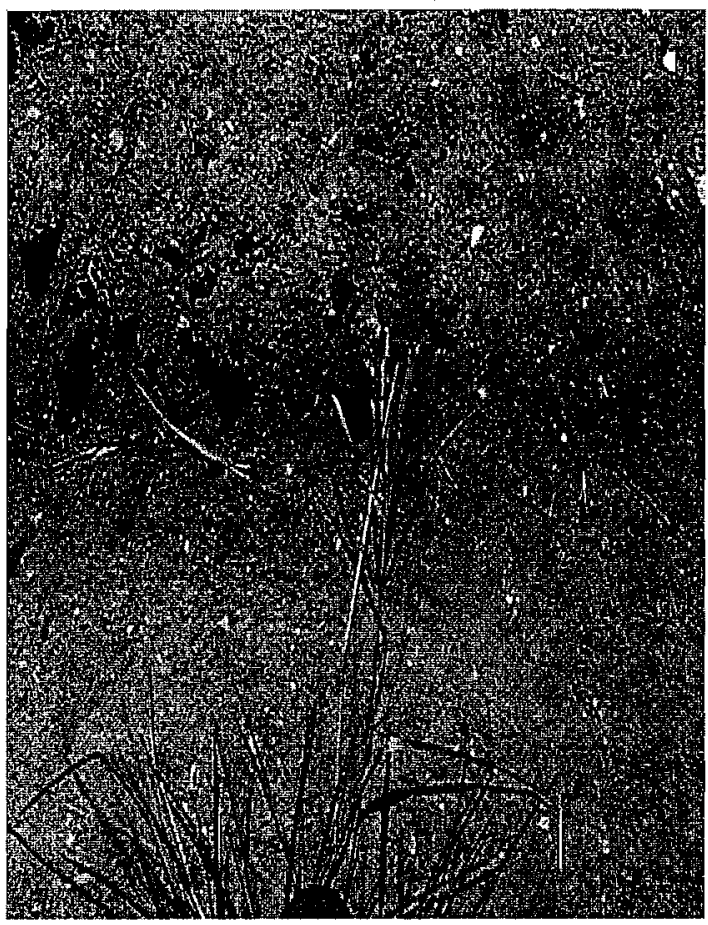

Goosegrass. 


\section{UNDESIRABLE VEGETATION}

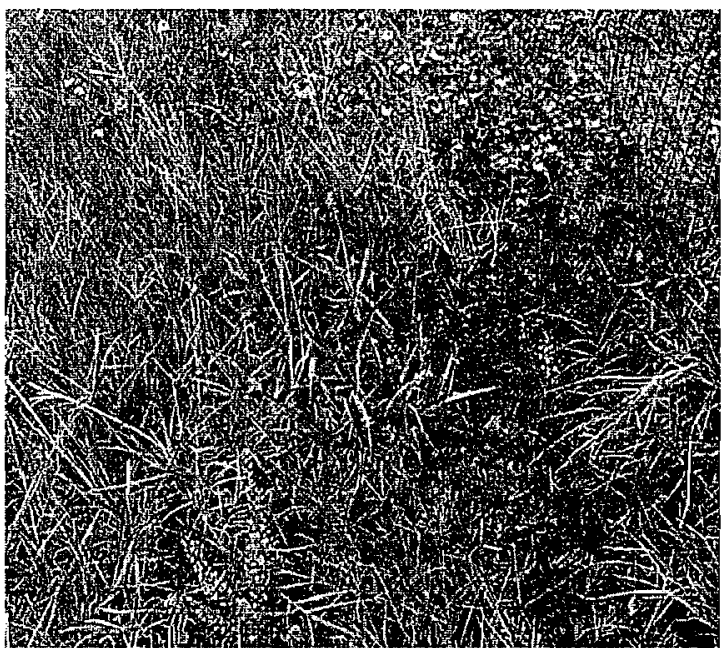

Sandspur / Cenchrus incertus

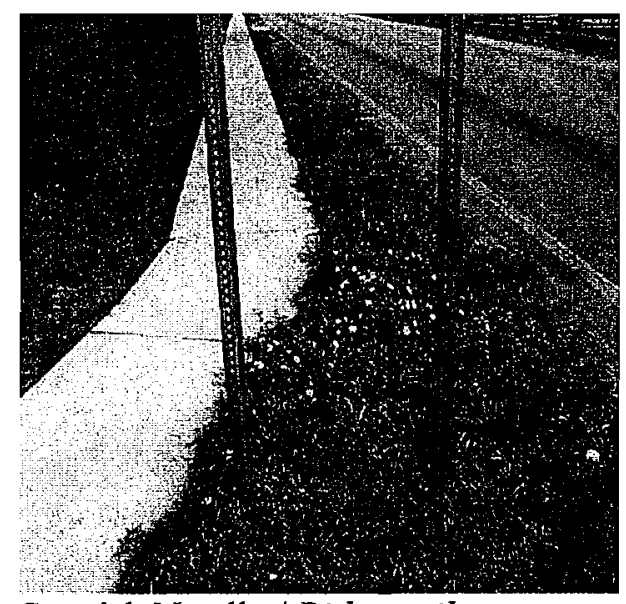

Spanish Needle / Bidens pilosa

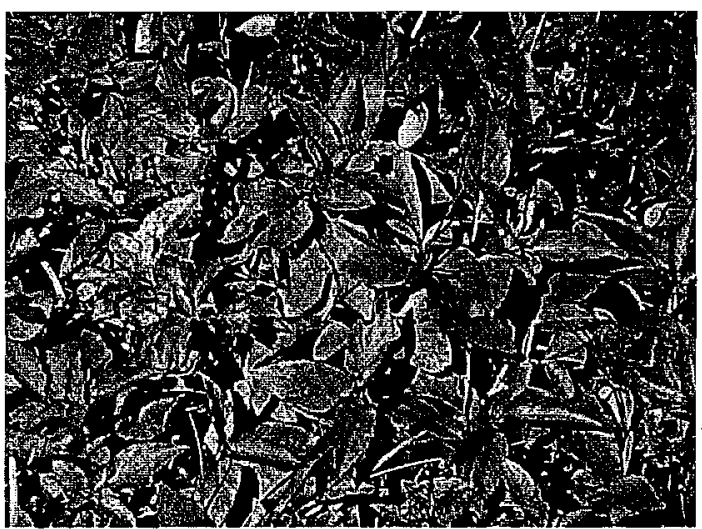

Spanish Needle without flower

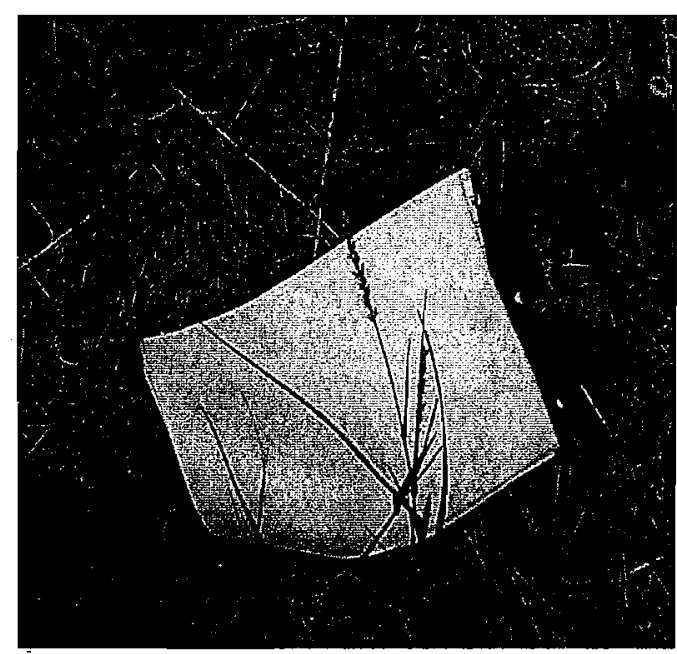

Sandspur

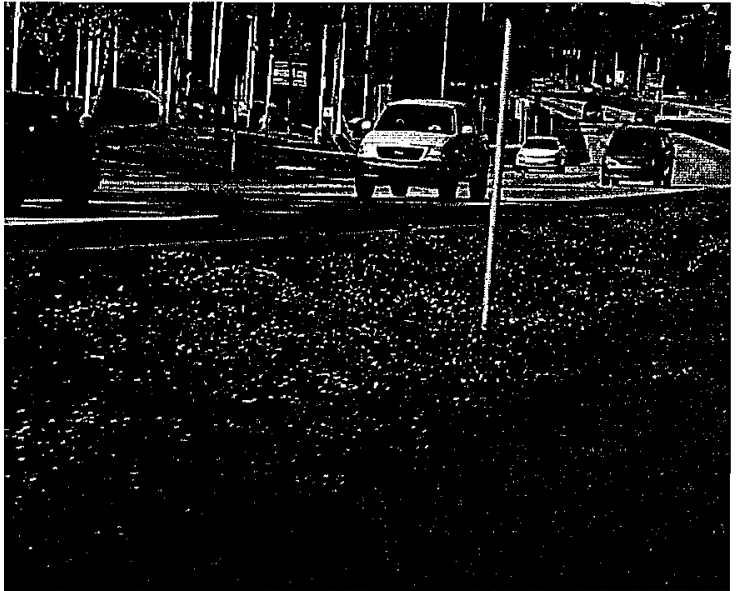

Spanish Needle

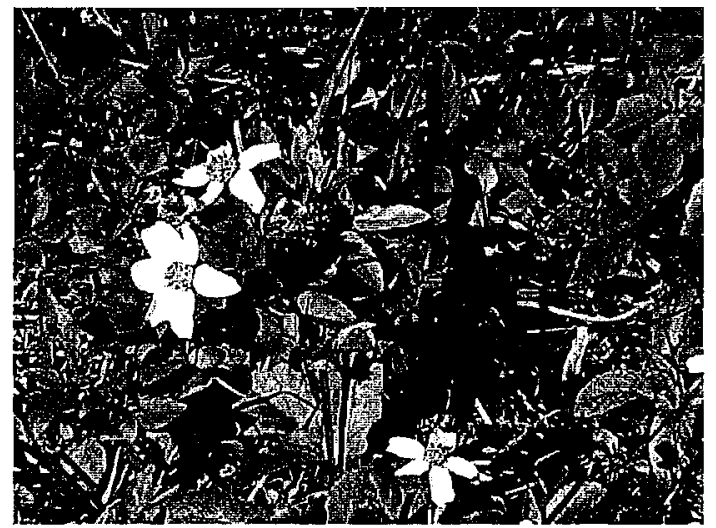

Spanish Needle with flower 
UNDESIRABLE VEGETATION

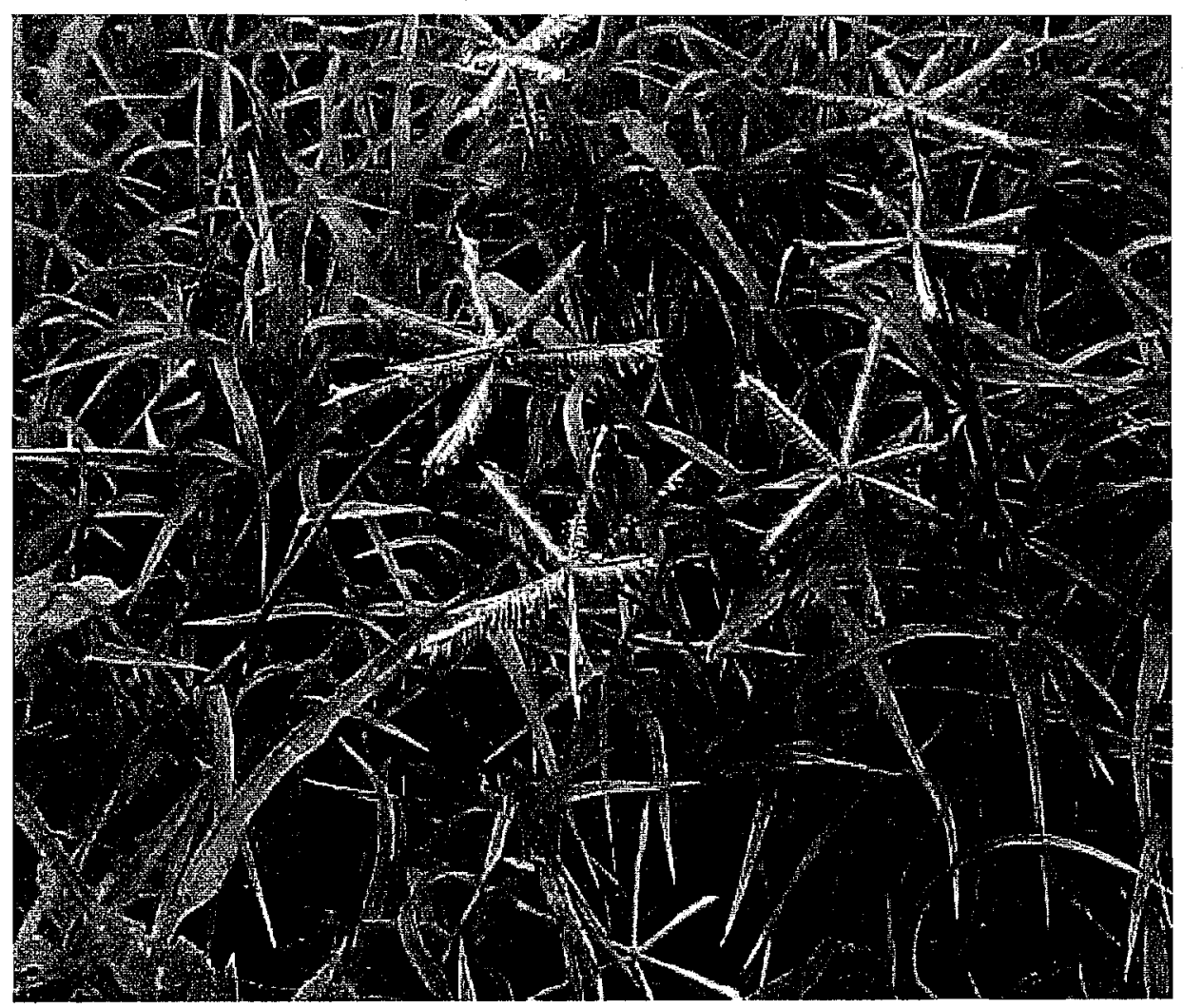

Crowfootgrass / Dactyloctenium aegyptium
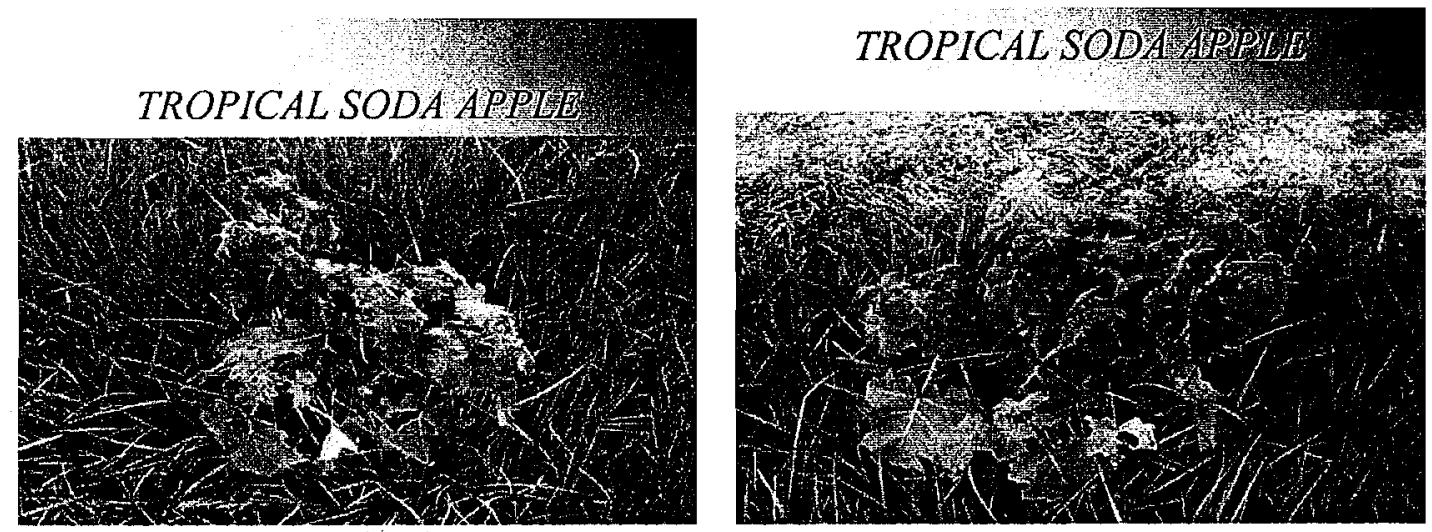

Tropical Soda Apple / Solanum viarum 


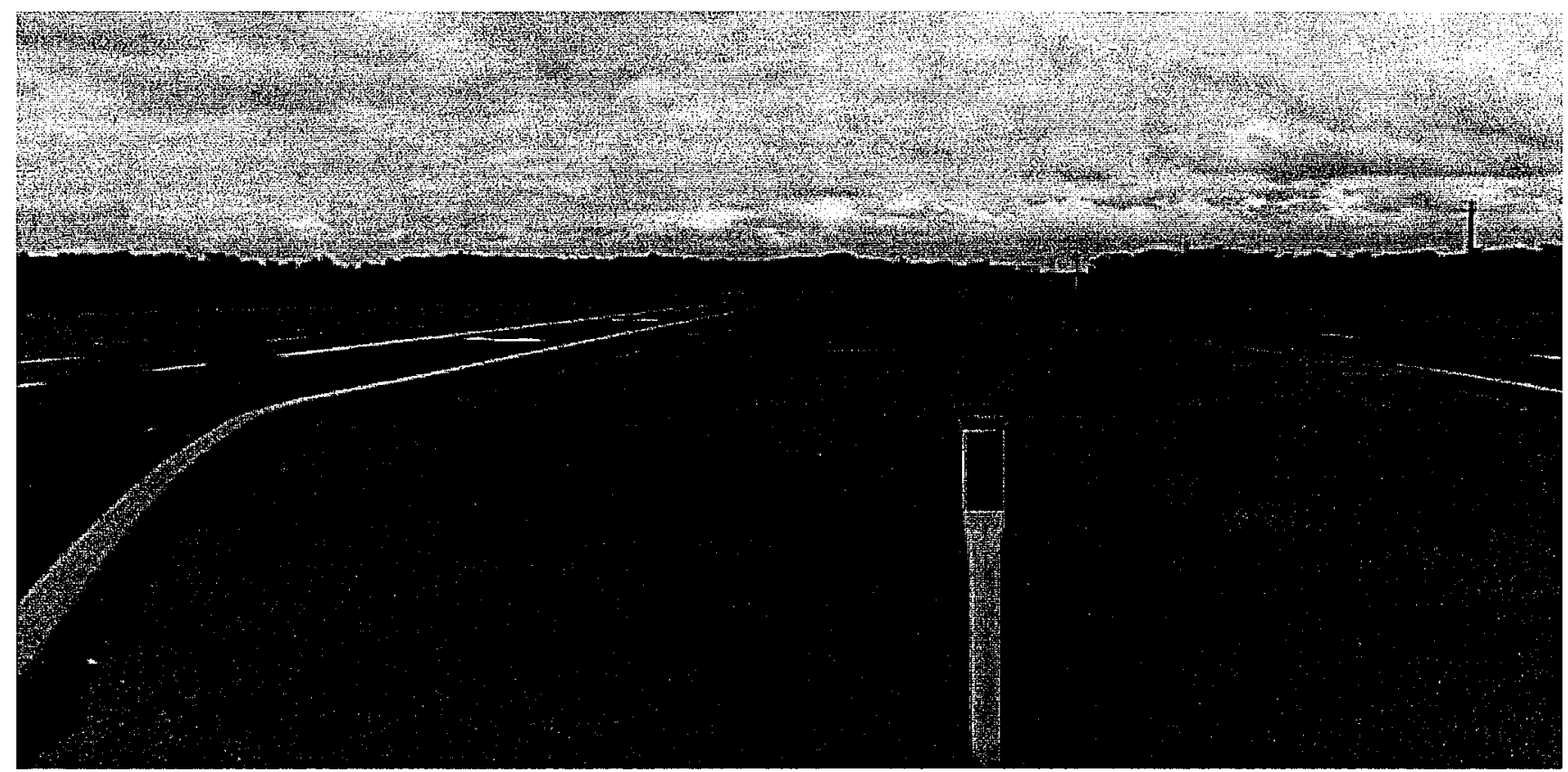

Good turf condition.

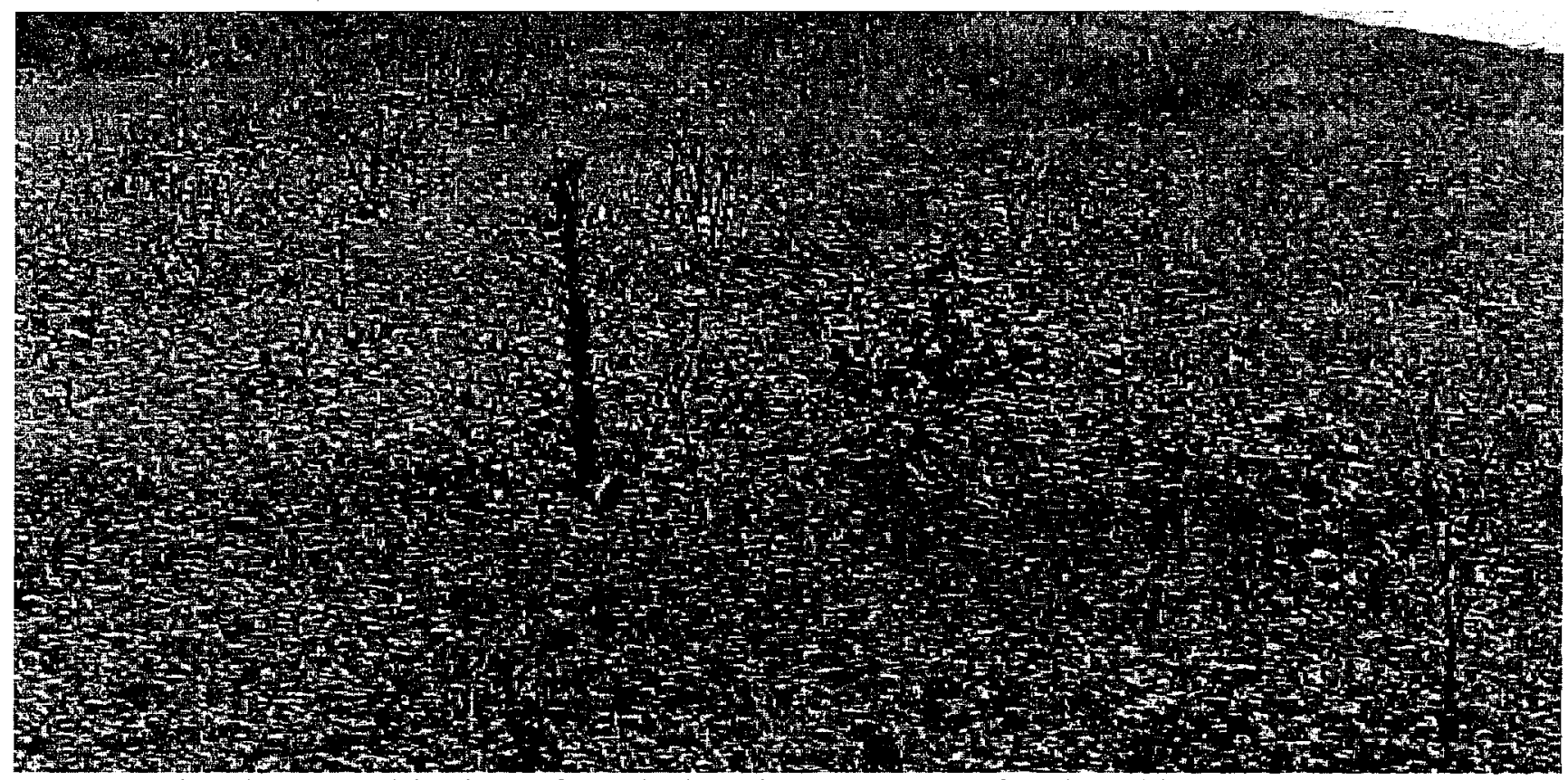

Dog Fennel and Ragweed in the turf. Calculate the percentage of undesirables in the mowing area. If more than the standard, then it would not meet MRP conditions. 


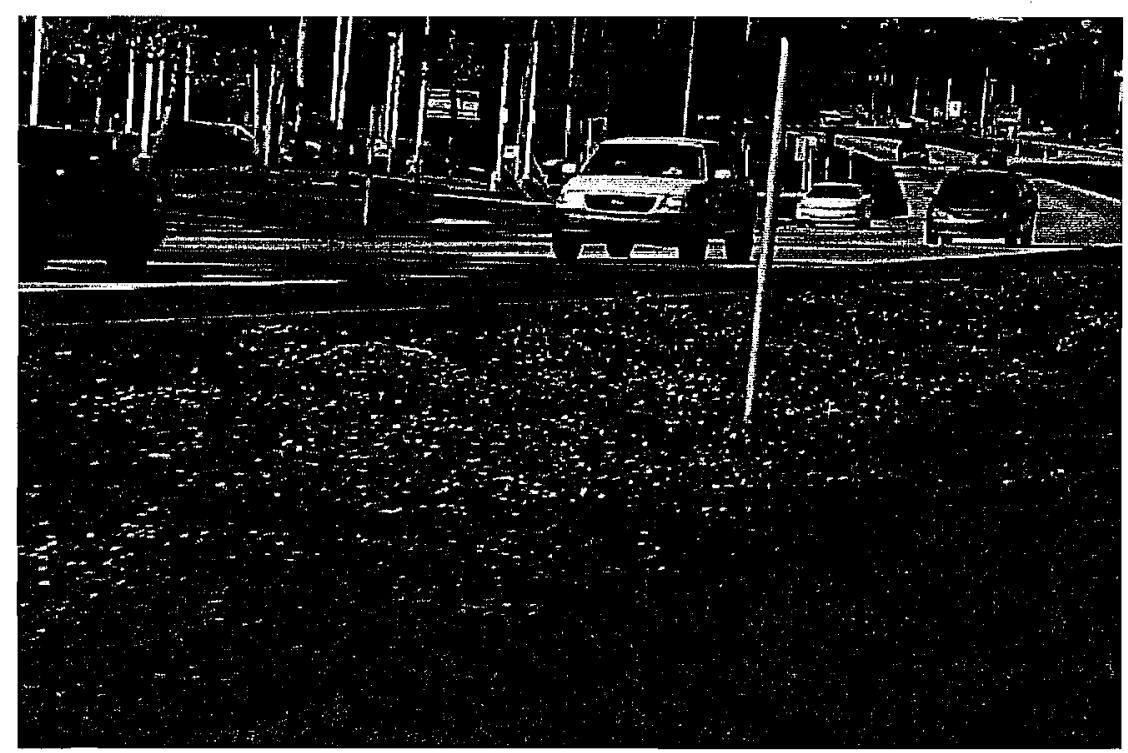

Spanish Needle in the mowing area.

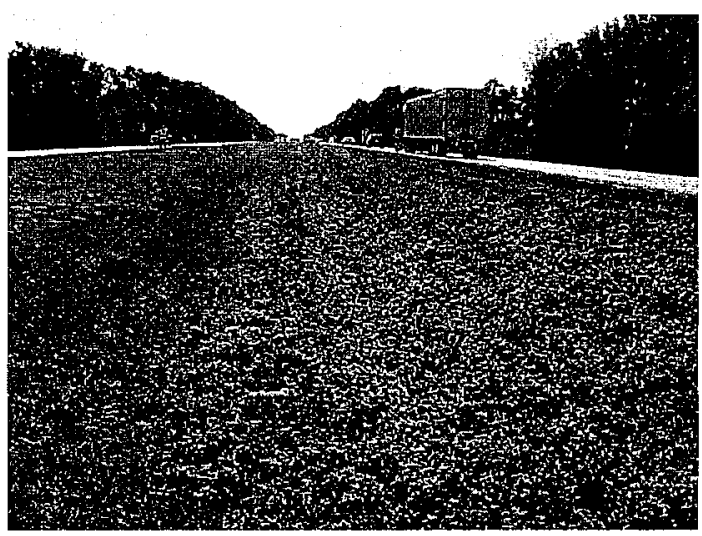

Spanish Needle in median
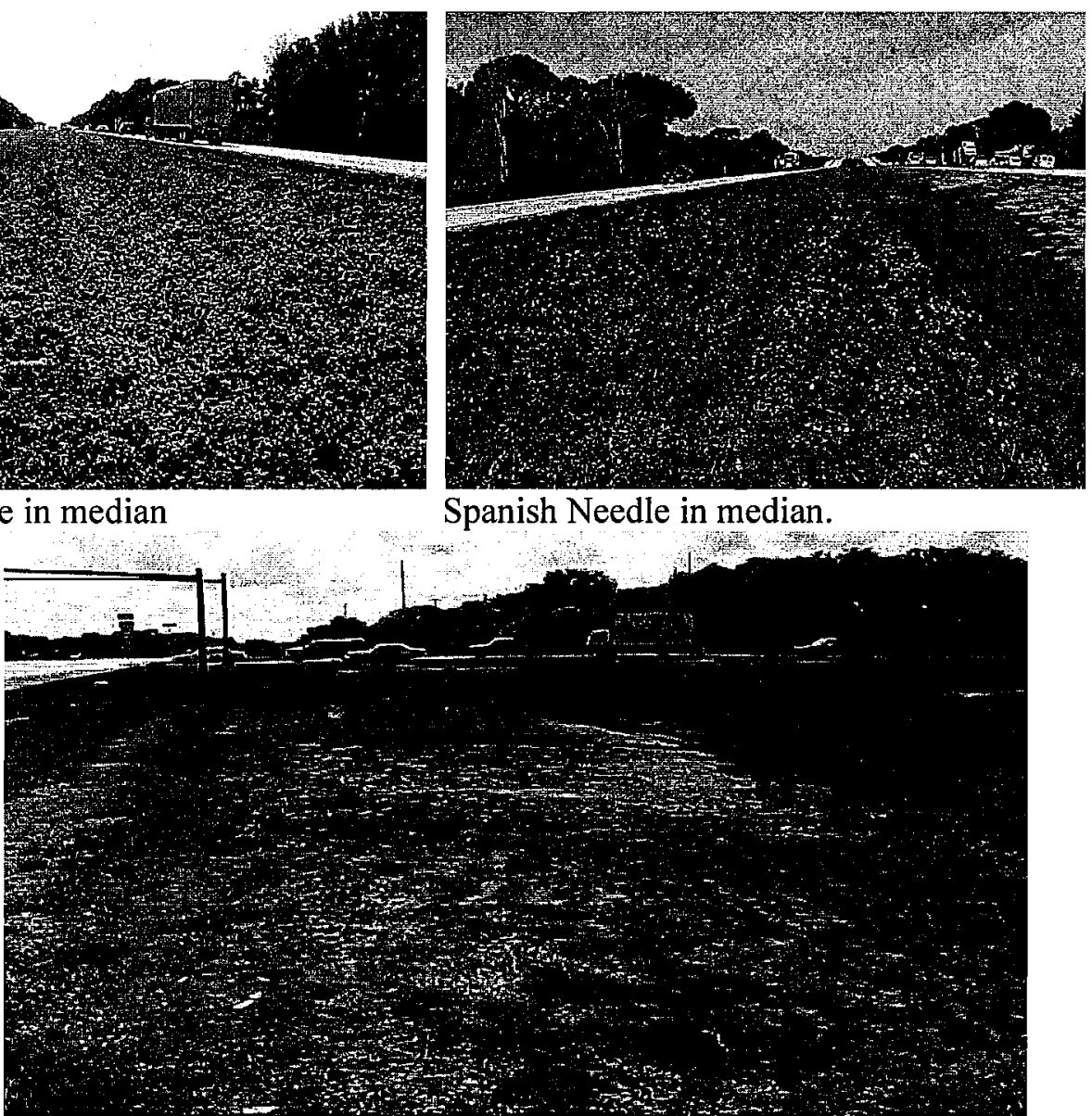

Bare ground in the mowing area. This would not meet desired MRP conditions. 


MAINTENANCE RATING PROGRAM CRITICAL ELEMENT
CONSTSTENCY CHECK
DISTRICT
REVIEW PERFORMED BY:
REVIBW DATES

DOES THE TEAM AND TEAM VEHICLE COMPLY WITH FDOT SAPETY STANDARDS AND THOSE ESTABLISHED BY MRP PRODEDURE?

2. DOES THB TEAM HAVE THE EQUIPMENT AND PUBLICATIONS TO PERFORM THE EVALUATIONS IN ACCORDANCE WTTH PROCEDURES?

3. DOES THE TBAM PROPERLY SELECT AND MARK THE SITE?

4. ARE CHARACTERISTICS BEING EVALUATED IN ACCORDANCE WITH MRP MANUAL?

5. HAS THE SURVEY ROUTE BEEN LOGICALLY PLANNED FOR EFFICIBNCY?

6. ASSESSMENT STATISTICS, GENERAL INPORMATION AND RESULTS.

a. Number of locations evaluated

b. Number of characteristics evaluaced by each team:

QA/QC TOTAL MRP TEAM TOTAL

Actual individual difference of characteristics selected.

Percent difference NOTE: Up to 5 is acceptable

Actual difference of yes/no

Percent difference Wot Up to $5 \%$ is acceptable.

c. Rating difference generated from MRP reports is:

(Optional)

NOTE: Plus/Minus 3 points difference is acceprable.

Time required of Distriek personnel:

NAME

TITLE

HOURS

Comments/Recommendations 


\section{DATA ENTRY}

This section describes the steps necessary to key in the sample scores which will be included in the final report. A valid FDOT user identification and password is required. In addition, access must be granted to the user by the Office of Maintenance in Tallahassee. 
Logon to TSO using an FDOT assigned user identification (userid) and password. If your Logon is successful, three asterisks $\left({ }^{* *}\right)$ will be displayed. Press the ENTER key to continue. The Master Application Menu will be displayed.

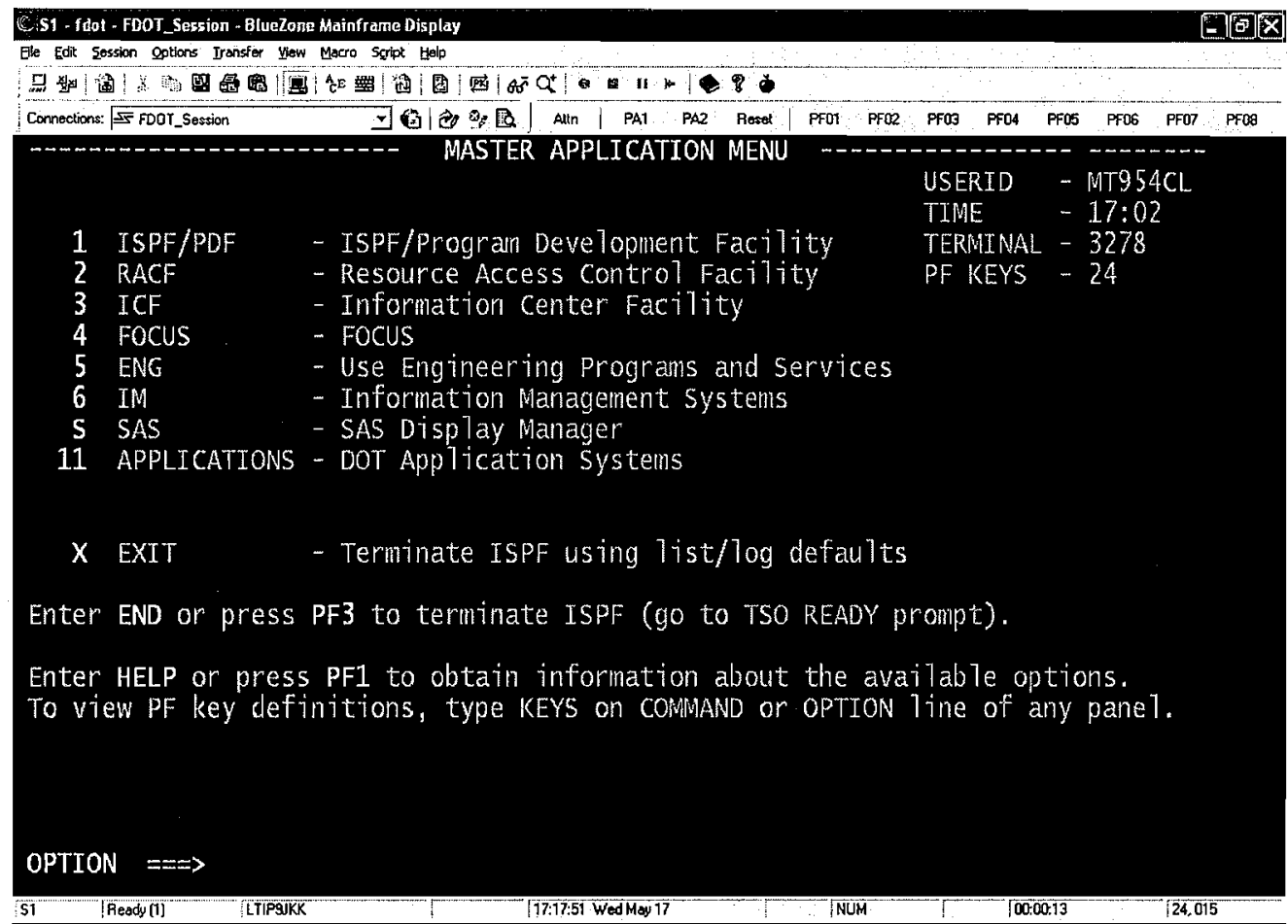

User response: Press PF3 to get to a READY Prompt.

At the READY prompt, type MAINT and press the ENTER key. The following broadcast message screen will be displayed.

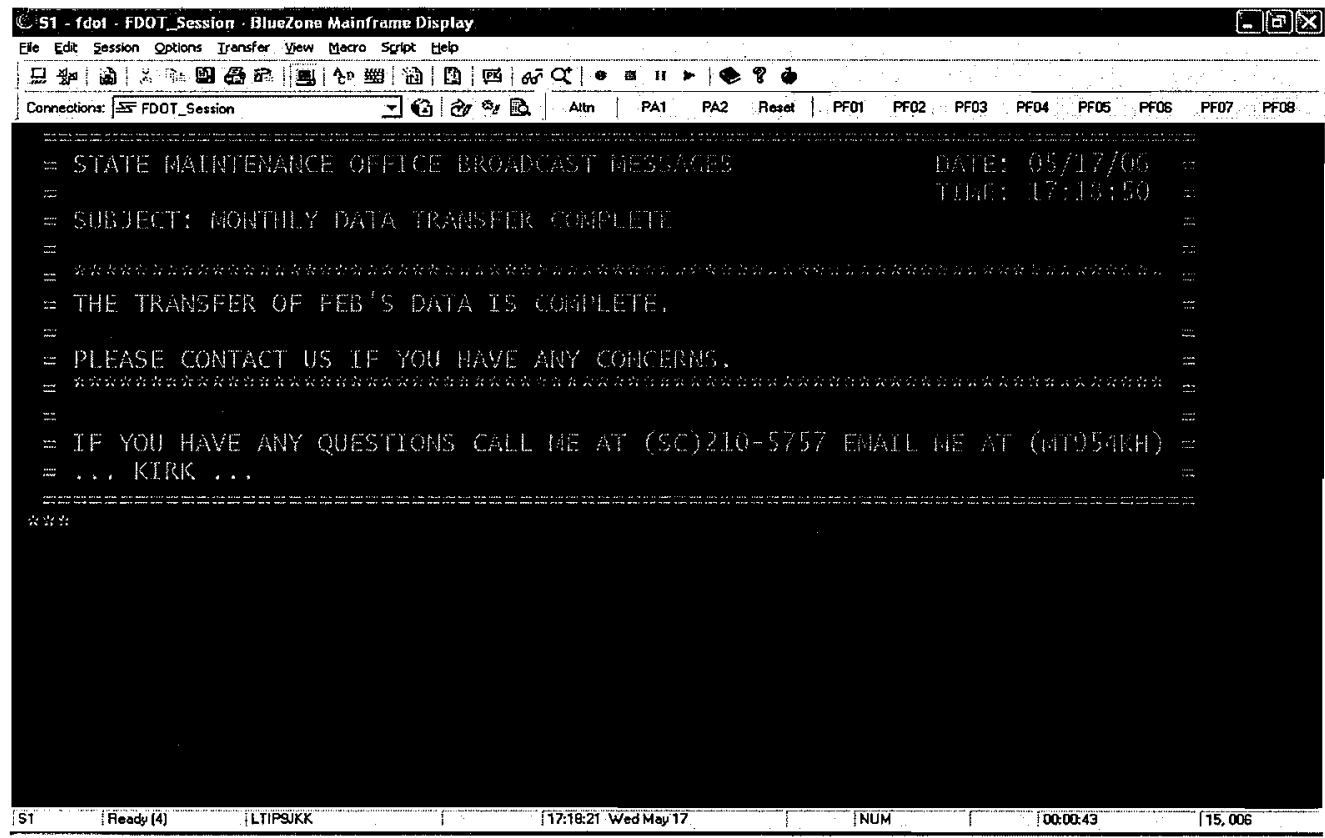


The Maintenance Menus will be displayed.

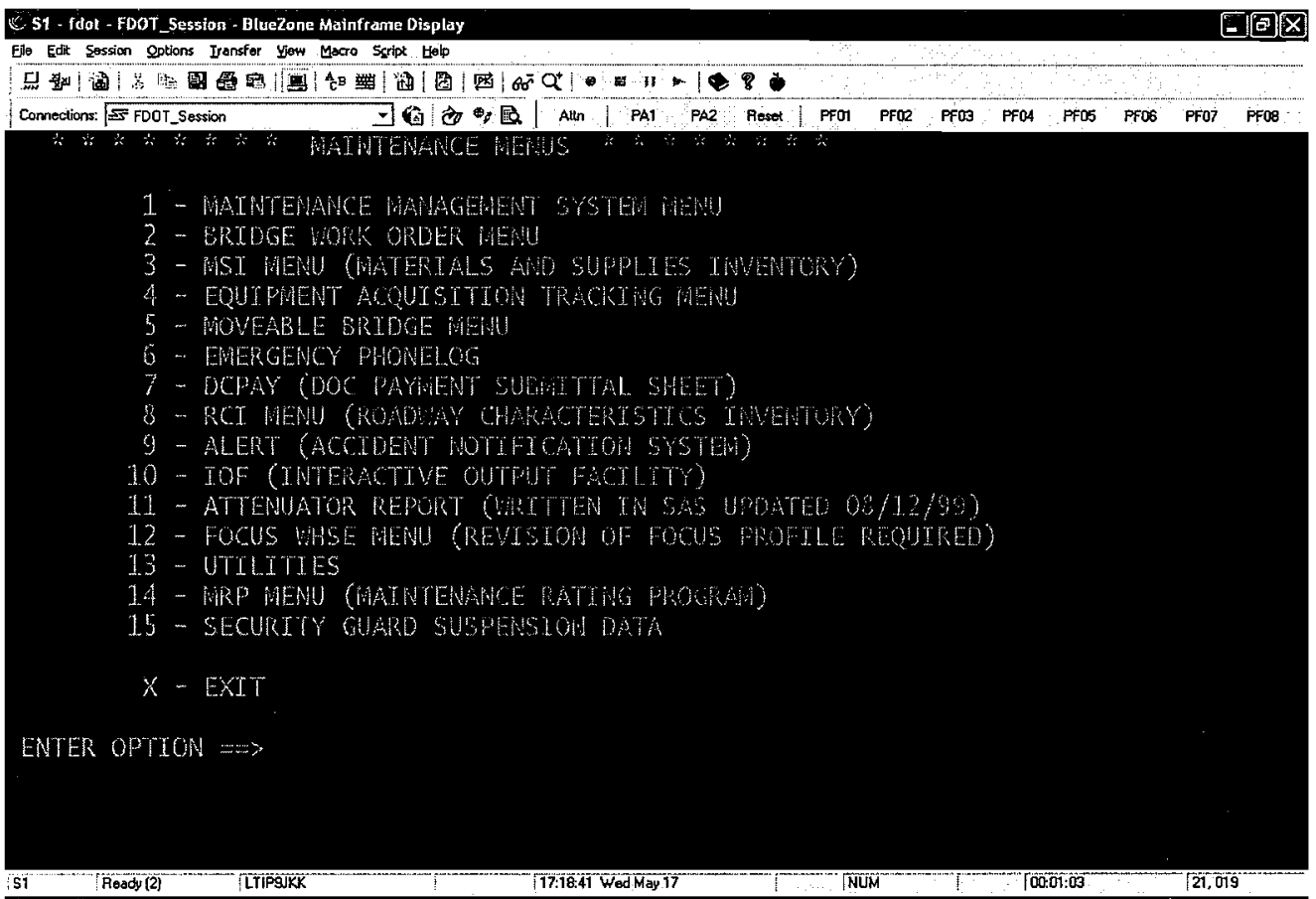

User response: Choose option 14 (MRP MENU) and press the ENTER key.

The MRP Menu will be displayed.

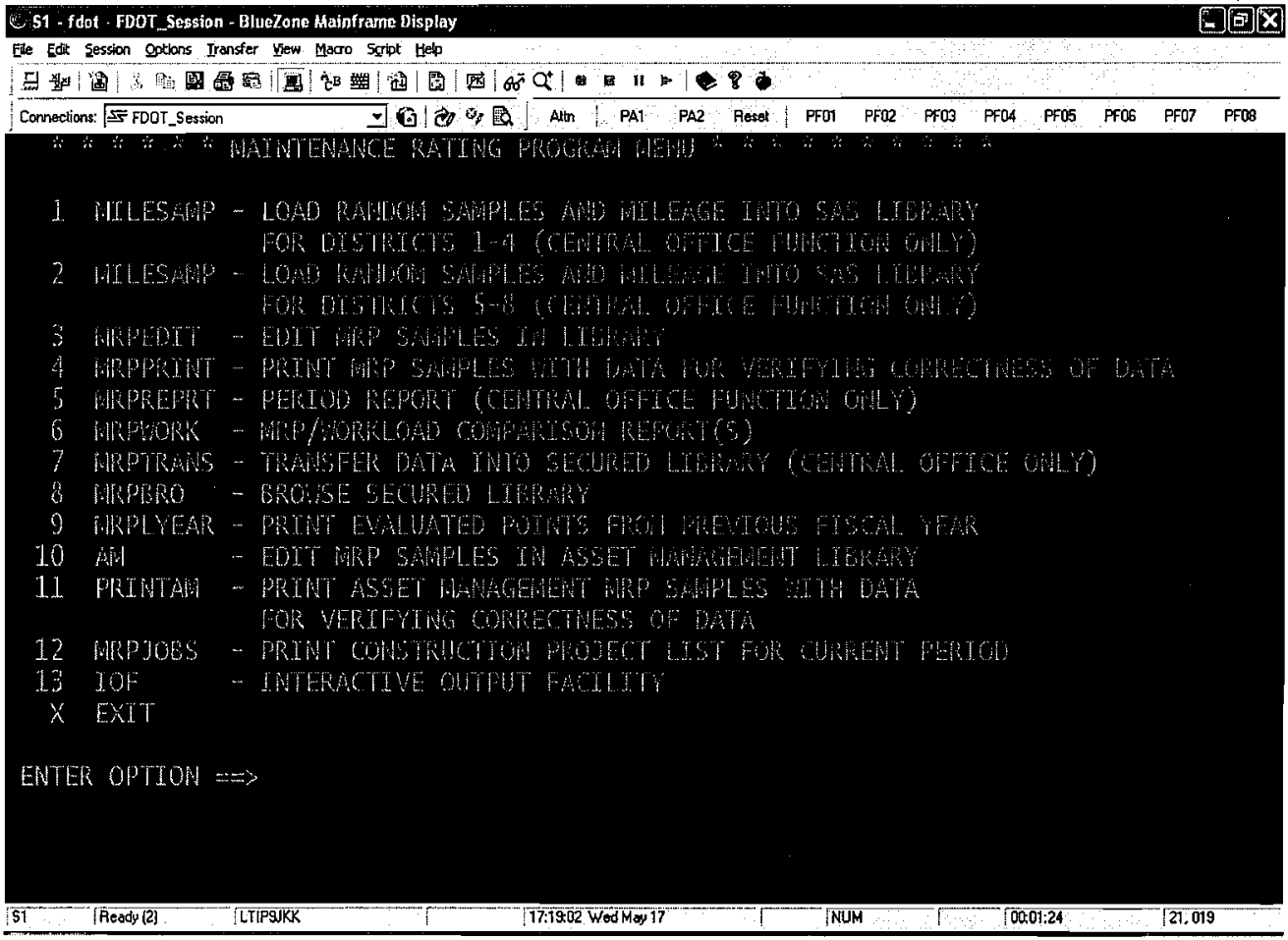

User response: Choose option 3 (MRPEDIT) and press the ENTER key. 
The MRP Edit Main Menu will be displayed.

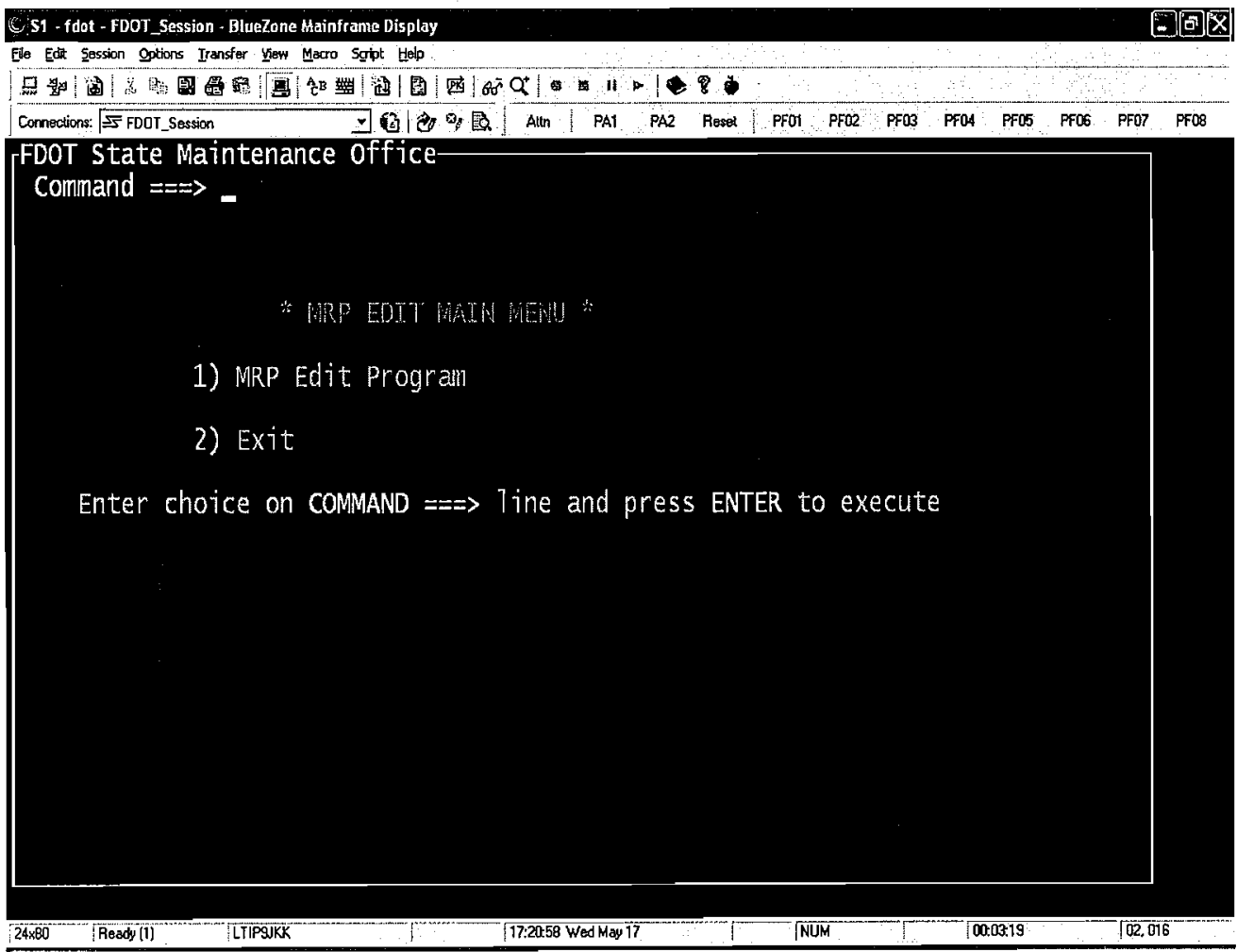

User response: Select option 1 and press ENTER to begin edit process.

The data entry panel will be displayed.

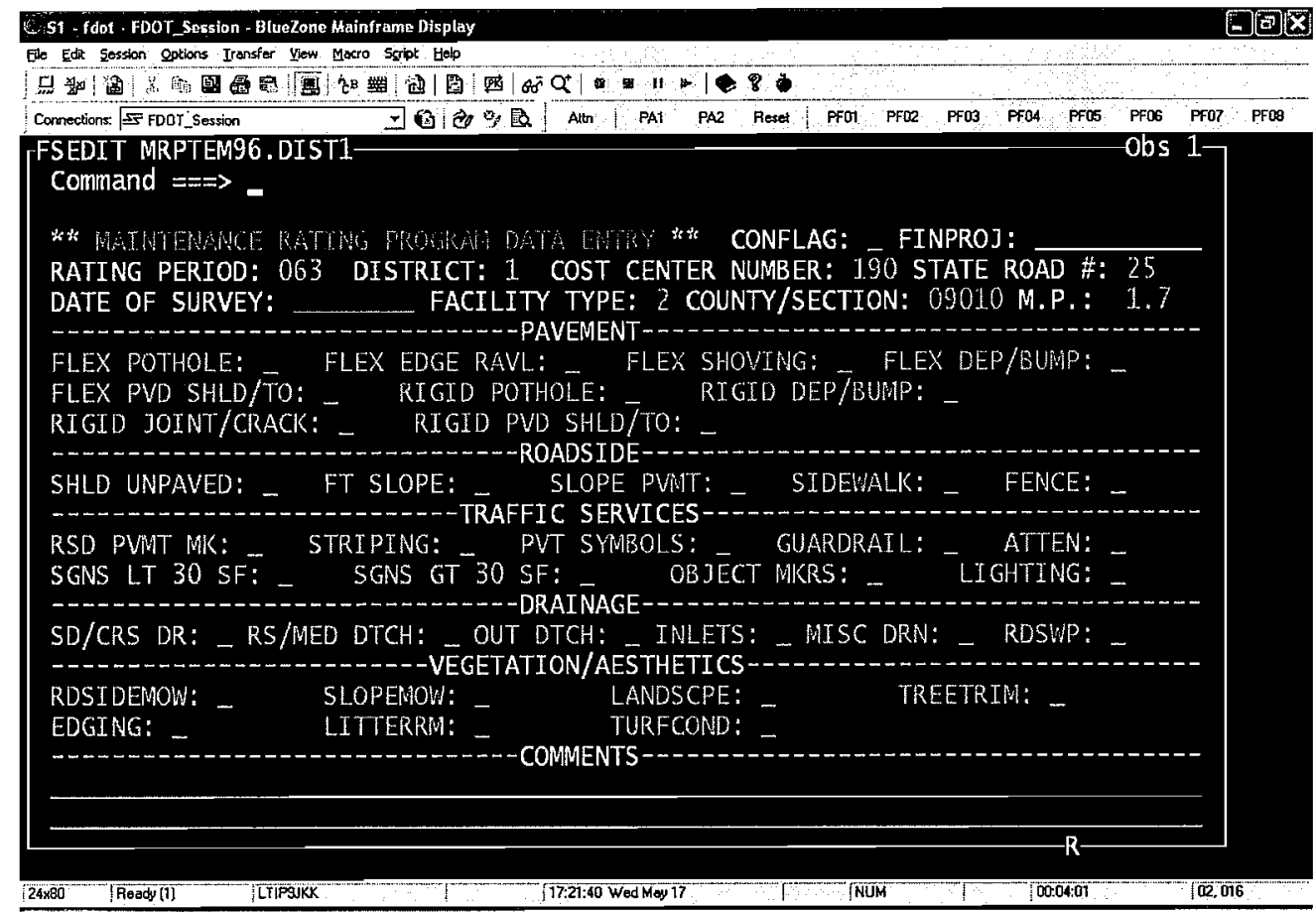

User response: Key in data from field coding sheet. Use TAB key to move cursor. 
Please Note: The rating period and sample location information cannot be changed. The Construction Flag (CONFLAG) may be removed only if it has been determined that the sample is not to be used in the annual MRP Construction Report. This determination is the responsibility of the District and may be based on the project scope of work. If the project did not impact a reasonable number of characteristics the sample should not be included. Once again, this is a judgment call to be made at the District level.

Enter the applicable data for each sample surveyed.

\section{PAY CLOSE ATTENTION TO THE COUNTY/SECTION/SUBSECTION MILEPOST YOU ARE WORKING ON!}

\section{USE THE RECORD NUMBER (REC \#) ON THE CODING SHEET TO HELP IDENTIFY THE SAMPLE!}

\section{DO NOT RELY SOLELY ON THE OBSERVATION NUMBER (OBS \#).}

You can scroll through the samples using (F7 -Backward) and (F8 - Forward) or to locate specific sample, press PF12 and you will return to the Command Line. From the Command Line, type the Record Number (REC \# on coding sheet) and press ENTER. The edit screen for the sample you requested will be displayed. Follow the same procedure to input additional samples.

When you are finished entering your data, press F3 to exit and return to the MRP Edit Main Menu. From there select option 2 to exit. You will be returned to the MRP Menu.

When all data has been entered, it is a good idea to print the samples using option 4 on the MRP Menu (see page 109 - MRPPRINT) to verify the correctness of the data entry. A report is generated in a coding sheet format with the Y's and N's as they were keyed in. You can compare this report with the field coding sheet. 


\section{OUTPUT REPORT}

The sample report below is for all facility types from a statewide survey. The report lists the $5 \mathrm{MRP}$ elements, each with its associated characteristics. Each characteristic shows the number (\#) of samples surveyed, the number of characteristics that met (YES) the desired maintenance condition and what percent $\left(^{*}\right)$ that number is of the total samples surveyed. The report then lists the Level of Maintenance overall for the survey. Reports are also produced by facility type for maintenance areas and districts in addition to the statewide level.

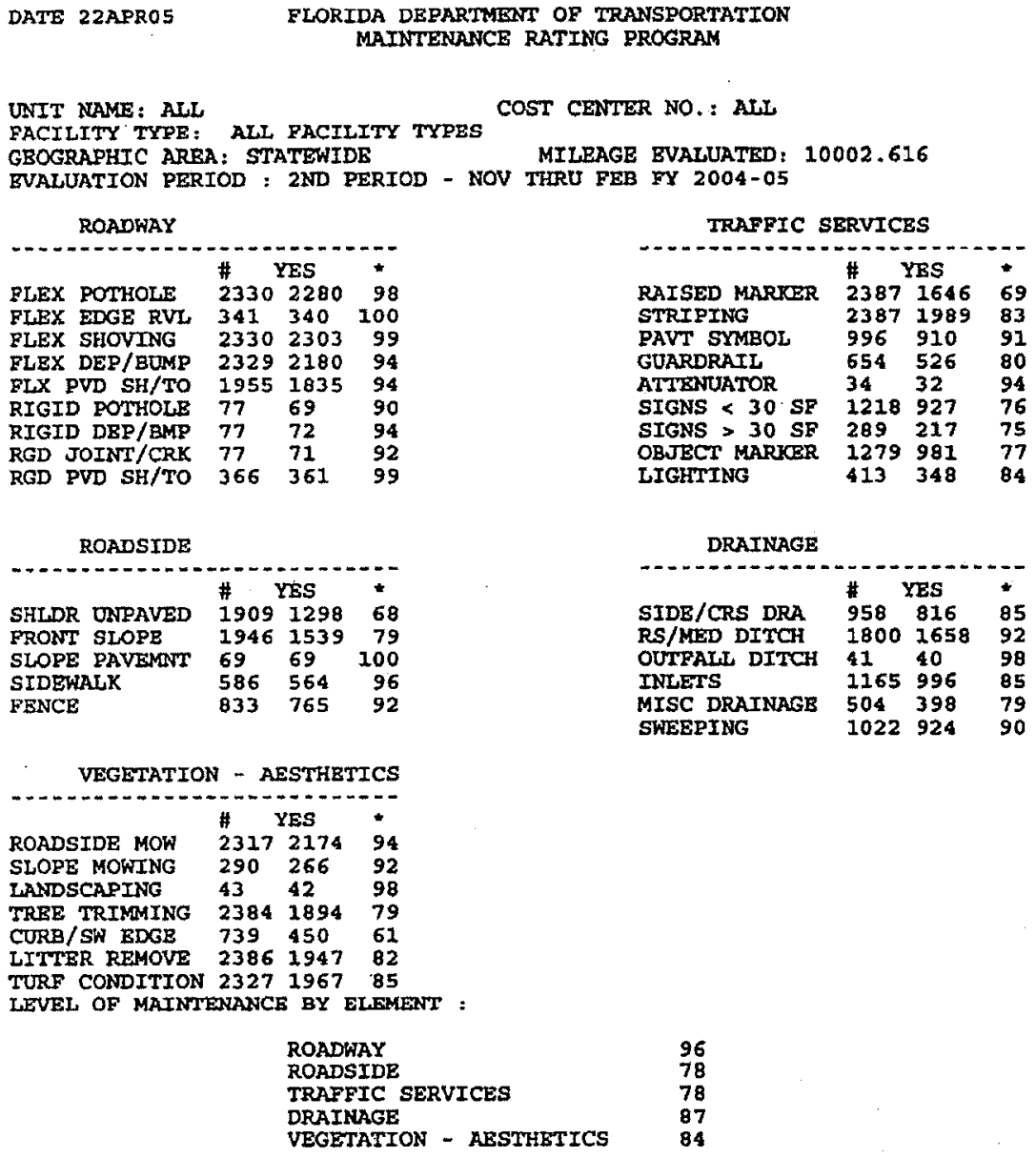

* MIZEAGE EXCLUDES RAMPG AND BRIDGES ** 
Appendix L

TXDOT Overhead Accounts 


\begin{tabular}{|ll|}
\hline $\begin{array}{l}\text { Segment } \\
\text { ID }\end{array}$ & $\begin{array}{l}\text { Detail } \\
\text { Number }\end{array}$ \\
\hline 70 & $\begin{array}{l}\text { Equipment Operations } \\
\text { Service Center }\end{array}$
\end{tabular}
Service Center Who Charges/ What is Charged No. and Function Code - include time, fuel, parts, tires, depreciation, for costs identifiable to a contracted repairs and maintenance reasonably repair order 0210 Indirect Costs 0250 Accumulation and identifiable to an individual equipment item (service order). Examples of indirect costs (0210) include time and expense of equipment supervisor, shop redistribution of 0200 and foremen, utilities, and supplies not reasonably 0210 costs. identifiable to specific equipment (service order) when charged to the service center. Capitalized expenditures are to be added to equipment's capitalized cost, and are not to be charged to this account. Use detail 0430 to accumulate costs to be capitalized later. Costs applicable to non EOS the account for the equipment item or activity, rather by non Service Center personnel). than to this Service Center, along with a distribution of detail 0210 for a proportion of the indirect costs of the Service Center.

70

70

\section{Ferry Maintenance} Detail 0260

Manufacturing
Activities-Other
Detail 0430 plus Task
No. assigned by D/D.

All time and other expenses identifiable to maintenance and minor repairs of ferries and their facilities.

All employee time, material, equipment use, and contract services reasonably identifiable to manufacturing of materials or equipment, or capitalized additions thereto, which cannot be charged directly to the applicable account.
Functions Covered and Use Instructions

These accounts are to accumulate the direct and indirect costs of EOS equipment and redistribute them to the accounts on which the equipment was used. Redistribution of costs is based on miles or time the equipment is used. The district or division operating the Service Center will submit JVs 20 each month as close as possible to the end of the month to distribute the costs using the month's equipment activity reports maintained locally and the state-wide applicable equipment rental rate determined by EOS. The FIMS end-of-month redistribution program will transfer the end-of-month balance of details 0200 and 0210 to 0250 . Routine activities to prepare a vehicle for normal operation or make work to use idle time will not be charged by nonrepair shop personnel to these details (e.g., obtaining fuel, checking oil levels or air pressure, or unnecessary work
All costs are redistributed by the district each month to the district's Segment 71 details 2801, 2811, or 2821

This account is used for accumulating costs for manufacturing activities or other projects (e.g., salvage) not identified elsewhere. Computer edits require all charges made to this account use a task number (work order) assigned by the district or division to identify the individual job. When the task is completed and all applicable costs have been distributed (e.g., SLD), the total costs on the task number (FIMS.EXP2004) will be transferred promptly to the applicable EOS, MES or MSMS account, and the task number closed (FTM TE 99) immediately. Repairs to minor equipment or assets are not to be charged to this account. These repair costs will be charged to the account(s) of the activities responsible for the assets. Sign manufacture costs will not be charged to this account. Use detail 0520 for all sign manufacture costs. There is no variance limit for the account. The account manager and the district accountant will verify each month that the end-of-month Current Variance Balance amount of the account is applicable only to the work in progress (amounts on the task numbers
The FIMS end-of-the month program distributes the month. end Current Variance Balance by (1) Distributing the Materials and Test Division 0510 Current variance Balance to the district 0510 details based on the district's respective percent of the total of all the districts' 0510 balances; then (2) distributes the district 0510 balances to the district segments 76,77 and 78 details/function codes based on the "material equivalent" (see TFIM107) charges to the function code during the month. The amount distributed to the respective function code is based on the function code's percent of the district's total material equivalent charges during the month in the three segments. 


\begin{tabular}{|ll|}
\hline $\begin{array}{ll}\text { Segment } \\
\text { ID }\end{array}$ & Netail \\
\hline 70 & Signber Manufacturing \\
& Detail 0520
\end{tabular}

Who Charges/ What is Charged

All time and other expenses identifiable to sign manufacture, including materials and contracted work. Use Detail 0430 for all other manufacturing activities.
Functions Covered and Use Instructions

This account collects and redistributes to MSMS stock accounts all costs of all signs manufactured. No costs of this account will be redistributed directly to projects or other accounts. All signs manufactured under this account will be returned to MSMS stock using a quantity of square feet of signs and the total of all the center's expenses applicable to the signs returned to the MSMS stock. The life-to-date dollar balance in the account will be only the costs applicable to the work in progress still in the shop. All other costs will be assigned to the completed signs returned to MSMS stock. The account manager and district accountant will verify each month that the end-ofmonth Current Variance Balance of the account is applicable only to the work in progress still in the shop.
Compressed Natural Gas Operations Detail 0525 Detail 0530
All costs reasonably identifiable to the acquisition of Includes, labor, utilities and supplies. The District of the natural gas and processing (compressing) for use as activity will distribute the life-to-date balance (Current a fuel.

All time, supplies, materials and equipment use expenses of core drill crew and supervisors reasonably identifiable to the activity. High cost items, such as diamond bits, used exclusively for a project will be charged directly to the project Variance Balance) in the account to MSMS stock account at the end of the month.

This account is to collect and redistribute the month's costs to the individual projects that received the service. The redistribution of charges will be based on cost per hour calculated as follows: Current Variance Balance plus estimated total costs of the account for the remainder of All costs reasonably identifiable to Preventive Preventive Maintenance Maintenance budget activity, for which the job has Materials Detail 0550 not been set up. Used for preventive maintenance materials to be placed in MSMS stock account. Non

\section{Acquisition of Contracted Routine Maintenance Material Detail 0551}

\section{Non-Capitalized Equipment Service Detail 0560}

Print Shop Operations Detail 0565

District Traffic
Operation Centers
Detail 0570

TranStarTransportation Management SystemMaintenance/Support Detail 0571 the month, divided by the setup, drilling and dismantling hours for the month

District with the account will distribute the Current Variance Balance of the account to the MSMS stock account at the end of each month. Detail will not be used early acquisition of preventive maintenance materials should be charged directly to the job Can appropriate account before the next end of month. also be used for other programs requiring a contracted preventive maintenance budget strategy.

All cash payments requiring the contracted routine maintenance material budget strategy (144) which will not be required by charging the payment to the appropriate stock or maintenance account.

All time, materials and other costs associated with "rental of GSD minor equipment to districts and other divisions.

All time, material and other expenditures identifiable to GSD Print Shop Operations.

All labor and other expenses reasonably identifiable to the Center, including direct supervision, supplies, utilities, and travel.
District with the account will redistribute with JV50 the charges in this account to the appropriate account before the next end of month.

GSD minor equipment loaned (rented ) to other divisions and district

GSD enters JV050s to distribute print shop products to the appropriate TxDOT account or other agency receivable.

Only districts which actually have a traffic management center (e.g., Trans Star) will have this detail. The center is considered to be an extension of the traffic signal system on the roadway. Therefore, the district will distribute the costs each month to the applicable segment 78 roadway accounts.

All labor and other expenses reasonably identifiable Redistribute costs each month using same procedures as to the Center, including direct supervision, supplies, specified for Detail 0570. utilities, and travel. 


\begin{tabular}{|c|c|c|c|}
\hline $\begin{array}{l}\text { Segment } \\
\text { ID }\end{array}$ & $\begin{array}{l}\text { Detail } \\
\text { Number }\end{array}$ & $\begin{array}{l}\text { Who Charges/ } \\
\text { What is Charged }\end{array}$ & Functions Covered and Use Instructions \\
\hline 70 & $\begin{array}{l}\text { District Survey } \\
\text { Operations }\end{array}$ & $\begin{array}{l}\text { All time, materials, vehicle use and other costs } \\
\text { identifiable to district special survey team activities. }\end{array}$ & $\begin{array}{l}\text { Redistribute costs each month using same procedures as } \\
\text { specified for Detail } 0530 \text {. }\end{array}$ \\
\hline
\end{tabular}
Detail 0580

$\begin{array}{ll}\text { District Contract } & \text { All district costs of roadway Maintenance contract } \\ \text { Management -Roadway } & \text { Development and management Not reasonably } \\ \text { Maintenance } & \text { identifiable to specific roadway or other accounts }\end{array}$
Detail 0585 Management-Roadway Development and management not reasonably Maintenance Detail identifiable to specific roadway or other accounts. 0590

Contractor
Maintenance Materials
on Hand Detail 0599

This clearing account should be used when a contractor requests payment for materials on hand in accordance with section 9.7 of the Standard Specifications. This account was set up due to problems with paying for materials on hand on a routine maintenance contract in which the work locations were unknown.
The FIMS end of month program Distributes the life-todate (Current Variance Balance) of the detail to the district 's segment 78 function codes that have contract payments during the month, based on the respective function's contract payments during the month as a percent of the district's total maintenance contract payments for the month.

The FIMS end-of -month program Distributes the life-todate balance (Current Variance Balance) of the detail to the district's details 0585 based on the respective details balance as a percent of the statewide total.

Payment for material on hand, if allowed, will be charged to clearing account Segment 70, account 0599. As work is performed, pay for the work based upon the quantity of work performed multiplied by the original bid item cost. This will be charged to Segment 78 and the highway just like you do now. Charge materials used in the work by issuing a negative charge back to the clearing account Segment 70, 0599. The net payment will be the correct amount, ie, the bid item cost minus materials already paid. When the project is over the clearing account should be back to zero and the contractor will be paid the correct amount.
Area Engineers Indirect All time and expense of area office and its assigned Costs Details 06500697;0699

\author{
District Special Crews \\ Indirect Costs
}

Details 0830-0845 personnel not reasonably identifiable to individual projects or other accounts. Usually includes area office clerical support, cleaning, protecting and maintaining area office building and grounds. Includes development of area engineer programs, budgets, "for free" work, and other administrative activities. Supervisors, including the area engineer and his or her immediate staff, will make reasonable efforts to identify (charge)( their time and other expenses to individual projects or other accounts (i.e., charges to this account will be kept to the minimum possible with the above rules and department policy on accuracy of charges).

\section{All Project Management Costs not specifically} identifiable to a CSJ.

\section{MANAGEMENT}

TURNPIKE PROJECT

Detail 0698

Roadway Maintenance Section Indirect Costs Details 0801-0829

All labor and other costs of the Maintenance Section and its assigned personnel not reasonably identifiable to roadway or other accounts.
All labor and other costs of the special crew and its assigned personnel not reasonably identifiable to other accounts.
This account is for the indirect costs of the area engineers. It is the means to collect and redistribute these indirect costs to individual projects worked on by the area office personnel during the month. Redistribution is completely Automated, based on the hours the area office personnel charged to other accounts during the month. Distribution occurs on the last Business day of the month, rather than as a part of the end-of -month process.

Therefore, charges on the last day are not distributed until the next month. Not to be used to collect charges for later transfer to jobs not yet set up. The work is not to be performed or expense incurred until the job is authorized properly.

Redistribution is completely Automated, based on the hours the project personnel charged to other accounts during the month. are distributed by the FIMS end-of-month program to all the roadway account function codes in the section based on the respective function code's total charges during the month.

The Current Variance Balance of the details are distributed by the FIMS end-of-month program to all the maintenance section indirect cost details 0801-0829 in the district based on the respective detail's percent of the district total of the details. 


\begin{tabular}{|llll|}
\hline $\begin{array}{l}\text { Segment } \\
\text { ID }\end{array}$ & Detail & Who Charges/ & Functions Covered and Use Instructions \\
\hline 70 & Employee Payroll & What is Charged & All direct expenses associated with employee pay \\
Composite & and benefits. Includes salaried and hourly & Distributes to the applicable accounts during the SLD \\
process. The distributed amount will be the respective \\
Details 9XXX & $\begin{array}{l}\text { employees. Benefits include employee absences, } \\
\text { insurance, retirement, etc. Accounts are used and }\end{array}$ & $\begin{array}{l}\text { employee's base pay plus the payroll additive multiplied by } \\
\text { the hours reported on the time sheet for the account to be }\end{array}$ \\
& selected under computer program control during the & charged. The payroll additive is a statewide rate and \\
& salary and labor distribution process. Except for & includes all employee-associated expenses to the state \\
& employee absences, only BUD uses the accounts & (e.g., leave, holidays, retirement, overtime premium and \\
& for direct charges. & insurance).
\end{tabular}

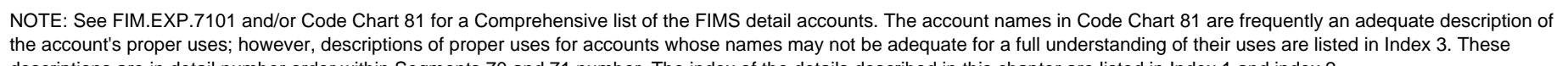
descriptions are in detail number order within Segments 70 and 71 number. The index of the details described in this chapter are listed in Index 1 and index 2.

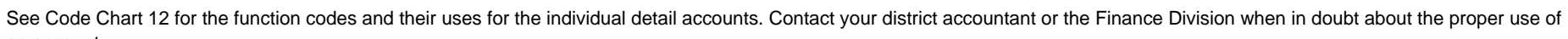
an account.

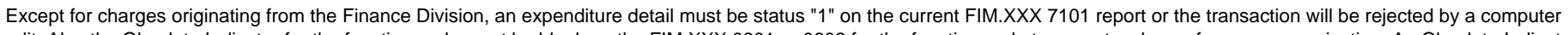

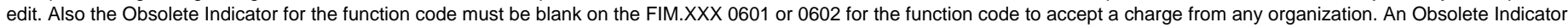
of other than blank means that the function code for the detail has either been frozen or deleted. 